US Army Corps of Engineers

Prepared for the U.S. Army Corps of Engineers, Portland District

Under an Interagency Agreement with the U.S. Department of Energy

Contract DE-AC05-76RL01830

\title{
Evaluation of Cumulative Ecosystem Response to Restoration Projects in the Lower Columbia River and Estuary, 2010
}

\section{FINAL REPORT}

\section{Prepared by: \\ Pacific Northwest National Laboratory \\ National Marine Fisheries Service \\ Columbia River Estuary Study Taskforce \\ University of Washington}

May 2012

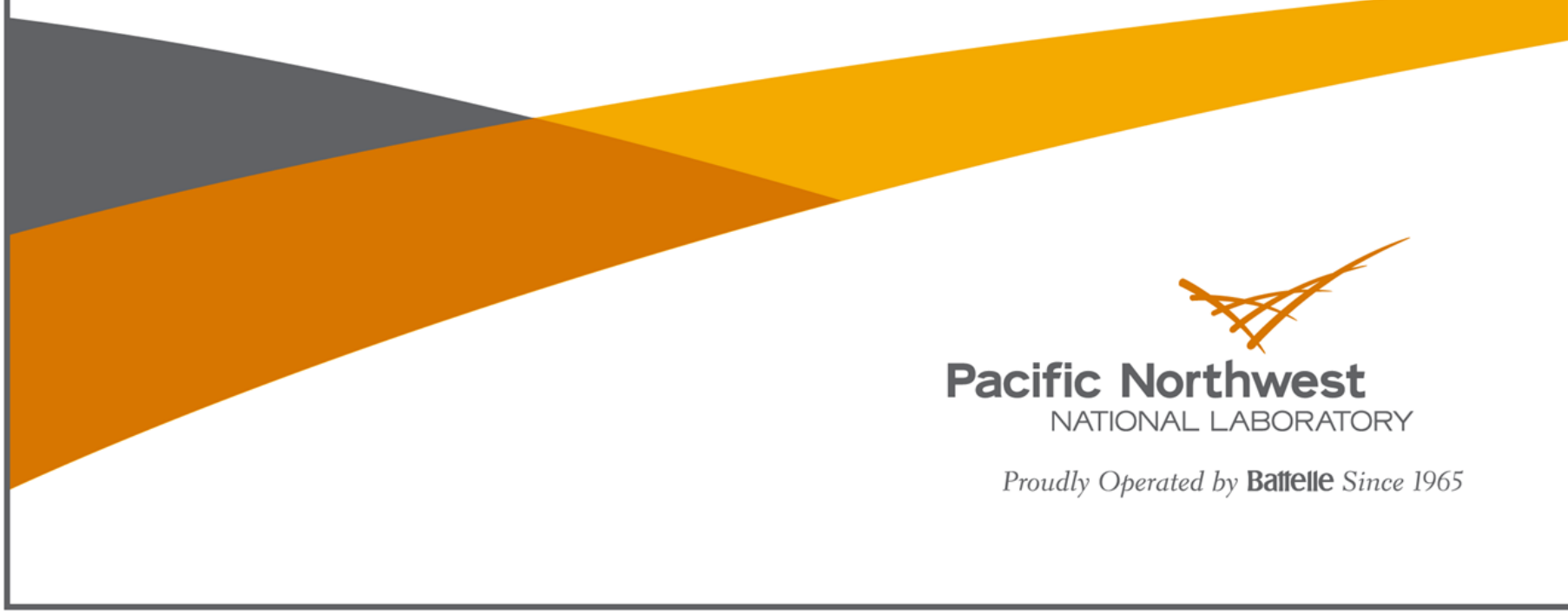




\title{
DISCLAIMER
}

This report was prepared as an account of work sponsored by an agency of the United States Government. Neither the United States Government nor any agency thereof, nor Battelle Memorial Institute, nor any of their employees, makes any warranty, express or implied, or assumes any legal liability or responsibility for the accuracy, completeness, or usefulness of any information, apparatus, product, or process disclosed, or represents that its use would not infringe privately owned rights. Reference herein to any specific commercial product, process, or service by trade name, trademark, manufacturer, or otherwise does not necessarily constitute or imply its endorsement, recommendation, or favoring by the United States Government or any agency thereof, or Battelle Memorial Institute. The views and opinions of authors expressed herein do not necessarily state or reflect those of the United States Government or any agency thereof.

\author{
PACIFIC NORTHWEST NATIONAL LABORATORY \\ operated by \\ BATTELLE \\ for the \\ UNITED STATES DEPARTMENT OF ENERGY \\ under Contract DE-AC05-76RL01830
}

Printed in the United States of America
Available to DOE and DOE contractors from the Office of Scientific and Technical Information,
P.O. Box 62, Oak Ridge, TN 37831-0062;
ph: (865) 576-8401
fax: $(865)$ 576-5728
email: reports@adonis.osti.gov

\begin{abstract}
Available to the public from the National Technical Information Service, U.S. Department of Commerce, 5285 Port Royal Rd., Springfield, VA 22161 ph: (800) 553-6847 fax: $(703) 605-6900$ email: orders@ntis.fedworld.gov online ordering: http://www.ntis.gov/ordering.htm
\end{abstract}

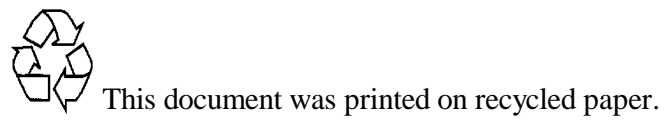




\section{Evaluation of Cumulative Ecosystem Response to Restoration Projects in the Lower Columbia River and Estuary, 2010}

\section{FINAL REPORT}

\begin{tabular}{|c|c|}
\hline GE Johnson & HL Diefenderfer \\
\hline RM Thom & GC Roegner \\
\hline BD Ebberts ${ }^{1}$ & JR Skalski ${ }^{2}$ \\
\hline AB Borde & EM Dawley $^{3}$ \\
\hline AM Coleman & DL Woodruff \\
\hline SA Breithaupt & AS Cameron ${ }^{4}$ \\
\hline CA Corbett ${ }^{5}$ & EE Donley \\
\hline DA Jay ${ }^{6}$ & $\mathrm{Y} \mathrm{Ke}$ \\
\hline KE Leffler ${ }^{6}$ & CB McNeil ${ }^{6}$ \\
\hline CA Studebaker ${ }^{1}$ & JD Tagestad \\
\hline
\end{tabular}

May 2012

Prepared for

U.S. Army Corps of Engineers, Portland District

under a Government Order with the U.S. Department of Energy

Contract DE-AC05-76RL01830

Pacific Northwest National Laboratory

Richland, Washington 99352

\footnotetext{
${ }^{1}$ U.S. Army Corps of Engineers, Portland District, Portland, Oregon

${ }^{2}$ University of Washington, Seattle, Washington

${ }^{3}$ National Marine Fisheries Service (retired), Astoria, Oregon

${ }^{4}$ Columbia River Estuary Study Taskforce, Astoria, Oregon

${ }^{5}$ Lower Columbia River Estuary Partnership, Portland, Oregon

${ }^{6}$ Portland State University, Portland, Oregon
} 


\begin{abstract}
This is the seventh and final annual report of a project (2004-2010) addressing evaluation of the cumulative effects of habitat restoration actions in the 235-km-long lower Columbia River and estuary (LCRE). The project, called the Cumulative Effects (CE) study, was conducted for the U.S. Army Corps of Engineers Portland District by collaborating research agencies led by the Pacific Northwest National Laboratory. The primary goal of the CE study was to develop a methodology to evaluate the cumulative effects of habitat actions in the Columbia Estuary Ecosystem Restoration Program (CEERP). The project produced 1) effectiveness monitoring protocols and methods to standardize monitoring activities; 2) the theoretical and empirical basis for a CE methodology using a levels-of-evidence approach; 3) evaluations using ecological relationships, geo-referenced data, hydrodynamic modeling, and meta-analyses; and 4) an adaptive management process to coordinate and coalesce restoration efforts in the LCRE. Although more data and information are needed about the mechanisms linking restoration of LCRE ecosystems to effects on juvenile salmonids, a solid foundation has been laid for future comprehensive evaluations of progress made by the CEERP to understand, conserve, and restore ecosystems in the LCRE.
\end{abstract}




\section{Executive Summary}

This is the seventh and final annual report of a 7-year project (2004 through 2010) concerning the cumulative effects of habitat restoration actions in the lower Columbia River and estuary (LCRE). The project, called the Cumulative Effects (CE) study, was conducted for the U.S. Army Corps of Engineers Portland District (USACE) by the Marine Sciences Laboratory of the Pacific Northwest National Laboratory, the Pt. Adams Biological Field Station of the National Marine Fisheries Service, the Columbia River Estuary Study Taskforce, Portland State University, and the University of Washington.

The primary goal of this study was to develop a methodology to evaluate the cumulative effects ${ }^{1}$ of habitat restoration projects in the Columbia Estuary Ecosystem Restoration Program ${ }^{2}$ (CEERP) aimed at restoring LCRE ecosystems and increasing population levels of listed Columbia River basin salmon. We designed an ecosystem-based methodology and protocols to ensure comparable data sets across multiple restoration monitoring efforts estuary-wide. The products of this research are intended to provide CEERP decision-makers a way to 1) evaluate the ecological performance of the collective habitat restoration effort in the LCRE and its effects on listed salmon, and 2) apply scientific knowledge from ongoing monitoring within a formal adaptive management framework to prioritize cost- and ecologically effective restoration projects in the future. The CE study had the following four main objectives:

- Monitoring Protocols - Develop monitoring protocols and methods to standardize monitoring activities to determine the effectiveness of LCRE ecosystem restoration actions.

- Methodology - Develop the theoretical and empirical basis for a CE methodology, together with a set of metrics and a conceptual model depicting the cumulative effects of LCRE restoration projects on key major ecosystem functions supporting listed salmon.

- Evaluation - Design and implement evaluations of the CE methods by applying standard methods in studies of ecological relationships, a geographic information system (GIS) database of restorationrelated data, hydrodynamic modeling, and meta-analyses to assess ecosystem response of the cumulative effects of multiple habitat restoration projects.

- Adaptive Management - Develop an adaptive management process to coordinate and coalesce the restoration efforts in the LCRE to support decisions by the USACE and others regarding LCRE habitat restoration activities, and provide a general approach and description of work and key accomplishments from 2004 through 2010.

\section{S.1 Background}

Starting in earnest about 10 years ago, many federal, state, and local agencies and non-governmental organizations began working to restore estuarine and tidal freshwater habitats for juvenile salmon in the LCRE. This work is driven by recovery plans for salmon and steelhead species listed under the Endangered Species Act and Biological Opinions (BiOps) on operation of the Federal Columbia River Power System (FCRPS), among other drivers. A major portion of the CEERP effort is funded primarily

\footnotetext{
${ }^{1}$ Cumulative restoration effects are the net change in ecosystem-wide metrics and ecosystem state resulting from cumulative restoration impacts.

${ }^{2}$ This is the name we use to identify the collective restoration efforts in the LCRE by the Bonneville Power Administration, USACE, and others.
} 
by the Bonneville Power Administration (BPA) and the USACE. Since 2000, they have provided over $\$ 10$ million for over 100 restoration projects in the LCRE. Furthermore, the BPA and USACE have committed to specific targets for improved survival of juvenile salmon under the 2008 FCRPS BiOp49 survival benefit units for ocean-type salmon and 30 survival benefit units for stream-type salmon by 2018. (Survival benefit units are an index intended to represent the effect of LCRE habitat restoration projects on juvenile salmon survival.) CEERP decision-makers need scientific evaluations of the extent to which the program is meeting targets for survival benefit units and the program's overall goal to understand, conserve, and restore ecosystems in the LCRE. In summary, the primary management questions for the CEERP are as follows:

- Are the habitat restoration activities in the LCRE having a cumulative beneficial effect on salmon and achieving the desired ecological effects across the LCRE landscape?

- Are the habitat actions resulting in continued loss, no net loss, or net ecosystem improvement in the context of continuing land conversion?

- Are there limiting factors or threats in the estuary/ocean preventing the achievement of desired habitat or fish performance objectives?

- Which restoration actions are most effective at improving habitat opportunity and capacity for juvenile salmon through increased habitat connectivity, flood attenuation, sediment trapping, nutrient processing, export of marsh macrodetritus, and other ecosystem functions?

- Are the habitat restoration actions improving juvenile salmon performance in terms of growth, fitness, and survival benefit units?

\section{S.2 Approach}

Addressing the management questions requires research, monitoring, and evaluation. Monitoring protocols for data on the effectiveness of habitat restoration projects were initiated at the start of the CE study in 2004. Protocols were developed for six categories of core monitored indicators, and we identified higher-order indicators for CE assessments, as described below.

\section{S.2.1 Core Indicators - Ecosystem Controlling Factors and Structures}

- Hydrology: water-surface elevation, catchment area, tidal exchange volume, wetland delineation

- Water Quality: temperature, salinity, dissolved oxygen

- Topography/Bathymetry: elevation, sediment accretion rate, channel cross-sectional area

- Landscape: photo points, aerial photos

- Vegetation: percent cover, species composition, species richness, similarity index

- Fish: presence, abundance, species composition, size structure. 


\section{S.2.2 Higher-Order Indicators - Ecosystem Processes and Realized Functions}

- Habitat Availability: area-time inundation, wetted-channel edge length, floodplain wetted area

- Material Flux: flux rates for nutrients, chlorophyll, dissolved organic matter, plant biomass, total organic carbon, macro-invertebrates

- Fish Usage: residence time, diet, growth rate, fitness, prey availability, genetic stock.

Methodology development for CE evaluations commenced in 2004 with a comprehensive literature review that found no published formal methods to quantify the cumulative effects of multiple restoration projects across a given estuary. Literature review results, and the ecological complexity, habitat diversity, and geographic expanse of the LCRE, led us to recommend development of a levels-of-evidence approach to evaluate restoration cumulative effects involving a hierarchical suite of phases: design, data, analysis, synthesis and evaluation, and application (Figure S.1). We formulated a conceptual model, established indicators in coordination with work on the monitoring protocols, developed statistical methods, and stated hypotheses.

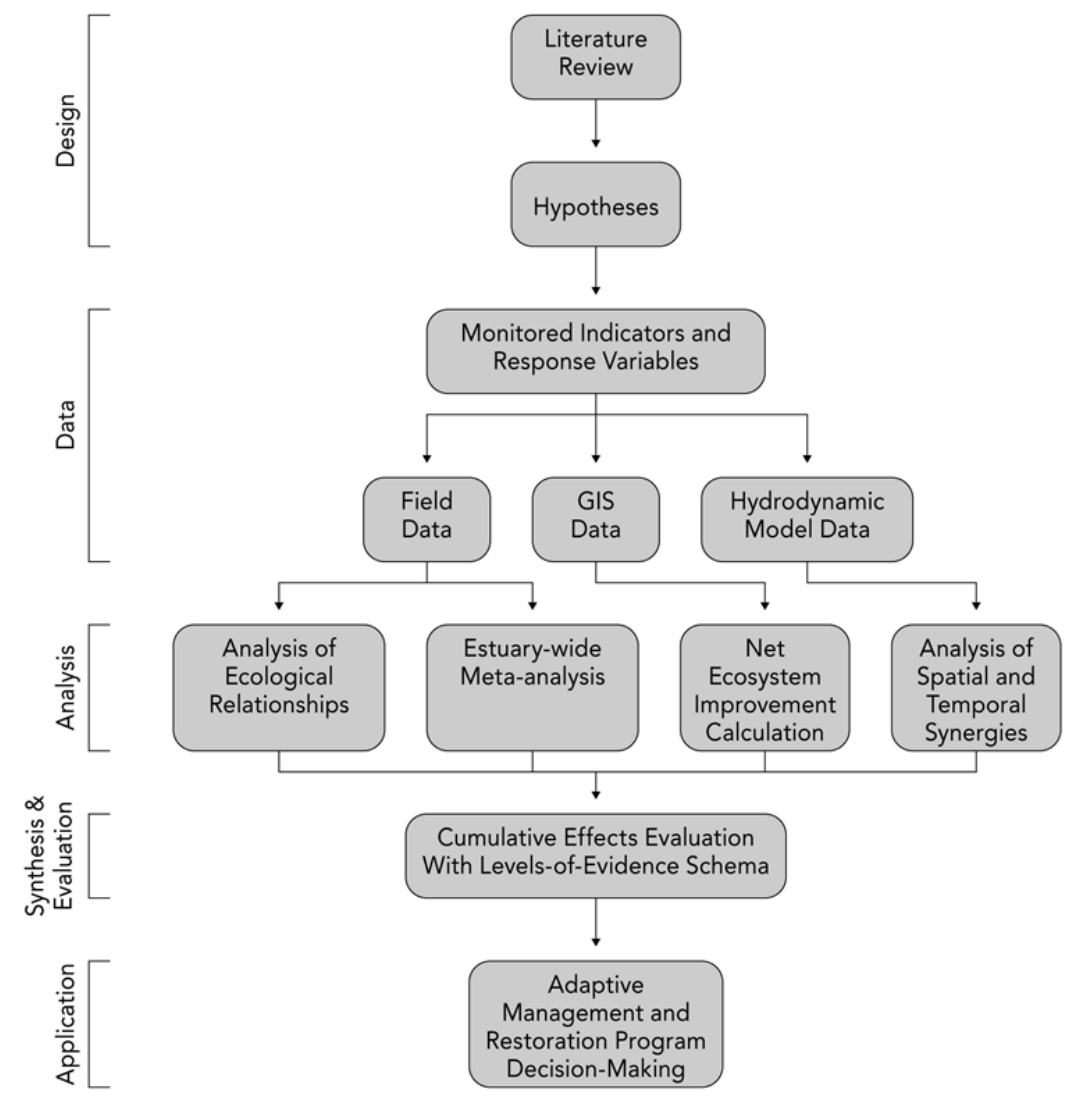

Figure S.1. Levels-of-Evidence Approach for Evaluation of the Cumulative Effects of Ecosystem Restoration 
The hierarchy of hypotheses for a levels-of-evidence evaluation of the cumulative effects of LCRE ecosystem restoration includes an overarching working hypothesis, a landscape-scale hypothesis, and indicator hypotheses:

- Overarching Working Hypothesis - Habitat restoration activities in the LCRE have a cumulative beneficial effect on salmon.

- Landscape-Scale Hypothesis - Restoration actions in the LCRE are producing increased habitat connectivity and an increased area of floodplain wetlands trending toward historical levels present prior to land conversion for agriculture and the construction of dams.

- Indicator Hypotheses - Indicators listed above, as measured at restoration sites, are trending toward reference site conditions.

Research related to the four main study objectives was conducted within the levels-of-evidence framework over the course of the CE study (2004-2010). Specific research objectives each year were formulated based on previous year results, progress to date in populating the levels of evidence with data, and year in the 7-year study period. From 2005 through 2010, annual field research involved intensive, comparative studies paired by habitat type (tidal swamp versus marsh), trajectory (restoration versus reference site), and restoration action (tide gate replacement vs. culvert replacement vs. dike breach). Evaluation of CE methodologies was undertaken by applying standard methods in studies of ecological relationships, a GIS database of restoration-related data, hydrodynamic modeling, and meta-analyses of multiple habitat restoration projects. Field work occurred from 2005 through 2009 at three primary restoration projects and associated reference sites: Crims Island, Kandoll Farm, and Vera Slough (Figure S.2). (The restoration and reference site codes are CI and CR, KF and KR, and VS and VR,

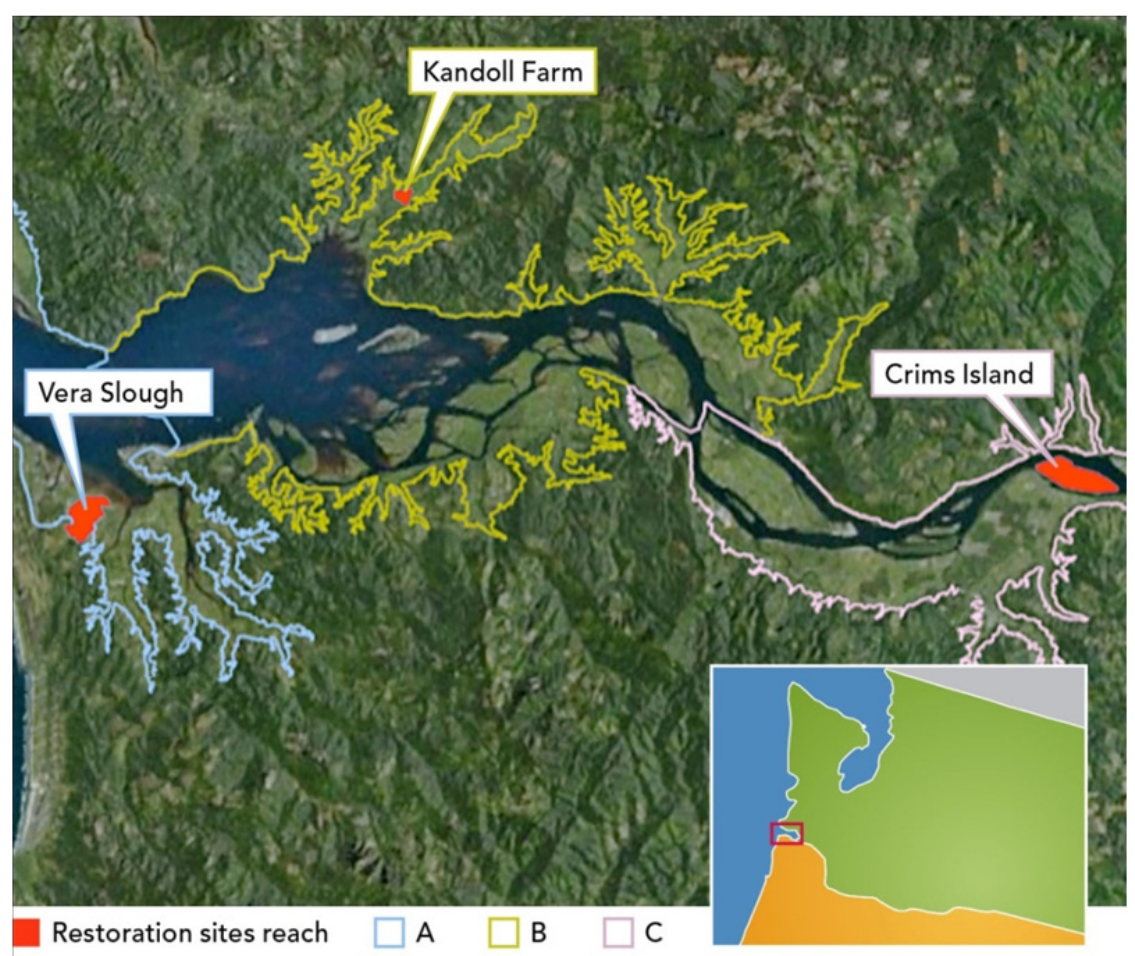

Figure S.2. Field Sites for the 2004-2010 Cumulative Effects Study 
respectively.) Research on the CE evaluation objective was important because it provided first-hand experience in the LCRE with proposed data collection methods and helped determine of the usefulness of the data for the purposes of CE study.

Finally, an adaptive management (AM) process was custom-designed for the CEERP during 2006 and 2007. The intent was for the CE evaluations to be conducted within this process and the results applied to decision-making for the program. Detailed and executive versions of the AM process were released in 2007 and 2008. In 2010, we updated the AM process and made specific recommendations for AM phases, responsible parties, deliverables, schedules, and implementation tasks. The intent is to offer a practical AM process that regional stakeholders can support and use to understand, conserve, and restore ecosystems in the LCRE.

\section{S.3 2010 Findings}

In this report, we synthesize CE study research on the ecology and hydrology of restoring wetlands in the LCRE, update the CEERP AM process and suggest specific work to implement it, and present new results pertinent to the CE study objectives. The report, however, is not a stand-alone summary of all CE research, nor does it emphasize accomplishments and advances made in this particular study year like previous annual reports have. We do synthesize and reference findings documented previously in CE study reports and publications. The objectives and key findings from the research presented in this report include the following, organized by report chapter and appendix.

Ecology and Hydrology of Restoring Wetlands in the LCRE (Chapter 2.0) - This chapter summarizes field research on the ecological response of diked former tidal wetland habitats in the LCRE to restoration activities involving hydrologic reconnection. We had two primary objectives: first, to provide a synthesis of field research on ecological responses to LCRE tidal reconnection restoration at three sites, trajectories, and patterns of development, organized according to the hypotheses generated from a levels-of-evidence approach; and, second, to develop indicators for assessing restoration response, including the analysis of ecological relationships, and present recommendations drawn from the results at intensive (i.e., site scale) and extensive (i.e., ecosystem) scales. We summarize (Table S.1) the generalized responses of the various restoration actions relative to the categories of indicators. Although we studied only one replicate of each type of action, we believe that these sites are representative of the response a site would show to each action type. That said, there are nuances to every site and action. It was clear to us that the degree and quality of the cascade of responses by the indicators from tidal hydrological reconnection was dependent on the degree of natural connection achieved. In particular, we found that the stronger the connection the better the flow of materials and species between the habitat and the broader ecosystem. For example, organic matter produced in the habitat was both used in the habitat and exported far from the habitat to the estuary. In addition, migrating juvenile salmon were able to find their way from the main stem to a point $\sim 8 \mathrm{~km}$ up into the Grays River tributary where they used prey produced in the restored Kandoll Farm site. These and other findings verified that site-specific habitat restoration actions benefit offsite conditions, and that many projects would result in an overall improvement in the ecosystem. 
Table S.1. Summary of the Relative Effects of the Various Restoration Actions on the Core and HigherOrder Indicators

\begin{tabular}{|c|c|c|c|}
\hline Indicators Category & $\begin{array}{l}\text { Tide Gate Retrofit } \\
\text { (Vera Slough) }\end{array}$ & $\begin{array}{c}\text { Full Breach } \\
\text { (Kandoll Farm) }\end{array}$ & $\begin{array}{c}\text { Elevation Modification \& } \\
\text { Breach (Crims Island) }\end{array}$ \\
\hline Hydrology & $\begin{array}{l}\text { Restricted tidal } \\
\text { hydrodynamics; no flooding }\end{array}$ & $\begin{array}{l}\text { Natural tidal hydrodynamics } \\
\text { and flooding; larger than } \\
\text { historical tidal prism }\end{array}$ & $\begin{array}{l}\text { Natural tidal } \\
\text { hydrodynamics and } \\
\text { flooding }\end{array}$ \\
\hline Water Quality & Altered temperatures & $\begin{array}{l}\text { Favorable temperatures in } \\
\text { most channels; some spatial } \\
\text { variability }\end{array}$ & Favorable temperatures \\
\hline Topography/Bathymetry & $\begin{array}{l}\text { Small change in topography; } \\
\text { channel morphology change } \\
\text { primarily at outlet; higher } \\
\text { accretion than reference }\end{array}$ & $\begin{array}{l}\text { Small change in topography; } \\
\text { channel morphology change } \\
\text { primarily at outlet; higher } \\
\text { accretion than reference }\end{array}$ & $\begin{array}{l}\text { Large change in } \\
\text { topography and channel } \\
\text { morphology; higher } \\
\text { accretion than reference }\end{array}$ \\
\hline Landscape & $\begin{array}{l}\text { Detectable change in } \\
\text { vegetation throughout site }\end{array}$ & $\begin{array}{l}\text { Detectable change in } \\
\text { vegetation throughout site }\end{array}$ & NA \\
\hline Vegetation & $\begin{array}{l}\text { Major loss in vegetation; } \\
\text { severely restricted } \\
\text { colonization of new } \\
\text { assemblage }\end{array}$ & $\begin{array}{l}\text { Major shift in vegetation; } \\
\text { rapid colonization of new } \\
\text { assemblage }\end{array}$ & $\begin{array}{l}\text { Major shift in vegetation; } \\
\text { rapid colonization of new } \\
\text { assemblage }\end{array}$ \\
\hline Habitat Availability & $\begin{array}{l}\text { Availability greatly } \\
\text { restricted }\end{array}$ & $\begin{array}{l}\text { Availability greatly } \\
\text { enhanced }\end{array}$ & $\begin{array}{l}\text { Availability greatly } \\
\text { enhanced }\end{array}$ \\
\hline Material Flux & Restricted & Natural exchange & Natural exchange \\
\hline Fish Usage & Greatly restricted & Proven enhancement & Proven enhancement \\
\hline
\end{tabular}

Adaptive Management of Ecosystem Restoration in the LCRE (Chapter 3.0) - A formal AM process that has active participation and buy-in from key stakeholders would be useful to plan and prioritize projects, evaluate the effectiveness of constructed projects, and periodically synthesize results in a manner that significantly improves restoration program strategy and decision-making. We offer an AM process that integrates elements from existing program documents and activities to formalize procedures that will enable the CEERP to successfully meet its goal to understand, conserve, and restore LCRE ecosystems. The AM process we propose is intended to provide direction for annual management decisions in the context of long-term CEERP planning. The process could be adopted and modified as needed by others to serve the needs of individual restoration programs. We describe the background, CEERP AM process, teams, and deliverables (Figure S.3 and Table S.2), as well as schedule and infrastructure (e.g., database, data management, data dissemination portals). It is up to the primary funding agencies, stakeholders, and monitoring/research agencies to make AM a reality for the betterment of LCRE ecosystems and the salmon populations these ecosystems support. 


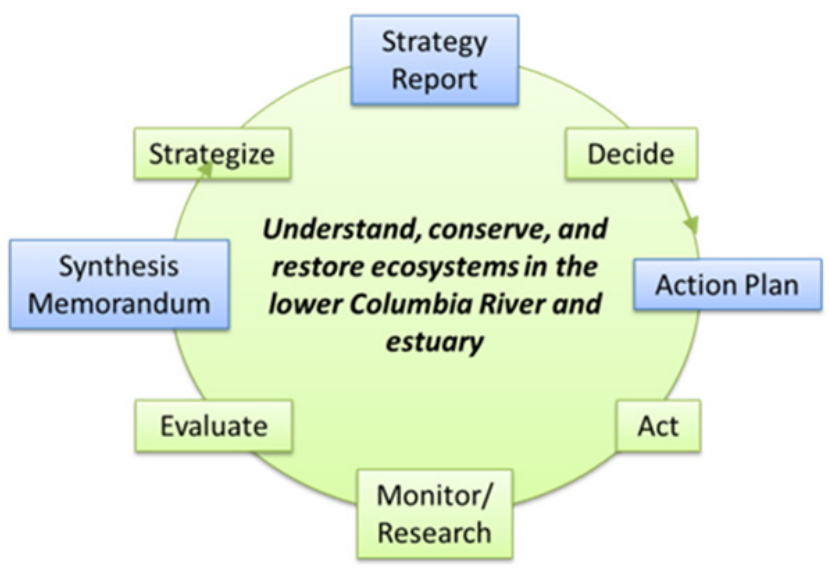

Figure S.3. CEERP Adaptive Management Process

Table S.2. AM Phases, Teams, and Deliverables

\begin{tabular}{lll}
\hline \multicolumn{1}{c}{ AM Phase } & \multicolumn{1}{c}{ Responsible Party or AM Team } & \multicolumn{1}{c}{ AM Deliverable } \\
\hline Decide & Stakeholders Team and Funding Entities & Action Plan \\
Act & Restoration Practitioners & As-Built Report \\
Monitor/Research & RME Practitioners & Site Evaluation Cards \\
Evaluate & Technical Analysis Team & Synthesis Memorandum \\
Strategize & ERTG and Stakeholders Team & Strategy Report \\
\hline RME = research, monitoring, and evaluation; ERTG = Expert Regional Technical Group \\
\hline
\end{tabular}

Management Considerations (Chapter 4.0) - This chapter summarizes the management considerations from the CE study in terms of deliverables, legacy products, restoration lessons, critical uncertainties, and recommendations. (Legacy products and restoration lessons are included below in this Executive Summary.)

Temporal Land Cover Analysis for Net Ecosystem Improvement (Appendix A) - Understanding the distribution and changes of land cover in the LCRE is an important element of the evaluation of ecosystem state in pre- and post-restoration periods. While restoration activities are occurring at the site scale, evaluating larger ecosystem change at an estuary scale helps to provide guidance for future estuarine ecosystem management. In particular, forest cover, impervious surfaces, and wetlands are important landscape indicators for assessing stressors to salmon habitats. Research objectives were to 1) determine land cover change, in particular change in forest cover, impervious surface/urban area, and wetlands, from 2001 to 2006, based on remote-sensing data; and 2) analyze and evaluate the change area at three spatial scales - contributing watershed scale, historic floodplain reach scale, and site scale. The results of the analysis of National Oceanic and Atmospheric Administration Coastal Change Analysis Program (NOAA C-CAP) data showed losses of forest cover in the contributing watersheds of the estuary totaling $190.2 \mathrm{~km}^{2}$ during the first 6 years of BiOp implementation, 2001-2006. Results of the analysis for wetland land cover change were inconclusive. We do not recommend NOAA C-CAP data for sitescale monitoring, because higher-resolution aerial imagery or high-resolution multi-spectral imagery provide a better guide to site-scale change. However, with the availability of NOAA C-CAP's updated 
land cover data set in 2011, the analysis of land cover change trajectories during the first 10 years of BiOp implementation from 2001 to 2010 could be conducted based on the methods we developed.

\section{The Columbia River Tidal-Fluvial Regime: Water-Level Variations, Inundation, and} Vegetation Patterns (Appendix B) - The LCRE water-level regime is influenced by tides, river flow, hydropower operations, and atmospheric effects. Water-surface elevation and duration of inundation affect plant communities integral to juvenile salmon habitats. This research sought to quantify and separate water-level variations related to the various sources of external forcing, to represent with simple models the dominant process interactions, and to describe the impacts of water-level variations on wetland vegetation patterns as a fundamental indicator of ecosystem processes. In this study, we analyzed water-surface elevation records from 35 "floodplain" stations (located in peripheral and/or wetland areas exposed to the tide) and 18 main channel stations showed the same zonation as the channel stations. The results reveal four biophysical zones in the LCRE, defined in terms of physical dynamics and vegetation effects, as follows: 1) the lower estuary zone ( $\mathrm{rkm} 0-21$ ) is affected by tides and salinity intrusion; 2) the energy minimum zone (rkm 21-87) is affected by tides and river flow, but not by salinity intrusion; 3) the tidal river zone ( $\mathrm{rkm} 87-229$ ) is where river-flow effects increasingly dominate in the landward direction over tidal effects; and 4) the landslide-controlled zone (rkm 229-235) consists of the final $6 \mathrm{~km}$ of the system below Bonneville Dam and is identified by a distinctive vegetation assemblage and a much steeper bed slope than the tidal river than elsewhere in tidal freshwater of the LCRE.

Available herbaceous marsh cover data sets from historically present marshes were analyzed with respect to their fit to the hydrologic zonation. We showed the proportion of plant cover variance explained by our zonation model was the highest relative to the other five other available zonation systems used in our analysis. Understanding of relationships between natural (e.g., tides) and anthropogenic (e.g., power peaking) effects on ecosystem controlling factors (e.g., water-surface elevation), structures (e.g., vegetation communities), and processes (e.g., detrital export) and tidal wetland development is foundational to implementation of successful ecological restoration projects for salmon habitat recovery.

Estimating Realized Habitat Utilization for Chinook, Chum, and Coho Salmon in a Restoring Tidal Freshwater Wetland (Appendix C) - In intertidal wetlands, cumulative annual habitat use by migrating juvenile salmonids is determined by species-specific migration timing and seasonal residency characteristics and by periods of inundation and water quality. The potential habitat opportunity (PHO) is the total time available that salmon can access intertidal sites based on physical drivers, and the realized habitat utilization (RHU) is the subset of the PHO when salmon are residing or migrating through the system. The objective of this research was to estimate the seasonal RHU by Chinook, chum, and coho salmon in the KF site based on field measurements of salmon presence, area of inundation, and temperature values. Semidiurnal tidal fluctuations were the primary determinants of access to productive marsh zones. Wetland inundation varied nonlinearly with tidal height, and fish had access to the productive marsh edge for only about 40 to $50 \%$ of the time periods evaluated. The marsh surface was available $<40 \%$ of the time. In contrast, there was a relatively moderate impact of spring-neap variation on PHO over most measurement periods, with weekly differences usually being $<50 \mathrm{hr}$ ( $\sim 30 \%$ difference). Interannual variation in salmon presence had a strong impact on the cumulative hours salmon could use the wetland habitat. The marsh was thus used by the different salmon species for different lengths and periods of time. Tidal inundation levels constrained access to productive marsh habitat, but biological factors dictated the realized cumulative benefit to the salmon run. The RHU could be useful for assessing the cumulative effects of restoration on salmon. 
Electrofishing in Swamp Habitats in the Vicinity of Grays Bay During Spring 2010 - Data Summary (Appendix D) - Fish sampling at the KR site by the CE study team in 2005 and 2006 did not produce acceptable results because the gear types used (minnow traps, beach seines, and trap nets) could not successfully capture fish in the muddy, woody, steep-banked conditions at the site, a Sitka spruce swamp. Accordingly, we designed an electrofishing effort at the KR site and two other spruce swamps for 2010, carried out by the U.S. Fish and Wildlife Service, to address hypotheses that 1) juvenile salmon species composition, density, and length-frequency distribution would be the same for the restoration and reference sites; and 2) juvenile salmon, particularly coho salmon, would be present in the tidal swamp habitats. The duration of successful electrofishing from March through June was limited to just under 10 hours, during which a total of 47 salmon were captured. Results showed the three salmon species present in trap nets at the KF site in 2006 and 2007 were also present at the KR swamp during the spring migration of 2010. Also, the presence of juvenile salmon of all three species was verified in three small channels of the Sitka spruce swamp ecosystem in the vicinity of Grays Bay during the spring migration in 2010. This effort indicates that electrofishing methods have utility in the smaller channels of swamps of the LCRE where other gear is not viable.

\footnotetext{
Material and Nutrient Flux from Restoring Wetlands in the Tidal Freshwater of the Lower Columbia River and Estuary (Appendix E) - Restoration of hydrologically isolated wetlands to more natural tidal and fluvial forces may lead to re-establishment of productive tidal wetland systems with concurrent increases in such processes as macrodetritus export, nutrient processing, and the sequestering of sediments. To date this outcome has not been tested in the Columbia River, and there are minimal studies throughout the world that focus on exchange between restoring tidal wetland systems and the larger system. We studied material and nutrient flux components from the KF site, pre- and post-removal of the culvert, to address the following questions: Is the tidal freshwater wetland a source of or a sink for organic and inorganic matter and nutrients? Is there a detectable difference between pre- and postrestoration in ecological processes and function related to dissolved and particulate matter? An intensive flux study indicated, based on the calculated weight of material exchanged, that the KF site appears to be a sink for total organic carbon, silicate, and total suspended sediments. In contrast, the KF site appears to be a source of nitrite during both a spring and neap tide (i.e., net export). Computational fluid dynamic modeling of particulate organic matter (POM) showed that a substantial proportion of the POM would be mobilized at the KF site and, of this mobilized material, approximately $52 \%$ would reach the estuary and $48 \%$ would remain in the lower Grays floodplain and river. We offer specific research recommendations concerning material and nutrient flux.
}

\section{Statistical and Other Considerations for Restoration Action-Effectiveness Monitoring and} Research (AEMR) (Appendix F) - Action effectiveness is a critical element of the CEERP AM process. It is important to monitor the effectiveness of restoration actions to know how well they are performing relative to the intended purpose. Funds for AEMR, however, are limited and need to be spent wisely to obtain useful, cost-effective information for management. In this appendix, we present program- and project-level considerations for AERM, including 1) a method for specifying statistical relationships between intensive action-effectiveness research and extensive action-effectiveness monitoring, including a method for indicating how much AEMR sampling is enough; 2) a statistical approach for conducting quantitative meta-analysis of AEMR data; 3 ) approaches to prioritizing action-effectiveness monitoring and research and critical uncertainties research; 4) considerations in selecting the appropriate remotesensing data for monitoring vegetation; and 5) templates for project descriptions, AEMR plans, and site evaluation cards. 
Meta-Analysis of Action Effectiveness at Three Restoration Projects in the Lower Columbia River and Estuary (Appendix G) - Gathering, merging, and analyzing effectiveness monitoring data from various restoration projects is fundamental to the evaluation of the success or failure of ecosystem restoration. The challenge is to integrate multiple site-scale monitoring results to make inferences at an estuary-wide scale. An applicable technique for this is meta-analysis, or the use of statistical methods to summarize research findings across studies. Our objective was to perform a qualitative meta-analysis of the collective effectiveness of the restoration actions at Crims Island, Kandoll Farm, and Vera Slough. (A statistical meta-analysis of CEERP effectiveness data is beyond the capabilities of the current state of the data, although such an analysis should be possible in the near future.) We compiled available AEMR data into Site Evaluation Cards (SECs) for each project. "Grades" for restoration results are forthcoming, pending availability of independent practitioners. This meta-analysis was limited to three sites. Future efforts should be undertaken systematically CEERP-wide.

Detailed Outline for the FY 2012 CEERP Action Plan (Appendix H) - The Action Plan is the most important deliverable of the CEERP AM process. The Action Agencies (primarily USACE and BPA) and other CEERP stakeholders, along with restoration and monitoring/research practitioners, could systematically use the Action Plan for guidance and tracking progress. The Action Plan could also serve as a vehicle for communicating CEERP activities to 1) upper management in the Action Agencies, 2) regional resource agencies through the Anadromous Fish Evaluation Program Science Review Work Group and Systems Configuration Team, 3) regional restoration partners and interested parties on the Lower Columbia River Estuary Partnership's Science Work Group, and 4) the Northwest Power and Conservation Council and its Independent Scientific Review Panel. To initiate a formal CEERP AM process, we developed a detailed outline for the 2012 Action Plan with the intent to communicate, coordinate, and modify the plan in collaboration with the USACE and the Bonneville Power Administration and other regional stakeholders. The draft outline here includes sections on restoration project implementation, monitoring and research, and adaptive management.

Photo Points (Appendix I) - Photo points are presented for the Kandoll Farm, Vera Slough, and Crims Island study areas at various times from 2005 through 2009.

Plant List (Appendix J) - A comprehensive plant list is included in the final appendix.

\section{S.4 Management Considerations}

Based on our experience with ecosystem restoration activities in the LCRE over the past 7 years, we offer the following opinions on lessons regarding planning and design, AEMR, and CEERP AM.

\section{Planning and Design}

- Potential sites for restoration are limited, even in an area as large as the LCRE floodplain, because of land-use practices, accessibility, and suitability, among other reasons. Therefore, opportunities for restoration should be actively and aggressively pursued in a coordinated manner across multiple restoration funders and sponsors.

- The ecosystem-based restoration prioritization strategy used by the Lower Columbia River Estuary Partnership — integrating stressors at the landscape and local scale in the LCRE—identifies areas 
where restoration is more likely to succeed relative to other areas. To our knowledge, likely areas for success have not been mapped back to opportunities for potential restoration sites identified by positive functional factors.

- Alternative sources of large wood might need to be considered to meet restoration goals, even though some wood can become available to previously diked restoration sites through tree fall and re-exposure of previously buried wood due to changing hydrodynamics. This is worth considering because ecohydrological processes that provide large wood and produce ecosystem structures in tidal channels could be important in the restoration of tidal forested wetlands.

- Opening a system does not necessarily mean fish will access the site. For sites designed to directly benefit juvenile salmon, practitioners need to consider whether juvenile salmon are in reasonably close proximity to the restored area to begin with, i.e., migration patterns.

- Design should be informed by pre-construction topography and/or bathymetry because historical channel networks that remain in agricultural lands can achieve new purpose to convey flows after hydrologic reconnection.

- As-built drawings are essential for evaluation of the effectiveness of the restoration program because they document what was actually done at the project site.

\section{Monitoring and Research}

- It is critically important to apply the AEMR protocols when and wherever possible because this will allow valid analysis across multiple restoration sites and times. Applying the protocols, however, may require onsite adjustments in many cases to adapt to the conditions of the site.

- Access to restoration and reference sites for pre- and post-monitoring can be very difficult at times because water-level variations affect the ability to sample. Wherever possible, paired reference sites should be sampled at the same frequency and with the same methods as restoration sites.

\section{Adaptive Management}

- In the LCRE, AM is practiced on an ad hoc basis and does not have comprehensive regional leadership or buy-in. The Action Agencies, especially, are often pressed for time as they respond to one crisis after another. The restoration lesson is that managers and staff should step back, consider the AM phases outlined in Chapter 3.0, and systematically implement them in a dedicated manner.

- Adaptive management is only successful if the parties to the program commit to sustained roles and responsibilities.

- Adaptive management can be efficient if existing, required reporting functions are adapted to ensure the flow of information from project monitoring staff to project planning staff, and if monitoring is fully funded. To date, the Expert Regional Technical Group has found that insufficient monitoring has occurred at restoration projects in the LCRE.

- At times, regularly scheduled, multi-party AM meetings or workshops have the potential to replace expensive, time-consuming written documents and function well as communication tools.

In conclusion, although more data and information are needed on the mechanisms linking restoration of LCRE ecosystems to effects on juvenile salmonids, we achieved the primary goal of the CE study to 
develop a methodology for evaluating the cumulative effects of habitat actions in the CEERP. We delivered 1) effectiveness monitoring protocols and methods to standardize monitoring activities; 2) the theoretical and empirical basis for a CE methodology using a levels-of-evidence assessment approach; 3) evaluations of cumulative effects using ecological relationships, geo-referenced data, hydrodynamic modeling, and meta-analyses; and 4) an AM process to coordinate and coalesce restoration efforts in the LCRE. A solid foundation has been laid for future comprehensive evaluations of progress made by the CEERP to understand, conserve, and restore ecosystems in the LCRE. 


\section{Preface}

This research, called the Cumulative Effects (CE) study, was performed under the auspices of the U.S. Army Corps of Engineers Anadromous Fish Evaluation Program (study code EST-P-02-04). The study was funded by the U.S. Army Corps of Engineers, Portland District (USACE) (Ref. No. AGRW66QKZ80031101) under agreements with the U.S. Department of Energy and the U.S. Department of Commerce for work by Pacific Northwest National Laboratory (PNNL) and the National Marine Fisheries Service (NMFS), respectively. Subcontractors to PNNL included the Columbia River Estuary Study Taskforce, Portland State University, University of Washington, and Mr. Earl M. Dawley (National Marine Fisheries Services-retired). Mr. Blaine D. Ebberts was the USACE's technical lead for the 2004-2010 study, with assistance from Ms. Cynthia A. Studebaker (USACE) during 2010. For more information about the study, contact Mr. Gary E. Johnson, PNNL's project manager (503 417-7567).

In this, the seventh and last annual report for the CE study, we synthesize CE study research on the ecology and hydrology of restoring wetlands in the LCRE, update the Columbia Estuary Ecosystem Restoration Program adaptivement management framework and suggest specific work to implement it, and present new results pertinent to the four overall study objectives. The report is not a stand-alone summary of all CE research, nor does it emphasize accomplishments and advances made in this particular study year like previous annual reports have. Methods and findings documented previously in CE study reports and publications are referenced.

Technical reports and peer-reviewed publications, essential mechanisms for disseminating scientific findings, are products of this project. Technical reports from the CE study are described in the Introduction chapter. The project's publications and pending publications include the following:

- Diefenderfer HL and DR Montgomery. 2008. "Pool Spacing, Channel Morphology, and the Restoration of Tidal Forested Wetlands of the Columbia River, U.S.A." Restoration Ecology $17: 158-168$.

- Diefenderfer HL, AM Coleman, AB Borde, and IA Sinks. 2008. "Hydraulic Geometry and Microtopography of Tidal Freshwater Forested Wetlands and Implications for Restoration, Columbia River, U.S.A.” International Journal of Ecohydrology and Hydrobiology 8:339-361.

- Roegner GC, HL Diefenderfer, AB Borde, RM Thom, EM Dawley, AH Whiting, SA Zimmerman, and GE Johnson. 2009. Protocols for Monitoring Habitat Restoration Projects in the Lower Columbia River and Estuary. U.S. Department of Commerce, National Oceanic and Atmospheric Administration Technical Memorandum NMFS-NWFSC-97, Northwest Fisheries Science Center, Seattle, Washington.

- Roegner GC, EW Dawley, M Russell, AH Whiting, and DJ Teel. 2010. "Juvenile Salmonid Use of Reconnected Tidal Freshwater Wetlands in Grays River, Lower Columbia River Basin." Transactions of the American Fisheries Society 139:1211-1232

- Diefenderfer HL, RM Thom, GE Johnson, JR Skalski, KA Vogt, BD Ebberts, GC Roegner, and EM Dawley. 2011. "A Levels-of-Evidence Approach for Assessing Cumulative Ecosystem Response to Estuary and River Restoration Programs.” Ecological Restoration 29:111-132. 
- Diefenderfer HL, GE Johnson, JR Skalski, SA Breithaupt, and AM Coleman. 2012. "Application of the Diminishing Returns Concept in the Hydroecologic Restoration of Riverscapes." Landscape Ecology 27:671-682.

- Coleman, AM, HL Diefenderfer, DL Ward, AB Borde. In Preparation. “A Spatially Based AreaTime Inundation Index Model for Tidal Wetlands and Restoration Sites of the Lower Columbia River Floodplain and Estuary."

- Thom RM, HL Diefenderfer, AM Coleman, AB Borde, CG Roegner, JD Tagestad, GE Johnson. In Preparation. "Ecology and Hydrology of Restored Wetlands in the Lower Columbia River and Estuary."

- Borde AB, HL Diefenderfer, SA Zimmerman, RM Thom, and VI Cullinan. In Preparation. "Wetland Vegetation Community Distribution and Inundation Patterns in the Tidally Influenced Columbia River, USA."

- Woodruff, DL, RM Thom, CR Roegner, S Breithaupt, G Johnson, J Vavrinec. In Preparation. "Nutrient and organic matter flux in a Restoring Tidal Freshwater Wetland of the Columbia River Estuary."

- Diefenderfer HL, AB Borde, GC Roegner, and VI Cullinan. In Preparation. "Ecological Trajectories and Salmon Habitat Functions of Historical Dike Breaches and Created Islands in the Columbia River Floodplain, USA."

- Diefenderfer HL, AB Borde, KA Vogt, KL Sobocinski. In Preparation. “Conceptual Model-Driven Research to Conserve and Restore Temperate Zone Picea sitchensis Tidal Wetland Habitat for Endangered Salmonid Fishes."

Scientific conferences, symposia, and workshops are also important ways to transfer knowledge gained from this research. Project scientists presented papers concerning various aspects of the study at the following events from 2004 through 2010:

- USACE Anadromous Fish Evaluation Program Annual Review (December 2005 through 2011; Walla Walla or Portland).

- Columbia River Estuary Conference (April 2006 and 2008, May 2010; Astoria).

- Restore America's Estuaries (December 2006; New Orleans).

- National Conference on Ecosystem Restoration (April 2007, Kansas City; July 2009, Los Angeles).

- Coastal and Estuarine Research Federation Biennial Conference (November 2009; Portland).

- American Society of Limnology and Oceanography (June 2010; Albuquerque).

Recommended citation for the entire report: Johnson GE, HL Diefenderfer, RM Thom, GC Roegner, BD Ebberts, JR Skalski, AB Borde, EM Dawley, AM Coleman, DL Woodruff, SA Breithaupt, AS Cameron, CA Corbett, EE Donley, DA Jay, Y Ke, KE Leffler, CB McNeil, CA Studebaker, and JD Tagestad. 2012. Evaluation of Cumulative Ecosystem Response to Restoration Projects in the Lower Columbia River and Estuary, 2010. PNNL-20296, prepared for the U.S. Army Corps of Engineers, Portland District, Portland, Oregon, by Pacific Northwest National Laboratory, Richland, Washington. 
Recommended citation for a chapter in the report: Roegner GC and EM Dawley. 2012. "Estimating Realized Habitat Utilization for Chinook, Chum, and Coho Salmon in a Restoring Tidal Freshwater Wetland," pp. C.1-C.11, in Evaluation of Cumulative Ecosystem Response to Restoration Projects in the Lower Columbia River and Estuary, 2010, Johnson et al. PNNL-20296, prepared for the U.S. Army Corps of Engineers, Portland District, Portland, Oregon, by Pacific Northwest National Laboratory, Richland, Washington. 


\section{Acknowledgments}

This study could not have been conducted without the help of the Bonneville Power Administration, Columbia Land Trust, Columbia River Estuary Study Taskforce, Lower Columbia Estuary Partnership National Marine Fisheries Service, Portland State University, University of Washington, and U.S. Army Corps of Engineers. In addition, the authors are extremely grateful to the following people for their contributions to the study:

- Ian Sinks, Nadia Gardner, and Scott McEwen of the Columbia Land Trust

- Alejandro Bancke, Harry Rectenwald, Micah Russell, and Alan Whiting (now with PC Trask and Associates) of the Columbia River Estuary Study Taskforce

- Dave Nichols of the Illwaco Fuel Dock

- Keith Marcoe of the Lower Columbia Estuary Partnership

- Kate Buneau, Val Cullinan, Susan Ennor, Kate Hall, Kenneth Ham, Lyle Hibler, Rhonda Karls, Ron Kaufmann, Mike Parker, William Pratt, Nikki Sather, Jeni Smith, Meghan Chalk, and John Vavrinec of the Pacific Northwest National Laboratory

- John Kranda and Mike Langeslay of the USACE Portland District

- Kenneth Ostrand, Benjamen Kennedy, and James Samagaio of the U.S. Fish and Wildlife Service

- Mike Balch and Dan Bardsley of the Wahkiakum County Sheriff's office

- Poul Toftemark, Wahkiakum County resident. 


\section{Acronyms and Abbreviations}

7-DAM

AEMR

AFEP

AMST

AMTAT

ANOSIM

ArcGIS

ATIIM

BARR

BG

BiOp

BPA

${ }^{\circ} \mathrm{C}$

C-CAP

CE

CEERP

CFR

$\mathrm{CHM}$

CI

CLT

$\mathrm{cm}$

$\mathrm{cm} / \mathrm{yr}$

CNEI

CPUE

$\mathrm{CR}$

CRD

CRE

CREC

CREST

CREC

3D

d

D $\infty$

D8

$\mathrm{dbh}$

DO 7-day average maximum (daily temperature)

action-effectiveness monitoring and research

Anadromous Fish Evaluation Program

Adaptive Management Stakeholders Team

Adaptive Management Technical Analysis Team

Analysis of Similarity

ArcInfo Geographic Information System

Area-Time Inundation Index Model

before-after restoration-reference

bare ground

Biological Opinion

Bonneville Power Administration

degrees Celsius

Coastal Change Analysis Program

cumulative effects (study, etc.)

Columbia Estuary Ecosystem Restoration Program

Code of Federal Regulations

Chinook River Marsh

Crims Island

Columbia Land Trust

centimeter(s)

centimeter(s) per year

cumulative net ecosystem improvement

catch per unit effort

Crims Island reference (site)

Columbia River Datum

Columbia River Estuary

Columbia River Estuary Research Conference

Columbia River Estuary Study Taskforce

Columbia River Estuary Research Conference

three-dimensional

day

deterministic infinity (method)

deterministic-8 (method)

diameter at breast height

dissolved oxygen 


\begin{tabular}{|c|c|}
\hline dry wt & dry weight \\
\hline DW & debris wrack \\
\hline EP & (Lower Columbia River) Estuary Partnership \\
\hline ERTG & Expert Regional Technical Group \\
\hline ESA & Endangered Species Act \\
\hline ESU & Evolutionarily Significant Unit \\
\hline FCRPS & Federal Columbia River Power System \\
\hline FGA & filamentous green algae \\
\hline FY & fiscal year \\
\hline g & $\operatorname{gram}(\mathrm{s})$ \\
\hline GDTR & greater diurnal tidal range \\
\hline GIC & Goat Island created marsh \\
\hline GIS & geographic information system \\
\hline $\mathrm{g} / \mathrm{m}^{2}$ & gram(s) per square meter \\
\hline GPS & global positioning system \\
\hline $\mathrm{h}$ & hour(s) \\
\hline HHW & higher high water \\
\hline al & hydrologic unit \\
\hline IRI & index of relative importance \\
\hline IRLS & iteratively re-weighted least-squares regression \\
\hline ISS & inorganic suspended sediments \\
\hline $\mathrm{kg} / \mathrm{m}^{3}$ & kilogram(s) per cubic meter \\
\hline $\mathrm{km}$ & kilometer(s) \\
\hline JBH & Julia Butler Hanson \\
\hline $\mathrm{L}$ & liter(s) \\
\hline LCRE & lower Columbia River and estuary (rkm 0-235) \\
\hline LCRFB & Lower Columbia Fish Recovery Board \\
\hline LiDAR & light detection and ranging \\
\hline LLW & lower low water \\
\hline LOR & length of record \\
\hline LWD & large woody debris \\
\hline $\mathrm{m}$ & meter(s) \\
\hline$m^{-2}$ & square meters \\
\hline $\mathrm{m}^{3} / \mathrm{s}$ & cubic meter(s) per second \\
\hline MG & mixed grass \\
\hline $\mathrm{mg} / \mathrm{m}^{3}$ & milligram(s) per cubic meter \\
\hline MLW & mean low water \\
\hline $\mathrm{mm}$ & millimeter(s) \\
\hline
\end{tabular}




\begin{tabular}{|c|c|}
\hline $\mathrm{mT}$ dry wt & metric ton(s) dry weight \\
\hline MTWI & modified topographic wetness index \\
\hline NA & not applicable \\
\hline NAPP & net aerial primary production \\
\hline NAVD88 & North American Vertical Datum of 1988 \\
\hline ND & no data available \\
\hline NEI & net ecosystem improvement \\
\hline NF & nutrient flux \\
\hline $\mathrm{NH}_{4}$ & ammonia \\
\hline NHD & (USGS) National Hydrography Dataset \\
\hline NMFS & National Marine Fisheries Service \\
\hline NOAA & National Oceanic and Atmospheric Administration \\
\hline $\mathrm{NO}_{2}$ & nitrate \\
\hline $\mathrm{NO}_{3}$ & nitrite \\
\hline NWR & National Wildlife Refuge \\
\hline OPUS & Online Positioning User Service \\
\hline OSS & organic suspended sediments \\
\hline OWEB & Oregon Watershed Enhancement Board \\
\hline PHO & potential habitat opportunity \\
\hline PNAMP & Pacific Northwest Aquatic Monitoring Partnership \\
\hline PNNL & Pacific Northwest National Laboratory \\
\hline $\mathrm{PO}_{4}$ & phosphate \\
\hline POM & particulate organic matter \\
\hline PP & photo point \\
\hline PSU & Portland State University \\
\hline QRAT & quick response assessment team \\
\hline RHU & realized habitat utilization \\
\hline $\mathrm{rkm}$ & river kilometer \\
\hline RMS & Root Mean Square(d) \\
\hline RTK & real-time kinematic \\
\hline $\mathrm{s}$ & second(s) \\
\hline SAR & smolt-to-adult return \\
\hline SBU & survival benefit unit \\
\hline SD & standard deviation \\
\hline $\mathrm{SE}$ & standard error \\
\hline SEC & Site Evaluation Card \\
\hline SEV & sum exceedance value \\
\hline $\mathrm{SiO}_{4}$ & silicate \\
\hline
\end{tabular}


SSE

SSW

TGO

TIN

TM

TN

TN1, TN2

TOC

TRI

TSS

UID

USACE

USFWS

UW

VR

VS

WA

WETS

WRDA

WSDOE

WSE

YBP

yr
Seal Slough East

Seal Slough West

Trimble Geomatics Office

Triangulated Irregular Network

(Landsat) Thematic Mapper

trap net

trap-net site 1, trap-net site 2, etc.

total organic carbon

topographic ruggedness index

total suspended sediment

unidentified

U.S. Army Corps of Engineers

U.S. Fish and Wildlife Service

University of Washington

Vera Slough reference (site)

Vera Slough

wetted area

wetland determination (table)

Water Resources Development Act

Washington Department of Ecology

water-surface elevation

years before present

year(s) 


\section{Contents}

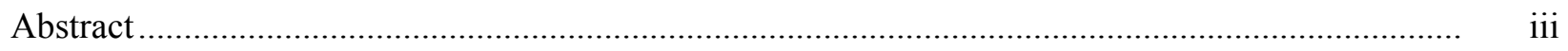

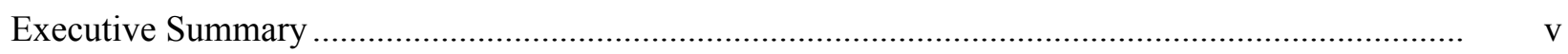

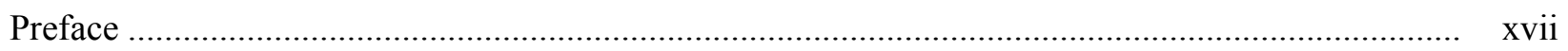

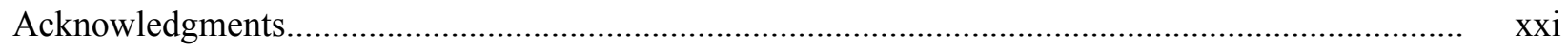

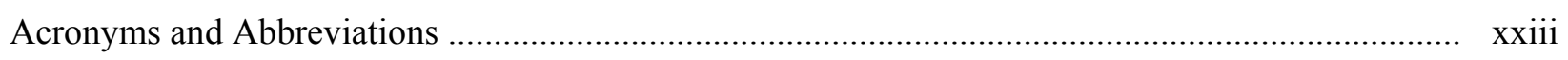

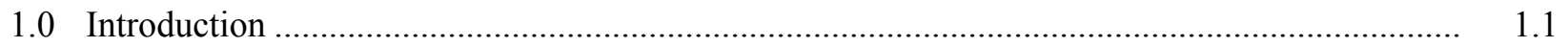

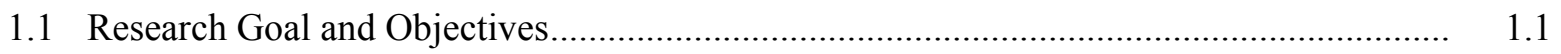

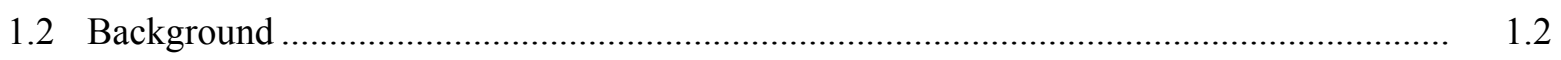

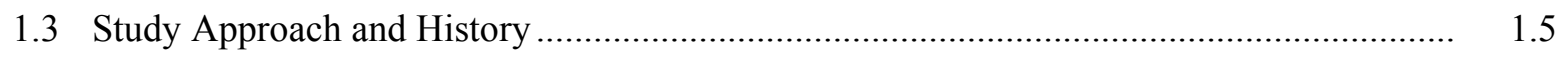

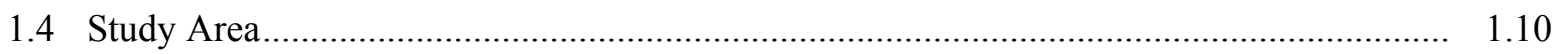

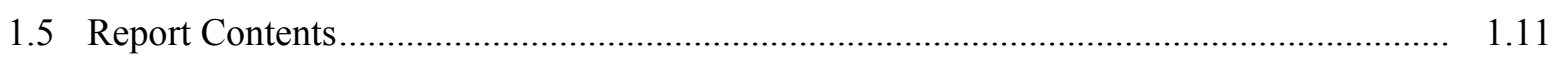

2.0 Ecology and Hydrology of Restoring Wetlands in the Lower Columbia River and Estuary ....... 2.1

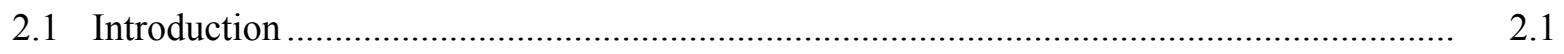

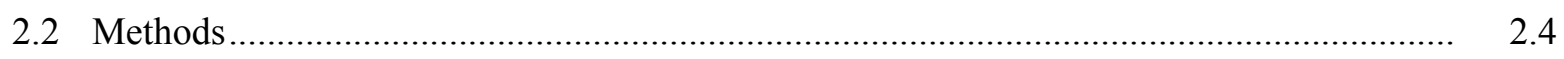

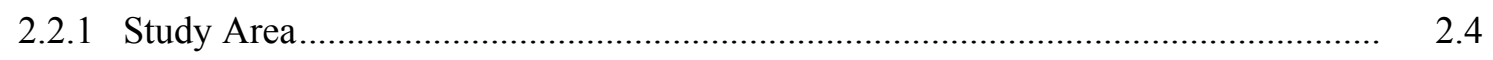

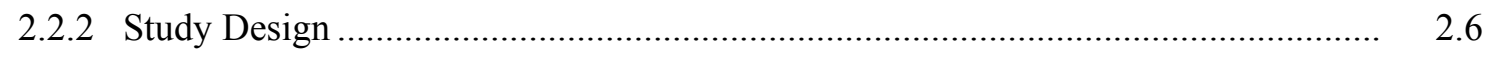

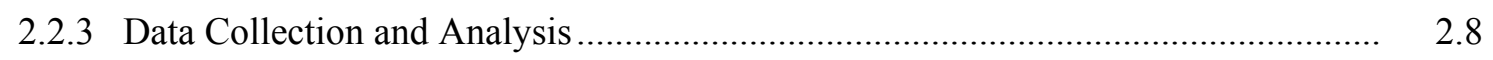

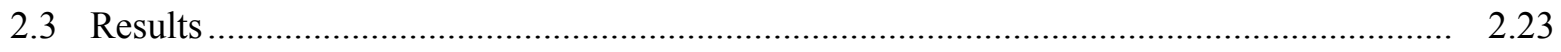

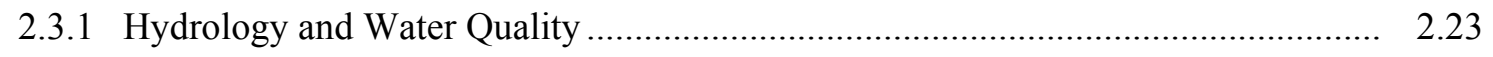

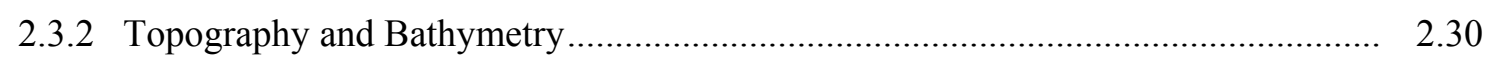

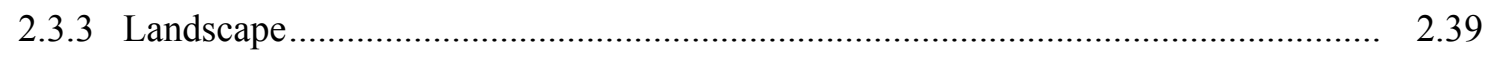

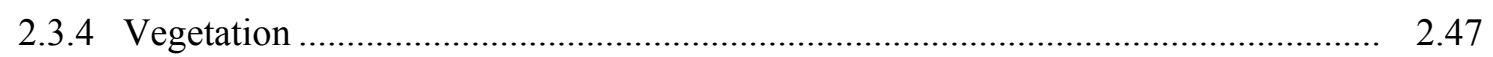

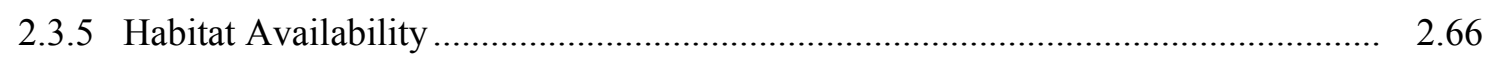

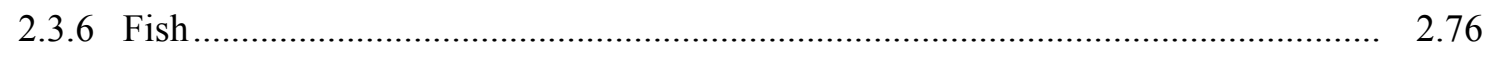

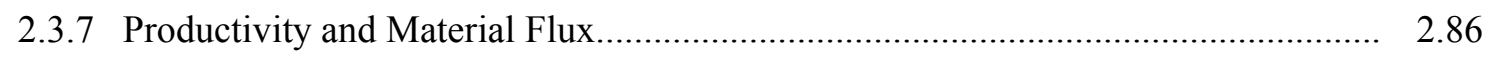

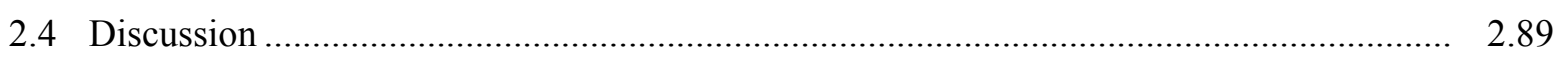

2.4.1 Ecological Responses of Restored Sites ........................................................ 2.89

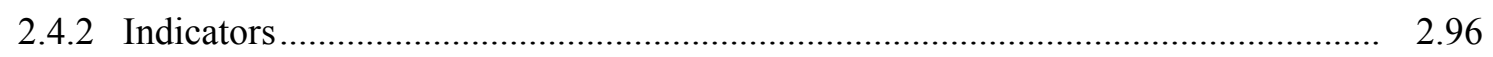

2.4.3 Summary of Restoration Responses................................................................ 2.97

2.4.4 Summary of Findings and Implications for Cumulative Effects Evidence .............. 2.98

3.0 Adaptive Management of Ecosystem Restoration in the Lower Columbia River and

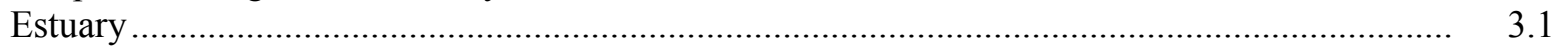

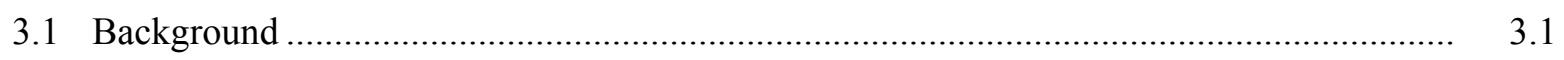

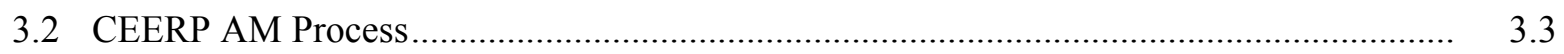

3.2.1 The Decide Phase ......................................................................................... 3.5

3.2.2 The Act, Monitor/Research, and Evaluate Phases............................................... 3.8

3.2.3 The Strategize Phase ............................................................................. 3.12 


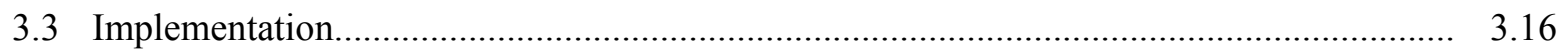

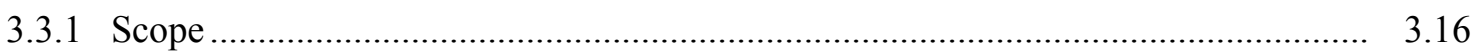

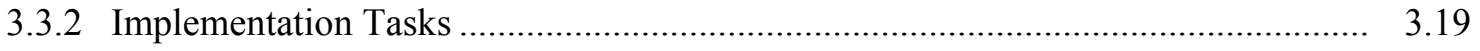

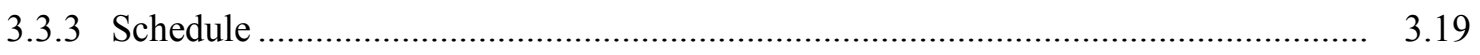

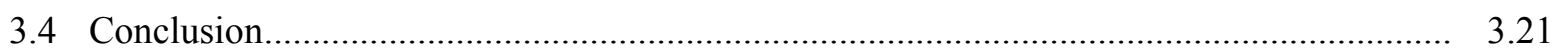

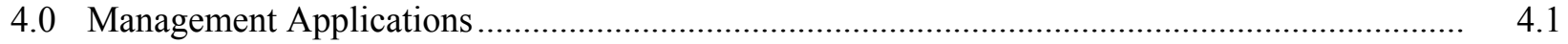

4.1 Water Resources Development Acts: Restoration in the LCRE ..................................... 4.1

4.2 Collaborative Planning for Large-Scale River Systems Restoration ................................ 4.2

4.3 Columbia Basin-Wide Cumulative Effects Assessments................................................... 4.3

4.4 Columbia Estuary Ecosystem Restoration Program ........................................................ 4.3

5.0 Conclusions and Recommendations ........................................................................ 5.1

5.1 CE Deliverables and Supporting Publications ........................................................... 5.1

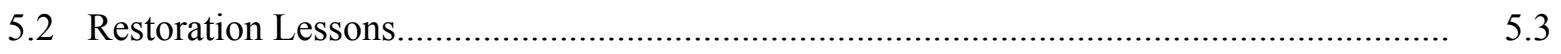

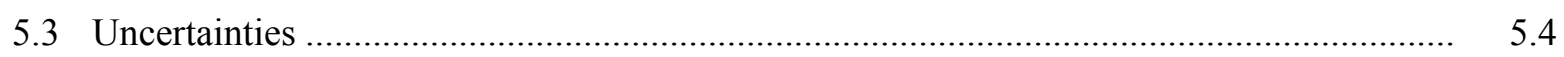

5.4 Research and Development Recommendations ......................................................... 5.5

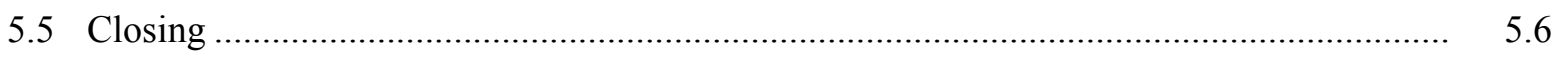

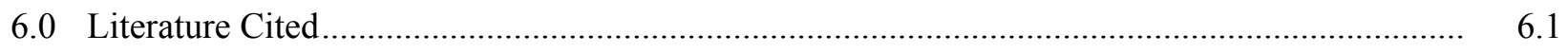

Appendix A - Temporal Land Cover Analysis for Net Ecosystem Improvement ............................ A.1

Appendix B - The Columbia River Tidal-Fluvial Regime: Water-Level Variations, Inundation, and Vegetation Patterns................................................................... B. B

Appendix C - Estimating Realized Habitat Utilization for Chinook, Chum, and Coho Salmon in a Restoring Tidal Freshwater Wetland ............................................................... C. 1

Appendix D - Electrofishing in Swamp Habitats in the Vicinity of Grays Bay During Spring 2010 - Data Summary

D.1

Appendix E - Material and Nutrient Flux from Restoring Wetlands in the Tidal Freshwater of the Lower Columbia River and Estuary

Appendix F - Statistical and Other Considerations for Restoration Action-Effectiveness Monitoring and Research ............................................................................... F.

Appendix G - Meta-Analysis of Action Effectiveness at Three Restoration Projects in the Lower Columbia River and Estuary ...................................................................... G.1

Appendix H - Detailed Outline for the FY 2012 CEERP Action Plan ........................................... H.1

Appendix I - Photo Points ................................................................................................... I.

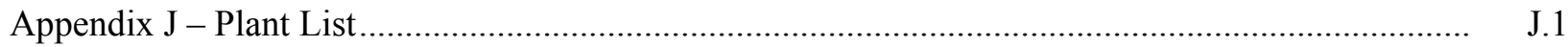




\section{Figures}

1.1 The Lower Columbia River and Estuary from Bonneville Dam to the Pacific Ocean ............... 1.1

1.2 Levels-of-Evidence Approach for Evaluation of the Cumulative Effects of Ecosystem

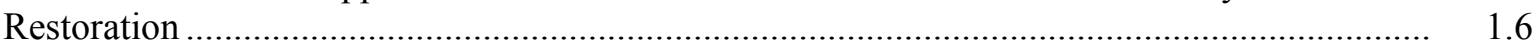

1.3 Field Sites for the Cumulative Effects Study ................................................................. 1.11

2.1 Three Main CE Study Sampling Locations .................................................................... 2.5

2.2 Detailed Maps of Paired Vera Slough Restoration and Reference Sites Showing the Locations of Data Collection .................................................................................................. 2.8

2.3 Kandoll Farm Restoration and Kandoll Reference Sites ......................................................... 2.9

2.4 Crims Island Restoration and Crims Reference Sites ...................................................... 2.10

2.5 Hourly Water-Surface Elevation at KF Inside and KR Channel During the Months Spanning the Tide Gate Removal, Dike Breach, and Culvert Replacement............................. 2.23

2.6 Hourly Water-Surface Elevation at the VS Site, Inside and Outside of the New Tide Gates, Winter 2008

2.7 Exposure-Height Curves Comparing Inundation Levels Before and After Tidal Reconnection at the KF Site

2.8 Exposure-Height Curves Comparing Inundation Levels Before and After Tidal Reconnection

2.9 Hourly Water Levels at the Mouth of Crims Island's East Channel and Inside the Southeast Channel in March 2009

2.10 Daily Maximum Water Levels at the Mouth of Crims Island's East Channel and Inside the Southeast Channel

2.11 7-DAM Temperatures of the KF Inside and KR Channel Stations During the Warmest Water Temperatures of the Year in Late Summer...

2.12 Seven-Day Average Maximum Daily Temperature at Sites in the Vicinity of Kandoll Farm from January to July, 2005-2007

2.13 Temperature Records at Five Locations on Kandoll Farm Restoration Site in 2006-2007 After Restoration in 2005.

2.14 The 7-DAM Temperature for the Vera Slough Inside and Vera Reference Channel Stations, Spring and Summer Months, 2009.

2.15 The 7-DAM Temperature for the Vera Slough Inside and Vera Outside Channel Stations Winter Months After Tide Gate Installation, 2005-2006

2.16 Seven-Day Average Maximum Daily Temperature at Restoration and Reference Stations at Vera Slough from January through July, 2005, 2006, and 2007.

2.17 Sediment Accretion Rates and Elevation. Rates are from 2005 Through 2009 for the VS, VR, and KF Sites, and from 2006 Through 2009 for the CI, CR, and KR Sites

2.18 Vegetation Cover in 2005 at the Kandoll Reference and Kandoll Farm Sites .......................... 2.42

2.19 Vegetation Cover in 2009 at the Kandoll Reference and Kandoll Farm Sites .......................... 2.43

2.20 Vegetation Cover in 2005 at the Vera Slough and Vera Reference Sites ................................ 2.44

2.21 Vegetation Cover in 2009 at the Vera Slough and Vera Reference Sites ............................... 2.45

2.22 Site Elevation Survey for Marsh Area and Potential Reed Canarygrass Area......................... 2..47 
2.23 Herbaceous Vegetation Cover and Species Elevation Ranges at the Vera Slough

Restoration and Reference Sites in 2005 and 2009.

2.24 Herbaceous Vegetation Cover and Species Elevation Ranges at Kandoll Farm Restoration and Reference Sites During 2005

2.25 Herbaceous Vegetation Cover and Species Elevation Ranges at Kandoll Farm Restoration and Reference Sites During 2009

2.26 Herbaceous Vegetation Cover and Species Elevation Ranges at Crims Island Restoration and Reference Sites in 2005 and 2009.

2.27 Pattern of Change in Vegetation Similarity Between Sites over Time Since Restoration.

2.28 Species-Area Curves and Bray-Curtis Distance Curves from First- and Last-Year Herbaceous Vegetation Sampling at Paired Restoration and Reference Sites.....

2.29 Percent Habitat Opportunity at Paired Restoration and Reference Sites as a Function of WSE

2.30 Inundation Perimeters at the Paired Reference and Restoration Sites for CI/CR, KF/KR, $\mathrm{VS}$, and VR

2.31 Inundation Perimeter at Paired Restoration and Reference Sites

2.32 Hypsometric Curves for Paired Restoration and Reference Sites

2.33 Relationship of WSE to Volume................................................................................... 2.72

2.34 Topographic Ruggedness Index for Paired Restoration and Reference Sites ......................... 2.74

2.35 Modified Topographic Wetness Index Values for Paired Restoration and Reference Sites ....... 2.75

2.36 Pre- and Post-Restoration Diversity at Kandoll Farm for the Kandoll 1 Site, Kandoll 2 Site, and the Reference Site

2.37 Pre- and Post-Restoration Diversity at Vera Slough

2.38 Mean Salmon Size by Time from 2006 Through 2009 at the KF Site......

2.39 Total Annual Catch of Salmonids in Kandoll Farm Trap Nets from 2006 Through 2009

2.40 Size Frequency Histograms of Salmonids at Restoration and Reference Sites in the Grays River System in 2006 and 2007.

2.41 Salmon Relative CPUE at Restoration and Reference Sites in the Grays River System, 2006 and 2007 .....

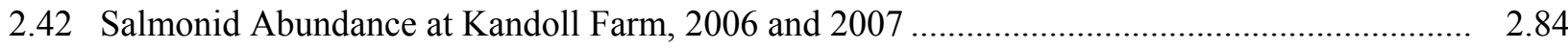

2.43 Habitat Use of Salmonids at Kandoll Farm, 2006 Through 2009.......................................... 2.84

2.44 Diet of Subyearling Coho Salmon at Kandoll Farm During April, May and June 2008 ........... 2.85

3.1 CEERP Adaptive Management Process............................................................................. 3.4

3.2 The Decide Phase in the CEERP Adaptive Management Process .......................................... 3.5

3.3 The Act, Monitor/Research, and Evaluate Phases in the CEERP Adaptive Management Process

3.4 The Strategize Phase in the CEERP Adaptive Management Process ..................................... 3.12

3.5 A System Development Matrix Summarizing the State of the Estuary and the Basic Actions Recommended

3.6 Chart Depicting the Tentative Schedule and Integration of AM Phases, Work Products, Meetings, and Existing Activities 


\section{Tables}

1.1 Activity Matrix by Objective and Sub-Objective for the CE Study, 2004-2010_.................. 1.6

1.2 History of the 2004-2010 Cumulative Effects Study ........................................................... 1.8

2.1 Categories of Environmental Measurements Collected at the Six Primary Study Sites ............ 2.3

2.2 Indicators of the Effect of Wetland Restoration on Salmon Populations ................................ 2.7

2.3 Vegetation and Other Land Cover Types Derived from Satellite Imagery.............................. 2.15

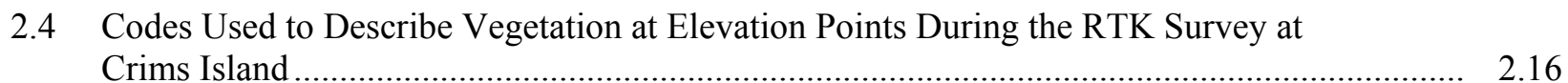

2.5 Summary of Sediment Accretion Rates at Paired Restoration and Reference Sites ................. 2.31

2.6 Channel Morphological Adjustments Between 2005 and 2009 at Restoration and

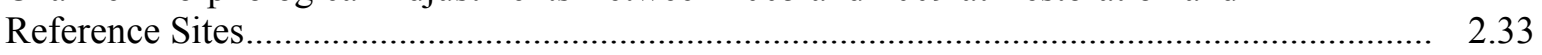

2.7 The Apparent Change in 19 Plant Community Cover Types Between 2005 and 2009 at the Kandoll Farm and Vera Slough Restoration Sites and Corresponding Reference Sites.

2.8 Dominant Species, Elevation Ranges, and Area for Vegetation Categories at Crims Island in 2007

2.9 Average Percent Cover of the Dominant Plant Species at the Kandoll Restoration Site Sampling Locations in 2005 and $2006 .$.

2.10 Relative Sorensen Similarity Indexes for Herbaceous Vegetation in 2005, 2006, and 2009

2.11 Abbreviated Table of Similarity Between Years at a Site, and Between the Restored and Reference Sites.

2.12 Summary of Species Richness, Evenness, Shannon-Wiener Diversity Index, and Simpson's Diversity Index for Infinite Population

2.13 Summary of 2009 Shrub Stem Frequency, Density, and Elevation at the KR Site

2.14 Summary of 2009 Tree Cover at the KR Swamp

2.15 Plant Species on a Line-Intercept Transect in Five Fields at Kandoll Farm in 2005, 2006, and 2009.

2.16 Presence of Previously Unrecorded Species in Five Fields on a Line-Intercept Transect at Kandoll Farm in 2009

2.17 Site-Scale Metrics Evaluating Habitat Opportunity.

2.18 Surveyed and Modeled Bankfull Elevations and WSE Frequency ........................................ 2.67

2.19 Inundation Perimeter at Maximum Frequency WSE with Mean TRI and MTWI................... 2.67

2.20 Biomass Flux Results for Six Paired Restoration and Reference Sites Before and After Restoration, and Julia Butler Hansen Before Tide Gate Installation

2.21 POM Export for Three Locations in the Lower Grays River Area ........................................ 2.. 2.89

2.22 Summary of the Relative Effects of the Various Restoration Actions on the Core and Higher-Order Indicators

2.23 Summary of Findings and Inferences to the Site and Ecosystem Scales, and Salmonids

3.1 AM Phases, Teams, and Deliverables. 
3.2 Draft Outline for the Annual CEERP Action Plan.............................................................. 3.7

3.3 Draft Outline for the Annual CEERP Synthesis Memorandum........................................... 3.11

3.4 Draft Outline for the Annual CEERP Strategy Report ........................................................ 3.15 


\subsection{Introduction}

This is the seventh and final annual report of a project (conducted from 2004 through 2010) addressing evaluation of the cumulative effects of habitat restoration actions in the 235-km-long lower Columbia River and estuary (LCRE; ${ }^{1}$ Figure 1.1). The project, called the Cumulative Effects (CE) study, was conducted for the U.S. Army Corps of Engineers Portland District (USACE or the Corps) by the Marine Sciences Laboratory of the Pacific Northwest National Laboratory, the Pt. Adams Biological Field Station of the National Marine Fisheries Service (NMFS), the Columbia River Estuary Study Taskforce (CREST), the University of Washington (UW), and Portland State University (PSU).

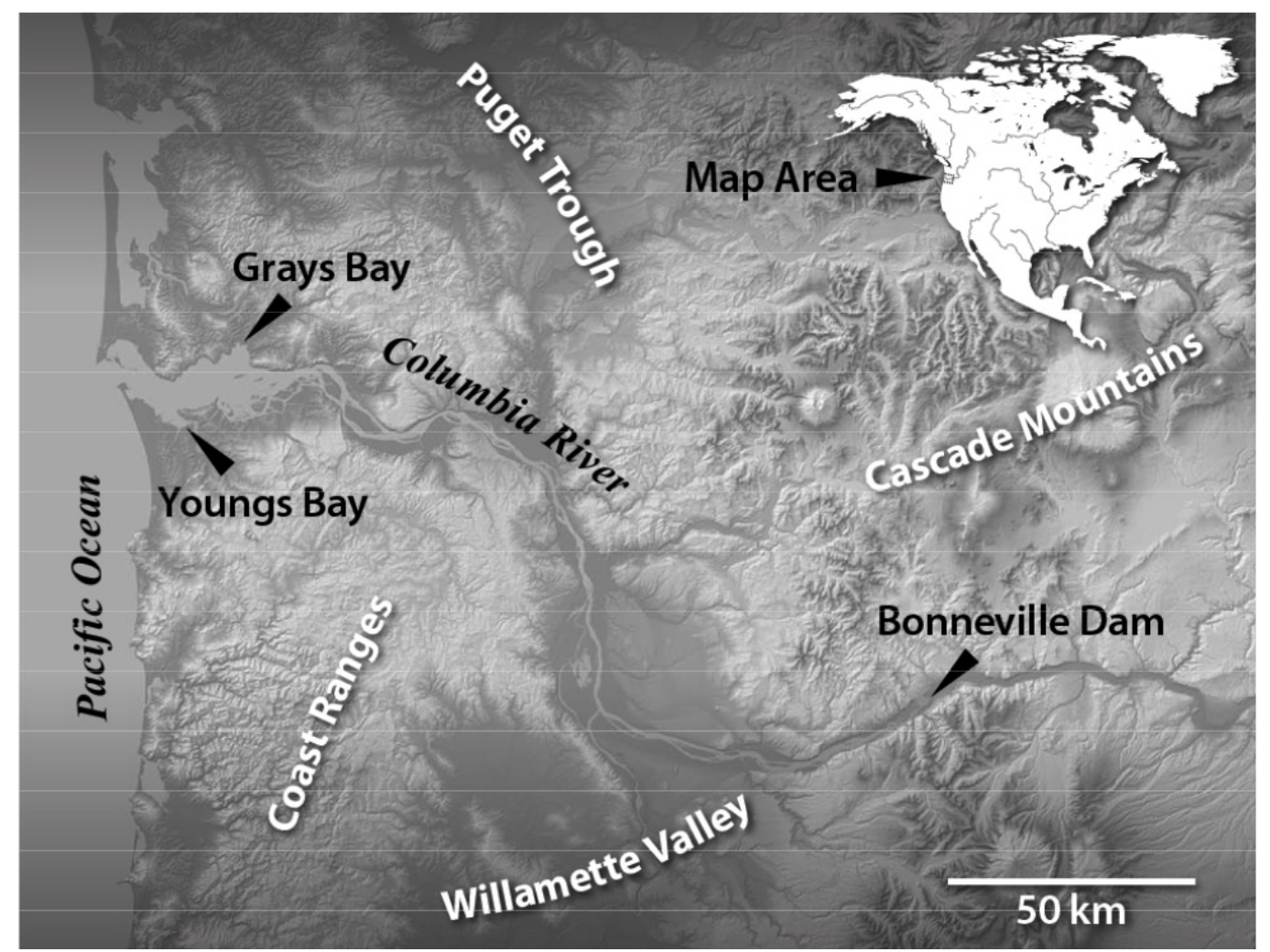

Figure 1.1. The Lower Columbia River and Estuary from Bonneville Dam to the Pacific Ocean

\subsection{Research Goal and Objectives}

The primary goal of this multi-year study was to develop a methodology to evaluate the cumulative effects $^{2}$ of habitat actions in the Columbia Estuary Ecosystem Restoration Program ${ }^{3}$ aimed at restoring LCRE ecosystems and increasing population levels of listed Columbia River basin salmon. We designed an ecosystem-based methodology and protocols to ensure comparable data sets across multiple restoration monitoring efforts estuary-wide. The products of this research allow management decision-makers to

\footnotetext{
${ }^{1}$ By definition, the LCRE includes the floodplain and tidally influenced areas from Bonneville Dam to the ocean.

${ }^{2}$ Cumulative restoration effects are the net change in ecosystem-wide metrics and ecosystem state resulting from cumulative restoration impacts (Leibowitz et al. 1992).

${ }^{3}$ This is the name we use to identify the collective restoration efforts in the LCRE by the Bonneville Power Administration, USACE, and others.
} 
1) evaluate the ecological performance of the collective habitat restoration effort in the LCRE and its effects on listed salmon, and 2) apply scientific knowledge from ongoing monitoring within a formal adaptive management framework to prioritize cost- and ecologically effective restoration projects in the future. The CE study had four main objectives:

- Monitoring Protocols - Develop monitoring protocols and methods to standardize monitoring activities to determine the effectiveness of LCRE ecosystem restoration actions.

- Methodology - Develop the theoretical and empirical basis for a CE methodology, together with a set of metrics and a conceptual model depicting the cumulative effects of LCRE restoration projects on key major ecosystem functions supporting listed salmon.

- Evaluation - Design and implement evaluations of the CE methodologies by applying standard methods in studies of ecological relationships, a geographic information system (GIS) database of restoration-related data, hydrodynamic modeling, and meta-analyses to assess ecosystem response of the cumulative effects of multiple habitat restoration projects.

- Adaptive Management - Develop an adaptive management process to coordinate and coalesce the restoration efforts in the LCRE to support decisions by the USACE and others regarding LCRE habitat restoration activities.

\subsection{Background}

Many federal, state, and local agencies and non-governmental organizations are working to restore estuarine and tidal freshwater habitats for juvenile salmon in the LCRE. This work is driven by federal Water Resources Development Acts from 1986, 1990, 1996, and 2000; recovery plans for salmon and steelhead species listed under the Endangered Species Act (ESA) (Lower Columbia Fish Recovery Board 2010; National Marine Fisheries Service [NMFS] 2011; and Biological Opinions (BiOps) on operation of the Federal Columbia River Power System (FCRPS) (NMFS 2000, 2004, 2008, 2010). A major portion of the effort, herein called the Columbia Estuary Ecosystem Restoration Program (CEERP), is coordinated, funded, and evaluated by the federal Action Agencies, primarily the Bonneville Power Administration (BPA) and the USACE. The intent is to improve the functionality of LCRE ecosystems through ecosystem-based habitat restoration (Johnson et al. 2003). Since 2000, the federal Action Agencies have provided over $\$ 10$ million for more than 100 restoration projects in the LCRE. CEERP decision-makers need scientific evaluations of the extent to which the CEERP is meeting its overall goal to understand, conserve, and restore ecosystems in the LCRE.

Furthermore, the Action Agencies have committed to specific targets for improved survival of juvenile salmon under the 2008 FCRPS BiOp (NMFS 2008) - 49 survival benefit units for ocean-type salmon and 30 survival benefit units for stream-type salmon by 2018. Survival benefit units are an index intended to represent the effect of LCRE habitat restoration on juvenile salmon survival. Developed for the 2007 Biological Assessment on FCPRS operations (Action Agencies 2007), survival benefit units were incorporated into the 2008 FCRPS BiOp as targets for survival improvements from LCRE habitat restoration actions prescribed in the $2008 \mathrm{BiOp}$. To assign survival benefit units for LCRE habitat restoration projects, the Action Agencies have formed the Expert Regional Technical Group (ERTG) on estuary habitat actions. The ERTG (2010) describes the method to assign survival benefit units. 
The primary management questions for the CEERP are as follows:

- What are the limiting factors or threats, i.e., stressors and controlling factors, in the estuary preventing the achievement of desired habitat or fish performance?

- Which estuary habitat restoration actions are most effective at addressing the limiting factors preventing achievement of habitat, fish, or wildlife performance objectives?

- Which restoration actions are most effective at improving habitat opportunity and capacity for juvenile salmon through increased habitat connectivity, flood attenuation, sediment trapping, nutrient processing, export of marsh macrodetritus, and other ecosystem functions?

- Are the habitat actions resulting in continued loss, no net loss, or net ecosystem improvement in the context of continuing land conversion?

- Are the estuary habitat restoration actions achieving the expected biological and environmental benefits?

- Are the habitat restoration activities in the LCRE having a cumulative beneficial effect on salmon and achieving the desired ecological effects across the LCRE landscape?

Addressing these management questions requires research, monitoring, and evaluation. Based on information to date, there is little basis on which to assess whether enacted restoration actions have had or proposed actions will have a net cumulative benefit to LCRE health and functionality to support rebuilding salmon populations. It is not practical, however, to intensively monitor the results of every project. Therefore, methods need to be established to prioritize and manage limited monitoring and research budgets. In addition, data from numerous restoration monitoring efforts must be as comparable as possible for decision-makers to learn from the collective project-specific monitoring data (Neckles et al. 2002). Standardized monitoring protocols are necessary to compare restoration effectiveness through time at a given project site and through space among multiple projects. Focused, prioritized, and standardized monitoring at the project level will support monitoring, research, and evaluation at landscape and estuary-wide levels that will ultimately help determine the success of the CEERP.

Although it is relatively straightforward to measure the area of habitat restored, it is difficult to assess the effects of individual restoration projects on ecosystem function, much less the cumulative effects of multiple projects. When the CE study began, a formal method did not exist to quantify whether restoration of habitats is having a measurable effect on the health and functionality of the ecosystem or on the performance of salmon populations. Small projects, for example, may result in local improvements, confined to a relatively short distance from the restoration site. Many small projects may only improve conditions within a small area and not have any significant effect on the larger ecosystem. In contrast, it is possible that a mix of large and small projects, placed strategically within the system, containing the appropriate mix of habitats, and managed in a way to maximize success, may provide significant improvements. Implementation of the methodology developed in the CE study will likely be affected by the types and sizes of potential projects and, therefore, must allow for objectively incorporating this variable. The CEERP has an opportunity to develop and use science-based, defensible methods to evaluate the potential cumulative gains in ecosystem structures, processes, and functions provided by multiple restoration projects.

The challenge of balancing enhancement of estuarine ecosystems against estuarine economic development remains among the top priorities for coastal planners and researchers this century 
(Thom et al. 2005). In this context, we introduced the concept of "net ecosystem improvement" of previously degraded sites, which is defined as "following development, there is an increase in the size and natural functions of an ecosystem or natural components of the ecosystem" (Thom et al. 2005). In theory, it is assumed that any improvement to a component, e.g., enhancement of a selected habitat attribute (Shreffler and Thom 1993), will contribute to ecosystem improvement. However, the size, amount, number of projects, types of projects, etc. that will have the greatest benefit are unknown. In a situation where the state of the system has been altered, such as in the LCRE, knowing how many, what type, and where to place projects to result in a reversal of degradation and measurable return to a former and less disturbed state would help guide restoration programs and justify the expenditures of funds directed toward restoration. And, furthermore, accounting for the total, cumulative effect of multiple restoration actions on the functioning of entire ecosystems is one of the most important challenges in restoration science.

The restoration of damaged ecosystems is fraught with uncertainty. The uncertainties can be grouped into two types: 1) general uncertainty about the response of the ecosystem to restorative actions and 2) uncertainty associated with random, uncontrollable events that can affect restoration outcomes (Diefenderfer et al. 2005). The CE study investigated the first type of uncertainty (see Chapter 2.0). Given uncertainty, it is difficult to accurately predict when and if the ecosystem will meet restoration goals even as LCRE ecosystems continue to change (Appendix A). Because of this, and the fact that restoration projects can be expensive, information that helps improve predictability is critically needed. Thus, the development of methods to detect and evaluate the cumulative net improvement toward a former system state (Diefenderfer et al. 2011) was a focus of this research.

Adaptive management provides a framework and process for improving the predictability of restoration projects (Thom 1997, 2000). There is a growing awareness of the need to conduct restoration projects within an adaptive management framework in order to maximize the benefit to the ecosystem from the effort to restore the system. The multi-year CE study developed an adaptive management framework for restoration of the LCRE (see Chapter 3.0). The framework includes the most common components: goal statements, a conceptual model, a monitoring program, evaluation and decision guidance, and an information dissemination system (Diefenderfer et al. 2003; Thom and Wellman 1996). The ultimate aims are to dramatically improve the success of restoration projects in the LCRE and to contribute, by example, to the science of ecosystem restoration.

The CE study addressed these issues and provided information that can be used to make management decisions primarily regarding the cumulative effects of LCRE restoration that are designed to enhance ecological functions benefiting the LCRE ecosystems and their juvenile salmon inhabitants. The work was intended to provide a means to assess and quantify the cumulative improvements associated with restoration projects and to lay the foundation for the evaluation and prediction of the effectiveness of the CEERP restoration activities. Importantly, this study examined the effects of habitat restoration in the LCRE on a comprehensive, ecosystem basis. The premises guiding our research and development efforts were as follows.

- Standardization of monitoring methods can result in comparable data sets.

- The LCRE can be viewed at the landscape scale to assess cumulative effects of habitat actions.

- A conceptual model of the LCRE, including the food web, can provide organization and focus to the research and assessment. 
- Key measurable indicators of ecosystem response to restoration can be developed.

- An adaptive management system based on project and ecosystem-monitoring data can aid decisionmakers in implementing salmon habitat restoration in the LCRE.

Understanding the cumulative effects of ecological restoration projects in the LCRE is a formidable task because of ecological uncertainties and the size and complexity of the LCRE landscape. Despite the challenges presented by the LCRE, developing and implementing appropriate indicators and methods to evaluate cumulative effects was possible, enabling resource managers to assess and improve the overall effectiveness of investments in LCRE restoration projects. The CE study developed methods to quantify the effects of restoration projects and laid a foundation for future effectiveness, ${ }^{1}$ evaluation, and validation $^{2}$ assessments of the CEERP.

\subsection{Study Approach and History}

We undertook a study approach for cumulative effects that was based on levels of evidence (Downes et al. 2002). This approach involved a hierarchical suite of phases: design, data, analysis, synthesis and evaluation, and application (Figure 1.2). Research related to the four main study objectives was conducted within this framework over the course of the CE study, a finite 7-year project (Table 1.1). Specific research objectives each year were formulated based on previous year results, progress to date in populating the levels of evidence with data, and year in the 7-year study period. Brief descriptions of the study history are provided separately for the four main objectives below, along with significant accomplishments related to the elements of the levels of evidence (see Table 1.2 at the end of this section).

Monitoring protocols for data on the effectiveness of habitat restoration projects were initiated at the start of the CE study in 2004. This work was a top priority because such protocols did not exist and would be needed for subsequent future data collection and analysis by CE researchers and others. Protocols were developed for six categories of core monitored indicators (Roegner et al. 2009a), and we identified higher-order indicators for CE assessments, as follows (Diefenderfer et al. 2011):

- Core Indicators - Ecosystem Controlling Factors and Structures

- Hydrology: water-surface elevation, catchment area, tidal exchange volume, wetland delineation

- Water Quality: temperature, salinity, dissolved oxygen

- Topography/Bathymetry: elevation, sediment accretion rate, channel cross-sectional area

- Landscape: photo points, aerial photos

- Vegetation: percent cover, species composition, species richness, similarity index

- Fish: presence, abundance, species composition, size structure.

\footnotetext{
${ }^{1}$ Effectiveness monitoring involves activities designed and undertaken to assess how well a particular restoration project performs relative to reference site(s).

${ }^{2}$ Validation monitoring involves activities directed at testing cause-and-effect relationships between management activities and monitoring indicators (Busch and Trexler 2003).
} 


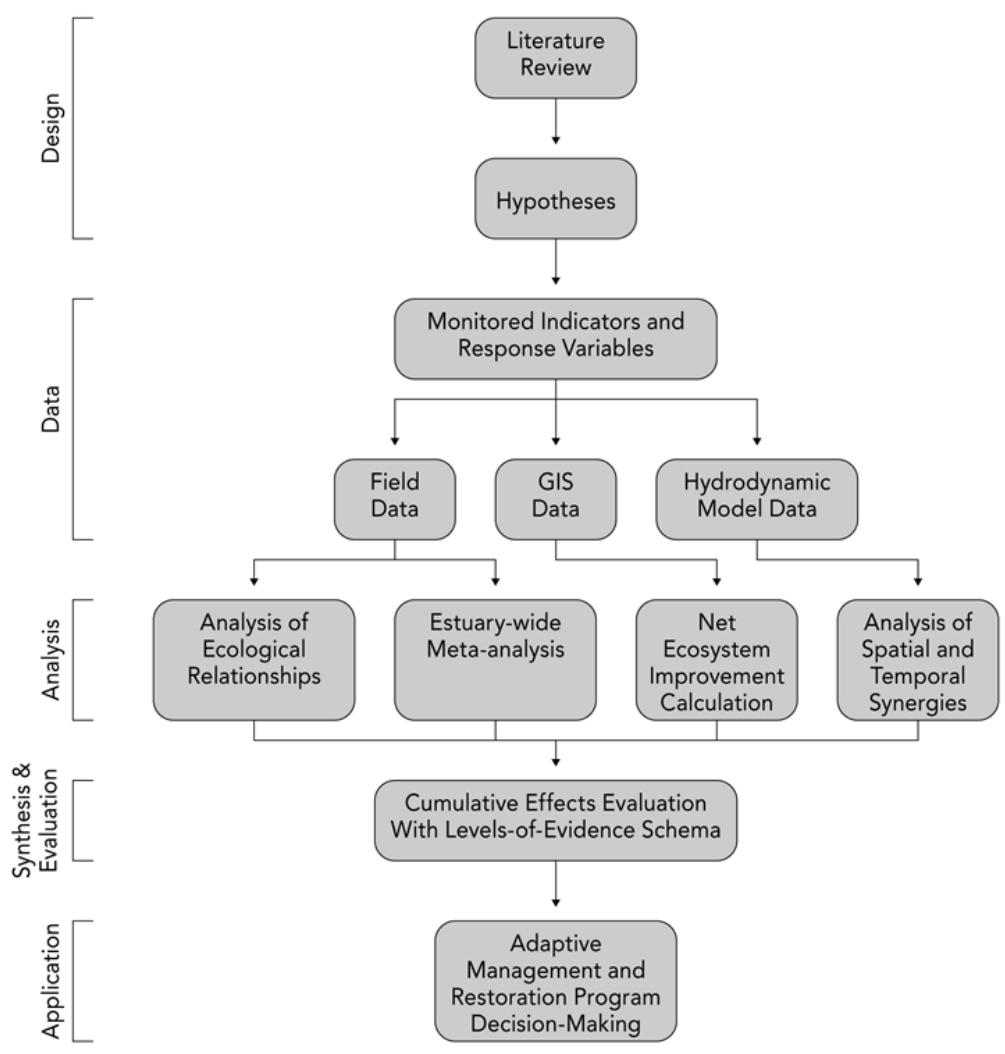

Figure 1.2. Levels-of-Evidence Approach for Evaluation of the Cumulative Effects of Ecosystem Restoration (from Diefenderfer et al. 2011)

Table 1.1. Activity Matrix by Objective and Sub-Objective for the CE Study, 2004-2010

\begin{tabular}{|c|c|c|c|c|c|c|c|}
\hline & 2004 & 2005 & 2006 & 2007 & 2008 & 2009 & 2010 \\
\hline \multicolumn{8}{|l|}{ Monitoring Protocols } \\
\hline \multicolumn{8}{|l|}{ Field testing } \\
\hline \multicolumn{8}{|l|}{ Regional workshops } \\
\hline \multicolumn{8}{|l|}{ Draft and final versions } \\
\hline \multicolumn{8}{|l|}{ Methodology } \\
\hline \multicolumn{8}{|l|}{ Literature review } \\
\hline \multicolumn{8}{|l|}{ Conceptual model } \\
\hline \multicolumn{8}{|l|}{ Hypotheses } \\
\hline \multicolumn{8}{|l|}{ Indicators } \\
\hline \multicolumn{8}{|l|}{ Sampling design and statistics } \\
\hline \multicolumn{8}{|l|}{ Levels-of-evidence framework } \\
\hline \multicolumn{8}{|l|}{ Evaluation } \\
\hline \multicolumn{8}{|l|}{ Field work } \\
\hline \multicolumn{8}{|l|}{ Hydrodynamic modeling } \\
\hline \multicolumn{8}{|l|}{ GIS modeling } \\
\hline \multicolumn{8}{|l|}{ Meta-analysis } \\
\hline \multicolumn{8}{|l|}{ Adaptive Management } \\
\hline \multicolumn{8}{|l|}{ Framework } \\
\hline \multicolumn{8}{|l|}{ Executive version } \\
\hline \multicolumn{8}{|l|}{ Implementation and integration } \\
\hline Annual Reporting & & & & & & & \\
\hline
\end{tabular}


- Higher-Order Indicators - Ecosystem Processes and Realized Functions

- Habitat Availability: area-time inundation, wetted-channel edge length, floodplain wetted area

- Material Flux: flux rates for nutrients, chlorophyll, dissolved organic matter, plant biomass, total organic carbon, macro-invertebrates

- Fish Usage: residence time, diet, growth rate, fitness, prey availability, genetic stock.

Methodology development for CE evaluations commenced in 2004 with a comprehensive literature review that found no published formal methods to quantify the cumulative effects of multiple restoration projects across a given estuary (Diefenderfer et al. 2005). This meant we would have to build the methodology from scratch; we adopted a levels-of-evidence approach (Downes et al. 2002) to evaluate cumulative effects. A conceptual model was formulated, hypotheses were stated, indicators were established in coordination with work on the monitoring protocols, and statistical methods were developed. Over the course of the CE study, we worked to customize the levels-of-evidence approach for assessing the cumulative effects of multiple restoration projects in the LCRE, culminating in a peerreviewed publication (Diefenderfer et al. 2011). The hierarchy of hypotheses included an overarching working hypothesis, a landscape-scale hypothesis, and indicator hypotheses, as follows:

- Overarching Working Hypothesis - Habitat restoration activities in the LCRE have a cumulative beneficial effect on salmon.

- Landscape-Scale Hypothesis - Restoration actions in the LCRE are producing increased habitat connectivity and an increased area of floodplain wetlands trending toward historical levels present prior to land conversion for agriculture and the construction of dams.

- Indicator Hypotheses - Indicators listed above, as measured at restoration sites, are trending toward reference site conditions.

Evaluation of CE methodologies was undertaken by applying standard methods in studies of ecological relationships: a GIS database of restoration-related data, hydrodynamic modeling, and metaanalyses of multiple habitat restoration projects. Field work occurred from 2005 through 2009 at sites described in Section 1.4. The evaluation objective was important because it provided first-hand experience in the LCRE with proposed data collection methods and determination of the usefulness of the data for the purposes of $\mathrm{CE}$ evaluation.

An adaptive management (AM) process was custom-designed for the CEERP during 2006 and 2007. The intent was for the CE evaluations to be conducted within this process and the results applied to decision-making for the program. This process, however, will be widely applicable to the CEERP as a whole. Thom et al. (2008) and Johnson and Diefenderfer (eds.) (2009) released detailed and executive versions of the AM process, respectively. In Chapter 3.0 of this report, we update the AM process and make specific recommendations for AM phases, responsible parties, deliverables, schedules, and implementation tasks. The intent is to offer a practical process that regional stakeholders can support and use for the betterment of LCRE ecosystems. 
Table 1.2. History of the 2004-2010 Cumulative Effects Study

\begin{tabular}{|c|c|c|}
\hline $\begin{array}{l}\text { Study- } \\
\text { Year }\end{array}$ & Accomplishments & $\begin{array}{l}\text { Annual Report } \\
\text { Citation }\end{array}$ \\
\hline \multirow[t]{4}{*}{2004} & $\begin{array}{l}\text { Performed a comprehensive literature review that found no published formal methods } \\
\text { to quantify the cumulative effects of multiple restoration projects across one estuary. }\end{array}$ & \multirow[t]{4}{*}{$\begin{array}{l}\text { Diefenderfer } \\
\text { et al. (2005) }\end{array}$} \\
\hline & $\begin{array}{l}\text { Initiated development of protocols for monitoring indicators for restoration activities } \\
\text { with a meeting open to all estuary restoration project managers, which is an important } \\
\text { step toward achieving a cumulative assessment of restoration effects across multiple } \\
\text { projects. }\end{array}$ & \\
\hline & $\begin{array}{l}\text { Adopted the following definition of cumulative effects: "The impact on the } \\
\text { environment which results from the incremental impact of the action when added to } \\
\text { other past, present, and reasonably foreseeable future actions regardless of what } \\
\text { agency (federal or non-federal) or person undertakes such other actions" (Title } 40 \\
\text { of the Code of Federal Regulations [CFR] } § 1508.7 \text { ). }\end{array}$ & \\
\hline & Proposed a levels-of-evidence approach to evaluate cumulative effects. & \\
\hline \multirow[t]{5}{*}{2005} & $\begin{array}{l}\text { Finalized hypotheses regarding the effects of hydrological-reconnection restoration } \\
\text { methods; refined the selection of measurable metrics. }\end{array}$ & \multirow[t]{5}{*}{$\begin{array}{l}\text { Diefenderfer } \\
\text { et al. (2006) }\end{array}$} \\
\hline & $\begin{array}{l}\text { Tested protocols for restoration effectiveness indicators; continued to develop a } \\
\text { sampling design supporting an estuary-wide CE analysis. }\end{array}$ & \\
\hline & Initiated development of an AM framework for the LCRE Restoration Program. & \\
\hline & $\begin{array}{l}\text { In the field, applied effectiveness monitoring methodology before construction } \\
\text { restoration actions at two restoration sites and two reference sites in the Columbia }\end{array}$ & \\
\hline & $\begin{array}{l}\text { River Estuary (CRE)—Vera Slough and Kandoll Farm—as paired site studies of } \\
\text { marsh and swamp habitats, respectively. }\end{array}$ & \\
\hline \multirow[t]{2}{*}{2006} & $\begin{array}{l}\text { Conducted post-restoration research at the selected field study sites to support the } \\
\text { ongoing development of ecological relationships for the technical approach for } \\
\text { assessing the cumulative effects of multiple aquatic habitat restoration projects in the } \\
\text { LCRE. }\end{array}$ & \multirow[t]{2}{*}{$\begin{array}{l}\text { Johnson (ed.) } \\
(2007)\end{array}$} \\
\hline & $\begin{array}{l}\text { Collected field data for CE analysis of ecological relationships from the following } \\
\text { three sources using the levels-of-evidence approach ( } 2005 \text { and } 2006 \text { combined): } \\
\text { in-depth paired site studies (marsh and swamp), selected core indicators at all } \\
\text { monitored restoration project and reference sites, and CE indicators. }\end{array}$ & \\
\hline \multirow[t]{6}{*}{2007} & Released draft monitoring protocols and conducted a regional workshop for them. & \multirow{6}{*}{$\begin{array}{l}\text { Johnson and } \\
\text { Diefenderfer } \\
\text { (eds.) (2008) }\end{array}$} \\
\hline & Developed a detailed AM framework for the CEERP. & \\
\hline & $\begin{array}{l}\text { Continued development of the scientific approach for CE assessment, including } \\
\text { ecological theory and levels-of-evidence schema. }\end{array}$ & \\
\hline & $\begin{array}{l}\text { Presented key results on ecological relationships for hydraulic geometry and channel } \\
\text { morphology, elevation and vegetation, invasive plants and restoration, sediment } \\
\text { accretion and restored tidal wetlands, vegetation similarity among sites, and juvenile } \\
\text { salmon use of restored areas. }\end{array}$ & \\
\hline & $\begin{array}{l}\text { Provided monitoring data summaries for Julia Butler Hanson National Wildlife } \\
\text { Refuge, Crims Island, hydrology, material flux, and the natural breach assessment. }\end{array}$ & \\
\hline & Created a comprehensive AM framework. & \\
\hline
\end{tabular}


Table 1.2. (contd)

\begin{tabular}{|c|c|}
\hline $\begin{array}{l}\text { Study- } \\
\text { Year }\end{array}$ & Accomplishments \\
\hline \multirow[t]{8}{*}{2008} & Finalized the monitoring protocols and released them regionally. \\
\hline & $\begin{array}{l}\text { Applied results from } 2005-2008 \text { field research and modeling to develop predictive } \\
\text { structure/function ecological relationships as indicators of fundamental processes, } \\
\text { including relationships between water elevation and wetted area, water temperature } \\
\text { and fish abundance, and habitat type and fish stock. }\end{array}$ \\
\hline & $\begin{array}{l}\text { Conducted hydrodynamic modeling to test for synergies in wetted area resulting from } \\
\text { various dike breach scenarios. }\end{array}$ \\
\hline & $\begin{array}{l}\text { Performed a GIS assessment of the relationship between water elevation and wetted } \\
\text { area. }\end{array}$ \\
\hline & $\begin{array}{l}\text { Acquired intensive and extensive effectiveness monitoring data from restoration and } \\
\text { reference sites and performed a preliminary meta-analysis of effectiveness monitoring } \\
\text { data, in cooperation with the Lower Columbia River Estuary Partnership and CREST. }\end{array}$ \\
\hline & $\begin{array}{l}\text { Performed a preliminary assessment of net ecosystem improvement using the export } \\
\text { of macrodetritis as an example. Uncovered significant weaknesses in the available } \\
\text { data for additive modeling from wetlands on the LCRE. }\end{array}$ \\
\hline & $\begin{array}{l}\text { Using water temperature and fish presence as indicators, conducted a preliminary } \\
\text { CE evaluation with levels-of-evidence schema and causal criteria. }\end{array}$ \\
\hline & Developed a short, executive version of the AM framework. \\
\hline
\end{tabular}

2009 Published the monitoring protocols as a National Oceanic and Atmospheric Administration Technical Memorandum.

Johnson and

Supported the CE assessment at pilot and estuary-wide scales through field work to Diefenderfer document selected higher-order metrics, develop a time series, and expand the spatial and temporal diversity of sites for CE analysis, as follows:

- At Crims Island, Kandoll Farm, and Vera Slough restoration and reference sites, sampled all core metrics.

- At selected historical breach and created sites, sampled hydrology, morphology, vegetation, and fish abundance.

Performed an intensive material-exchange study at the Kandoll Farm culvert over 48-hour periods during a spring-tide and a neap-tide series.

Tested estuary-wide the CE methodology developed in previous years, including GIS assessments of wetted area, discrete hydrodynamic modeling, and meta-analyses of effectiveness data.

2010 Revisited and revised the literature review of CE methods.

This report

Described the ecology of restored wetlands in the LCRE through effectiveness monitoring of the three, paired sets of restoration and reference sites monitored since the onset of the study, representing dike breaching, tide gate replacement, and culvert installation methods: Kandoll Farm, Vera Slough, and Crims Island.

Provided summary analyses for a levels-of-evidence assessment of the cumulative effects of ecosystem restoration:

- GIS analysis of net ecosystem improvement

- meta-analysis of effectiveness monitoring data

- $\quad$ summary of key ecological relationships

- results from analysis of spatial and temporal synergies.

Developed a detailed quantitative design to integrate the levels-of-evidence schema. 


\subsection{Study Area}

For the general purposes of the CE study, Diefenderfer et al. (2005) describe the LCRE study area. A number of publications also provide useful descriptive information about the study area, including Salmon at River's End (Bottom et al. 2005b), Role of the Estuary in the Recovery of Columbia River Basin Salmon and Steelhead (Fresh et al. 2005), and Ecosystem-Based Approach to Habitat Restoration Projects (Johnson et al. 2003).

Based on analysis of physical properties, Jay et al. (Appendix B) delineated four zones of the LCRE: the lower estuarine zone of salinity intrusion ( $\mathrm{rkm}$ 0-21); the energy minimum zone (rkm 21-87) to the constriction in the river at Beaver; the tidal fluvial zone (rkm 87-229); and a steep, landslide-influenced section just below Bonneville Dam (rkm 229-235). Below Beaver (rkm 87), tidal and atmospheric forcing largely controls water levels, with some influence from river flow. Our main study sites were below Beaver.

We conducted field studies during 2005-2009. Three sites in the LCRE—Crims Island, Kandoll Farm, and Vera Slough (Figure 1.3) - were selected based in part on the timing of planned restoration, because the monitoring protocols recommend collecting data before and after implementation of restoration actions. These three sites are described in more detail in Chapter 2.0. In addition, we conducted field studies at the Julia Butler Hanson (JBH) National Wildlife Refuge (NWR) and various natural breach sites. By design, field work in total involved the following four types of sites:

- Habitat sites allowed paired comparison of two distinct LCRE habitat types over the same time frame - emergent marsh and tidal freshwater swamp, two plant communities representing the salmon habitat types that were historically most common and most likely to be restored in the future (Kandoll Farm and Vera Slough).

- Reference and restoration sites allowed analysis of the effectiveness of the restoration action relative to reference conditions (Crims Island, Kandoll Farm, and Vera Slough).

- Spatially sequenced sites allowed analysis of the synergistic effects of multiple restoration actions over time in the same general area (JBH).

- Natural breach sites allowed evaluation of long-term ecological restoration trajectories for given monitored indicators at sites with various habitat types and prior restoration history (various sites).

This report focuses on the Crims Island, Kandoll Farm, and Vera Slough sites, although a limited amount of data from the JBH NWR and the natural breaches are also included. The spatial sequence of restoration actions at the JBH NWR did not materialize during the CE study period as planned, preventing assessment of the hypothesis of the synergistic effects of multiple restoration actions over time in the same general area. Borde et al. (2008b, 2009a) documented vegetation, cross sections, and other monitoring data from the JBH NWR. The natural breach sites revealed conditions many years after the breaching event (Diefenderfer et al. 2010; Borde and Diefenderfer 2009; Borde et al. 2008a). 


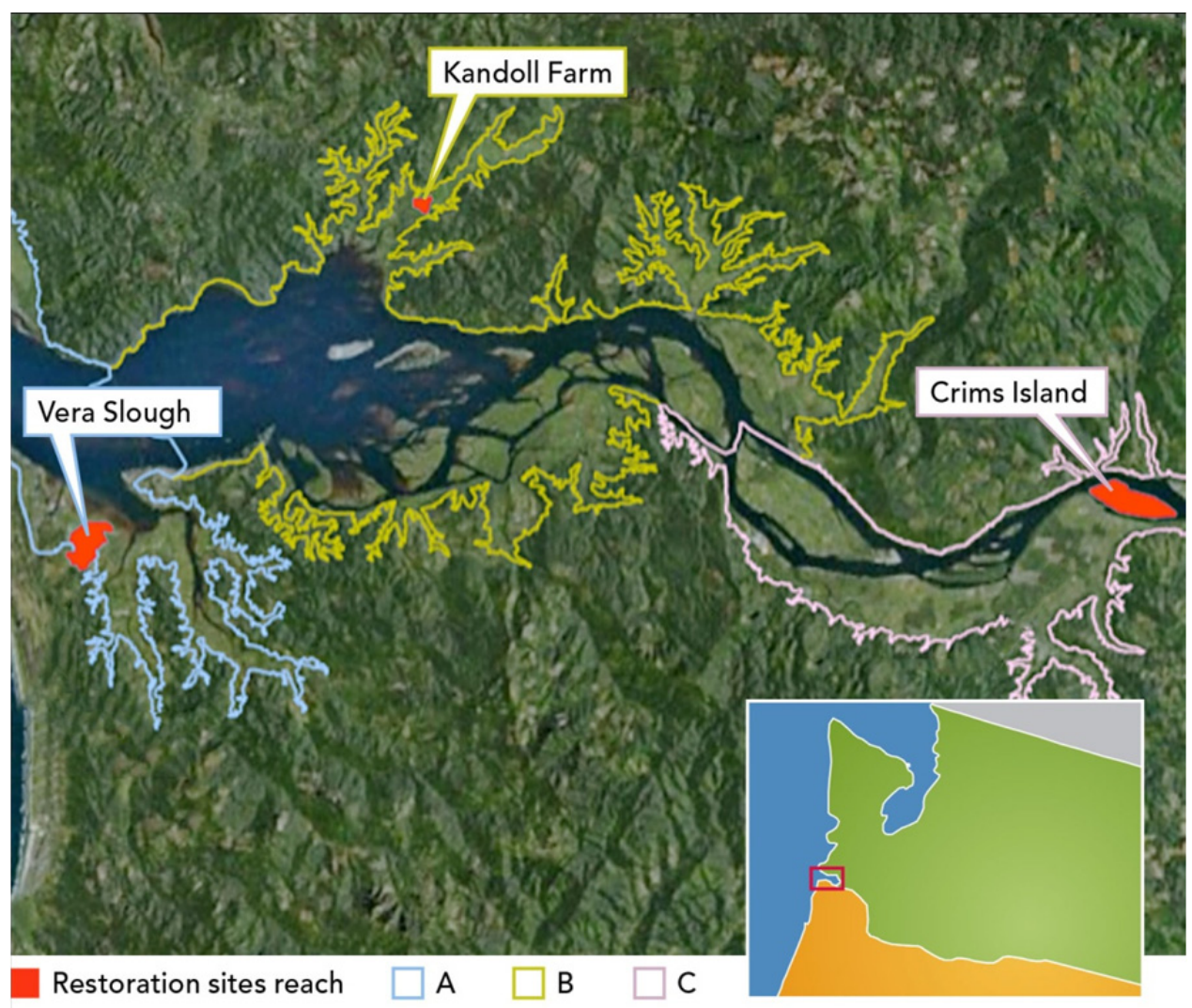

Figure 1.3. Field Sites for the Cumulative Effects Study

\subsection{Report Contents}

This report contains four main chapters and eight appendices. In the ensuing chapters, we first synthesize field and laboratory research conducted for the CE study on the ecology of restored wetlands in the LCRE in Chapter 2.0. In Chapter 3.0, we present a detailed, custom-designed AM process for the CEERP. Chapter 4.0 contains lists and summaries of management considerations, such as $\mathrm{CE}$ deliverables, legacy products, restoration lessons, and recommendations. More material about applied research for estuary ecosystem restoration is presented in the appendices, as follows:

- Appendix A: Temporal Land Cover Analysis for Net Ecosystem Improvement

- Appendix B: The Columbia River Tidal-Fluvial Regime: Water-Level Variations, Inundation, and Vegetation Patterns

- Appendix C: Estimating Realized Habitat Utilization for Chinook, Chum, and Coho Salmon in a Restoring Tidal Freshwater Wetland

- Appendix D: Electrofishing in Swamp Habitats in the Vicinity of Grays Bay During Spring 2010 Data Summary

- Appendix E: Material and Nutrient Flux from Restored Wetlands in the Tidal Freshwater of the Lower Columbia River and Estuary

- Appendix F: Statistical and Other Considerations for Restoration Action-Effectiveness Monitoring and Research 
- Appendix G: Meta-Analysis of Action Effectiveness at Three Restoration Projects in the Lower Columbia River and Estuary

- Appendix H: Detailed Outline of the FY 2012 CEERP Action Plan

- Appendix I: Photo Points

- Appendix J: Plant List. 


\title{
2.0 Ecology and Hydrology of Restoring Wetlands in the Lower Columbia River and Estuary
}

\author{
Prepared by Ron Thom, Heida Diefenderfer, Andre Coleman, Amy Borde, \\ Curtis Roegner, Jerry Tagestad, and Gary Johnson
}

This chapter summarizes field research on the ecological response of diked former tidal wetland habitats in the LCRE to restoration activities involving hydrologic reconnection.

\subsection{Introduction}

In the last 230 years, much of the land area in the LCRE that was once wetland habitat has been lost to diking, filling, development, and dredging (Mitsch and Gosselink 2007). For example, the present global extent of wetlands is approximately 7 to 10 million $\mathrm{km}^{2}$, which is estimated to be roughly half of the wetland area that historically existed on earth in the late 1780s (Mitsch and Gosselink 2007). Today, there are about 114.6 million hectares of wetland habitat in the conterminous United States and Alaska. This figure is estimated to represent only about $53 \%$ of all wetlands that once existed in this region (Mitsch and Gosselink 2007). Tidal wetlands (tidal salt marshes and tidal freshwater marshes) account for approximately 2.7 million hectares in the United States and have suffered losses like all U.S. wetlands (Mitsch and Gosselink 2007). However, since about the mid-1970s, wetland loss has slowed-a 105,700 -ha decrease from the $1970 \mathrm{~s}$ to $1980 \mathrm{~s}$ ( $2.5 \%$ loss) to a 23,700 -ha decrease from the mid-1980s to mid-1990s ( $0.6 \%$ loss), and a gain of 12,900 ha of wetlands ( $0.44 \%$ gain) from 1998 to 2004 (Mitsch and Gosselink 2007).

Today, efforts to restore former tidal wetlands continue to grow in many regions of the United States (NRC 1992). Some of the most successful projects have involved restoring hydrodynamics to the diked system (NRC 1992). The rewetting of the formerly disconnected sites as well as the input of nutrients and sediments has driven recovery of some of these (tidal) wetland systems. Because wetlands tend to subside in elevation while diked, sediment deposition, hydration of soils, and stimulation of plant growth by nutrients contribute to recovery of the elevation of the wetland plain (Zedler 2001). Recovery of the vegetation assemblage is linked to these processes as is the delivery of seeds from outside the site and the germination of seeds contained in the seed bank on the site (Zedler 2001). Access to the site by fish and other aquatic species is facilitated also, as is the export of organic matter from the site to other parts of the ecosystem (Small et al. 1990). The rates and patterns of the recovery of the wetland after hydrological reconnection vary considerably and are likely tied to the restored processes, which are highly dependent on the quality of the surrounding landscape (NRC 1992). Wetlands formerly dominated by ephemeral short-lived species can recover within a few years (Thom et al. 2011), whereas recovery of wetlands historically dominated by forested swamps may be protracted from decades to centuries (Diefenderfer et al. 2008).

Like other estuaries, loss of tidal wetlands in the LCRE has been substantial. Tidal swamp and tidal marsh habitats have suffered the largest relative declines based on a habitat change analysis (1890 vs. 1992 habitat maps for the lower 46 miles of the LCRE). Much of the loss is attributed to diking for agriculture purposes, filling, and flow operations (Johnson et al. 2003). Tidal spruce swamps once dominated lower elevation coastal ecosystems between northern California and southeast Alaska (Diefenderfer et al. in preparation). Christy and Putera (1992) reported that while the largest spatial 
occurrence of spruce swamps on the Pacific coast is in the Columbia River floodplain, only $6 \%$ of the spruce swamps within the Columbia River floodplain are still on the north shore (700 acres) and 23\% are still on the south shore (1500 acres).

Because built wetlands have proven to yield little functional benefit (Kentula et al. 1992), there is a growing emphasis on restoration to result in restored ecological processes and functions (Kentula et al. 1992). Alteration and loss of these habitats in the LCRE has resulted in impacts on the ecosystem functions and processes (Johnson et al. 2003). Sherwood et al. (1990) concluded that the loss of marshes and swamps resulted in a major shift in the amount and quality of organic matter delivered to the food web in the LCRE. They reported that marsh macro-detritus mass reaching the estuary food web declined by $\sim 82 \%$ compared to the mass contributed historically. The organic matter source that showed the greatest increase over the same time period was from planktonic production in the reservoirs behind the Bonneville Dam and likely other dams upstream. This shift may have favored planktonic-feeding secondary consumers and disfavored epibenthic feeders such as juvenile salmon. Finally, flow regulation has altered the hydrograph in the LCRE (Kukulka and Jay 2003b). Basically, flows are now not as dynamic, with lower and more attenuated peak flood flows and less severe low water periods. Hence, "environmental flows," which contribute strongly to the formation and maintenance of habitats, the access to wetland habitats by aquatic species, and drive the export of materials from these habitats, have been altered.

Juvenile salmon receive direct support through access to prey items by residence in restored wetlands, and indirect support through export of prey from the wetlands to the main stem. Juvenile salmon diets are composed of prey from aquatic and terrestrial sources, including dipterans, amphipods, mysids, and other taxa (e.g., Storch and Sather 2011). Hydrologic reconnection of floodplain with main stem habitats should help restore LCRE food webs (ISAB 2011). Restoring access to wetland habitats through reconnection of off-channel areas to the main stem is a primary strategy in the effort to improve juvenile salmon survival and fitness in the LCRE (Johnson et al. 2003).

Although there is a growing body of work that reports the effectiveness of restoration actions, very few action-effectiveness results have been reported in the LCRE (Johnson et al. 2010), especially with regard to functions and processes (Johnson et al. 2003). The goal of the reported projects was to restore habitat structure, processes, and function, especially those potentially beneficial to young salmon. Our work addresses key uncertainties in restoration planning associated with alteration of habitat-forming processes, access by aquatic species, and contributions to the broader ecosystem of exported material as the ecological context for assessing the rates, processes, and functions associated with restored tidal wetlands in the LCRE. Our studies were conducted at three restored sites and three associated reference sites over a 6-year period. We targeted the effects of habitat restoration actions on salmon, both direct onsite (habitat usage) and indirect offsite (via fluxes/ecosystem subsidies). Our research covers representative restoration actions/ecosystem types/positions in the landscape with a paired restoration and reference site design (described in detail under "Study Area" below). Because previous work has reported on some details of our work, we will reference those findings and not present the results in detail here. That work dealt with floodplain wetted area and the area-time inundation index, material flux into Grays River, measured subsidence at the Kandoll Farm restored site, and fish response at the Kandoll Farm restored site. Among the products of our early work was a set of protocols for monitoring habitat development (Roegner et al. 2009a). 
Verification of the benefits of restoration projects on endangered salmon stocks would be best made by direct measurement of the contribution of juveniles that used wetlands to returns of adult salmon. Such measurements would require extensive marking of juvenile salmon in LCRE restoration action and reference areas, followed by confirmation of their return to the Columbia basin as adult fish several years later. At present, this type of effort is under consideration.

Barring direct measures of the influence of habitat restoration on salmon populations, we turn to inferential data by which we can assess benefits to salmon provided by restoring wetlands, based on a weight-of-evidence approach (Diefenderfer et al. 2010). Several physical and biological metrics are available to rate the relative success of projects, based on a before-after restoration-reference (BARR) sampling design (Roegner et al. 2009a; Diefenderfer et al. 2010). Physical metrics include measures of habitat connectivity (hydrology) and suitability (water-quality parameters such as temperature, salinity and dissolved oxygen). Biological metrics include aspects of fish habit use, including species composition and community diversity, and, for salmon, fish presence/absence, life-history type, production (hatchery or natural), and diet. The BARR sampling framework provides a means to compare restoration trajectories and targeted conditions (Roegner et al. 2009a). Together, these metrics comparatively describe physical habitat opportunity coupled with metrics of fish use of the habitats before and after restoration actions. Table 2.1 lists the relevant indicators (additional details are provided in Section 2.2.2).

Table 2.1. Categories of Environmental Measurements Collected at the Six Primary Study Sites. Indicators for which data were reported in other papers during the study period are italicized, and the results are referenced in the discussion.

\begin{tabular}{ll}
\hline \multicolumn{1}{c}{ Category } & \multicolumn{1}{c}{ Indicator } \\
\hline Core Indicators - Ecosystem & Controlling Factors and Structures \\
Hydrology & Water-surface elevation, catchment area, tidal exchange volume \\
Water Quality & Temperature \\
Topography/Bathymetry & Elevation, sediment accretion rate, channel cross-sectional area \\
Landscape & Photo points, aerial photos, and/or satellite imagery analysis \\
Vegetation & Percent cover, species composition, species richness, similarity index \\
Fish & Presence, abundance, species composition, size structure \\
Higher Order Indicators - Ecosystem Processes and Realized Functions \\
Habitat Availability & Area-time inundation, wetted-channel edge length, floodplain wetted area \\
Material Flux & Flux rates for nutrients, chlorophyll, dissolved organic matter, plant biomass, total \\
& organic carbon, macro-invertebrates \\
Fish Usage & Diet, condition index, prey availability, genetic stock \\
\hline
\end{tabular}

We have two primary objectives: first, to provide a synthesis of field research on ecological responses to LCRE tidal reconnection restoration at three sites, trajectories, and patterns of development, organized according to the hypotheses generated from a levels-of-evidence approach (Diefenderfer, in press); and, second, to develop indicators for assessing restoration response, including the analysis of ecological relationships, and present recommendations drawn from the results at intensive (i.e., site) and extensive (i.e., ecosystem) scales. The studies conducted over the past 6 years provide a wide array of 
data that can be used to establish key ecological relationships. We believe that our analysis will provide at least partial answers to some frequently asked questions regarding ecosystem restoration, including the following:

- How large should the project be to provide measureable ecological benefit?

- How long will it take before the habitat changes occur and the ecological benefits become apparent?

- What are the key factors that need to be developed to maximize the rate of development and production of benefits?

- Is the restoration site benefitting the broader ecosystem?

- How long can we expect the restored habitat to provide desirable benefits?

Using intensively studied sites, we evaluated indicators of habitat development rates and patterns, and how these habitat indicators related to ecological benefits. Our data sets are relatively short in time such that we captured only the initial phase of development of the restored sites. However, studies done in 2009 (Diefenderfer et al. 2010) extended the habitat trajectory analysis using sites breached or created over the past 4 decades or more. The data from replicate intensively studies sites allowed us to use ratio estimators for extrapolating results from the intensive studies to extensive areas in the estuary. Through development of these estimators we evaluated metrics that can be relatively easily measured at all sites and can be used to estimate higher-order metrics more indicative of ecosystem processes and functions.

\subsection{Methods}

The study area and study design are described below, followed by the data collection and analysis methods related to hydrology and water, topography and bathymetry, landscape, vegetation, habitat availability, fish presence, productivity and material flux, and fish usage. The analysis of ecological relationships is described last.

\subsubsection{Study Area}

The LCRE is the 235-rkm region between Bonneville Lock and Dam and the mouth of the Columbia River. The LCRE is a drowned river valley that drains a $724,025 \mathrm{~km}^{2}$ river basin, with mean discharge today of $7,730 \mathrm{~m}^{3} / \mathrm{s}$ (Stanford et al. 2005). Historical flows, prior to river regulation by some 30 major dams and numerous minor dams (Kukulka and Jay 2003a), are estimated to have reached maximums of up to $28,317 \mathrm{~m}^{3} / \mathrm{s}$ during spring freshets (Sherwood et al. 1990). The extent of saltwater intrusion in the LCRE is approximately $20 \mathrm{~km}$ to $40 \mathrm{~km}$, governed by seasonal flows (Chawla et al. 2008), and tidal range in the estuary is $\sim 3.6 \mathrm{~m}$ (Neal 1972; Sherwood and Creager 1990). The effects of the mixed semidiurnal tidal regime on water levels diminish upriver but are still measurable immediately below Bonneville Lock and Dam.

Plant communities along waterways of the LCRE, including islands and the floodplain, fall into four general categories: herbaceous wetlands or marshes, shrub wetlands, coniferous forested wetlands, and deciduous forested wetlands (swamps). In the LCRE, marshes and shrub wetlands may be either brackish or freshwater, while swamps are primarily freshwater communities. Plant communities are generally arrayed along the elevation gradient, with forested communities located at the highest elevations, marshes at the lowest, and shrubs in between (Fox et al. 1984). 
Large reductions in the wetland plant communities of the LCRE have occurred as the result of land conversion (diking) and modifications to the hydrologic regime of the Columbia River system (Kukulka and Jay 2003a, b). Estimates produced by analysis of changes in the estuary since 1870 suggest that tidal swamps were reduced by $77 \%$ and tidal marshes by $65 \%$, while new marshes totaling about $22 \%$ of the original area have been formed (a net loss of 43\%) (Thomas 1983). Other estimates suggest that losses may be even greater, e.g., up to 91\% of Sitka spruce (Picea sitchensis) swamps (Tabor 1976; Christy and Putera 1992).

Currently, a large effort is underway to restore tidal wetlands of the LCRE as partial mitigation for the effects of the FCRPS on threatened and endangered salmonid fishes (NMFS 2008). Juvenile salmonid fishes typically use estuarine and tidal freshwater habitats during migration from large rivers on the West Coast of North America (Levy and Northcote 1982; Levings et al. 1991; Levings and Bouillon 1994). In 2004, early in the development of the program, we selected three planned restoration sites and paired reference sites for each, to monitor before and after restoration (Figure 2.1). The restoration objectives for these sites were brackish marsh (Vera Slough restoration [VS] site), freshwater Sitka spruce swamp (Kandoll Farm restoration [KF] site), and freshwater marsh (Crims Island restoration [CI] site). The three sites represent different, typical elements of the landscape: a bay (VS), a tributary to the estuary (KF), and an island (CI).

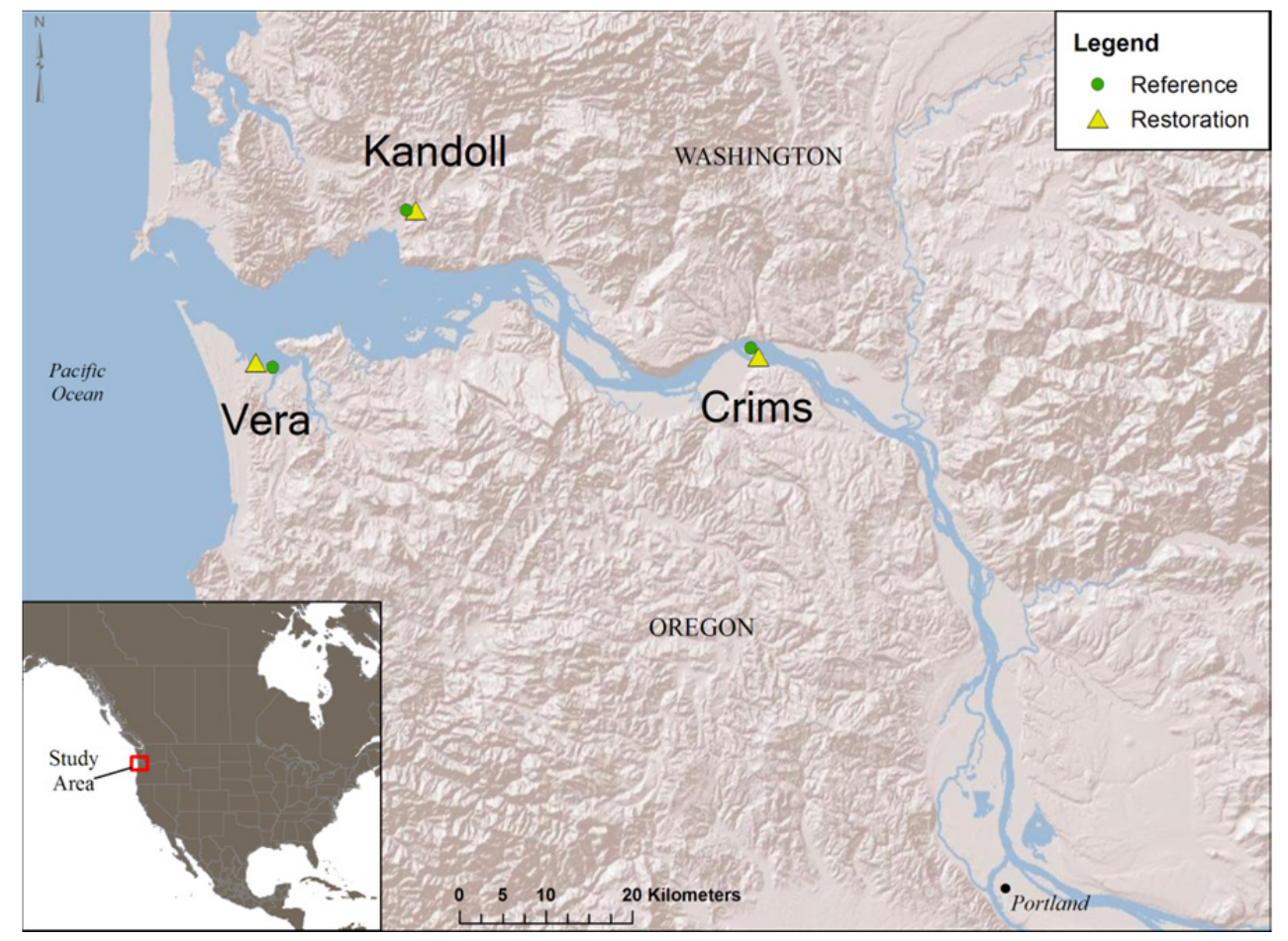

Figure 2.1. Three Main CE Study Sampling Locations

Restoration Sites: All of the most common restoration actions planned for the LCRE were implemented at one or more of the three sites in 2005: tide gate retrofit (VS); culvert installation, tide gate removal, and dike breach (KF); and scrapedown and channel excavation (CI). Common objectives of these restoration projects were to develop wetland plant communities, increase access for juvenile salmonid fishes, improve water quality (e.g., lower summer temperatures), and increase food-web productivity and export to the main stem river system (e.g., macroinvertebrates). 
Reference Sites: We selected reference sites for each of the three restoration sites according to the following criteria: 1) similarity of hydrology; 2) similarity of landform; 3) proximity to paired restoration site; and 4) a plant community similar to the one planned for the restoration site. Thus, the Vera Slough reference (VR) site is a brackish marsh on Young's Bay, the Kandoll Farm reference (KR) site is a Sitka spruce swamp on the Grays River, and the Crims Island reference (CR) site is a freshwater marsh on Gull Island, which was originally a created island.

\subsubsection{Study Design}

The BARR experimental design of this study is described by Diefenderfer et al. (in press). In general, monitoring before and after restoration at restoration and reference sites can be used to describe restoration trajectories and develop predictive ecological relationships (e.g., Thom et al. 2002). Reference sites represent the state of an environment insofar as possible undisturbed by human activity, while control sites are as similar as possible to the impact location prior to the impact (Downes et al. 2002). This study does not incorporate control sites because the differences between the initial state and postrestoration state are expected to be large, and the differences between initial conditions at the paired restoration and reference sites are large. Therefore, there is little need to demonstrate that the postrestoration condition is different from control sites in the pre-restoration condition, and the primary objective of monitoring is to confirm whether the restoration site is becoming more similar to the reference site, which represents targeted ecological conditions for the restoration project. In this design, the reference site also serves as an environmental control to help identify changes in the landscape (e.g., hydrologic regime) that may affect progress at the restoration site. The habitat goal of restoration is not a single, fixed condition, but a range of conditions that is subject to change because of environmental conditions, and restoration success occurs when the site merges into the range of reference conditions and tracks reference site responses over time (Thom 1997).

The clearest predictive ability is provided by ecological indicators with clear cause-and-effect relationships (NRC 2000). This study attempted to link the changing pattern and quality of habitats with the effects on juvenile salmonids, so the challenge was to identify key measurable linkages between habitats and salmon that are sensitive to restoration actions. Early in the study, we selected a small number of indicators based on a synthesis of what was known about the ecosystem and others like it, and we developed protocols for action-effectiveness monitoring in the LCRE (Roegner et al. 2009a). In addition to the "core" indicators of ecosystem controlling factors and structure described in the protocols, we intensively sampled "higher-order" indicators of ecosystem processes and realized functions for salmonid fishes (Table 2.1). Additional important indicators of realized function, not monitored in this study, are the residence time and growth rate of juvenile salmonids.

Although (as stated previously) the benefits of restoration projects on endangered salmon stocks would be best verified by direct measurement of the contribution of juveniles using wetlands to adult returns, the measurement of smolt-to-adult return (SAR) rates would require an extensive marking or tagging and confirmation program that is neither practicable nor possible. Instead we use inferential data to assess benefits to salmon provided by restoring wetlands and use physical and biological metrics to rate the relative success of projects based on a BARR sampling design (Roegner et al. 2009a; Diefenderfer et al. 2010). Together, these metrics comparatively describe physical habitat opportunity coupled with metrics of fish use of the habitats before and after restoration actions. Table 2.2 details the relevant indicators. 
Under the BARR design, the hypotheses that guided this study state that each indicator (Tables 2.1 and 2.2) will trend toward reference site conditions. We collected pre-restoration data in 2005, and postrestoration data in 2006 and 2009, as well as continuously logged or accrued data from 2005 through 2009 for some indicators.

Table 2.2. Indicators of the Effect of Wetland Restoration on Salmon Populations

\begin{tabular}{|c|c|c|c|c|c|}
\hline Metric & Indicator & Measurement & Method & Analysis & Diagnosis \\
\hline $\begin{array}{l}\text { Physical } \\
\text { opportunity }\end{array}$ & $\begin{array}{l}\text { Water level/ } \\
\text { inundation time }\end{array}$ & $\begin{array}{c}\text { Pressure sensor } \\
\text { network }\end{array}$ & $\begin{array}{l}\text { Before-after change in } \\
\text { connectivity }\end{array}$ & $\begin{array}{l}\text { Hypsographic } \\
\text { curve }\end{array}$ & $\begin{array}{l}\text { Increase in } \\
\text { inundation. } \\
\text { Increase in } \\
50 \% \text { depth. }\end{array}$ \\
\hline \multirow{3}{*}{$\begin{array}{c}\text { Physical } \\
\text { habitat } \\
\text { suitability } \\
\text { (water- } \\
\text { quality } \\
\text { parameters) }\end{array}$} & Temperature & Data logger & $\begin{array}{c}\text { Before-After- } \\
\text { Restoration-Reference } \\
\text { Monitor time series }\end{array}$ & 7-DAM Temp & $\begin{array}{c}\text { Good: }<16^{\circ} \mathrm{C} \\
\text { Concern }>16 \text { to } \\
19^{\circ} \mathrm{C} \\
\text { Poor: }>19^{\circ} \mathrm{C}\end{array}$ \\
\hline & Dissolved oxygen & Data logger & $\begin{array}{l}\text { Before-After, } \\
\text { Restoration-Reference } \\
\text { Monitor time series }\end{array}$ & $\begin{array}{l}\text { Concentration, } \\
\% \text { saturation }\end{array}$ & $\begin{array}{c}\text { Good: } \\
>6 \mathrm{mg} / \mathrm{L} ;>70 \% \\
\text { Concern: } \leq 6 \text { to } \\
4 \mathrm{mg} / \mathrm{L} ; 30-70 \% \\
\text { Poor: } \leq 4 \mathrm{mg} / \mathrm{L} ; \\
\quad<30 \%\end{array}$ \\
\hline & Salinity & Data logger & Monitor time series & psu & Unknown? \\
\hline \multirow{2}{*}{$\begin{array}{l}\text { Fish } \\
\text { community }\end{array}$} & $\begin{array}{l}\text { Species Richness } \\
\text { (S) }\end{array}$ & Net samples & $\begin{array}{l}\text { Before-After, } \\
\text { Restoration-Reference } \\
\text { Monitor time series }\end{array}$ & $\begin{array}{l}\text { Number of } \\
\text { species }\end{array}$ & $\begin{array}{l}\text { Increase, trend } \\
\text { toward target }\end{array}$ \\
\hline & Diversity (H') & Net samples & $\begin{array}{l}\text { Before-After, } \\
\text { Restoration-Reference } \\
\text { Monitor time series }\end{array}$ & $\sum\left[-\mathrm{P}_{\mathrm{i}} \cdot\left(\ln \mathrm{P}_{\mathrm{i}}\right)\right]$ & $\begin{array}{l}\text { Increase, trend } \\
\text { toward target }\end{array}$ \\
\hline \multirow{4}{*}{$\begin{array}{l}\text { Salmon } \\
\text { wetland } \\
\text { occupation }\end{array}$} & Presence/absence & Net samples & $\begin{array}{l}\text { Before-After, } \\
\text { Restoration-Reference } \\
\text { Monitor time series }\end{array}$ & $\begin{array}{l}\text { Fish counts, } \\
\text { time series }\end{array}$ & $\begin{array}{c}\text { Increase } \\
\text { presence, trend } \\
\text { toward target }\end{array}$ \\
\hline & Life-history type & Net samples & Monitor time series & $\begin{array}{l}\text { Size-frequency } \\
\text { analysis }\end{array}$ & $\begin{array}{c}\text { Increase life- } \\
\text { history diversity }\end{array}$ \\
\hline & $\begin{array}{l}\text { Hatchery/wild } \\
\text { origin }\end{array}$ & Net samples & Monitor time series & $\begin{array}{c}\text { Marks, tags, } \\
\text { size by time; } \\
\text { hatchery } \\
\text { releases }\end{array}$ & $\begin{array}{l}\text { Increase wild } \\
\text { proportion, } \\
\text { trend toward } \\
\text { target }\end{array}$ \\
\hline & $\begin{array}{l}\text { Realized } \\
\text { residence }\end{array}$ & Electronic tags & $\begin{array}{c}\text { Cumulative hours, } \\
\text { mean }\end{array}$ & Mark/recapture & $\begin{array}{l}\text { Increase } \\
\text { residence }\end{array}$ \\
\hline $\begin{array}{l}\text { Salmon } \\
\text { wetland } \\
\text { utilization }\end{array}$ & $\begin{array}{l}\text { Use of wetland } \\
\text { production }\end{array}$ & Net samples & Gastric lavage & $\begin{array}{l}\text { Diet } \\
\text { composition, } \\
\text { Index of } \\
\text { Relative } \\
\text { Importance }\end{array}$ & $\begin{array}{l}\text { Document } \\
\text { utilization of } \\
\text { wetland prey }\end{array}$ \\
\hline $\begin{array}{l}\text { Restoration } \\
\text { benefit to } \\
\text { salmon } \\
\text { populations }\end{array}$ & $\begin{array}{l}\text { Contribution to } \\
\text { adult spawning }\end{array}$ & $\begin{array}{l}\text { Population } \\
\text { enhancement }\end{array}$ & Compute proportion & $\begin{array}{c}\text { Mark/recapture, } \\
\text { spawning } \\
\text { surveys, SARs }\end{array}$ & $\begin{array}{l}\text { Increase } \\
\text { proportion of } \\
\text { wetland } \\
\text { residence in } \\
\text { SARs. }\end{array}$ \\
\hline
\end{tabular}




\subsubsection{Data Collection and Analysis}

Field data were collected at the paired VS and VR (Figure 2.2), KF and KR (Figure 2.3), and CI and CR sites (Figure 2.4). Before-and-after satellite imagery was collected for all sites except CI and CR. Additional metrics describing channel networks were developed from light detection and ranging (LiDAR) data. Biomass, macroinvertebrate taxa identification, and juvenile salmonid genetic stock identification data were developed in the laboratory. This section describes the data collection and analysis methods for the indicator categories presented in the results: hydrology and water quality, topography and bathymetry, landscape, vegetation, fish presence, habitat availability, productivity and material flux, and fish usage. Methods for data collection of core indicators conform to the protocols previously released by the study team (Roegner et al. 2009a).

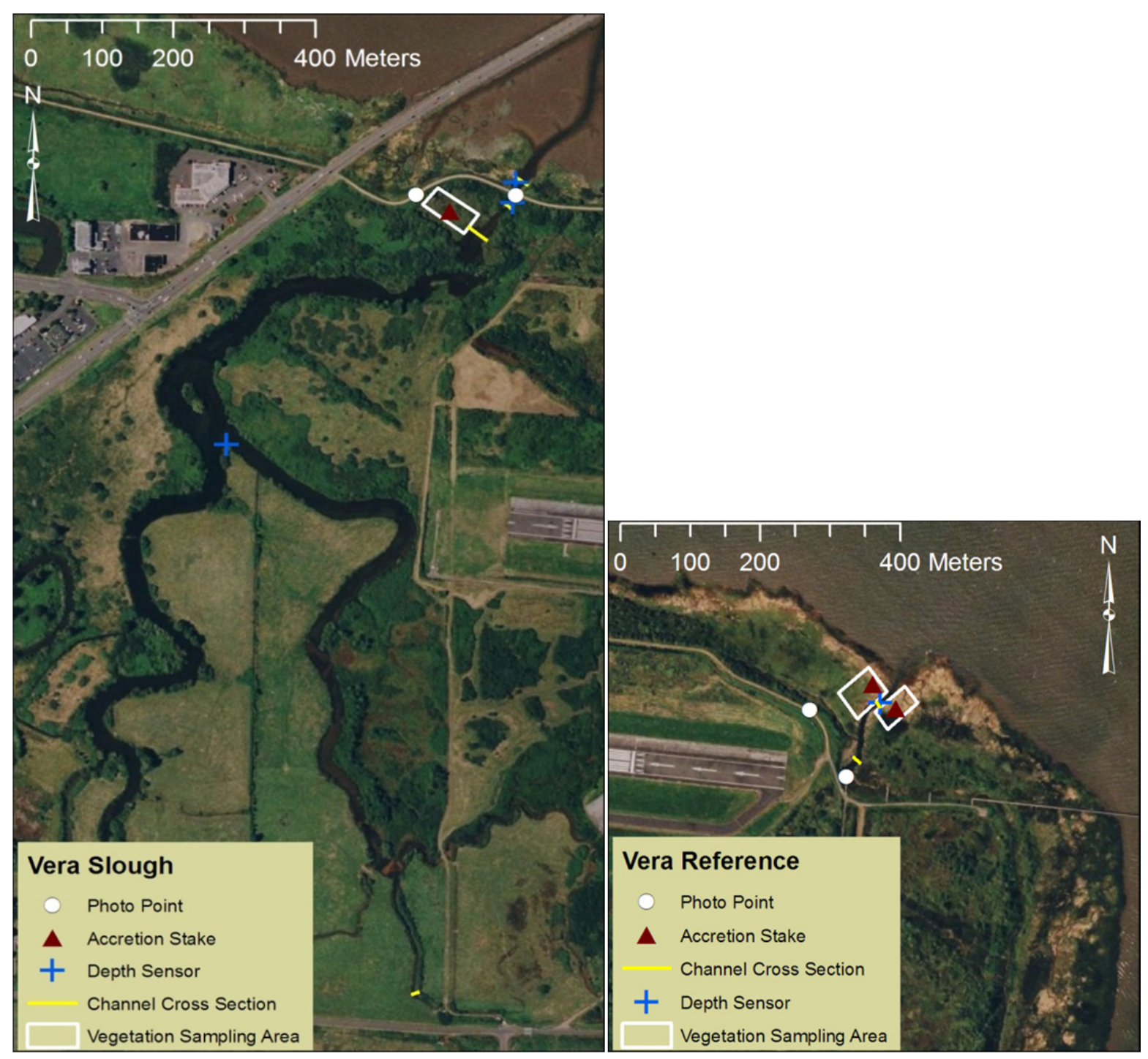

Figure 2.2. Detailed Maps of Paired Vera Slough Restoration and Reference Sites Showing the Locations of Data Collection 


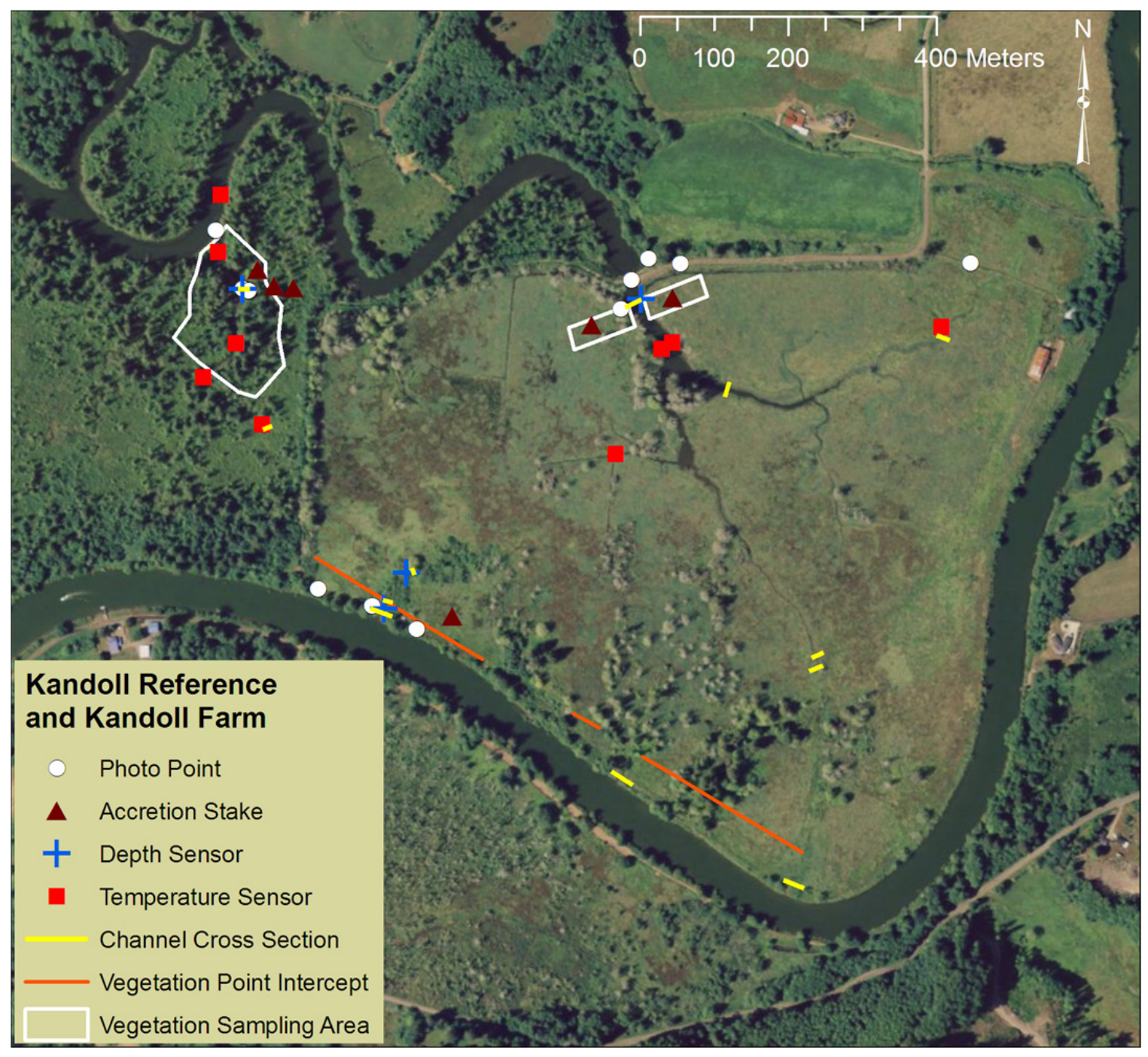

Figure 2.3. Kandoll Farm Restoration and Kandoll Reference Sites 

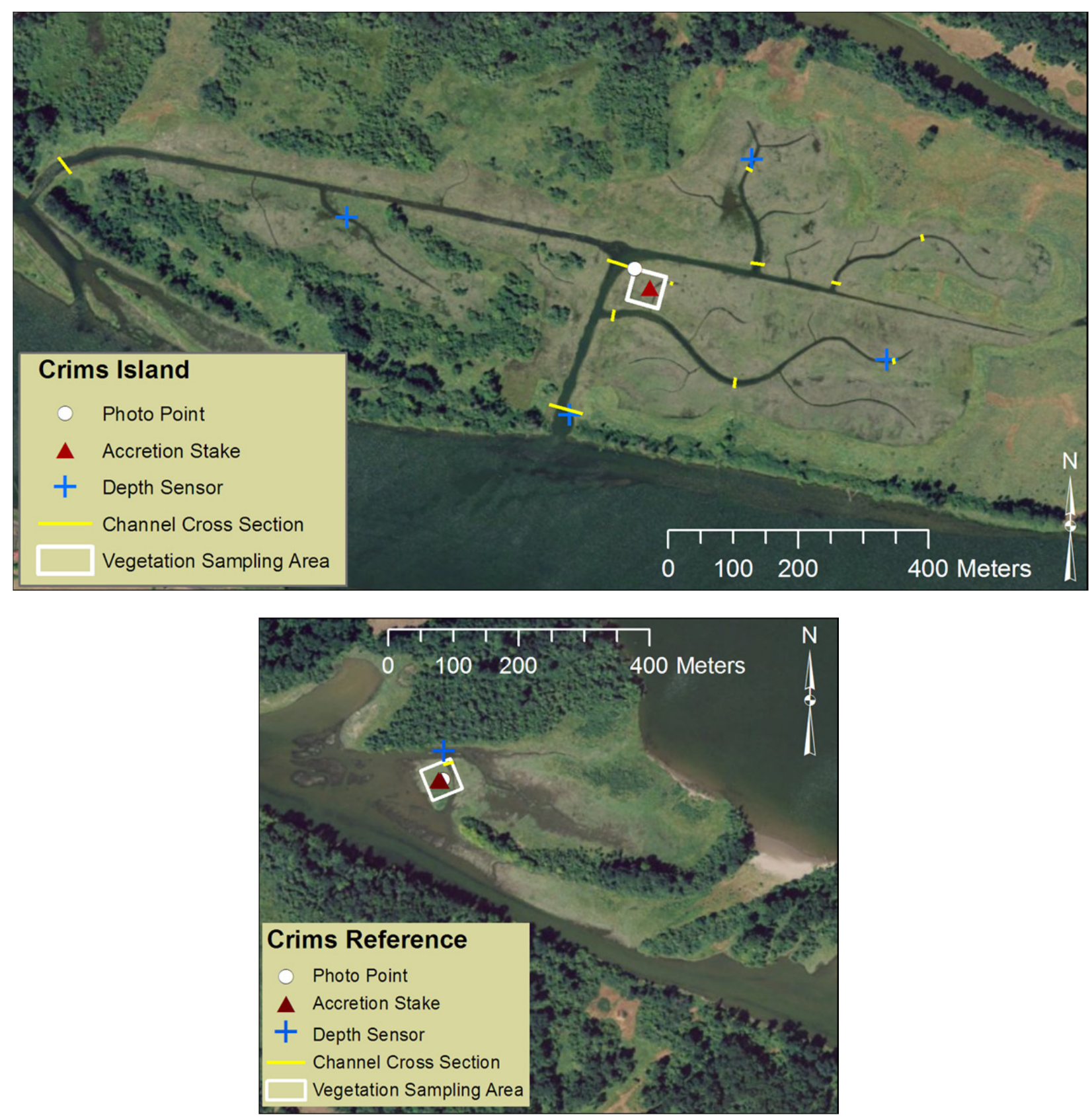

Figure 2.4. Crims Island Restoration and Crims Reference Sites

\subsubsection{Hydrology and Water Quality}

\section{Water-Surface Elevation}

Water-surface elevation (WSE) in the LCRE, largely a function of river flow and tidal fluctuations, is a controlling factor on wetland evolution following restoration. We documented changes in water levels before and after restoration using $\mathrm{HOBO}^{\circledR}$ model $\mathrm{U} 20$ water-level logger absolute pressure sensors installed in reference channels and in channels where culvert installation, tide gate retrofit or removal, or dike breaching occurred. Pressure data recorded year-round by level loggers at hourly or half-hourly 
intervals were corrected for measured water level. We installed a total of 14 sensors, beginning in 2005 prior to restoration at the KF, KR, VS, and VR sites, and in 2008 after restoration at the CI and CR sites: $\mathrm{VS}=3, \mathrm{VR}=1, \mathrm{KF}=2, \mathrm{KR}=2, \mathrm{CI}=3, \mathrm{CR}=1$. Three sensors were located outside of restoration sites to indicate landscape hydrologic conditions: two outside the KF site on the Grays River and one outside the tide gate at the VS site. We collected data and re-launched sensors as needed using the Onset Computer waterproof shuttle model U-DTW-1, collecting final data in 2009 with the exception of one sensor that failed in 2008. Environmental and equipment conditions beyond our control prevented the collection of complete time series at all installed locations.

\section{Tidal Exchange Volume}

To assess nutrient and material exchange through ebb and flow cycles at each site, the Area-Time Inundation Index Model (ATIIM) (Coleman et al. in preparation) was used to calculate the total volume of water at each hourly time-step through the study period. High-resolution bare-earth LiDAR elevation data provide ASCII triplets $(\mathrm{X}, \mathrm{Y}, \mathrm{Z})$ that are transformed into a continuous three-dimensional (3D) modeling surface. The deterministic infinity $(\mathrm{D} \infty)$ method (Tarboton 1997) within ATIIM, continuous flow direction, and flow accumulation data are generated and a site boundary is then defined by the effective drainage area of the site. Through the use of the ATIIM, two-dimensional inundation areas are developed at $10-\mathrm{cm}$ increments over the range of the water-level sensor measurements at the site. The boundaries defined by the series of inundation areas are used to define a new 3D terrain surface where a fill volume is calculated and stored to a master lookup table. The terrestrial LiDAR data used for this analysis provides data only for non-water surface areas; therefore, it should be noted that the total fill volume will be influenced by the minimum elevation of LiDAR data at the time of acquisition, likely resulting in some underestimation of the volume. For areas where the elevation of the water surface was known to be high at the time of data collection (CI and CR sites), the preparation of the final elevation surface included a channel enforcement process to convert a flat water-surface elevation to a representative channel (Hutchinson 1989). For this process, channel centerlines were captured from 2008 high-resolution aerial imagery and incorporated into the channel enforcement algorithm.

The calculation of the site water volume is driven by an hourly in situ WSE measurement, which is captured by a water-level absolute pressure sensor that is elevation surveyed to a National Geodetic Survey benchmark and corrected for atmospheric pressure. Calculations of water-surface area and volume within ATIIM are made once for each 10-cm water-level increment, after which, the WSE for the period of record is related to the appropriate volume through a lookup table. To determine the tidal exchange volume over a given time period, the minimum WSE is determined from the volume lookup table after which each time-step is evaluated. The difference between the current time-step and the previous time-step is evaluated; if there is a volumetric gain, the volume difference is added to a running total of volume, starting with the value of the initial volume. In addition to the total gain volume calculated for the time period, similar to the time-area inundation index (Coleman et al. 2010), an additional metric, the time-volume index, is calculated using the maximum possible volume for the site (assuming the site is inundated at maximum WSE for the full time period) and total time-volume for the site. An additional metric is calculated using a simple surface-area to volume ratio calculated as follows:

$$
S A V=\left(\frac{\text { Area }_{\text {Total }}}{\text { Volume }_{\text {Total }}}\right) * 100
$$


Because the ATIIM is intended to be a rapid assessment tool, it does not account for flow lag in the system and assumes the WSE measured at the sensor will propagate through the site within the 1-hour time-step. A time period from February 15 to June 30, 2008, was used to evaluate tidal exchange volume at the six paired restoration/reference sites.

\section{Water Temperature}

The model U20 water-level loggers also recorded water temperature at the same locations and time intervals as WSE measurements. In addition, we measured temperature with HOBO ${ }^{\circledR}$ model UA-002-64 sensors at four locations on the KF site from 2006 through 2009 to assess the spatial variability of water temperature patterns at the restoration site. Environmental and equipment conditions beyond our control prevented the collection of complete time series at all locations.

\subsubsection{Topography and Bathymetry}

\section{Elevation}

We collected elevation data for 1) vegetation sample locations and plant species, 2) longitudinal gradient surveys, 3) water-level sensors, 4) sediment accretion stakes, 5) channel cross sections, 6) temporary benchmarks, and 7) reference points as needed for auto-level surveys. We conducted surveys using only Trimble real-time kinematic global positioning system (RTK-GPS) methods at most marsh sites where overhead vegetation did not block satellite acquisition, while a combination of RTK and auto-level methods was necessary at riparian areas with tree cover and at KR swamp where large trees and shrubs frequently block satellites. All elevation surveys are referenced to the North American Vertical Datum of 1988 (NAVD88).

At each site, we used a benchmark to reference all survey data, preferably an established local benchmark if one could be located. We set up a Trimble RTK-GPS base receiver over the benchmark and entered the coordinates into the system. If an existing benchmark was not available, we established a temporary benchmark by setting up a Trimble base receiver at or near the site, logging GPS data over a 4- to 6-hour period, and sending these data to the automated Online Positioning User Service (OPUS) provided by the National Geodetic Survey.

The OPUS data provides a Root Mean Square(d) (RMS) value for each set of static data collected by the base receiver. The RMS, or circular positional error around a point, indicates the random error associated with each surveyed point. With this information, elevation data collected with the roving collection unit can be corrected after base receiver data have been processed. For each survey, we imported and reviewed data collected from the RTK using Trimble Geomatics Office (TGO) software, and points with a high RMS value were flagged by the processing software and removed from the survey data set. We exported survey data in a GIS shapefile format and visually checked them for validity using TGO and GIS software. If tree cover did not allow for RTK-GPS use, we established a temporary reference point with an RTK rover at a nearby location where satellites signals were available. In these cases, we set up an auto-level in a location with line-of-sight to both the reference point and the surveyed areas. We entered these data into a spreadsheet and corrected them using the RTK reference point elevations exported from TGO. Sources of error from the RTK methods include low satellite coverage, OPUS processing errors, and multipath errors. Our error estimates associated with the RTK data on average equate to approximately $\pm 4 \mathrm{~cm}$. Further analysis of our data is underway to evaluate spatial and temporal variation in the elevation data. 


\section{Sediment Accretion Rate}

We measured sediment accretion at 11 pairs of sediment accretion stakes at intervals throughout the study period. At each location, we drove a pair of stakes into the ground $1 \mathrm{~m}$ apart and leveled them across the top. We recorded measurements from the top-of-stake level to the ground-surface level, at 10 -cm intervals between the stakes, and averaged them. Prior years' measurements were subtracted from later years to obtain accretion rates. The number of pairs erected at each site was determined by the relative variability of the terrain: $\mathrm{VS}=1, \mathrm{VR}=2, \mathrm{KF}=3, \mathrm{KR}=2, \mathrm{CI}=1$, and $\mathrm{CR}=2$. We surveyed the elevation of each pair of sediment accretion stakes using RTK-GPS equipment.

We collected baseline data in 2005 prior to implementation of restoration actions at the VS, VR, and KF sites; data collection at the KR, CI, and CR sites began in 2006, 1 year after implementation. We collected final measurements in 2009. This method is coarse in that it does not account for vertical movements of the stakes, but it is cost-effective and suitable given the large accretion rates seen at restoring wetlands compared to reference sites.

\section{Channel Cross-Sectional Area}

Cross-sectional surveys are typical measurements of change in tidal channel morphology after hydrologic reconnection type restoration (Zedler 2001; Cornu and Sadro 2002). We collected channel cross-section survey data at 37 locations at the 6 study sites and at an additional dike breach restoration site on the Grays River called the Johnson Property, at intervals throughout the study period. All types of hydrologic reconnection restoration actions were represented in the set of cross sections; 10 were at or upstream of 5 dike breaches, 6 were above a culvert installation, 11 were on excavated channels, and 3 were upstream of and 1 downstream of a tide gate replacement. Eight were on reference sites. We selected survey locations at restoration sites to represent at minimum areas proximal to the restoration action, distal to it, and in between. Wherever possible, a cross section was surveyed along the baseline of the vegetation sampling plots (see Section 2.2.3.4).

We collected baseline data in 2005 prior to implementation of restoration actions at the VS, VR, KF, and KR sites, or in the case of dike breaches, with as-built surveys within the breaches immediately after excavation; data collection at excavated channels on the CI and CR sites began in 2006, 1 year after implementation. We collected final survey data in 2009.

Cross-section survey methods were detailed by Diefenderfer et al. (2008), who reported 2005-2007 results for four of the six sites. We marked transect endpoints set back from the bank of each channel with semi-permanent stakes, and determined their elevations using RTK-GPS equipment. If satellite coverage for the GPS was not available due to dense canopy cover, we used offset survey methods. We leveled a stadia rod at intervals along a measuring tape attached to the fixed endpoints and measured elevation with the RTK-GPS, an auto level, or a Trimble DR200+ total station. We measured greater horizontal intervals between measurements in areas of low slope (e.g., 1-2 m) and lesser ones in areas of steeper slope (e.g., $0.5 \mathrm{~m}$ ), and always surveyed the deepest point on the cross section. 
We estimated channel cross-sectional area from the data by summing the area of all segments of the cross section, as follows:

$$
\sum_{i=1}^{n} \frac{\left(E_{r e f}-E_{i+1}\right)+\left(E_{r e f}-E_{i}\right)}{2} *\left|H_{i+1}-H_{i}\right|
$$

where

$\begin{aligned} n & =\text { number of surveyed points on the cross section } \\ \mathrm{E}_{r e f} & =\text { elevation at base of stake } \\ \mathrm{E}_{i} & =\text { elevation of nearest point to stake } \\ \mathrm{E}_{i+1} & =\text { elevation of second nearest point to stake } \\ \mathrm{H}_{i} & =\text { horizontal distance from stake to point nearest to stake } \\ \mathrm{H}_{i+1} & =\text { horizontal distance from stake to second nearest point to stake. }\end{aligned}$

We performed the cross-sectional area calculations twice, using a different method for selecting the elevation at the base of the stake each time, in an effort to demonstrate the mathematical differences that result from two different conceptual approaches to the cross-sectional area calculation. In the first round of area calculations, we used the same elevation at the base of the stake (based on 2005 elevation measurements) for the 2005 and 2007 area calculations, and a unique elevation at the base of the stake (based on 2009 elevation measurements) for the 2009 calculations. The area calculations resulting from the first method are most appropriate for use with water-level data. In the second round of area calculations, we used the same elevation at the base of the stake (based on 2005 elevation measurements) for all years. The second method is most appropriate for use with channel morphology data.

\subsubsection{Landscape}

\section{Photo Points}

We collected photos taken at established photo points at all restoration and reference sites to provide a qualitative means of assessing change. We established initial photo point locations at each site during the first year of sampling, and revisited them at irregular intervals until taking a final photo in 2009, also establishing some new points at locations of interest during intervening years. We took care to replicate photos as exactly as possible, by using a compass to repeat the azimuth from a marked location, using the same camera model, and using photos from previous years as a guide to identify the location of reference points within the field of view and the level of zoom. In total, we photographed 14 points at the VS site, 14 at the VR site, 20 at the KF site, 5 at the KR site, 6 at the CI site, and 1 at the CR site. While tidal stage, time of day, and seasonality are important to photo interpretation, it was not always possible to replicate these environmental conditions in subsequent years.

\section{Satellite Imagery Analysis}

Vegetation maps for the KF and VS sites were created from multi-spectral remote-sensing imagery and ground-truth data. Imagery was acquired for each site in June 2005 and June 2009. The 2005 imagery was acquired with a fixed-wing aircraft and had a ground resolution of $0.25 \mathrm{~m}$ with four spectral bands (blue, green, red, and near-infrared). The 2009 imagery was acquired via commercial satellite and had a ground resolution of $0.50 \mathrm{~m}$ with four spectral bands (blue, green, red, and near-infrared). Imagery from 2005 was resampled to $0.5 \mathrm{~m}$ to match the larger resolution of the 2009 image. Normalized Difference Vegetation Index and image texture layers were calculated for each of the years. 
Ground-truth information was derived from vegetation transect data and specific ground-truth collection efforts. Point locations with vegetation type were cross-walked to a common legend for 22 vegetation cover types (Table 2.3 ).

Table 2.3. Vegetation and Other Land Cover Types Derived from Satellite Imagery

\begin{tabular}{llll}
\hline \multicolumn{1}{c}{ Herbaceous (Aquatic, Obligate Wetland, or } & \multicolumn{1}{c}{ Herbaceous } & \multicolumn{1}{c}{ Shrub or Tree } & \multicolumn{1}{c}{ Other } \\
\hline Baltic Rush & Herbaceous & Blackberry & Dead Tree \\
Carex & Juncus/Mixed Grass & Conifer & Water \\
Juncus & Pasture Mix & Deciduous Tree & \\
Juncus/Carex & Sparse Vegetation & Mixed Shrub & \\
Nuphar & Wet Pasture Mix & Willow & \\
Phalaris & & & \\
Phalaris/Juncus & & & \\
Rushes & & & \\
Scirpus & & & \\
Typha & & & \\
\hline
\end{tabular}

The point locations were buffered by $2 \mathrm{~m}$ to create ground-truth polygons representing areas dominated by the observed cover types. Ground-truth polygons were overlaid on the associated image to relate the known vegetation type with pixel statistics. A non-parametric supervised classification (Knick et al. 1997; Tagestad et al. 2006) was used to assign a vegetation community type to each pixel in the image, based on its spectral Euclidean distance from a known vegetation type. An expert model was used to refine some of the vegetation classes based on vegetative vigor and image texture (from the overhead imagery) and vegetation height (from LiDAR). Finally, hand edits were applied to some areas of the image based on expert knowledge.

\section{$\mathrm{Cl}$ and CR Sites Landscape-Scale Vegetation Assessment}

An elevation and vegetation community survey of the CI site was completed from September 6 to 8 , 2007. Transects were established perpendicular to the main east-west channel at 50-m intervals using a GIS. The end points for the transects were downloaded to the RTK system and used as navigation points to ensure that data collection occurred systematically. Each point was measured for a minimum of 10 seconds every $20 \mathrm{~m}$ along the transects. Data points were collected at higher frequency where transects crossed elevation features, such as channels. At channels, a point was collected at the top of each bank and at the bottom of the channel. In cases where the channel was wide or there were unusual features, e.g., slumping, extra data points were collected for a more accurate representation of the channel bathymetry. A code was stored with each point to represent the dominant vegetation category. These broad vegetation categories were used to determine a general vegetation characterization with associated elevations (Table 2.4). The upland and tree categories were used outside the excavated area and are not reported here. 
Table 2.4. Codes Used to Describe Vegetation at Elevation Points During the RTK Survey at Crims Island

\begin{tabular}{cc}
\hline Code & Description \\
\hline $\mathrm{O}$ & Open water/submerged aquatic vegetation \\
$\mathrm{L}$ & Low marsh \\
$\mathrm{H}$ & High marsh \\
$\mathrm{P}$ & Phalaris arundinacea \\
$\mathrm{U}$ & Upland \\
$\mathrm{T}$ & Trees \\
\hline
\end{tabular}

Elevation data were downloaded from the RTK system and entered into a GIS and a spreadsheet for analysis. Elevations and vegetation were plotted in Excel to determine the means and ranges of elevations for species or communities. Elevation bins were created for each primary vegetation category. The low marsh and high marsh categories had considerable overlap, which required the creation of an additional elevation bin (low/high). The ArcInfo Geographic Information System (ArcGIS) was used to create polygons representing the entire survey area and the excavated area from point data elevations and aerial imagery. The excavated area polygon was used to clip the point data, then ArcGIS was used to build Triangulated Irregular Networks (TINs) based on point elevations. Contours were created from the TINs at intervals matching the elevation bins. The contours were converted to polygons, and the polygons were used to calculate the area for each of the elevation bins. Elevation bins were determined for potential area colonized by reed canarygrass (Phalaris arundinacea), an invasive species, using the data collected at Crims Island and Gull Island in 2006 and 2007. Contours at the minimum and maximum elevation range of reed canarygrass were created from the TINs and the process for determining area was repeated as above.

\subsubsection{Vegetation}

Vegetation is recognized as an important indicator of ecological conditions at restoring sites (Zedler 2001), and tidal reconnections can substantially affect species abundance and distribution (Cornu and Sadro 2002; Roman et al. 2002; Thom et al. 2002). At estuarine restoration sites in the Pacific Northwest, vegetation sampling typically quantifies changes in species percent cover along transects (Frenkel and Morlan 1990, 1991; Thom et al. 2002). We collected data on transects proximal to the locations of restoration actions, and selected similar areas at each reference site in terms of proximity to the channel, channel size, and the width of the area sampled (riparian area) to allow comparison between the sites. Plot size and shape were determined by the size of the dominant vegetation at the site, which was herbaceous at all sites except the KR swamp, where we also sampled shrubs and trees. We selected all transect and plot locations according to the systematic sampling from a random start procedure. We also used line-intercept data collection methods at one location on the KF site to capture changes longitudinally along the Grays River.

\section{Plot Sampling - Herb}

We established a permanent baseline at each herbaceous site, designed to span the elevation gradient perpendicular to the main channel (on both sides if possible), because of the importance of elevation in 
determining plant assemblages in the LCRE (Fox et al. 1984). We placed transects perpendicular to the baseline, and plots on the transects. New transect and plot locations were selected for each subsequent sampling event using the systematic sampling from a random start method. In each $1-\mathrm{m}^{2}$ plot, we visually estimated percent cover in 5\% increments, using a "trace" category for species that covered less than $5 \%$ of the area within the quadrat. We established a subset of the plots sampled in the first year as permanent plots with marked corners for trends analysis and resampled them in all subsequent sampling events. We sampled the VS, VR, KF, and KR sites in 2005, 2006, and 2009, with the exception that the KR site was not sampled in 2006. We sampled the CI and CR sites in 2006 and 2009. The total herbaceous vegetation sampling areas in square meters were as follows: VS $=2,285$; VR $=4,200$; KF Seal Slough East $(\mathrm{SSE})=2,475$; KF Seal Slough West $(\mathrm{SSW})=2,325$; KR $(2005)=16,242$; $\mathrm{KR}(2009)=21,248 ; \mathrm{CI}=2500 ; \mathrm{CR}=2,500$. At the VR site, we sampled 40 plots in 2005, 37 in 2006, and 46 in 2009, and at the VS site, we sampled 40 plots in 2005, 40 in 2006, and 50 in 2009. At the KR site, we sampled 36 plots in 2009, and at the KF site, we sampled 102 plots in 2005, 127 in 2006, and 125 in 2009. At the CI and CR sites, we sampled 25 plots in 2006 and 30 in 2009.

\section{Plot Sampling - Shrub}

Of the three restoration sites and their associated reference sites, we sampled shrubs only at the KR swamp site, because of their relatively insignificant presence at the marsh sites. In 2009, we oriented the 200-m baseline along the channel and 5 cross-channel transects perpendicular to that, with 10 plots on the transects. The plot size for 2009 sampling was a $1-\times 10-\mathrm{m}$ belt set within a 10 -m-diameter circular tree plot (Havens et al. 2003). Following the protocols of Peet et al. (1998), we counted stems at a 1.4-m height and identified them to species and size class, and individual stems were defined as follows: "Multiple stems arising from a common root system are recorded separately if they branch below $0.5 \mathrm{~m}$ above ground level (stems branching above $0.5 \mathrm{~m}$ and below $1.4 \mathrm{~m}$ are measured at the narrowest point below the branch)." We measured stems longer than $40 \mathrm{~cm}$ and the size classes in centimeters were as follows: $0-1 \mathrm{~cm}, 1-2.5,2.5-5,5-10,10-15,15-20,20-25,25-30,30-35$, and 35-40 (Peet et al. 1998). In the previous sampling effort in 2005 , we attempted a percent cover method using 3-m-diameter circle plots, but because the line-of-sight is exceedingly limited in the swamp, we were not highly confident in these shrub percent cover estimates and therefore changed the method for 2009. In addition, the total shrub vegetation sampling area at the KR site in square meters changed from 16,242 in 2005 to 21,248 in 2009. Therefore, statistical analysis of change between 2005 and 2009 is not supported.

\section{Plot Sampling - Tree}

At the KR swamp, in 2009 we oriented the 200-m baseline along the channel and 5 cross-channel transects perpendicular to that, with 30 circular tree plots on the transects. The line-of-sight was exceedingly limited in the swamp and there is extensive large wood on the ground, and as a result, the 20-m-diameter circle plot size we used in preliminary sampling of 12 plots in 2005 made tree sampling unnecessarily time-consuming. We changed the plot size to $10-\mathrm{m}$ in diameter for the 2009 sampling and protocols (Roegner et al. 2009a), i.e., from fewer larger plots to more smaller plots, so the statistical analysis of change between 2005 and 2009 is not supported because of expected differences in the accuracy of cover data on common species, in the bias of cover estimates of rare species, and inclusion of rare to uncommon species (McCune and Grace 2002, p. 23). In addition, the total tree vegetation sampling area at the KR site in square meters changed from 16,242 in 2005 to 21,248 in 2009. 
In each plot, we identified all trees in the plot to species and measured the diameter at breast height (dbh) at $1.4 \mathrm{~m}$ of all trees in the plot with calipers or a dbh tape. We measured the height and age of a subset of trees using a clinometer or laser rangefinder for height and an increment borer for ring count.

\section{Plot Sampling - Calculations}

We calculated similarity and alpha diversity indices, and species accumulation curves, for herbaceous vegetation cover using PCORD version 5.32 software (McCune and Grace 2002). Diversity is calculated by two methods, based on percent cover averages for the six sites. First, the Shannon-Wiener index:

$$
H=-\sum_{i}^{S} p_{i} \log p_{i}
$$

where $\mathrm{S}$ is the number of species, and $\mathrm{p}_{\mathrm{i}}$ is the proportion of cover belonging to species $\mathrm{i}$.

Second, the Simpson's diversity index for infinite population:

$$
D=1-\sum_{i}^{S} p_{i}^{2}
$$

where $\mathrm{S}$ is the number of species, and $\mathrm{p}_{\mathrm{i}}$ is the percent cover relativized by the cover in the plot, representing the importance probability of the element $\mathrm{i}$ (species).

Using the Shannon_Wiener index and species richness, evenness (Pielou 1966, 1969) was computed as:

$$
E=H / \log S
$$

where $\mathrm{H}$ is the Shannon-Wiener diversity measure (Eq. (2.3)) and $\mathrm{S}$ is the average species richness.

To express distance or dissimilarity, we calculated a proportion coefficient, or a city-block distance, expressed as proportion of maximum distance in PCORD (McCune and Grace 2002): the relativized Sorensen similarity method, also known as relativized Manhattan coefficient (Faith et al. 1987) or BrayCurtis coefficient (Bray and Curtis 1957; Faith et al. 1987) based on the method originally proposed by Czekanowski (1913). We developed species-area curves for herbaceous species only using Bray-Curtis (Sorensen) distance.

\section{Line-Intercept Sampling (Herbaceous)}

In 2005, we established an 800-m transect paralleling the Grays River on Kandoll Farm, inside the dike, because we had observed the occurrence of possibly distinctive plant associations between each pair of channels prior to the three dike breaches created in this area. We sampled the fields between the channels, and one forested area between channels D and E, using a line-intercept method with 1-m intervals. We did not sample the dense shrub mounds, which tended to be composed of Himalayan blackberry (Rubus spp); instead, we noted the species composition of the shrubs. 


\section{Vegetation and Elevation}

The methods we used to determine elevation of vegetation species depended on vegetation cover type. In marshes, our objective was to survey all vegetation plot centers, but in rare cases, line-of-sight or satellite-related issues prevented collection at some of the plots. In the KR swamp, we surveyed plots and individual species along a subset of the transects with the objective of sampling replicates of all species and capturing the highest and lowest elevation of all species.

\subsubsection{Habitat Availability}

A number of terrain analysis methods have been implemented to evaluate the characteristics of a site in terms of habitat opportunity. Fundamental to this process is the availability of high-resolution LiDAR elevation data that can resolve the microtopography in an estuarine environment (Diefenderfer et al. 2008). While many of the methods and metrics presented here are based upon the availability of WSE data at a site, there are other metrics that purely describe the physical topographic characteristics. The ATIIM, as described earlier, provides the capability for generating these metrics (Coleman et al. 2010).

\section{Features of the Channel Network}

The determination of habitat opportunity at a site begins with the derivation of a raster-based channel network using the Do method (Tarboton 1997). The definitions in the channel network provide site-wide distributed data accumulating upslope flow values to a point of flow concentration, after which, channels are defined through gradient drops/low points in the terrain processing window. In addition, a total hydrologic contributing area is defined and provides a site boundary within which all further processing is contained. The raster-based channel network and contributing area are converted into a vector stream network and site watershed boundary, respectively, that are applied in the spatial modeling routines of ATIIM.

General site-level metrics, including the topographically determined site area and site perimeter are basic spatial calculations determined directly from ATIIM through the underlying GIS. From the input WSE time-series record and the standard processing in ATIIM, a frequency table is generated where the maximum WSE frequency is determined. The total channel density, or drainage density, provides a metric of stream length per unit area and an indication of habitat opportunity (Horton 1932). This metric is calculated by simply dividing the total center-of-channel length at the site by the total site area. Although not presented here, the ATIIM also calculates the channel density at each WSE to provide a measure of density in the aquatic/terrestrial interface over varying tidal/flow levels. The total channel edge length is determined by multiplying the total center-of-channel length by two, thereby capturing the total potential habitat opportunity on either side of the channel. For this calculation, no explicit consideration is made for channel separation and reconnection, thus increasing the potential for habitat opportunity. As with drainage density, the ATIIM incorporates the spatiotemporal aspect of this metric and determines channel edge length at each WSE. For these methods, what is formally being presented as the habitat opportunity metric determines the percent of total access opportunity, by summing the length of inundated channels at a given WSE and dividing by the sum of channel length for the entire site. 


\section{Topographic Landform and Hypsometric Curve}

The topographic landform of the site is captured using a hypsometric curve, a cumulative probability distribution using statistical moments to capture the elevation-area relationship in a drainage area (Harlin 1978; Luo 2000). A hypsometric curve can be represented in absolute terms if one is interested in evaluating it against other data using real elevation values, or in relative terms if looking for a dimensionless representation. The hypsometric curve provides a quick assessment of the landform shape at a site, opportunity for inundation, and habitat opportunity. Additional metrics can be derived from the hypsometric curve, including hypsometric skewness, kurtosis, skewness of the density function, etc. (Luo 2000).

\section{Ground Structure}

The ground structure as captured by last-return topographic LiDAR can be captured using a topographic ruggedness index (Riley et al. 1999). As presented by Diefenderfer et al. (2008), reference sites tend to have a higher surface roughness over restoration sites. This may be due largely to significant woody material and dense biomass at the ground level as opposed to a restoration site that may exhibit characteristics from a former land use such as agricultural or pasture land. The topographic roughness index can be used as a metric for restoration progress and habitat opportunity; e.g., at Sitka spruce swamp sites characterized by hummocky microtopgraphy.

\section{Topographic Wetness Index}

The modified topographic wetness index (MTWI) (Boehner et al. 2002) estimates a spatially distributed steady-state condition of soil saturation and, ultimately, runoff generation. The algorithm uses the contributing area of a given cell, an approximated soil transmissivity value, and slope gradient for its parameters. The modified index differs from the standard index in that a modified catchment area calculation is used to handle low gradient zones in a more effective manner. The MTWI can provide some value in determining existing and potential restoration wetlands based on natural topography. While the MTWI algorithm doesn't account for tidal influence, the use of the spatiotemporal inundation frequency data from ATIIM could be used to enhance the MTWI for use in tidal environments. This MTWI, combined with newly developed rule-based object-oriented classification methods, has been applied in non-estuarine wetland mapping programs with a high-degree of success (Coleman 2010).

\subsubsection{Fish Presence}

\section{Physical Monitoring}

We assessed connectivity and water-quality suitability with a network of data-logging instrumentation as described by Roegner et al. (2009a, 2010b) and Diefenderfer et al. (2011). Briefly, system hydrography was monitored with pressure/temperature sensors (Hobo model U20-001-04, Onset Corp) and temperature-light sensors (Hobo model U20-001-04, Onset Corp) established at stations within and surrounding the restoration sites. Pressure sensors measure water-level fluctuations caused by tides and river runoff. Connectivity was assessed calculating exposure-height (hyposgraphic curves) before and after changes in water control structures. Temperature time series are used to evaluate periods of suitable water-quality conditions for rearing salmonids. As an index of water quality, we calculated the 7-day 
average maximum daily temperature (7-DAM) and referred to a critical threshold of $16^{\circ} \mathrm{C}$ as the upper criterion for optimum thermal conditions (EPA 2003; Richter and Kolmes 2005). Temperatures above $19^{\circ} \mathrm{C}$ can be stressful for salmonids. Salinity and dissolved oxygen conditions were measured with a Sea-Bird Model 19 plus a conductivity-temperature-depth recorder in conjunction with fish sampling.

\section{Fish Sampling}

Fish were sampled by beach seine or fyke net (Roegner et al. 2009a, 2010b), and specimens were identified to species, enumerated, and measured to the nearest millimeter. The sampling gear did not have difficulty capturing fish if they were present. Because determining the presence/absence of salmonids was a goal, we concentrated fishing effort during May, June, and August (the main migration period for subyearling Chinook salmon) at the VS and natural breach sites (see site descriptions above), while at the KF site we sampled at bimonthly to monthly frequencies and generated a more intensive time series.

\section{Fish Community Analysis}

We used fish species abundance data, expressed as catch per unit effort (CPUE), to describe general patterns of community structure among reconnected wetlands and reference habitats. Variation between restoration and reference sites (pooled for each site and year) was evaluated using two standard community metrics: species richness $(\mathrm{S})$ and the Shannon-Wiener species diversity index $\mathrm{H}^{\prime}=$ $\sum$ [-Pi (ln Pi)], where $\mathrm{Pi}$ is the proportion of species in the sample. H' values closer to zero indicate a less diverse fish assemblage.

\section{Salmon Life History and Habitat Use}

Salmon life-history stage was estimated by size and date of capture. For the period January-July, salmon $<60 \mathrm{~mm}$ were considered fry, and we used the equation: Size $(\mathrm{mm})=0.5 *$ (Day of year) +50 to distinguish fingerlings from yearlings (data modeled from Dawley et al. 1985). Size-frequency distributions of salmon served to quantify the proportions of individuals composing the life-history types present at restoration and reference sites. We also generalized temporal trends in the abundance data with scatterplots of salmon CPUE by day of year.

\section{Salmon Size and Hatchery Production}

We examined all salmon for adipose fin clips or other external marks indicating hatchery origin. The Grays system proved to be a special case, because clipped individuals could be from hatchery releases (intentional or not) but also from possible migration from outside the watershed. We therefore plotted the size of adipose fin clipped and unclipped individuals as time series in relation to the timing of hatchery releases. Note that because only a proportion of all hatchery fish are marked, we could not unambiguously distinguish whether unmarked individuals were naturally spawned or produced in a hatchery. In the Grays River system, we therefore conducted genetic surveys in 2007 and 2008 to determine the stock of origin by collecting non-lethal samples of fin tissue (Roegner et al. 2010b). 


\section{Electrofishing at Kandoll Reference Swamp}

In addition, because beach seine samples were collected in the main stem Seal Slough not the smaller reference channel associated with the vegetation and other monitoring (Roegner et al. 2010b), we used electrofishing methods in 2010 for verification of salmonid presence in the KR swamp. Electrofishing samples were obtained from the KR channel in one pass per month in March, April, and June 2010, on the same 200-m channel segment surveyed by Diefenderfer and Montgomery (2009). Based on atmospherically corrected data from a HOBO model U20 water-level logger absolute pressure sensor deployed in the channel from February through July 2010 following Roegner et al. (2009a) protocols, all sampling occurred at or near low tide. The total electrofishing effort was 165 minutes at the KR site. The equipment included an electroshocker (Model LR24, Smith Root Inc.), two dip nets, a scale, and a ruler. Standard electrofishing methods were used.

\subsubsection{Productivity and Material Flux}

We sampled aboveground biomass in summer and the following winter in order to calculate flux rates, according to the following schedule: in 2005-2006, 2006-2007, and 2009-2010, at VS, VR, KF, and KR (with the exception of 2009-2010 at KR); and in 2006-2007, 2007-2008, and 2009-2010 at CI and CR (with the exception of 2007-2008 at CR). To collect samples, we randomly selected a subset of $\sim 25-30 \%$ of the $1-\mathrm{m}^{2}$ plots measured for percent cover using the systematic sampling from a random start method. In these, we randomly selected one corner of the vegetation sampling quadrat, and clipped all vegetation within a $0.10-\mathrm{m}^{2}$ quadrat at the substrate level. At KR swamp in 2006-2007, we increased the size of the sample to $1 \mathrm{~m}^{2}$ because of very low recoveries in the first year of sampling and selected plots using the haphazard method. We stored aboveground biomass samples on ice or in a cold room until rinsing the entire sample in freshwater over 1- or 2-mm mesh to remove sediment and anything but macrovegetation. The dead (brown and flaccid) and live green plant matter were separated in some years, dried in an oven at $\sim 80-90^{\circ} \mathrm{C}$, and weighed after cooling.

\subsubsection{Fish Usage}

Salmon diets were measured as an indicator of habitat use. Stomach contents of sufficiently large Chinook and coho salmon (chum were too small) were collected by gastric lavage, a non-lethal technique (Seaburg 1957). In the laboratory, prey items were wet-weighed and then sorted and identified to the lowest possible taxonomic level (depending on the extent of digestion and taxonomic authority) under a dissection microscope. For analysis we grouped the data into major taxa categories to emphasize dominant prey groups by count and weight. The index of relative importance (IRI) was calculated to indicate the relative level at which the prey categories were consumed by juvenile salmon (Pinkas et al. 1971; Roegner et al. 2010b).

We conducted an insect fallout trap sampling at the VS, VR, KF, and KR sites during three months in the spring of 2006. In addition, we replicated the insect fallout trap experimental design at Kandoll Farm only in 2009 , to examine potential effects of the increase in reed canarygrass cover on salmon prey production. These data will be described further in future reporting. 


\subsection{Results}

The results include hydrology and water quality, topography and bathymetry, landscape characteristics, vegetation, habitat availability, fish presence, productivity and material flux, and fish usage.

\subsubsection{Hydrology and Water Quality}

The water-level and temperature data were analyzed in various spatio-temporal combinations to assess several hypotheses, or objectives.

\subsubsection{Water-Surface Elevation}

The objective was to compare hydrographs produced by two restoration methods: dike breach and tide gate. Data examined represent a full range of tidal cycles before and after the restoration actions, where available, comparing locations inside and outside the restoration action. The area inside the culvert replacement at the KF site immediately resumed hydrologic patterns like that of the reference site (Figure 2.5). In contrast to conditions at the KF site, the dynamics of the hydrograph in the VS channel immediately outside of the tide gates in Youngs Bay were muted by the tide gates (Figure 2.6).

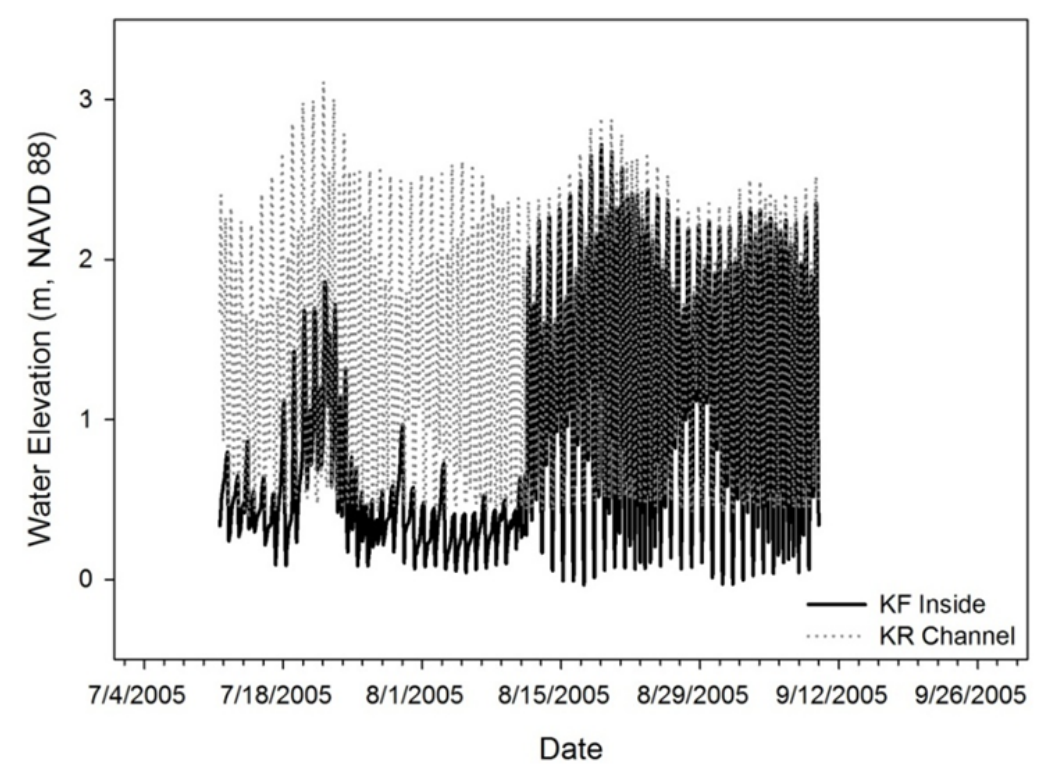

Figure 2.5. Hourly Water-Surface Elevation at KF Inside and KR Channel (a surrogate for "outside") During the Months Spanning the Tide Gate Removal, Dike Breach, and Culvert Replacement 


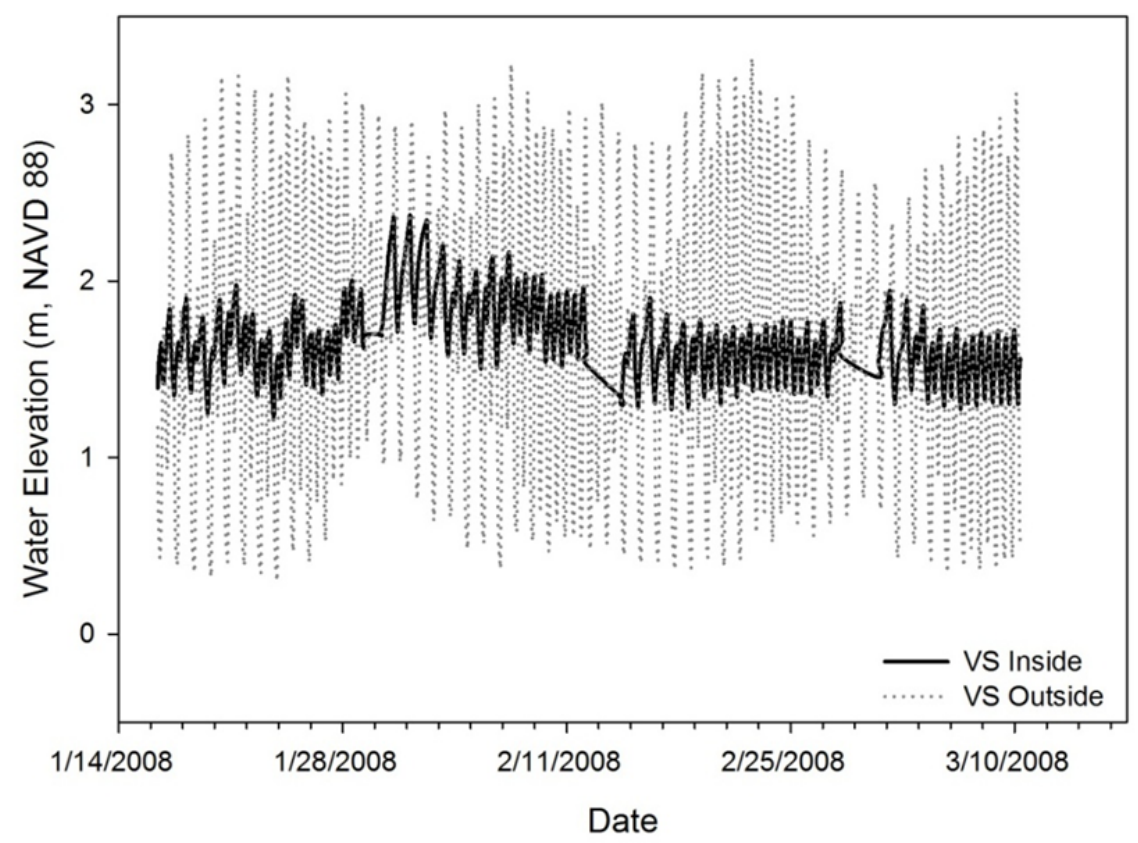

Figure 2.6. Hourly Water-Surface Elevation at the VS Site, Inside and Outside of the New Tide Gates, Winter 2008. Horizontal lines indicate missing data records at the VS Inside station.

Tide gate removal had an immediate effect on water-level fluctuations within the KF site (Figure 2.7). Pre-breach fluctuations changed from a weak tidal signal to a fully semidiurnal tidal pattern. Exposureheight curves indicated that maximum amplitudes increased from about 2.0 to $3.0 \mathrm{~m}$, although preconnection water levels were $<1.0 \mathrm{~m} 85 \%$ of the time period evaluated, and mean water level increased from 0.6 to $1.5 \mathrm{~m}$ during the 2 -week period around the tide gate removal.

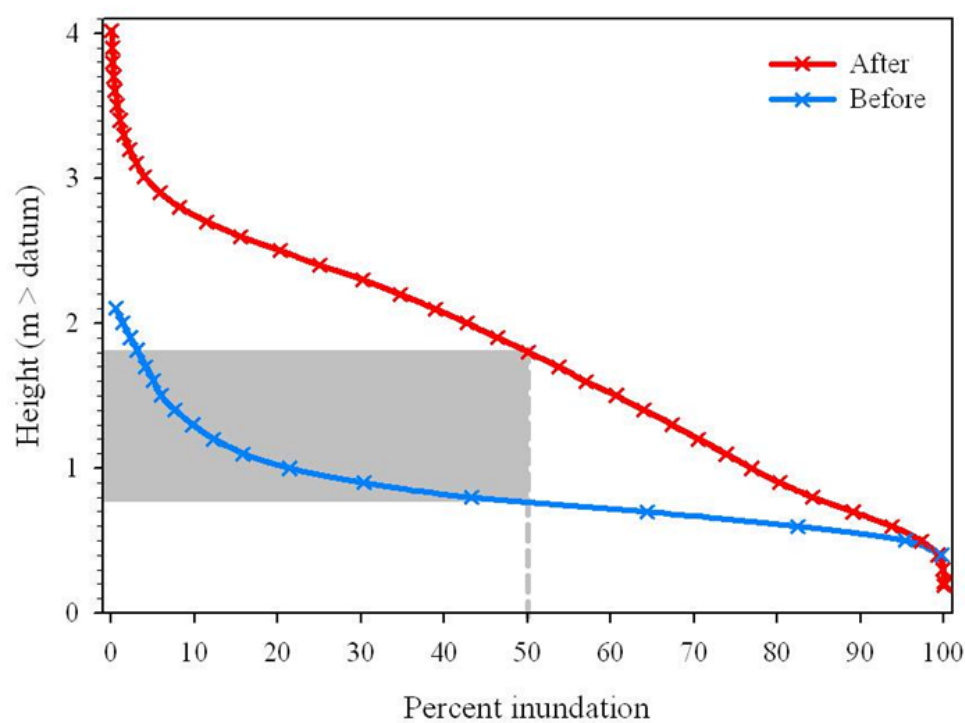

Figure 2.7. Exposure-Height Curves Comparing Inundation Levels Before and After Tidal Reconnection at the KF Site. The change in the 50\% inundation level is denoted by the grey area. 
Water level and temperature were monitored at stations immediately inside and outside of the tide gate, at a reference site upstream in Vera Slough, and at a nearby references site (see site description). In the pre-replacement condition, tidal fluctuations at the inside station were about $0.1 \mathrm{~m}$, while outside the tide gate and in the reference slough, a full semidiurnal tidal range of amplitude between 1 and $3 \mathrm{~m}$ occurred. The new tide gates enabled an increase in tidal amplitude to about $0.5 \mathrm{~m}$ at the VS Inside station (Figure 2.8). The truncated vertical amplitudes exhibited in both pre- and post-replacement time series demonstrate the effectiveness of the tide gates at limiting full tidal connection (Johnson and Deifenderfer 2008).

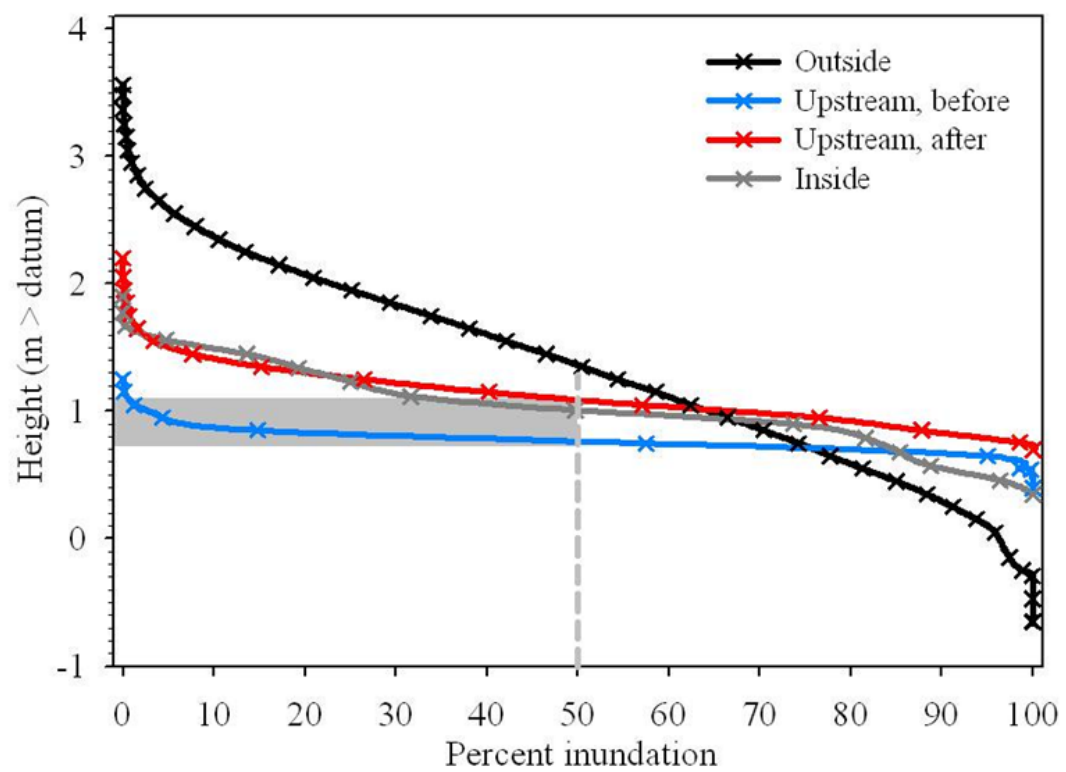

Figure 2.8. Exposure-Height Curves Comparing Inundation Levels Before and After Tidal Reconnection. Vera Slough, showing Outside, Upstream Before, Upstream After, and Inside stations.

Analysis of water levels at the Vera Slough stations illustrates the effect of increased tidal reconnection over larger spatial and temporal scales (Figure 2.6). During the pre-replacement period of May to October 2005, mean water level at the upstream station was $0.9+0.1 \mathrm{~m}$, and daily fluctuations were generally $<0.5 \mathrm{~m}$. In contrast, during the post-replacement period after October, the mean water level increased to $1.3+0.2 \mathrm{~m}$, and the daily water-level fluctuations increased to a maximum of $0.6 \mathrm{~m}$.

Spectral analysis of the time series detected a weak semidiurnal peak but a lack of a diurnal peak in variance (data not shown). A semidiurnal tidal period was evident in the water-level spectrum postreplacement, indicating tidal fluctuations had increased upstream of the tide gate.

To assess spatial variability of water levels at a single restoration site (CR), the WSE at Crims Island was measured. WSE is variable and influenced by both tidal and fluvial flows (Figure 2.9). Multiple sensors were placed at the site to try to determine variability at the site scale. Small differences were seen in the maximum daily water levels, with the sensors farther up channels having higher maximum water levels (Figure 2.10). Further investigation is needed at a more frequent time scale to determine the timing and extent of this difference. 


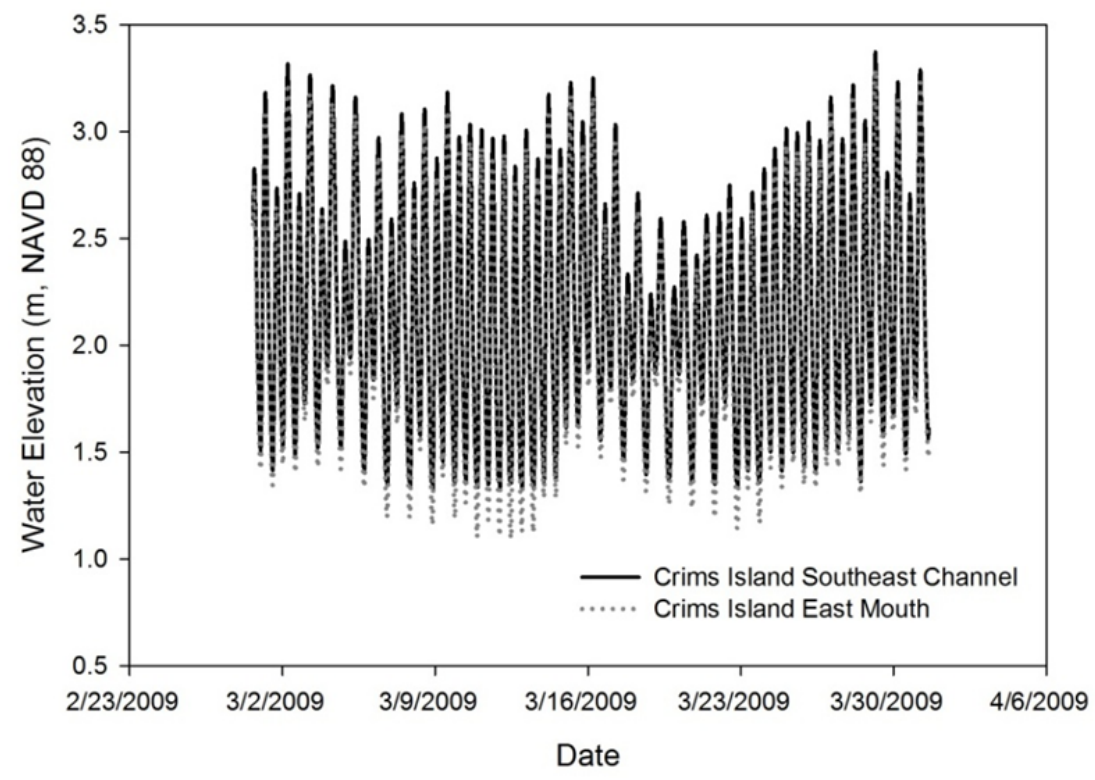

Figure 2.9. Hourly Water Levels at the Mouth of Crims Island's East Channel and Inside the Southeast Channel in March 2009

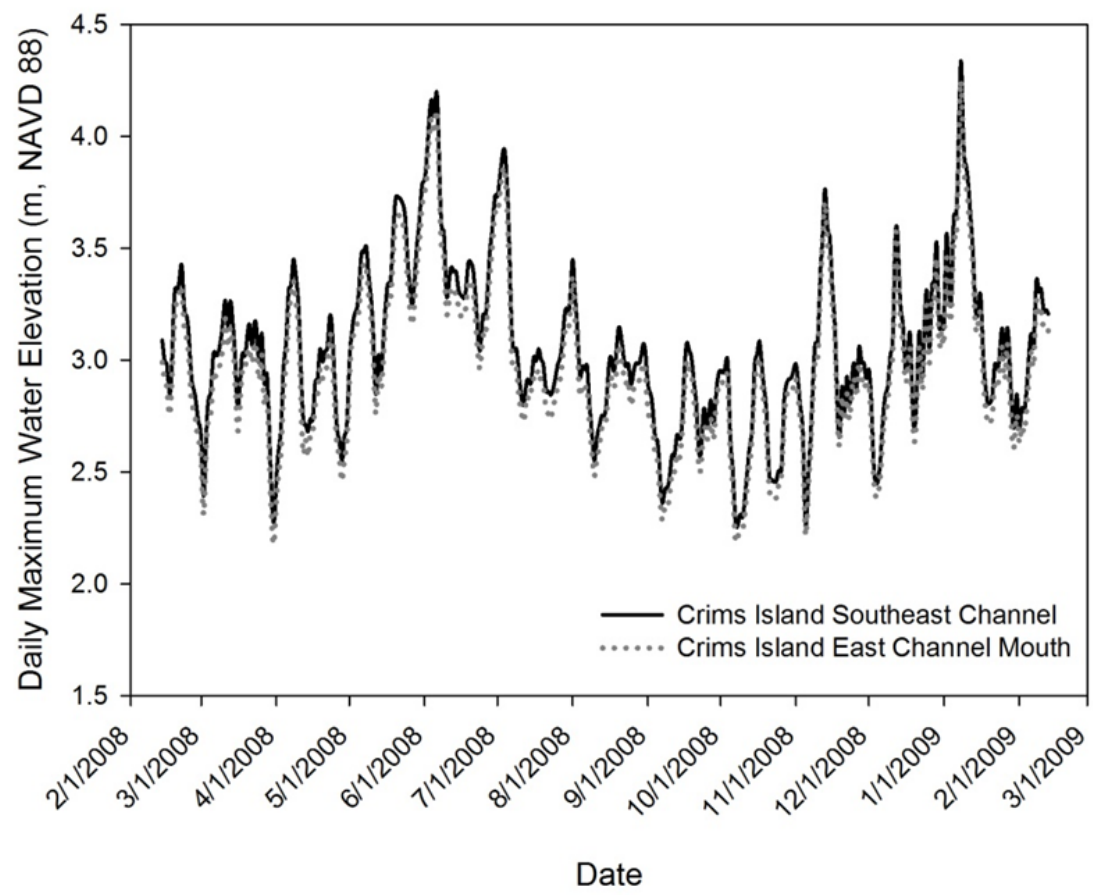

Figure 2.10. Daily Maximum Water Levels at the Mouth of Crims Island's East Channel and Inside the Southeast Channel. One year is shown, beginning February 14, 2008.

\subsubsection{Water Temperature}

Comparing temperatures inside and outside, trends in 7-DAM temperatures clearly become more similar after restoration (Figure 2.11). It should be noted, however, that the pool containing the sensor 
inside the KF site is much deeper than that at the KR site, which may explain the sometimes cooler temperatures at the KF site even though that location is exposed to the sun, whereas KR site has forest cover.
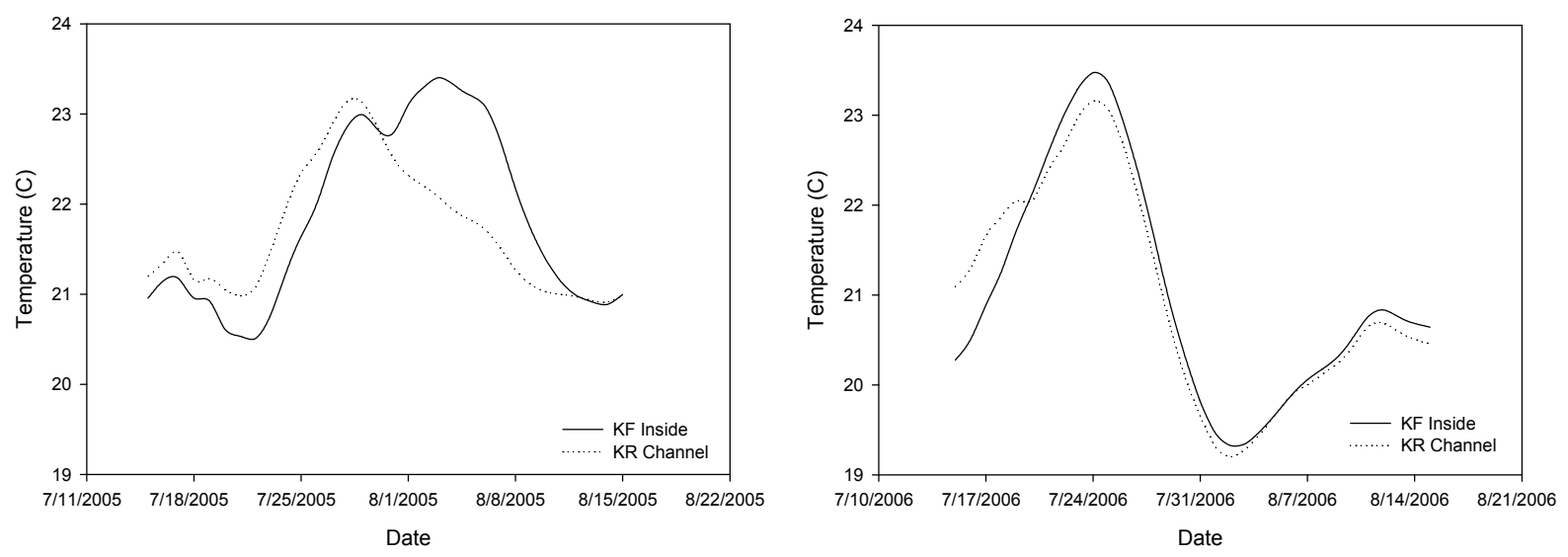

Figure 2.11. 7-DAM Temperatures of the KF Inside and KR Channel Stations During the Warmest Water Temperatures of the Year in Late Summer (comparing the same months before restoration in 2005 [left panel] and after restoration in 2006 [right panel] so restoration is not confounded with season)

From 2005 through 2007, temperatures in the Grays River system were monitored from the upper and lower hydrologic end-members and contrasted with temperatures at the restoration site. Temporal trends in the 7-DAM temperature time series during the period of high salmonid abundance exhibited similar temporal trends within and across years but varied in magnitude between stations (Figure 2.12). The temperature time series upstream diverged in spring and remained 3 to $5^{\circ} \mathrm{C}$ lower than temperatures downstream at the mouth of Grays River and within the KF site throughout summer. Each year, the 7-DAM temperature exceeded the $16^{\circ} \mathrm{C}$ criterion earlier at the lower stations (May versus June) and remained above $16^{\circ} \mathrm{C}$ for a longer period (usually through September) than at the upstream station. The maximum daily temperature regularly exceeded $20^{\circ} \mathrm{C}$ at the Grays River mouth and within the restoration site, but only occasionally at the upstream station. These data indicate that temperatures at the restored site are more similar to temperatures of the Columbia River, and in contrast to Vera Slough, water heats up as it moves downstream.

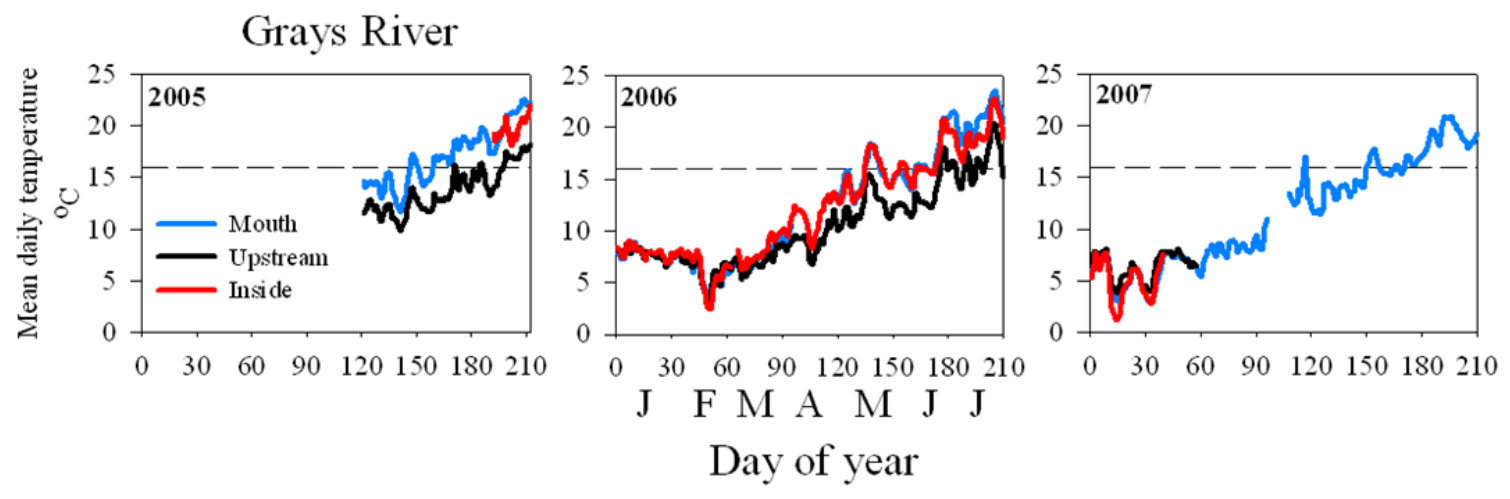

Figure 2.12. Seven-Day Average Maximum Daily Temperature at Sites in the Vicinity of Kandoll Farm from January to July, 2005-2007. "Mouth" is the mouth of Grays River; "Inside" is within the Kandoll farm restoration site; "Upstream" is at the head of tide in the Grays River. 
During the 2007-2009 period, we monitored temperatures near the trap net (TN) deployments. The 7-DAM temperature time series from trap net sites in 2008 were anomalous compared with previous years. Both sensors recorded much warmer temperatures than expected during March and April. The time series deviated from each other from April to May, with trap net site 1 (TN1) tracking a more expected seasonal trajectory while trap net site 2 (TN2) indicated many days exceeding the $16^{\circ} \mathrm{C}$ threshold. The two time series re-aligned in mid-May and exhibited a rapid increase in June. These higher temperatures are likely due to sensor placement in shallow water where atmospheric heating is greater than the at the deeper pressure-temperature deployment sites. During 2009, the 7-DAM temperature time series in three TN tidal channels were remarkably similar among sites from February through May. Temperature was lower in TN1 during late June and July, likely as a result of sensor burial. All 7-DAM temperature time series exceeded the $16^{\circ} \mathrm{C}$ criterion during late April through August, and exceeded $19^{\circ} \mathrm{C}$ for most of June and July. Spectral analysis of the temperature time series shows strong periodicity at semidiurnal tidal time periods, indicating tidal flux is responsible for much of the temperature variation.

To assess spatial variability of temperature at a single restoration site (KF), five temperature sensors were compared (Figure 2.13). Three were located in the main channel of Seal Slough inside the KF site, one just inside the culvert replacement, and these track very closely with each other and with one sensor in a deep narrow fork to the southwest. To the east is a shallow, ponded area, without steep sides and relatively vegetated (e.g., rushes [Juncus]), which showed exceedingly high temperatures in the spring and summer of the second year. The cross section located very close to this sensor (Seal Slough North Fork upper channel) is also inconsistent with other cross sections up-channel from the culvert installation, evincing measurable accretion in both a lower total cross-sectional area and a lower thalweg.

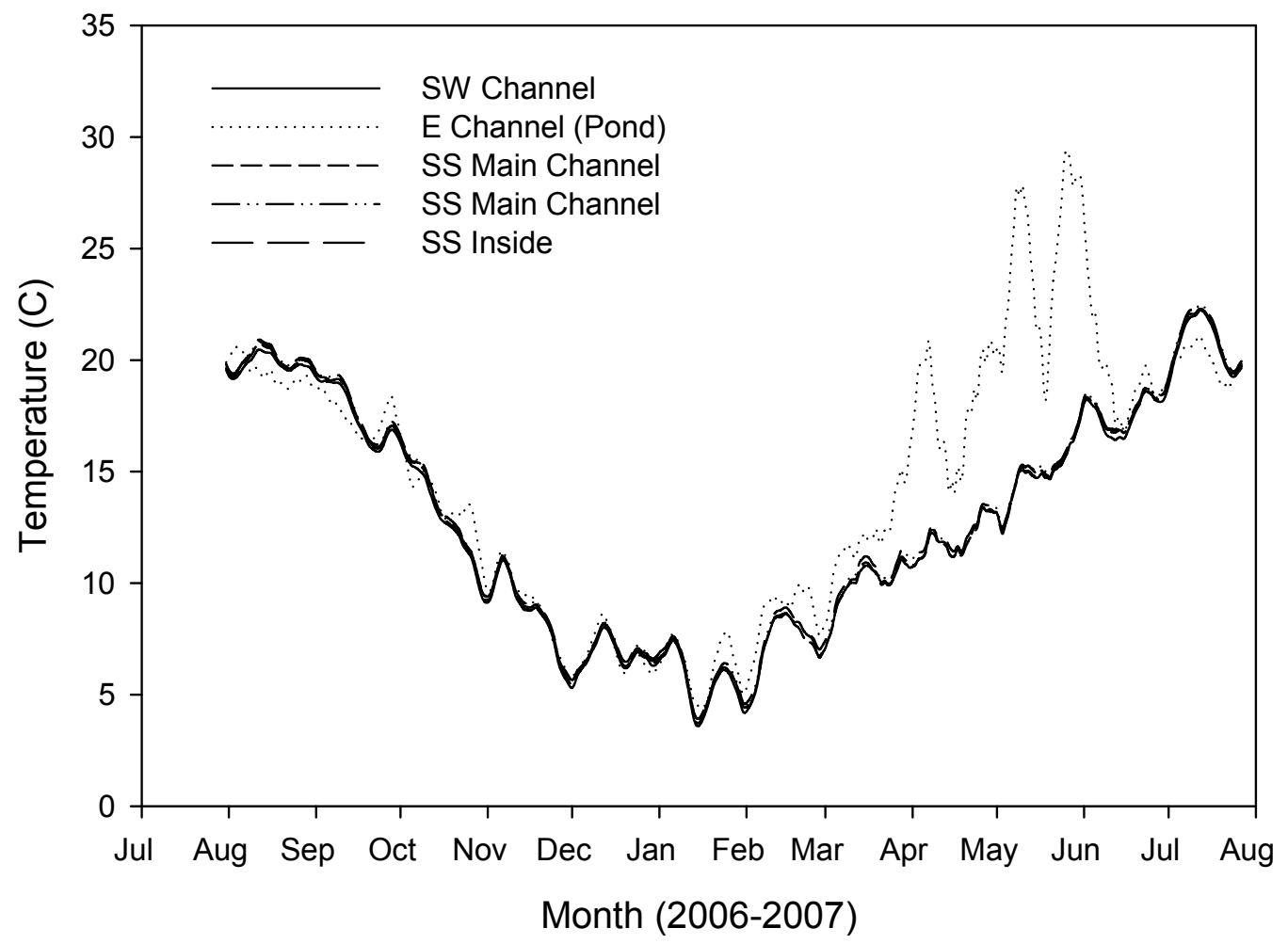

Figure 2.13. Temperature Records at Five Locations on Kandoll Farm Restoration Site in 2006-2007 After Restoration in 2005 
The sensor at VS Inside was downloaded and re-launched offsite, accounting for the gaps in the data record in Figure 2.14. Despite these gaps, it is clear from this record from early spring through early fall that inside the tide gates at the VS site temperatures are typically much warmer than in the reference channel, and during the summer they are frequently unsuitable for salmon (Figure 2.14). In contrast, during the winter months, the water temperature inside the tide gate closely tracks that of the channel outside the tide gate in Youngs Bay, remaining within the tolerance of juvenile salmon (Figure 2.15).

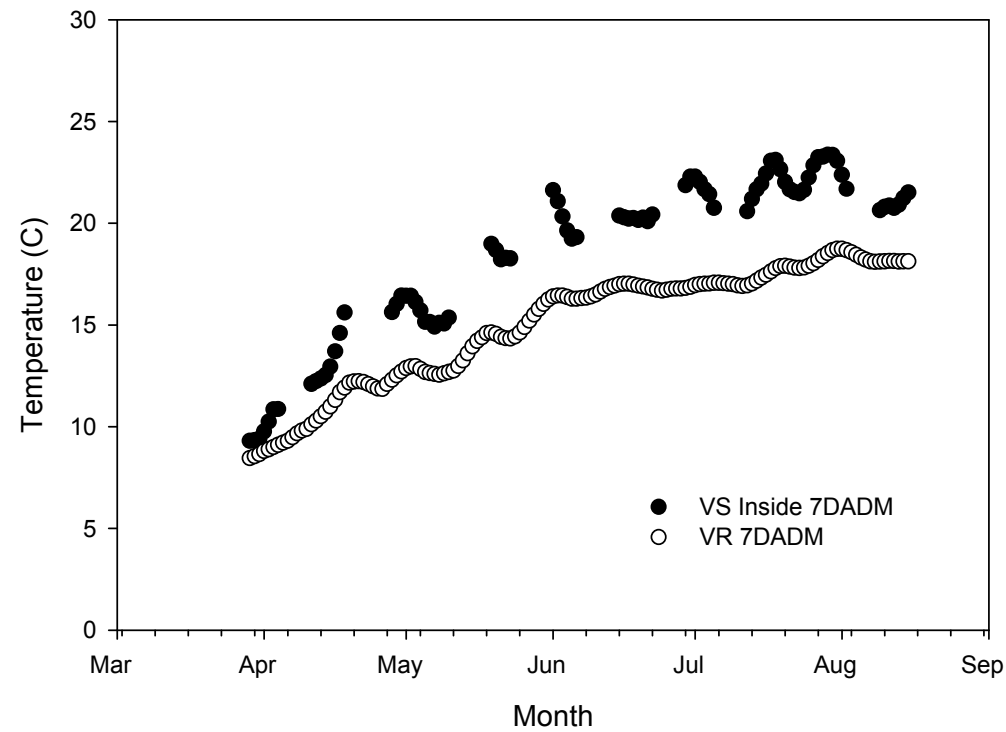

Figure 2.14. The 7-DAM Temperature for the Vera Slough Inside and Vera Reference Channel Stations, Spring and Summer Months, 2009

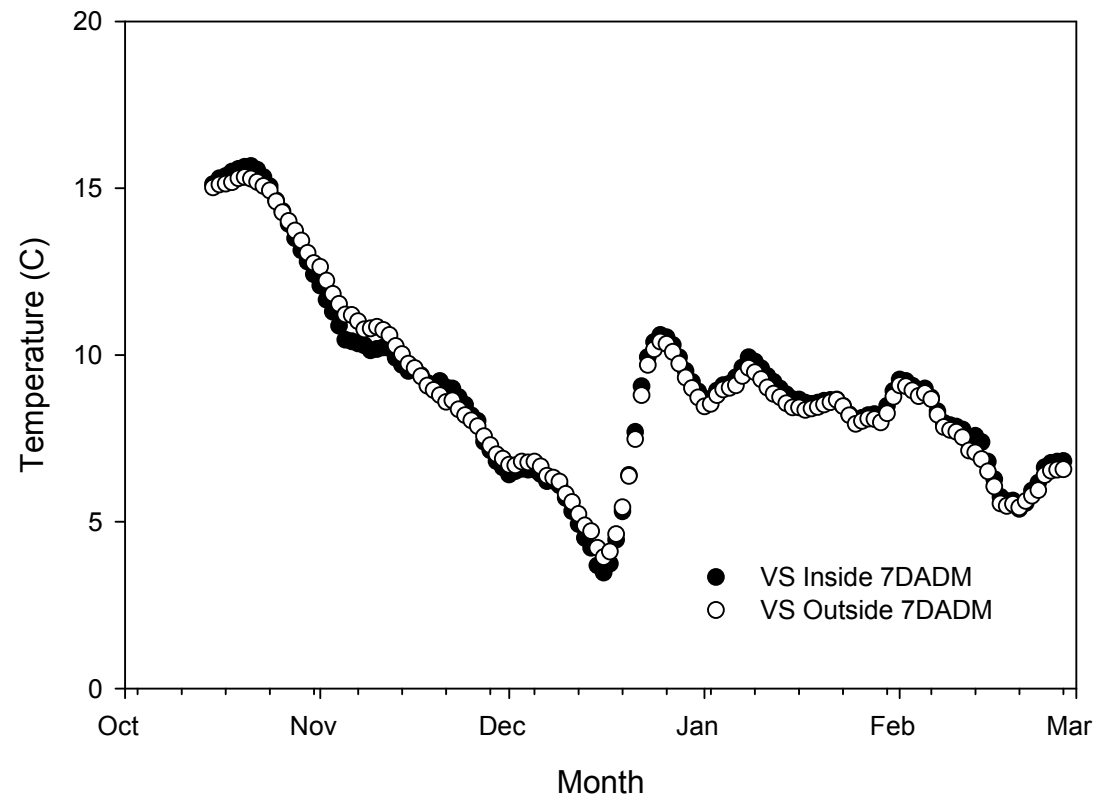

Figure 2.15. The 7-DAM Temperature for the Vera Slough Inside and Vera Outside Channel Stations Winter Months After Tide Gate Installation, 2005-2006 
Trends in the temperature time series were similar at all stations in degree and concurrent changes occurred across the landscape scale (Figure 2.16). By May, temperatures in 2005 and 2006 reached the $19^{\circ} \mathrm{C}$ deemed stressful to salmonids. In 2007 , temperatures at the inside and outside stations were nearly isothermal and were below $19^{\circ} \mathrm{C}$ until late June. The Forks station tended to be warmer than the outside station during both pre- and post-restoration periods for which there are complementary data. The Inside station tended to be warmer than the Outside station in the pre-restoration period (summer), but it showed no difference after restoration (winter). The Inside station was about isothermal with the Fork station before restoration in the winter period after restoration, but it was cooler than the Fork station after restoration. These data indicate a thermal gradient with the maintenance of generally warmer water at the upstream section of the Vera Slough system. There is a suggestion that temperature remained cooler at the Inside station after the tide gate replacement.
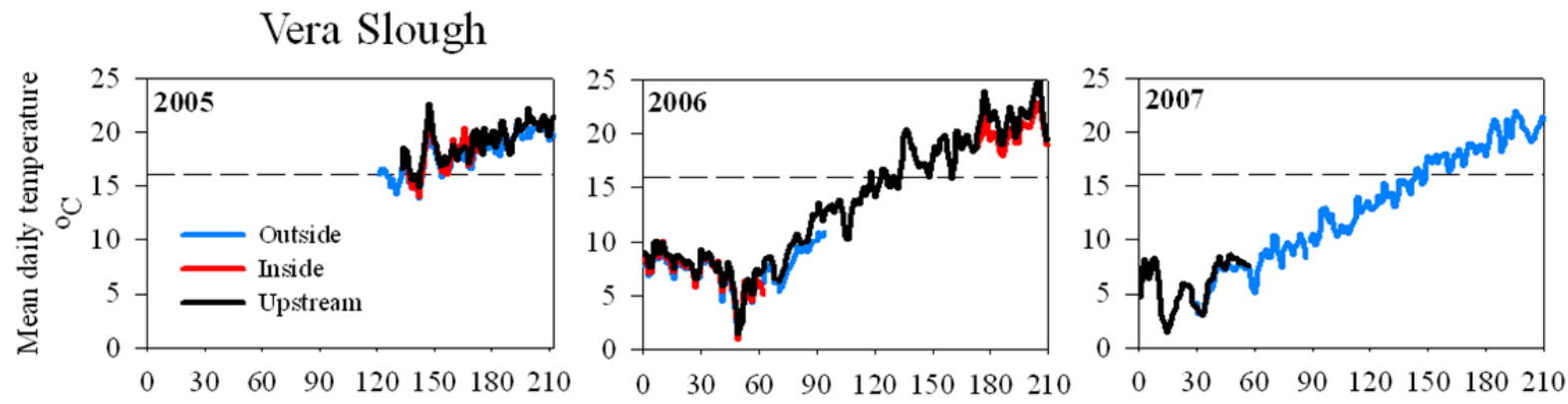

Figure 2.16. Seven-Day Average Maximum Daily Temperature at Restoration and Reference Stations at Vera Slough from January through July, 2005, 2006, and 2007. "Outside" is at the estuary side of the Vera Slough tide gate; "Inside" is just landward of the tide gate; "Upstream" is $0.5 \mathrm{~km}$ upstream from the tide gate inside Vera Slough.

\subsubsection{Topography and Bathymetry}

Sediment accretion rates and channel cross-sectional areas are pertinent to topography and bathymetry.

\subsubsection{Sediment Accretion Rate}

Sediment accretion rates at the VS site were high $(3.2 \mathrm{~cm} / \mathrm{yr})$ after tide gate replacement (between 2005 and 2007) and decreased by 2009 to a cumulative rate of $1.2 \mathrm{~cm} / \mathrm{yr}$ (Table 2.5). Rates at the VR locations were substantially less, and while one showed a decline of about half between 2007 and 2009 assessments, the other increased slightly. These reference rates serve as an environmental control for the restoration site. They indicate that the high initial sediment accretion rate and the declining but still high rate after 4 years were caused by the tide gate replacement.

The mean sediment accretion rate from two sets of stakes proximal to the KR channel for 2006-2009 was $0.4 \mathrm{~cm} / \mathrm{yr}$, in contrast to a mean of $2.6 \mathrm{~cm} / \mathrm{yr}$ at the KF site in 2005-2007; 2009 data from the KF site are not included in these calculations (Table 2.5). Like Vera Slough, the contrast between the data from stakes at various locations on the KF and KR sites indicate that high initial sediment accretion rates were caused by the culvert replacement (stakes KFE and KFW) and dike breaching (stake KF-GRD).

At Crims Island, where restoration actions were completed in 2005, the restoration site also exhibited higher accretion rates than the reference site, and there was little difference between the assessments 
conducted from 2006 through 2009 and 2008 through 2009 ( 1.4 versus $1.5 \mathrm{~cm} / \mathrm{yr}$ ). Accretion rates assessed at the reference site were $1.0 \mathrm{~cm} / \mathrm{yr}$ from 2006 to 2009 and $0.4 \mathrm{~cm} / \mathrm{yr}$ from 2008 to 2009 at a different set of stakes.

Generally, at paired restoration and reference sites, the sediment accretion stakes are located at higher elevations on reference than on restoration sites (Figure 2.17), because the restoration sites have subsided behind dikes and mean elevation is lower than at paired reference sites (Diefenderfer et al. 2008). This appears to explain the fact that sediment accretion rates are higher at restoration sites than at paired reference sites (Figure 2.17).

Table 2.5. Summary of Sediment Accretion Rates at Paired Restoration and Reference Sites. Blank space implies no data.

\begin{tabular}{|c|c|c|c|c|}
\hline $\begin{array}{l}\text { Site-Stake } \\
\text { Code }\end{array}$ & $\begin{array}{l}\text { 2005-2009 Rate } \\
(\mathrm{cm} / \mathrm{yr})\end{array}$ & $\begin{array}{l}\text { 2005-2007 Rate } \\
(\mathrm{cm} / \mathrm{yr})\end{array}$ & $\begin{array}{l}\text { 2006-2009 Rate } \\
(\mathrm{cm} / \mathrm{yr})\end{array}$ & $\begin{array}{l}\text { 2008-2009 Rate } \\
(\mathrm{cm} / \mathrm{yr})\end{array}$ \\
\hline $\mathrm{CI}$ & & & 1.4 & 1.5 \\
\hline CR 1 & & & 1.0 & \\
\hline CR 2 & & & & 0.4 \\
\hline KF-GRD & 2.7 & 3.5 & & \\
\hline KFE & $2.4^{(\mathrm{a})}$ & 1.3 & & \\
\hline KFW & $0.7^{(b)}$ & 3.1 & & \\
\hline KR 1-1 & & & 0.1 & 0.2 \\
\hline KR 1-2 & & & 0.7 & 0.4 \\
\hline VS & 1.2 & 3.2 & & \\
\hline VRN & 0.3 & 0.6 & & \\
\hline VRS & 0.6 & 0.5 & & \\
\hline \multicolumn{5}{|c|}{$\begin{array}{l}\text { (a) In } 2009 \text {, the stake had been battered by large woody debris and lost; measurement was estimated from only } \\
\text { one stake. }\end{array}$} \\
\hline
\end{tabular}

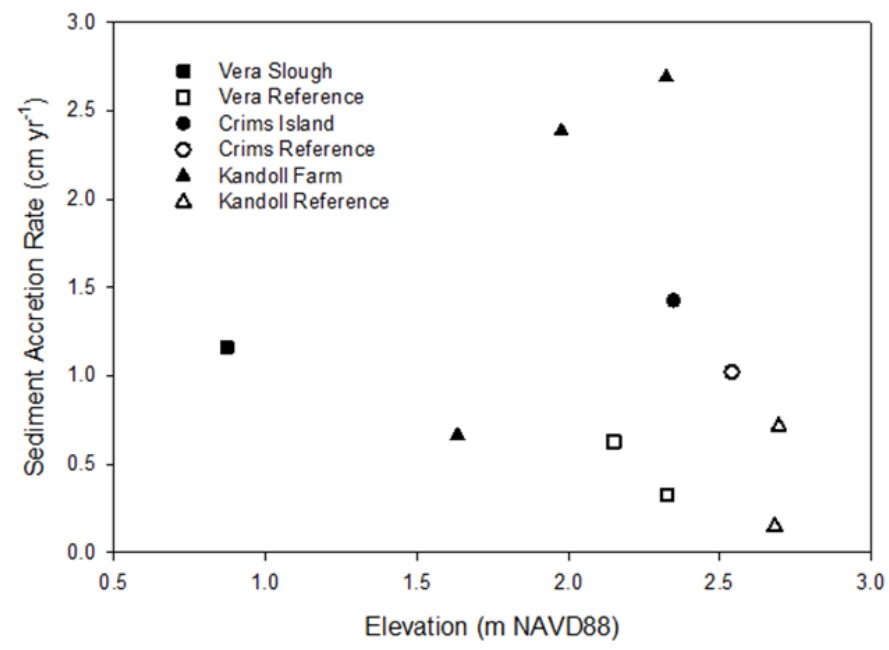

Figure 2.17. Sediment Accretion Rates and Elevation. Rates are from 2005 Through 2009 for the VS, VR, and KF Sites, and from 2006 Through 2009 for the CI, CR, and KR Sites. Elevations at sediment stake bases were surveyed in 2009. 


\subsubsection{Channel Cross-Sectional Area}

Several of the 2005 through 2007 trends in channel morphological adjustment to hydrologic reconnection described by Diefenderfer et al. (2008) have remained consistent through the 2009 surveys, but later surveys have provided additional trends information. The observations listed below are based on the Method 1 calculations for change in cross-sectional area.

- The largest changes in cross-sectional area and incision between 2005 and 2009 are seen in the cross sections located most proximal to the restoration action (Table 2.6, "Restoration Cross Sections at Channel Outlets"). At Crims Island, this holds true for the main channel not others. In addition, the change outside of the tide gates at the VS site was much greater than inside, by both measures. Change in cross-sectional area proximal to restoration actions between 2005 and 2009 was between $0.25 \mathrm{~m}^{2}(2.5 \%)$ inside the VS site and $58.11 \mathrm{~m}^{2}(125.1 \%)$ inside the KF site.

- Change in as-built surveyed dike breach cross sections with very small contributing channel areas, e.g., along the Grays River on Kandoll Farm, accelerated from 2007 through 2009.

- The relatively small incisions and/or increases in cross-sectional areas seen up-channel from restoration actions in some cases are assumed to be morphological responses to the need to convey increased flow volumes associated with subsidence of the sites during diked years, but these flows are expected to lessen as the sites accrete (see preceding section) and the tidal prism correspondingly decreases.

- The accretion of bed level and decrease in channel cross-sectional area at reference sites up-channel of the mouth was seen at all five locations at three sites. Explanations accounting for this include the beaver activity at the upper KR site on Seal Slough, and management closing the tide gate and subsequent stagnation of the VR site. These are specific, localized events not likely to hold generally true, and they do not explain these same trends at Seal Slough mid channel and at Gull Island (CR site). At the CI site, the thalweg elevation generally increased slightly between 2007 and 2009, with a corresponding slight decrease in channel cross-sectional area. We expected changes in the channel morphology at Crims Island because these channels were excavated and normal slumping and erosion caused by hydrologic action should modify the morphology. 
Table 2.6. Channel Morphological Adjustments Between 2005 and 2009 at Restoration and Reference Sites. Culvert replacement (Seal Slough inside Kandoll Farm), dike breaching (Grays River at Kandoll Farm and Johnson Property, and Deep River), tide gate replacement (Vera Slough), and channel excavation (Crims Island) are compared. NA implies no data.

\begin{tabular}{|c|c|c|c|c|c|c|c|c|c|c|c|c|}
\hline Site & $\begin{array}{c}\text { Restoration } \\
\text { Action/Date, or } \\
\text { Reference } \\
\text { Plant } \\
\text { Community }\end{array}$ & $\begin{array}{c}\text { Years } \\
\text { Surveyed }\end{array}$ & $\begin{array}{l}\text { Cross- } \\
\text { Sectional } \\
\text { Area }\left(\mathrm{m}^{2}\right) \\
\text { (baseline) }\end{array}$ & $\begin{array}{c}{ }^{(\mathrm{a})} \text { Change } \\
\text { in Cross- } \\
\text { Sectional } \\
\text { Area }\left(\mathrm{m}^{2}\right) \\
2005- \\
2007\end{array}$ & $\begin{array}{c}{ }^{(\mathrm{a})} \text { Change } \\
\text { in Cross- } \\
\text { Sectional } \\
\text { Area }\left(\mathrm{m}^{2}\right) \\
2007- \\
2009\end{array}$ & $\begin{array}{l}{ }^{(\mathrm{a})} \text { Change } \\
\text { in Cross- } \\
\text { Sectional } \\
\text { Area }\left(\mathrm{m}^{2}\right) \\
2005- \\
2009\end{array}$ & $\begin{array}{c}{ }^{(\mathrm{b})} \text { Change } \\
\text { in Cross- } \\
\text { Sectional } \\
\text { Area }\left(\mathrm{m}^{2}\right) \\
2005- \\
2007\end{array}$ & $\begin{array}{c}\text { (b) Change } \\
\text { in Cross- } \\
\text { Sectional } \\
\text { Area }\left(\mathrm{m}^{2}\right) \\
2007- \\
2009\end{array}$ & $\begin{array}{c}{ }^{(b)} \text { Change } \\
\text { in Cross- } \\
\text { Sectional } \\
\text { Area }\left(\mathrm{m}^{2}\right) \\
2005- \\
2009\end{array}$ & $\begin{array}{c}\text { Change } \\
\text { in Bed } \\
\text { Level } \\
(\mathrm{m}) \\
2005- \\
2007\end{array}$ & $\begin{array}{c}\text { Change } \\
\text { in Bed } \\
\text { Level } \\
(\mathrm{m}) \\
2007- \\
2009\end{array}$ & $\begin{array}{c}\text { Change } \\
\text { in Bed } \\
\text { Level } \\
(\mathrm{m}) \\
2005- \\
2009\end{array}$ \\
\hline \multicolumn{13}{|c|}{ Restoration Cross Sections at Channel Outlets } \\
\hline $\begin{array}{l}\text { Grays River } \\
1 \text { West }\end{array}$ & $\begin{array}{l}\text { Dike Breach } \\
2005\end{array}$ & $\begin{array}{l}2005 \\
2006, \\
2007 \\
2009\end{array}$ & 20.26 & -0.34 & 0.29 & -0.06 & -0.34 & -2.65 & -2.99 & -0.68 & 0.01 & -0.67 \\
\hline $\begin{array}{l}\text { Grays River } \\
2 \text { Middle }\end{array}$ & $\begin{array}{l}\text { Dike Breach } \\
2005\end{array}$ & $\begin{array}{l}2005 \\
2006 \\
2007 \\
2009\end{array}$ & 30.87 & 1.31 & -4.00 & -2.68 & 1.31 & -0.83 & 0.49 & -0.25 & -0.07 & -0.32 \\
\hline $\begin{array}{l}\text { Grays River } \\
3 \text { East }\end{array}$ & $\begin{array}{l}\text { Dike Breach } \\
2005\end{array}$ & $\begin{array}{l}2005 \\
2006 \\
2007 \\
2009\end{array}$ & 15.80 & -1.66 & -2.90 & -4.56 & -1.66 & -3.89 & -5.55 & 0.02 & 0.35 & 0.36 \\
\hline $\begin{array}{l}\text { Grays River } \\
4 \text { West }\end{array}$ & $\begin{array}{l}\text { Dike Breach } \\
2004\end{array}$ & $\begin{array}{l}2004 \\
2005 \\
2007\end{array}$ & 20.82 & 4.90 & NA & NA & 4.90 & NA & NA & -0.64 & NA & NA \\
\hline $\begin{array}{l}\text { Grays River } \\
5 \text { East }\end{array}$ & $\begin{array}{l}\text { Dike Breach } \\
2004\end{array}$ & $\begin{array}{l}2004 \\
2005 \\
2007\end{array}$ & 24.67 & 13.98 & NA & NA & 13.98 & NA & NA & -0.26 & NA & NA \\
\hline $\begin{array}{l}\text { Seal Slough } \\
\text { (inside) }\end{array}$ & $\begin{array}{l}\text { Culvert } \\
\text { Installation } \\
2005\end{array}$ & $\begin{array}{l}2005 \\
2006 \\
2007 \\
2009\end{array}$ & 46.44 & 30.68 & 10.86 & 41.54 & 30.68 & -5.76 & 24.92 & -2.13 & 0.25 & -1.88 \\
\hline $\begin{array}{l}\text { Vera } \\
\text { Slough } \\
\text { (inside) }\end{array}$ & $\begin{array}{l}\text { Tide Gate } \\
\text { Replacement } \\
2005\end{array}$ & $\begin{array}{l}2005 \\
2006 \\
2007 \\
2009\end{array}$ & 9.86 & 6.53 & -9.11 & -2.57 & 6.53 & -0.78 & -5.75 & -0.34 & -0.02 & -0.36 \\
\hline
\end{tabular}


Table 2.6. (contd)

\begin{tabular}{|c|c|c|c|c|c|c|c|c|c|c|c|c|}
\hline Site & $\begin{array}{c}\text { Restoration } \\
\text { Action/Date, or } \\
\text { Reference } \\
\text { Plant } \\
\text { Community }\end{array}$ & $\begin{array}{c}\text { Years } \\
\text { Surveyed }\end{array}$ & $\begin{array}{l}\text { Cross- } \\
\text { Sectional } \\
\text { Area }\left(\mathrm{m}^{2}\right) \\
\text { (baseline) }\end{array}$ & $\begin{array}{c}{ }^{(\mathrm{a})} \text { Change } \\
\text { in Cross- } \\
\text { Sectional } \\
\text { Area }\left(\mathrm{m}^{2}\right) \\
2005- \\
2007\end{array}$ & $\begin{array}{c}{ }^{(\mathrm{a})} \text { Change } \\
\text { in Cross- } \\
\text { Sectional } \\
\text { Area }\left(\mathrm{m}^{2}\right) \\
2007- \\
2009\end{array}$ & $\begin{array}{c}{ }^{(\mathrm{a})} \text { Change } \\
\text { in Cross- } \\
\text { Sectional } \\
\text { Area }\left(\mathrm{m}^{2}\right) \\
2005- \\
2009\end{array}$ & $\begin{array}{c}{ }^{(b)} \text { Change } \\
\text { in Cross- } \\
\text { Sectional } \\
\text { Area }\left(\mathrm{m}^{2}\right) \\
2005- \\
2007\end{array}$ & $\begin{array}{c}{ }^{(\mathrm{b})} \text { Change } \\
\text { in Cross- } \\
\text { Sectional } \\
\text { Area }\left(\mathrm{m}^{2}\right) \\
2007- \\
2009\end{array}$ & $\begin{array}{c}{ }^{(b)} \text { Change } \\
\text { in Cross- } \\
\text { Sectional } \\
\text { Area }\left(\mathrm{m}^{2}\right) \\
2005- \\
2009\end{array}$ & $\begin{array}{c}\text { Change } \\
\text { in Bed } \\
\text { Level } \\
(\mathrm{m}) \\
2005- \\
2007\end{array}$ & $\begin{array}{c}\text { Change } \\
\text { in Bed } \\
\text { Level } \\
(\mathrm{m}) \\
2007- \\
2009\end{array}$ & $\begin{array}{c}\text { Change } \\
\text { in Bed } \\
\text { Level } \\
(\mathrm{m}) \\
2005- \\
2009\end{array}$ \\
\hline \multicolumn{13}{|c|}{ Restoration Cross Sections at Channel Outlets } \\
\hline $\begin{array}{l}\text { Vera } \\
\text { Slough } \\
\text { (outside) }\end{array}$ & $\begin{array}{l}\text { Tide Gate } \\
\text { Replacement } \\
2005\end{array}$ & $\begin{array}{l}2005 \\
2006 \\
2007 \\
2009\end{array}$ & 43.97 & -1.45 & 9.44 & 7.99 & -1.45 & 5.04 & 3.61 & -0.30 & -0.49 & -0.79 \\
\hline Deep River & $\begin{array}{l}\text { Dike Breach } \\
2005\end{array}$ & 2007 & - & $>29.37$ & NA & NA & $>29.37$ & NA & NA & -2.86 & NA & NA \\
\hline $\begin{array}{l}\text { Crims } \\
\text { Island W. } \\
\text { Channel } \\
\text { Mouth }\end{array}$ & $\begin{array}{l}\text { Channel } \\
\text { Excavation- } \\
\text { Scrapedown } \\
2005\end{array}$ & $\begin{array}{l}2007 \\
2009\end{array}$ & $48.71^{(c)}$ & NA & 2.73 & NA & NA & -0.02 & NA & NA & 0.01 & NA \\
\hline $\begin{array}{l}\text { Crims } \\
\text { Island Main } \\
\text { Channel } \\
\text { Mouth }\end{array}$ & $\begin{array}{l}\text { Channel } \\
\text { Excavation- } \\
\text { Scrapedown } \\
2005\end{array}$ & $\begin{array}{l}2007 \\
2009\end{array}$ & $49.19^{(\mathrm{c})}$ & NA & 19.44 & NA & NA & -2.69 & NA & NA & 0.21 & NA \\
\hline $\begin{array}{l}\text { Crims } \\
\text { Island SE } \\
\text { Side } \\
\text { Channel@ } \\
\text { Mouth }\end{array}$ & $\begin{array}{l}\text { Channel } \\
\text { Excavation- } \\
\text { Scrapedown } \\
2005\end{array}$ & $\begin{array}{l}2007 \\
2009\end{array}$ & $15.57^{(\mathrm{c})}$ & NA & 0.91 & NA & NA & 1.08 & NA & NA & 0.07 & NA \\
\hline $\begin{array}{l}\text { Crims } \\
\text { Island } \\
\text { North } \\
\text { Channel } 1 \\
\text { @ Mouth }\end{array}$ & $\begin{array}{l}\text { Channel } \\
\text { Excavation- } \\
\text { Scrapedown } \\
2005\end{array}$ & $\begin{array}{l}2007 \\
2009\end{array}$ & $18.10^{(\mathrm{c})}$ & NA & -1.06 & NA & NA & -2.99 & NA & NA & 0.25 & NA \\
\hline $\begin{array}{l}\text { Crims } \\
\text { Island N3 } \\
\text { Mouth }\end{array}$ & $\begin{array}{l}\text { Channel } \\
\text { Excavation- } \\
\text { Scrapedown } \\
2005\end{array}$ & $\begin{array}{l}2007 \\
2009\end{array}$ & $10.41^{(c)}$ & NA & -1.05 & NA & NA & -0.93 & NA & NA & 0.18 & NA \\
\hline
\end{tabular}


Table 2.6. (contd)

\begin{tabular}{|c|c|c|c|c|c|c|c|c|c|c|c|c|}
\hline Site & $\begin{array}{c}\text { Restoration } \\
\text { Action/Date, or } \\
\text { Reference } \\
\text { Plant } \\
\text { Community }\end{array}$ & $\begin{array}{c}\text { Years } \\
\text { Surveyed }\end{array}$ & $\begin{array}{l}\text { Cross- } \\
\text { Sectional } \\
\text { Area }\left(\mathrm{m}^{2}\right) \\
\text { (baseline) }\end{array}$ & $\begin{array}{c}\text { (a) Change } \\
\text { in Cross- } \\
\text { Sectional } \\
\text { Area }\left(\mathrm{m}^{2}\right) \\
2005- \\
2007\end{array}$ & $\begin{array}{c}{ }^{(a)} \text { Change } \\
\text { in Cross- } \\
\text { Sectional } \\
\text { Area }\left(\mathrm{m}^{2}\right) \\
2007- \\
2009\end{array}$ & $\begin{array}{c}{ }^{(a)} \text { Change } \\
\text { in Cross- } \\
\text { Sectional } \\
\text { Area }\left(\mathrm{m}^{2}\right) \\
2005- \\
2009\end{array}$ & $\begin{array}{c}\text { (b) Change } \\
\text { in Cross- } \\
\text { Sectional } \\
\text { Area }\left(\mathrm{m}^{2}\right) \\
2005- \\
2007\end{array}$ & $\begin{array}{c}\text { (b) Change } \\
\text { in Cross- } \\
\text { Sectional } \\
\text { Area }\left(\mathrm{m}^{2}\right) \\
2007- \\
2009\end{array}$ & $\begin{array}{c}{ }^{(b)} \text { Change } \\
\text { in Cross- } \\
\text { Sectional } \\
\text { Area }\left(\mathrm{m}^{2}\right) \\
2005- \\
2009\end{array}$ & $\begin{array}{c}\text { Change } \\
\text { in Bed } \\
\text { Level } \\
(\mathrm{m}) \\
2005- \\
2007\end{array}$ & $\begin{array}{c}\text { Change } \\
\text { in Bed } \\
\text { Level } \\
(\mathrm{m}) \\
2007- \\
2009\end{array}$ & $\begin{array}{c}\text { Change } \\
\text { in Bed } \\
\text { Level } \\
(\mathrm{m}) \\
2005- \\
2009\end{array}$ \\
\hline \multicolumn{13}{|c|}{ Reference Cross Sections at Channel Outlets } \\
\hline Seal Slough & Swamp & 2007 & 21.01 & $\overline{\mathrm{NA}}$ & $\mathrm{NA}$ & $\mathrm{NA}$ & NA & NA & NA & NA & $\mathrm{NA}$ & NA \\
\hline Secret River & Swamp & 2007 & 29.15 & NA & NA & NA & NA & NA & NA & NA & NA & NA \\
\hline $\begin{array}{l}\text { Crooked } \\
\text { Creek }\end{array}$ & Swamp & 2007 & 34.01 & NA & NA & NA & NA & NA & NA & NA & NA & NA \\
\hline \multicolumn{13}{|c|}{ Restoration Cross Sections Up-Channel } \\
\hline Deep River & $\begin{array}{l}\text { Dike Breach } \\
2005\end{array}$ & $\begin{array}{l}2004 \\
2006, \\
2007\end{array}$ & 72.93 & -1.71 & NA & NA & -1.71 & NA & NA & 0.02 & NA & NA \\
\hline $\begin{array}{l}\text { Grays River } \\
1 \text { (inside) }\end{array}$ & $\begin{array}{l}\text { Dike Breach } \\
2005\end{array}$ & $\begin{array}{l}2005 \\
2006 \\
2007 \\
2009\end{array}$ & 4.94 & 0.01 & 1.81 & 1.82 & 0.01 & 14.31 & 14.32 & -0.17 & -1.16 & -1.33 \\
\hline $\begin{array}{l}\text { Grays River } \\
1 \text { Mid } \\
\text { Channel }\end{array}$ & $\begin{array}{l}\text { Dike Breach } \\
2005\end{array}$ & $\begin{array}{l}2005 \\
2006 \\
2007 \\
2009\end{array}$ & 2.48 & 0.46 & 0.19 & 0.65 & 0.46 & -0.32 & 0.14 & -0.33 & 0.10 & -0.23 \\
\hline $\begin{array}{l}\text { Grays River } \\
4 \text { Mid } \\
\text { Channel }\end{array}$ & $\begin{array}{l}\text { Dike Breach } \\
2004\end{array}$ & $\begin{array}{l}2004 \\
2007\end{array}$ & 15.73 & -0.39 & NA & NA & -0.39 & NA & NA & 0.08 & NA & NA \\
\hline $\begin{array}{l}\text { Seal Slough } \\
\text { N. Fork } \\
\text { Mid } \\
\text { Channel }\end{array}$ & $\begin{array}{l}\text { Culvert } \\
\text { Installation } \\
2005\end{array}$ & $\begin{array}{l}2005 \\
2006, \\
2007 \\
2009\end{array}$ & 17.75 & 1.30 & 0.50 & 1.80 & 1.30 & -1.61 & -0.32 & -0.40 & 0.04 & -0.36 \\
\hline $\begin{array}{l}\text { Seal Slough } \\
\text { N. Fork } \\
\text { Upper } \\
\text { Channel }\end{array}$ & $\begin{array}{l}\text { Culvert } \\
\text { Installation } \\
2005\end{array}$ & $\begin{array}{l}2005 \\
2006 \\
2007 \\
2009\end{array}$ & 7.99 & -1.32 & -0.08 & -1.40 & -1.32 & -1.91 & -3.23 & -0.03 & 0.39 & 0.36 \\
\hline
\end{tabular}


Table 2.6. (contd)

\begin{tabular}{|c|c|c|c|c|c|c|c|c|c|c|c|c|}
\hline Site & $\begin{array}{c}\text { Restoration } \\
\text { Action/Date, or } \\
\text { Reference } \\
\text { Plant } \\
\text { Community } \\
\end{array}$ & $\begin{array}{c}\text { Years } \\
\text { Surveyed }\end{array}$ & $\begin{array}{c}\text { Cross- } \\
\text { Sectional } \\
\text { Area }\left(\mathrm{m}^{2}\right) \\
\text { (baseline) }\end{array}$ & $\begin{array}{c}{ }^{(\mathrm{a})} \text { Change } \\
\text { in Cross- } \\
\text { Sectional } \\
\text { Area }\left(\mathrm{m}^{2}\right) \\
2005- \\
2007\end{array}$ & $\begin{array}{c}{ }^{(\mathrm{a})} \text { Change } \\
\text { in Cross- } \\
\text { Sectional } \\
\text { Area }\left(\mathrm{m}^{2}\right) \\
2007- \\
2009\end{array}$ & $\begin{array}{c}{ }^{(\mathrm{a})} \text { Change } \\
\text { in Cross- } \\
\text { Sectional } \\
\text { Area }\left(\mathrm{m}^{2}\right) \\
2005- \\
2009 \\
\end{array}$ & $\begin{array}{c}\text { Change } \\
\text { in Cross- } \\
\text { Sectional } \\
\text { Area }\left(\mathrm{m}^{2}\right) \\
2005- \\
2007 \\
\end{array}$ & $\begin{array}{c}{ }^{(b)} \text { Change } \\
\text { in Cross- } \\
\text { Sectional } \\
\text { Area }\left(\mathrm{m}^{2}\right) \\
2007- \\
2009 \\
\end{array}$ & $\begin{array}{c}{ }^{(b)} \text { Change } \\
\text { in Cross- } \\
\text { Sectional } \\
\text { Area }\left(\mathrm{m}^{2}\right) \\
2005- \\
2009 \\
\end{array}$ & $\begin{array}{c}\text { Change } \\
\text { in Bed } \\
\text { Level } \\
(\mathrm{m}) \\
2005- \\
2007 \\
\end{array}$ & $\begin{array}{c}\text { Change } \\
\text { in Bed } \\
\text { Level } \\
(\mathrm{m}) \\
2007- \\
2009 \\
\end{array}$ & $\begin{array}{c}\text { Change } \\
\text { in Bed } \\
\text { Level } \\
(\mathrm{m}) \\
2005- \\
2009 \\
\end{array}$ \\
\hline \multicolumn{13}{|c|}{ Restoration Cross Sections Up-Channel } \\
\hline $\begin{array}{l}\text { Seal Slough } \\
\text { S. Fork Mid } \\
\text { Channel }\end{array}$ & $\begin{array}{l}\text { Culvert } \\
\text { Installation } \\
2005\end{array}$ & $\begin{array}{l}2005 \\
2006 \\
2007 \\
2009\end{array}$ & 3.98 & -0.29 & 1.28 & 0.99 & -0.29 & -1.51 & -1.80 & -0.28 & 0.10 & -0.18 \\
\hline $\begin{array}{l}\text { Seal Slough } \\
\text { S. Fork } \\
\text { Upper } \\
\text { Channel }\end{array}$ & $\begin{array}{l}\text { Culvert } \\
\text { Installation } \\
2005\end{array}$ & $\begin{array}{l}2005 \\
2006 \\
2007 \\
2009\end{array}$ & 1.17 & 0.07 & 0.46 & 0.53 & 0.07 & -0.20 & -0.13 & -0.35 & 0.05 & -0.31 \\
\hline $\begin{array}{l}\text { Seal Slough } \\
\text { W. Fork } \\
\text { Upper } \\
\text { Channel }\end{array}$ & $\begin{array}{l}\text { Dike Breach } \\
2005\end{array}$ & $\begin{array}{l}2005 \\
2006 \\
2007\end{array}$ & 2.47 & -0.81 & NA & NA & -0.81 & NA & NA & 0.08 & NA & NA \\
\hline $\begin{array}{l}\text { Crims } \\
\text { Island Main } \\
\text { Channel @ } \\
\text { Junction }\end{array}$ & $\begin{array}{l}\text { Channel } \\
\text { Excavation- } \\
\text { Scrapedown } \\
2005\end{array}$ & $\begin{array}{l}2006 \\
2007 \\
2009\end{array}$ & $43.57^{(\mathrm{c})}$ & NA & -0.35 & NA & NA & -0.96 & NA & NA & 0.01 & NA \\
\hline $\begin{array}{l}\text { Crims } \\
\text { Island Side } \\
\text { Channel @ } \\
\text { Veg Plot }\end{array}$ & $\begin{array}{l}\text { Channel } \\
\text { Excavation- } \\
\text { Scrapedown } \\
2005\end{array}$ & $\begin{array}{l}2006 \\
2007 \\
2009\end{array}$ & $2.09^{(\mathrm{c})}$ & NA & -0.46 & NA & NA & -4.59 & NA & NA & 0.43 & NA \\
\hline $\begin{array}{l}\text { Crims } \\
\text { Island SE } \\
\text { Channel } \\
\text { Mid } \\
\text { Channel }\end{array}$ & $\begin{array}{l}\text { Channel } \\
\text { Excavation- } \\
\text { Scrapedown } \\
2005\end{array}$ & $\begin{array}{l}2007 \\
2009\end{array}$ & $13.27^{(\mathrm{c})}$ & NA & -0.23 & NA & NA & -1.28 & NA & NA & 0.12 & NA \\
\hline $\begin{array}{l}\text { Crims } \\
\text { Island SE } \\
\text { Side } \\
\text { Channel } \\
\text { Upper }\end{array}$ & $\begin{array}{l}\text { Channel } \\
\text { Excavation- } \\
\text { Scrapedown } \\
2005\end{array}$ & $\begin{array}{l}2007 \\
2009\end{array}$ & $4.35^{(\mathrm{c})}$ & NA & -0.16 & NA & NA & -0.71 & NA & NA & 0.35 & NA \\
\hline
\end{tabular}


Table 2.6. (contd)

\begin{tabular}{|c|c|c|c|c|c|c|c|c|c|c|c|c|}
\hline Site & $\begin{array}{c}\text { Restoration } \\
\text { Action/Date, or } \\
\text { Reference } \\
\text { Plant } \\
\text { Community }\end{array}$ & $\begin{array}{c}\text { Years } \\
\text { Surveyed }\end{array}$ & $\begin{array}{c}\text { Cross- } \\
\text { Sectional } \\
\text { Area }\left(\mathrm{m}^{2}\right) \\
\text { (baseline) }\end{array}$ & $\begin{array}{c}{ }^{(a)} \text { Change } \\
\text { in Cross- } \\
\text { Sectional } \\
\text { Area }\left(\mathrm{m}^{2}\right) \\
2005- \\
2007\end{array}$ & $\begin{array}{c}{ }^{(\mathrm{a})} \text { Change } \\
\text { in Cross- } \\
\text { Sectional } \\
\text { Area }\left(\mathrm{m}^{2}\right) \\
2007- \\
2009\end{array}$ & $\begin{array}{c}{ }^{(a)} \text { Change } \\
\text { in Cross- } \\
\text { Sectional } \\
\text { Area }\left(\mathrm{m}^{2}\right) \\
2005- \\
2009\end{array}$ & $\begin{array}{c}{ }^{(\mathrm{b})} \text { Change } \\
\text { in Cross- } \\
\text { Sectional } \\
\text { Area }\left(\mathrm{m}^{2}\right) \\
2005- \\
2007\end{array}$ & $\begin{array}{c}\text { (b) Change } \\
\text { in Cross- } \\
\text { Sectional } \\
\text { Area }\left(\mathrm{m}^{2}\right) \\
2007- \\
2009\end{array}$ & $\begin{array}{c}{ }^{(b)} \text { Change } \\
\text { in Cross- } \\
\text { Sectional } \\
\text { Area }\left(\mathrm{m}^{2}\right) \\
2005- \\
2009\end{array}$ & $\begin{array}{c}\text { Change } \\
\text { in Bed } \\
\text { Level } \\
(\mathrm{m}) \\
2005- \\
2007\end{array}$ & $\begin{array}{c}\text { Change } \\
\text { in Bed } \\
\text { Level } \\
(\mathrm{m}) \\
2007- \\
2009\end{array}$ & $\begin{array}{c}\text { Change } \\
\text { in Bed } \\
\text { Level } \\
(\mathrm{m}) \\
2005- \\
2009\end{array}$ \\
\hline \multicolumn{13}{|c|}{ Restoration Cross Sections Up-Channel } \\
\hline $\begin{array}{l}\text { Crims } \\
\text { Island } \\
\text { North } \\
\text { Channel } 1 \\
\text { Upper }\end{array}$ & $\begin{array}{l}\text { Channel } \\
\text { Excavation- } \\
\text { Scrapedown } \\
2005\end{array}$ & $\begin{array}{l}2007 \\
2009\end{array}$ & $6.18^{(\mathrm{c})}$ & $\mathrm{NA}$ & -1.07 & $\mathrm{NA}$ & $\mathrm{NA}$ & -2.39 & $\mathrm{NA}$ & $\mathrm{NA}$ & 0.41 & $\mathrm{NA}$ \\
\hline $\begin{array}{l}\text { Crims } \\
\text { Island N3 } \\
\text { Upper X }\end{array}$ & $\begin{array}{l}\text { Channel } \\
\text { Excavation- } \\
\text { Scrapedown } \\
2005\end{array}$ & $\begin{array}{l}2007 \\
2009\end{array}$ & $4.58^{(\mathrm{c})}$ & NA & -0.02 & NA & NA & -0.19 & NA & NA & 0.01 & NA \\
\hline $\begin{array}{l}\text { Vera } \\
\text { Slough Mid } \\
\text { Channel }\end{array}$ & $\begin{array}{l}\text { Tide Gate } \\
\text { Replacement } \\
2005\end{array}$ & $\begin{array}{l}2005 \\
2006 \\
2007 \\
2009\end{array}$ & 9.56 & 0.52 & -1.14 & -0.61 & 0.52 & -2.62 & -2.09 & -0.04 & 0.07 & 0.04 \\
\hline $\begin{array}{l}\text { Vera } \\
\text { Slough } \\
\text { Upper } \\
\text { Channel }\end{array}$ & $\begin{array}{l}\text { Tide Gate } \\
\text { Replacement } \\
2005\end{array}$ & $\begin{array}{l}2006 \\
2007 \\
2009\end{array}$ & 12.39 & $-0.06^{(d)}$ & -5.45 & $-5.51^{(c)}$ & $-0.79^{(d)}$ & 0.16 & $-0.63^{(c)}$ & -1.57 & $0.05^{(\mathrm{d})}$ & $-1.52^{(\mathrm{d})}$ \\
\hline \multicolumn{13}{|c|}{ Reference Cross Sections Up-Channel } \\
\hline $\begin{array}{l}\text { Unnamed } \\
\text { Slough } \\
\text { Lower Mid } \\
\text { Channel }\end{array}$ & Marsh & $\begin{array}{l}2005 \\
2006 \\
2007 \\
2009\end{array}$ & 12.06 & 0.41 & -4.73 & -4.32 & 0.41 & -3.21 & -2.80 & 0.58 & 0.2 & 0.77 \\
\hline $\begin{array}{l}\text { Unnamed } \\
\text { Slough } \\
\text { Upper Mid } \\
\text { Channel }\end{array}$ & Marsh & $\begin{array}{l}2005 \\
2006 \\
2007 \\
2009\end{array}$ & 19.40 & -0.36 & -1.25 & -1.60 & -0.36 & -3.21 & -2.80 & 0.03 & 0.29 & 0.32 \\
\hline $\begin{array}{l}\text { Seal Slough } \\
\text { Mid } \\
\text { Channel }\end{array}$ & Swamp & $\begin{array}{l}2005 \\
2006 \\
2007 \\
2009\end{array}$ & 22.11 & 0.17 & -1.73 & -1.55 & 0.17 & -1.89 & -1.71 & 0.02 & 2.35 & 2.38 \\
\hline
\end{tabular}


Table 2.6. (contd)

\begin{tabular}{|c|c|c|c|c|c|c|c|c|c|c|c|c|}
\hline Site & $\begin{array}{c}\text { Restoration } \\
\text { Action/Date, or } \\
\text { Reference } \\
\text { Plant } \\
\text { Community }\end{array}$ & $\begin{array}{c}\text { Years } \\
\text { Surveyed }\end{array}$ & $\begin{array}{c}\text { Cross- } \\
\text { Sectional } \\
\text { Area }\left(\mathrm{m}^{2}\right) \\
\text { (baseline) }\end{array}$ & $\begin{array}{c}{ }^{(\mathrm{a})} \text { Change } \\
\text { in Cross- } \\
\text { Sectional } \\
\text { Area }\left(\mathrm{m}^{2}\right) \\
2005- \\
2007\end{array}$ & $\begin{array}{c}{ }^{(\mathrm{a})} \text { Change } \\
\text { in Cross- } \\
\text { Sectional } \\
\text { Area }\left(\mathrm{m}^{2}\right) \\
2007- \\
2009\end{array}$ & $\begin{array}{c}{ }^{(\mathrm{a})} \text { Change } \\
\text { in Cross- } \\
\text { Sectional } \\
\text { Area }\left(\mathrm{m}^{2}\right) \\
2005- \\
2009\end{array}$ & $\begin{array}{c}{ }^{(b)} \text { Change } \\
\text { in Cross- } \\
\text { Sectional } \\
\text { Area }\left(\mathrm{m}^{2}\right) \\
2005- \\
2007\end{array}$ & $\begin{array}{c}{ }^{(\mathrm{b})} \text { Change } \\
\text { in Cross- } \\
\text { Sectional } \\
\text { Area }\left(\mathrm{m}^{2}\right) \\
2007- \\
2009\end{array}$ & $\begin{array}{c}{ }^{(\mathrm{b})} \text { Change } \\
\text { in Cross- } \\
\text { Sectional } \\
\text { Area }\left(\mathrm{m}^{2}\right) \\
2005- \\
2009\end{array}$ & $\begin{array}{c}\text { Change } \\
\text { in Bed } \\
\text { Level } \\
(\mathrm{m}) \\
2005- \\
2007\end{array}$ & $\begin{array}{c}\text { Change } \\
\text { in Bed } \\
\text { Level } \\
(\mathrm{m}) \\
2007- \\
2009\end{array}$ & $\begin{array}{c}\text { Change } \\
\text { in Bed } \\
\text { Level } \\
(\mathrm{m}) \\
2005- \\
2009\end{array}$ \\
\hline \multicolumn{13}{|c|}{ Reference Cross Sections Up-Channel } \\
\hline $\begin{array}{l}\text { Seal Slough } \\
\text { Upper } \\
\text { Channel }\end{array}$ & Swamp & $\begin{array}{l}2005, \\
2006, \\
2007, \\
2009\end{array}$ & 3.19 & -0.31 & -0.32 & -0.63 & -0.31 & -1.02 & -1.34 & 0.19 & 0.09 & 0.28 \\
\hline Gull Island & Marsh & $\begin{array}{l}2006 \\
2009\end{array}$ & NA & NA & NA & $-0.63^{(d)}$ & NA & NA & $4.26^{(\mathrm{c})}$ & NA & NA & $0.02^{(\mathrm{d})}$ \\
\hline
\end{tabular}

(a) Calculation performed using the same elevation at the base of the stake in 2005 and 2007 (based on 2005 elevation measurements), and unique elevation at the base of the stake in 2009 (based on 2009 elevation measurements).

(b) Calculation performed using the same elevation at the base of the stake (based on 2005 measurements) for 2005, 2007 , and 2009.

(c) Baseline of Crims Island sites reported with 2007 data.

(d) Baselines of Vera Slough upper channel and Gull Island were surveyed 1 year post-restoration. 


\subsubsection{Landscape}

We used photo points, satellite imagery, and vegetation mapping to characterize the landscape at the main study sites. Photo points for the three restoration and reference sites are presented in Appendix I.

\subsubsection{Photo Points}

\section{Crims Island}

The photographs taken at the photo point at the CR site show the significant change in vegetation cover between 2006, year 1 post-restoration and subsequent years. In 2006 the vegetation was in an early stage of development, with many small colonizing species present in the photo. In 2008 and 2009, the observable species were predominantly perennial grasses and rushes with the other obligate wetland species noted such as wapato (Sagittaria latifolia). In the photos at the CR site between 2006 and 2009, the seasonal difference between the sites is evident. In 2006, the photo was taken during the sampling in September and the prevalence of nodding beggartick (Bidens cernua), a late season yellow-flowered species, is notable. The July 2009 photo shows the prevalence of forget-me-nots (Myosotis scorpioides) when they were in full bloom at the site. The other prevalent species at the site, slough sedge (Carex obnupta), is not present in the field of view of this photo.

\section{Kandoll Farm}

Numerous photo points were established at the KF site, documenting different areas of change at the site. Photo points 1-3 (PP1-3) are located along the Grays River dike and show a change in the vegetation in fields $\mathrm{A}$ and $\mathrm{B}$. The most notable change is the reduction in pasture grasses and blackberry to wetter species such as small-fruited bulrush (Scirpus microcarpus). Also notable in the sequence of these photos are the dying deciduous trees in the background of all three photos starting in 2006. Photo points 4-6 were taken near the culvert replacement at Seal Slough and similar patterns of change are observable there, with a trend more toward reed canarygrass cover and the decline of blackberry and both deciduous and spruce trees in the background. Photo point 7 is located at the far east side of the farm, a greater distance from the restoration actions than the other photo points. The differences here are less notable changes from pasture grass to reed canarygrass. Photo point 8 is taken at the culvert replacement that occurred on Seal Slough. Looking south onto the farm, the primary change evident in the sequence of photos is the die-back of the spruce trees at the center of the photo. Little change is detectable in the photo looking north to the outside of the culverts. At the KR site the photographs from the photo points show little change except in the increased size of trees on the nurse log in KR-PP1. Remarkably, many of the logs in the channel are present in the same location between 2005 and 2009.

\section{Vera Slough}

Photo points were established at two locations at the VS site and at three stations at the VR site. At each of these points, photos were taken at multiple azimuths during sequential years. Most of these photos show little change occurring outside of the dike, whether at the reference or restoration area. However, two photos from VS-PP4 looking east and southeast document the changes that occurred in the vegetation sampling area between years of an increase in bare ground, open water, and cattails (Typha spp.). 


\subsubsection{Satellite Imagery Analysis}

The apparent change in plant communities at restoration and reference sites between 2005 and 2009 (Table 2.7) corresponds to changes shown on the maps (Figures 2.18-2.21). Correct assessment of actual change is dependent on the representativeness of the ground-truth data. Two factors suggest that this analysis should be interpreted with some caution. First, if field data were not available for a particular cover type at a location in a particular year, change may be depicted because the cover type would not be mapped at that location; thus, awareness of the distribution of the field data is important to interpretations. Second, the accuracy of the map varies between cover types; therefore, certain cover types may be overmapped or under-mapped, which could skew apparent change. Nevertheless, the primary trends we observed in vegetation plots, line-intercept sampling, and anecdotally at these sites were captured by these classification methods at the site scale. For example, at the KF site we see a reduction in mowed pasture and increase in other herbaceous plants, dead trees resulting from inundation, and an increase of reed canarygrass, rushes (Juncus species), and emergent wetland; at the VS site we see a reduction of slough sedge, an increase of blackberry, and a reduction of pasture mix and corresponding increase of rushes/wet pasture - a category more tolerant of inundation. 
Table 2.7. The Apparent Change in 19 Plant Community Cover Types Between 2005 and 2009 at the Kandoll Farm and Vera Slough Restoration Sites and Corresponding Reference Sites

\begin{tabular}{|c|c|c|c|c|c|c|c|c|c|c|c|c|c|c|c|c|c|c|c|}
\hline & 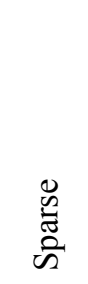 & 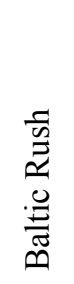 & $\begin{array}{l}\vec{E} \\
\frac{0}{0} \\
\frac{\overrightarrow{0}}{\pi} \\
\frac{\pi}{m}\end{array}$ & נ̋ & 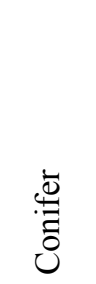 & 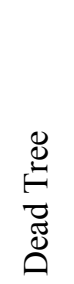 & 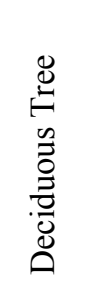 & 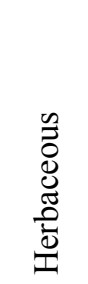 & 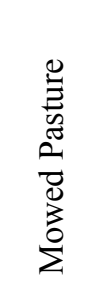 & 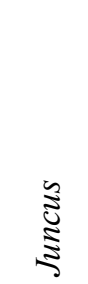 & 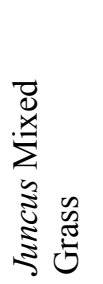 & 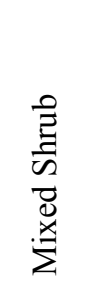 & $\frac{\bar{z}}{\frac{5}{5}}$ & 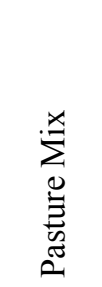 & $\begin{array}{l}\tilde{\Xi} \\
\frac{\tilde{E}}{\tilde{\Xi}} \\
\tilde{\Sigma}\end{array}$ & 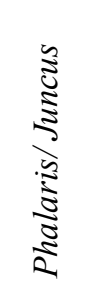 & $\frac{2}{2}$ & 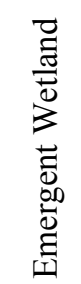 & 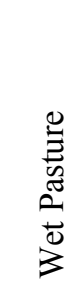 \\
\hline KR 2005 & $6 \%$ & $0 \%$ & $3 \%$ & $5 \%$ & $9 \%$ & $0 \%$ & $27 \%$ & $0 \%$ & $0 \%$ & $4 \%$ & $0 \%$ & $28 \%$ & $0 \%$ & $4 \%$ & $3 \%$ & $3 \%$ & $0 \%$ & $0 \%$ & $7 \%$ \\
\hline KR 2009 & $0 \%$ & $0 \%$ & $0 \%$ & $2 \%$ & $10 \%$ & $0 \%$ & $19 \%$ & $5 \%$ & $0 \%$ & $11 \%$ & $0 \%$ & $21 \%$ & $0 \%$ & $0 \%$ & $11 \%$ & $3 \%$ & $0 \%$ & $5 \%$ & $6 \%$ \\
\hline Apparent Change & $-6 \%$ & $0 \%$ & $-3 \%$ & $-3 \%$ & $1 \%$ & $0 \%$ & $-8 \%$ & $5 \%$ & $0 \%$ & $7 \%$ & $0 \%$ & $-7 \%$ & $0 \%$ & $-4 \%$ & $8 \%$ & $-1 \%$ & $0 \%$ & $5 \%$ & $-1 \%$ \\
\hline KF 2005 & $6 \%$ & $0 \%$ & $3 \%$ & $3 \%$ & $2 \%$ & $0 \%$ & $5 \%$ & $0 \%$ & $10 \%$ & $22 \%$ & $0 \%$ & $11 \%$ & $0 \%$ & $8 \%$ & $7 \%$ & $6 \%$ & $0 \%$ & $0 \%$ & $15 \%$ \\
\hline KF 2009 & $3 \%$ & $0 \%$ & $1 \%$ & $6 \%$ & $3 \%$ & $2 \%$ & $5 \%$ & $6 \%$ & $0 \%$ & $17 \%$ & $0 \%$ & $8 \%$ & $0 \%$ & $0 \%$ & $24 \%$ & $4 \%$ & $1 \%$ & $5 \%$ & $14 \%$ \\
\hline Apparent Change & $-3 \%$ & $0 \%$ & $-2 \%$ & $3 \%$ & $1 \%$ & $2 \%$ & $0 \%$ & $6 \%$ & $-10 \%$ & $-4 \%$ & $0 \%$ & $-3 \%$ & $0 \%$ & $-8 \%$ & $17 \%$ & $-2 \%$ & $1 \%$ & $5 \%$ & $-1 \%$ \\
\hline VR 2005 & $2 \%$ & $0 \%$ & $2 \%$ & $30 \%$ & $0 \%$ & $0 \%$ & $0 \%$ & $19 \%$ & $0 \%$ & $0 \%$ & $0 \%$ & $6 \%$ & $0 \%$ & $13 \%$ & $11 \%$ & $0 \%$ & $17 \%$ & $0 \%$ & $0 \%$ \\
\hline VR2009 & $6 \%$ & $0 \%$ & $4 \%$ & $28 \%$ & $0 \%$ & $0 \%$ & $0 \%$ & $27 \%$ & $0 \%$ & $0 \%$ & $2 \%$ & $15 \%$ & $0 \%$ & $1 \%$ & $2 \%$ & $0 \%$ & $14 \%$ & $0 \%$ & $0 \%$ \\
\hline Apparent Change & $5 \%$ & $0 \%$ & $2 \%$ & $-1 \%$ & $0 \%$ & $0 \%$ & $0 \%$ & $9 \%$ & $0 \%$ & $0 \%$ & $2 \%$ & $9 \%$ & $0 \%$ & $-12 \%$ & $-9 \%$ & $0 \%$ & $-2 \%$ & $0 \%$ & $0 \%$ \\
\hline VS 2005 & $4 \%$ & $0 \%$ & $2 \%$ & $14 \%$ & $0 \%$ & $0 \%$ & $0 \%$ & $7 \%$ & $0 \%$ & $0 \%$ & $8 \%$ & $13 \%$ & $0 \%$ & $48 \%$ & $0 \%$ & $0 \%$ & $4 \%$ & $0 \%$ & $0 \%$ \\
\hline VS 2009 & $2 \%$ & $0 \%$ & $7 \%$ & $5 \%$ & $0 \%$ & $0 \%$ & $0 \%$ & $11 \%$ & $0 \%$ & $0 \%$ & $12 \%$ & $13 \%$ & $0 \%$ & $45 \%$ & $1 \%$ & $0 \%$ & $2 \%$ & $0 \%$ & $0 \%$ \\
\hline Apparent Change & $-2 \%$ & $0 \%$ & $5 \%$ & $-10 \%$ & $0 \%$ & $0 \%$ & $0 \%$ & $4 \%$ & $0 \%$ & $0 \%$ & $4 \%$ & $0 \%$ & $0 \%$ & $-3 \%$ & $1 \%$ & $0 \%$ & $-1 \%$ & $0 \%$ & $0 \%$ \\
\hline
\end{tabular}




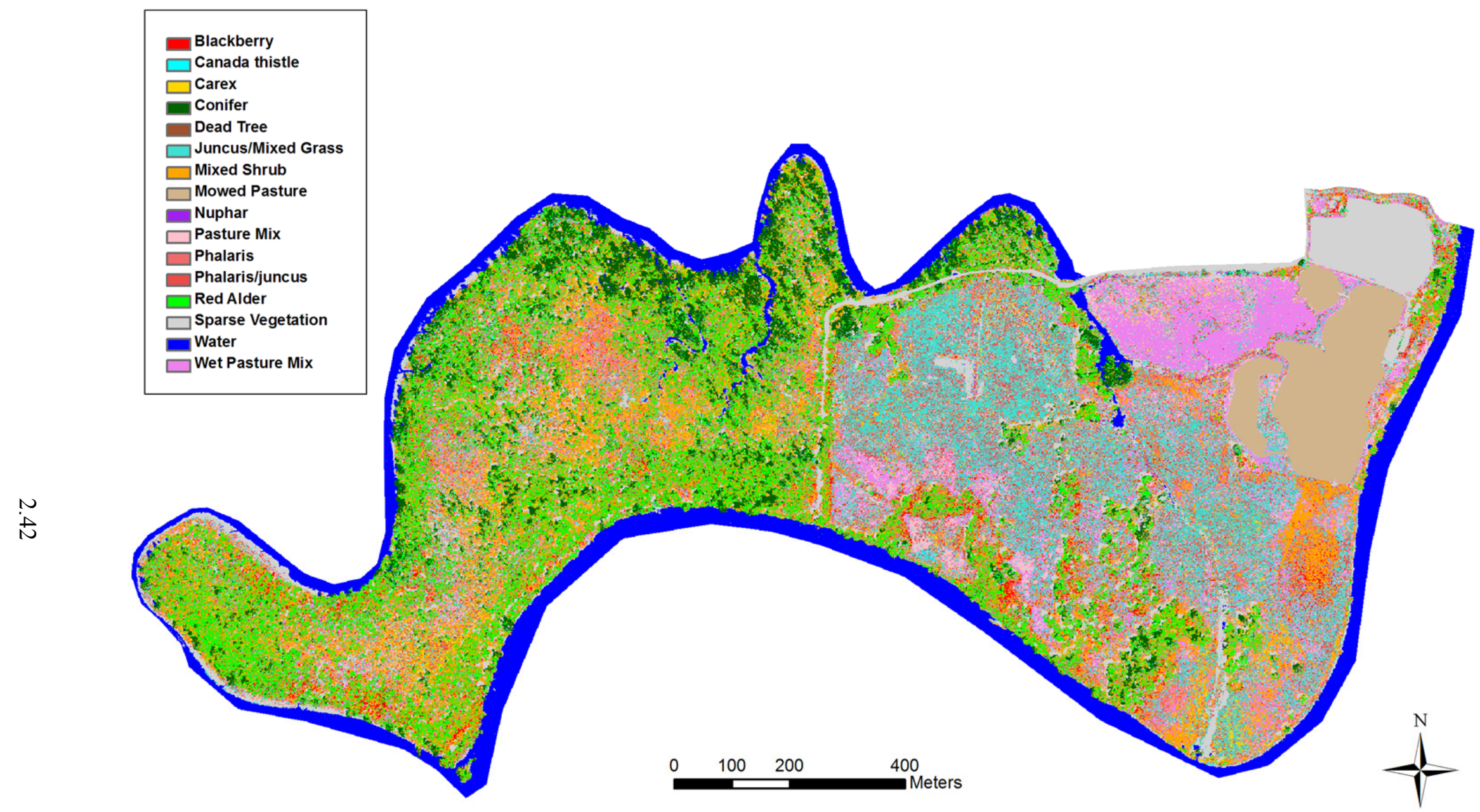

Figure 2.18. Vegetation Cover in 2005 at the Kandoll Reference (West of the Road) and Kandoll Farm (East of the Road) Sites 


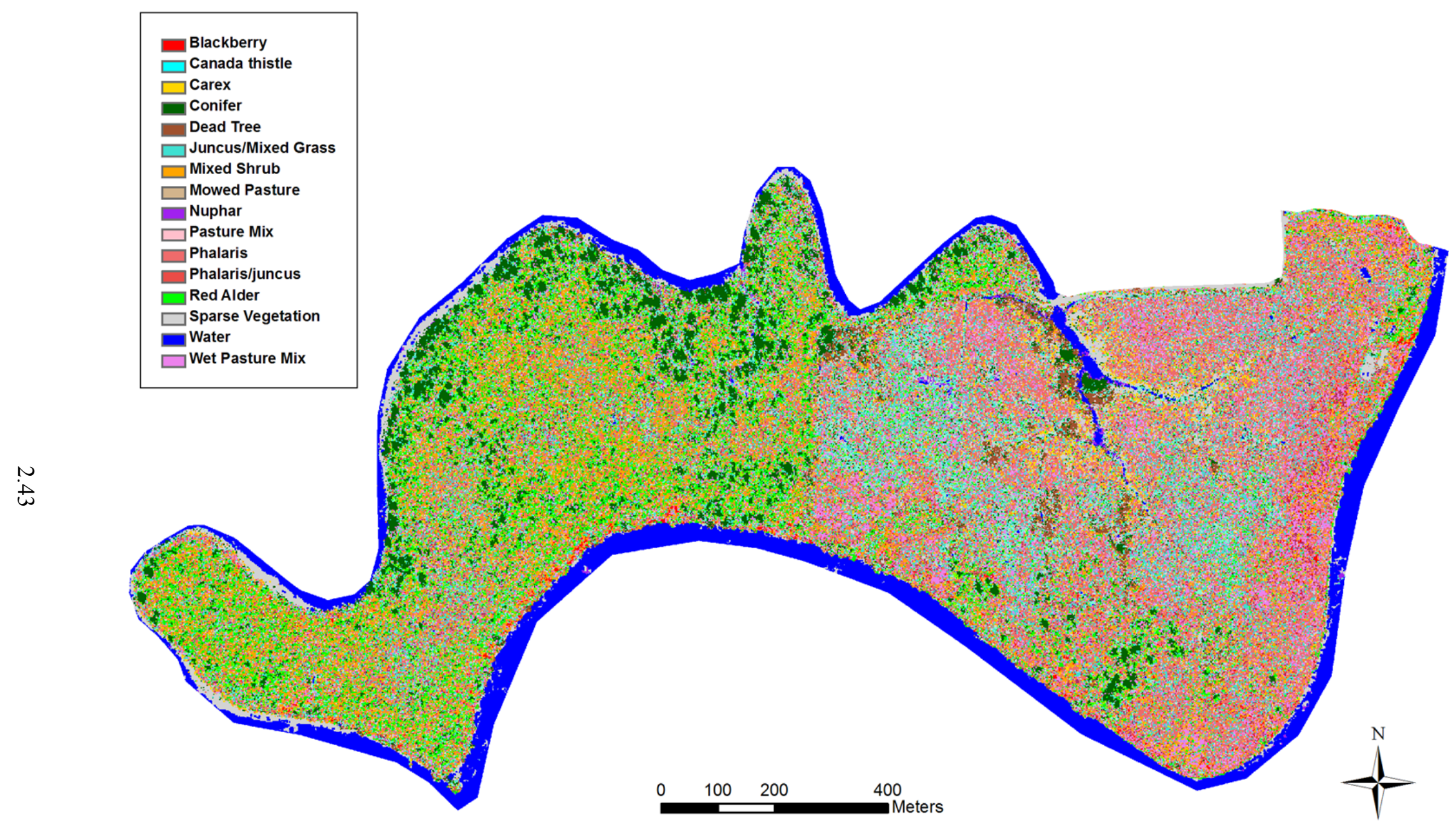

Figure 2.19. Vegetation Cover in 2009 at the Kandoll Reference (West of the Road) and Kandoll Farm (East of the Road) Sites 


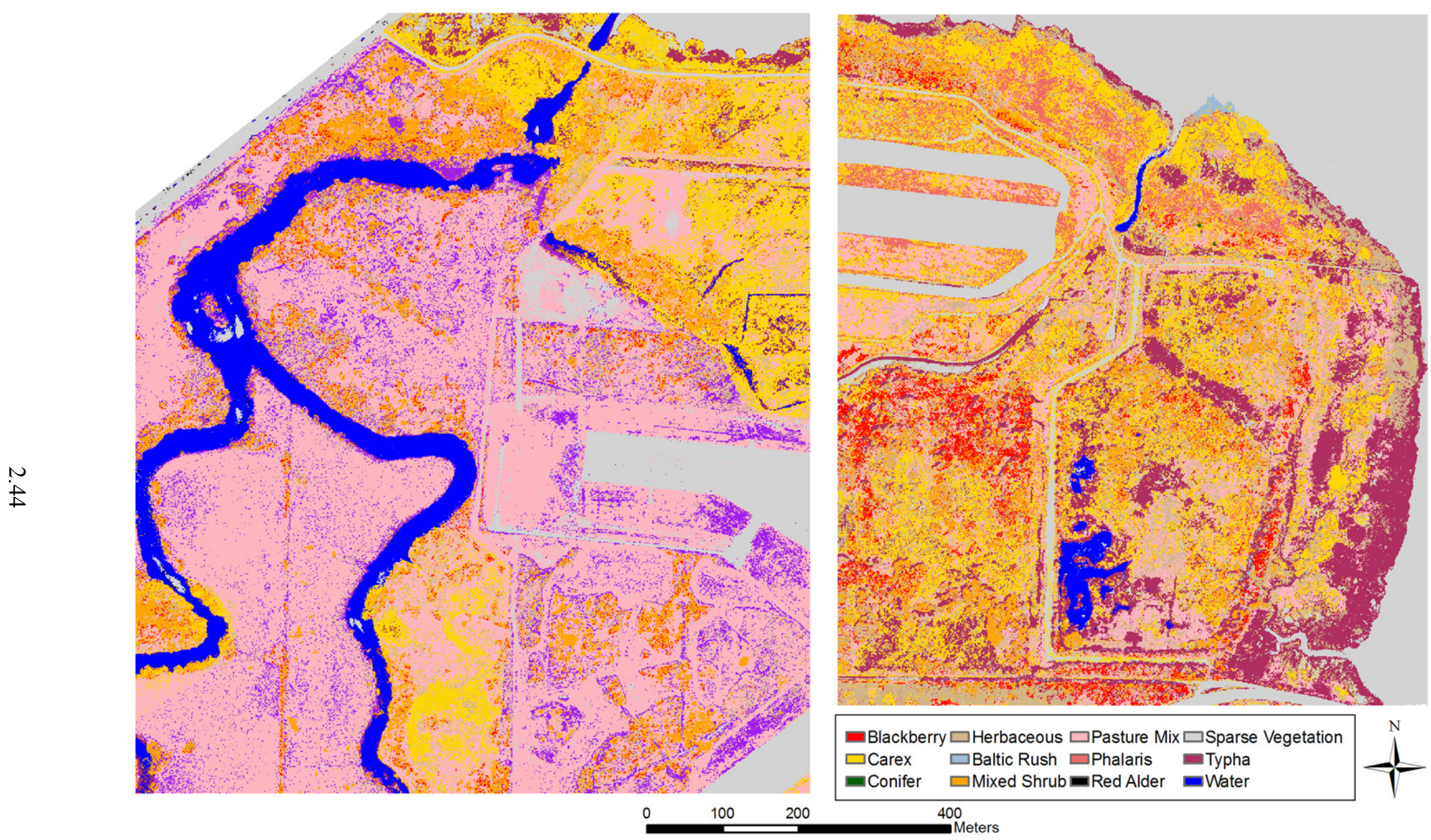

Figure 2.20. Vegetation Cover in 2005 at the Vera Slough (West Panel) and Vera Reference (East Panel) Sites 

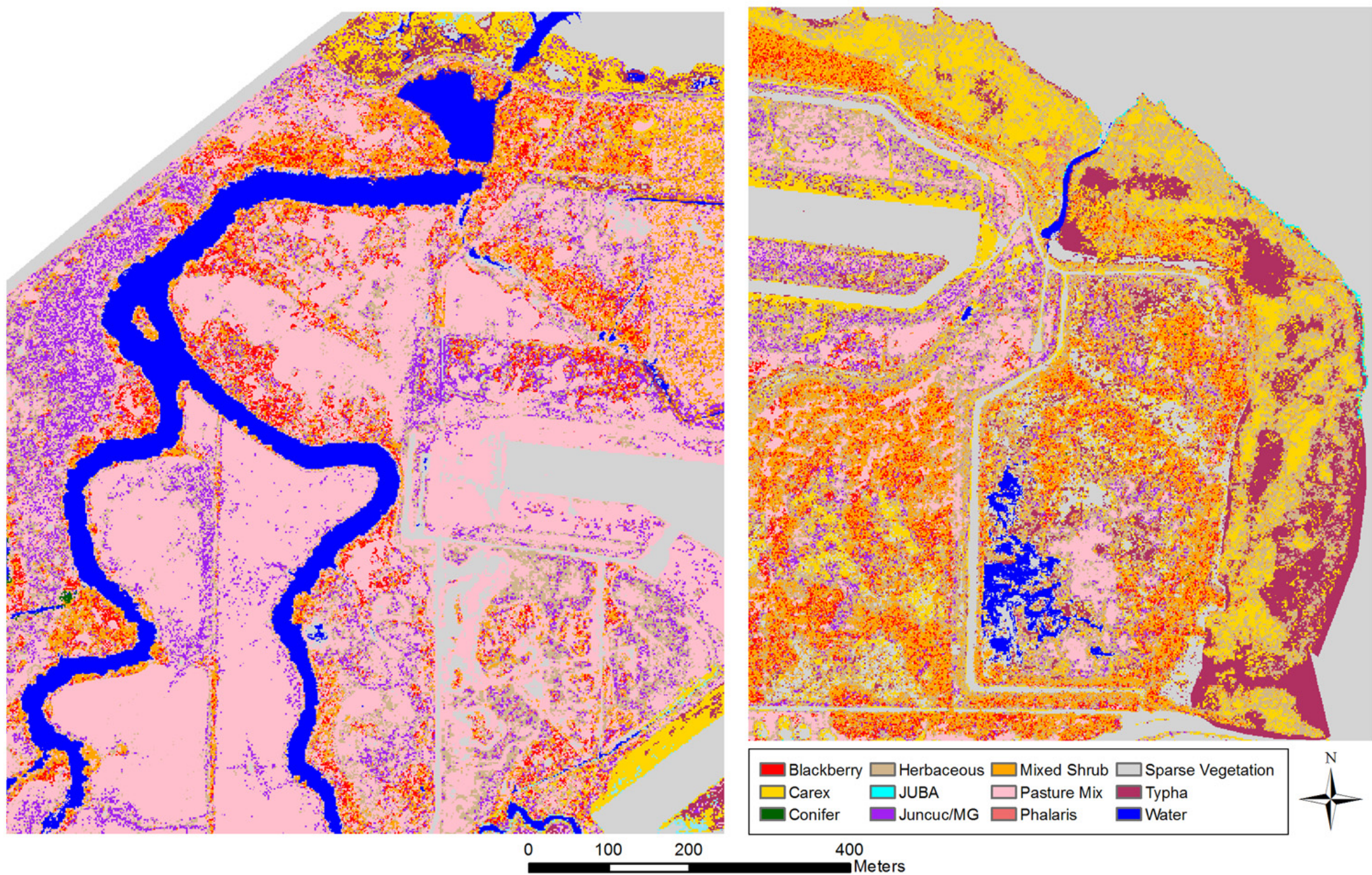

Figure 2.21. Vegetation Cover in 2009 at the Vera Slough (West Panel) and Vera Reference (East Panel) Sites 


\subsubsection{Vegetation Mapping, Crims Island}

In 2007, the CI site elevations were within the narrow range necessary to support a vegetation community dominated by native tidal wetland species. The elevation ranges and dominant species for each of the vegetation categories developed during the landscape-scale vegetation survey in 2007 are listed in Table 2.8. For this analysis, we separated the site into broad categories of excavated versus nonexcavated area because of differences in vegetation observations. Elevations at the site ranged from a low of $0.8 \mathrm{~m}$ (all elevations relative to NAVD88) in the channels to a high of $3.0 \mathrm{~m}$ within the excavated area. Figure 2.22 shows the areas covered by the vegetation categories and a depiction of the area that could potentially be dominated by reed canarygrass, based on the elevation ranges measured at Crims Island. This figure indicates that much of the excavated area is within the elevation range of this highly invasive species. In 2009, a vegetation survey of the aerial cover indicated that reed canarygrass increased from less than $10 \%$ to $30 \%$ cover. Given the invasive nature of this species, this trend is likely to continue in the coming years.

Table 2.8. Dominant Species, Elevation Ranges, and Area for Vegetation Categories at Crims Island in 2007

\begin{tabular}{|c|c|c|c|}
\hline Description & Dominant Species $^{(a)}$ & $\begin{array}{c}\text { Elevation Range } \\
\text { (m, NAVD88) }\end{array}$ & $\begin{array}{l}\text { Area } \\
(\text { ha })^{(b)}\end{array}$ \\
\hline \multicolumn{4}{|c|}{ Excavated Area } \\
\hline $\begin{array}{l}\text { Open water/submerged } \\
\text { aquatic vegetation }\end{array}$ & $\begin{array}{l}\text { Elodea nuttalia, Ceratophyllum demersum, } \\
\text { Myriophyllum spp., Potamogeton crispus }\end{array}$ & $<1.29$ & 2.5 \\
\hline Low marsh & $\begin{array}{l}\text { Alisma plantago-aquatica, Bidens cernua, Callitriche } \\
\text { heterophylla, Ludwigia palustris, Phalaris } \\
\text { arundinacea, Sparganium emersum }\end{array}$ & $1.29-2.26$ & 12.8 \\
\hline & $\begin{array}{l}\text { Eleocharis palustris, Glyceria grandis, Juncus } \\
\text { acuminatus, Leersia oryzoides, P. arundinacea, }\end{array}$ & & \\
\hline Low/high marsh & Scirpus lacustris, Typha latifolia & $2.27-2.48$ & 14.9 \\
\hline High marsh & $\begin{array}{l}\text { Glyceria grandis, Lotus corniculatus, Lythrum } \\
\text { salicaria, Mimulus guttatus, P. arundinacea }\end{array}$ & $2.49-2.80$ & 4.4 \\
\hline \multicolumn{2}{|c|}{ Predominantly $P$. arundinacea } & $2.06-2.99$ & $\mathrm{NA}^{(\mathrm{c})}$ \\
\hline \multicolumn{3}{|c|}{ Area within the elevation range of $P$. arundinacea } & 29.1 \\
\hline \multicolumn{3}{|c|}{ Total Excavated Area } & 35.1 \\
\hline \multicolumn{4}{|c|}{$\begin{array}{l}\text { (a) Dominant species based on observations at the site in } 2007 . \\
\text { (b) Area calculations based on contours developed from elevations measured at the site. } \\
\text { (c) Area for actual "phar" within the excavated area could not be calculated because the range overlapped with the } \\
\text { range for the marsh categories (at least } 365 \text { points classified as "l, } 1 / \mathrm{h} \text {, or h" within elevation range of } \\
\text { P. arundinacea and only } 31 \text { that were actually classified as "p"). } \\
\text { NA = not applicable. }\end{array}$} \\
\hline
\end{tabular}



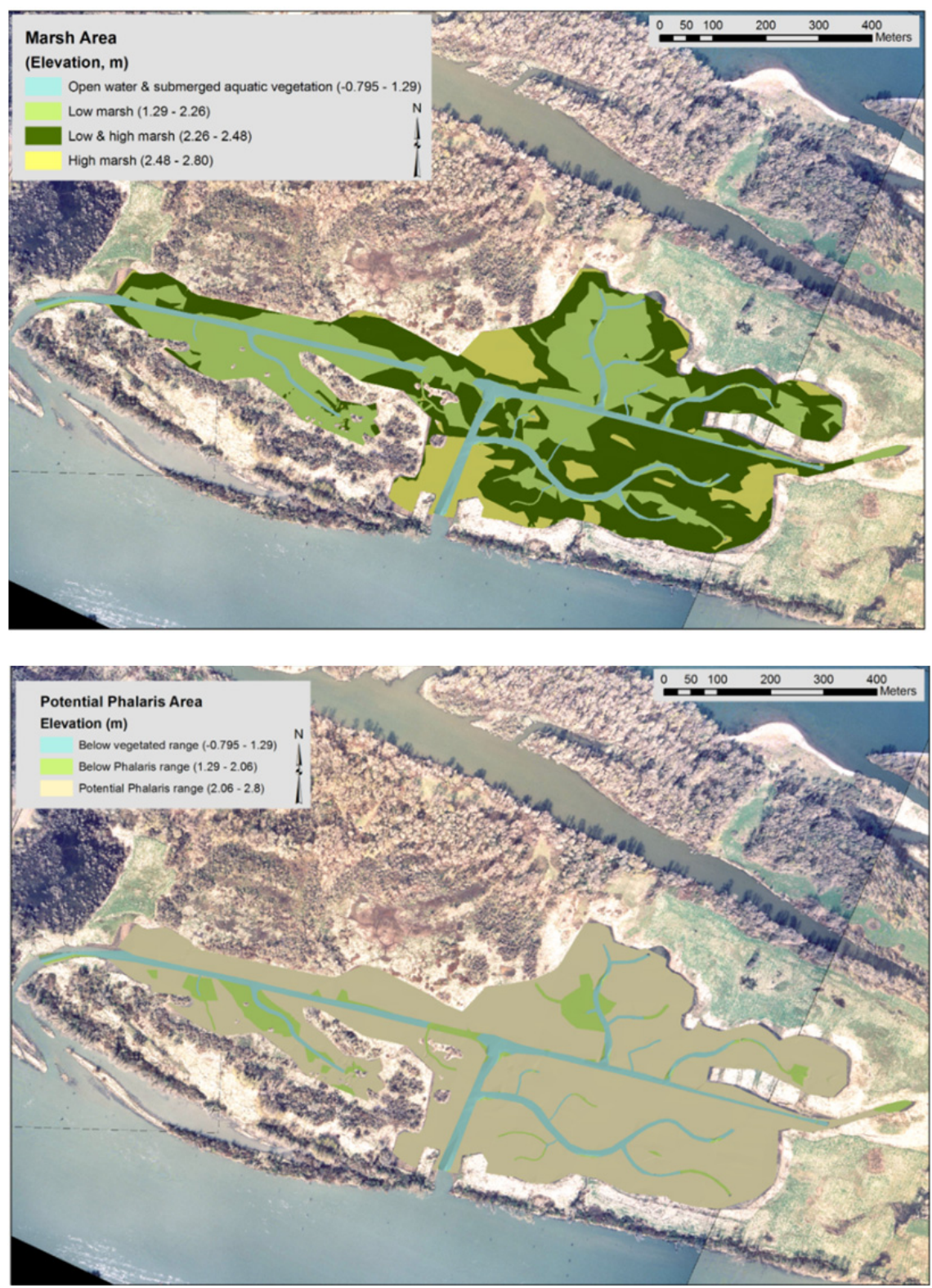

Figure 2.22. Site Elevation Survey for Marsh Area (top) and Potential Reed Canarygrass Area (bottom)

\subsubsection{Vegetation}

Vegetation data involve plot sampling, herbaceous species richness and diversity, species-area curves, shrub and tree cover, and line-intercept sampling.

\subsubsection{Plot Sampling}

\section{Herbaceous Vegetation and Elevation}

Herbaceous plant cover and elevation were sampled in 2005, 2006, and 2009 at the VS, VR, KF, and KR sites and in 2006 and 2009 at the CI and CR sites; an all-site plant species list is provided in 
Appendix J. The initial and final plant species cover and elevation range are grouped for each restoration and reference pair, for the purpose of comparison, in Figures 2.23 through 2.26. All three restoration sites are accreting sediment at faster rates than their paired reference sites (Table 2.5), which is reflected in the difference between initial and final elevation ranges of the plant species.

Vera Slough Restoration and Reference Sites. The change at the VS and VR sites between 2005 and 2006 was a slight decrease in the number of species, with five low-cover species no longer present and one low-cover species added. The dominant species, reed canarygrass, water parsley (Oenanthe sarmentosa), cattail, and Lyngbye's sedge (Carex lyngbyei), were consistent between years and had little variation in cover. Likewise, vegetative cover was similar at the reference site in 2005 and 2009 (95\% and $94 \%$, respectively), with species composition and predominant species remaining constant (Figure 2.23). Lyngbye's sedge cover was slightly reduced (4\% in 2009), while reed canarygrass increased the same amount. Overall, non-native cover increased from $15 \%$ to $18 \%$.

In the first year after restoration (between 2005 and 2006), species richness declined at Vera Slough from 19 to 14 . Sixteen species declined, with 10 species were eradicated. The three species with the most cover in 2005 continued to persist in 2006 and in fact had nearly the same or higher cover in both years. These species, water parsley, cattail, and slough sedge, are all obligate wetland species that likely had a higher inundation tolerance. Herbaceous vegetation cover changed dramatically at the restoration site by 2009 , with overall cover decreasing from $107 \%$ to $24 \%$ and the number of species reduced from 19 to 7 . Consequently, $52 \%$ of the area was bare ground, and the remaining area was dominated by drift wrack, filamentous green algae, and cattail.

The elevation of the vegetated sampling area at the reference site was consistent between years. However, surveys indicated that the restoration site increased in elevation on average $25 \mathrm{~cm}$. This increase is likely attributable to three primary factors: 1) accretion of sediment and organic matter, 2) the liquefaction of the sediment at the time of sampling, which can result in the sediment surface appearing higher than it would without water present, and 3) an approximately 6-cm increase attributable to use of different surveying methods between years. While the direction of sedimentation calculated from survey data is the same as that from sediment accretion stakes (accumulation), the magnitude of accretion seen in sediment stake data is much smaller. This may have to do with differences in methods, with sediment stakes being located at a smaller number of points than surveys, and being a coarse measure in that subsidence is not taken into account. In addition, the survey equipment used at these sites was designed to be flat on the bottom to reduce sinking in the mud and, as a result, it is difficult to measure the exact sediment surface in dense vegetation. Likely, these differences in methods are all contributing to the differences in the apparent accretion rates at the VS site, but the trends reported are the same at the VS site and all the restoration sites, indicating that the sites are accreting and elevations are increasing over time.

In 2009, at the VS site, the wetland behind the tide gate replacement remained substantially lower than at the reference site and it was dominated by bare ground, while the reference site was dominated by Lyngbye's sedge. 

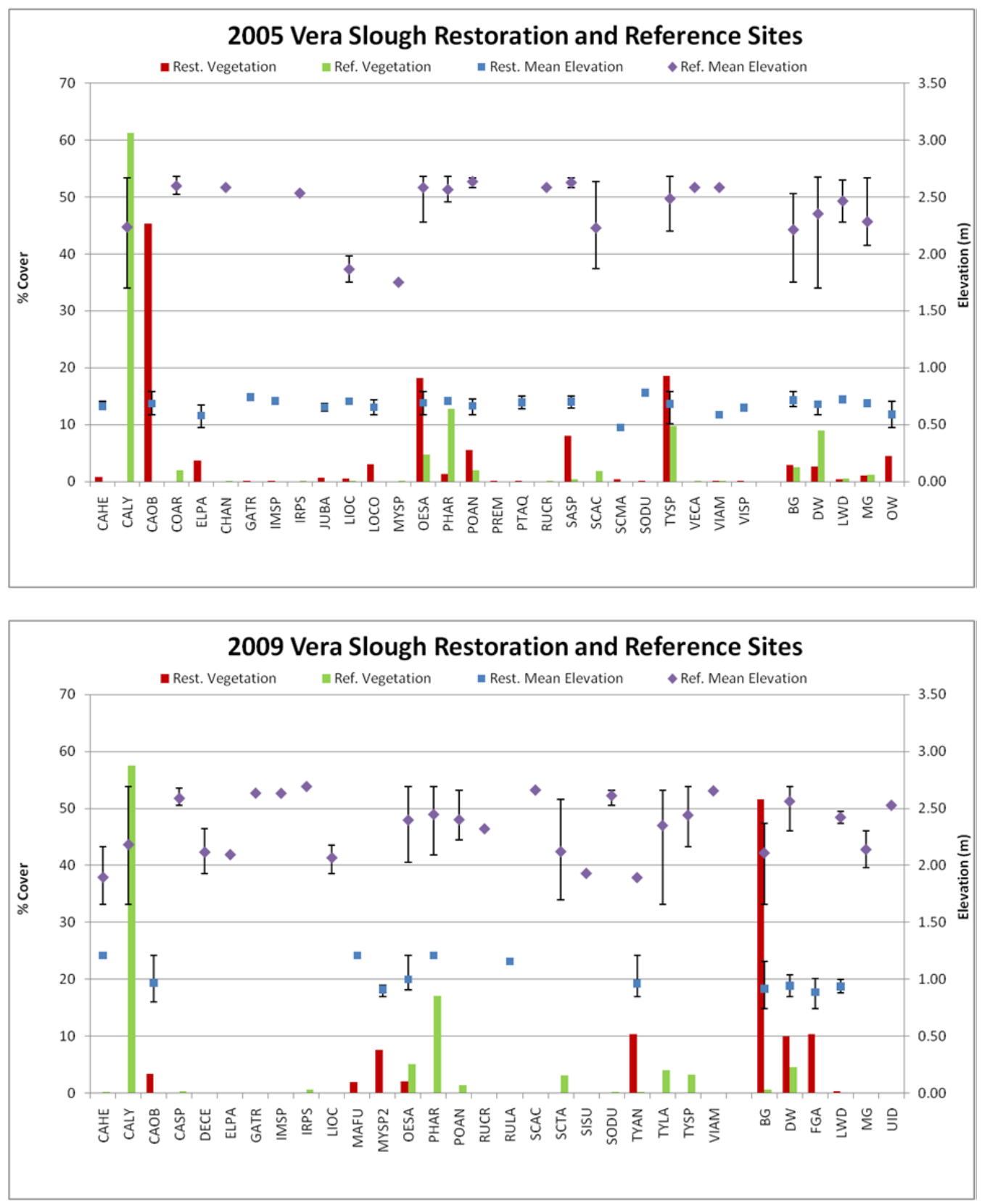

Figure 2.23. Herbaceous Vegetation Cover and Species Elevation Ranges at the Vera Slough Restoration and Reference Sites in 2005 (above) and 2009 (below). BG = bare ground, $\mathrm{DW}=$ debris wrack, FGA = filamentous green algae, $\mathrm{LWD}=$ large woody debris, $\mathrm{MG}=$ mixed grass, $\mathrm{UID}=$ unidentified. Four-letter species codes in these figures represent the first two letters of the genus and species.

The Kandoll Farm Restoration and Reference Sites. The KF and KR sites have substantially different floodplain elevations, and the latter exhibits more microtopography or vegetative roughness associated with large wood (Diefenderfer et al. 2008). The KF (herbaceous wetland) and KR (Sitka spruce swamp) sites also showed little similarity between cover, with plant species in the reference site typically located at higher elevations than at the restoration site, with some notable exceptions (Figures 2.24 and 2.25). 
Overall, vegetative cover and species richness increased at the reference site between 2005 and 2009 from 10 species with $26 \%$ cover to 23 species with $46 \%$ cover, but this was likely due to changes in the sampling methods rather than actual change. In 2009, there was relatively more bare ground, litter, and moss, and western skunk cabbage (Lysichiton americanus). In both years, the percentage of non-native species cover was low (5\% to $6 \%)$.

At the KF site, changes in herbaceous plant cover were observable within the first year after restoration. First-year trends in the six dominant species (Table 2.9) were indicative of the changing hydrologic regime. The number of obligate wetland species increased $70 \%$ and $50 \%$ in SSE and SSW, respectively. Reed canarygrass, an invasive species with a broad inundation tolerance range, increased $52 \%$ and $41 \%$ at SSE and SSW, respectively. Creeping buttercup (Ranunculus repens) decreased in both areas, perhaps due to a lower inundation tolerance. Six of the nine species present in 2005 and not in 2006 were species more often associated with upland conditions.

Table 2.9. Average Percent Cover of the Dominant Plant Species at the Kandoll Restoration Site Sampling Locations (SSE and SSW) in 2005 and 2006

\begin{tabular}{llcccc}
\hline \multicolumn{1}{c}{ Scientific Name } & \multicolumn{1}{c}{ Common Name } & SSE 2005 & SSE & SSW & SSW \\
\hline Juncus effusus & Soft rush & 0.88 & 1.51 & 14.2 & 3.92 \\
Phalaris arundinacea & Reed canarygrass & 27.1 & 57.0 & 33.1 & 56.3 \\
Ranunculus repens & Creeping buttercup & 21.5 & 13.7 & 6.78 & 1.85 \\
Rubus discolor & Himalayan blackberry & 0.00 & 0.00 & 16.8 & 3.42 \\
$\begin{array}{l}\text { Trifolium pratense, T. repens, } \\
\text { T. dubium }\end{array}$ & Red clover, white clover, sm. & 19.4 & 0.28 & 0.00 & 0.00 \\
NA & hopclover & 49.7 & 22.5 & 4.19 & 3.13 \\
\hline
\end{tabular}

From 2005 to 2009 at the KF site, overall vegetative cover increased on both the east and west sides of the channel by $5 \%$ and $10 \%$, respectively. Species richness also changed in both survey areas, with a slight increase on the east side of 3 species and more than doubling of the species on the west side (from 22 to 45 species). Non-native cover in the restoration site was already high prior to restoration due to the predominance of reed canarygrass and a mixture of pasture grasses. Non-native cover increased further after restoration due to the near monoculture of reed canarygrass on the east side. Elevation at the reference site did not change considerably, but the elevation range was greater in 2009. The sample size and distribution were smaller in 2005 and therefore did not cover as broad an elevation range as the 2009 sampling. In contrast, the average elevation at the restoration site increased $18 \mathrm{~cm}$ and $37 \mathrm{~cm}$ at the east and west sides of the restored channel, respectively. On the west side, which was originally lower in elevation, deep mats of horizontal reed canarygrass were noted with new shoots growing up out of the mat. This mat was at times up to $30 \mathrm{~cm}$ deep and was beginning to decompose at the bottom, making the sediment "surface" impossible to determine. As with the Vera Slough sites, the direction of sedimentation calculated from survey data is the same as that from sediment accretion stakes (accumulation), but the magnitude of accretion seen in sediment stake data is much smaller, which may be due to methodological differences or error in the methods discussed in the Vera Slough section above. 


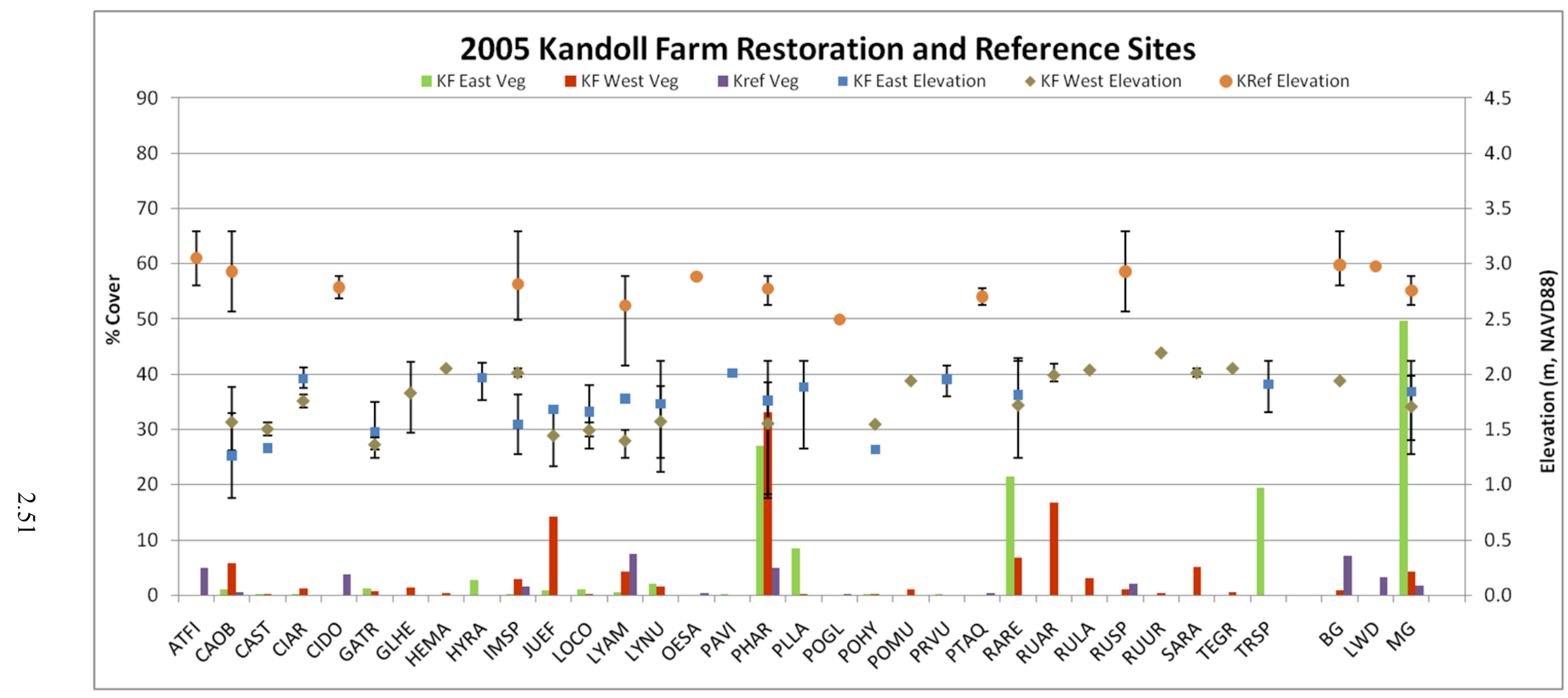

Figure 2.24. Herbaceous Vegetation Cover and Species Elevation Ranges at Kandoll Farm Restoration and Reference Sites During 2005. $\mathrm{BG}=$ bare ground, $\mathrm{DW}=$ debris wrack, $\mathrm{FGA}=$ filamentous green algae, $\mathrm{LW}=$ live wood rooted in quadrat $\mathrm{LWD}=$ large woody debris, $\mathrm{MG}=$ mixed grass, $\mathrm{UID}=$ unidentified. 


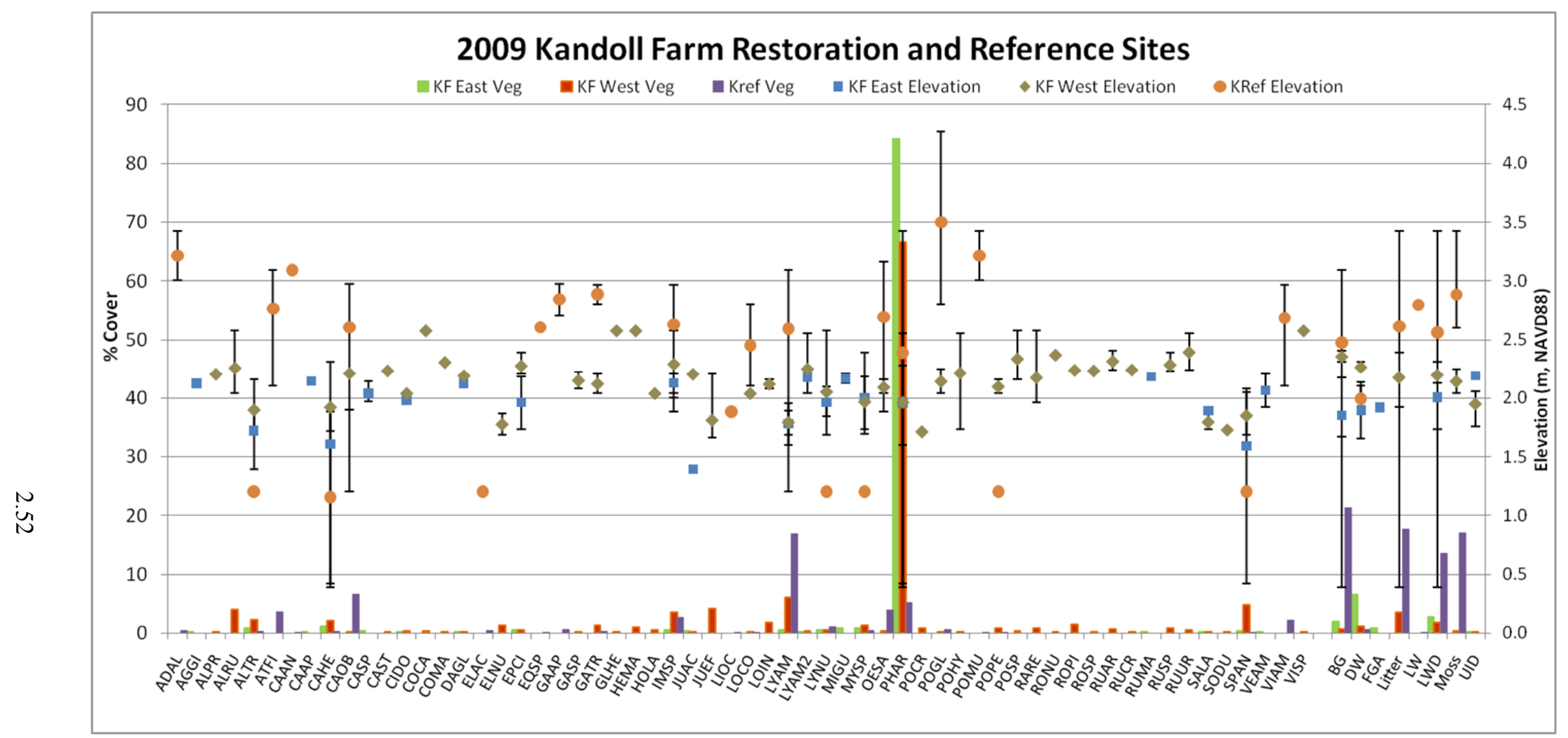

Figure 2.25. Herbaceous Vegetation Cover and Species Elevation Ranges at Kandoll Farm Restoration and Reference Sites During 2009. $\mathrm{BG}=$ bare ground, $\mathrm{DW}=$ debris wrack, $\mathrm{FGA}=$ filamentous green algae, $\mathrm{LW}=$ live wood rooted in quadrat, $\mathrm{LWD}=$ large woody debris, $\mathrm{MG}=$ mixed grass, $\mathrm{UID}=$ unidentified. 
The Crims Island Restoration and Reference Sites. The CI and CR sites have very similar elevations. Both restoration and reference sites show a slight increase in elevation at the vegetated sampling area, likely due to sediment accretion between the years 2006 and 2009. The dominant plant species at the CI and CR sites are dissimilar in 2006 and 2009 (Figure 2.26).

Overall, vegetative cover increased at the CR site between 2006 and 2009 from 101\% to 123\% cover. This increase is largely due to the increase of slough sedge, spike rush (Eleocharis palustris), and common forget-me-not, the former two being native species and the latter an invasive non-native species. Non-native vegetation cover increased from $18 \%$ to $48 \%$ at the reference site due primarily to the increase in forget-me-not. Vegetation changes at the CR site are in part due to seasonal differences in the sampling, with the 2006 data having been collected in early September and the 2009 data having been collected in July. Specifically, the difference in cover of nodding beggartick, which is a late season species, and forget-me-not, an earlier season species, are of note.

While overall vegetative cover at the restoration site did not change significantly (114\% to $119 \%)$ from 2006 to 2009, there was considerable change in the species composition. In 2006, the first growing season following excavation, the site was dominated by small annual and perennial colonizing species. In 2009 , the most notable change was the increase in the non-native, invasive reed canarygrass and soft rush (Juncus effusus). The latter is a native species, but J. effusus var. effusus is not, and although the species at the restoration site was not distinguished to variety, both varieties can be invasive. Overall non-native cover at the restoration site increased from $8 \%$ in 2006 to $34 \%$ in 2009, not including the common rush cover, the inclusion of which would result in $69 \%$ non-native cover.

\section{Permanent Plot Analysis}

The following permanent plot analyses are organized by study site.

Kandoll Farm Seal Slough East (SSE). The elevations of the permanent plots in the SSE sampling averaged $1.77 \mathrm{~m}$ NAVD88 in 2005 . Elevation increased in all plots approximately $10 \mathrm{~cm}$ from 2005 to 2009 , with the elevations in 2006 intermediate between years. A reduction in the number of species from 2005 to 2006 to 2009 was observed in all plots, with the exceptions occurring in the plots along the channel, where one plot increased in 2006 then decreased and the other increased by one species in 2009. Pasture-related species were reduced to $0 \%$ cover in all plots by 2009 (e.g., pasture grass species, clover, and buttercup). Most obligate wetland species had low cover in all years, but a slight increase occurred in 2006 for several species, which then declined to $0 \%$ cover again in 2009 . The primary change in cover occurred from the increase in reed canarygrass, which was $80 \%$ or greater in 11 out of 13 plots in 2009 .

Kandoll Farm Seal Slough West (SSW). In the SSW sampling area there is a topographic difference of about $0.5 \mathrm{~m}$ between the natural riparian levee along the channel (four plots; average elevation of $1.99 \mathrm{~m}$ NAVD88 in 2005) and the lower marsh area (eight plots; average elevation of $1.49 \mathrm{~m}$ NAVD88 in 2005). In 2009, the elevation had increased in the permanent plots to $2.24 \mathrm{~m}$ in the levee area and $1.92 \mathrm{~m}$ in the marsh, with an average accretion in the whole area of $0.37 \mathrm{~m}$. This variation in elevation between the levee and the marsh resulted in different changes in the permanent plots. In the higher elevation area, there was a complete eradication of all blackberry species, replaced primarily by common touch-me-not (Impatiens spp.), reed canarygrass, and slough sedge, and an overall increase in the number of species (from 2 to 4 species in 2005 to 5 to 10 species in 2009). In the lower elevation area there was generally a decrease in the number of species with five of the eight plots reduced to one species, reed canarygrass. 
Two plots had a slight increase in the number of obligate wetland species in 2009. Five of the six plots with common rush in 2005 decreased to $0 \%$ cover, while one plot increased slightly from $90 \%$ to $100 \%$ cover. Conversely, seven of the eight plots had an increase in reed canarygrass cover from a low of $5 \%$ in 2005 to $100 \%$ cover in 2009 .
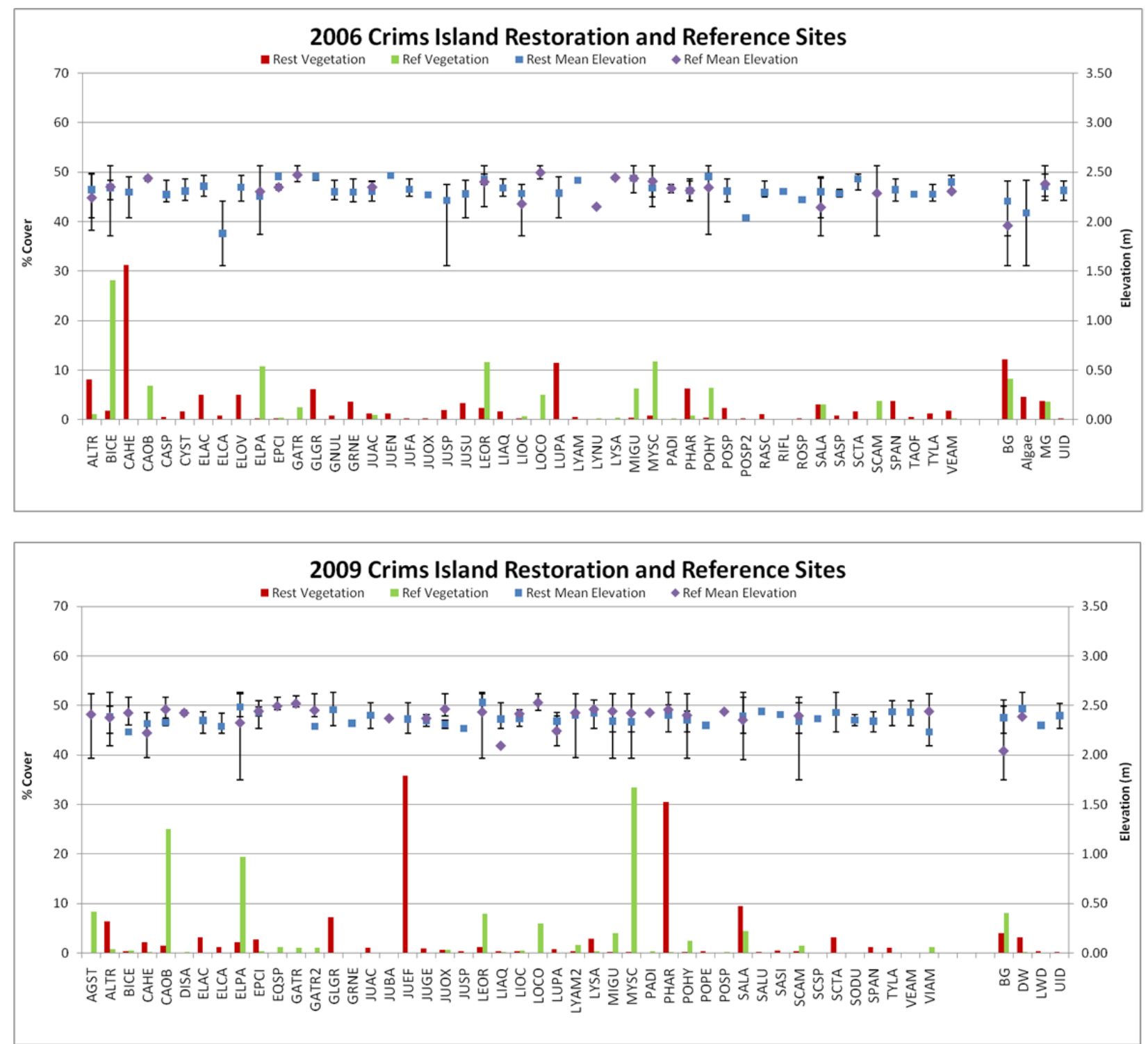

Figure 2.26. Herbaceous Vegetation Cover and Species Elevation Ranges at Crims Island Restoration and Reference Sites in 2005 (above) and 2009 (below). BG = bare ground, DW = debris wrack, LWD = large woody debris, UID = unidentified.

Vera Slough Restoration Site. Elevation of the permanent plots averaged $0.68 \mathrm{~m}$ NAVD88 in 2005 and accreted an average of $0.21 \mathrm{~m}( \pm 0.04 \mathrm{~m})$ for an average elevation of $0.90 \mathrm{~m}$ NAVD88 by 2009 . Over half of the accretion $(0.13 \mathrm{~m}[ \pm 0.06 \mathrm{~m}])$ occurred in the first year. The percent vegetative cover in the permanent plots at Vera Slough comprised a mix of obligate wetland species, primarily slough sedge, water parsley, and cattail. The cover of all of these species was reduced by 2009 , often completely eradicated. The plots were mostly bare in 2009 , with cattails being the only emergent wetland species 
present at greater than $15 \%$ cover and then only in 2 out of the 10 plots ( $40 \%$ and $70 \%$ cover). Milfoil (Myriophyllum spp.), a submerged aquatic species, was also present in two plots in 2009 at levels of $75 \%$ and $80 \%$.

Vera Slough Reference Site. The elevation of the permanent plots in the reference area averaged $2.27 \mathrm{~m}$ NAVD88 in 2005 and $2.26 \mathrm{~m}$ NAVD88 in 2009 (average change was $-0.01 \mathrm{~m} \mathrm{[} \pm 0.04]$ ). In the 10 permanent plots at the VR site the number of species was between one and four in all plots and all years. Six were dominated by Lyngbye's sedge and four were dominated by reed canarygrass. The changes between years were relatively minor, with one plot changing from 50\% Lyngbye's sedge and $50 \%$ reed canarygrass in 2005 to $100 \%$ reed canarygrass in 2009 . All other plots remained stable with little change in the number of species or cover.

Crims Island Restoration Site. Elevations of the permanent plots at the CI site increased from an average of $2.22 \mathrm{~m}$ NAVD88 in 2006 to $2.31 \mathrm{~m}$ NAVD88 in 2009 (average change $0.09 \mathrm{~m}$ [ \pm 0.05$]$ ). The number of species per plot, ranging from 5 to 14, decreased in three of the five plots and increased in two between 2006 and 2009. The primary change in cover was a shift from small obligate wetland species such as water starwort (Callitriche heterophylla) and false loosestrife (Ludwigia palustris) to wapato and facultative wetland species (soft rush and reed canarygrass). Three of the plots were dominated (90\% or more) by a combination of soft rush and reed canarygrass in 2009 , increased from $0 \%$ to $5 \%$ cover in the plots in 2006 , while the two other plots were a combination of obligate species.

Crims Reference Site. Elevations of the permanent plots at the CR site increased slightly from an average of $2.32 \mathrm{~m}$ NAVD88 to $2.38 \mathrm{~m}$ NAVD88 (average change $0.06 \mathrm{~m}[ \pm 0.02]$ ). The primary differences observed in the percent cover at the permanent plots can be attributed to seasonal changes, with the 2006 monitoring occurring in September and the 2009 monitoring in July. Several of the species that had high cover in 2006 are late season species (e.g., nodding beggartick and rice cutgrass [Leersia oryzoides]), while the species with high cover in 2009 (forget-me-nots and slough sedge) were possibly dying back in September 2006. One plot that was primarily bare in 2006 had increased to $80 \%$ cover of wapato and spike rush.

\section{Vegetation Assemblage Similarity Analysis}

We summarized the change in the vegetation species composition and species cover using the similarity analysis (Table 2.10). While the VR site remained nearly identical before and after restoration the other reference sites did not; however, KR analysis is confounded by changed sampling methods. Nevertheless, reference sites changed less than restoration sites, with the exception of SSW at the KF site, which was already a wet pasture with common rush and reed canarygrass before restoration. Trends at restoration sites: the VS and VR sites exhibited effectively no change, or slightly less similar (about 0.06); the KF (both SSW and SSE) and KR sites became less similar (about 0.1), but confounded by the KR sampling method change; and the CI and CR sites exhibited effectively no change in similarity (0.01). 
Table 2.10. Relative Sorensen Similarity Indexes for Herbaceous Vegetation in 2005, 2006, and 2009. CI $=$ Crims Island, CR $=$ Crims Reference, KR = Kandoll Reference, SSE = Seal Slough East plot at Kandoll Farm, SSW = Seal Slough West plot at Kandoll Farm, $\mathrm{VR}=$ Vera Reference, and VS $=$ Vera Slough.

\begin{tabular}{|c|c|c|c|c|c|c|c|c|c|c|c|c|c|c|c|c|c|c|c|c|c|}
\hline & CI06 & CI09 & CIR06 & CIR09 & KF05 & KF06 & KF09 & KR05 & KR09 & SSE05 & SSE06 & SSE09 & SSW05 & SSW06 & SSW09 & VR05 & VR06 & VR09 & VS05 & VS06 & VS09 \\
\hline CI06 & 1.00 & 0.30 & 0.13 & 0.08 & 0.09 & 0.12 & 0.14 & 0.10 & 0.09 & 0.08 & 0.11 & 0.11 & 0.10 & 0.11 & 0.15 & 0.09 & 0.08 & 0.09 & 0.04 & 0.02 & 0.02 \\
\hline CI09 & 0.30 & 1.00 & 0.12 & 0.12 & 0.33 & 0.33 & 0.36 & 0.08 & 0.10 & 0.23 & 0.31 & 0.33 & 0.46 & 0.36 & 0.38 & 0.15 & 0.18 & 0.22 & 0.07 & 0.04 & 0.04 \\
\hline CIR06 & 0.13 & 0.12 & 1.00 & 0.50 & 0.09 & 0.09 & 0.05 & 0.05 & 0.12 & 0.07 & 0.11 & 0.05 & 0.12 & 0.06 & 0.06 & 0.02 & 0.02 & 0.01 & 0.16 & 0.08 & 0.05 \\
\hline CIR09 & 0.08 & 0.12 & 0.50 & 1.00 & 0.04 & 0.04 & 0.04 & 0.01 & 0.11 & 0.03 & 0.05 & 0.03 & 0.07 & 0.02 & 0.05 & 0.00 & 0.02 & 0.01 & 0.30 & 0.24 & 0.05 \\
\hline KF05 & 0.09 & 0.33 & 0.09 & 0.04 & 1.00 & 0.58 & 0.35 & 0.16 & 0.18 & 0.75 & 0.65 & 0.31 & 0.64 & 0.47 & 0.37 & 0.13 & 0.14 & 0.18 & 0.06 & 0.04 & 0.05 \\
\hline KF06 & 0.12 & 0.33 & 0.09 & 0.04 & 0.58 & 1.00 & 0.65 & 0.17 & 0.16 & 0.46 & 0.87 & 0.63 & 0.58 & 0.83 & 0.64 & 0.14 & 0.15 & 0.19 & 0.04 & 0.02 & 0.02 \\
\hline KF09 & 0.14 & 0.36 & 0.05 & 0.04 & 0.35 & 0.65 & 1.00 & 0.16 & 0.18 & 0.26 & 0.58 & 0.87 & 0.46 & 0.73 & 0.86 & 0.13 & 0.16 & 0.20 & 0.03 & 0.01 & 0.00 \\
\hline KR05 & 0.10 & 0.08 & 0.05 & 0.01 & 0.16 & 0.17 & 0.16 & 1.00 & 0.51 & 0.09 & 0.10 & 0.10 & 0.24 & 0.26 & 0.20 & 0.11 & 0.09 & 0.08 & 0.06 & 0.02 & 0.04 \\
\hline KR09 & 0.09 & 0.10 & 0.12 & 0.11 & 0.18 & 0.16 & 0.18 & 0.51 & 1.00 & 0.09 & 0.11 & 0.12 & 0.31 & 0.22 & 0.22 & 0.13 & 0.12 & 0.13 & 0.17 & 0.16 & 0.16 \\
\hline SSE05 & 0.08 & 0.23 & 0.07 & 0.03 & 0.75 & 0.46 & 0.26 & 0.09 & 0.09 & 1.00 & 0.55 & 0.25 & 0.40 & 0.33 & 0.26 & 0.12 & 0.13 & 0.16 & 0.04 & 0.01 & 0.01 \\
\hline SSE06 & 0.11 & 0.31 & 0.11 & 0.05 & 0.65 & 0.87 & 0.58 & 0.10 & 0.11 & 0.55 & 1.00 & 0.57 & 0.49 & 0.70 & 0.56 & 0.13 & 0.14 & 0.18 & 0.05 & 0.02 & 0.02 \\
\hline SSE09 & 0.11 & 0.33 & 0.05 & 0.03 & 0.31 & 0.63 & 0.87 & 0.10 & 0.12 & 0.25 & 0.57 & 1.00 & 0.39 & 0.68 & 0.73 & 0.14 & 0.17 & 0.20 & 0.02 & 0.00 & 0.00 \\
\hline SSW05 & 0.10 & 0.46 & 0.12 & 0.07 & 0.64 & 0.58 & 0.46 & 0.24 & 0.31 & 0.40 & 0.49 & 0.39 & 1.00 & 0.62 & 0.50 & 0.16 & 0.16 & 0.21 & 0.09 & 0.07 & 0.06 \\
\hline SSW06 & 0.11 & 0.36 & 0.06 & 0.02 & 0.47 & 0.83 & 0.73 & 0.26 & 0.22 & 0.33 & 0.70 & 0.68 & 0.62 & 1.00 & 0.75 & 0.16 & 0.17 & 0.21 & 0.04 & 0.01 & 0.01 \\
\hline SSW09 & 0.15 & 0.38 & 0.06 & 0.05 & 0.37 & 0.64 & 0.86 & 0.20 & 0.22 & 0.26 & 0.56 & 0.73 & 0.50 & 0.75 & 1.00 & 0.13 & 0.16 & 0.19 & 0.03 & 0.02 & 0.01 \\
\hline VR05 & 0.09 & 0.15 & 0.02 & 0.00 & 0.13 & 0.14 & 0.13 & 0.11 & 0.13 & 0.12 & 0.13 & 0.14 & 0.16 & 0.16 & 0.13 & 1.00 & 0.88 & 0.89 & 0.20 & 0.16 & 0.20 \\
\hline VR06 & 0.08 & 0.18 & 0.02 & 0.02 & 0.14 & 0.15 & 0.16 & 0.09 & 0.12 & 0.13 & 0.14 & 0.17 & 0.16 & 0.17 & 0.16 & 0.88 & 1.00 & 0.91 & 0.11 & 0.10 & 0.12 \\
\hline VR09 & 0.09 & 0.22 & 0.01 & 0.01 & 0.18 & 0.19 & 0.20 & 0.08 & 0.13 & 0.16 & 0.18 & 0.20 & 0.21 & 0.21 & 0.19 & 0.89 & 0.91 & 1.00 & 0.17 & 0.15 & 0.16 \\
\hline VS05 & 0.04 & 0.07 & 0.16 & 0.30 & 0.06 & 0.04 & 0.03 & 0.06 & 0.17 & 0.04 & 0.05 & 0.02 & 0.09 & 0.04 & 0.03 & 0.20 & 0.11 & 0.17 & 1.00 & 0.80 & 0.27 \\
\hline VS06 & 0.02 & 0.04 & 0.08 & 0.24 & 0.04 & 0.02 & 0.01 & 0.02 & 0.16 & 0.01 & 0.02 & 0.00 & 0.07 & 0.01 & 0.02 & 0.16 & 0.10 & 0.15 & 0.80 & 1.00 & 0.28 \\
\hline VS09 & 0.02 & 0.04 & 0.05 & 0.05 & 0.05 & 0.02 & 0.00 & 0.04 & 0.16 & 0.01 & 0.02 & 0.00 & 0.06 & 0.01 & 0.01 & 0.20 & 0.12 & 0.16 & 0.27 & 0.28 & 1.00 \\
\hline
\end{tabular}


In Table 2.11 we only include similarity values for the three restored sites and their reference areas. In all cases the similarity of the vegetation assemblage decreased between the first year of sampling and the following years. The KF site assemblage 1 year post-breach was only $58 \%$ similar to the 2005 prebreach assemblage, and was $35 \%$ similar to the pre-breach assemblage 4 years after the levee breach. The VS site assemblage recorded in 2005 remained highly similar (i.e., 80\%) 1 year following the culvert retrofit. However, by the fourth year it was only $27 \%$ similar to the 2005 assemblage. The assemblage in 2009 at the CI site was only $30 \%$ similar to the early post-breach assemblage structure in 2006 . Of note is that during all between-year comparisons the restored site assemblages were $<20 \%$ similar to their associated reference site assemblage. Hence, there was a predictable trend in a rapidly changing plant assemblage shortly after the restoration action at all sites (Figure 2.27), but the sites remained very dissimilar to their reference sites even after 4 years. VR site flora remained very similar $(88 \%, 91 \%)$ to itself over time, whereas the KR (51\%) and CR (50\%) sites were only moderately similar to themselves over time.

Table 2.11. Abbreviated Table of Similarity (\%) Between Years at a Site, and Between the Restored and Reference Sites. Completely similar species composition and species cover $=100 \%$; completely dissimilar species composition and species cover $=0 \%$.

\begin{tabular}{|c|c|c|c|c|c|c|}
\hline & KF 2005 & KR 2005 & VS 2005 & VR 2005 & CI 2006 & CR 2006 \\
\hline KF 2006 & 58 & & & & & \\
\hline KF 2009 & 35 & & & & & \\
\hline KR 2005 & 16 & & & & & \\
\hline KR 2009 & 18 & 51 & & & & \\
\hline VS 2006 & & & 80 & & & \\
\hline VS 2009 & & & 27 & & & \\
\hline VR 2005 & & & 20 & & & \\
\hline VR 2006 & & & 16 & 88 & & \\
\hline VR 2009 & & & 20 & 91 & & \\
\hline CI 2009 & & & & & 30 & \\
\hline CR 2006 & & & & & 13 & \\
\hline CR 2009 & & & & & 08 & 50 \\
\hline
\end{tabular}

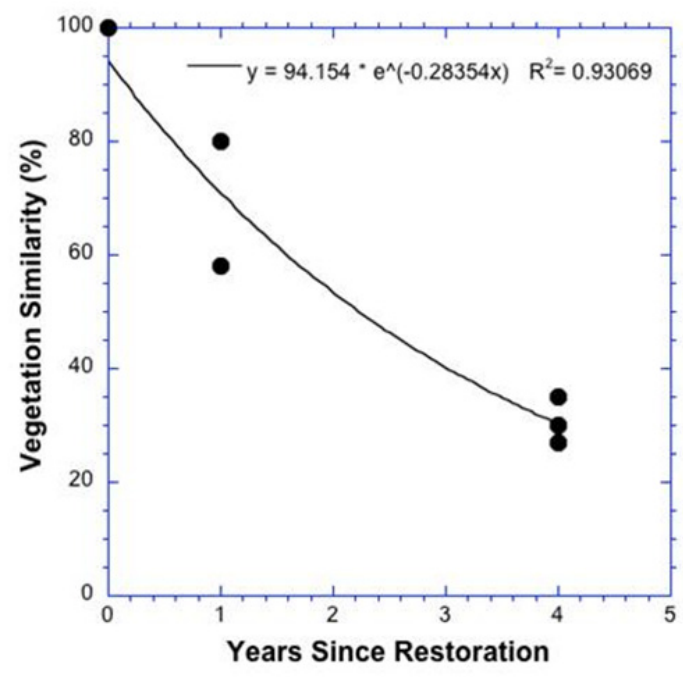

Figure 2.27. Pattern of Change in Vegetation Similarity Between Sites over Time Since Restoration 


\subsubsection{Herbaceous Vegetation Species Richness and Diversity}

Of a total of 108 herbaceous plant species sampled at the six sites, richness and diversity were highest at the CI and CR sites, followed generally by the KR and KF, and then by the VR and VS sites (Table 2.12). Species richness decreased in the first 4 years after restoration at the CI and VS, but increased substantially at the KF site, and stayed fairly constant or increased at all reference sites. Species diversity as measured by two indices (Shannon's and Simpson's) decreased at all restoration sites in the first 4 years, while remaining fairly constant or slightly increasing at all reference sites.

Table 2.12. Summary of Species Richness (S), Evenness (E), Shannon-Wiener Diversity Index (H), and Simpson's Diversity Index for Infinite Population (D)

\begin{tabular}{ccccc}
\hline Site & S & E & H & D \\
\hline CI06 & 40 & 0.78 & 2.89 & 0.90 \\
CI09 & 35 & 0.65 & 2.31 & 0.83 \\
CR06 & 21 & 0.79 & 2.41 & 0.87 \\
CR09 & 30 & 0.67 & 2.28 & 0.85 \\
KF05 & 23 & 0.68 & 2.14 & 0.83 \\
KF06 & 35 & 0.47 & 1.66 & 0.65 \\
KF09 & 45 & 0.32 & 1.22 & 0.40 \\
KR05 & 10 & 0.80 & 1.84 & 0.81 \\
KR09 & 23 & 0.68 & 2.13 & 0.81 \\
SSE05 & 18 & 0.62 & 1.78 & 0.78 \\
SSE06 & 25 & 0.53 & 1.71 & 0.71 \\
SSE09 & 20 & 0.16 & 0.47 & 0.15 \\
SSW05 & 19 & 0.70 & 2.05 & 0.79 \\
SSW06 & 22 & 0.41 & 1.28 & 0.49 \\
SSW09 & 39 & 0.47 & 1.73 & 0.60 \\
VR05 & 15 & 0.47 & 1.26 & 0.56 \\
VR06 & 12 & 0.44 & 1.09 & 0.49 \\
VR09 & 19 & 0.43 & 1.27 & 0.58 \\
VS05 & 18 & 0.57 & 1.64 & 0.72 \\
VS06 & 10 & 0.52 & 1.20 & 0.67 \\
VS09 & 6 & 0.69 & 1.23 & 0.67 \\
\hline
\end{tabular}

\subsubsection{Herbaceous Vegetation Species Accumulation Curves}

Species-area curves, or species accumulation curves, were developed for the six sites for the first and last years of sampling (Figure 2.28). These curves are useful for understanding the effect of area on the number of species expected at a site. They also facilitate comparisons between sites and between years at the same site by normalizing the area. Essentially, as the area sampled increases, new species are added (accumulated) to the species list. The curves in Figure 2.28 are the average number added per unit area, and the variation (SD) around the average is shown. Because the number and rate of new species encountered rises rapidly at first then tends to decrease as the area sampled reaches a point near the total 
Restoration

a

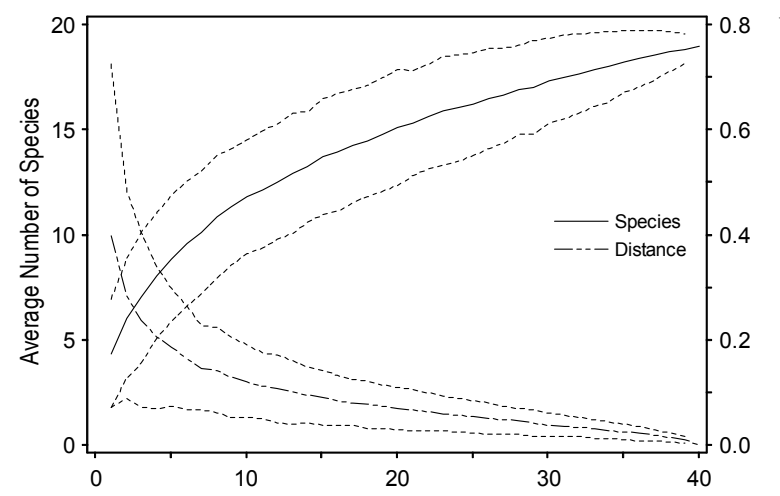

c

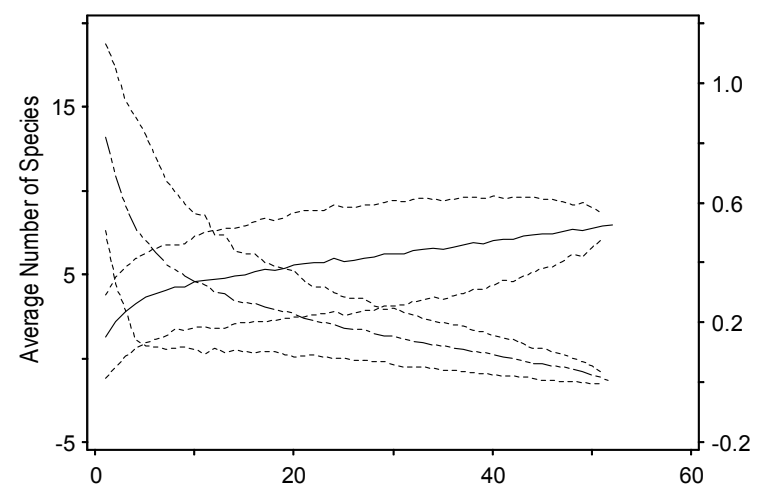

e

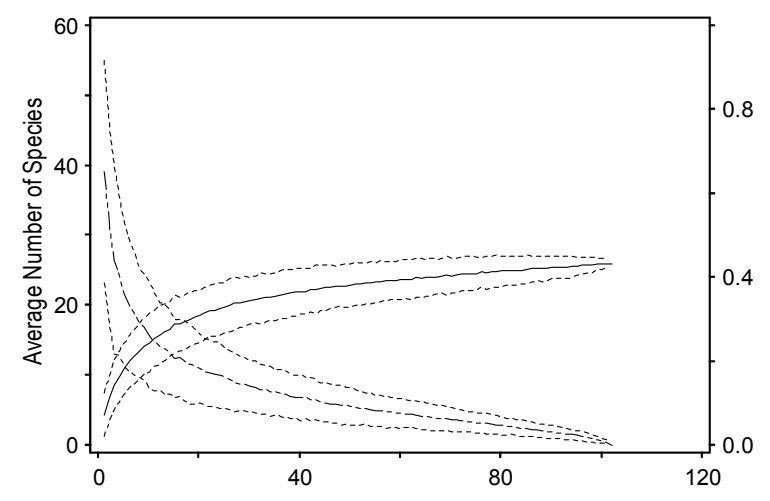

g

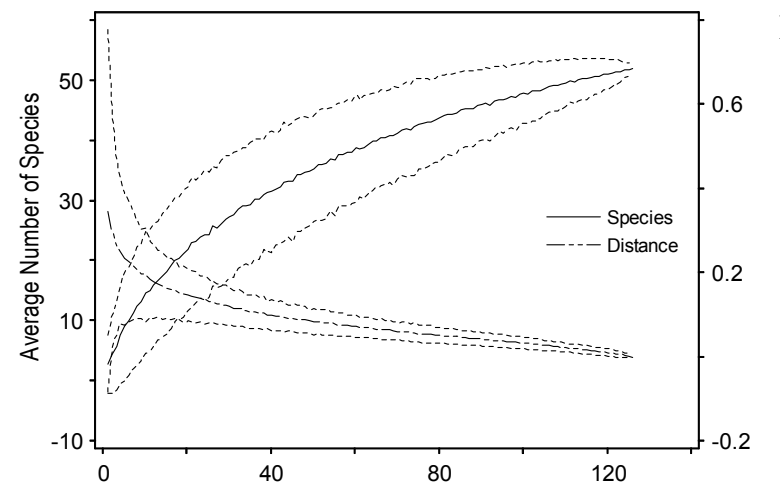

Reference

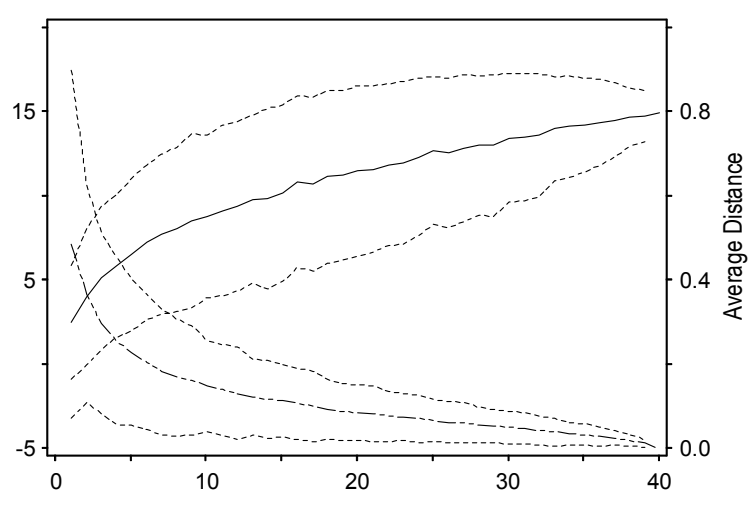

d
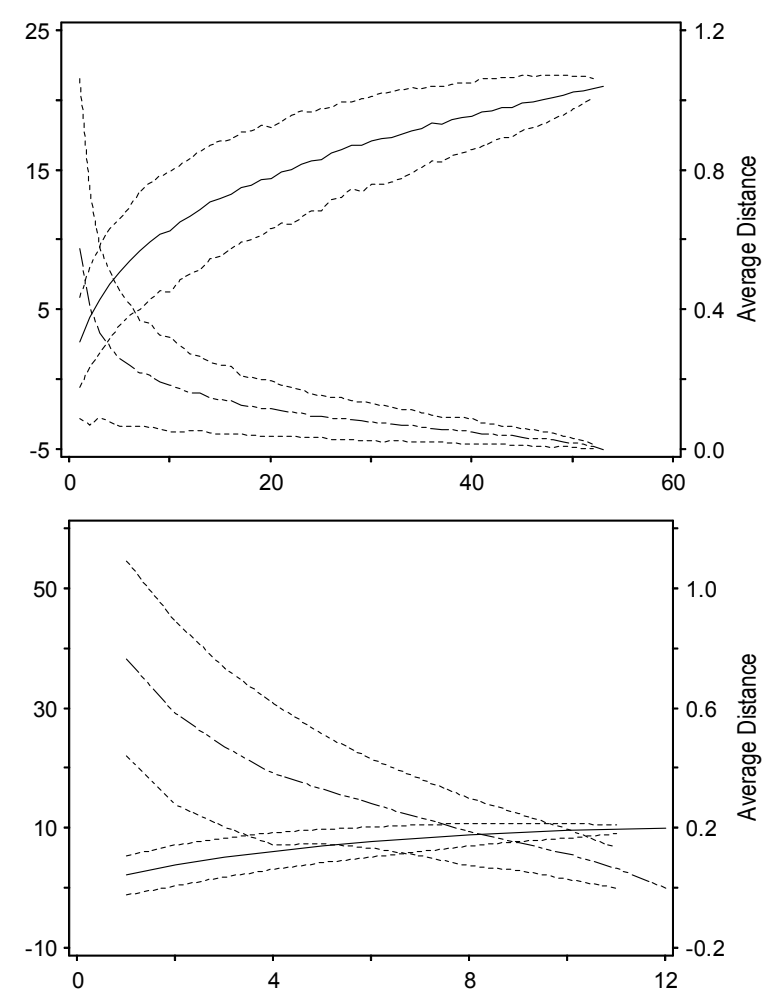

h

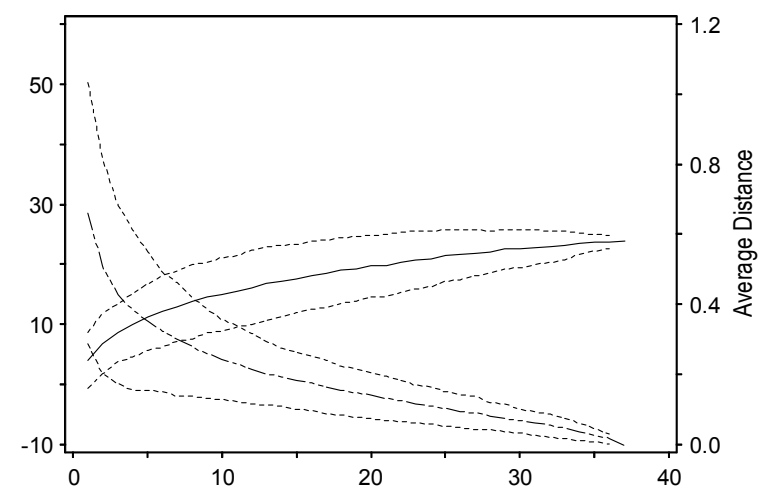


i
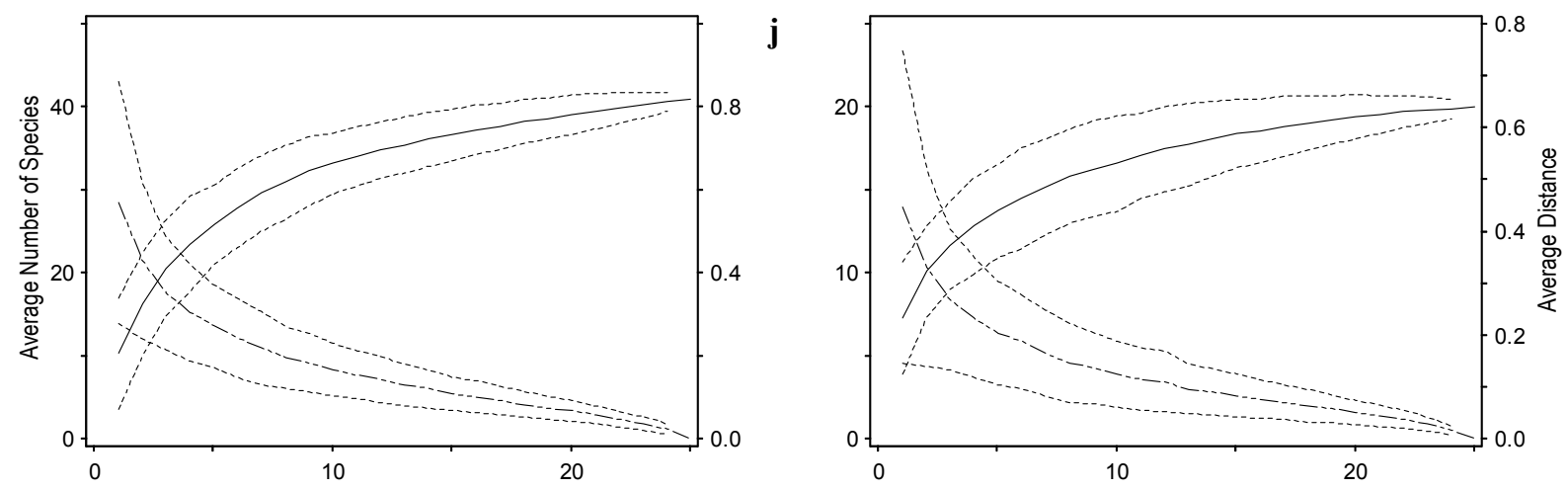

$\mathbf{k}$
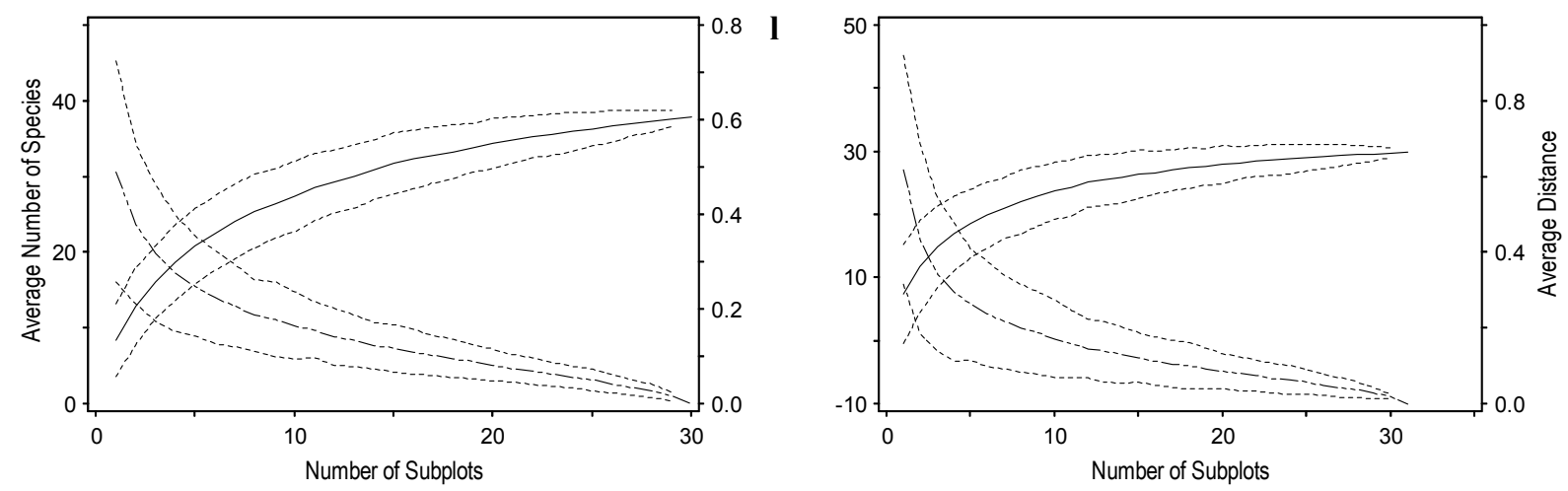

Figure 2.28. Species-Area Curves and Bray-Curtis (Sorensen) Distance Curves from First- (prerestoration) and Last- (post-restoration) Year Herbaceous Vegetation Sampling at Paired Restoration and Reference Sites. Restoration sites are in the left column, paired reference sites in the right column, and year one is presented in the row above the final year. The distance curve, calculated with plant species absolute percent cover for each site, describes the average Sorensen distance between the subsamples and the whole sample, as a function of subsample size. The scale maxima of the average number of species y-axis is fixed to the highest of each set of four paired restoration and reference sites to facilitate comparison between restoration and reference sites before and after restoration. a) Vera Slough 2005, b) Vera Reference 2005, c) Vera Slough 2009, d) Vera Reference 2009, e) Kandoll Farm 2005, f) Kandoll Reference 2005, g) Kandoll Farm 2009, h) Kandoll Reference 2009, i) Crims Island 2006, j) Crims Reference 2006, k) Crims Island 2009, 1) Crims Reference 2009.

species pool, the curves can be used to evaluate whether the number of samples collected is adequately encountering most of the species at a site. For example, the species-area analysis supported the decision to revise the sampling design and increase the number of samples for the KR swamp, which was undersampled in 2005.

At the VS site, the dramatic drop in the number of species between 2005 and 2009 is evident. It appears that the number of species in 2005 could have even been more than the $\sim 18$ encountered with additional samples above the 40 that were collected. In 2009, the curve was beginning to level off after about five samples. The species-area relationship at the VR site was very similar between 2005 and 2009. The KF site showed a marked increase in number of species by 2009 at the common sampling area of 90 samples. The KF site held a far greater number of herb species than the KR site in both years. Again, these sites are very different in elevation and morphology, with the KR site dominated by large trees and 
shrubs, and the KF site dominated by herbaceous species. We would expect that the present curve for both the VS and KF sites to trend toward the curve for their respective sites, but the rate at which this occurs is uncertain. The CI site contained more species per unit area in 2009 than 2006, the first year after reconnection. On average, one to two new species were added per year over that period to the CI wetland. The CR site gained species between 2006 and 2009 at a rate of about three per year. In both years, the CI site contained more species per unit area than did the CR site.

Based on past studies we expected to see declines in the number of species over the first few years, then an increase in species, and finally a leveling off of the number of species at or near the species pool in the region. Typically, as the site hydrology is restored, species are killed and new, early colonizing r-selected species colonize the bare space. These species may facilitate the colonization of other longlived perennial species. This process is occurring at the KF and CI sites. In contrast, the development of species has been limited at the VS site due to the higher water levels maintained there by the new tide gate and the limited access of species from outside the tide gate to the site.

\subsubsection{Shrub and Tree Cover}

Fifteen shrub species were identified at the KR site. The most frequently present species were salmonberry (Rubus spectabilis), trailing blackberry (Rubus ursinus), and red osier dogwood (Corus sericea L. ssp. sericea, formerly Cornus stolonifera). Two shrubs had densities greater than $18 \%$, substantially higher than any others: salmonberry and salal (Gaultheria shallon); the latter is typically associated with mounds around Sitka spruce trees. Three shrubs are typically associated with the higher hummocks of the swamp, where Sitka spruce trees also occur, as seen by their elevations (Table 2.13): vine maple (Acer circinatum), salal, and red huckleberry (Vaccinium parvifolium).

To compare the abundance of different shrub species, relative frequency percent and relative density percent are reported in Table 2.12. Relative frequency percent is the ratio of the proportion of plots in which a species occurs to the overall frequency (sum of frequencies of all species); similarly, relative density percent is the ratio of the density of one species to the sum of densities of all species (McCune and Grace 2002). While frequency is a useful descriptor of the spatial distribution of a species, it is dependent on the size of the sample unit; density, the number of individuals per unit area, is not dependent on the size of the sampling unit (McCune and Grace 2002). Both ways of looking at abundance can be useful for assessing the distribution and density of shrubs.

The swamp at the KR site is characterized by Sitka spruce as the dominant tree (Table 2.14), and western redcedar (Thuja plicata) as the subdominant. Dominance is the aggregate basal area of trees in a stand, and it is the measure of species abundance that is most closely proportional to leaf area and foliage mass (McCune and Grace 2002). Pacific crabapple (Malus fusca) exhibits the highest relative frequency percent and relative density percent (these metrics are defined in the previous section). The $0.9 \%$ relative dominance of Pacific crabapple illustrates the less useful aspect of the density metric for trees because of their great size variability (McCune and Grace 2002). Another small tree, Pursch's buckthorn (Frangula purshiana), has low dominance despite its frequency and density. Very similar roles in the overstory composition are played by red alder (Alnus rubra) and Oregon ash (Fraxinus latifolia). The abundance of western hemlock (Tsuga heterophylla) is low and plots with no trees have a relative frequency percent of 4.7. Tree species richness is seven, although vine maple is classified as a shrub in this study because of its growth habit in this ecosystem. 
Table 2.13. Summary of 2009 Shrub Stem Frequency, Density, and Elevation at the KR Site

\begin{tabular}{lcccc}
\hline \multicolumn{1}{c}{ Species } & $\begin{array}{c}\text { Density (stems } \\
\text { per hectare) }\end{array}$ & $\begin{array}{c}\text { Relative } \\
\text { Frequency } \%\end{array}$ & $\begin{array}{c}\text { Relative } \\
\text { Density \% }\end{array}$ & $\begin{array}{c}\text { Mean Elevation } \\
\text { (m, NAVD88) }\end{array}$ \\
\hline Acer circinatum & 200 & 2.8 & 0.3 & 3.99 \\
Amelanchier alnifolia & 2400 & 1.4 & 3.8 & ND \\
Cornus sericea & 6200 & 12.7 & 9.8 & 3.00 \\
Gaultheria shallon & 11500 & 9.9 & 18.1 & 3.30 \\
Lonicera involucrata & 3700 & 8.5 & 5.8 & 2.85 \\
Oemleria cerasiformis & 100 & 1.4 & 0.2 & ND \\
Physocarpus capitatus & 5600 & 9.9 & 8.8 & 3.13 \\
Ribes divaricatum & 1500 & 1.4 & 2.4 & 2.75 \\
Ribes lacustre & 1000 & 2.8 & 1.6 & 2.82 \\
Rosa nutkana & 2400 & 11.3 & 3.8 & 2.87 \\
Rubus parviflorus & 8300 & 8.5 & 13.1 & 3.27 \\
Rubus spectabilis & 11600 & 14.1 & 18.3 & 3.06 \\
Rubus ursinus & 6900 & 12.7 & 10.9 & 3.07 \\
Spiraea douglasii & 2100 & 2.8 & 3.3 & 2.70 \\
Vaccinium parvifolium & 600 & 4.2 & 0.9 & 3.45 \\
Unidentified & 200 & 1.4 & 0.3 & ND \\
\hline
\end{tabular}

NAVD88 = North American Vertical Datum of 1988; ND = No data available.

Table 2.14. Summary of 2009 Tree Cover at the KR Swamp

\begin{tabular}{|c|c|c|c|c|c|c|c|c|}
\hline Species & $\begin{array}{c}\text { Relative } \\
\text { Frequency } \\
\%\end{array}$ & $\begin{array}{c}\text { Relative } \\
\text { Density } \\
\%\end{array}$ & $\begin{array}{c}\text { Relative } \\
\text { Dominance } \\
\%\end{array}$ & $\begin{array}{l}\mathrm{dbh} \\
\min \\
(\mathrm{cm})\end{array}$ & $\begin{array}{l}\mathrm{dbh} \\
\max \\
(\mathrm{cm})\end{array}$ & $\begin{array}{l}\text { Mean } \\
\text { dbh } \\
(\mathrm{cm})\end{array}$ & $\begin{array}{l}\text { Median } \\
\text { dbh } \\
(\mathrm{cm})\end{array}$ & $\begin{array}{c}\text { Mean } \\
\text { Elevation } \\
(\mathrm{m}, \mathrm{NAVD} 88)\end{array}$ \\
\hline Alnus rubra & 10.9 & 9.8 & 10.7 & 1.0 & 60.5 & 20.3 & 13.9 & 3.01 \\
\hline $\begin{array}{l}\text { Fraxinus } \\
\text { latifolia }\end{array}$ & 10.9 & 7.0 & 11.0 & 1.0 & 78.3 & 19.5 & 11.5 & 3.35 \\
\hline Malus fusca & 23.4 & 38.5 & 0.9 & 1.0 & 11.0 & 3.1 & 2.2 & 3.02 \\
\hline $\begin{array}{l}\text { Picea } \\
\text { sitchensis }\end{array}$ & 20.3 & 22.4 & 57.3 & 1.0 & 79.9 & 28.9 & 21.2 & 3.74 \\
\hline $\begin{array}{l}\text { Frangula } \\
\text { purshiana }\end{array}$ & 15.6 & 12.6 & 1.3 & 1.0 & 14.7 & 6.4 & 5.1 & 3.68 \\
\hline Thuja plicata & 10.9 & 7.0 & 16.9 & 6.9 & 96.3 & 27.8 & 16.5 & 3.65 \\
\hline $\begin{array}{l}\text { Tsuga } \\
\text { heterophylla }\end{array}$ & 3.1 & 2.8 & 2.0 & 17.2 & 29.0 & 20.4 & 17.7 & 3.77 \\
\hline No trees & 4.7 & NA & NA & NA & NA & NA & NA & \\
\hline
\end{tabular}




\subsubsection{Line-Intercept Sampling}

The most frequent species in each field at Kandoll Farm in 2005, prior to restoration, were not all the same (Table 2.15). For example, while fields A, B, and $\mathrm{C}$ all had more than $75 \%$ cover in mixed pasture grasses (MG), field $\mathrm{D}$ was dominated by buttercup ( $85 \%$ frequency), and field $\mathrm{E}$ had a substantial component of reed canarygrass (PHAR, 38\% frequency) in addition to $68 \%$ frequency of mixed grasses. Field B also had a 17\% frequency of Canada thistle (Cirsium arvense), which was not present on any other field. Reed canarygrass was present on only the three easternmost fields and experienced some increase on all three in 2006, after breaching in 2005. The three easternmost fields also experienced substantial declines of mixed grass cover after breaching: $75 \%, 24 \%$, and $55 \%$ frequency, respectively. Buttercup increased by $35 \%$ in field C after dike breaching. By 2006, creeping jenny (Lysimachia nummularia) virtually disappeared from the easternmost two fields, was never present in the middle field (C), and remained constant or increased slightly in the westernmost fields.

Trends between 2005 and 2009 that were similar across all five fields were the elimination of clovers (Trifolium species [TRSP]), decreases or elimination of mixed grasses, decreases of creeping jenny, and substantial increases of reed canarygrass. Sedge species increased in two fields but were not present on the transect in the others, and Canada thistle, present in one field in 2005, decreased. Blackberry species increased in some fields and decreased in others, and buttercup increased in fields to the west and decreased in fields to the east. In addition, 25 previously unrecorded species were present in the 2009 survey (Table 2.16). This substantial increase in species richness occurred since the dike breaches and culvert replacements in 2005. Seven of the 25 species previously unrecorded were obligate wetland species. 
Table 2.15. Plant Species on a Line-Intercept Transect in Five Fields at Kandoll Farm in 2005, 2006, and 2009. If more than one layer of vegetation - that is more than one species - was present at a given point then all layers were recorded; thus, the number of points in a given row does not necessarily add up to the total number of points in that field. (See plant list in Appendix J for abbreviations.)

\begin{tabular}{|c|c|c|c|c|c|c|c|c|c|c|c|c|c|c|c|c|c|c|c|c|c|c|}
\hline & & & $\stackrel{\Xi}{\Sigma}$ & 合 & 嵌 & 産 & 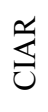 & 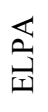 & $\underset{\text { 点 }}{\stackrel{O}{O}}$ & 㜽 & 岑 & 营 & 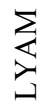 & $\sum_{\beth}$ & $\underset{\mathbb{2}}{\stackrel{d}{d}}$ & $\underset{\exists}{\leftrightarrows}$ & $\underset{\bigcup}{~}$ & 预 & 究 & $\begin{array}{l}\underset{n}{2} \\
\stackrel{\sim}{n}\end{array}$ & 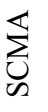 & $\begin{array}{l}\hat{\text { Dे }} \\
\text { مै }\end{array}$ \\
\hline \multirow{6}{*}{ 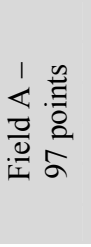 } & \multirow[t]{2}{*}{2005} & No. & 96 & 0 & 0 & 0 & 0 & 0 & 0 & 0 & 2 & 0 & 0 & 19 & 0 & 11 & 0 & 4 & 2 & 0 & 0 & 1 \\
\hline & & Freq\% & 98 & 0 & 0 & 0 & 0 & 0 & 0 & 0 & 2 & 0 & 0 & 19 & 0 & 11 & 0 & 4 & 2 & 0 & 0 & 1 \\
\hline & \multirow[t]{2}{*}{2006} & No. & 92 & 0 & 1 & 0 & 0 & 1 & 0 & 0 & 0 & 0 & 0 & 6 & 0 & 0 & 0 & 8 & 0 & 0 & 0 & 0 \\
\hline & & Freq\% & 95 & 0 & 1 & 0 & 0 & 1 & 0 & 0 & 0 & 0 & 0 & 6 & 0 & 0 & 0 & 8 & 0 & 0 & 0 & 0 \\
\hline & \multirow[t]{2}{*}{2009} & No. & 0 & 0 & 1 & 0 & 0 & 0 & 0 & 0 & 0 & 0 & 0 & 0 & 6 & 0 & 0 & 39 & 0 & 0 & 0 & 0 \\
\hline & & Freq\% & 0 & 0 & 1 & 0 & 0 & 0 & 0 & 0 & 0 & 0 & 0 & 0 & 6 & 0 & 0 & 40 & 0 & 0 & 0 & 0 \\
\hline \multirow{6}{*}{ 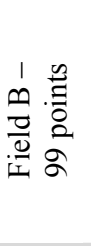 } & \multirow[t]{2}{*}{2005} & No. & 75 & 0 & 0 & 0 & 17 & 0 & 0 & 0 & 3 & 0 & 2 & 1 & 0 & 1 & 0 & 1 & 1 & 0 & 0 & 0 \\
\hline & & Freq\% & 76 & 0 & 0 & 0 & 17 & 0 & 0 & 0 & 3 & 0 & 2 & 1 & 0 & 1 & 0 & 1 & 1 & 0 & 0 & 0 \\
\hline & \multirow[t]{2}{*}{2006} & No. & 82 & 0 & 0 & 0 & 6 & 0 & 0 & 0 & 0 & 0 & 1 & 6 & 0 & 0 & 0 & 8 & 11 & 1 & 0 & 0 \\
\hline & & Freq. $\%$ & 83 & 0 & 0 & 0 & 6 & 0 & 0 & 0 & 0 & 0 & 1 & 6 & 0 & 0 & 0 & 8 & 11 & 1 & 0 & 0 \\
\hline & \multirow[t]{2}{*}{2009} & No. & 0 & 0 & 0 & 0 & 11 & 0 & 0 & 0 & 0 & 0 & 2 & 0 & 0 & 0 & 0 & 47 & 0 & 4 & 0 & 0 \\
\hline & & Freq\% & 0 & 0 & 0 & 0 & 11 & 0 & 0 & 0 & 0 & 0 & 2 & 0 & 0 & 0 & 0 & 48 & 0 & 4 & 0 & 0 \\
\hline \multirow{6}{*}{ 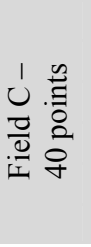 } & \multirow[t]{2}{*}{2005} & No. & 39 & 0 & 0 & 0 & 0 & 0 & 0 & 0 & 0 & 0 & 0 & 0 & 8 & 0 & 0 & 23 & 1 & 0 & 0 & 2 \\
\hline & & Freq\% & 98 & 0 & 0 & 0 & 0 & 0 & 0 & 0 & 0 & 0 & 0 & 0 & 20 & 0 & 0 & 58 & 3 & 0 & 0 & 5 \\
\hline & \multirow[t]{2}{*}{2006} & No. & 9 & 0 & 0 & 0 & 0 & 0 & 0 & 0 & 0 & 0 & 0 & 0 & 15 & 0 & 0 & 37 & 0 & 0 & 0 & 0 \\
\hline & & Freq\% & 23 & 0 & 0 & 0 & 0 & 0 & 0 & 0 & 0 & 0 & 0 & 0 & 38 & 0 & 0 & 93 & 0 & 0 & 0 & 0 \\
\hline & \multirow[t]{2}{*}{2009} & No. & 0 & 0 & 0 & 0 & 0 & 0 & 0 & 0 & 0 & 0 & 0 & 0 & 20 & 0 & 0 & 23 & 0 & 0 & 0 & 0 \\
\hline & & Freq\% & 0 & 0 & 0 & 0 & 0 & 0 & 0 & 0 & 0 & 0 & 0 & 0 & 50 & 0 & 0 & 58 & 0 & 0 & 0 & 0 \\
\hline \multirow{6}{*}{ 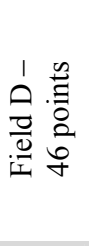 } & \multirow[t]{2}{*}{2005} & No. & 15 & 0 & 0 & 1 & 0 & 0 & 0 & 1 & 1 & 0 & 3 & 11 & 6 & 0 & 0 & 39 & 2 & 0 & 0 & 0 \\
\hline & & Freq\% & 33 & 0 & 0 & 2 & 0 & 0 & 0 & 2 & 2 & 0 & 7 & 24 & 13 & 0 & 0 & 85 & 4 & 0 & 0 & 0 \\
\hline & \multirow[t]{2}{*}{2006} & No. & 4 & 0 & 0 & 2 & 0 & 0 & 0 & 0 & 0 & 0 & 3 & 1 & 10 & 0 & 0 & 35 & 0 & 0 & 0 & 0 \\
\hline & & Freq\% & 9 & 0 & 0 & 4 & 0 & 0 & 0 & 0 & 0 & 0 & 7 & 2 & 22 & 0 & 0 & 76 & 0 & 0 & 0 & 0 \\
\hline & \multirow[t]{2}{*}{2009} & No. & 0 & 0 & 0 & 7 & 0 & 0 & 0 & 0 & 0 & 0 & 8 & 2 & 17 & 0 & 0 & 19 & 0 & 0 & 0 & 0 \\
\hline & & Freq\% & 0 & 0 & 0 & 15 & 0 & 0 & 0 & 0 & 0 & 0 & 17 & 4 & 37 & 0 & 0 & 41 & 0 & 0 & 0 & 0 \\
\hline \multirow{6}{*}{ 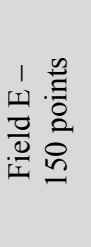 } & \multirow[t]{2}{*}{2005} & No. & 103 & 0 & 0 & 0 & 0 & 0 & 0 & 0 & 1 & 0 & 8 & 16 & 57 & 0 & 0 & 25 & 0 & 0 & 0 & 2 \\
\hline & & Freq.\% & 68 & 0 & 0 & 0 & 0 & 0 & 0 & 0 & 1 & 0 & 5 & 11 & 38 & 0 & 0 & 17 & 0 & 0 & 0 & 1 \\
\hline & \multirow[t]{2}{*}{2006} & No. & 20 & 4 & 0 & 0 & 0 & 1 & 1 & 1 & 0 & 8 & 3 & 0 & 95 & 0 & 1 & 22 & 0 & 0 & 8 & 0 \\
\hline & & Freq\% & 13 & 3 & 0 & 0 & 0 & 1 & 1 & 1 & 0 & 5 & 2 & 0 & 63 & 0 & 1 & 15 & 0 & 0 & 5 & 0 \\
\hline & \multirow[t]{2}{*}{2009} & No. & 2 & 0 & 0 & 0 & 0 & 0 & 0 & 0 & 0 & 0 & 11 & 2 & 120 & 0 & 0 & 8 & 2 & 0 & 0 & 0 \\
\hline & & Freq\% & 1 & 0 & 0 & 0 & 0 & 0 & 0 & 0 & 0 & 0 & 7 & 1 & 80 & 0 & 0 & 5 & 1 & 0 & 0 & 0 \\
\hline
\end{tabular}


Table 2.16. Presence of Previously Unrecorded Species in Five Fields on a Line-Intercept Transect at Kandoll Farm in 2009

\begin{tabular}{|c|c|c|c|c|c|c|c|c|c|c|c|c|c|c|c|c|c|c|c|c|c|c|c|c|c|c|c|}
\hline$\stackrel{\frac{\sigma}{0}}{\stackrel{0}{I}}$ & & 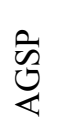 & $\frac{\widetilde{\alpha}}{2}$ & 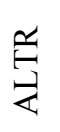 & ত্ত & 芯 & 究 & $\begin{array}{l}\vec{\partial} \\
\text { 거 }\end{array}$ & $\begin{array}{l}\vec{D} \\
\text { A } \\
\text { II }\end{array}$ & $\underset{\tilde{D}}{\stackrel{2}{O}}$ & 疋 & 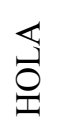 & $\sum_{i}^{\tilde{n}}$ & 导 & $\stackrel{\mathrm{I}}{\mathrm{I}}$ & ○్ & 3 & 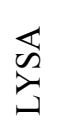 & 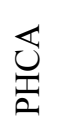 & 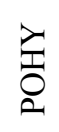 & $\begin{array}{l}\ddot{\tilde{2}} \\
0 \\
0\end{array}$ & 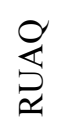 & 胥 & 矛 & $\sum_{U}$ & $\begin{array}{l}\text { z } \\
\text { 崩 }\end{array}$ & $\underset{\substack{\mid c \\
>}}{\sum}$ \\
\hline \multirow{2}{*}{ A } & No. & 0 & 71 & 4 & 0 & 1 & 0 & 4 & 2 & 0 & 0 & 5 & 0 & 2 & 13 & 4 & 1 & 0 & 0 & 0 & 0 & 0 & 1 & 2 & 3 & 10 & 0 \\
\hline & Freq\% & 0 & 73 & 4 & 0 & 1 & 0 & 4 & 2 & 0 & 0 & 5 & 0 & 2 & 13 & 4 & 1 & 0 & 0 & 0 & 0 & 0 & 1 & 2 & 3 & 10 & 0 \\
\hline \multirow{2}{*}{ B } & No. & 2 & 19 & 0 & 21 & 2 & 0 & 0 & 0 & 1 & 2 & 11 & 11 & 0 & 0 & 36 & 1 & 0 & 3 & 0 & 2 & 1 & 0 & 1 & 0 & 0 & 0 \\
\hline & Freq $\%$ & 2 & 20 & 0 & 22 & 2 & 0 & 0 & 0 & 1 & 2 & 11 & 11 & 0 & 0 & 37 & 1 & 0 & 3 & 0 & 2 & 1 & 0 & 1 & 0 & 0 & 0 \\
\hline \multirow{2}{*}{ C } & No. & 0 & 4 & 0 & 0 & 0 & 0 & 0 & 0 & 0 & 0 & 3 & 0 & 0 & 2 & 0 & 0 & 0 & 0 & 0 & 0 & 0 & 0 & 0 & 0 & 0 & 0 \\
\hline & Freq $\%$ & 0 & 10 & 0 & 0 & 0 & 0 & 0 & 0 & 0 & 0 & 8 & 0 & 0 & 5 & 0 & 0 & 0 & 0 & 0 & 0 & 0 & 0 & 0 & 0 & 0 & 0 \\
\hline \multirow{2}{*}{ D } & No. & 0 & 0 & 0 & 0 & 0 & 0 & 0 & 0 & 0 & 9 & 0 & 10 & 0 & 22 & 4 & 0 & 0 & 0 & 0 & 0 & 0 & 0 & 0 & 0 & 0 & 0 \\
\hline & Freq $\%$ & 0 & 0 & 0 & 0 & 0 & 0 & 0 & 0 & 0 & 20 & 0 & 22 & 0 & 48 & 9 & 0 & 0 & 0 & 0 & 0 & 0 & 0 & 0 & 0 & 0 & 0 \\
\hline \multirow{2}{*}{$E$} & No. & 0 & 9 & 0 & 0 & 0 & 2 & 0 & 0 & 0 & 5 & 0 & 20 & 0 & 14 & 1 & 0 & 1 & 0 & 1 & 0 & 0 & 4 & 1 & 15 & 0 & 2 \\
\hline & Freq\% & 0 & 6 & 0 & 0 & 0 & 1 & 0 & 0 & 0 & 3 & 0 & 13 & 0 & 9 & 1 & 0 & 1 & 0 & 1 & 0 & 0 & 3 & 1 & 10 & 0 & 1 \\
\hline
\end{tabular}




\subsubsection{Habitat Availability}

Calculated metrics for site-scale habitat opportunity are presented in Table 2.17. In cases where metrics are dependent upon the frequency and magnitude of the WSE, only the results under the maximum frequency WSE are presented in Table 2.17, providing a "normal" condition for the purpose of site comparison. In Figures 2.29, 2.31, and 2.33, the full min-max range of observed WSEs and its resulting function on the landscape is presented. The results are presented for the paired sites and provide overall site metrics such as area, channel density, and total edge length of the site channels. Metrics specifically tied to WSE are related to habitat opportunity with the basic premise that the hydrologic structure on the site will drive opportunity and the underlying basis of the hydrologic structure is the site topography. As a site increases in its WSE as a result of a flow tide, inundation patterns take form, initially following well-established channels then migrating to smaller, less-developed channels, including more subtle inundations through the microtopography at the upper end of the site or in the floodplain. The calculation of channel edge at the maximum frequency WSE for a given site provides a means of standardizing the amount of available habitat for the size of the site into a unit-area basis (Table 2.17).

Table 2.17. Site-Scale Metrics Evaluating Habitat Opportunity

\begin{tabular}{lrcccccc}
\hline & $\begin{array}{c}\text { Site } \\
\text { Area } \\
\text { (ha) }\end{array}$ & $\begin{array}{c}\text { Max. } \\
\text { Freq. } \\
\text { WSE }(\mathrm{m})\end{array}$ & $\begin{array}{c}\text { Total } \\
\text { Channel } \\
\text { Density }\end{array}$ & $\begin{array}{c}\text { Total } \\
\text { Channel Edge } \\
\text { Length }(\mathrm{m})\end{array}$ & $\begin{array}{c}\text { Habitat Opp. } \\
\text { at Max. Freq. } \\
\text { WSE }(\%)\end{array}$ & $\begin{array}{c}\text { Habitat Opp. at } \\
\text { Max. Freq. } \\
\text { WSE }(\mathrm{m})\end{array}$ & $\begin{array}{c}\text { Habitat Opp. at Max. } \\
\text { Freq. WSE per unit } \\
\text { Area }(\mathrm{m} / \mathrm{ha})\end{array}$ \\
\hline CI & 118.0 & 2.1 & 30.6 & 77,085 & 16.7 & 14,199 & 120.2 \\
CR & 11.1 & 2.1 & 22.8 & 9,741 & 33.6 & 3,277 & 295.2 \\
KF & 65.5 & 2.2 & 20.8 & 19,287 & 66.0 & 12,726 & 194.3 \\
KR & 7.8 & 1.4 & 79.3 & 6,494 & 14.6 & 945 & 120.5 \\
VS & 106.0 & 1.2 & 83.2 & 83,580 & 28.3 & 7,202 & 67.9 \\
VR & 7.5 & 1.6 & 19.9 & 3,763 & 24.0 & 1,807 & 240.9 \\
\hline
\end{tabular}

Elevation based on NAVD88 (North American Vertical Datum of 1988).

Another means of assessing habitat opportunity is to evaluate the frequency at which the WSE reaches the channel bankfull elevation, which typically represents the marsh edge. Table 2.18 provides the mean bankfull elevations as they were surveyed in the field and as they were modeled in ATIIM using high-resolution LiDAR as an elevation source. The bankfull elevation will vary within a site and thus a single site-scale mean bankfull elevation was determined. Multiple field-surveyed cross sections were used to derive a mean bankfull elevation and the ATIIM-derived mean bankfull elevation was determined using the point-of-inflection in the WSE-Inundated Area relationship. The WSE percent frequency at bankfull was determined using WSE frequencies greater than or equal to the mean bankfull elevation and is an indicator of the potential frequency at which fish could access the marsh edge for feeding. 
Table 2.18. Surveyed and Modeled Bankfull Elevations and WSE Frequency

\begin{tabular}{lccccc}
\hline & $\begin{array}{c}\text { Mean Bankfull } \\
\text { Elevation (surveyed) } \\
\text { Site }\end{array}$ & $\begin{array}{c}\text { Mean Bankfull } \\
\text { Elevation } \\
\text { (surveyed) }(\mathrm{m})\end{array}$ & $\begin{array}{c}n \\
\text { (number of } \\
\text { cross sections) }\end{array}$ & $\begin{array}{c}\text { Mean Bankfull } \\
\text { Elevation (modeled) } \\
(\mathrm{m})\end{array}$ & $\begin{array}{c}\text { WSE Frequency at } \\
\text { Bankfull Elevation }\end{array}$ \\
\hline $\mathrm{CI}$ & 2.28 & 0.45 & 11 & 2.0 & 44.9 \\
$\mathrm{CR}$ & 2.02 & 0.19 & 6 & 2.0 & 61.9 \\
$\mathrm{KF}$ & 2.00 & 0.42 & 5 & 1.6 & 41.5 \\
$\mathrm{KR}$ & 2.30 & 0.23 & 5 & 2.5 & 24.0 \\
$\mathrm{VS}$ & 1.25 & 0.99 & 3 & 1.8 & 60.6 \\
$\mathrm{VR}$ & 1.93 & 0.55 & 3 & 1.6 & 31.2 \\
\hline \multicolumn{5}{l}{ Elevation based on NAVD88 (North American Vertical Datum of 1988). } \\
\hline
\end{tabular}

The extent of habitat at a site can also be evaluated in a tidal environment by measuring the total inundation perimeter. This captures islands created by inundation, as well as the complexities in inundation boundary as a site is responding to ebb and flow tides. As with habitat opportunity, the results are presented for the inundation perimeter at both maximum frequency WSE (Table 2.19) and for the range of WSEs in Figure 2.29. Note that the perimeter length at various WSEs can and likely will exceed the total site perimeter because of the representation of inundation complexity at the lower to mid-range WSE. In general, it is expected that the inundation perimeter will recede after a mid-range WSE peak threshold due to a large number of isolated topographic features being inundated and giving way to a single inundation boundary resembling the site boundary. This measure of the aquatic-terrestrial interface provides information about site characteristics and the potential for habitat opportunity and nutrient/biomass flux. The site maximum and maximum frequency inundation perimeters are shown relative to the sites and vegetation sampling areas in Figure 2.30.

Table 2.19. Inundation Perimeter at Maximum Frequency WSE with Mean TRI and MTWI

\begin{tabular}{lcccccccc}
\hline & $\begin{array}{c}\text { Site Area } \\
\text { (ha) }\end{array}$ & $\begin{array}{c}\text { Site } \\
\text { Perimeter (m) }\end{array}$ & $\begin{array}{c}\text { Max. } \\
\text { Freq. } \\
\text { WSE (m) }\end{array}$ & $\begin{array}{c}\text { Inundation } \\
\text { Perimeter at Max. } \\
\text { Freq. WSE (m) }\end{array}$ & $\begin{array}{c}\text { Mean } \\
\text { TRI }\end{array}$ & $\begin{array}{c}\text { SD } \\
\text { TRI }\end{array}$ & $\begin{array}{c}\text { Mean } \\
\text { MTWI }\end{array}$ & $\begin{array}{c}\text { SD } \\
\text { MTWI }\end{array}$ \\
\hline CI & 118.0 & 6,756 & 2.1 & 13,842 & 0.03 & 0.08 & 8.8 & 1.9 \\
CR & 11.1 & 1,720 & 2.1 & 2,036 & 0.03 & 0.09 & 2.7 & 0.5 \\
KF & 65.5 & 5,015 & 2.2 & 7,468 & 0.01 & 0.01 & 11.9 & 1.6 \\
KR & 7.84 & 2,083 & 1.4 & 780 & 0.02 & 0.02 & 8.8 & 1.4 \\
VS & 106.0 & 11,591 & 1.2 & 6,216 & 0.01 & 0.02 & 10.7 & 3.9 \\
VR & 7.5 & 2,798 & 1.6 & 724 & 0.06 & 0.08 & 9.8 & 1.8 \\
\hline
\end{tabular}

Elevation based on NAVD88 (North American Vertical Datum of 1988).

TRI = topographic ruggedness index; MTWI = modified topographic wetness index 
Crims Island

Habitat Opportunity

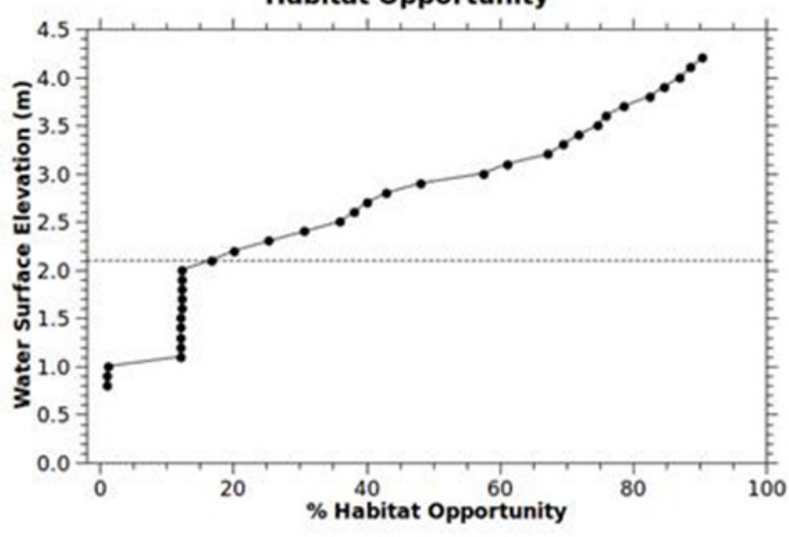

Kandoll Farm

Habitat Opportunity

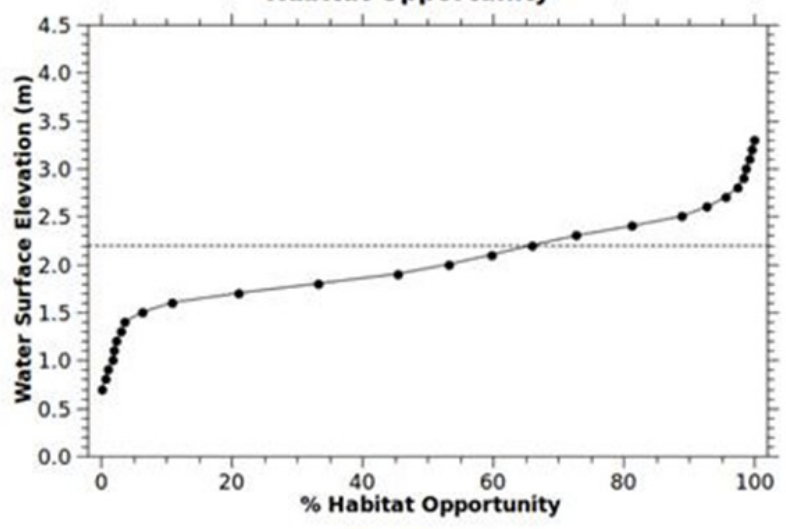

Vera Slough

Habitat Opportunity

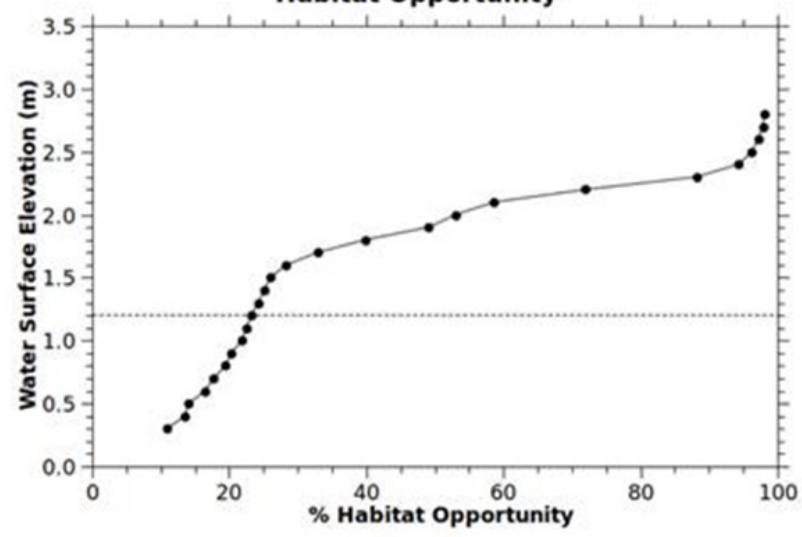

Crims Reference

Habitat Opportunity

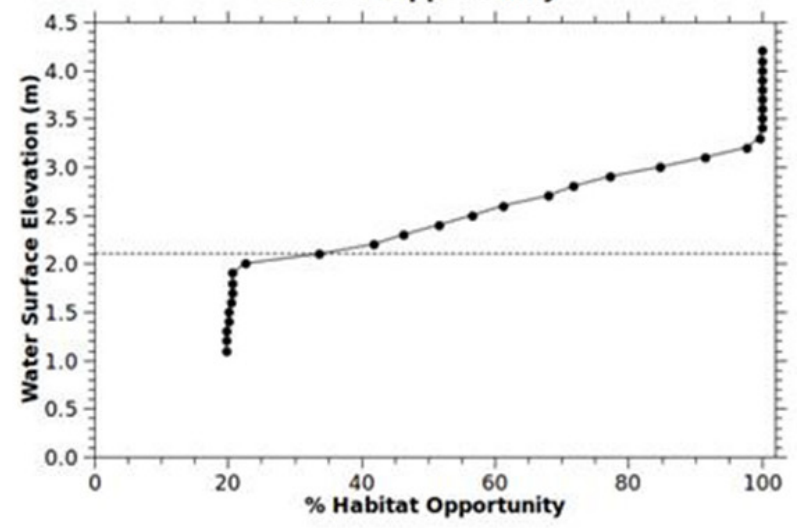

Kandoll Reference

Habitat Opportunity

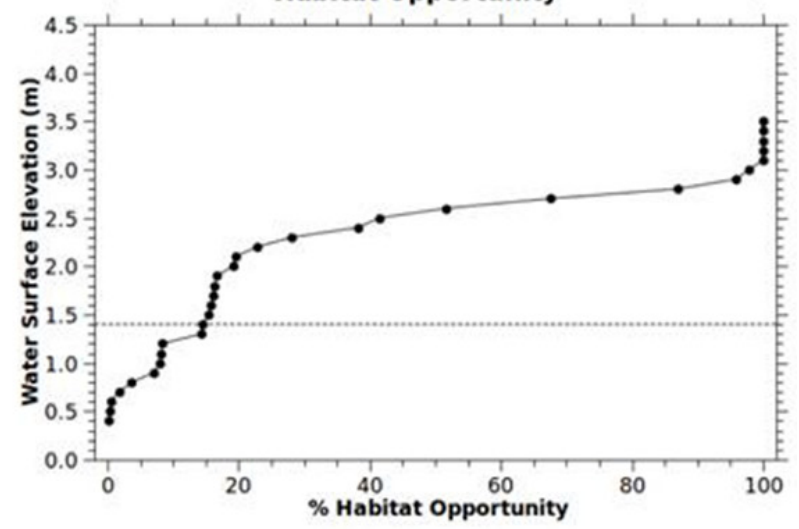

Vera Reference Habitat Opportunity

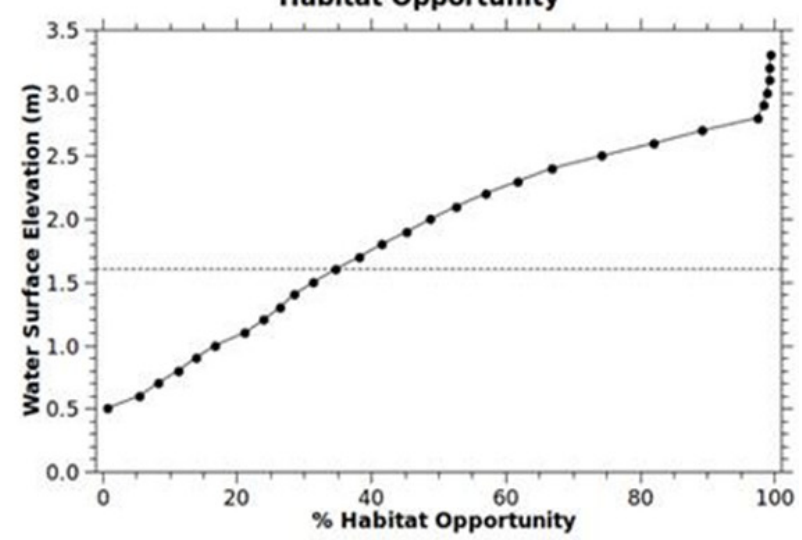

Figure 2.29. Percent Habitat Opportunity at Paired Restoration and Reference Sites as a Function of WSE. The gray dashed line represents the most frequent WSE during the sampling period. 

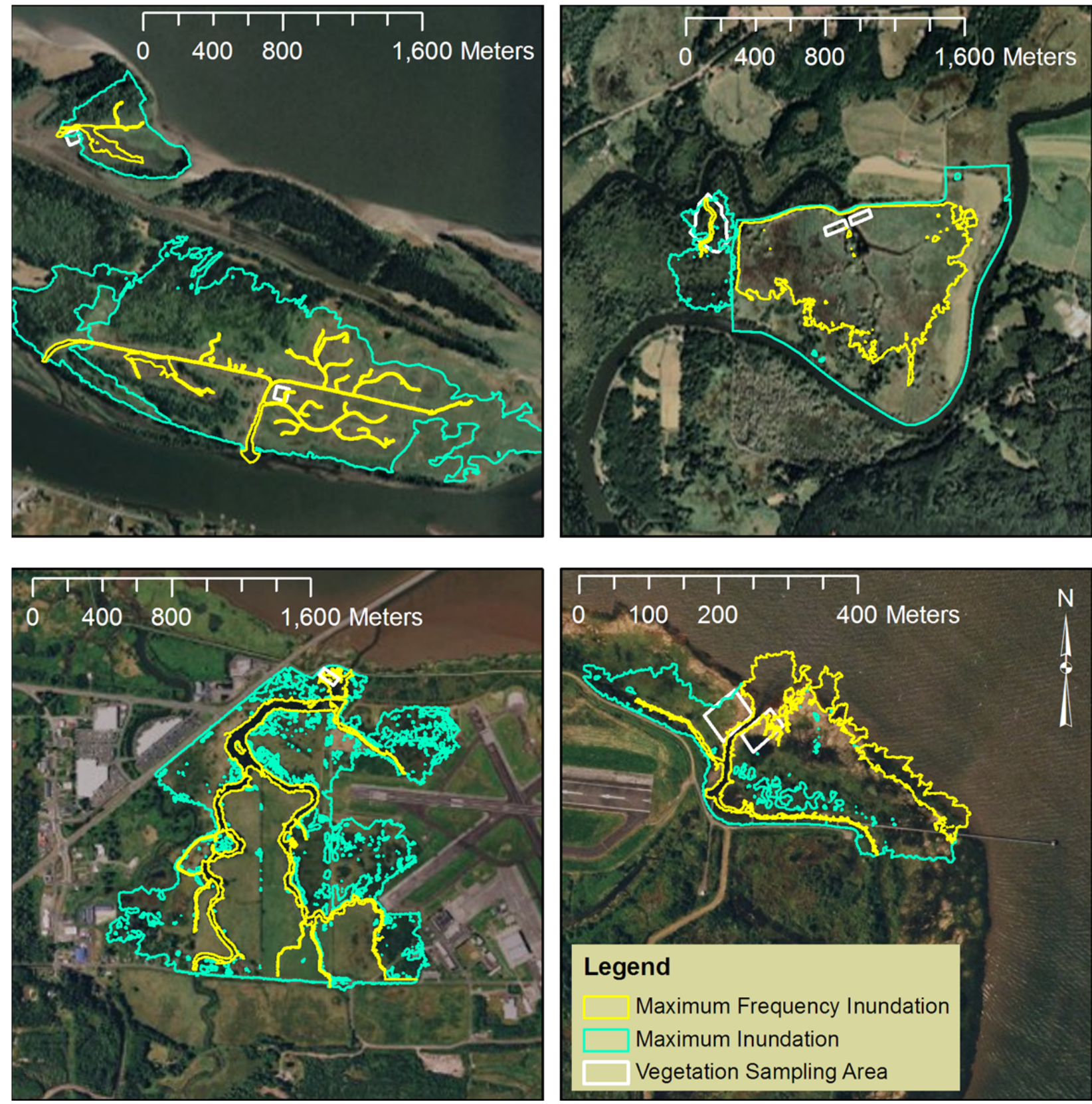

Figure 2.30. Inundation Perimeters at the Paired Reference and Restoration Sites for $\mathrm{CI} / \mathrm{CR}$ (top left), $\mathrm{KF} / \mathrm{KR}$ (top right), VS (bottom left), and VR (bottom right). The inundation perimeters are model derived and represent the most frequently occurring WSE (yellow) and the maximum WSE (green). 
Crims Island

Inundation Perimeter

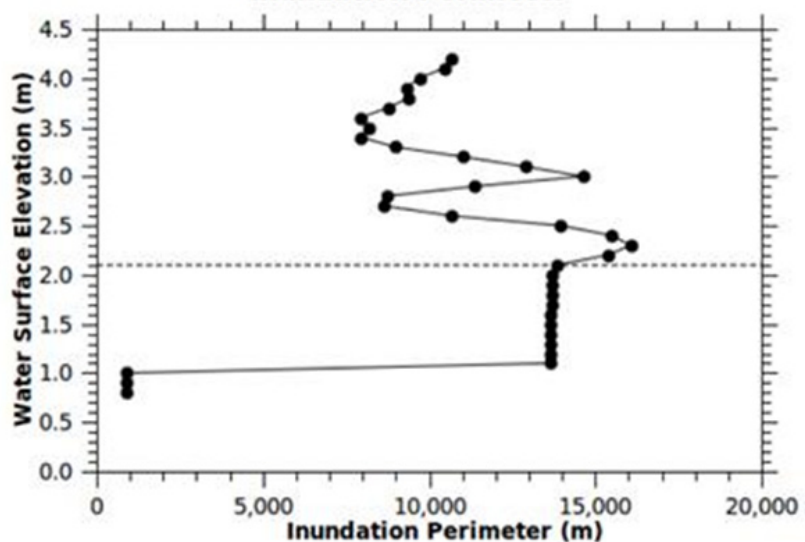

Kandoll Farm

Inundation Perimeter

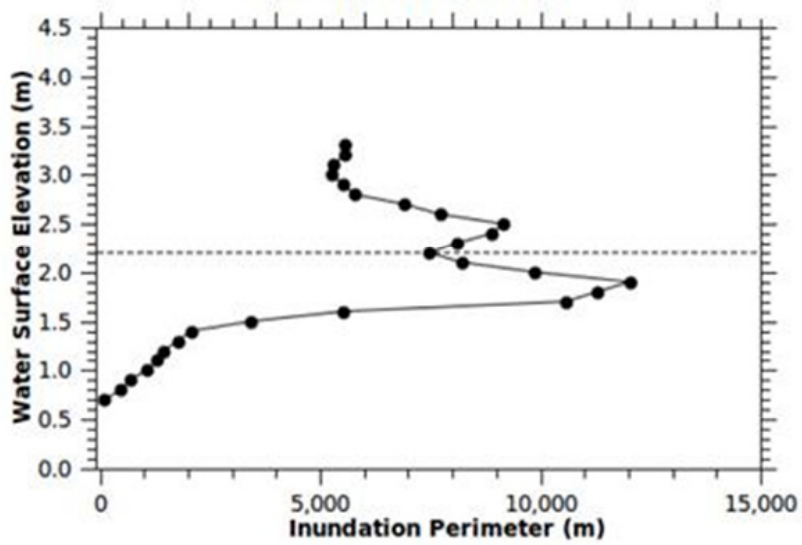

Vera Slough

Inundation Perimeter

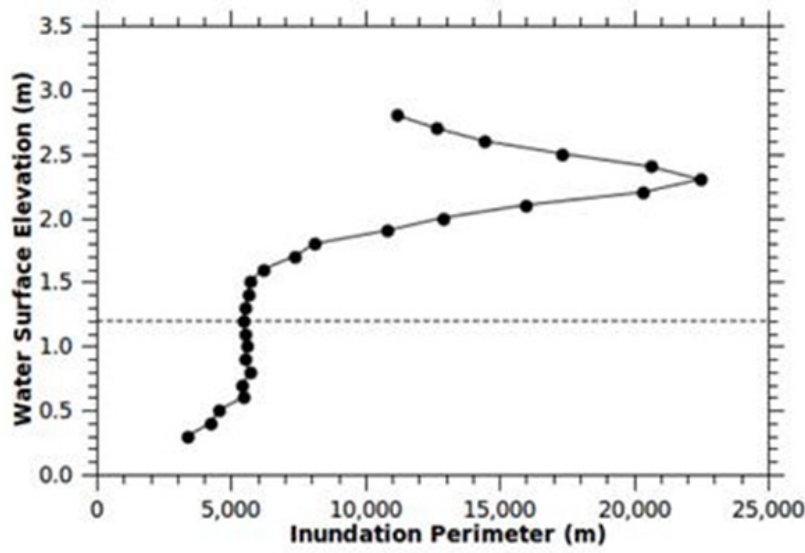

Crims Reference Inundation Perimeter

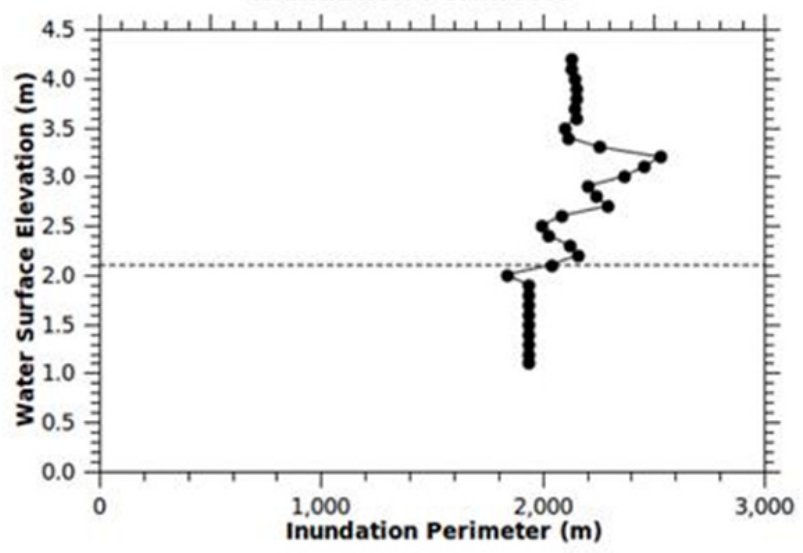

Kandoll Reference Inundation Perimeter

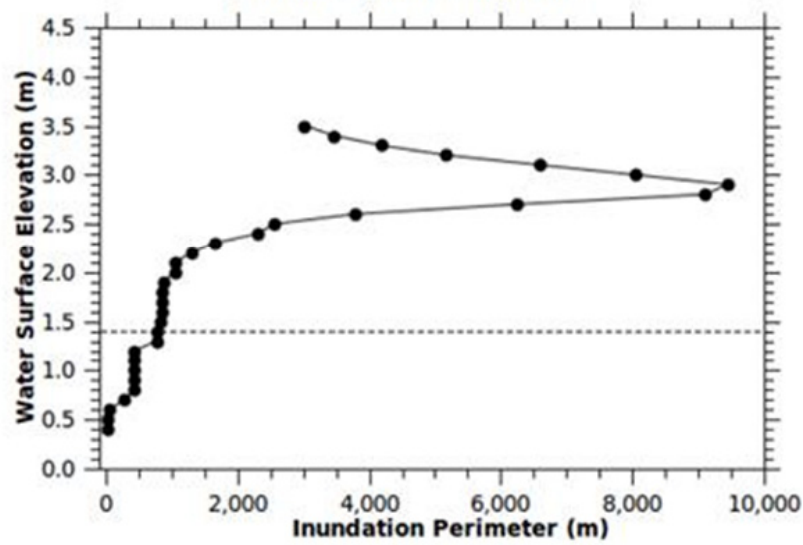

Vera Reference Inundation Perimeter

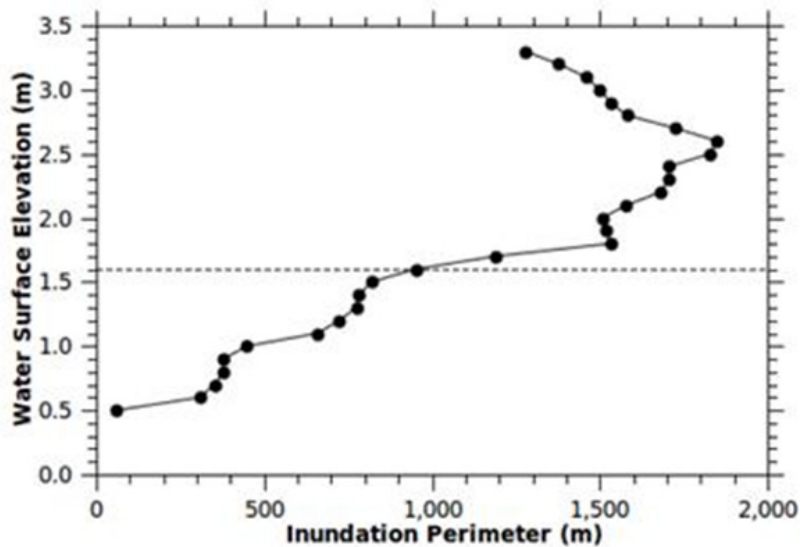

Figure 2.31. Inundation Perimeter at Paired Restoration and Reference Sites. These data provide an indicator of habitat opportunity. The gray dashed line represents the most frequent WSE during the sample period.

A series of hypsometric curves for the paired sites is presented in Figure 2.32. The hypsometric curve provides a general indication of the topographic site characteristics by plotting the area-elevation relationship. Combined with the vegetation analysis and water inundation behavior, the hypsometric 
curve can provide a general indication of vegetation community potential and sediment accretion/erosion potential. Volume-WSE relationships presented in Figure 2.33 provide the minimum-maximum range of water volume to enter each site and thus give an indication of nutrient and biomass flux.
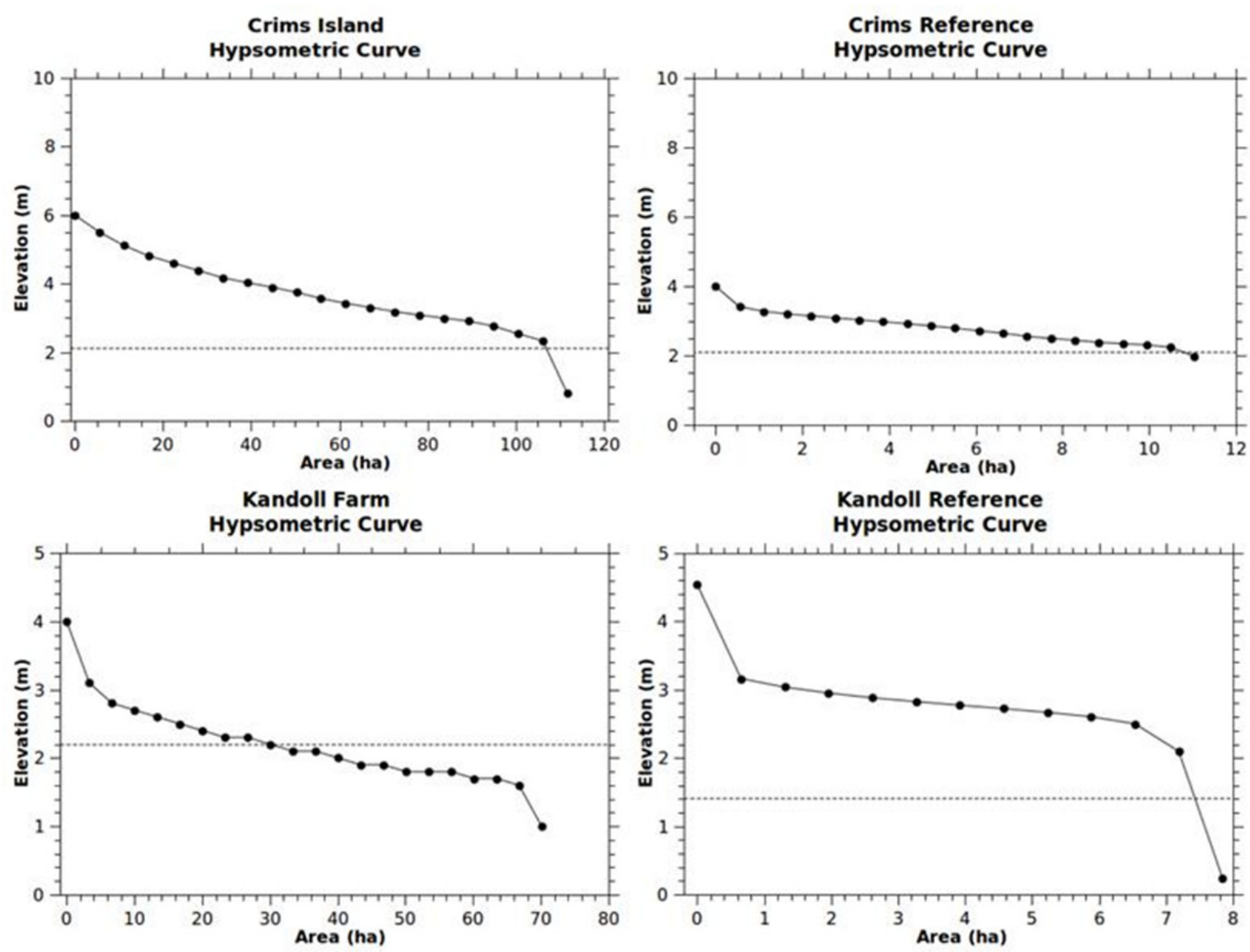

Vera Slough

Hypsometric Curve
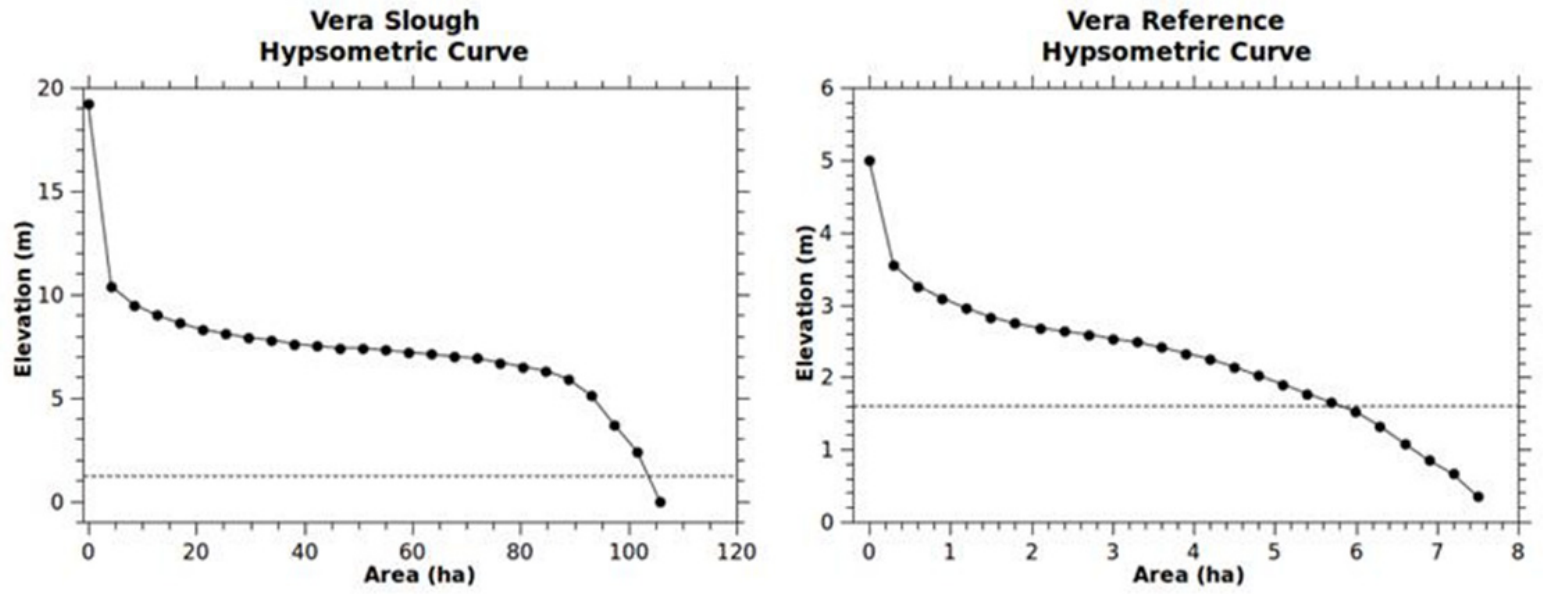

Figure 2.32. Hypsometric Curves for Paired Restoration and Reference Sites. Hypsometric curves provide the overall topographic shape for the paired restoration and reference sites. The gray dashed line represents the most frequent WSE during the sample period. 
Crims Island

Water Surface Elevation - Volume Relationship

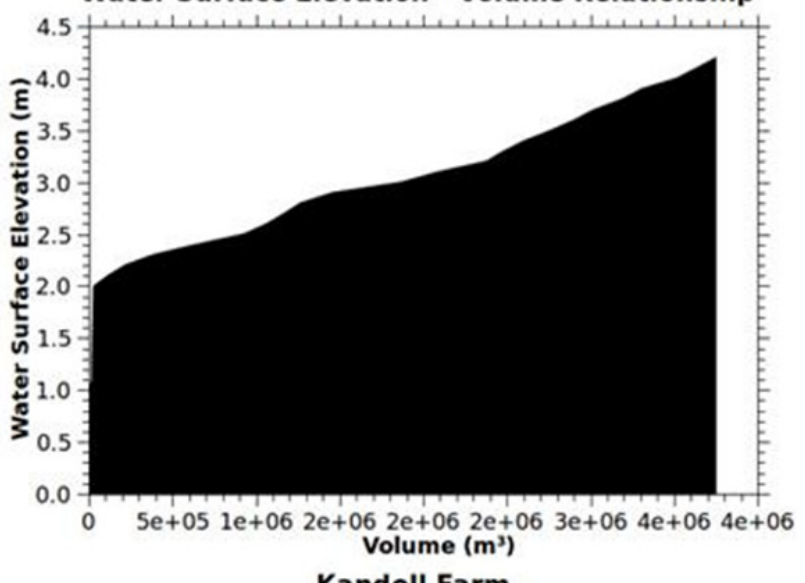

Water Surface Elevation - Volume Relationship

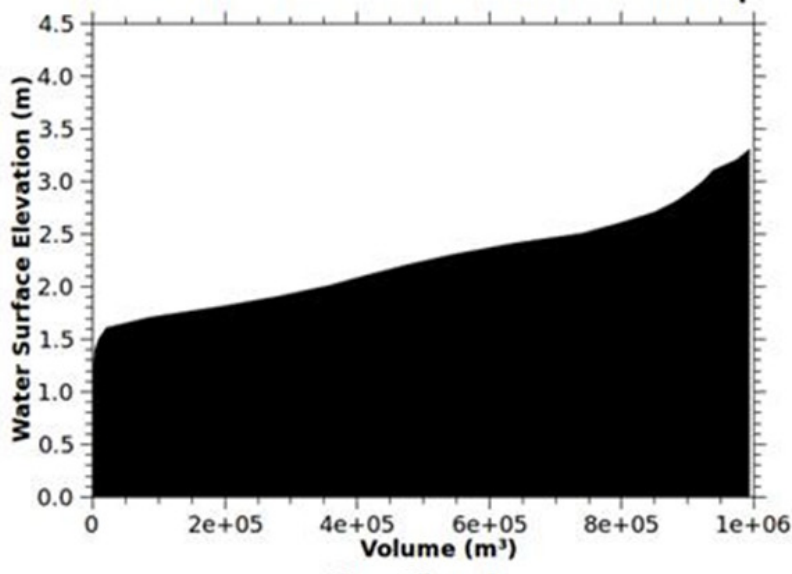

Vera Slough

Water Surface Elevation - Volume Relationship

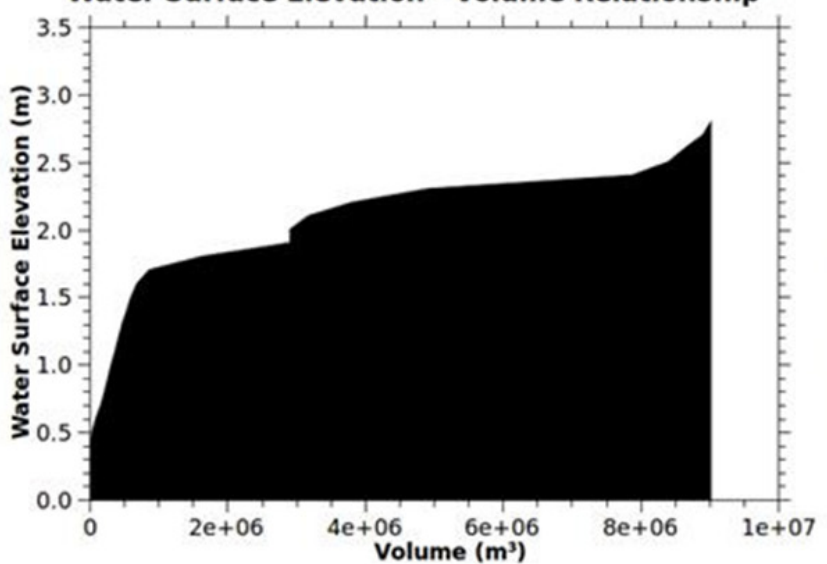

Crims Reference

Water Surface Elevation - Volume Relationship

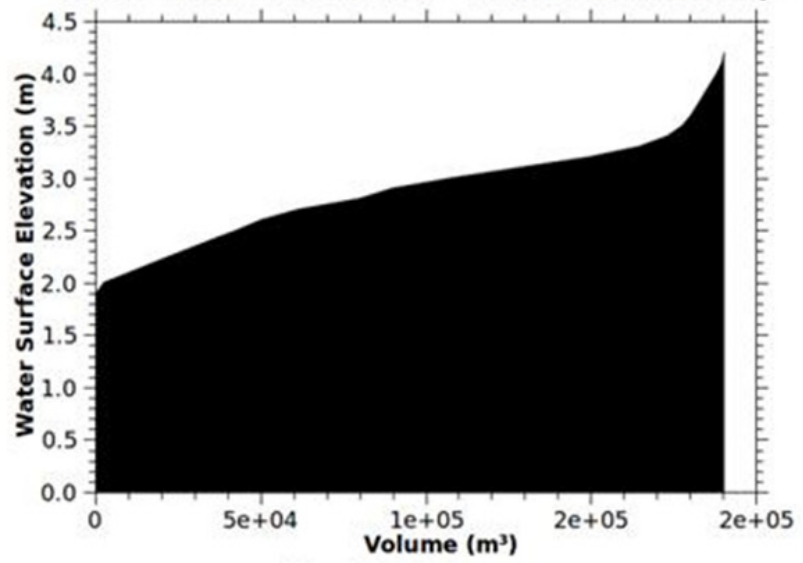

Kandoll Reference

Water Surface Elevation - Volume Relationship

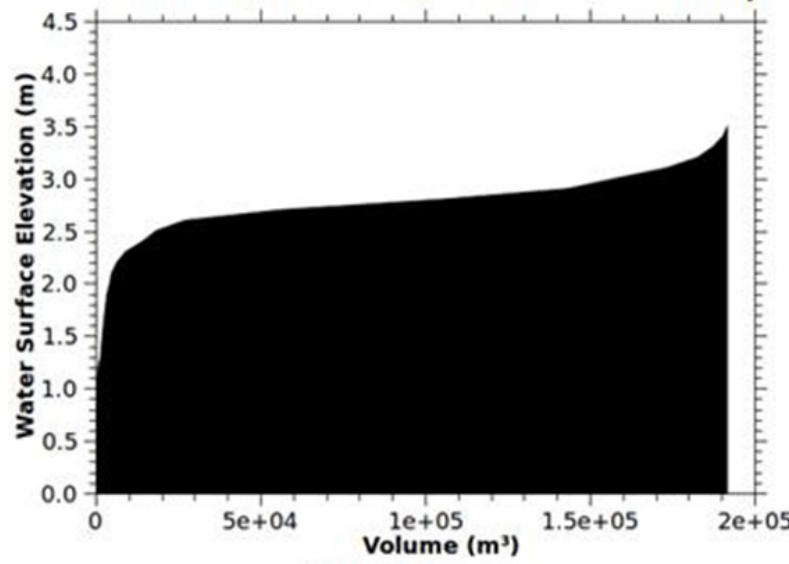

Vera Reference

Water Surface Elevation - Volume Relationship

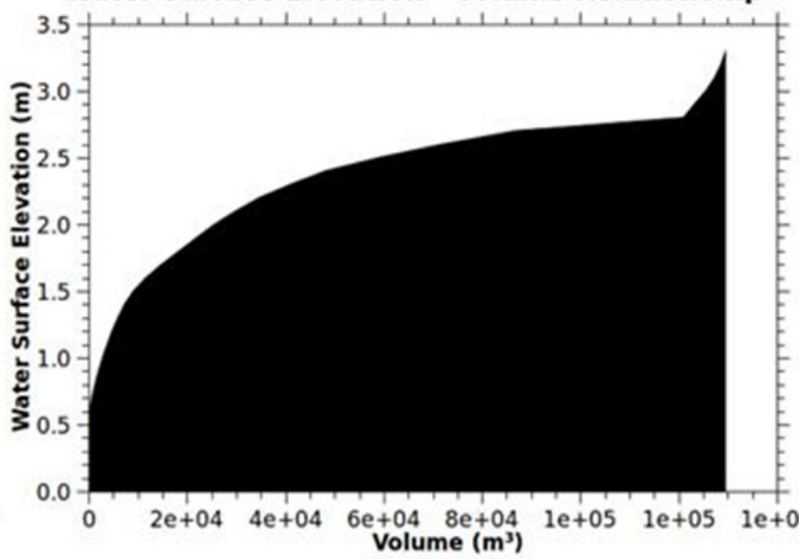

Figure 2.33. Relationship of WSE to Volume. The site WSE to water volume relationships can be used to estimate nutrient and biomass flux. 
The topographic ruggedness index (TRI) is a terrain-model-derived metric that can provide an indicator of site maturity. In general and depending on the prior land use, a new restoration site is expected to have low TRI value, meaning there is not a high degree of localized variations in the topography. Through restoration efforts and the productive development and maturity of vegetation communities, the localized topography begins to roughen. Diefenderfer et al. (2008) initially noted the contrast in topographic ruggedness between restoration and reference sites. These analysis are in general agreement with this notion with the exception of the CR site. Results are presented in Table 2.19 and Figure 2.34.

The MTWI (modified topographic wetness index) measures the topographically controlled hydrologic runoff processes that primarily provide a reasonable indicator of soil moisture and pooled water outside the primary channel networks. While this metric is not necessarily useful for flow tides, it is useful for understanding drainage off the site due to either natural precipitation events or an ebb tide. Areas on a site with high MTWI values can also indicate higher probabilities where suspended and settling sediments and thus sediment deposition is occurring. In evaluating the MTWI data, areas that are expected to have a low index value, include terrain ridges, high topographic points, and in many cases the larger stream channels, which are a component of the MTWI algorithm calculating elevation/distance from a stream channel. Results are presented in Table 2.19 and Figure 2.35. 

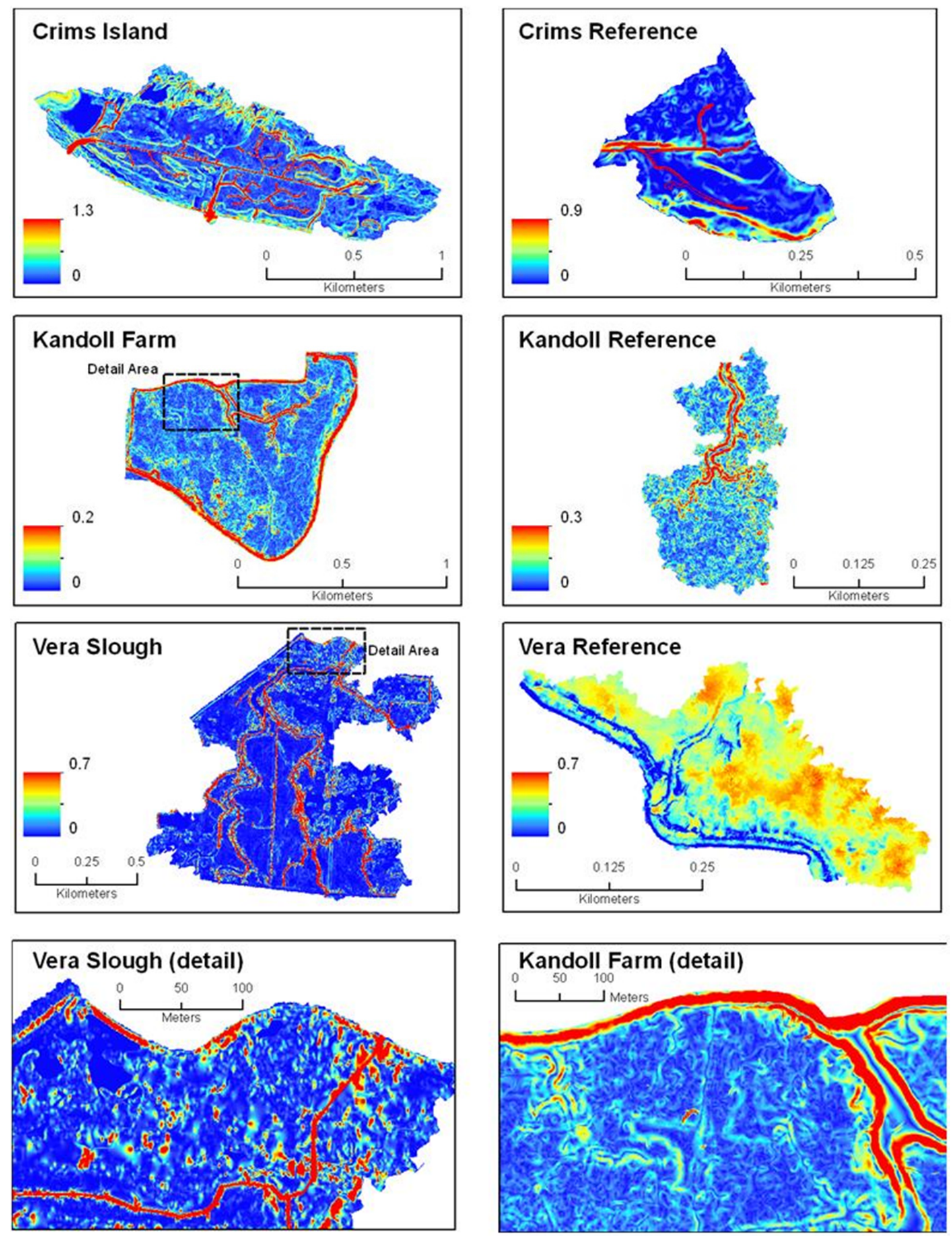

Figure 2.34. Topographic Ruggedness Index for Paired Restoration and Reference Sites 

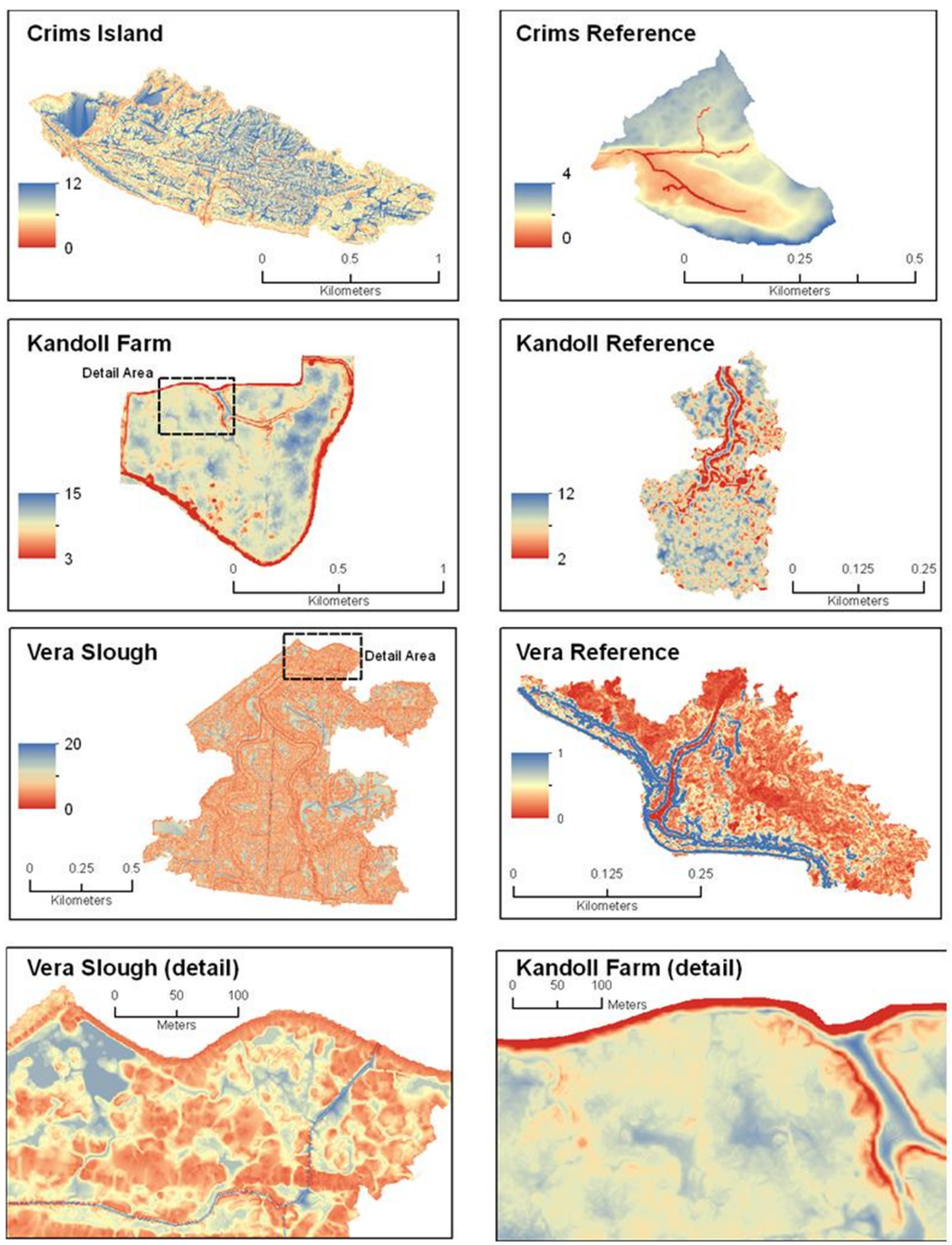

Figure 2.35. Modified Topographic Wetness Index (MTWI) Values for Paired Restoration and Reference Sites 


\subsubsection{Fish}

This section includes fish community analyses for the KF and VS sites, a description of salmon size and hatchery production, and results from electrofishing at the KR site in spring 2010.

\subsubsection{Fish Community Analysis}

\section{Kandoll Farm}

Fish abundance was monitored before (2005) and after (2006-2009) tide gate removal. From 2005 through 2007, we compared the fish community inside the KF site to sites in Seal Slough (Roegner et al. 2010b). During 2008 and 2009, we concentrated on fish distributions at dual trap net locations within the KF wetland (Johnson and Diefenderfer 2010).

In the Grays River system, we collected 45 seine samples from 2005 to 2007, and sampled 15 tides by trap net at the KR site in 2006 and 2007, as well as 25 tides at the nearby Johnson restoration site from 2005 to 2007 (see Roegner et al. 2010a for details). Nearly 52,000 individual fish were identified. Threespine stickleback (Gasterosteus aculeatus) dominated most samples (93.6\% of total). The next most abundant species was chum salmon (Oncorhynchus keta; $2.1 \%$ ) followed by the banded killifish (Fundulus diaphanous; 1.6\%), coho salmon (O. kisutch; 0.9\%), prickly sculpin (Cottus asper; 0.5\%), Chinook salmon (O. tshawytscha; 0.5\%), and peamouth (Mylocheilus caurinus; 0.5\%). Other species were caught incidentally and together composed $<0.3 \%$ of the total. Overall, diversity was negatively related to stickleback abundance $\left(\mathrm{r}^{2}=-0.92 ; \mathrm{P}<0.001\right)$. Omitting stickleback, overall diversity increased from 0.35 to 1.78 , and Chinook, chum, and coho salmon proportions increased to $8.3,32.7$, and $13.4 \%$ of the total catch, respectively.

Before the KF tide gate removal, no fish other than stickleback were found inside the tide gate controlled area (Figure 2.36), while at Seal Slough reference sites we captured seven species, including coho salmon $\left(\mathrm{N}=418, \mathrm{H}^{\prime}=0.92\right)$. In 2006 , after tide gate removal at the KF site, trap net samples yielded nine species, three of which were salmonids $\left(\mathrm{N}=19575, \mathrm{H}^{\prime}=0.07\right)$. Diversity remained low due to the high numbers of stickleback. Species counts and total individuals decreased at trap net sites in 2007 with the loss of incidental species and decline in the number of stickleback $(\mathrm{N}=1330, \mathrm{~S}=6$, $H^{\prime}=0.72$ ). In comparison, the mean values of $S$ and $H^{\prime}$ from beach seine samples at lower Columbia River main stem freshwater sites from 2002 to 2008 were 13.1 and 0.55 , respectively. However, note that overall salmonid abundance remained relatively high in the restoration sites. 

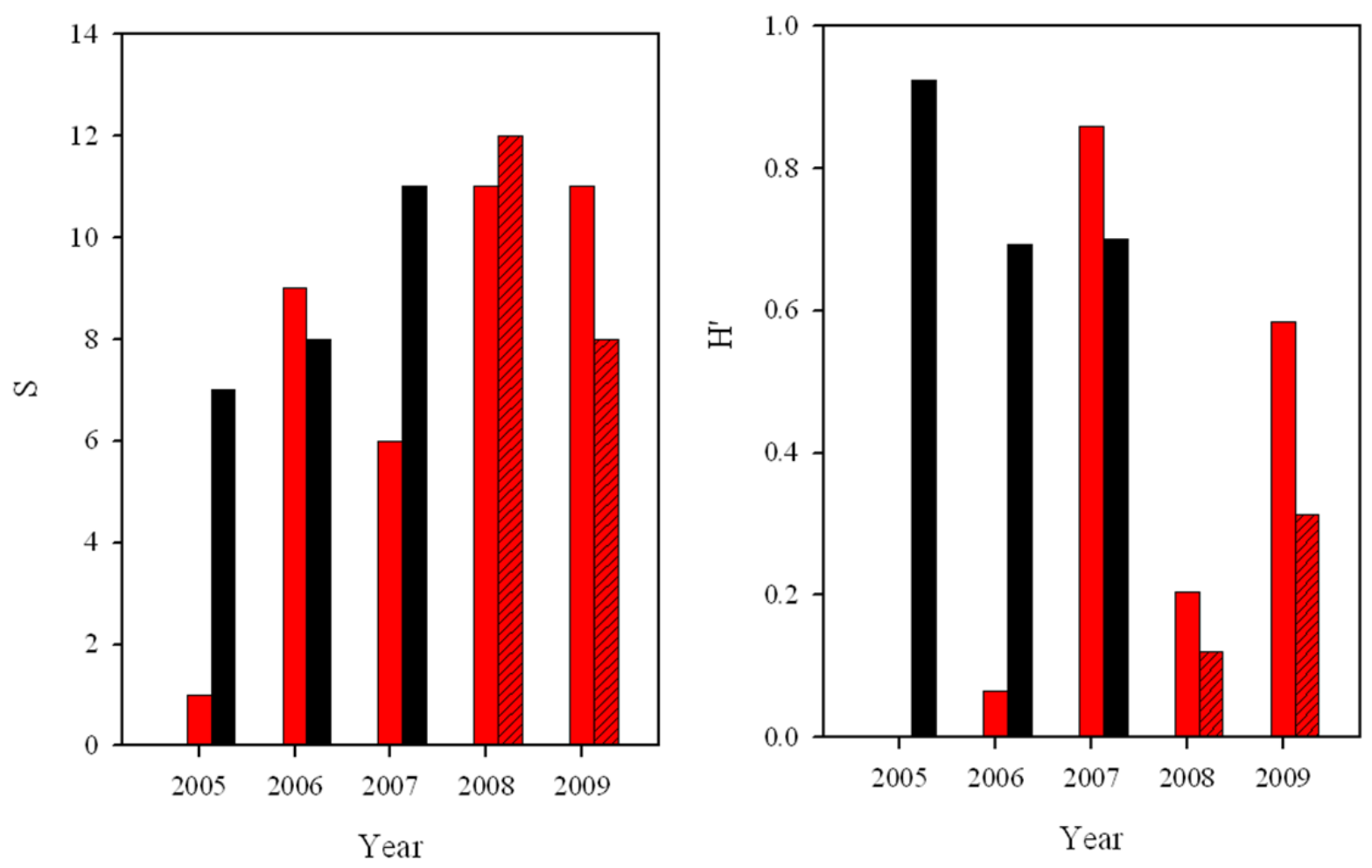

Figure 2.36. Pre- and Post-Restoration Diversity at Kandoll Farm for the Kandoll 1 Site (red), Kandoll 2 Site (stippled), and the Reference Site (black). S = Species richness; H= Shannon-Weiner Diversity Index.

\section{Vera Slough}

We sampled the fish community with beach seines before (2005) and after (2006) tide gate replacement at the VS site. Sampling locations included stations inside and immediately outside the VS site, as well as at the VR site. Sampling coincided with peak migration of subyearling Chinook salmon (May and June 2005 and April through June 2006). Before tide gate replacement, there was a lower species richness $(\mathrm{S}=3)$ and lower diversity $\left(\mathrm{H}^{\prime}=0.15\right)$ inside the VS site compared to outside or reference sites (Figure 2.37). After tide gate replacement, $\mathrm{S}$ and $\mathrm{H}^{\prime}$ of the fish community increased inside the VS site ( 8 and 0.30 , respectively) and were more comparable to the outside and reference sites. Note the fish community in this area was relatively impoverished compared to nearby sites on the main stem Columbia River. At Point Adams Beach (5.9 km from the VS site) during spring 2005 through 2007, mean species richness \pm standard deviation was $15 \pm 3$ and mean diversity was $1.4 \pm 0.4$. 

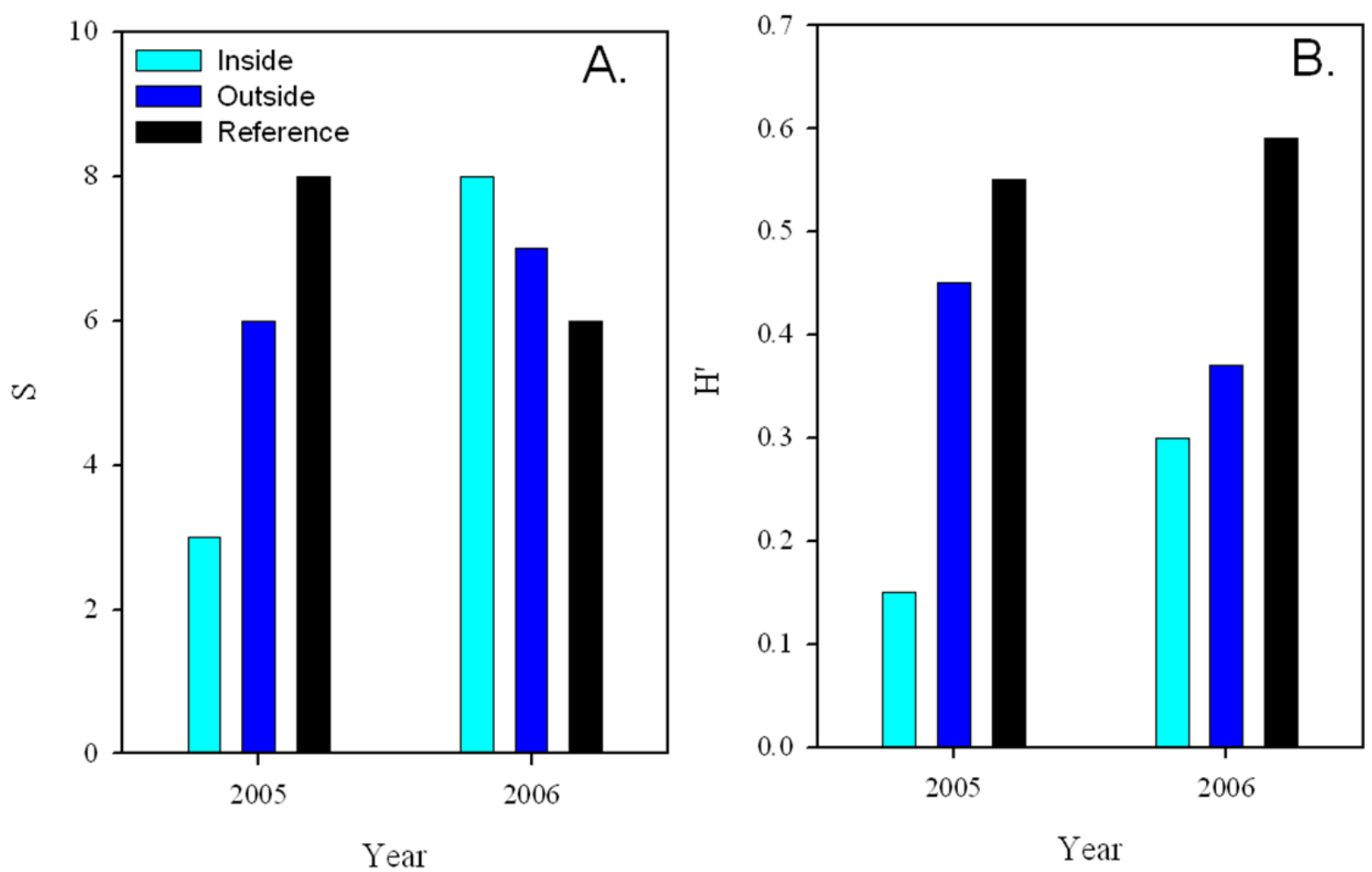

Figure 2.37. Pre- and Post-Restoration Diversity at Vera Slough. A) Species richness and B) ShannonWeiner Diversity Index.

\subsubsection{Salmon Size and Hatchery Production at the Kandoll Farm Site}

For subyearling and yearling life-history types, we determined the mean size by sample date (Figure 2.38). We also indicated adipose-fin clipped fish and display the sizes of hatchery released chum and coho salmon. Data from 2006 through 2009 were plotted as a function of the day of the year. The Chinook salmon aggregate time series was dominated by non-adipose fin-clipped (unclipped) subyearling fish. Fry were present throughout the monitoring period, and most were likely wild salmon. There was no significant trend in mean size with time $(\mathrm{P}=0.17)$, suggesting limited rearing in the wetland.

No hatchery-reared Chinook salmon were released into the Grays River, yet we captured two clipped subyearling and three clipped yearling fish, evidence that hatchery fish from outside the basin are using the reconnected wetland. Genetic analysis of Chinook salmon within the system revealed that their stock of origin includes the expected West Cascade Tributary Fall group but also admixtures of Rogue River stock, which likely strayed from hatchery introductions in Oregon (Roegner et al. 2010b). Chum salmon were all fry and, based on the size of hatchery releases, most were of natural origin. Chum size increased marginally with time $\left(\mathrm{P}=0.04, \mathrm{R}^{2}=0.22\right)$ with a group growth rate of only $0.07 \mathrm{~mm} / \mathrm{d}$. This indicates individual chum likely migrated rapidly through the system. In contrast, subyearling coho salmon size increased appreciably with time $\left(\mathrm{P}<0.01, \mathrm{R}^{2}=0.84\right)$ with a group growth rate of $0.36 \mathrm{~mm} / \mathrm{d}$. This suggests the coho are rearing within the system. Fry-sized coho dominated the time series until May. Both clipped and unclipped schools of yearling coho were found to use the reconnected wetland. The size and timing of the unclipped group indicates a wild origin, while the clipped yearlings were sampled a few days after the hatchery release. 

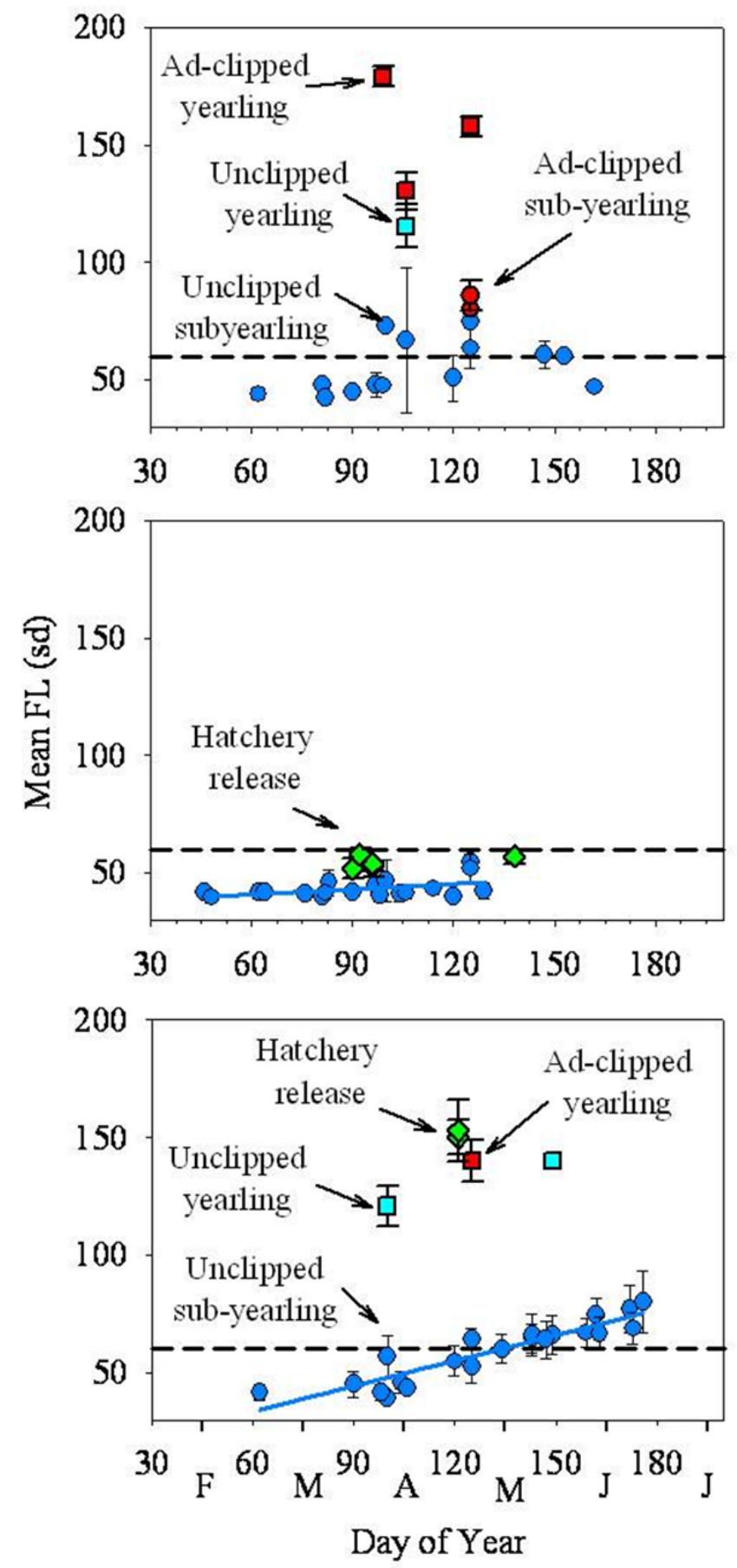

Figure 2.38. Mean Salmon Size ( \pm SD) by Time from 2006 Through 2009 at the KF Site. Top) Chinook salmon, middle) chum, bottom) coho salmon. Life history is denoted by symbol type ( square $=$ yearlings; circle $=$ subyearlings). Hatchery status is denoted by color $($ red $=$ adipose fin clip; blue = unclipped subyearling; cyan unclipped yearling fish; green $=$ hatchery release). Dashed horizontal line is the fry size threshold. 


\subsubsection{Electrofishing}

Electrofishing in the KR side channel off Seal Slough during the spring migration in 2010 captured salmonid species in the following numbers: 1 chum salmon, 4 unmarked coho salmon, and 1 cutthroat trout in March (60 minutes, water level 0.652 m-NAVD88); 2 unmarked coho salmon in April (45 minutes, water level 0.938 m-NAVD88); and 2 unmarked coho salmon in June (60 minutes, water level 0.949). These data represent salmonids holding in pools at or near low tide when much of the channel is dewatered. A summary of the electrofishing data is provided in Appendix D.

\subsubsection{Salmon Life History and Habitat Use}

\section{Kandoll Farm}

During the post-breach period from 2006 through 2009, chum and coho salmon made extensive use of the reconnected wetland (Figure 2.39). Chinook salmon abundance was relatively low and decreased with time. Steelhead and cutthroat trout were occasional visitors to the site. Based on size frequency histograms, Chinook, chum, and coho salmon the life-history stages present in the wetland varied (Figure 2.40). Over the 4-year monitoring period, only 46 Chinook salmon were captured in the KF trap nets; $45.6 \%$ of these were fry, $43.5 \%$ were fingerlings, and $10.9 \%$ were yearlings. Chum salmon were numerous in the wetland and nearly all were fry-sized individuals $(98.7 \%)$ with $86.2 \%$ being $<45 \mathrm{~mm}$. Coho were moderately abundant and the population was composed of fry (29.4\%), fingerlings (60.6\%), and yearlings $(10.0 \%)$. Thus, the chum were all fry migrants. Chinook salmon were composed predominately of fry- and fingerling-sized subyearling fish, and the coho population exhibited fry, fingerling, and yearling fish.

During 2006 and 2007, we compared salmon populations inside and outside of the wetland (Figure 2.41). Chinook size frequency patterns were similar in 2006, but only five Chinook salmon were found inside during 2007. Chum were much more abundant inside than at the reference site but the size distribution was similar. Coho distributions were also similar inside and outside the restoration site (although there were fewer fry inside during 2006), but we captured yearlings only in 2007. The timing of abundance was also roughly coincident between wetland and reference sites (Figure 2.42).

Chinook, chum, and coho salmon exhibited different patterns of habitat use (Figure 2.43). Chinook were not abundant in the wetland in any year, but had a relatively wide temporal window extending from February to June. Chum salmon were very abundant each year, especially during 2009 when over 1000 individuals per tide were captured in one trap net. We likely sampled during the peak migration period. Chum had a relatively narrow window lasting $\sim 6$ weeks each year; overall occupation of the wetland was from mid-February through late April with a maximum in early April. Coho were moderately abundant each year with a variable maximum. Overall distribution was wide and extended from March through June (and possibly later). See Appendix E for a discussion of how variation in migration timing affects net habitat use. Chinook salmon were present at 7-DAM temperatures between 6 and $21^{\circ} \mathrm{C}$, chum in the range 7 to $16^{\circ} \mathrm{C}$, while coho exhibited the warmest and narrowest range between 13 and $21^{\circ} \mathrm{C}$. 


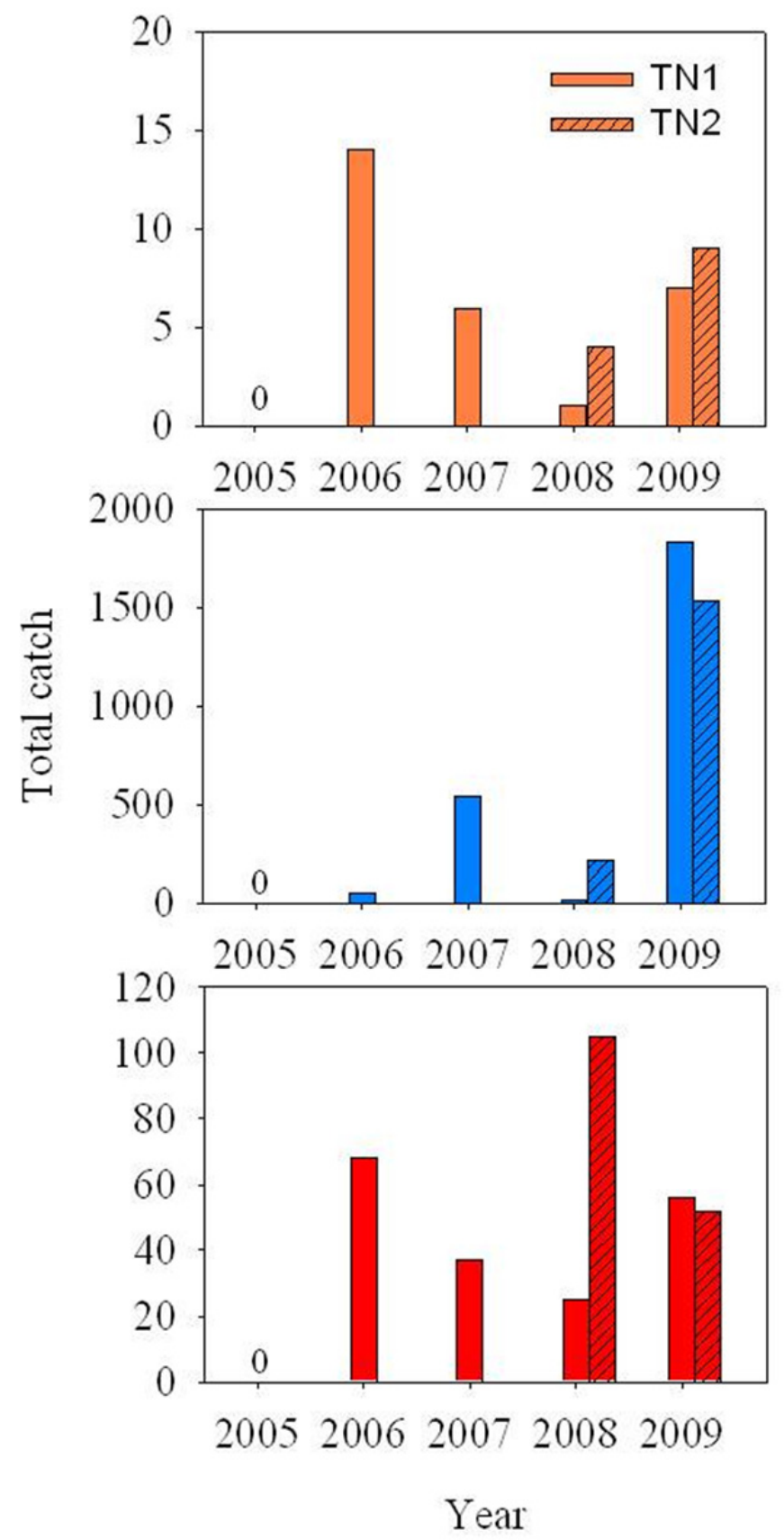

Figure 2.39. Total Annual Catch of Salmonids in Kandoll Farm Trap Nets from 2006 Through 2009. A) Chinook salmon (top), B) chum (middle), C) coho (bottom). Dual traps were deployed in 2009 and 2009. 

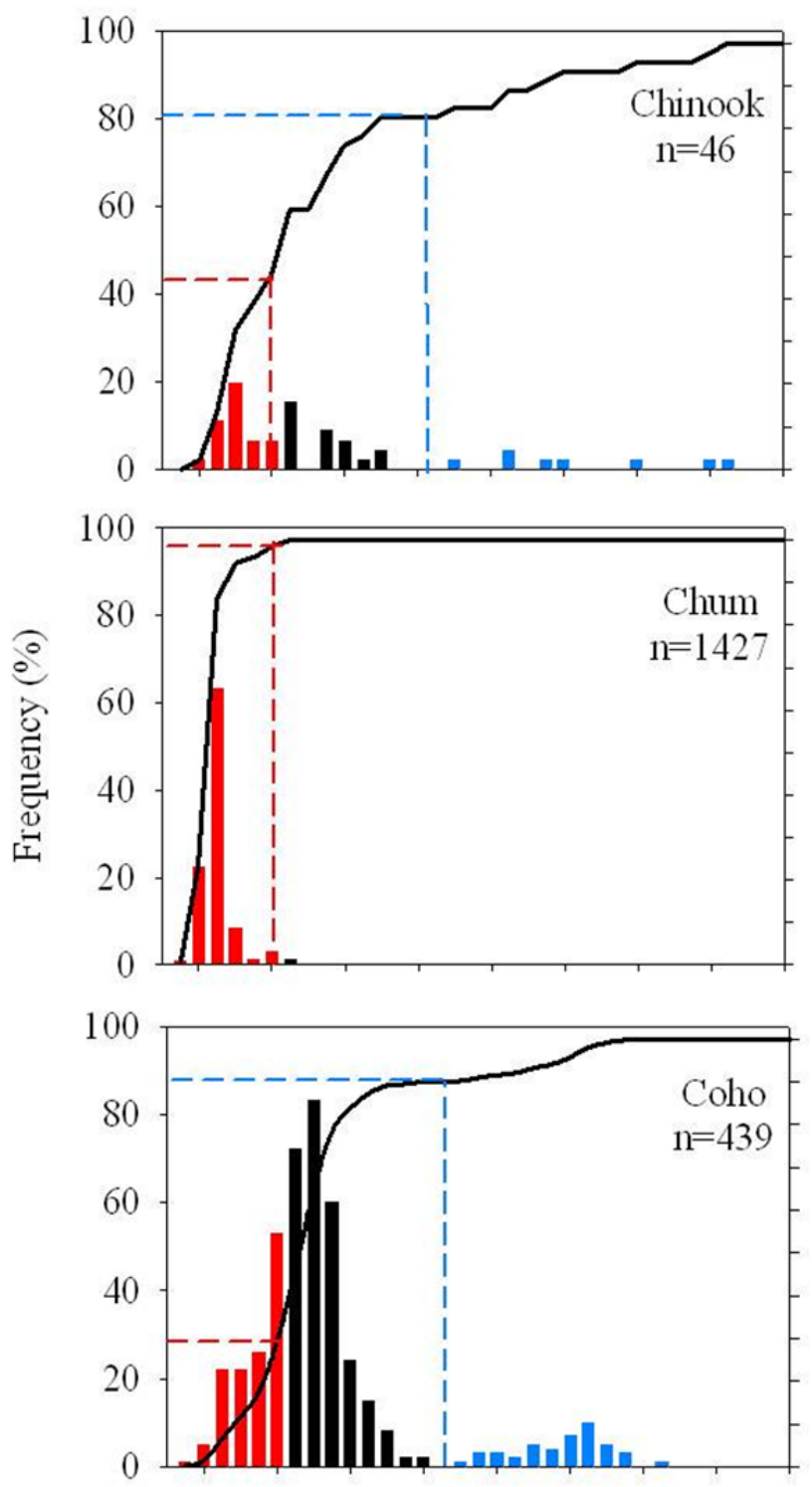

$40 \quad 60 \quad 80 \quad 10012014016018020($

Fork length (mm)

Figure 2.40. Size Frequency Histograms of Salmonids at Restoration and Reference Sites in the Grays River System in 2006 and 2007. Horizontal bars indicate fork length at 5-mm intervals. Symbols show mean size $(+\mathrm{SD})$ of hatchery chum and coho at release. The vertical line at $60 \mathrm{~mm}$ delineates fry from fingerling-sized individuals, and that at $109 \mathrm{~mm}$ approximates the yearling-subyearling division. Numbers indicate the quantity of fish composing the frequency distribution. 


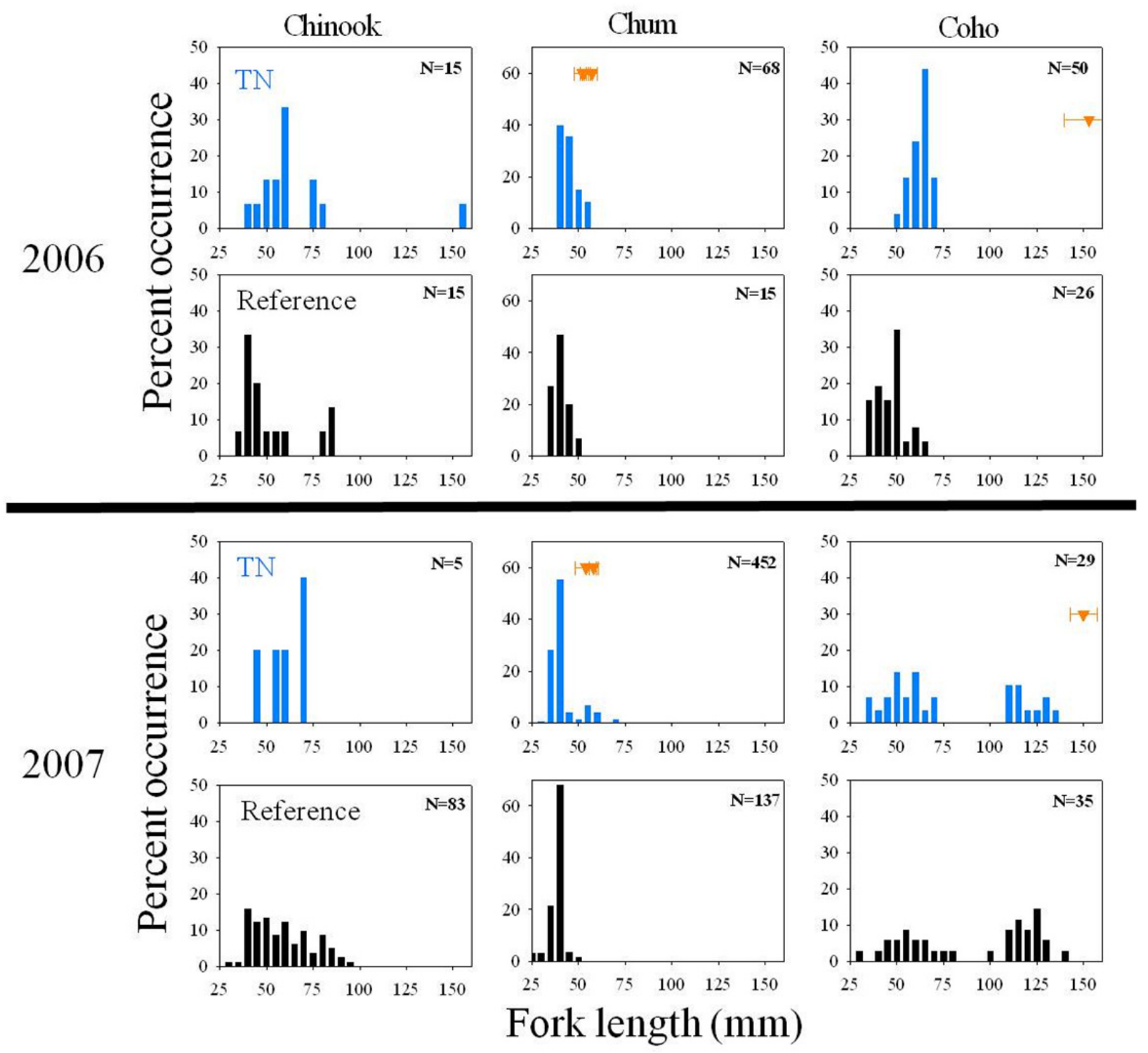

Figure 2.41. Salmon Relative CPUE (\% of Annual Total) at Restoration and Reference Sites in the Grays River System, 2006 and 2007. Top row: Kandoll Farm trap net site; bottom row: Seal Slough reference. Triangles denote hatchery release dates (Chum: grey, 2006; black, 2007; Coho: 1 May for all years). 


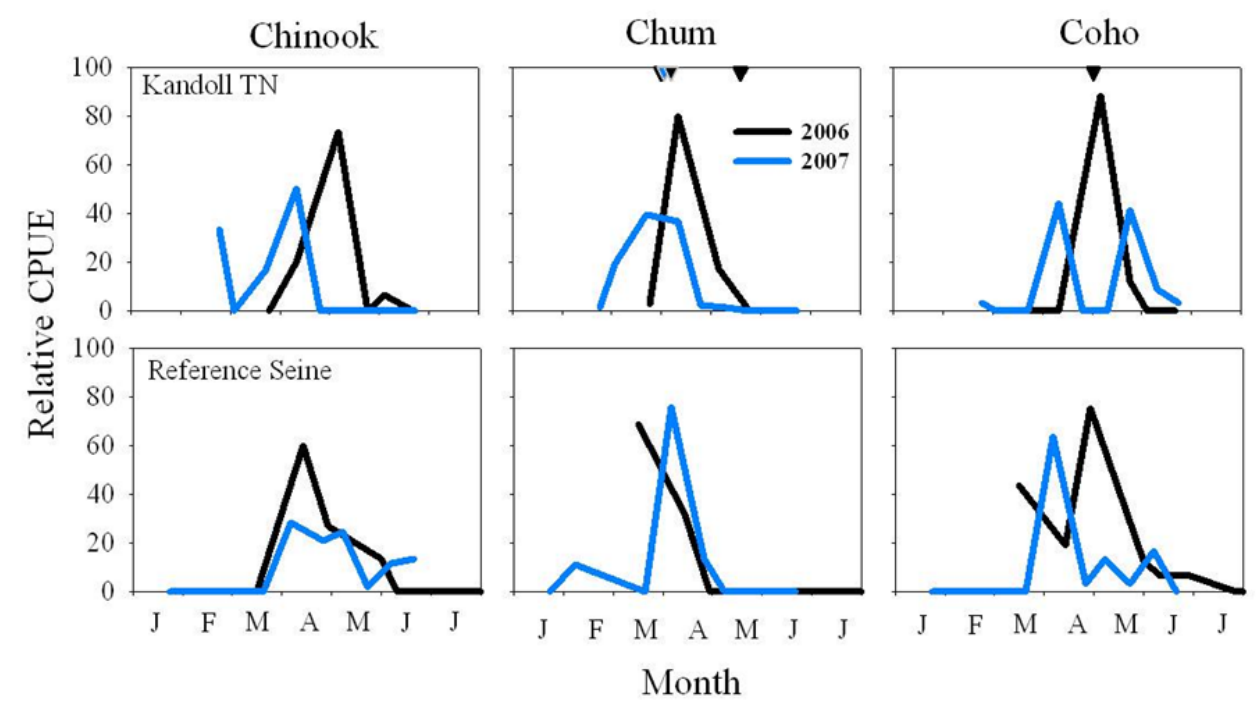

Figure 2.42. Salmonid Abundance at Kandoll Farm, 2006 and 2007. A) Chinook salmon, B) chum, C) coho. Dual trap nets were deployed in 2008 and 2009.
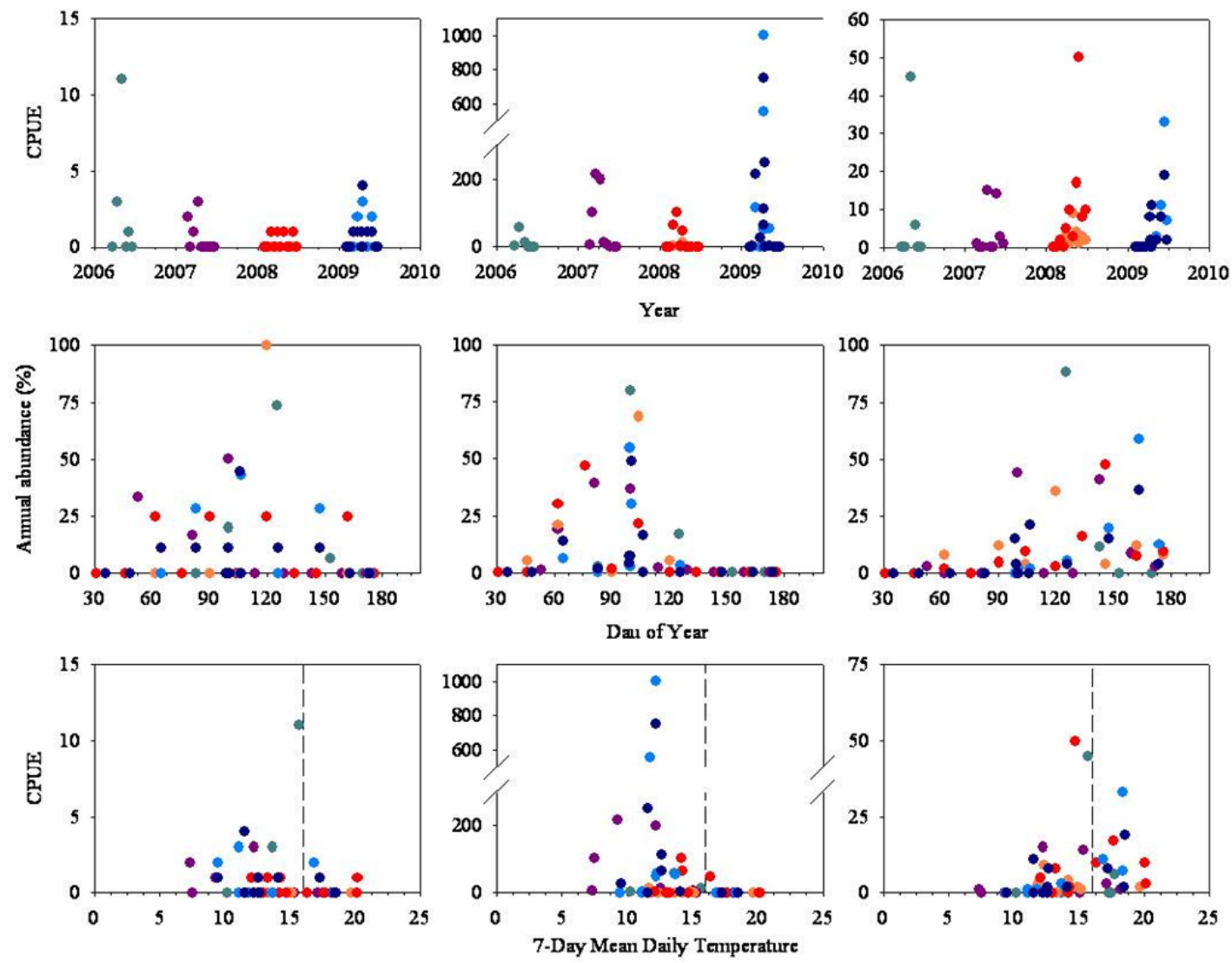

Figure 2.43. Habitat Use of Salmonids at Kandoll Farm, 2006 Through 2009. Top row: time series of CPUE; middle row: relative annual abundance by day of year; bottom row: CPUE by 7-day average maximum temperature (7-DAM). Colors code for years as in the top row, with color shades in 2008 and 2009 indicating dual trap net deployments. Vertical line at $16^{\circ} \mathrm{C}$ denotes temperature criterion. The three columns convey data on Chinook, chum, coho salmon, respectively. 


\section{Vera Slough}

Salmon made up a minor component of the fish community at sites inside and around the VS site. Few salmonids were caught at any of the sites (11 individuals out of 75 seine samples). In prereplacement sampling, we captured three coho, one Chinook, and one chum salmon in May and none in June; all salmon were sampled outside of the tide gate or in the reference area. After tide gate replacement in 2006, two Chinook and one coho were captured at outside or reference sites, and two coho and one Chinook were captured at the VS Inside station. All measured salmon were fry $(<60 \mathrm{~mm})$ except one yearling fish that likely originated at the net-pen facility on the east side of Youngs Bay. These catch numbers are very low compared to nearby sites in the CRE. At Point Adams Beach during spring 2005 through 2007, the mean Chinook salmon CPUE was 65 (range: 26-155).

\subsubsection{Salmon Diets}

\section{Kandoll Farm}

The predominance of diet data at the KF site were acquired from coho salmon. In 2007, we analyzed gut contents from 38 subyearling and 6 yearling coho salmon (Figure 2.44). Subyearling and yearling fish consumed somewhat different items. For subyearlings at all sites, insects were the primary prey (numerical abundance and \%IRI). Coho within restoration sites ate a variety of additional organisms including annelids, cladocerans, amphipods, and larval fish. Coho captured at Grays River seine sites ate primarily insects but also fed on arachnids, amphipods, and mysids. Six yearling coho salmon were caught together at the KR site. They consumed a wider array of prey types including annelids, insects, amphipods, and fish (including chum salmon). See Roegner et al. (2010b) for a wider comparison of fish diets in the Grays River system. Similar results were found during 2008 and 2009. Salmon thus appeared to be eating prey produced in the wetland.

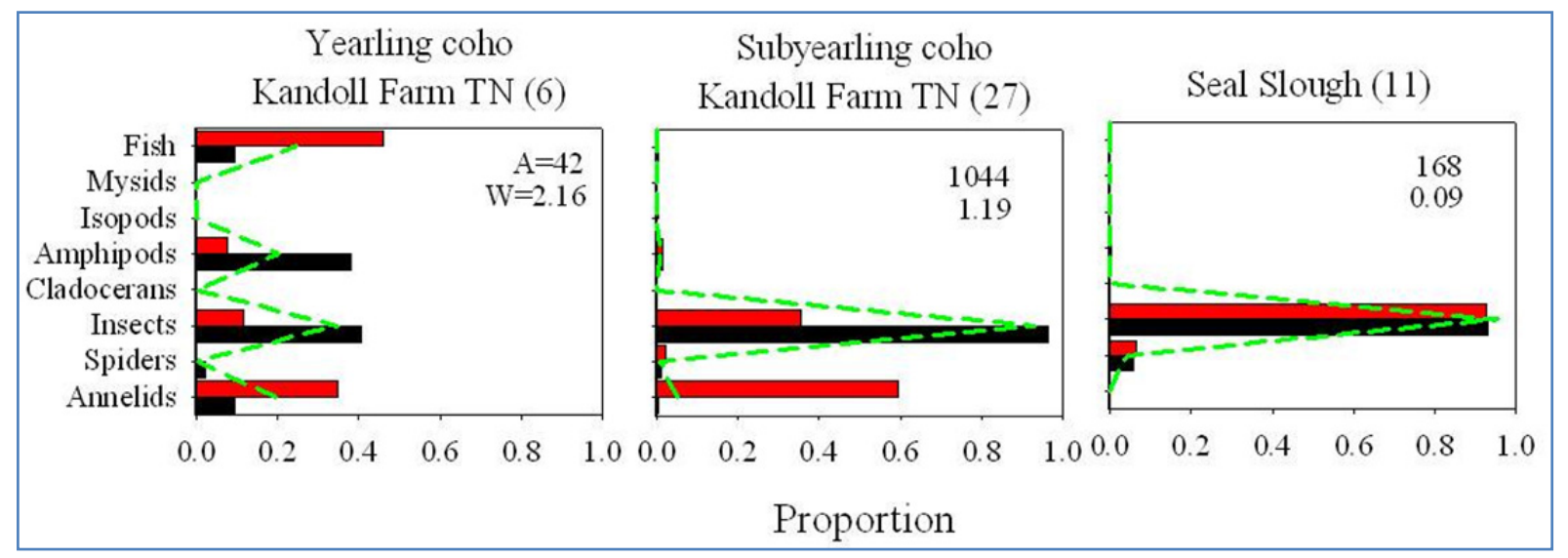

Figure 2.44. Diet of Subyearling Coho Salmon at Kandoll Farm During April, May and June 2008. $\mathrm{A}=$ number of prey items, $\mathrm{W}=$ wet weight of prey items. The number of stomachs analyzed is presented in parentheses. 


\subsubsection{Productivity and Material Flux}

Interpretation of flux rates (Table 2.20) must consider the fact that at both the VS and KF sites, restoration actions occurred between the collection of summer and winter samples; thus, these do not represent true "before" conditions because of the much greater inundation that occurred after the installation of culverts and tide gates. However, "before" conditions in 2005 summer standing stock are accurately represented at these two sites. The VS site saw a surge in summer standing stock the year after the tide gate replacement, but by year 4 summer standing stock had halved (Table 2.20) and much of the area proximal to the restoration action was bare ground (Figure 2.20). During this period, summer standing stock at the VR site increased somewhat. Flux rates at the reference site varied from 490 to $697 \mathrm{~g} / \mathrm{m}^{2}$, and at the reference site they were between 100 and 200 except in the year after tide gate installation when they nearly reached $1000 \mathrm{~g} / \mathrm{m}^{2}$.

Table 2.20. Biomass Flux Results for Six Paired Restoration and Reference Sites Before and After Restoration, and Julia Butler Hansen Before Tide Gate Installation

\begin{tabular}{lccccc}
\hline \multicolumn{1}{c}{ Site Name } & Site Code & $\begin{array}{c}\text { Year } \\
\text { Range }\end{array}$ & $\begin{array}{c}\text { Average Summer } \\
\text { Biomass }\left(\mathrm{g} / \mathrm{m}^{2}\right)\end{array}$ & $\begin{array}{c}\text { Average Winter } \\
\text { Biomass }\left(\mathrm{g} / \mathrm{m}^{2}\right)\end{array}$ & $\begin{array}{c}\text { Biomass } \\
\text { Flux }\left(\mathrm{g} / \mathrm{m}^{2}\right)\end{array}$ \\
\hline Crims Island & CI & $2006-2007$ & 230.5 & 83.7 & 146.8 \\
Crims Island & CI & $2007-2008$ & 539.9 & 511.7 & 28.2 \\
Crims Island & CI & $2009-2010$ & 383.8 & 369.0 & 14.8 \\
Crims Reference & CR & $2006-2007$ & 574.6 & 108.7 & 465.9 \\
Crims Reference & CR & $2009-2010$ & 500.7 & 371.4 & 129.3 \\
Kandoll Farm (East \& & KF & $2005-2006$ & 588.5 & 238.4 & 350.1 \\
West) & & & & & \\
Kandoll Farm (East \& & KF & $2006-2007$ & 635.2 & 185.0 & 450.2 \\
West) & & & & & \\
Kandoll Farm (East \& & KF & $2009-2010$ & 819.1 & 287.1 & 532.0 \\
West) & KFE & $2005-2006$ & 526.7 & 104.6 & 422.2 \\
Kandoll Farm (East) & KFE & $2006-2007$ & 537.9 & 194.8 & 343.1 \\
Kandoll Farm (East) & KFE & $2009-2010$ & 846.6 & 173.8 & 672.7 \\
Kandoll Farm (East) & KFW & $2005-2006$ & 668.8 & 840.8 & -172.0 \\
Kandoll Farm (West) & KFW & $2006-2007$ & 750.1 & 171.1 & 579.0 \\
Kandoll Farm (West) & KFW & $2009-2010$ & 785.7 & 380.4 & 405.3 \\
Kandoll Farm (West) & KR & $2005-2006$ & 220.9 & ND & ND \\
Kandoll Reference & KR total (RF) & $2006-2007$ & 33.9 & 184.8 & -150.9 \\
Kandoll Reference & KR wood (RF) & $2006-2007$ & 91.3 & 552.8 & -461.6 \\
Kandoll Reference & KR non-wood (RF) & $2006-2007$ & 18.3 & 55.9 & -37.6 \\
Kandoll Reference & VR & $2005-2006$ & 755.1 & 265.0 & 490.1 \\
Vera Reference & VR & $2006-2007$ & 798.7 & 101.4 & 697.3 \\
Vera Reference & VR & $2009-2010$ & 989.3 & 402.4 & 586.9 \\
Vera Reference & VS & $2005-2006$ & 829.3 & 708.9 & 120.4 \\
Vera Slough & & & & & \\
& & & & & \\
\end{tabular}


Table 2.20. (contd)

\begin{tabular}{lccccc}
\hline \multicolumn{1}{c}{ Site Name } & Site Code & $\begin{array}{c}\text { Year } \\
\text { Range }\end{array}$ & $\begin{array}{c}\text { Average Summer } \\
\text { Biomass }\left(\mathrm{g} / \mathrm{m}^{2}\right)\end{array}$ & $\begin{array}{c}\text { Average Winter } \\
\text { Biomass }\left(\mathrm{g} / \mathrm{m}^{2}\right)\end{array}$ & $\begin{array}{c}\text { Biomass } \\
\text { Flux }\left(\mathrm{g} / \mathrm{m}^{2}\right)\end{array}$ \\
\hline Vera Slough & VS & $2006-2007$ & 1282.9 & 284.7 & 998.3 \\
Vera Slough & VS & $2009-2010$ & 416.0 & 228.1 & 187.9 \\
$\begin{array}{l}\text { Julia Butler Hanson }- \\
\begin{array}{l}\text { Duck Lake Slough } \\
\text { Julia Butler Hanson - }\end{array}\end{array}$ & JBH-DLS & $2007-2008$ & 1530.0 & 1064.7 & 465.3 \\
Ellison Slough & JBH-EL & $2007-2008$ & 1147.0 & 519.9 & 627.2 \\
\hline
\end{tabular}

Average standing biomass and flux rates at the KF site are presented separately for the east and west sides of Seal Slough and totaled (Table 2.20). Interannual changes in summer biomass at the KF site consistently showed increasing trends after culvert installation. The low total flux rate in 2005-2006 is partly explained by the negative flux rate (more biomass in winter than in summer) calculated after culvert installation; in the summer of 2005, cows were grazing the site and mowing occurred in the vicinity, which should be considered in interpretation of this low summer standing stock result. Interannual trends at the east and west sides of the slough are not consistent; the average flux at the KF site in 2006-2007 was $450 \mathrm{~g} / \mathrm{m}^{2}$, and in 2009-2010 it was $532 \mathrm{~g} / \mathrm{m}^{2}$, yet this increase came from the east side while the west side decreased. Prior to culvert installation, the east side was characterized by wet pasture mix and the west side by rushes and mixed grass (Figure 2.19), and they became more similar by 2009 (Figure 2.21). At the KR site, herbaceous plant biomass was sampled using the standard marsh method only in the summer of 2005, and totaled $221 \mathrm{~g} / \mathrm{m}^{2}$, characteristic of the much sparser herbaceous cover layer in the swamp. A larger sampling unit was implemented for sampling at the swamp in 2006-2007, to include shrub cover, but only three samples were collected and variability was exceedingly high in both woody and non-woody components. Calculated flux rates were negative but sample size should be increased to determine actual rates for herbaceous plant flux. Litterfall flux rates are reported by Diefenderfer et al. (in preparation).

Biomass flux rates at both the CI and CR sites were substantially lower in 2009-2010 than in 2006-2007, indicating that environmental conditions and/or the date of sampling relative to marsh development in those years may have played a role. In both years, the CR site produced much greater flux than the CI site: three times greater in 2006-2007 and nine times greater in 2009-2010. The dominant plant species at both the CI and CR sites changed substantially between 2005 and 2009 (Table 2.20) and may explain the different export rates.

The biomass flux rate within the Julia Butler Hansen site (not to the main stem river, because tide gate installation had not occurred), was similar to that at KF and VR sites, but the summer standing biomass at Julia Butler Hansen was an order of magnitude higher than the other sites. Management practices at the National Wildlife Refuge should be considered in interpretation of this result. Additional flux studies are presented in Appendix E.

\subsubsection{Ratio-Based Estimators}

The data generated through the ecological field studies and modeling efforts provide the basis for estimating the ecological response of restoration actions in the estuary. Here we use results to calculate 
ratio estimators for the structural metrics, processes, and functions we studied. For example, one of our key research questions centered on whether restoring tidal wetlands would return marsh macrodetritus to the LCRE food web. Using field data and modeling results we can provide a preliminary estimator that can be used for broader-scale estimates of this process. The general estimator formula is as follows:

$$
\operatorname{Total}_{\text {int }}=\operatorname{Total}_{\text {ext }}\left(\mu_{\text {int }} / \mu_{\text {ext }}\right)
$$

where Total ${ }_{\text {int }}$ is the total amount of X produced over the area of interest, Total ${ }_{\text {ext }}$ is the total amount of area that produces $\mathrm{X}$, and $\left(\mu_{\mathrm{nt}} / \mu_{\mathrm{ext}}\right)$ is the ratio of mean $\mathrm{X}$ produced per mean unit area.

This formula can be used to expand information from intensively studied areas to larger areas that are the same but have not been studied intensively. Essentially this relates the intensive findings of our work to the broader estuarine ecosystem.

\subsubsection{Application to Particulate Organic Matter Export}

Data on biomass loss from Table 2.21 were used here to develop the estimator. We used data from three restored sites and their associated reference sites, taken over several years. These are estimates of $\left(\mu_{\mathrm{nt}} / \mu_{\mathrm{ext}}\right)$ :

- Restored site mean loss $=373 \mathrm{~g}$ dry wt $\mathrm{m}^{-2}$

- Reference site mean loss including $\mathrm{KR}=224 \mathrm{~g}$ dry $\mathrm{wt} \mathrm{m}^{-2}$

- Reference site mean loss excluding $\mathrm{KR}=444 \mathrm{~g}$ dry $\mathrm{wt} \mathrm{m}^{-2}$.

Using data on tidal marshes area loss ( $4050 \mathrm{ha})$ in the LCRE provided by Sherwood et al. (1990), we calculated the amount of particulate organic matter (POM) that would be restored if all of the lost wetlands were restored in this region:

$$
\text { Total }_{\text {int }}=4,050 \text { ha }\left(373 \mathrm{~g} \mathrm{dry} \mathrm{wt} \mathrm{m}^{-2}\right)=15.1 \times 10^{6} \mathrm{~kg} \text { dry wt }=15.1 \mathrm{mT} \text { dry wt. }
$$

Using the POM export ratio for reference areas $\left(444 \mathrm{~g}\right.$ dry $\left.\mathrm{wt} \mathrm{m}^{-2}\right)$ and comparing it to the estimated export from the restored areas, the reference export for the 4,050 ha would be would $18.0 \mathrm{mT}$ dry wt. The ratio between restored and reference export then is $0.83: 1$. Values of export from KF, CI, and VS sites are estimated to be as follows:

- $\underline{\text { Kandoll }}$ Total POM export $=655,994 \mathrm{~m}^{2}\left(447 \mathrm{~g}\right.$ dry wt $\left.\mathrm{m}^{-2}\right)=293,229 \mathrm{~kg}$ dry wt

- $\underline{\text { Crims }}$ Total POM export $=1,180,000 \mathrm{~m}^{2}\left(63.3 \mathrm{~g}\right.$ dry wt $\left.\mathrm{m}^{-2}\right)=74,694 \mathrm{~kg}$ dry wt

- $\underline{\text { Vera }}$ Total POM export $=1,060,000 \mathrm{~m}^{2}\left(435 \mathrm{~g}_{\text {dry }} \mathrm{wt}^{-2}\right)=461,100 \mathrm{~kg}$ dry wt.

Because the data on biomass were collected from a confined area and not over the entire wetted restored site, we felt it necessary to project biomass loss to the entire area using another method. We compared the export estimated using the ratio above with the export calculated by the POM model from the KF site. The POM model used the elevation to estimate biomass loss over the entire site, and the energy distributed over the site to move biomass off the entire site. This is a more realistic (and expectedly lower value) than that produced from the site immediately adjacent to the mouth of the site.

POM model estimate/ Sample site estimate $=96,200 \mathrm{~kg}$ dry wt/293,229 $\mathrm{kg}$ dry $\mathrm{wt}=0.33$. 
This means that the estimate based on our sampling of the proximal site produced an estimate of export about three times greater than that produced by the model. Until more estimates are developed, we will use this ratio of 0.33:1 to calculate actual biomass lost over an entire site using data from a restricted sampling area on the site. Applying this correction to the data on export for the three sites above results in the following export estimates:

- Kandoll $=96,766 \mathrm{~kg}$ dry wt

- Crims $=24,649 \mathrm{~kg}$ dry $\mathrm{wt}$

- Vera $\quad=152,163 \mathrm{~kg}$ dry wt.

Using the estimates of POM mass reaching various points downstream of the culvert in Seal Slough, we calculated the rate of loss with distance between the culvert and the river mouth (Table 2.21). Based on these data, $52 \%$ of the POM leaving the KF site reached Grays Bay, and $48 \%$ is deposited in the floodplain between the KF site and Grays Bay. This suggests that POM exported from tidal wetlands between the mouth and about $15.5 \mathrm{~km}$ upstream would reach Grays Bay. The regression relationship for this export is as follows:

$$
\text { Proportion of mass }=0.969-0.062(\text { distance }, \mathrm{km}) \quad\left(\mathrm{n}=3 ; \mathrm{r}^{2}=0.87\right) \text {. }
$$

Table 2.21. POM Export for Three Locations in the Lower Grays River Area

\begin{tabular}{lccc}
\hline \multicolumn{1}{c}{ Location } & Mass (kg dry wt) & Loss Ratio & Distance from Culvert $(\mathrm{km})$ \\
\hline Seal Slough & 96,200 & 1.0 & 0.51 \\
Grays River/Seal Slough Confluence & 62,200 & 0.65 & 3.45 \\
Grays River Mouth & 49,600 & 0.52 & 7.9 \\
\hline
\end{tabular}

\subsection{Discussion}

Our research has pursued a wide range of related topics, which are all directed at providing evidence for resolving and estimating the cumulative effects of multiple restoration projects on the CRE ecosystem. In addition, our studies provide new information about several aspects of tidal wetland restoration in the CRE. We have organized the discussion first around the topics that were studied, then broader ecological relationships to address the questions outlined in the Introduction. Finally we cover the two objectives for this work: 1) provide a synthesis of field research on ecological responses to LCRE tidal reconnection restoration at three sites, trajectories, and patterns of development, organized according to the hypotheses generated from a levels-of-evidence approach (Diefenderfer et al. 2011); and 2), develop indicators for assessing restoration response, including the analysis of ecological relationships, and present recommendations drawn from the results at intensive (i.e., site) and extensive (i.e., ecosystem) scales.

\subsubsection{Ecological Responses of Restored Sites}

The ecological responses of restored sites may be related to hydrology and water quality, topography and bathymetry, landscape, vegetation, habitat availability, fish community, and productivity and material exchange. 


\subsubsection{Hydrology and Water Quality}

We monitored water level because the primary driver of restoration of diked floodplain wetlands is the return of natural hydrology. The data showed that the hydrograph at a large culvert installation is effectively instantaneously reconciled with the exterior conditions. However, at the site where the tide gate was retrofitted the hydrograph was improved but remained unnatural. It was clear that replacing the small tide gate at the KF site resulted immediately in the flooding of the site. Water-level variation mimicked the KR site, which suggested that natural tidal hydrodynamics was restored. In contrast, the VS site retained highly restricted hydrodynamics after replacement of the old tide gate with a new but still restrictive tide gate. The restoration at Crims Island, which included a scrapedown of elevation, constructed tidal channels, and breeching of the levee, resulted in daily inundation of the site. Flooding of the KF and CI sites occurred during spring high-water events.

Hydrologic reconnection was increased at both the VS and KF sites as a result of restoration activity. However, while the tide gate removal at the KF site resulted in complete reestablishment of the semidiurnal tidal amplitude, the improved tide gate restoration at the VS site resulted in modest increases in amplitude and flushing. Of course, because it was necessary to maintain flood control in the Vera Slough system, this was an expected result.

Water temperature, an important factor affecting fish health and use of shallow-water areas, responded to the establishment of natural tidal hydrodynamics. Our monitoring showed that the more complete the tidal hydrological connection, the stronger the return to more natural water temperatures. The temperatures inside the VS site were much warmer than those of the VR site in summer, which indicated restricted connection with water from Youngs Bay. Higher water temperatures indicate that the water held in Vera Slough probably was stagnant at times because of the muted connection. We did not measure dissolved oxygen (DO) but we suspect that stagnation would result in lower DO levels at times.

There appeared to be a slight delay in the timing of the tide between the mouth and the upper end of the constructed channel at the CI site. In addition, the height of the water was slightly greater at the upper end of the channel. These two observations suggest that the geometry of the channel affects hydrodynamics, and point to the need to understand channel design when considering elevations, fish access, and vegetation targets.

Water temperature in the interior of the VS site warmed up quickly and exceeded the $19^{\circ} \mathrm{C}$ threshold by mid-May. Outside temperatures were generally 1 to $3^{\circ} \mathrm{C}$ cooler than within the system. Moderate increases in tidal flow had an associated moderate amelioration of temperatures. An opposite effect was observed in the Kandoll Farm system. Temperatures upstream were 3 to $5^{\circ} \mathrm{C}$ cooler than those in the restored marsh or at the river mouth. Water entering $\mathrm{KF}$ site was more associated with the warmer Columbia River water than the upstream Grays River water. Temperature at the downstream sites exceeded the $19^{\circ} \mathrm{C}$ threshold by mid-June or July and may affect fish migration patterns. Upstream sites may serve as a refuge for resident species like coho. Natural breach sites had similar temperatures within and without, and temperatures also reached critical thresholds by June. In contrast, to these temperature concerns, DO levels did not appear limiting at any of the monitored sites. 


\subsubsection{Topography and Bathymetry}

By improving hydrological connections, we expected sediment delivery to be improved. This process is critical to rebuilding elevations within the subsided wetland surface. The change in hydrology at all sites, including the VS site, was sufficient to produce higher sediment accretion rates at restoration sites than at reference sites, even at the tide gate site. Sediment accretion rate tails off after a few years at some sites, but not necessarily at others. As evidenced from multiple accretion rate locations at Kandoll Farm, there was appreciative spatial variation in sedimentation rates. Thus, we did not likely adequately capture the spatial pattern of this process. Even without doing so, rates were clearly higher at the low-elevation restoration sites relative to paired reference sites in all cases.

Tidal channel morphology changed at all sites after hydrological connection. In general, the tidal forcing at newly restored sites will carve historical channels, reshape the channel morphology to what should mimic historical channels, and will change dramatically over at least the first 4 years of the project. The most dramatic changes were seen at the KF site, where historical channels were reformed. Constructed channels at the CI site showed variation in thalweg elevation and cross-sectional area as the constructed channels responded to hydrology and sediment processes.

Although we are unsure of the specific ecological effects of topographic rugosity, in general a greater diversity of elevation, vegetation, and substrata should affect the quantity and quality of niches at a site. Topographic ruggedness was markedly higher at the reference than restored site for the tributary swamp (KR), and within the VR marsh and the VS site. The hummocky nature of tidal forested swamps is common, especially in spruce swamps. The fact that spruce swamps are formed on nurse logs facilitates this dramatic topographical relief (Diefenderfer et al. 2009). Ruggedness was greater in the created CI site than the CR site. This may be due to the fact that the CR site is Gull Island, which was a created by dredged material disposal. However, we are not sure if main stem island landforms may in general be less rugose than tributary sites.

\subsubsection{Landscape}

Photo points provided an easy way to capture visual changes in the surface landscape features. Although qualitative, we found that the most dramatic changes in vegetation cover were evident, and this proved useful in helping us describe these changes. Some of the most evident changes were the 1) reduction in trees and increase in emergent marsh vegetation at the KF site; 2) loss of vegetated cover at the VS site and dominance of bare space for the duration of our study; and 3) the rapid expansion of vegetative cover at the $\mathrm{CI}$ site.

Our satellite imagery analysis of vegetation changes at KF and KR sites displayed spatial patterns of changes and quantified the change in major vegetation types. The reduction in mowed pasture and subsequent increase in reed canarygrass were dramatic between 2005 and 2009 at the KF site. Dead trees bordering the tidal channels were evident by 2009. It appeared to us that the most dramatic shifts occurred proximal to the culvert and to the notches in the dike made along the dike at the main stem river. The KR site also showed apparent changes between 2005 and 2009. There were apparent increases in reed canarygrass and decreases in sedge, rushes, and deciduous trees. The VS site saw a dramatic loss of sedge and an increase in blackberry. The mapping at the CI site showed rapid vegetation development, as well as the predicted area of reed canarygrass colonization based on elevation surveys. 


\subsubsection{Vegetation}

Vegetation provides the most visible element indicating the rate, pattern, and quality of habitat recovery. The plant community responded with substantial changes in vegetation species and coverage. Increases in the number of plant species and the percentage of wetland plants were seen within the first year at the KF site. All trends are not positive for the ecosystem, however, or are toward similarity with the reference sites. At the KF site we found a high percentage cover of reed canarygrass after culvert replacement. At the VS site, a very dense and diverse plant assemblage existed before the tide gate retrofit. After the retrofit, a high percentage cover of bare ground, milfoil, and algae replaced the plant assemblage. CI site vegetation changed dramatically between 2006 and 2009, with an increase in reed canarygrass and soft rush. Overall, non-native species cover increased from $8 \%$ in 2006 to 34\% in 2009 . These changes happened very rapidly at all sites. Within 1 year (2005 to 2006 at the KF and VA sites) after the initiation of the projects, species plant composition changed significantly. Of note at the KF site was the reduction of creeping buttercup and Himalayan blackberry between 2005 and 2006.

The rate of change from the before-action conditions varied somewhat, but there was a general downward trend to the last sampling in 2009. After 4+ years, the vegetation assemblage at the restored sites was on average $31 \%$ similar to pre-action assemblage. The similarities of the vegetation in the restored sites to the reference sites were very low after 4 years, with an average of $15 \%$ similarity.

The vegetation community at the VR site showed little change in the year after the tide gate retrofit. Although some change was recorded at the KR site, we believe this was an artifact of changing the sampling method. The KR site, because of the dominance by large trees and the understory of shrubs, is a relatively stable assemblage and would not be expected to change much annually. CR site vegetation changed very little through time, although the similarity value between 2006 and 2009 was only 50\%. We believe that this was caused by a difference in the cover of one species. We sampled in September in 2006 and in July in 2009 and noted this species, although present in July, was small and not abundant. Having sampled in September may have resulted in larger plants and higher cover, with a concordant increase in similarity between the 2 years.

The number of species and species diversity indices showed some trends over time. Species richness and diversity remained relatively stable at all reference sites, except at the KR site where sampling methods improved species inclusion in 2009. Both of the KF plots contained more species but a lower diversity when comparing 2005 with 2009 . The CI site showed both a reduction in species and diversity between 2006 and 2009. The VS site showed the most pronounced reduction in species and diversity between 2005 and 2009.

We were not surprised by the response of the plant assemblage to the restoration actions. It has been shown that tidal marshes undergo a dynamic change in plant cover and species composition at least for the first 5 years after reconnection to natural hydrodynamics (Thom et al. 2002). As conditions change, the initial assemblage dies back and is replaced by early colonizing species, and may contain a high diversity of many small plant species. Bare space is common during this initial period of change. After 5 to 6 years, larger perennial species begin to dominate the assemblage, and changes in species composition slows. The persistence of bare space at the VS site suggests that the muted hydrodynamics keeps the water level too high for establishment of an emergent marsh, and perhaps restricts the flow of seeds into the site. 
The satellite imagery analysis of the KF and KR complex provided the best indication of spatial patterns of change between 2005 and 2009. First, the changes in vegetation were detectable over the entire 65-ha site. We purposefully sampled intensively very close (proximal) to the culverts, where we expected the greater "signal" to be detected. It is apparent that this area showed the greatest relative change compared to other areas on the site. However, the shift in vegetation was detectable even at points farthest from the culvert - up to $\sim 1 \mathrm{~km}$ from the culverts. We expect that this shift far from the culverts was helped by the fact that hydrological connection was made by restoring connections to the river via notches in the levee on the Grays River side of the property, as well as the fact that the site has low topographic relief, and contains numerous shallow channels that routed water to the interior of the site. The data collected along the line-intercept transect located proximal to the breaches on riverside levee proved that major changes in the vegetation occurred between 2005 and 2009. The KR site also showed apparent changes, especially at the interior of the site, which is dominated by herbaceous wetland species. At this point, we assume that natural variation in hydrological conditions between the 2005 and 2009 sampling caused the changes within the KR site.

\subsubsection{Habitat Availability}

Because opportunity to access site by salmonids is critical to providing benefit to the fish, we explored various methods for estimating the habitat available to aquatic species. The two primary elements in this analysis are hydrology and topography/bathymetry. Other elements believed to be important are the channel-tidal marsh edge interface. These edges often are regions of high productivity, invertebrate biomass, and are easily accessed by fish when the water level is high enough. In addition, we were interested in the area of the site that had the potential for fish access. We also felt that wetted area, as well as inundation perimeter and modified topographic wetness, provided the best approximation of the functional size of the site not only for fish use but also for processing of nutrients, and the production and export of organic matter. Hence, we calculated channel edge length at the sites as well as wetted area using water level and topographic relief. In addition, several other site-scale metrics were calculated, and these may become more useful as predictors of opportunity and functional area when more studies are conducted.

These calculations showed that the restored and reference sites differed in all site-scale metrics. The KF site had the greatest habitat opportunity $(66.0 \%)$ among all of the sites. The opportunity at the KF site was far greater than the opportunity offered at the KR site $(14.6 \%)$, because of the higher elevations at the latter. The total channel edge length was also much greater at the KF site than at the KR site. These data suggest that fish would be able to access the KF site and be exposed to the channel edges far more frequently than at the KR site. Both VS and CI sites had lower opportunity values but greater edge lengths than their respective reference sites. The CI site had the greatest edge length of all the sites (both restored and reference). When the results are standardized for the size of the sites, the CR and VR sites exceed their respective restoration sites in habitat opportunity. However, the differences in the restoration actions will likely result in differences in habitat opportunity between the sites over time. At the CI site, habitat opportunity is likely to increase over time as the excavated channels become more dendritic. This process was observed in the field in 2007 (Borde et al. 2008a) and is notable in the 2009 LiDAR, which was used to determine the habitat connectivity. Conversely, at the VS site the habitat opportunity is not likely to change due to limited tidal exchange and inundation afforded by the tide gates. The high habitat opportunity at the KF site is likely due the existence of remnant channels that were present at the site prior to restoration and the open hydrologic exchange at the site. 


\subsubsection{Fish}

At Vera Slough, we found little difference in the fish community structure at Inside, Outside, or Reference sites in 2005 or 2006 (pre- and post-restoration). Fish populations were dominated by threespine stickleback, sculpin, and introduced killifish. Few salmon were captured inside or outside, during pre- or post-restoration periods. At the KF site in contrast, there was a dramatic increase in catches, diversity, and species counts after tidal reconnection. Salmonids, peamouth, and starry flounder (Platichthys stellatus) juveniles composed large proportions of the catch. All of these indicators were higher those at the estuarine site. Trap net samples made inside the restored marsh had fewer species but a higher proportion of salmonids than seine samples made outside the breach site.

At the VS site, we sampled a very low number of salmonids at any site or time. Despite a large amount of hatchery releases from pen nets across Youngs Bay, all Chinook and coho we sampled except one were $<70 \mathrm{~mm}$ long. At nearby estuarine sites, juvenile salmonids were abundant during the period we sampled. We conclude there is a low delivery of migrating fish to Vera Slough system. In contrast, indicators for salmon wetland occupation were all positive at the KF site. The Grays River has both natural and hatchery-produced salmonids, and these fish were present in the newly restored KF site the run year after reconnection. Chum salmon dominated the salmonid catch with moderate coho counts and a low number of Chinook salmon. The presence of chum was sharply punctuated, while coho and Chinook had a more protracted presence. Size-frequency data indicate a majority of chum and Chinook were fry $<60 \mathrm{~mm}$ long, although fingerling Chinook and coho and yearling coho were also present. The size-at-release data and lack of external marks suggest most salmon sampled were of natural origin. Similarly, salmon occupied inside natural breach sites at the same frequency as the outside sites, and likewise exhibited very similar Chinook salmon life-history distributions.

Insects produced in wetlands are the dominate prey type for salmon foraging in many habitats, including fluvial, tidal freshwater, and estuarine environments. However, comparisons between restoration wetlands and channel habitats in the Grays River system have shown that restoration sites provided greater diet diversity than did sampling stations in the Grays River. Fish inside restoration sites ate more annelids and fish, and although the abundance of these prey items in stomachs was relatively low, the prey items were large and likely of high caloric value.

The large difference in salmonid habitat use between sites is informative for site selection of restoration projects. The topographic setting of the VS site (tucked in a corner and flanked by an extensive mudflat) and the lack of upstream spawning beds, probably limits the number of salmon that will access the site, regardless of the improved connectivity. In contrast the KF site lies along the migration route of a major chum spawning population as well as a migrant source of Chinook and coho salmon. Reconnection of the KF site allowed these juvenile salmonids to use productive new habitat. Similarly, natural breach sites situated on the main stem river generally had higher CPUE values than sites in Youngs Bay.

\subsubsection{Productivity and Material Exchange}

Two ecological processes of primary importance to ecosystems are the production of organic matter and export of the organic matter into the ecosystem. We used the peak summer standing crop (biomass) of wetland vegetation as an indicator of net annual primary production (NAPP), and the difference between the standing crop in summer and the following winter to indicate export of NAPP to the broader 
ecosystem. The results indicate that NAPP is within the range reported previously for the CRE and for other regions of the Northwest (Simenstad et al. 1990). Patterns between years and among sites varied in terms of NAPP. NAPP was lowest in the KR site because only the understory vegetation was included. NAPP appeared to increase with the age of the KF site. NAPP was greater in 2009 than 2006 at the CI site. The VS site contained high NAPP in 2005 through 2007. The brackish marsh at the VR site maintained a relatively high NAPP throughout the 2005-2010 period.

The biomass loss (assumed to be exported) ranged from 4 to $87 \%$ of the summer standing crop, with exception of the KR site which showed negative export (i.e., higher winter biomass) in all years. Apparent negative export can be explained by either the patchiness of the herbaceous wetland vegetation, which made sampling replication difficult, or the higher elevation of the reference site compared to the restored site. The rapid colonization and dominance of the CI site with reed canarygrass we believe explains the low export rates of 5 and $4 \%$ during the last two sampling periods. Reed canarygrass develops a thick mat of material that is probably not readily removed by winter floods. Although the $\mathrm{KF}$ site saw a rapid increase in this species, the site was not as highly dominated as the CI site. The KF site exported 71 and $65 \%$ of the summer biomass during the last two sampling periods. Export from the VS site ranged from 14 to $78 \%$ over the three periods of measurement.

The mass that is exported can be substantial. Using a simple calculation of potential biomass flux from the KF site with a peak standing crop of $635 \mathrm{~g} \mathrm{~m}^{-2}$, and multiplying that by the total area of the site $\left(655,994 \mathrm{~m}^{2}\right)$ results in a potential mass loss of $413 \mathrm{mT}$ dry weight. Simenstad et al. (1990) reported that, of the peak standing crop, about $47 \%$ was likely exported from tidal marsh sites in the CRE. This means that $194 \mathrm{mT}$ dry wt would have been exported from the KF site between 2009 and 2010. Our refined calculations of export for the KF, VS, and CI sites were approximately 97, 152, and $25 \mathrm{mT}$ dry wt, respectively. We question the VS estimate because of the limited connection through the tide gate, and that vegetation remained sparse through our last sampling.

One key question we wanted to address was the potential contribution of marsh macrodetritus back into the broader LCRE food web. The POM modeling showed that a substantial proportion of the organic matter leaving the KF site would reach the estuary (Appendix E). For the KF site, approximately 52\% of the material exported would reach Grays Bay, and 48\% would remain in the floodplain and river. Further, based on the location and model runs for the KF site, POM produced in wetlands as far $15.5 \mathrm{~km}$ upstream from the mouth of the Grays River tributary would reach Grays Bay.

The mass of organic matter reaching the estuary $\left(\mathrm{POM}_{\text {estuary }}\right)$ is a function of the peak standing crop $\left(\mathrm{NAPP}_{\text {peak }}\right)$, proportion of mass lost over winter $\left(\mathrm{NAPP}_{\text {loss }}\right)$, proportion of that mass that is actually exported (EX) (i.e., not eaten on site or translocated to the roots, etc.), area (A) of the site, distance (D) between the site and the estuary proper (i.e., the mouth of a tributary stream or river), and rate (R) that mass is lost according to distance from the estuary. We have used the estimate of $\mathrm{EX}=0.47$ provided by Simenstad et al. (1990).

$$
\mathrm{POM}_{\text {estuary }}=\left(\mathrm{NAPP}_{\text {peak }} \mathrm{x} \mathrm{NAPP}_{\text {loss }}\right)(\mathrm{EX})(\mathrm{A})(\mathrm{R})
$$

where $\mathrm{R}=0.969-0.062(\mathrm{D}, \mathrm{km})$.

Related to POM export is the ability of a system to process inorganic nutrients, trap sediment, affect temperature and DO, and exchange dissolved organic matter. In Appendix E, we summarize the 
short-term intensive flux study conducted at the KF site in April 2009. During the spring, the wetland appeared to serve as a source for inorganic nitrogen, and act as a sink for total organic carbon, suspended sediments, and silicate. Tidal hydrodynamics was a significant driver in the observed oscillation of dissolved material during the short-term flux study. The seasonal aspects of the nutrient and dissolved organic matter were not studied, but we expect that a source and sink shift may occur for some, if not all parameters throughout the year. The sediment accretion rate studies verified the suspended sediment import noted in the spring. We also found that insects were being exported from the site via tidal action. Thus the system was serving as a source of insects to the broader ecosystem. Because the insects were associated with neuston, including marsh macrodetritus, we believe that prey produced in these systems were probably reaching the floodplain and may be reaching the estuary.

\subsubsection{Indicators}

Using intensively studied sites, we evaluated indicators of habitat development rates and patterns, and how these habitat indicators related to ecological benefits. Our data sets are relatively short in time such that we captured only the initial phase of development of the restored sites. However, research by Diefenderfer et al. (2010) extended the habitat trajectory analysis using sites breached or created over the past $4+$ decades. The data from replicate intensively studied sites allowed us to use ratio estimators for extrapolating results from the intensive studies to extensive areas in the estuary. Through development of these estimators, we evaluated metrics that can be relatively easily measured at all sites and can be used to estimate higher-order metrics more indicative of ecosystem processes and functions.

The six core metric types and the three higher-order metric types were effective in quantifying changes at the sites. Thus these metrics are effective "indicators" of site response to restoration actions. The linkages appear to be clear between many of the factors. For example, WSE information links well with the vertical distribution of vegetation species. Water temperature showed a response to various actions and also to the presence of fish, with fish appearing to leave sites when the temperature exceeded a certain level. The cross-sectional area, channel morphology, and other features of the topography of the site did change as would be expected when hydrology changes. We recorded a net increase in accretion rate compared with reference sites, which is critical for restoring subsided sites.

Habitat availability presented a unique challenge for us. We were able to show that there are many potential indicators of habitat availability for fish and other aquatic species. We surmise, based on the literature, that the more water over a site the better the opportunity for fish to access productive areas within the wetland, and for vegetation to shift to more natural conditions, and for more exchange to happen between the water and the wetland. We felt that estimates of the "effective" area for fish could be further refined. Hence, we developed indicators of channel edge length. The effectiveness for these processes probably is not linear. For example, at the VS site, water depths after the tide gate retrofit probably remain too high for emergent wetland vegetation to develop. Also, just having more water did not result in more fish accessing that site. Other factors contributed to the lack of salmonids reaching that site. We believe that studies evaluating the relevance of habitat availability indicators and fish benefit are in order. This would help in the design of projects, as well as predictions of growth benefit associated with potential restoration sites.

Perhaps most interesting, and relevant to restoring the floodplain, was the proof that materials developed in the wetland do eventually reach the estuary, even from as far as $15 \mathrm{~km}$ up a tributary. In addition, the presence of "out of basin" salmonids in the tributary site at the KF site proved that fish do move up the tributaries at least $8 \mathrm{~km}$ from the mouth of the Grays River to rear. Finally, the presence of 
prey produced in the wetland reaching the broader ecosystem is likely. New observations by Weitkamp (personal communication March 2011) indicated that salmonids that undergo rapid outmigrations (e.g., 2 to 5 days) through the estuary are feeding extensively on prey produced in wetlands in the estuary. Thus fish are accessing food through direct contact with the restored marshes and through indirect access through material exported from these wetlands. Our research on juvenile salmonids allowed us to evaluate indicators for assessing the benefit of wetland restoration to salmon (Tables 2.1 and 2.2).

\subsubsection{Summary of Restoration Responses}

We summarize in Table 2.22 the generalized responses of the various restoration actions relative to the categories of indicators. Although we studied only one replicate of each type of action, we believe that these sites are representative of the response a site would show to each action type. That said, there are nuances to every site and action. For example, the fact that no salmonids were recovered at the VS site does not necessarily mean that they were excluded from the site by the tide gate. It was clear to us that the degree and quality of the cascade of responses by the indicators from tidal hydrological reconnection was dependent on the degree of natural connection achieved.

Table 2.22. Summary of the Relative Effects of the Various Restoration Actions on the Core and HigherOrder Indicators (Roegner et al. 2009a)

\begin{tabular}{|c|c|c|c|}
\hline Indicators Category & $\begin{array}{l}\text { Tide Gate Retrofit } \\
\text { (Vera Slough) }\end{array}$ & $\begin{array}{c}\text { Full Breach } \\
\text { (Kandoll Farm) }\end{array}$ & $\begin{array}{c}\text { Elevation Modification } \\
\& \text { Breach } \\
\text { (Crims Island })\end{array}$ \\
\hline Hydrology & $\begin{array}{l}\text { Restricted tidal } \\
\text { hydrodynamics no flooding }\end{array}$ & $\begin{array}{l}\text { Natural tidal hydrodynamics } \\
\text { and flooding; larger than } \\
\text { historical tidal prism }\end{array}$ & $\begin{array}{l}\text { Natural tidal } \\
\text { hydrodynamics and } \\
\text { flooding }\end{array}$ \\
\hline Water Quality & Altered temperatures & $\begin{array}{l}\text { Favorable temperatures in } \\
\text { most channels; some spatial } \\
\text { variability }\end{array}$ & Favorable temperatures \\
\hline Topography/Bathymetry & $\begin{array}{l}\text { Small change in } \\
\text { topography; channel } \\
\text { morphology change } \\
\text { primarily at outlet; higher } \\
\text { accretion than reference }\end{array}$ & $\begin{array}{l}\text { Small change in topography; } \\
\text { channel morphology change } \\
\text { primarily at outlet; higher } \\
\text { accretion than reference }\end{array}$ & $\begin{array}{l}\text { Large change in } \\
\text { topography and channel } \\
\text { morphology; higher } \\
\text { accretion than reference }\end{array}$ \\
\hline Landscape & $\begin{array}{l}\text { Detectable change in } \\
\text { vegetation throughout site }\end{array}$ & $\begin{array}{l}\text { Detectable change in } \\
\text { vegetation throughout site }\end{array}$ & NA \\
\hline Vegetation & $\begin{array}{l}\text { Major loss in vegetation; } \\
\text { severely restricted } \\
\text { colonization of new } \\
\text { assemblage }\end{array}$ & $\begin{array}{l}\text { Major shift in vegetation; } \\
\text { rapid colonization of new } \\
\text { assemblage }\end{array}$ & $\begin{array}{l}\text { Major shift in vegetation; } \\
\text { rapid colonization of new } \\
\text { assemblage }\end{array}$ \\
\hline Habitat Availability & $\begin{array}{l}\text { Availability greatly } \\
\text { restricted }\end{array}$ & $\begin{array}{l}\text { Availability greatly } \\
\text { enhanced }\end{array}$ & $\begin{array}{l}\text { Availability greatly } \\
\text { enhanced }\end{array}$ \\
\hline Material Flux & Restricted & Natural exchange & Natural exchange \\
\hline Fish Usage & Greatly restricted & Proven enhancement & Proven enhancement \\
\hline
\end{tabular}




\subsubsection{Summary of Findings and Implications for Cumulative Effects Evidence}

Here we summarize the findings from this chapter and other chapters, appendices, and reports. Our summary highlights conclusions that can be inferred from the studies over the past 6 years that are directly related to site and ecosystem restoration and salmonid benefits. Based on quantitative results and qualitative observations from our studies, we verbalized the types of inference that can be implied at these three scales. Some of the findings are directly relevant to restoration project design and prioritization (e.g., type of action, type of plant community, landscape location). We also reference here the source of the finding. We were guided in the selection of these topics by An Ecosystem-Based Approach to Habitat Restoration Projects with Emphasis on Salmonids in the Columbia River Estuary (Johnson et al. 2003), which presented a general strategy for ecosystem restoration in the estuary. Our study addressed a large number of elements listed within the 11 recommendations from that document. The elements drawn from the original recommendations of Johnson et al. (2003) that we made progress toward addressing are paraphrased below:

- Resolve critical uncertainties concerning salmonid habitat requirements, including juvenile salmonid use of tidal freshwater habitats.

- Resolve linkages between biological and physical processes in various habitat types.

- Resolve the landscape qualities of preferred habitat types.

- Resolve habitat-forming processes for key habitat types.

- Resolve food-web interactions and prioritize restoration projects that promote long-term sustainability of ecosystem function and structure at the landscape scale.

- Perform effectiveness monitoring for implemented projects.

- Develop methods to evaluate the cumulative effects of multiple projects.

- Establish an adaptive management process as part of the habitat restoration efforts.

Our proposed method to evaluate the cumulative effects of multiple restoration projects is described by Diefenderfer et al. (2011). The method involves summing positive responses of actions versus negative or no responses. Inferences for salmonids listed in Table 2.23 in general are positive based on our research. Taken together with site and ecosystem responses, we conclude that restoration projects will have a cumulative effect depending nuances of size, function supported, distance from the estuary, etc., as summarized in Table 2.23. The information contained in this chapter will feed into the upcoming levels-of-evidence analysis of cumulative effects. 
Table 2.23. Summary of Findings and Inferences to the Site and Ecosystem Scales, and Salmonids. The source of the finding is referenced in parentheses.

\begin{tabular}{|c|c|c|c|}
\hline Finding & Inferences for the Site & Inferences for the Ecosystem & Inferences for Salmonids \\
\hline $\begin{array}{l}\text { Clear response of vegetation } \\
\text { assemblage to restoration actions } \\
\text { within } 1 \text { year following hydrological } \\
\text { reconnection (Chapter } 2.0 \text { ) }\end{array}$ & $\begin{array}{l}\text { Recovery of site habitat structure } \\
\text { initiated quickly; restoration of } \\
\text { natural biodiversity; enhanced site } \\
\text { resilience }\end{array}$ & $\begin{array}{l}\text { Processes associated with structure } \\
\text { initiated within } 1 \text { year }\end{array}$ & $\begin{array}{l}\text { Juvenile salmonid habitat access } \\
\text { opportunity and feeding and rearing } \\
\text { capacity are increased within } 1 \text { year }\end{array}$ \\
\hline $\begin{array}{l}\text { Initiation of sediment accretion } \\
\text { (Chapter 2.0) }\end{array}$ & $\begin{array}{l}\text { Will lead to restoring elevations } \\
\text { lost through subsidence }\end{array}$ & $\begin{array}{l}\text { Rapid vegetation assemblage } \\
\text { development will extend for much } \\
\text { longer than the } 4 \text { years of this study }\end{array}$ & $\begin{array}{l}\text { Juvenile salmonid feeding and rearing } \\
\text { capacity will change through time toward } \\
\text { natural conditions }\end{array}$ \\
\hline $\begin{array}{l}\text { Redevelopment of historical tidal } \\
\text { channels (Chapter 2.0; Diefenderfer } \\
\text { and Montgomery 2009) }\end{array}$ & $\begin{array}{l}\text { Development of productive marsh } \\
\text { edges and natural wetland } \\
\text { morphology }\end{array}$ & $\begin{array}{l}\text { Increased channel area and } \\
\text { productive marsh edges in the } \\
\text { floodplain; enhanced area for } \\
\text { nutrient processing and export of } \\
\text { organic matter }\end{array}$ & $\begin{array}{l}\text { Juvenile salmonid habitat feeding and } \\
\text { rearing capacity increased; enhanced } \\
\text { organic matter export to estuarine } \\
\text { ecosystem salmonid food web }\end{array}$ \\
\hline $\begin{array}{l}\text { Exposure of buried large wood and } \\
\text { development of stepped pools in tidal } \\
\text { channels (Chapter 2.0; Diefenderfer } \\
\text { and Montgomery 2009) }\end{array}$ & $\begin{array}{l}\text { Development of natural wetland } \\
\text { morphology to support microhabitat } \\
\text { development, and natural } \\
\text { biodiversity }\end{array}$ & $\begin{array}{l}\text { Increased channel area in the } \\
\text { floodplain; enhanced area for } \\
\text { nutrient processing, organic matter } \\
\text { deposition, secondary production }\end{array}$ & $\begin{array}{l}\text { Enhanced quality for salmonid rearing } \\
\text { and prey production in the floodplain }\end{array}$ \\
\hline $\begin{array}{l}\text { Improved water-quality conditions } \\
\text { (e.g., temperature) where substantial } \\
\text { hydrological connectivity was } \\
\text { restored (Chapter 2.0) }\end{array}$ & $\begin{array}{l}\text { Development of natural wetland } \\
\text { water properties and support of } \\
\text { aquatic species }\end{array}$ & $\begin{array}{l}\text { Improved water properties in } \\
\text { estuarine ecosystem }\end{array}$ & $\begin{array}{l}\text { Enhanced quality for salmonid rearing } \\
\text { and prey production in the floodplain and } \\
\text { estuary }\end{array}$ \\
\hline $\begin{array}{l}\text { Frequent, prolonged, and repeated } \\
\text { between-year use of restored sites by } \\
\text { juvenile salmon (Chapter } 2.0 \text {; } \\
\text { Roegner et al. } 2010 \text { b) }\end{array}$ & Natural biodiversity development & $\begin{array}{l}\text { Natural ecosystem biodiversity } \\
\text { development }\end{array}$ & $\begin{array}{l}\text { Long-term enhancement of salmonid life- } \\
\text { history diversity }\end{array}$ \\
\hline $\begin{array}{l}\text { Use of tributary restored wetlands by } \\
\text { "out of basin" fish (Chapter 2.0; } \\
\text { Roegner et al. 2010b) }\end{array}$ & Natural biodiversity development & $\begin{array}{l}\text { Natural ecosystem biodiversity } \\
\text { development }\end{array}$ & $\begin{array}{l}\text { Enhancement of salmonid populations } \\
\text { and life-history diversity in the ecosystem }\end{array}$ \\
\hline
\end{tabular}


Table 2.23. (contd)

\begin{tabular}{|c|c|c|c|}
\hline Finding & Inferences for the Site & Inferences for the Ecosystem & Inferences for Salmonids \\
\hline $\begin{array}{l}\text { Nutrient processing and organic } \\
\text { carbon production (Chapter } 2.0 ; \\
\text { Appendix E) }\end{array}$ & $\begin{array}{l}\text { Development of natural wetland } \\
\text { biogeochemical processes }\end{array}$ & $\begin{array}{l}\text { Enhancement of natural ecosystem } \\
\text { biogeochemical processes }\end{array}$ & $\begin{array}{l}\text { Contribution of organic matter to support } \\
\text { prey production in estuary }\end{array}$ \\
\hline $\begin{array}{l}\text { Export of marsh macrodetritus } \\
\text { (Chapter 2.0; Appendix E) }\end{array}$ & $\begin{array}{l}\text { Development of natural wetland } \\
\text { primary production cycle }\end{array}$ & $\begin{array}{l}\text { Enhancement of marsh } \\
\text { macrodetritus entering the } \\
\text { ecosystem; restoration of food web }\end{array}$ & $\begin{array}{l}\text { Contribution of organic matter to support } \\
\text { prey production in estuary }\end{array}$ \\
\hline $\begin{array}{l}\text { Greater tidal reconnection produces } \\
\text { quicker recovery (Chapter 2.0) }\end{array}$ & $\begin{array}{l}\text { Quicker development of natural } \\
\text { wetland structure and processes }\end{array}$ & $\begin{array}{l}\text { Quicker recovery of ecosystem } \\
\text { processes }\end{array}$ & $\begin{array}{l}\text { Quicker recovery of support for } \\
\text { salmonids }\end{array}$ \\
\hline $\begin{array}{l}\text { Evidence of potential synergism and } \\
\text { optimization of projects (Chapter 2.0; } \\
\text { Appendix E) }\end{array}$ & $\begin{array}{l}\text { Site functions depend on sites } \\
\text { surrounding them }\end{array}$ & $\begin{array}{l}\text { Ecosystem functions depend on } \\
\text { synergistic aspects of suites of sites }\end{array}$ & $\begin{array}{l}\text { Synergistic support of salmonids through } \\
\text { opportunity and capacity enhancement }\end{array}$ \\
\hline $\begin{array}{l}\text { Evaluation of the utility of the } \\
\text { methods/protocols (Appendix F) }\end{array}$ & $\begin{array}{l}\text { Efficient measures of highly } \\
\text { relevant site conditions }\end{array}$ & $\begin{array}{l}\text { Provide scale-up to ecosystem-wide } \\
\text { estimates }\end{array}$ & $\begin{array}{l}\text { Provide direct assessment of factors } \\
\text { affecting salmonid growth and survival }\end{array}$ \\
\hline $\begin{array}{l}\text { Size of project needed to provide } \\
\text { measureable ecological response } \\
\text { (Chapter } 2.0)\end{array}$ & $\begin{array}{l}\text { Project size for design and } \\
\text { prioritization }\end{array}$ & $\begin{array}{l}\text { Size at which project shows signal } \\
\text { in the ecosystem }\end{array}$ & $\begin{array}{l}\text { Size of project needed to attract juvenile } \\
\text { salmon and provide reasonable } \\
\text { opportunity and capacity enhancement }\end{array}$ \\
\hline $\begin{array}{l}\text { Level and type of restoration affects } \\
\text { rates and patterns of vegetation } \\
\text { development, and site conditions } \\
\text { (Chapter 2.0) }\end{array}$ & $\begin{array}{l}\text { Project type and level of action for } \\
\text { design and prioritization; and } \\
\text { naturally sustainable and resilient }\end{array}$ & $\begin{array}{l}\text { Project type and level of action at } \\
\text { which project shows a signal in the } \\
\text { ecosystem }\end{array}$ & $\begin{array}{l}\text { Project type and level of action needed to } \\
\text { attract juvenile salmon and provide } \\
\text { reasonable opportunity and capacity } \\
\text { enhancement }\end{array}$ \\
\hline $\begin{array}{l}\text { Location of site in the landscape } \\
\text { affects the system functions } \\
\text { (Chapter 2.0; Roegner et al. 2010b) }\end{array}$ & $\begin{array}{l}\text { Project site selection to maximize } \\
\text { site functions and resilience }\end{array}$ & $\begin{array}{l}\text { Suite of project sites that act } \\
\text { together to produce a signal in the } \\
\text { ecosystem; distance between the } \\
\text { site and the estuary affects function } \\
\text { to the estuary }\end{array}$ & $\begin{array}{l}\text { Suite of project sites which act together to } \\
\text { produce a signal in salmonid populations }\end{array}$ \\
\hline $\begin{array}{l}\text { Nonlinear change in floodplain area } \\
\text { with increase in levee breaches } \\
\text { (Johnson et al. 2009) }\end{array}$ & $\begin{array}{l}\text { Fewer breaches needed to restore } \\
\text { near-maximum floodplain-wetted } \\
\text { area }\end{array}$ & $\begin{array}{l}\text { Exchange of species and materials } \\
\text { between sites maximized with less } \\
\text { than full breaching of all potential } \\
\text { sites }\end{array}$ & $\begin{array}{l}\text { Access and benefits of habitats in the } \\
\text { ecosystem to salmonids maximized with } \\
\text { less than full restoration of historical } \\
\text { floodplain area }\end{array}$ \\
\hline
\end{tabular}


Table 2.23. (contd)

\begin{tabular}{|c|c|c|c|}
\hline Finding & Inferences for the Site & Inferences for the Ecosystem & Inferences for Salmonids \\
\hline $\begin{array}{l}\text { Key factors that need to be developed } \\
\text { to maximize the rate of development } \\
\text { and production of benefits } \\
\text { (Chapter } 2.0 \text { ) }\end{array}$ & $\begin{array}{l}\text { Hydrology, elevation, and size } \\
\text { drive vegetation development and } \\
\text { initiation of processes }\end{array}$ & $\begin{array}{l}\text { Location of sites in the ecosystem } \\
\text { affects relative impact on the } \\
\text { ecosystem }\end{array}$ & $\begin{array}{l}\text { Water level, driven by tidal hydrology } \\
\text { and river flow, determine the active } \\
\text { wetland/floodplain area that supports } \\
\text { salmonids }\end{array}$ \\
\hline $\begin{array}{l}\text { Length of time the restored habitat } \\
\text { will provide desirable benefits } \\
\text { (Chapter } 2.0 \text { ) }\end{array}$ & $\begin{array}{l}\text { With restoration of natural habitat- } \\
\text { forming processes, should last at } \\
\text { least } 50 \text { years; development to full } \\
\text { functioning may take a decade to } \\
\text { centuries }\end{array}$ & $\begin{array}{l}\text { Duration of functioning within the } \\
\text { ecosystem is tied to both the } \\
\text { individual sites and the synergies } \\
\text { among sites }\end{array}$ & $\begin{array}{l}\text { Benefit to salmon is linked to site and } \\
\text { ecosystem functional life; duration of } \\
\text { restoration projects should provide } \\
\text { benefits long enough to affect salmon } \\
\text { populations }\end{array}$ \\
\hline $\begin{array}{l}\text { Implications for restoration of the } \\
\text { riverscape from Bonneville Dam to } \\
\text { the mouth (Chapter } 2.0)\end{array}$ & $\begin{array}{l}\text { Sites provide functions near } \\
\text { (proximal) the site and to the } \\
\text { broader ecosystem (distal) }\end{array}$ & $\begin{array}{l}\text { Suites of sites provide functions to } \\
\text { the broader ecosystem (extensive) }\end{array}$ & $\begin{array}{l}\text { Restoration of functions throughout the } \\
\text { riverscape should have at least some } \\
\text { salmon through direct contact, processing } \\
\text { of water properties, and by export of } \\
\text { materials }\end{array}$ \\
\hline
\end{tabular}




\title{
3.0 Adaptive Management of Ecosystem Restoration in the Lower Columbia River and Estuary
}

\author{
Prepared by Ron Thom, Gary Johnson, Blaine Ebberts, Cynthia Studebaker, \\ Heida Diefenderfer, and Catherine Corbett
}

Any adaptive management (AM) process hinges on a clear goal statement. For the CEERP, the goal is to understand, conserve, and restore ecosystems in the LCRE. To fulfill the goal, the program's objectives are as follows:

- Understand the primary stressors affecting ecosystem controlling factors, such as ocean conditions and invasive species.

- Conserve and restore factors controlling ecosystem structures and processes, e.g., hydrodynamics and water quality.

- Increase the quantity and quality of ecosystem structures, e.g., habitats juvenile salmonids use during outmigration through the estuary.

- Maintain the food web to benefit ecosystems and salmonid performance.

- Improve salmonid performance in terms of life-history diversity, foraging success, growth, and survival.

An AM process that has active participation and buy-in from key stakeholders is needed to plan and prioritize projects, evaluate the effectiveness of constructed projects, and periodically synthesize results in a manner that significantly improves restoration program strategy and decision-making. Our purpose is to summarize a regional AM process for the CEERP that integrates elements from existing program documents and activities to formalize procedures that will enable the CEERP to successfully meet its goal. The CEERP covers ecosystem restoration in tidally influenced areas of the LCRE and its floodplain funded by BPA through the Columbia Land Trust (CLT), CREST, and Lower Columbia River and Estuary Partnership (EP), the USACE through its Water Resources Development Act (WRDA) authorities, and others through the Oregon Watershed Enhancement Board (OWEB), Lower Columbia Fish Recovery Board (LCFRB), etc. The focus is on the federal restoration effort, but the CEERP and its AM process includes all restoration avenues in the LCRE, as appropriate. The AM process proposed here is intended to provide direction for annual management decisions in the context of the long-term CEERP program planning. The process could be adopted and modified as needed by others to serve the needs of individual restoration programs. In this chapter, we describe the background, CEERP AM process (phases, teams, and deliverables), schedule, and infrastructure.

\subsection{Background}

Adaptive management is a basic element of other programs in the Columbia River basin, which have issues similar to the LCRE, including monitoring/research, evaluating, strategizing, and making decisions on program actions. Some of the most relevant efforts are the FCRPS AM Implementation Plan (Action Agencies 2009), the Supplemental 2010 BiOp (NMFS 2010a), and the AM programs associated with salmon recovery plans and modules, such as the Willamette Recovery Plan (NMFS 2010b) and the Estuary Module (NMFS 2011). The AM Implementation Plan focuses on actions that minimize the loss 
of salmon passing through the dams, whereas the Estuary Module focuses on habitat restoration and related actions to enhance salmon populations. Because salmon integrate the use of the river, tributaries, and estuary, some effort to communicate information among these three programs is appropriate. We describe an approach to this communication in Section 3.3 below. Because the EP restoration effort was developing rapidly in the mid-2000s, an EP-centric plan was developed to provide guidance to that program (Thom et al. 2007). EP staff and the EP Science Work Group have been diligent in incorporating AM into their annual cycle for restoration project funding, thereby refining the process through practice. The document titled Research, Monitoring, and Evaluation for the Federal Columbia River Estuary Program (Johnson et al. 2008), jointly developed by the BPA, NMFS, and USACE Portland District in collaboration with the EP, provides recommendations for an AM plan for the estuary restoration effort. These elements included a program goal and five general objectives, along with performance measures, recommendations related to critical uncertainties, monitoring/research, and synthesis and evaluation.

With issuance of the 2008 FCRPS BiOp (NMFS 2008), which contained several estuarine restoration actions, even more effort has been placed on restoration of LCRE habitats that support salmon. The federal Action Agencies (BPA and USACE), along with non-profit organizations (e.g., EP), watershed action groups, and others, are focusing their attention and resources on LCRE restoration to benefit not only listed salmon populations but also LCRE ecosystem functions and values. In fact, there are on the order of 20 stakeholder organizations for whom it is part of their mission to restore salmon, estuarine habitat, and water quality. Some groups, such as the EP, have implemented a process for inviting, prioritizing, and selecting restoration projects, then evaluating their success. More recently, the 2008 $\mathrm{BiOp}$ resulted in the development of a process to select projects for funding that will provide significant benefit to salmon survival in the estuary. Under the BiOp process, decisions are driven by a developing set of selection criteria, which are then used by project proponents and the Action Agencies to find the best projects. Restoration project proposals are subject to a review by a panel of experts (the ERTG). All involved, however, recognize that decisions are made in the context of uncertainties associated with ecosystem and habitat recovery and the benefits thereof.

A wide array of material is written about AM in ecosystem management. For example, the works by Lee (1993) and Walters (2001) are relevant to the LCRE. The National Research Council (2004) provided a review of USACE efforts to incorporate AM into its water resources project planning, and provided general recommendations about how to do this. In 2009, the USACE's Chief of Planning and Policy Division issued a memorandum summarizing guidance to the Districts on implementation for monitoring ecosystem restoration under Section 2039 of the WRDA of 2007. This guidance included a section on AM.

Several documents describe the applicability of AM to LCRE restoration, general background on AM, and critical elements of any AM program. Starting with the 2000 BiOp on operation of the FCRPS, there was new and significant emphasis on the importance of the estuary to ESA-listed species in the Columbia River basin (NMFS 2000). Responding to a mandate in this opinion, Johnson et al. (2003) provided an ecosystem-based approach for restoration in the estuary, recommending activities (paraphrased below) that are still relevant 8 years later:

- Organize and empower a coordinating body to provide technical and policy oversight of habitat restoration activities in the LCRE.

- Resolve the critical uncertainties concerning salmon habitat requirements in the LCRE. 
- Intensify the ongoing habitat-mapping effort, and apply the results to develop a comprehensive, unified, and quantified habitat inventory for the LCRE.

- Finalize draft project selection guidelines and maintain a running list of specific restoration projects, potential sites, and status.

- Prioritize restoration projects that promote the long-term sustainability of ecosystem function and structure at the landscape scale wherever possible.

- Establish a trust fund for LCRE habitat restoration projects.

- Perform action effectiveness monitoring and research for implemented projects and develop methods to evaluate the cumulative effects of multiple projects.

- Establish a data system for LCRE habitat restoration.

- Apply the restoration approach and implementation guidelines in this document and, as new information becomes available, institute follow-up work to develop a project implementation guidebook and a revised strategic plan for LCRE habitat restoration.

- Embrace a true AM process as part of LCRE habitat restoration efforts.

\subsection{CEERP AM Process}

The national guidebook on AM published by the Department of Interior (Williams et al. 2007) summarizes the conditions that warrant an AM approach. Two key conditions must exist: 1) a mandate to take action in the face of uncertainty, and 2) institutional capacity and commitment to undertake and sustain an AM program. In addition to these, six more conditions directly relate to AM application: 1) a real management choice is to be made; 2) there is an opportunity to apply learning; 3) clear and measureable management objectives can be identified; 4) the value of information for decision-making is high; 5) uncertainty can be expressed as a set of testable models; and 6) a monitoring/research system can be established to reduce uncertainty. At this point we feel that these conditions could be met in the LCRE, depending on clear identification of management objectives, decisions, and uncertainties, and, most importantly, a commitment by CEERP stakeholders to implement AM.

There are five scales at which decisions are potentially made. The role and composition of decisionmakers, frequency and specificity of decisions, and the role of social and economic drivers vary by scale. Stakeholders should be cognizant of various scales for decision-making. The scales may be described as follows:

- Individual structure/actions (Structure scale). These are actions where an engineer and construction contractor may decide the optimal design for creating shallow-water habitat that is specific to the conditions at a specific site, and incorporate landowner management objectives such as controlling invasive species and managing for multiple species (e.g., turtles, red-legged frogs, waterfowl). As guidance, they need biological information regarding the size, shape, depth, etc. of habitat that would produce the optimal benefit to the targeted resource species.

- Cumulative actions within a reach (Reach scale). This is a set of actions within the riverscape of a reach that, taken together, produce the most beneficial conditions for recovery of the targeted resource. Again, engineers need biological information that guides the structural design, such as the 
number, type, size, and distribution of structures that are optimal for the targeted species. Engineers also need physical and hydrodynamic data and models to best design the actions in that particular reach.

- Cumulative actions in multiple reaches within an estuarine hydrological unit (HU scale). Like cumulative actions in a reach, this biological information identifies and prioritizes the reaches within the three HUs that compose the estuary where actions would provide the most cumulative benefit to the targeted species.

- Cumulative actions in the entire estuary (Estuary scale). Finally, biological information is needed to identify and prioritize the HUs where actions would provide the most cumulative benefit to the targeted species. This scale is the most appropriate for incorporating flow manipulations because of the influence of flow on the entire river. Flow manipulation involves potential impingement on land as well as authorized uses of the river for such things as navigation. Also, this scale may be the most appropriate for actually assessing the cumulative effects of multiple actions on species recovery over the entire estuary.

- Program direction (Program scale). This is a very high-level scale that addresses whether the overall program is being effective in all performance aspects, including social and economic.

The standard phases in an AM cycle include deciding, acting, monitoring/researching, evaluating, and strategizing (Thom 2000; Figure 3.1). Each phase is dependent on results of previous phases. The process feeds back on itself so that decisions about actions to meet the goal are based on data from monitoring/research, information from evaluation, and guidance from strategizing. The phases for a CEERP AM process (Figure 3.1) are described below. In each phase, the AM process should include key teams of agency staff to perform specific roles, assume specific responsibilities, and produce the main deliverables (Table 3.1).

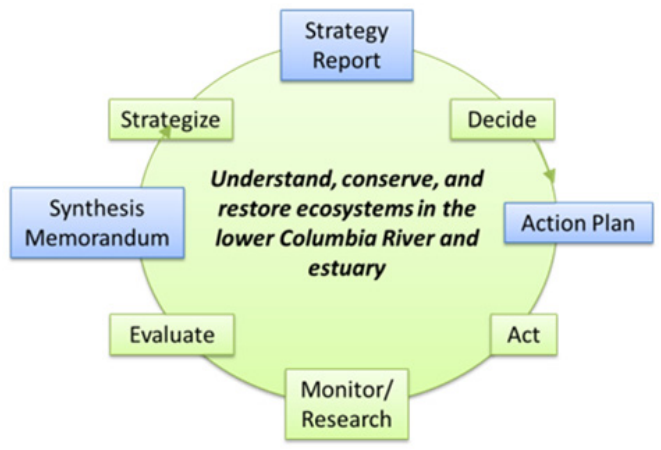

Figure 3.1. CEERP Adaptive Management Process

Table 3.1. AM Phases, Teams, and Deliverables

\begin{tabular}{lll}
\hline \multicolumn{1}{c}{ AM Phase } & \multicolumn{1}{c}{ Responsible Party or AM Team } & \multicolumn{1}{c}{ AM Deliverable } \\
\hline Decide & Funding Entities & Action Plan \\
Act & Restoration Practitioners & As-Built Report \\
Monitor/Research & RME Practitioners & Site Evaluation Cards \\
Evaluate & Technical Analysis Team & Synthesis Memorandum \\
Strategize & ERTG and Stakeholders Team & Strategy Report \\
\hline RME = research, monitoring, and evaluation; ERTG = Expert Regional Technical Group \\
\hline
\end{tabular}




\subsubsection{The Decide Phase}

The AM process could start with deciding what actions to undertake. To accomplish the goals of the CEERP, decisions would be made at various times and various levels, and should relate to program objectives and strategies. The decisions would be based on a complex interaction of policy, technical, social, and economic factors. For example, a project might be well-aligned except for high risk about its restoration technique, thereby presenting a difficult situation to decision-makers. The recommendations for 1) what to implement to alter the results of the program to better meet program goals and objectives, 2) what not to change, 3) what to eliminate, and 4) whether the goals, objectives, management questions or hypotheses need to be modified could lie with the AM Stakeholders Team (AMST), who would make recommendations to the funding entities. The Synthesis Memorandum and the Strategy Report (described below) would provide critical information for the decisions. The stakeholders' coordination process to make recommendations, the funding entities' decisions, and the mechanisms to implement actions should be developed from within by AMST members. The final decisions about funding restoration and monitoring/research are the responsibility of the funding entities. The product of the stakeholder process and funding agency decision-making would be the Action Plan (Figure 3.2; see details below). The funding entities would have a primary role in the development of the Action Plan.

\section{The "DECIDE" Phase}

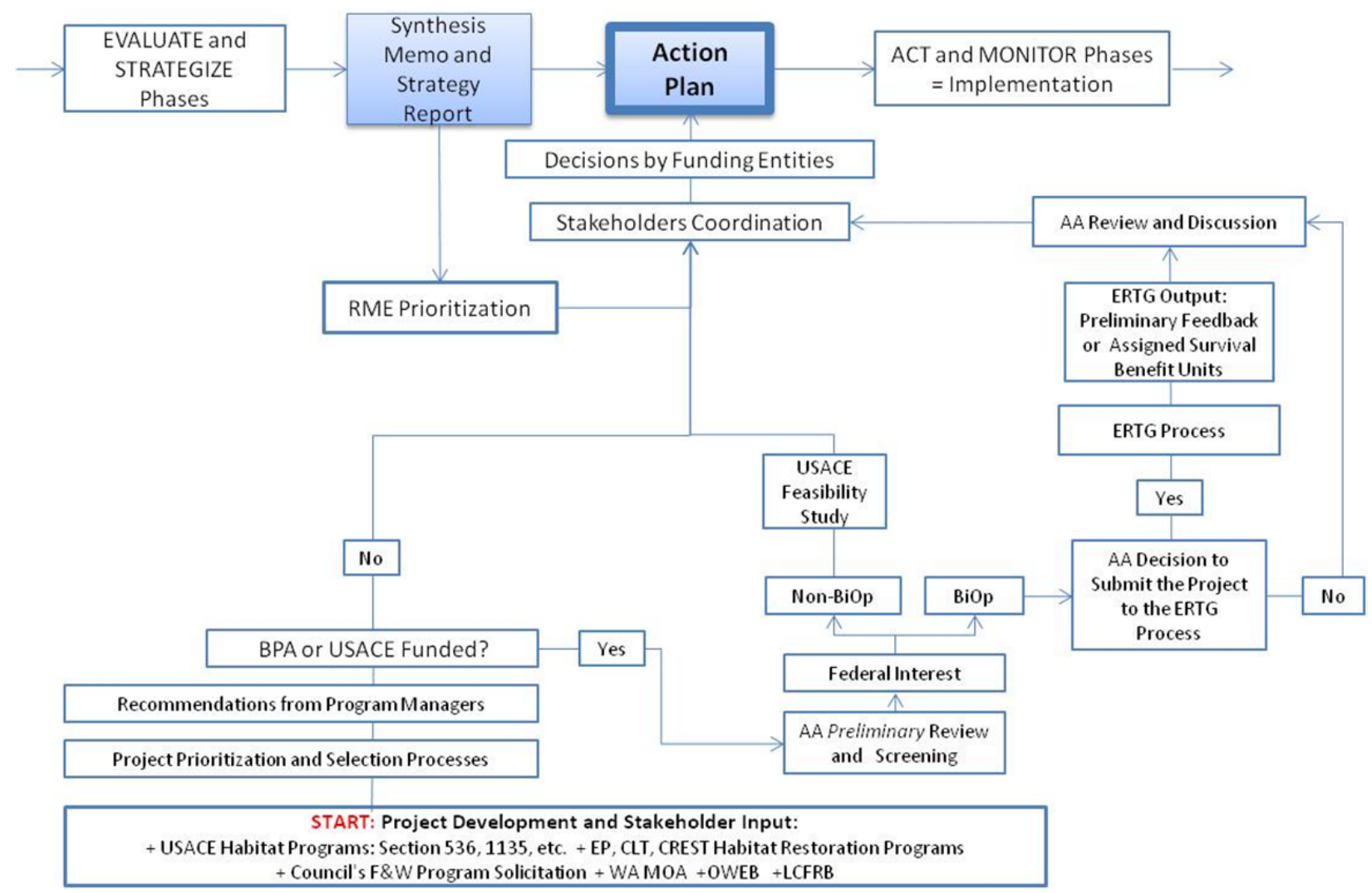

Figure 3.2. The Decide Phase in the CEERP Adaptive Management Process

The AMST would coordinate program actions and make recommendations about funding for specific projects and monitoring/research activities. The AMST would be tasked with 1) providing guidance for the program with regard to LCRE restoration, including changes to the implementation strategy from the 
use of AM and "the coordination of the development of consistent policies, strategies, plans, programs, projects, activities and priorities" for the program; 2) recommending the priority of actions for the subsequent annual and longer-term cycles; 3) coordinating among stakeholders; and 4) communicating CEERP progress to the region and to the nation. The AMST could be coordinated by the EP. The funding entity would make final decisions about restoration and research, monitoring, and evaluation (RME) funding. Recommendations by the AMST would be wide-ranging and based on learning through the annual AM process and captured as part of the Synthesis Report. The primary product from the AM process would be the annual Action Plan, which would be developed and issued by the funding entities, in collaboration with the AMST. A key deliverable of the AMST would be the Strategy Report. The AMST would be composed of representatives from BPA, the CLT, CREST, LCFRB, EP, OWEB, USACE, and others. As stated above, the EP would convene, coordinate, facilitate, and document AMST activities. Participation by the non-federal agencies could be funded through their respective restoration project contracts with BPA or other sources; it will take funding for participants for CEERP AM to succeed.

In the Decide phase, once the projects are selected through stakeholder processes (e.g., using the EP's Science Working Group and prioritization process), they would be brought forward to the ERTG. The ERTG would be responsible for scientific review of the projects, and assignment of survival benefit units to them using transparent, science-based methods incorporating the latest knowledge. The results of the ERTG process would be provided to the AMST and the funding entities.

The Action Plan, as informed by the annual Strategy Report, could be the most important deliverable from the AM process for the CEERP. This plan would be developed by the funding entities from recommendations contained in the annual Strategy Report. The Strategy Report would incorporate by reference the findings contained in the Synthesis Report, and would report those findings in the context of CEERP program goals. The Strategy Report would provide recommendations and guidance on future RME and project development priorities. The Action Plan could be the blueprint for restoration actions and monitoring/research. Restoration practitioners, monitoring and research practitioners, and the AMST periodically could refer to the Action Plan for guidance and as a baseline against which to track progress. Priorities in the annual Action Plan would rely on recommendations made in the Strategy Report and respective organizational goals, authorities, and appropriateness. The adjustments and priorities in the Action Plan would rely on evaluation results from the Synthesis Memorandum and strategies established in the Strategy Report. These categories could be addressed as explicit sections of the Action Plan, which is outlined in Table 3.2.

In summary, roles and deliverables for the AMST and the funding entities could be as follows:

- Adaptive Management Stakeholder Team - Role: provide guidance on RME and project development, coordinate stakeholders, communicate accomplishments, develop reports. Deliverables:

- Annual Synthesis Report - Reports 1) key findings from RME studies and results of metaanalysis and 2) project development (status)

- CEERP Strategy Report - Reports CEERP program status relative to year's accomplishments and findings (refer to Synthesis Report) and CEERP goals and objectives. 
- Funding Entities - Role: make decisions based on recommendations in the CEERP Strategy Report and specific authorities, organization priorities, etc.

- Deliverable: Annual Action Plan - Reports decisions for next fiscal year on RME and project development based on recommendations from the CEERP Strategy Report and respective organizational goals, objectives, authorities, and authorizations.

Table 3.2. Draft Outline for the Annual CEERP Action Plan

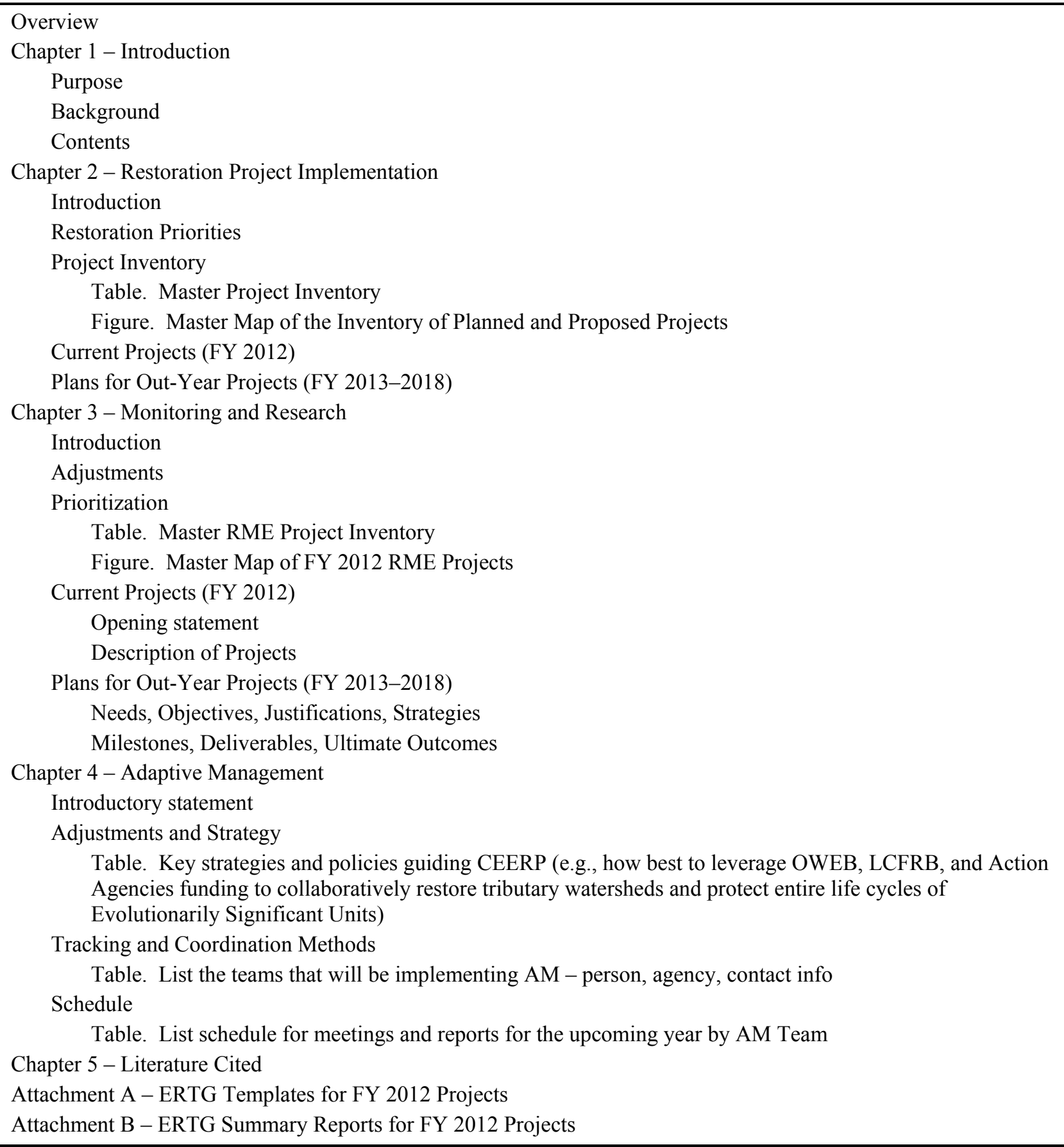




\subsubsection{The Act, Monitor/Research, and Evaluate Phases}

For conciseness, we combined the Act, Monitor/Research, and Evaluate phases into one diagram (Figure 3.3). Restoration project actions are implemented in the context of AM at the program and project scales. Project-scale AM is not presented here; see Diefenderfer et al. (2003) and Johnson et al. (2003) for guidance. The status of project implementation could be tracked in the CEERP master project database.

\subsubsection{Monitoring/Research}

This CEERP AM process should involve monitoring and research that would be conducted primarily to evaluate the success of the actions taken by the program, but also to supply information that can improve project design and program strategy and planning. These AM phases would include projectspecific action-effectiveness monitoring and research at site, reach, and estuary scales (see material above about scale), status and trends monitoring, and critical uncertainties research. Monitoring and research would be guided by an annual RME Plan, a section in the Action Plan (Figure 3.3). The information from these elements would feed the Synthesis Memorandum (Figure 3.3).

\section{The "ACT, MONITOR/RESEARCH, and EVALUATE" Phases}

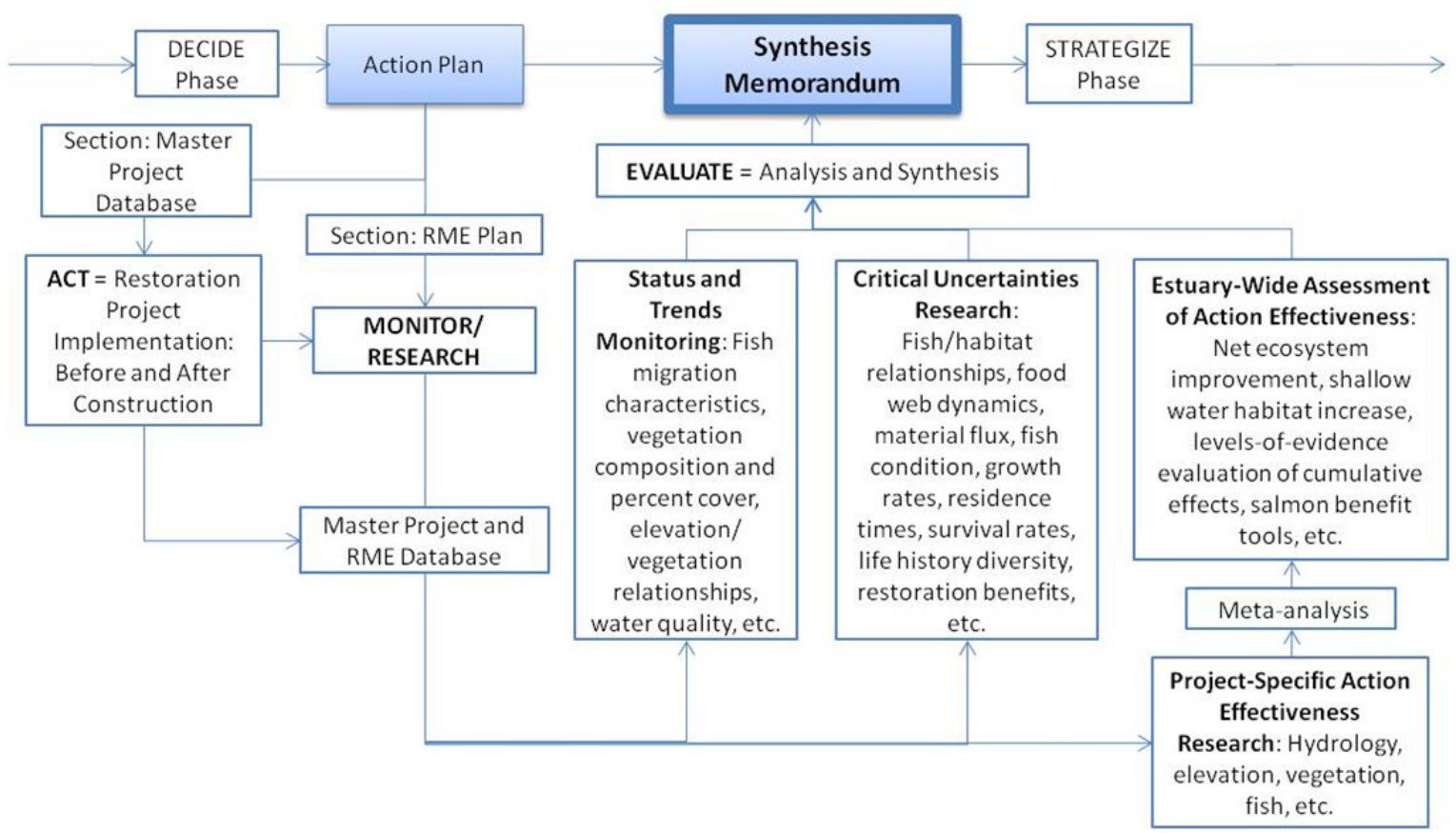

Figure 3.3. The Act, Monitor/Research, and Evaluate Phases in the CEERP Adaptive Management Process

Project-Specific Action-Effectiveness Research includes the fundamental sets of information about the individual restoration actions implemented by the program. A detailed plan and design for intensive and extensive monitoring and research to support action-effectiveness investigations is presented in Appendix F. The time frame for post-construction AEMR can be 1, 5, and 10 years, depending on the site and its monitoring/research priority. Monitoring and research priorities should be established by the 
AMST in the annual Strategy Report. The AMST and funding entities, in consultation with the AM Technical Analysis Team (AMTAT), should prioritize monitoring and research. The AMST would also be responsible for coordinating the preparation of the Synthesis Report with the AMTAT and the Strategy Report with the funding entities.

The AMTAT would be a group of engineers, project managers, and scientists responsible for providing technical analysis and recommendations to the AMST. The AMTAT would receive policy guidance from the AMST. Tasks to accomplish this include assessing monitoring and research data, developing the meta-analysis of AEMR projects (see Appendix G), developing and managing the database for the program, refining models, revising monitoring and research protocols and strategies, updating critical uncertainties research topics, and producing science-based recommendations for restoration actions at all scales. The AMTAT would be responsible for technical communications through normal scientific and technical venues, such as the biennial Columbia River Estuary Research Conference (CREC). The primary product of the AMTAT would be the annual Synthesis Memorandum.

Two or more representatives each from the AMST and AMTAT would be tasked to coordinate and facilitate information flow between the two groups, as well as other groups/organizations. This crossteam subset would also be responsible for CEERP data and information management. The Action Agencies should determine the AMTAT composition and consider funding its work. Existing groups that could be possibilities to build from, include the following:

- Estuary/Ocean Subgroup for Federal RME

- EP Science Work Group

- Estuary subgroup of the Anadromous Fish Evaluation Program's (AFEP's) Scientific Review Work Group

- Estuary Action-Effectiveness Research group proposed by BPA to perform periodic, comprehensive evaluations and predict potential effectiveness of restoration actions.

Each project that is implemented should report the results of monitoring/research in a Site Evaluation Card (SEC; Appendices F and G). To collect SEC data using established protocols, a rapid-assessment unit could be formed and funded. Other sources of information for the SEC could include the feasibility study report (in the case of a USACE-funded project), plan and specifications, as-built surveys, and monitoring/research reports. Together these documents would provide the detail about what was built, when and where it was built, the analysis that went into the design, and a summary of pre-existing and post-restoration conditions. The SECs could be filled out on-line using the CEERP database (see Section 3.6.3). Information contained in the SECs would be summarized in the meta-analysis (Figure 3.3). The meta-analysis would provide a simple way to portray the results of all of the restoration actions relative to the goals and objectives of the program. It would represent the "report card" on restoration actions implemented in the entire estuary back to the stakeholders and provide input to the ecosystem-wide Synthesis and Evaluation (Figure 3.3).

To help understand what action-effectiveness research on a single project provides relative to the CEERP, recall the program objectives (Section 3.1). To evaluate progress toward informing these objectives, and to drive improved decisions regarding future actions, there needs to be a set of measures 
for each action and a way to collect and analyze the information. An example of the sequence for setting up these project-specific measures is as follows:

- Project Objective - Develop salmonid access to a former wetland and restore natural tidal wetland functions.

- Habitat Action - Breach a levee at locations of former main channels to return tidal and river hydrodynamics to a former tidal wetland.

- Performance Metrics - Wetted area; presence of salmonids; wetland vegetation cover and community structure; accretion rate; survival benefit units.

- Performance Criteria -

- Wetted area at mean higher high water extends over $80 \%$ of the project site within 12 months of levee breach.

- Juvenile salmonids occur in densities within the range found in reference sites over a 3-year period after breaching.

- Wetland species composition and percent cover trend positively toward being similar to those in appropriate reference sites.

- Sediment and organic matter are actively accreting at the site over a 5-year period after breaching.

- Triggers - Poor performance of any of the criteria after 1 year may require intervention to correct. Because the development of the site and the functions are strongly dependent on restoring hydrology, wetted area may provide the best indicator of issues with hydrology.

- Project Site Evaluation Cards - These are developed by the entities involved in assessing the performance of the projects. Provide a simple, concise format for reporting on projects annually (see Appendix B).

Status and Trends Monitoring involves monitoring of ecosystems not necessarily associated with action-effectiveness monitoring. The purpose is to understand whether the health of the ecosystems and selected species populations are getting better, worse, or remain unchanged. Status and trends monitoring also quantifies the factors that contribute to natural within-year and interannual variation in monitored metrics. By knowing this, the results from action-effectiveness projects can be better understood in the context of natural variations and anomalous (e.g., heavy flood years) conditions. Also included are reference site characterization studies. Reference sites are generally minimally disturbed natural habitats, can be used as "models" for the design of restoration projects, and can provide data on natural abundance of animal and vegetation species and habitat gradients.

Critical Uncertainties Research includes research projects that supply information of potential high applicability to understanding the results of the restoration projects in broader terms, and how to better design, locate, and prioritize actions. The research projects are often driven by the program objectives and uncertainties about them. Research priorities are established by the AMST and AMTAT. One example is the priority to verify that the ERTG's assigned survival benefit units are positively related to juvenile salmon production or other measurable outcomes of restoration actions. 


\subsubsection{Evaluation}

Available information from monitoring and research, such as data summaries, data reports, technical reports, and scientific articles, could be used in the Evaluation phase (Figure 3.3). A central tool for the evaluation would be the Estuary-Wide Assessment of Action Effectiveness. The levels-of-evidence approach to evaluating the cumulative effects of multiple restoration projects (Diefenderfer et al. 2011) could be applied to the above information summaries to address overall progress toward the management questions for the estuary, critical uncertainties, and hypotheses. The analysis would assess whether there has been an overall net improvement in the ecosystem and the resources it supports, and provide recommendations for adjustments to the program. This work could involve use of conceptual and numerical model predictions for alternative actions or adjustments so as to influence decisions about actions. Both conceptual and numerical models might play an integrative role in compiling and synthesizing data, and in predicting outcomes of suites of actions at the various scales to meet a goal. They also could play an integral role in prioritizing actions, relative to the goal, over all scales. The models should be continually refined as new monitoring and research data and understanding become available. At times, experimental efforts are required to answer some critical questions. Again, the models must be developed for the appropriate scales of analysis and application of actions.

RME results would be rolled up in the annual Synthesis Memorandum. The AMTAT would be responsible for providing a technical Synthesis Memorandum (Table 3.3). This memorandum evaluates the results of the AEMR in the context of other sources of information. The Synthesis Memorandum would succinctly summarize the results from the analysis relative to the individual key management questions and hypotheses developed around the program uncertainties (see Section 3.2). Along with the estuary-wide analysis, the Synthesis Memorandum would include a set of recommendations regarding how to better address the CEERP objectives as well as the critical uncertainties. We recommend that the Memorandum be concise, specific, and not exceed 15 pages.

Table 3.3. Draft Outline for the Annual CEERP Synthesis Memorandum

Overview
Chapter 1 - Introduction
Purpose
Background
Study Area
Contents
Chapter 2 - Management Needs
Introduction
CEERP Goal and Objectives
Key Federal Management Questions
CEERP RME Objectives
Chapter 3 - Research and Monitoring
Introduction
Categories: status \& trends, action effectiveness, uncertainties research
Performance Indicators and Monitored Attributes
Project Descriptions
Gap Analysis
Summary


Table 3.3. (contd)

Chapter 4 - Synthesis of Major Findings

Introduction

Major Findings

Synthesis

Chapter 5 - Assessment

Introduction

Implications of CEERP RME Findings for Federal Project Design

Implications of Findings for CEERP Development and Management

Evaluation of Information Dissemination/Sharing/Management

Gap Analysis

Adaptive Management Needs

Chapter 6 - Conclusions and Recommendations

Chapter 7 - References

\subsubsection{The Strategize Phase}

The Strategize phase would receive input from the Act, Monitor/Research, and Evaluate phases via the Synthesis Memorandum and would deliver the Strategy Report (Figure 3.4). At its heart, the CEERP is being implemented using an ecosystem-based strategy that reflects the goal of the program (Figure 3.4).

\section{The "STRATEGIZE" Phase}

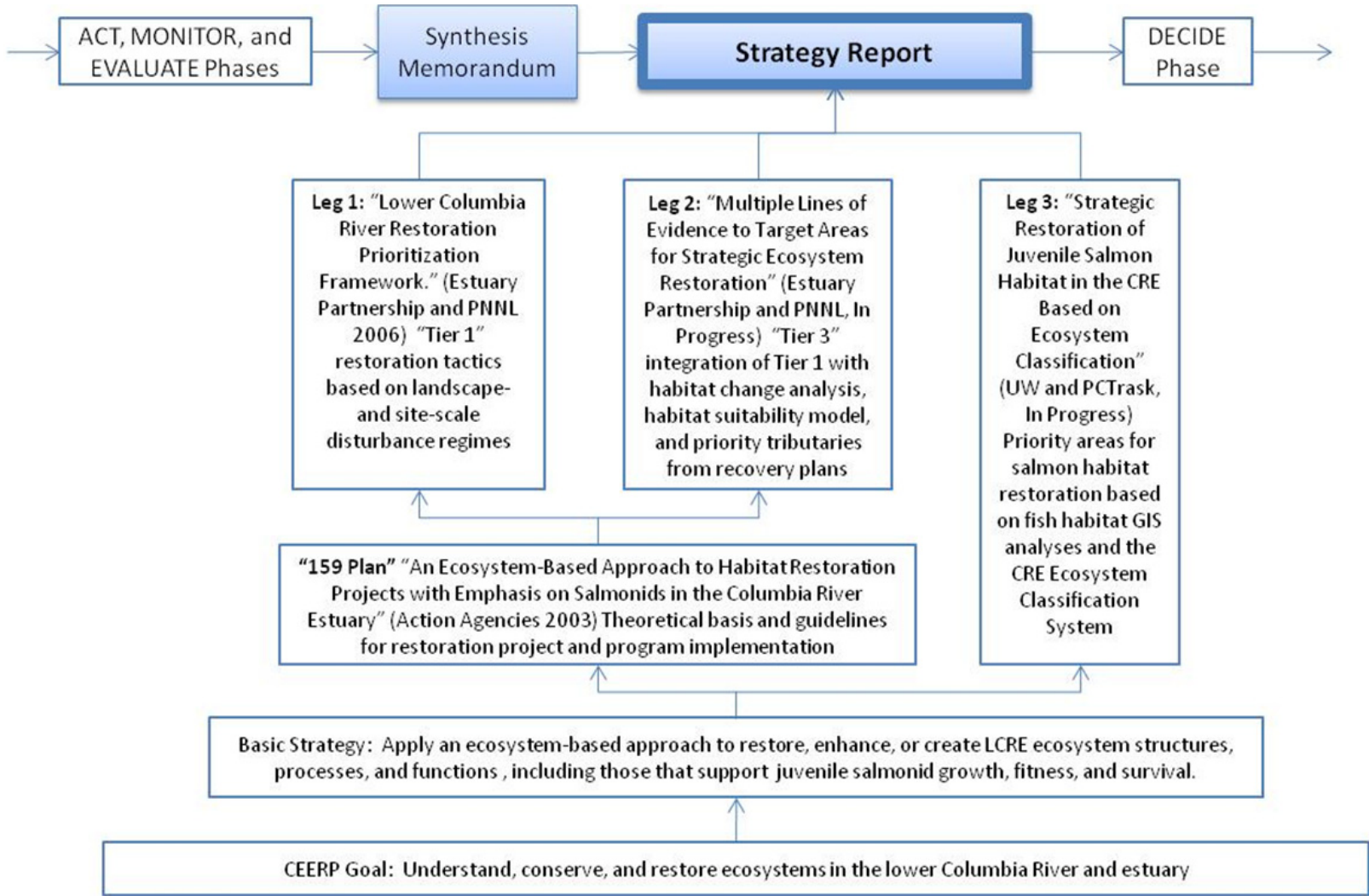

Figure 3.4. The Strategize Phase in the CEERP Adaptive Management Process 
Johnson et al. (2003) described the theoretical basis for this strategy, along with guidance for restoration project and program implementation. The EP and PNNL, with funding from BPA, developed restoration tactics based on a landscape- and site-scale disturbance model (Evans et al. 2006). Further work to refine the ecosystem-based approach is underway. The EP and PNNL, with funding from the U.S. Environmental Protection Agency, are developing a GIS platform with layers for a habitat change analysis, a habitat aptness model, and priority tributaries from recovery plans. Concurrently, the UW and PC Trask and Associates are developing a method based on the Columbia River Estuary Ecosystem Classification System to determine priority areas for salmon habitat restoration. The basic ecosystem-based approach to strategic restoration is applied in tools to prioritize restoration projects. The output of the Strategize phase would be the Strategy Report. The ERTG could be integral in the process of producing the Strategy Report.

Numerous tools exist for prioritization of actions at the site and reach scales. These include existing prioritization frameworks such as that now used by the EP, as well as other sources of information such as the ERTG scoring of projects for salmon survival benefits, salmon stock distribution, and limiting factors analysis. Priorities for actions at the estuary scale would best be developed through analysis of alternative actions using numerical models. For example, the models now being developed for environmental flows can be used to predict where actions might be taken to maximize the wetted area in the floodplain that would be accessible by juvenile salmon, and to predict what effect flow regulation will have on improving or reducing the access of salmon to high-quality shallow-water habitat.

Predictive models should be further developed to represent system variables and the dynamics that affect these variables over time. These models should be both conceptual and numerical, and provide a means of predicting the consequences of actions as they relate to program objectives. Coupled with monitoring and research results, models are the central tools for making refined predictions of outcomes from the actions taken. The models would use inputs from monitoring and research data and the AMTAT to refine model assumptions over time. They would be used to predict biological responses to management actions over time in order to help the AMST select an implementation strategy with the potential to meet the success metrics identified for the stated objectives.

Relative to CEERP strategy, there are many uncertainties associated with optimizing the design, location, distribution, size, arrangement, etc. of structures and actions relative to the scale of analysis. Monitoring, targeted research, and experimental studies and modeling provide the mechanisms by which engineering and biological information is developed and refined. The engineering design is based on hydrodynamic studies, modeling, and experience with the performance of various actions under various physical conditions. The biological guidance comes from studies of populations, their preferred habitats, the mechanisms and life-history stage support provided by the habitats, and empirical data about the performance of actions to produce responses by the species. Coupling the physical performance of the engineering actions, e.g., the formation and maintenance of habitats, with the biological outcomes provides the empirical evidence that verifies actions are having the desired effect relative to the program goal.

Using the Synthesis Memorandum from the Evaluate phase, and other relevant information, the AMTAT along with a subcommittee of members (including implementers) of the AMST and the ERTG would develop the annual Strategy Report. This report would contain a synthesis of information gathered each year, and would use that information to summarize progress toward program goals and objectives (see Section 3.1). The results could be portrayed in a system-development matrix as shown in Figure 3.5. 
This matrix summarizes the "state" of the program and the general actions required to improve the state. The Strategy Report should contain recommendations for improved success, assess the long-term program strategy, advance organizing models, and summarize recommendations of critical research and monitoring and research needs. The Strategy Report is intended to communicate program strategy to interested parties, and to convey adjustments to improve program results. The report also would serve as the primary communication products with other AM programs in the basin. The annual Action Plan would rely on the Strategy Report. An outline for the report is provided in Table 3.4.

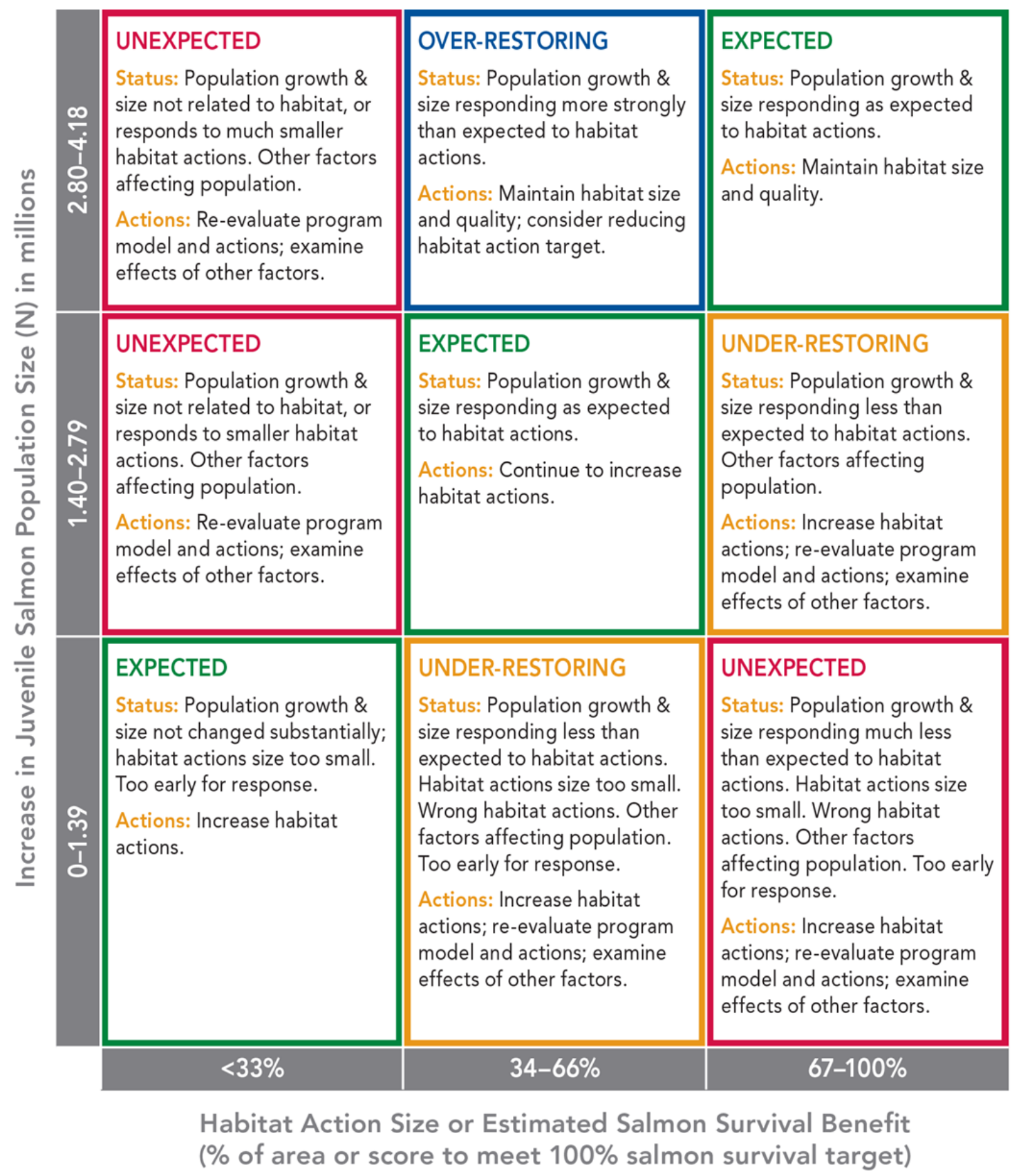

Figure 3.5. A System Development Matrix Summarizing the State of the Estuary and the Basic Actions Recommended 
Table 3.4. Draft Outline for the Annual CEERP Strategy Report

\section{Overview}

Chapter 1 - Introduction

Intent and Evolution of the Annual Strategy Report (ASR)

History of AM and the ASR

Review of Past Recommendations and Decisions

Process for Decision-Making

Schedule

Chapter 2 - Program Summary

Goal of the Program

Objectives and Performance Metrics - Each objective is presented with the following information, which is used to evaluate its status, and information on the appropriate geographic scale(s) for evaluation:

Performance metric(s) - qualitative or quantitative metric used to target how an objective will be assessed.

Measurement - the way in which data are collected for an individual objective.

Target - the value of metric(s) used to trigger a decision.

Program Hypotheses

Operational Conceptual Model - Net Ecosystem Improvement (NEI)

Program Critical Uncertainties Associated with Hypotheses

Science Questions

Chapter 3 - Monitoring and Research Data

Data sets associated with each objective and performance metric

Calculation of NEI value

Report Card Table for Past Year

Table _ contains a summary of the 2010 monitoring and research data and comparison against the performance metrics identified in the draft AMST AM Strategy

\begin{tabular}{|l|l|l|l|l|l|}
\hline \multicolumn{1}{|c|}{ Objective } & Performance Metric & Target & 2010 Value & Change from previous Year & 3-Year Average \\
\hline 1 & & & & & \\
\hline 3 & & & & & \\
\hline 4 & & & & & \\
\hline
\end{tabular}

Chapter 4 - Decision Matrix

The Decision Matrix (Table__ assesses the status of recovery based upon the $\mathrm{X}, \mathrm{Y}$, and $\mathrm{Z}$ in relation to equilibrium values or target values. Each potential state is classified according to the management trajectory it lies on, in reference to the species objective (achieve target population) and habitat objective (minimize construction):

Expected: species objectives are/will be met while optimizing habitat restoration

Over-restoring: species objectives are/will be met, but habitat restoration is not efficient (too much or too rapidly)

Under-restoring: species objectives will not be met unless habitat restoration is accelerated.

Unexpected: unlikely outcomes; model requires extensive revision

Summary of Anecdotal Observations

Recommendations from Data Analysis 
Table 3.4. (contd)

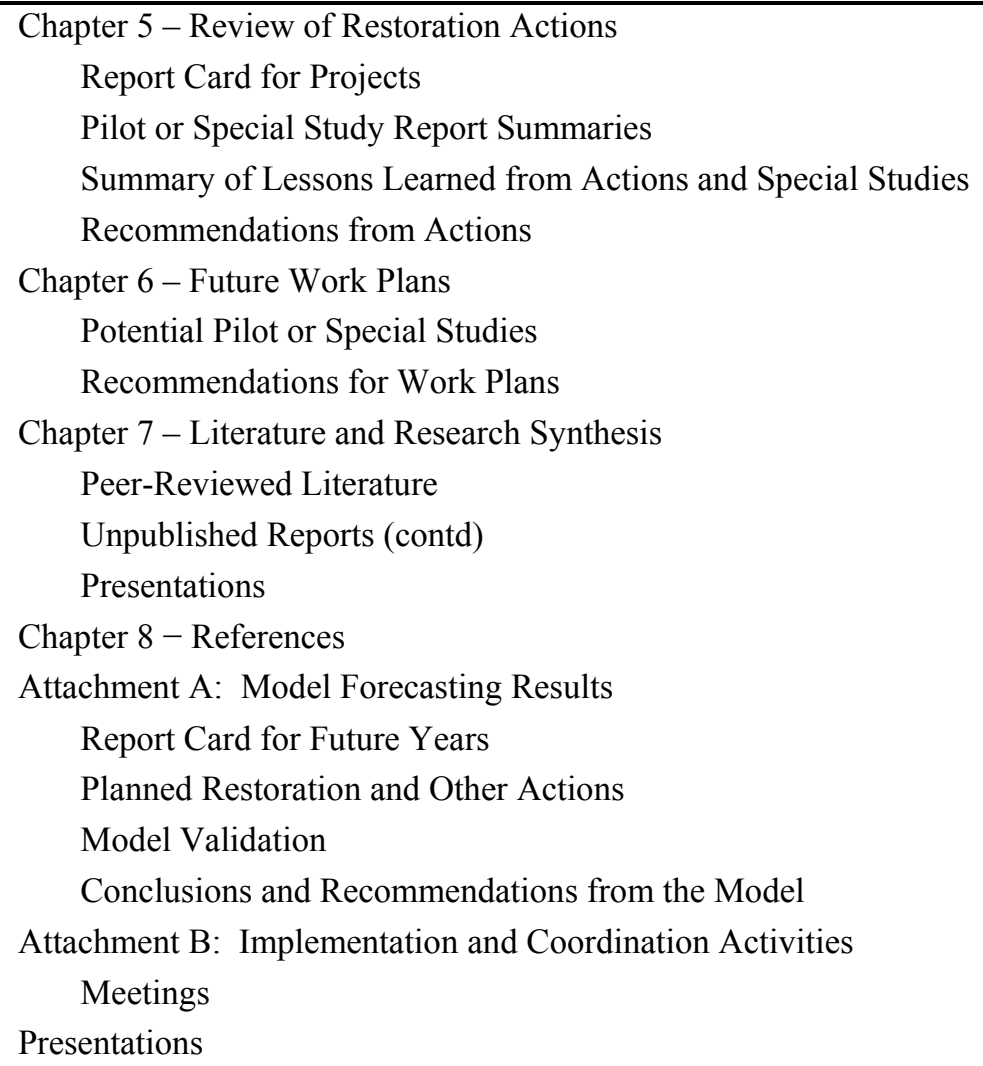

\subsection{Implementation}

Implementation of the CEERP AM process should have a defined scope, tasks, and schedule. Suggestions for these AM points are presented below.

\subsubsection{Scope}

The scope for the CEERP AM process includes clear understanding and fulfillment of roles and responsibilities, regular meetings, workshops, and conferences, and data management.

\subsubsection{Roles and Responsibilities}

A first step involves the establishment of roles and responsibilities for the AM program. To succeed, AM requires active and constructive participation, communication, and support from the key partiesfunding agencies, estuary managers, and restoration implementers, and researchers. For the most effective and efficient use of funds toward ecosystem and salmon restoration in the LCRE, coordination of stakeholders and decision-makers is the primary element of this strategy. Decision-makers are those individuals or organizations that decide what restoration actions to implement, where and when. The reality in the LCRE is that there are potentially numerous decision-makers, and decisions are presently made at different times, at different scales, and for different reasons. Coordination among stakeholders 
and decision-makers is critical to implementing estuary AM across multiple entities whose projects, programs, and processes address the estuary RME objectives.

\subsubsection{Regular Meetings, Workshops, and Conferences}

The reinvigorated CEERP AM process for the CEERP should be kicked off with a workshop held in fiscal year (FY) 2011 to describe and coordinate the CEERP and its future implementation within this AM process. A matrix of roles and responsibilities (see below) would be useful to clarify respective elements of the restoration program. A steering committee - the AMST — also would be warranted.

The AMST should meet regularly and make program decisions. The composition of participants on the team may vary depending on the agenda. The monthly meetings could be 2-day affairs with an agenda template having the following possible topics.

- BPA/Corps coordination on estuary actions

- ERTG steering committee topics

- Washington Memorandum of Agreement discussion points

- Project list: edits and upcoming actions

- Project prioritization and selection

- New research findings

- AMTAT guidance

- Guidance for meetings of monitoring/research and restoration practitioners, CREC

- $\mathrm{BiOp}$ reporting requirements.

Semi-annual meetings of managers, practitioners, and analysts to discuss and coordinate monitoring and research should be scoped and implemented, and coordinated with other relevant meetings. The first meeting would be in late winter to coordinate upcoming monitoring and research activities based on the Action Plan. The second event would be in late fall to exchange preliminary results from the previous monitoring and research seasons. Outcomes of the second annual meeting could include a list of key research results for input to the Synthesis Memorandum, the Strategy Report, and the Action Plan.

To disseminate data and report information for the LCRE Restoration Program, we recommend periodic meetings, an annual or biennial conference, publication of technical and nontechnical documents, and a well-maintained, professionally designed website.

\subsubsection{Data Management and Dissemination}

It should be the primary responsibility of the AM process to house, manage, and disseminate all data relevant to the CEERP. Development of a data management system designed to allow easy input of SECs and monitoring and research data should be a priority. Access to the data by the AMTAT and others should be facilitated. 


\section{CEERP Database}

The data function is currently performed to varying degrees at the project level, but not at the program level. Although project-level analysis is critical, the CEERP will require its own comprehensive database and synthesis of data (as mentioned above). No single entity is presently responsible for data management and dissemination related to the LCRE. The estuary RME projects and CEERP restoration AM process should feed data to a central, program-level location and provide web-based reports and public access as a key mechanism for data dissemination. A CEERP data center linked to the Pacific Northwest Aquatic Monitoring Partnership (PNAMP) or other regional data entities could fill this role, but does not exist at this time either alone or as part of a larger effort. Entities such as NOAA, LCRFB, OWEB, and the EP are expected to use the information to track salmon recovery and restoration actions. The CEERP data center would be consistent with PNAMP in efforts to 1) develop an RME information system architecture, 2) use existing data centers where appropriate, 3) develop a cost-sharing approach, 4) promote free exchange of information, and 5) emphasize the metadata. That is, the purpose, methods, quality assurance, proper usage, etc. are essential.

The specific requirements for estuary RME data and their management remain to be developed. For example, to form a data management system, we need to 1) decide what data will be collected, by whom, how often, where, and when; 2) define data standards; 3) define meta-data needs; 4) establish access methods and policies; 5) establish how the data will be used; and 6) designate and fund staff to implement the data standards and maintain the database. A long-term funding commitment would be necessary for this effort. Attention should be given to this critical issue.

The database would include all CEERP-related data, e.g., copies of the annual AM deliverable documents, project templates and SECs, and monitoring/research data. Monitoring and research data are diverse in type, volume, spatial and temporal extents, and how and where they are archived. Data management and analysis is, by necessity, typically conducted at the project or study level. While the project-level approach has served the region well, the program needs a formal data system. The overarching drivers are that 1) multi-year projects need to produce multi-year synthesis analyses and reports; 2) similar data from multiple projects need to be integrated across projects; 3 ) data from different sources and of different types need to be integrated and analyzed; 4) retrospective analyses need to be performed; 5) data need to be shared among collaborators across multiple agencies; 6) summary data in the form of tables, figures, and maps need to be disseminated; and 7) project data need to be submitted to funding agencies as a deliverable.

\section{CEERP Website}

The CEERP website could include 1) a comprehensive library of PDF files, or at least citations, for restoration-related literature concerning all aspect of the estuary; 2) contact information for restoration managers, practitioners, and researchers; 3 ) maps showing where research, monitoring, and restoration are presently being conducted, with meta-data on these activities; 4) full maps showing the historical and present conditions of the habitats; 5) linkages to restoration and monitoring/research data (see following bullet); 6) linkages to regional climate models and ocean circulation models; 7) a module for the LCRE conceptual ecosystem model (see below); and 8) and an AM module. The CEERP website should include password-protected access to the database. 


\subsubsection{Implementation Tasks}

We recommend the following tasks be started immediately to "hand off" AM tools from the CE study to the region. The intent would be to institutionalize AM for the Federal Estuary Ecosystem Restoration Program. At this stage, the responsible parties are the Action Agencies unless noted otherwise.

1. Establish a Memorandum of Understanding among BPA, USACE, EP, CLT, CREST, etc. to do AM for the CEERP.

2. Form the AMST and start the AM process.

3. Draft an FY 2012 Action Plan (see Appendix H for a detailed outline).

4. Convene a CEERP AM kick-off meeting to introduce the AM process, identify roles and responsibilities, explain the annual schedule, and set expectations.

5. Fund database development using the $\mathrm{CE}$ database as a starting point.

6. Develop and compile SECs for all restoration projects conducted to date and enter them into the database.

7. Identify who will be responsible for meta-analysis of the action-effectiveness data and empower them to do the work.

8. Write a 2011 Synthesis Memorandum, develop the 2012 Strategy Report, and draft a 2012 Action Plan.

9. Interface with the ERTG and present CE methods.

The annual deliverables from the CEERP AM process could have application elsewhere. The Action Plan, Synthesis Memorandum, and Strategy Report could be used in reporting obligations for the FCRPS BiOp and Action Agency planning documents, among other applications, including the following:

- Comprehensive BiOp Reports

- BiOp Implementation Plans

- Annual BiOp Progress Reports

- BiOp RME Assessments

- USACE 5-Year Research Plans.

\subsubsection{Schedule}

The schedule for the phases of the AM process shows their interdependencies (Figure 3.6). As described above, implementing the planned restoration program starts with actions that are monitored, feeding the Evaluation Phase the results of which are used to decide on adjustments to the program and plan the next year's activities. Restoration program actions take place year-round. While the other AM phases could be conducted in some fashion concurrently year-round, there will likely be periods of focused effort. Monitoring and research data collection and analysis typically occur during spring through fall. The evaluation and adjust/plan phases usually are conducted in winter at the end of a given AM cycle in preparation for the beginning of the next cycle. 
As shown in the Act phase (Figure 3.6), project-specific actions would take place continuously, dayto-day, nearly 365 days per year. Projects would be developed and proposed, reviewed by the ERTG, considered by the Action Agencies, and decisions made. Different projects, however, could have different schedules and no single annual cycle of events will fit all projects. Therefore, the AMST should regularly meet and move projects through the project development process. This means that the AM process should provide a series of checkpoints and deliverables (the AM work products) fixed in time that program stakeholders could access for guidance and decision-making.

J $F$ M A M J J J A S

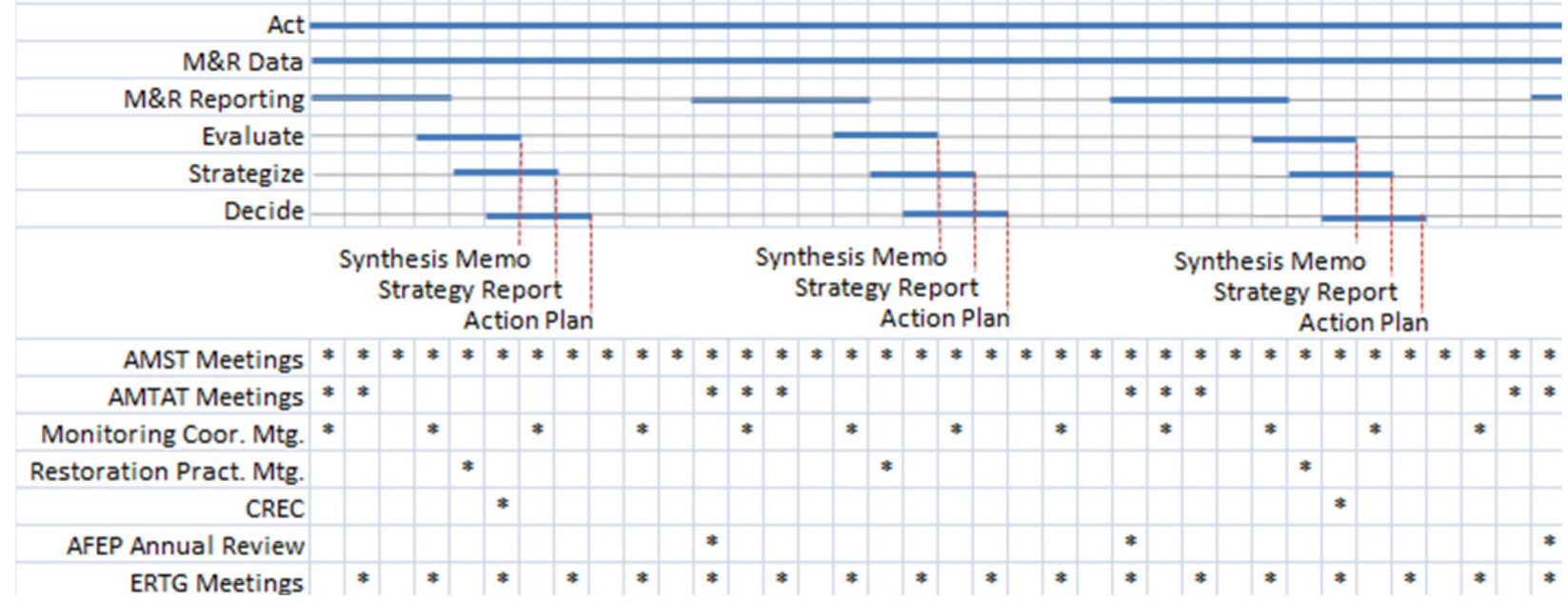

Figure 3.6. Chart Depicting the Tentative Schedule and Integration of AM Phases, Work Products, Meetings, and Existing Activities. (The AMST will decide on the schedule for reporting and decisions on actions.)

For the AM process to benefit the restoration program, the AM annual work products would need to be delivered at set times each year. This means that any and all available information would be used, and that the process would not wait for monitoring and research data. For example, the Synthesis Memo should use any available results at the time. The timing for the memo is such that preliminary results from the previous field season should be available, such as results from AFEP research projects, which are required to present preliminary results at the annual review meeting in December each year. The same holds true for the Strategy Report and Action Plan; they would use available data and be produced and delivered on a strict schedule.

The CEERP would be no different than other technical programs where decisions on structures, construction activities, monitoring and research, and funding allocations must be made before the results from the previous year's activities are finalized. This situation is inherent to the process, but work could be done to minimize its impact, including the following infrastructure and activities:

- Develop and establish a web-friendly restoration program data and information base. Include a citation database as a module.

- Regularly upload and compile data and reports from monitoring/research activities, along with presentations and other useful materials. Upload and compile new information monthly as it becomes available - a running summary. This will allow the AMTAT to get started on analysis and evaluation without having to spend time compiling data. 
- House the SECs on a module on the website, or at least in the database.

- Develop a restoration project tracking system for the AMST.

- Develop an RME tracking system of which parties are doing what monitoring and research, and where and when they are scheduled to do it. This will be useful to coordinate and implement monitoring/research.

- Develop an activity matrix of what, when, and where to monitor during the out-years 2011-2017 (see Appendix G). The measured monitored indicators for site-scale structures and processes and the derived response variables for landscape-scale emergent properties should become engrained.

- Establish a "quick response assessment team" (QRAT) to perform 1-day visits for pre- and postconstruction monitoring of indicators that can be readily measured. The data would be qualitychecked, uploaded to the CEERP database, and reported in the SECs in near real time.

\subsection{Conclusion}

In conclusion, recall the two key conditions that must exist to have a real and effective AM program (Williams et al. 2007): 1) a mandate to take action in the face of uncertainty and 2) institutional capacity and commitment to undertake and sustain an AM program. The mandate has been established with the 2008 FCRPS BiOp, along with the Upper Columbia and the Lower Columbia and Willamette Recovery Plans and the Estuary Partnership's Comprehensive Conservation and Management Plan. The collective institutional capacity and commitment, however, have been insufficient to date. We have attempted to suggest specific phases, roles and responsibilities, and work products for CEERP AM. It is up to the primary funding agencies (BPA and USACE), stakeholders (CLT, CREST, EP, etc.), and monitoring/ research agencies (the NMFS, PNNL, U.S. Fish and Wildlife Service, U.S. Geological Survey, etc.) to cooperate and make AM a reality for the betterment of LCRE ecosystems and the salmon populations these ecosystems support. 


\title{
4.0 Management Applications
}

\author{
Prepared by Gary Johnson, Blaine Ebberts, Heida Diefenderfer, Ron Thom, and Curtis Roegner
}

This study helped consolidate our understanding of the variety of restorative and management actions designed to improve ecosystem structures, processes, and functions in the LCRE. This research has applications for resource management agencies, environmental organizations, BPA, and the Corps in the Columbia basin, as follows.

\subsection{Water Resources Development Acts: Restoration in the LCRE}

The authorities under which the Corps can develop restoration projects are Section 1135 of the WRDA of 1986, Project Modification for Improvement of the Environment; Section 206 of WRDA 1996, Aquatic Ecosystem Restoration; Section 536 of the WRDA 2000, Lower Columbia River Ecosystem Restoration; and Section 306 of WRDA 1990, General Investigation Studies for Environmental Restoration. All Corps ecosystem restoration authorities require the determination of a "federal interest" before commencing with feasibility studies. These four Corps authorities are all expected to benefit from the evaluation of the cumulative effects of LCRE ecosystem restoration.

Section 1135 provides the authority to modify existing Corps projects to restore the environment and construct new projects to restore areas degraded by Corps projects. This is a cost-shared authority and requires a non-federal sponsor to contribute $25 \%$ of the costs. A project is accepted for construction after a detailed investigation shows it is technically feasible, environmentally acceptable, and provides costeffective environmental benefits. Each project must be complete within itself, not a part of a larger project. The maximum federal expenditure per project is $\$ 5$ million, which includes both planning and construction costs.

Section 206 is very similar to Section 1135 and provides authority for the Corps to restore aquatic ecosystems that are not associated or connected with Corps projects. Like Section 1135, a project is accepted for construction after a detailed investigation shows it is technically feasible, environmentally acceptable, and provides cost-effective environmental benefits; each project must be complete within itself, not a part of a larger project; and the maximum federal expenditure per project is $\$ 5$ million, which includes both planning and construction costs. Project costs are shared $-65 \%$ federal, $35 \%$ non-federal. Costs of lands, easements, and rights-of-way are non-federal and are creditable towards the $35 \%$ nonfederal cost share. The non-federal sponsor must assume responsibility for operation and maintenance of the project upon completion.

Section 536 provides authority for the Corps to carry out ecosystem restoration projects necessary to protect, monitor, and restore fish and wildlife habitat. Section 536 will serve as the catalyst to bring together and implement current efforts by a number of governmental and private organizations to identify and share costs of restoration projects. These organizations include the National Estuary Program, six state agencies from Oregon and Washington, four Federal agencies, recreation, ports, industry, agriculture, labor, commercial fishing, environmental interests as well as private citizens. The Washington Memorandum of Agreement on Estuary Habitat Actions (Washington-Action Agencies 2009) allows for LCRE habitat restoration funding using BPA resources leveraged with additional federal funding through a Corps cost-sharing program, such as Section 536. 
Section 306 provides authority to the Corps to undertake studies and build projects for environmental restoration and for water and related land resources problems and opportunities in response to directives, called authorizations, from the Congress. Congressional authorizations are contained in public laws and in resolutions of either the House Transportation and Infrastructure Committee or the Senate Environment and Public Works Committee. The focus of the studies is on determining whether a federal project responding to the problems and opportunities of concern should be recommended, within the general bounds of Congressional interest, in authorizing federal participation in water resources development. Currently, the Corps has one ongoing General Investigation Study involving in the LCRE.

Although the emphasis of the cumulative ecosystem response analysis was originally on the LCRE, with an emphasis on ESA-listed salmonids, it is apparent the outcome will have much farther reaching effects. In this study, a conceptual model of the site and landscape is presented as a central organizing structure for predicting and evaluating changes to the system after restoration, following prototcols presented in an Institute for Water Resources study (Thom and Wellman 1996). This is responsive to USACE directives that restoration projects be conceived in a systems context (USACE 2000) using an ecosystem and/or watershed approach (USACE 1999). The implementation of ecological tools and concepts in the USACE planning process for ecosystem restoration continues to develop (Pastorok et al. 1997; Thom 1997; Yozzo et al. 1996).

Thus, the CE study builds on earlier ecological understanding and existing planning tools to create an approach that supports several key planning processes associated with ecosystem restoration projects in the estuary, including those without fisheries-related goals. These processes include project prioritization, project effectiveness evaluation, and AM. Restoration projects developed under any of the four Corps authorities can apply the results of this analysis. In addition, other Corps and national ecosystem restoration programs will likely benefit from this work. It is not to say that this will be the blueprint for the evaluation of all ecosystem restoration activities; however, it likely will act as the outline and guiding documentation for additional works to come.

\subsection{Collaborative Planning for Large-Scale River Systems Restoration}

An analysis by the National Research Council (NRC), clarifying the Corps' ecosystem restoration mission, demonstrates the complexity of factors that need to be considered in order to restore the hydrologic and geomorphic processes of large river and coastal systems. The NRC (2004a-d) recommended the Corps adopt strategies including the following: integrated large-scale systems planning, AM methods, expanded post-project evaluations, and a collaborative approach. Multijurisdictional environments complicate large-scale river basin and coastal systems planning (e.g., multiple states and tribes in the Columbia Basin), necessitating a collaborative approach. The development of a framework for $\mathrm{CE}$ assessment and standard protocols for the evaluation of individual projects in the LCRE by the Portland District in this study exemplifies all four of these NRC recommendations. In effect, standardizing data collection throughout the estuary is critical for analyzing changes that occur after restoration treatments, and the development of a regional protocols manual by the Corps contributes to this end. Thus, the NRC's recommendations are guiding the effort to assess the cumulative effects of restoration in the LCRE. With this study, the Corps is demonstrating the implementation of national level guidelines - large-scale systems planning, AM, post-project evaluation, and a collaborative approach-in the Pacific Northwest region on the estuary of one of the largest rivers in the nation. 


\subsection{Columbia Basin-Wide Cumulative Effects Assessments}

The Northwest Power and Conservation Council's Fish and Wildlife Program implements over $\$ 100 \mathrm{M}$ annually in projects involving on-the-ground habitat restoration, monitoring, and research in the Columbia Basin. In any given subbasin, multiple habitat restoration projects are conducted, many of which are impractical to monitor individually because of their small scale, limited funds, and other reasons. This necessitates monitoring action effectiveness in the form of cumulative effects at the subbasin scale (Jordan et al. 2003). Analysis methods for cumulative effects have been developed for the Council's Fish and Wildlife Program (e.g., Hillman 2004). The objectives of these efforts are analogous to those of the CE study in the estuary in that both intend to establish the effects of habitat restoration actions on salmon. However, due to inherent differences in the ecological systems, the statistical sampling designs and the sampling methods necessarily differ. Nevertheless, by producing comparable scientific results describing the cumulative effects of restoration actions, managers will be able to assess the relative benefits of monies spent among various habitats from freshwater streams to the estuarine wetlands. Likewise, although metrics will differ (i.e., productivity and survival rates in the tributaries, presence/absence and growth and residence time in the estuary), managers will be able to use the combined data to track basin-wide effects of actions undertaken from the headwaters to the LCRE.

\subsection{Columbia Estuary Ecosystem Restoration Program}

Action effectiveness monitoring and research, including CE evaluations, is a key RME element in the CEERP (BPA/Corps 2012). For example, two of the CEERP management questions are, "Which estuary habitat restoration actions are most effective at addressing the limiting factors preventing achievement of habitat, fish, or wildlife performance objectives? Are the estuary habitat restoration actions achieving the expected biological and environmental benefits?" Periodic CE evaluations using the levels-of-evidence approach are planned. This will likely entail meta-analysis of action effectiveness data, analyses of net ecosystem improvement, statistical analysis of the ancillary hypotheses, hydrodynamic modeling, and other levels of evidence. A regional, web-accessible, geospatial database is planned to house and disseminate the effectiveness monitoring data collected using the Roegner et al. (2009a) protocols, as well as other data and information. CE evaluations of action effectiveness and other data will inform CEERP stakeholders and decision-makers.

There is enormous potential to establish effective habitat restoration strategies, as well as management of the LCRE system as a whole, using a comprehensive data set developed from data collected using the standard set of effectiveness monitoring protocols. Given the protocols, application of them within a definitive programmatic infrastructure based on the AM framework developed in this study will be instrumental to 1) coordinate among groups conducting habitat restoration projects, 2) promulgate the protocols, 3) compile and analyze the data, and 4) develop specific management recommendations using results from applied research. In short, the outcome of analysis produced by this infrastructure could provide insight into ecosystem structures, processes, and functions not fully understood at this time. Managers can apply this information as important "lessons learned" for future restoration actions and regulatory guidance (e.g., CEERP restoration actions, implementation of recovery plans, flood hazard mitigation, etc.).

In addition, reporting requirements are specified in the protocols so that data would be submitted in a standard format (the Site Evaluation Card), which facilitates data interpretation, comparison, and 
synthesis. If applied widely, these indicators and protocols will provide the basis for inter-comparison among all restoration projects, and for accumulation of the net results in terms of quantifiable metrics. For example, managers will be able to identify how much area is restored, how much of that area is composed of the various habitat types, and how much plant matter is produced and exported to the LCRE food web. We will also be able to assess impediments to full restoration and established goals for projects, and identify ways to fix problems with poorly performing sites. These ultimately will help improve the success of the projects and result in more cost-efficient projects. The results can then be rolled up into summaries for both internal and external reports produced by agencies, such as annual CEERP Synthesis Memoranda.

Despite the challenges, developing and implementing appropriate indicators and methods, applying them, and reporting results is the best way to enable estuary managers to track the effectiveness of large investments in LCRE ecosystem restoration projects and to improve conservation and restoration measures over time. The CE study was directed at showing whether projects have a "signal" in the ecosystem. For example, one signal in the Mississippi River delta is the amount and rate at which marsh area is regenerating. This signal has direct and indirect implications for maintaining ecological functions in the system, as well as reducing threats to infrastructure, such as roads, on the delta. In a similar way, restoration of ecosystems in the LCRE has direct and indirect implications for key processes and functions, such as organic matter production, biodiversity, and juvenile salmon growth and survival. Analogous to the protection of roads in Louisiana is the protection of roads, homes, and businesses through the flood storage capacity afforded by tidal wetlands and swamps in the LCRE. The CE methodologies we developed will allow managers the capability to measure the effects of the LCRE ecosystem restoration effort on a collective, estuary-wide basis. 


\title{
5.0 Conclusions and Recommendations
}

\author{
Prepared by Gary Johnson, Blaine Ebberts, Heida Diefenderfer, Ron Thom, and Curtis Roegner
}

This chapter provides conclusions from the CE study in terms of deliverables and supporting publications, restoration lessons, uncertainties, and research and development recommendations. The material is based on the collective accomplishments and experience gained during the 2004-2010 CE study period.

\subsection{CE Deliverables and Supporting Publications}

The overall CE study objectives (Section 1.1) were met with a suite of deliverables that involved peer-reviewed technical reports and scientific publications over the course of the study. To conclude the study, the deliverables are listed below by study objective and include brief descriptions, internet links, and/or citations.

- Monitoring Protocols - Develop monitoring protocols and methods to standardize monitoring activities to determine the effectiveness of LCRE ecosystem restoration actions.

- Roegner et al. (2009a) published protocols for selected metrics for action-effectiveness monitoring of habitat restoration projects. The protocols are currently being used regionally in project-effectiveness monitoring; however, based on findings in recent years, they could be updated and additional metrics could be added (see recommendations below).

- Thom et al. (2008) suggested methods for prioritizing intensive and extensive effectiveness monitoring. Further guidance on RME is offered in Appendix F.

- Methodology - Develop the theoretical and empirical basis for a CE methodology, together with a set of metrics and a conceptual model depicting the cumulative effects of LCRE restoration projects on key major ecosystem functions supporting listed salmon.

- Diefenderfer et al. (2011) developed a peer-reviewed, scientific method for evaluating the cumulative effects of multiple habitat restoration projects in the LCRE. This method is applicable to future comprehensive evaluations of the effectiveness of CEERP actions, as well as restoration efforts at various scales in other ecosystems. For example, scientists and regulators from the Puget Sound, the Upper Missouri River, and the Mississippi delta have expressed interest in the CE methodology.

- Roegner et al. (2009a) and Diefenderfer et al. (2011) provide a set of metrics for CE assessments. (We listed the set of key metrics for the CE approach in Section 1.3.) These metrics were central to the investigations of Ecological Relationships (Chapter 2.0) and meta-analysis of action effectiveness (Appendix E), among other topics in this report.

- Diefenderfer et al. (2009) provide a preliminary investigation of a set of naturally breached and created sites in the region, from as early as the 1960s, as a means of extending the temporal basis of findings from this 2004-2011 study. Thom et al. (2004) created a web-based conceptual 
model of the LCRE that we applied to cumulative effects. The model ${ }^{1}$ identified the factors that inform calculations of net ecosystem improvement. For example, does increasing the wetted area result in an increase in marsh channel length and diversity, and thus rearing and feeding habitat for salmonids? Below, we specify needed updates to the conceptual model given new information derived since 2004.

- Evaluation - Design and implement evaluations of the CE methodologies by applying standard methods in studies of ecological relationships, a GIS database of restoration-related data, hydrodynamic modeling, and meta-analyses to assess ecosystem response of the cumulative effects of multiple habitat restoration projects.

- Diefenderfer and Johnson (2008) and Johnson and Diefenderfer (eds.) (2009; 2010) presented findings relevant to LCRE ecological relationships. Specific results regarding the design and assessment of swamp restoration are provided by Diefenderfer et al. (2008) and Diefenderfer and Montgomery (2009), and findings concerning salmon-habitat relationships at restored and reference sites are given by Roegner et al. (2010a). More results are presented in Appendices C and $\mathrm{E}$. The definitive work by the $\mathrm{CE}$ study on ecological relationships is described in Chapter 2.0 of this report.

- Coleman et al. (2010) developed a site-specific geo-referenced database of elevation data to model wetted area. Coleman et al. (2010) developed a new, GIS-based wetted-area modeling method, with the potential to evaluate or predict tidal exchange volume, wetted area, total wetted channel length, and other hydrologic metrics based on water-level and bathymetric/topographic data. Preliminary results were presented by Diefenderfer et al. (2008), and results for the six CE paired sites are presented by Thom et al. (in preparation).

- Borde et al. (2008a, b; 2009a, b; 2010) used statistical and GIS-tools to analyze vegetation data gathered by the CE project and the BPA-EP reference sites project, to establish the ecological relationships of plant communities, elevation, and hydrologic regime in the LCRE that are fundamental to restoration design and assessment. This document adapts a sum exceedance value method to describe the hydrologic regime of tidal wetlands of the LCRE.

- Diefenderfer et al. (2012) used a hydrodynamic model to test the hypothesis that the cluster size of hydrological reconnection projects has a nonlinear effect on the area of floodplain inundation. Appendix B contains methods and results for hydrodynamic modeling showing transport of POM from a restored wetland to the main stem Columbia River.

- Johnson et al. $(2009,2010)$ presented preliminary attempts at a meta-analysis of actioneffectiveness data. Appendix G contains meta-analysis for the three main CE study sites (Kandoll Farm, Vera Slough, and Crims Island). Meta-analysis of restoration actioneffectiveness will be critical for future assessments of the progress of the CEERP.

- Johnson and Diefenderfer (eds.) (2009) used fish presence and water temperature as metrics in a limited, preliminary levels-of-evidence evaluation of LCRE cumulative effects. The exercise

\footnotetext{
${ }^{1}$ At the core of the model is the assumption that ecosystem stressors, such as passage barriers, and physical and chemical processes termed controlling factors directly affect, form, and maintain ecosystem structures or habitats. In turn, the habitats carry out ecological processes that result in ecological functions, including those that support salmon. We applied the model for CE analysis using the ultimate linkage between relieving a stressor, e.g., restoration of a blocked culvert, and increased ecosystem processes and functions for salmon, e.g., access to habitat for feeding, growth, and improved survival in the ocean.
} 
showed the potential of the approach, but also the rigor, monitoring consistency, and data sophistication that will be necessary to successfully execute it.

- The initial, comprehensive CE evaluation using the levels-of-evidence approach is dependent on the data and findings presented in this last annual report. As such, it must occur later and be reported elsewhere.

- Adaptive Management - Develop an AM process to coordinate and coalesce the restoration efforts in the LCRE to support decisions by the USACE and others regarding LCRE habitat restoration activities.

- Thom et al. (2008) developed an AM process for the USACE Portland District's habitat restoration program in the LCRE. Subsequent to this, Johnson and Diefenderfer (eds.) (2009) produced AM decision-making guidance (Section 6.3 of that report) and an abbreviated version of the AM process for broad dissemination.

- With the culmination of the CE study, we developed specific guidance for the USACE and others to implement AM for the CEERP (Chapter 3.0). This guidance initiated the CEERP AM process and includes the three main annual CEERP documents: Synthesis Memorandum, Strategy Report, and Action Plan.

\subsection{Restoration Lessons}

Based on our experience with ecosystem restoration activities in the LCRE over the past 7 years, we offer the following opinions on lessons regarding planning and design, AEMR, and AM for the CEERP.

- Planning and Design

- Potential sites for restoration are limited, even in an area as large as the LCRE floodplain, because of land-use practices, accessibility, suitability, among other reasons. Therefore, opportunities for restoration should be actively and aggressively pursued in a coordinated manner across multiple restoration funders and sponsors.

- The ecosystem-based restoration prioritization strategy used by the EP-integrating stressors at the landscape and local scale in the LCRE-identifies areas where restoration is more likely to succeed relative to other areas (Evans et al. 2006). To our knowledge, likely areas for success have not been mapped back to opportunities for potential restoration sites identified by positive functional factors.

- Alternative sources of large wood might need to be considered to meet goals for certain ecosystems, even though some wood can become available to previously diked restoration sites through tree fall and re-exposure of previously buried wood due to changing hydrodynamics (Diefenderfer and Montgomery 2008). This is worth considering because ecohydrological processes that provide large wood and produce ecosystem structures in tidal channels could be important in the restoration of tidal forested wetlands (Diefenderfer and Montgomery 2008).

- For sites designed to directly benefit juvenile salmon, practitioners need to consider whether juvenile salmon are in reasonably close proximity to the restored area to begin with, i.e., migration patterns (Roegner et al. 2009b). 
- Design should be informed by pre-construction topography and/or bathymetry because historical channel networks that remain in agricultural lands can achieve a new purpose to convey flows after hydrologic reconnection (Diefenderfer et al. 2008; Thom et al. in preparation).

- As-built drawings are essential for evaluation of the effectiveness of the restoration program because they document what was actually done at the project site.

- Natural restoration trajectories toward desired outcomes are often prohibitively long (decades). The cost of ecologically engineering a site to improve the pace of environmental processes and functions should be considered.

- Monitoring

- It is critically important to apply the AEMR protocols (Roegner et al. 2009a) when and wherever possible because this will allow valid analysis across multiple restoration sites and times. Applying the protocols, however, may require onsite adjustments in many cases to adapt to the conditions of the site. In all cases, effort should be made to present data in compatible formats.

- Stakeholders cannot afford to intensively research every site, so relationships between extensive and intensive monitored indicators (see Appendix F) must continue to be developed to aid CEERP decision-makers and evaluate program-wide action effectiveness.

- Access to restoration and reference sites for pre- and post-monitoring can be very difficult at times because water-level variations affect the ability to sample. Where possible and when intensive AEMR is desired, paired reference sites should be sampled at the same frequency and with the same methods as restoration sites. Where not possible, the EP Reference Sites study (Borde et al. 2009a) results should be referenced for prediction and assessment following the guidelines provided by Diefenderfer et al. (2011).

- Adaptive Management

- Adaptive management is only successful if the parties to the program commit to sustained roles and responsibilities.

- Adaptive management can be efficient if existing, required reporting functions are adapted to ensure the flow of information from project monitoring staff to project planning staff, and if monitoring is fully funded.

- The CEERP AM process has become institutionalized within BPA and the Corps, as well as with most regional stakeholders. Continuing to implement the AM process will ensure lessons learned are captured and applied to future restoration actions.

\subsection{Uncertainties}

Uncertainties remain regarding the ecology of juvenile salmon relative to ecosystem restoration and habitat function in general in the LCRE. In our opinion, these uncertainties include the following:

- predictive, ratiometric indicators of linkages between habitat conditions and fish metrics, e.g., condition, fitness, growth, and survival

- competitive and predatory interactions between juvenile salmon, stickleback, and other fishes

- site-specific agents of mortality (disease, predation, stranding, temperature stress) 
- rates of juvenile salmon passage through culverts and tide gates under roads, tracks, levees, dikes, and other obstructions between restored off-channel sites and the river main stem

- relationships between restoration actions and juvenile salmon production or indices of the survival benefits of restoration

- contribution of wetland-produced prey to the larger ecosystem (prey flux)

- habitat types that provide the most ecosystem support to juvenile salmon, e.g., fidelity of important insect taxa to plant species or communities

- hatchery/wild interactions in the LCRE and effects on wild fish survival

- expected trajectories of restoration sites with different plant communities, e.g., time to reasonable functional equivalency with natural wetlands in the LCRE.

\subsection{Research and Development Recommendations}

Future work could be conducted to build on the accomplishments of the CE study. Further development of the CE methodology and restoration-related tools is recommended for consideration, as follows:

- Perform the first comprehensive levels-of-evidence evaluation for the cumulative effects of juvenile salmonid habitat restoration in the LCRE (2000-2010). This work, which will depend on results contained in this 2010 annual report and elsewhere, will entail the following: 1) summarizing the definitions for each causal criterion in the levels-of-evidence approach (Diefenderfer et al. 2011) and how they were examined and measured; 2) reviewing literature and results from the CE study and other studies regarding the effects of habitat restoration and extract information required to evaluate the effects on key monitored indicators using the causal criteria; 3 ) for each monitored indicator identified, conducting a separate review to examine the main sources of variability outside the control of or in the absence of the habitat restoration program; 4) listing the effects expected from the habitat restoration effort (in the form of ancillary hypotheses) and evaluating the amount and kinds of evidence supporting each effect by examining the ancillary hypotheses; 5) considering whether the monitoring design could be improved by factoring natural influences on monitoring variables into the design and removing these as potential explanations (alternative hypotheses); and 6) using the evidence to draw inferences about the cumulative effects of habitat restoration.

- Continue development of an estuary-wide, historical floodplain-wide hydrodynamic model for LCRE wetted area. Wetted area modeling could be used to assess baseline and cumulative effects of floodplain channel habitat restoration in reaches $\mathrm{A}-\mathrm{H}$ designed to increase habitat opportunity for juvenile salmonids. There also is a critical need to evaluate environmental flows to these habitats under alternative restoration and flow scenarios, e.g., the effects of climate change on the snow pack and hydrosystem regulation. Modeling efforts currently underway by the USACE Portland District, Oregon Health Sciences University, and U.S. Geological Survey/Portland State University should be reviewed relative to the need.

- Update the AEMR protocols to include additional biogeochemical indicators related to organic matter flux and process (e.g., total organic carbon, nutrients) as well as habitat capacity functions, such as diet analysis, feeding rate, and growth. In the current environment, we believe that making the protocols available via a "wiki" system would provide efficient updates and communication, whereby 
users at governmental agencies and non-governmental organizations may comment on their experiences with the protocols and share recommendations, i.e., a "living document."

- Perform periodic estuary-wide, quantitative meta-analyses as necessary for CEERP management, using all available effectiveness monitoring data from estuary habitat restoration projects collected following the protocols. Meta-analysis requires a central, up-to-date database for all available effectiveness data from restoration projects. In addition, an inter-agency team for technical collaboration and analytical work is needed to collaborate and produce periodic meta-analyses.

- Project the cumulative net ecosystem effect in GIS using values from the literature and the project monitoring data for a set of estuary-wide restoration scenarios developed in collaboration with the USACE and its partners. Because of the historical focus of research in the estuary proper, many values for tidal freshwater areas are missing and would need to be extrapolated from early calculations, e.g., plant productivity, invertebrate prey taxa. These values should be the attention of new research in coming years.

- Update and populate the conceptual model with new data and information available since 2004. The model (Thom et al. 2004) brings together into one easily navigated electronic tool the information provided by existing models of subcomponents of the estuary, as well as the state of the science and knowledge of general estuarine controlling factors, stressors, structures, processes, and functions. It provides a basis for and structure in which new knowledge about the LCRE can be incorporated through updates to a spreadsheet, such as new information from Borde et al. (2010), Bottom et al. (2005a, b; 2008), Diefenderfer et al. (2008), Diefenderfer and Montgomery (2009), Roegner et al. (2008, 2010a), Sather et al. (2011), Storch (2011), and Storch and Sather (2011).

- Determine relationships between restoration actions and survival benefit indices for juvenile salmon. One of CEERP's most important uncertainties is evidence, direct or indirect, of the effects of restoration on juvenile salmon survival or other measures, such as growth, condition, and returns of adult salmon.

\subsection{Closing}

Although more data and information are needed on the mechanisms linking the restoration of LCRE ecosystems to the effects on juvenile salmonids, we achieved the primary goal of the CE study to develop a methodology to evaluate the cumulative effects of habitat actions in the CEERP. We delivered 1) monitoring protocols and methods to standardize monitoring activities; 2) the theoretical and empirical basis for a CE methodology using a levels-of-evidence approach; 3) evaluations of cumulative effects using ecological relationships, geo-referenced data, hydrodynamic modeling, and meta-analyses; and 4) an AM process for coordinating and coalescing restoration efforts in the LCRE. The CE study may be ending, but the tools and methods developed by it should continue to be used and refined by CEERP stakeholders. Toward this end, the CEERP should perform the first-ever levels-of-evidence evaluation; design and build a geospatial database for LCRE monitoring, research, and other data; perform internal and external outreach of CE deliverables and supporting products; and continue to institutionalize and operationalize the CEERP AM process. A solid foundation has been laid for improved decision-making, more cost-effective and ecologically effective restoration actions, and future comprehensive evaluations of progress made by the CEERP to understand, conserve, and restore ecosystems in the LCRE. 


\subsection{Literature Cited}

The literature cited in the chapters and appendixes of this report are listed collectively in this final chapter of the report.

40 CFR 1508.7. Title 40 of the Code of Federal Regulations, Protection of the Environment, Part 1508, "Terminology and Index," Section 7, Cumulative Impact.

Action Agencies (BPA and USACE). 2007. Biological Assessment for Effects of Federal Columbia River Power System and Mainstem Effects of Other Tributary Actions on Anadromous Salmonid Species Listed Under the Endangered Species Act. U.S. Army Corps of Engineers, Bonneville Power Administration, and U.S. Bureau of Reclamation, Portland, Oregon.

Action Agencies (BPA and USACE). 2009. FCRPS Adaptive Management Implementation Plan, 2008-2018 Federal Columbia River Power System Biological Opinion. Available at http://www.salmonrecovery.gov/Files/BiologicalOpinions/AMIP_09 10 09.pdf.

Allan JD. 2004. "Landscapes and riverscapes: the influence of land use on stream ecosystems." Annual Review of Ecology, Evolution, and Systematics 35:257-284.

Amin M. 1983. "On perturbations of harmonic constants in the Thames estuary." Geophysical Journal, Royal Astronomical Society 73:587-603.

Amphlett MB and TE Brabben. 1991. "Measuring freshwater flows in large tidal rivers." In: Braga, Jr., BPF and CA Fernandez-Jauregui (eds.), Water Management of the Amazon Basin Manaus 5-9, 1990.

UNESCO, Montevideo, Uruguay.

Araya YN, J Silvertown, DJ Gowing, KJ McConway, HP Linder, and G Midgley. 2011. “A fundamental, eco-hydrological basis for niche segregation in plant communities." New Phytologist 189:253-258. doi: 10.1111/j. 1469-8137.2010.03475.x.

Baldwin AH, MS Egnotovich, and E Clarke. 2001. "Hydrologic change and vegetation of tidal freshwater marshes: field, greenhouse, and seed-bank experiments." Wetlands 21:519-531.

Bezerra MOM, RK da S Pontes, MN Gallo, AMC Carmo, SB Vinzon, and RP Rosario. 2008. "Forcing and mixing processes in the Amazon estuary: A study case." Il Nuovo Cimento C 31:743-756.

Boehner J, R Koethe, O Conrad, J Gross, A Ringeler, and T Selige. 2002. "Soil Regionalisation by Means of Terrain Analysis and Process Parameterisation." In: E Micheli, F Nachtergaele, and L Montanarella (eds.), Soil Classification 2001. Research Report No. 7, EUR 20398 EN, pp. 213-222, European Soil Bureau, Luxembourg.

Booth DB, D Hartley, and R Jackson. 2002. "Forest cover, impervious-surface area, and the mitigation of stormwater impacts." Journal of the American Water Resources Association 38:835-845. 
Booth DB, JR Karr, S Schauman, CP Konrad, SA Morley, MG Larson, P Henshaw, EJ Nelson, and SJ Burges. 2001. Urban Stream Rehabilitation in the Pacific Northwest. Grant Report R82-5284-010, United States Environmental Protection Agency, Seattle, Washington.

Borde AB and HL Diefenderfer. 2009. "Assessment of Previously Breached and Created Sites Analysis Summary." Appendix C, in: Evaluating Cumulative Ecosystem Response to Restoration Projects in the Lower Columbia River and Estuary, 2008, GE Johnson and HL Diefenderfer (eds.). PNNL-18677, prepared for the U.S. Army Corps of Engineers, Portland District, Portland, Oregon, by Pacific Northwest National Laboratory, Richland, Washington, and the National Marine Fisheries Service, Seattle, Washington.

Borde AB, E Dawley, G Curtis Roegner, and H Diefenderfer. 2008a. "Natural Breach Assessment Data Summary - Selection of Sites for Temporal Comparison to Restored Sites." Appendix F, in: Evaluating Cumulative Ecosystem Response to Restoration Projects in the Columbia River Estuary, Annual Report 2007, GE Johnson and HL Diefenderfer (eds.). PNNL-17437, prepared for the U.S. Army Corps of Engineers, Portland District, Portland, Oregon, by Pacific Northwest National Laboratory, Richland, Washington.

Borde AB, HL Diefenderfer, and SA Zimmerman. 2008b. "Julia Butler Hansen National Wildlife Refuge - Monitoring Data Summary." Appendix B, in: Evaluating Cumulative Ecosystem Response to Restoration Projects in the Columbia River Estuary, Annual Report 2007, GE Johnson and HL Diefenderfer (eds.). PNNL-17437, prepared for the U.S. Army Corps of Engineers, Portland District, Portland, Oregon, by Pacific Northwest National Laboratory, Richland, Washington.

Borde AB, HL Diefenderfer, and SA Zimmerman. 2009a. "Julia Butler Hansen Wildlife Refuge Monitoring Data Summary." Appendix F, in: Evaluating Cumulative Ecosystem Response to Restoration Projects in the Lower Columbia River and Estuary, 2008, GE Johnson and HL Diefenderfer (eds.). PNNL-18677, prepared for the U.S. Army Corps of Engineers, Portland District, Portland, Oregon, by Pacific Northwest National Laboratory, Richland, Washington, and the National Marine Fisheries Service, Seattle, Washington.

Borde AB, HL Diefenderfer, SA Zimmerman, NK Sather, and RM Thom. 2009b. Lower Columbia River and Estuary Restoration Reference Site Study 2008 Report. PNWD-4133, Battelle-Pacific Northwest Division, Richland, Washington.

Borde AB, HL Diefenderfer, SA Zimmerman, and RM Thom. 2010. "Wetland Vegetation Community Distribution and inundation Patterns in the Tidally Influenced Columbia River, USA" Appendix B, in: Evaluating Cumulative Ecosystem Response to Restoration Projects in the Lower Columbia River and Estuary, 2009, GE Johnson and HL Diefenderfer (eds.). PNNL-19440, prepared for the U.S. Army Corps of Engineers, Portland District, Portland, Oregon, by Pacific Northwest National Laboratory, Richland, Washington. 
Bottom DL, G Anderson, A Baptista, J Burke, M Burla, M Bhuthimethee, L Campbell, E Casillas, S Hinton, K Jacobson, D Jay, R McNatt, P Moran, GC Roegner, CA Simenstad, V Stamatiou, D Teel, and JE Zamon. 2008. Salmon Life Histories, Habitat, and Food Webs in the Columbia River Estuary: An Overview of Research Results, 2002-2006. Report prepared for the U.S. Army Corps of Engineers, Portland District, Northwest Division, Portland, Oregon, and Bonneville Power Administration, Environment, Fish, and Wildlife Division, Portland, Oregon, by the Northwest Fisheries Science Center, National Marine Fisheries Service, Seattle, Washington.

Bottom DL, KK Jones, TJ Cornwell, A Gray, and CA Simenstad. 2005a. "Patterns of Chinook Salmon Migration and Residency in the Salmon River Estuary (Oregon)." Estuarine Coastal and Shelf Science 64:79-93.

Bottom DL, CA Simenstad, J Burke, AM Baptista, DA Jay, KK Jones, E Casillas, and M Schiewe. 2005b. Salmon at River's End: The Role of the Estuary in the Decline and Recovery of Columbia River Salmon. U.S. Department of Commerce, National Oceanic and Atmospheric Administration, Technical Memorandum NMFS-NWFSC-68, Northwest Fisheries Science Center, Seattle, Washington.

BPA/Corps. 2012. Columbia Estuary Ecosystem Restoration Program: 2012 Strategy Report. DRAFT, Bonneville Power Administration and U.S. Army Corps of Engineers, Portland, Oregon.

Bray JR and JT Curtis. 1957. "An ordination of the upland forest communities in southern Wisconsin." Ecological Monographs 27:325-349.

Breithaupt SA and T Khangaonkar. 2007. Hydraulic and Hydrodynamics Modeling of the Grays River and Its Floodplain for the Kandoll Road Restoration Project. PNWD-3780, prepared for Ducks Unlimited, Vancouver, Washington, by Battelle-Pacific Northwest Division, Richland, Washington.

Breithaupt SA and T Khangaonkar. 2008. "Forensic Hydrodynamic Evaluation Following the Restoration of a Tidal Freshwater Wetlands." In: Proceedings of the 10th International Conference on Estuarine and Coastal Modeling. American Society of Civil Engineers, Reston, Virginia.

Bunn S and A Arthington. 2002. "Basic Principles and Ecological Consequences of Altered Flow Regimes for Aquatic Biodiversity." Environmental Management 30:492-507.

Busch DE and JC Trexler (eds.). 2003. Monitoring Ecosystems-Interdisciplinary Approaches for Evaluating Ecoregional Initiatives. Island Press, Washington, D.C.

Buschman FA, AJF Hoitink, M van der Vegt, and P Hoekstra. 2010. "Subtidal flow division at a shallow tidal junction.” Water Resources Research 46, W12515, doi:10.1029/2010WR009266.

Byrd KB, NM Kelly, AM Merenlender. 2007. "Temporal and spatial relationships between watershed land use and salt marsh disturbance in a Pacific estuary." Environmental Management 39:98-112.

Castaing P and GP Allen. 1981. "Mechanisms controlling seaward escape of suspended sediment from the Gironde: A macrotidal estuary in France." Marine Geology 40: 101-118.

Chapman PM, BG McDonald, and GS Lawrence. 2002. "Weight of evidence issues and frameworks in sediment quality (and other) assessments." Human and Ecological Risk Assessment 8:1489-1515. 
Chawla A, DA Jay, AM Baptista, M Wilkin, and C Seaton. 2008. "Seasonal Variability and EstuaryShelf Interactions in Circulation Dynamics of a River-Dominated Estuary." Estuaries and Coasts 31:269-288.

Chen C, RC Beardsley, and G Cowles. 2006. An Unstructured Grid, Finite-Volume Coastal Ocean Model, FVCOM User Manual. SMAST/UMASSD-06-060, University of Massachusetts-Dartmouth, Dartmouth, Massachusetts.

Christy JA and JA Putera. 1992. Lower Columbia River Natural Area Inventory. Report to The Nature Conservancy, Washington Field Office, Seattle, Washington.

Clarke KR. 1993. "Non-parametric multivariate analyses of changes in community structure." Australian Journal of Ecology 18:117-143.

Clarke KR and RN Gorley. 2006. PRIMER v6: User Manual/Tutorial. PRIMER-E, Plymouth, United Kingdom.

Clarke KR and RM Warwick. 1994. Change in Marine Communities: An Approach to Statistical Analysis and Interpretation. Natural Environment Research Council, London.

Cochran WG. 1977. Sampling Techniques. John Wiley \& Sons, New York.

Coleman AM. 2010. Terrain Analysis Methods Supporting Land Cover Classification for Snohomish County Critical Area Monitoring. PNWD-4145, Battelle-Pacific Northwest Division, Richland, Washington.

Coleman AM, HL Diefenderfer, DL Ward, and AB Borde. 2010. "Spatially Based Area-Time Inundation Index Model Applied in Tidal Wetlands of the Lower Columbia River and Estuary." Appendix A, in: Evaluating Cumulative Ecosystem Response to Restoration Projects in the Lower Columbia River and Estuary, 2009, GE Johnson and HL Diefenderfer (eds.). PNNL-19440, prepared for the U.S. Army Corps of Engineers, Portland District, Portland, Oregon, by Pacific Northwest National Laboratory, Richland, Washington.

Cornu C and S Sadro. 2002. "Physical and functional responses to experimental marsh surface elevation manipulation in Coos Bay's South Slough.” Restoration Ecology 10:474-486.

Czekanowski J. 1913. Zarys Metod Statystiycnck. E. Wendego, Warsaw, Poland.

Diefenderfer HL. 2007. "Channel morphology and restoration of Sitka spruce (Picea sitchensis) tidal forested wetlands, Columbia River, U.S.A.” Doctoral Dissertation, University of Washington, College of Forest Resources, Seattle, Washington.

Diefenderfer HL, AB Borde, GC Roegner, EM Dawley, MT Russell, and AS Cameron. 2010. "Ecological Trajectories and Salmon Habitat Functions of Historical Dike Breaches and Created Islands in the Columbia River Floodplain, USA." Appendix C in: Evaluating Cumulative Ecosystem Response to Restoration Projects in the Lower Columbia River and Estuary, 2009, GE Johnson and HL Diefenderfer (eds.). PNNL-19440, prepared for the U.S. Army Corps of Engineers, Portland District, Portland, Oregon, by Pacific Northwest National Laboratory, Richland, Washington. 
Diefenderfer HL, AB Borde, K Vogt, K Sobocinski, and RM Thom. In preparation. “Conceptual ModelDriven Research to Conserve and Restore Temperate Zone Picea sitchensis Tidal Wetland Habitat for Endangered Salmonid Fishes.”

Diefenderfer HL, AM Coleman, AB Borde, and IA Sinks. 2008. "Hydraulic geometry and microtopography of tidal freshwater forested wetlands and implications for restoration, Columbia River, U.S.A.” Ecohydrology and Hydrobiology 8:339-361.

Diefenderfer HL and GE Johnson. 2008. "Key Results of the Cumulative Effects Study." Chapter 4.0 in: Evaluating Cumulative Ecosystem Response to Restoration Projects in the Columbia River Estuary, Annual Report 2007, GE Johnson and HL Diefenderfer (eds.). PNNL-17437, prepared for the U.S. Army Corps of Engineers, Portland District, Portland, Oregon, by Pacific Northwest National Laboratory, Richland, Washington.

Diefenderfer HL, GE Johnson, JR Skalski, SA Breithaupt, and AM Coleman. 2012. "Application of the diminishing returns concept in the hydroecologic restoration of riverscapes." Landscape Ecology 27:671-682.

Diefenderfer HL and DR Montgomery. 2009. "Pool spacing, channel morphology, and the restoration of tidal forested wetlands of the Columbia River, U.S.A.” Restoration Ecology 17:158-168.

Diefenderfer, HL, GC Roegner, RM Thom, EM Dawley, AH Whiting, GE Johnson, KL Sobocinski, MG Anderson, and BD Ebberts. 2005. Evaluating Cumulative Ecosystem Response to Restoration Projects in the Columbia River Estuary, Annual Report 2004. PNNL-15102, prepared for the U.S. Army Corps of Engineers, Portland District, Portland, Oregon, by Pacific Northwest National Laboratory, Richland, Washington.

Diefenderfer HL, KL Sobocinski, RM Thom, CW May, AB Borde, SL Southard, J Vavrinec, and NK Sather. 2009. "Multiscale analysis of restoration priorities for marine shoreline planning." Environmental Management 44:712-731.

Diefenderfer HL, RM Thom, and JE Adkins. 2003. A Systematic Approach to Coastal Ecosystem Restoration. PNWD-3237, prepared for the National Oceanic and Atmospheric Administration Coastal Services Center by Battelle-Pacific Northwest Division, Richland, Washington.

Diefenderfer HL, RM Thom, AB Borde, GC Roegner, AH Whiting, GE Johnson, EM Dawley, JR Skalski, J Vavrinec, and BD Ebberts. 2006. Evaluating Cumulative Ecosystem Response to Restoration Projects in the Columbia River Estuary, Annual Report 2005. PNNL-15934, prepared for the U.S. Army Corps of Engineers, Portland District, Portland, Oregon, by Pacific Northwest National Laboratory, Richland, Washington.

Diefenderfer HL, RM Thom, GE Johnson, JR Skalski, KA Vogt, BD Ebberts, GC Roegner, and EM Dawley. 2011. "A levels-of-evidence approach for assessing cumulative ecosystem response to estuary and river restoration programs." Ecological Restoration 29:111-132. 
DiLorenzo JL, P Huang, ML Thatcher, and TO Najarian. 1993. "Dredging impacts of Delaware estuary tides." In: Proceedings of the 3rd International Conference Sponsored by the Waterway, Port, Coastal and Ocean Division, ASCE, September 8-10, 1993. Estuarine and Coastal Modeling III, Oak Brook, Illinois, pp. 86-104.

Doodson AT. 1921. "The harmonic development of the tide-generating potential." In: Proceedings of the Royal Society of London, Series A, 100(704):305-329.

Downes BJ, LA Barmuta, PG Fairweather, DP Faith, MJ Keough, PS Lake, BD Mapstone, and GP Quinn. 2002. Monitoring Ecological Impacts: Concepts and Practice in Flowing Waters. Cambridge University Press, Cambridge, United Kingdom.

Dronkers JJ. 1964. Tidal Computations in Rivers and Coastal Waters. North-Holland Publishing Company, Amsterdam, pp. 296-304.

Endangered Species Act. 16 USC 1531 et seq.

Evans NR, RM Thom, GD Williams, J Vavrinec, KL Sobocinski, LM Miller, AB Borde, VI Cullinan, JA Ward, CW May, and C Allen. 2006. Lower Columbia River Restoration Prioritization Framework. Prepared for the Lower Columbia River Estuary Partnership by Battelle-Pacific Northwest Division, Richland, Washington.

Ewing K. 1986. "Plant growth and productivity along complex gradients in a Pacific Northwest brackish intertidal marsh." Estuaries 9:49-62.

Expert Regional Technical Group (ERTG). 2010. ERTG Template for LCRE Habitat Restoration Project Summary. Document \# ERTG 2010-01, available from the Bonneville Power Administration or the U.S. Army Corps of Engineers, Portland District, Portland, Oregon.

Faith DP, PR Minchin, and L Belbin. 1987. "Compositional dissimilarity as a robust measure of ecological distance." Vegetatio 69:57-68.

Flinchem EP and DA Jay. 2000. "An introduction to wavelet transform tidal analysis methods." Estuarine, Coastal, and Shelf Science 51:177-200.

Foreman MGG. 1977. Manual for Tidal Heights Analysis and Prediction. Pacific Marine Report 77-10, Institute of Ocean Sciences, Patricia Bay Victoria, BC, Canada.

Fox DS, S Bell, W Nehlsen, and J Damron. 1984. The Columbia River Estuary: Atlas of Physical and Biological Characteristics. Columbia River Estuary Data Development Program, Columbia River Estuary Study Taskforce, Astoria, Oregon.

Frenkel RE and JC Morlan. 1990. Restoration of the Salmon River Salt Marshes: Retrospect and Prospect. Final report to U.S. Environmental Protection Agency, Region 10, by the Department of Geosciences, Oregon State University, Corvallis, Oregon.

Frenkel RE and JC Morlan. 1991. "Can we restore our salt marshes? Lessons from the Salmon River, Oregon.” Northwest Environmental Journal 7:119-135. 
Fresh K, E Casillas, L Johnson, and D Bottom. 2005. Role of the Estuary in the Recovery

Columbia River Basin Salmon and Steelhead: An Evaluation of Selected Factors on Population Viability. U.S. Department of Commerce, National Oceanic and Atmospheric Administration, Technical Memorandum NMFS-NWFSC-69, Northwest Fisheries Science Center, Seattle, Washington.

Gallo M and S Vinzon. 2005. "Generation of overtides and compound tides in Amazon estuary." Ocean Dynamics 55:5-6.

Gergel SE, MG Turner, JR Miller, JM Melack, and EH Stanley. 2002. "Landscape indicators of human impacts to riverine systems." Aquatic Science 64:118-128.

Geyer WR, JT Morris, FG Prahl, and DA Jay. 2000. Estuarine Science: A Synthetic Approach to Research and Practice, JE Hobbie (ed.), pp. 177-206. Island Press, Washington, D.C.

Giese BS and DA Jay. 1989. "Modeling tidal energetics of the Columbia River Estuary." Estuarine, Coastal, and Shelf Science 29: 549-571.

Godin G. 1999. "The propagation of tides up rivers with special considerations on the upper Saint Lawrence River." Estuarine, Coastal, and Shelf Science 48: 307-324.

Gotelli NJ and DJ McCabe. 2002. "Species Co-Occurrence: A Meta-Analysis of J.M. Diamond's Assembly Rules Model.” Ecology 83:2091-2096.

Gowing DJ and G Spoor. 1998. United Kingdom Floodplains. R Bailey, P Jose, and B Sherwood (eds.), pp. 185-196. Otley, United Kingdom, Westbury.

Gurevitch J and LV Hedges. 1999. "Statistical Issues in Ecological Meta-Analyses.” Ecology 80:1142-1149.

Hale SS, JF Paul, and JF Heltshe. 2004. "Watershed landscape indicators of estuarine benthic condition." Estuaries 27:283-295.

Harlin JM. 1978. "Statistical moments of the hypsometric curve and its density function." Journal of the International Association for Mathematical Geology 10:59-72.

Haskell CA and KF Tiffan. 2011. Crims Island-Restoration and monitoring of juvenile salmon rearing habitat in the Columbia River Estuary, Oregon, 2004-10. Scientific Investigations Report 2011-5022, U.S. Geological Survey, Seattle, Washington.

Haskell CA, K Tiffan, and J Olson. 2007. Crims Island Habitat Restoration in the Columbia River Estuary - Fisheries Monitoring and Evaluation, 2006. Final Report of Research Submitted to U.S. Army Corps of Engineers, Portland District, Cook, Washington.

Havens KJ, D O'Brien, D Stanhope, R Thomas, and G Silberhorn. 2003. Initiating Development of a Forested Depressional Wetland HGM Model for Wetland Management in Virginia. Final report to U.S. Environmental Protection Agency, Region III, by the College of William and Mary, Virginia Institute of Marine Science, Gloucester Point, Virginia. 
Heck KL, G Hays, and RJ Orth. 2003. "Critical evaluation of the nursery role hypothesis for seagrass meadows." Marine Ecology Progress Series 253:123-136.

Hedges LV, J Gurevitch, and PS Curtis. 1999. "The Meta-Analysis of Response Ratios in Experimental Ecology." Ecology 80:1150-1156.

Hedges LV and I Olkin. 1985. Statistical Methods for Meta-Analysis. Academic Press, Orlando, Florida.

Hida N, JG Maia, O Shimmi, M Hiraoka, and N Mizutani. 1998. "Annual and Daily Changes of River Water Level at Breves and Caxiuana, Amazon Estuary." Geographical Review of Japan Series B 77:100-105.

Hillman TW. 2004. Monitoring Strategy for the Upper Columbia Basin. Draft report prepared for the Upper Columbia Regional Technical Team, Upper Columbia Salmon Recovery Board, Wenatchee, Washington, February 1, 2004. Prepared by BioAnalysts, Inc., Eagle, Idaho.

Horton RE. 1932. "Drainage Basin Characteristics." Transactions American Geophysical Union $13: 350-361$.

Huber PJ. 1996. Robust Statistical Procedures, 2nd Ed., No. 68, in CBMS-NSF Regional Conference Series in Applied Mathematics Society of Industrial and Applied Mathematics, Society for Industrial and Applied Mathematics, Philadelphia, Pennsylvania.

Hudon C. 1997. "Impact of water level fluctuations on St. Lawrence River aquatic vegetation." Canadian Journal of Fisheries and Aquatic Sciences 54:2853-2865.

Hutchinson MF. 1989. "A New Method for Gridding Elevation and Streamline Data with Automatic Removal of Pits." Journal of Hydrology 106:211-232.

Independent Scientific Advisory Board (ISAB). 2011. Columbia River Food Webs: Developing a Broader Scientific Foundation for Fish and Wildlife Restoration. ISAB 2011-1, Portland, Oregon.

Jay DA. 1991. "Green's law revisited: tidal long wave propagation in channels with strong topography." Journal of Geophysical Research 96:20,585-20,598.

Jay D A and EP Flinchem. 1997. "Interaction of fluctuating river flow with a barotropic tide: A test of wavelet tidal analysis methods." Journal of Geophysical Research 102:5705-5720.

Jay DA and EP Flinchem. 1999. "A comparison of methods for analysis of tidal records containing multi-scale non-tidal background energy." Continental Shelf Research 19:1695-1732.

Jay DA, BS Giese, and CR Sherwood. 1990. "Energetics and sedimentary processes in the Columbia River Estuary." Progress in Oceanography 25:157-174.

Jay DA, K Leffler, and S Degens. 2011. "Long-term evolution of Columbia River tides.” ASCE Journal of Waterway, Port, Coastal, and Ocean Engineering 137(4):182-191. 
Jay DA and P Naik. 2011. "Distinguishing human and climate influences on the Columbia River: changes in the disturbance processes." Submitted to Hydrological Sciences Journal.

Jay DA and JD Smith. 1990. "Circulation, density distribution and neap-spring transitions in the Columbia River Estuary.” Progress in Oceanography 25:81-112.

Jiao N, Y Zhao, T Luo, and X Wang. 2006. "Natural and anthropogenic forcing on the dynamics of virioplankton in the Yangtze river estuary." Journal of the Marine Biological Association of the United Kingdom 86:543-550.

Johnson, GE (ed.). 2007. Evaluating Cumulative Ecosystem Response to Restoration Projects in the Columbia River Estuary, Annual Report 2006. PNNL-16561, prepared for the U.S. Army Corps of Engineers, Portland District, Portland, Oregon, by Pacific Northwest National Laboratory, Richland, Washington.

Johnson GE, A Camedron, C Corbett, and RM Thom. 2010. "Action Effectiveness Meta-Analysis." Chapter 3.0, in: Evaluating Cumulative Ecosystem Response to Restoration Projects in the Lower Columbia River and Estuary, 2009, Johnson GE and HL Diefenderfer (eds.). PNNL-19440, prepared for the U.S. Army Corps of Engineers, Portland District, Portland, Oregon, by Pacific Northwest National Laboratory, Richland, Washington.

Johnson GE and HL Diefenderfer (eds.). 2008. Evaluating Cumulative Ecosystem Response to Restoration Projects in the Columbia River Estuary, Annual Report 2007. PNNL-17437, prepared for the U.S. Army Corps of Engineers, Portland District, Portland, Oregon, by Pacific Northwest National Laboratory, Richland, Washington.

Johnson GE and HL Diefenderfer (eds.). 2009. Evaluating Cumulative Ecosystem Response to Restoration Projects in the Lower Columbia River and Estuary, 2008. PNNL-18677, prepared for the U.S. Army Corps of Engineers, Portland District, Portland, Oregon, by Pacific Northwest National Laboratory, Richland, Washington, and the National Marine Fisheries Service, Seattle, Washington.

Johnson GE and HL Diefenderfer (eds.). 2010. Evaluating Cumulative Ecosystem Response to Restoration Projects in the Lower Columbia River and Estuary, 2009. PNNL-19440, prepared for the U.S. Army Corps of Engineers, Portland District, Portland, Oregon, by Pacific Northwest National Laboratory, Richland, Washington, and the National Marine Fisheries Service, Seattle, Washington.

Johnson GE, HL Diefenderfer, BD Ebberts, C Tortorici, T Yerxa, JC Leary, and JR Skalski. 2008. Research, Monitoring, and Evaluation for the Federal Columbia River Estuary Program. PNNL-17300, Pacific Northwest National Laboratory, Richland, Washington.

Johnson GE, RM Thom, AB Borde, HL Diefenderfer, K Jones, and C Corbett. 2009. "Effectiveness Monitoring Data - Preliminary Meta-Analysis." Appendix H in Evaluating Cumulative Ecosystem Response to Restoration Projects in the Lower Columbia River and Estuary, 2008, Johnson GE and HL Diefenderfer (eds.). PNNL-18677, prepared for the U.S. Army Corps of Engineers, Portland District, Portland, Oregon, by Pacific Northwest National Laboratory, Richland, Washington. 
Johnson GE, RM Thom, AH Whiting, GB Sutherland, T Berquam, BD Ebberts, NM Ricci, JA Southard, and JD Wilcox. 2003. An Ecosystem-Based Approach to Habitat Restoration Projects with Emphasis on Salmonids in the Columbia River Estuary. PNNL-14412, prepared for the Bonneville Power

Administration, Portland, Oregon, by Pacific Northwest National Laboratory, Richland, Washington.

Jordan C, J Geiselman, M Newsom, and J Athearn (eds.). 2003. Research, Monitoring, and Evaluation Plan for the NOAA-Fisheries 2000 Federal Columbia River Power System Biological Opinion. Draft. September 11, 2003. Available at http://www.nwfsc.noaa.gov/research/divisions/cbd/mathbio/isemp/docs/rme_plan_09-03.pdf.

Junk WJ. 1999. "The Flood Pulse Concept of Large Rivers: Learning from the Tropics." Archive fur Hydrobiologie 115:261-280.

Kaiser JF. 1966. System Analysis by Digital Computers. FF Kuo and JF Kaiser (eds.), pp. 218-284, New York, Jon Wiley.

Kentula ME, RP Brooks, SE Gwin, CC Holland, AD Sherman, and JC Sifneos. 1992. An Approach to Improving Decision Making in Wetland Restoration and Creation. EPA/600/R-92/150, U.S. Environmental Protection Agency Environmental Research Laboratory, Corvallis, Oregon.

King IP. 2005. Update Documentation, RMA2 - A Two-Dimensional Finite-Element Model for Flow in Estuaries and Streams, Version 7.4g. Resource Modelling Associates, Sydney, Australia.

Kingsford RT. 2000. "Ecological impacts of dams, water diversions and river management on floodplain wetlands in Australia." Austral Ecology 25:109-127.

Knick ST, JT Rotenberry, and TJ Zarriello. 1997. "Supervised Classification of Landsat Thematic Mapper Imagery in a Semi-arid Rangeland by Nonparametric Discriminate Analysis." Photogrammetric Engineering and Remote Sensing 63:79-86.

Koeln G and J Bissonnette. 2000. "Cross-correlation analysis: mapping landcover change with a historic landcover database and a recent, single-date multispectral image." In: Proceedings of 2000 ASPRS Annual Conference, Washington, D.C.

Kostachuk R. 2002. "Flow and sediment dynamics in migrating salinity intrusions: Fraser River Estuary, Canada.” Estuaries 25:197-203.

Kukulka T and DA Jay. 2003a. "Impacts of Columbia River discharge on salmonid habitat I. a nonstationary fluvial tide model." Journal of Geophysical Research 108:3293. doi 10.1029/2002JC001382.

Kukulka T and DA Jay. 2003b. "Impacts of Columbia River discharge on salmonid habitat II. Changes in shallow-water habitat." Journal of Geophysical Research 108:3294. doi 10.1029/2003JC001829.

Kunze LM. 1994. Preliminary Classification of Native, Low Elevation, Freshwater Wetland Vegetation in Western Washington. Washington State Department of Natural Resources, Olympia, Washington. 
Landis WG, PB Duncan, EH Hayes, AJ Markiewicz, and JF Thomas. 2004. "A regional retrospective assessment of the potential stressors causing the decline of the Cherry Point Pacific herring run." Human and Ecological Risk Assessment 10:271-297.

LeBlond PH. 1978. "On tidal propagation in shallow rivers." Journal of Geophysical Research. $83: 4717-4721$.

Lee KH, TM Isenhart, and RC Schultz. 2003. "Sediment and nutrient removal in an established multispecies riparian buffer." Journal of Soil and Water Conservation 58:1-8.

Lee KN. 1993. Compass and Gyroscope. Island Press, Washington, D.C.

Leffler K and DA Jay. 2009. "Enhancing tidal harmonic analysis: Robust (hybrid L1/L2) solutions." Continental Shelf Research 29:78-88.

Leibowitz, SG, B Abbruzzese, PR Adamus, LE Hughes, and JT Irish. 1992. A Synoptic Approach to Cumulative Impact Assessment: A Proposed Methodology. EPA/600/R-92/167. U.S. Environmental Protection Agency, Environmental Research Laboratory, Corvallis, Oregon.

Levings CD and D Bouillon. 1994. Estuarine and Ocean Survival of Northeastern Pacific Salmon. U.S. Department of Commerce, National Oceanic and Atmospheric Administration (NOAA) Technical Memorandum NOAA-NMFS-NWFSC TM-29, Seattle, Washington.

Levings CD, K Conlin, and B Raymond. 1991. "Intertidal Habitats Used by Juvenile Chinook Salmon (Oncorhynchus Tshawytscha) Rearing in the North Arm of the Fraser River Estuary." Marine Pollution Bulletin 22:20-26.

Levy DA and TG Northcote. 1982. "Juvenile Salmon Residency in a Marsh Area of the Fraser River Estuary." Canadian Journal of Fisheries and Aquatic Sciences 39:270-276.

Leyer I. 2005. "Predicting plant species' responses to river regulation: the role of water level fluctuations." Journal of Applied Ecology 42:239-250.

Lower Columbia Fish Recovery Board. 2010. 2010 Lower Columbia Salmon Recovery and Fish \& Wildlife Subbasin Plan. Revision of the 2006 interim recovery plan for the Washington portion of the lower Columbia River recovery domain. Available at http://www.nwr.noaa.gov/Salmon-RecoveryPlanning/Recovery-Domains/Willamette-Lower-Columbia/LC/interim.cfm.

Lunetta RS and CD Elvidge. 1999. Remote Sensing Change Detection: Environmental Monitoring Methods and Applications. CRC Press, New York.

Luo W. 2000. "Quantifying groundwater-sapping landforms with a hypsometric technique." Journal of Geophysical Research 105(E1):1685-1694.

Maier GO and CA Simenstad. 2009. "The role of marsh-derived macrodetritus to the food webs of juvenile Chinook salmon in a large altered estuary." Estuaries and Coasts 32:984-998. 
McCullough DA. 1999. A Review and Synthesis of the Effects of Alterations to the Water Temperature Regime on Freshwater Life Stages of Salmonids, with Special Reference to Chinook Salmon.

EPA 910-R-99-010, U.S. Environmental Protection Agency, Portland, Oregon.

McCune B and JB Grace. 2002. Analysis of Ecological Communities. MJM Software Design, Gleneden Beach, Oregon. www.pcord.com.

Mikhailova MV and MV Isupova. 2006. "Water circulation, sediment dynamics, erosional and accumulative processes in Gironde Estuary (France)." Water Research 33:10-23.

Miller SW, Phaedra Budy, and JC Schmidt. 2010. "Quantifying Macroinvertebrate Responses to InStream Habitat Restoration: Applications of Meta-Analysis to River Restoration." Restoration Ecology 18:(1):8-19.

Miller BA and S Sadro. 2003. "Residence Time and Seasonal Movements of Juvenile Coho Salmon in the Ecotone and Lower Estuary of Winchester Creek, South Slough, Oregon." Transactions of the American Fisheries Society 132:546-559.

Mitsch WJ and JG Gosselink. 2000. "The value of wetlands: Importance of scale and landscape setting." Ecological Economics 35(1):25-33.

Mitsch WJ and JG Gosselink. 2007. Wetlands. Fourth Edition, John Wiley \& Sons; New York.

Moffett KB, DA Robinson, and SM Gorelick. 2010. "Relationship of salt marsh vegetation zonation to spatial patterns in soil moisture, salinity, and topography." Ecosystems 13:1287-1302.

Naik PK and DA Jay. 2005. "Virgin flow estimation of the Columbia River (1879-1928)." Hydrologic Processes 10.1002/hyp.5636.

Naik P and DA Jay. 2011. "Distinguishing human and climate influences on the Columbia River: changes in mean flow and sediment transport." Submitted to Journal of Hydrology.

National Marine Fisheries Service (NMFS). 2000. Biological Opinion: Reinitiation of Consultation on Operation of the Federal Columbia River Power System, Including the Juvenile Fish Transportation Program, and 19 Bureau of Reclamation Projects in the Columbia Basin. National Marine Fisheries Service - Northwest Region, Seattle, Washington. Available at http://www.salmonrecovery.gov/.

National Marine Fisheries Service (NMFS). 2004. Biological Opinion: Operation of the Federal Columbia River Power System (FCRPS) Including 19 Bureau of Reclamation Projects in the Columbia Basin (Revised and reissued pursuant to court order, NWF v. NMFS, Civ. No. CV 01-640-RE (D. Oregon)). National Marine Fisheries Service - Northwest Region, Seattle, Washington. Available at http://www.salmonrecovery.gov/.

National Marine Fisheries Service (NMFS). 2008. Biological Opinion-Consultation on Remand for Operation of the Federal Columbia River Power System, 11 Bureau of Reclamation Projects in the Columbia Basin and ESA Section 10(a)(1)(A) Permit for Juvenile Fish Transportation Program. NOAA's National Marine Fisheries Service - Northwest Region, Seattle, Washington. Available at http://www.salmonrecovery.gov/. 
National Marine Fisheries Service (NMFS). 2010a. Endangered Species Act Section 7(a)(2)

Consultation Supplemental Biological Opinion Supplemental Consultation on Remand for Operation of the Federal Columbia River Power System, 11 Bureau of Reclamation Projects in the Columbia Basin and ESA Section 10(a)(I)(A) Permit for Juvenile Fish Transportation Program. Consultation conducted by NOAA's National Marine Fisheries Service -- Northwest Region, Seattle, Washington. NOAA Fisheries Log Number: F/NWR/2010/02096. Date Issued: May 20, 2010.

National Marine Fisheries Service (NMFS). 2010b. "Proposed Upper Willamette River Conservation and Recovery Plan for Chinook Salmon and Steelhead." Available at http://www.nwr.noaa.gov/SalmonRecovery-Planning/Recovery-Domains/Willamette-Lower-Columbia/Will/Will-plan.cfm.

National Marine Fisheries Service (NMFS). 2011. Columbia River Estuary ESA Recovery Plan Module for Salmon and Steelhead. NMFS Northwest Region, Seattle, Washington. Available at http://www.nwr.noaa.gov/Salmon-Recovery-Planning/ESA-Recovery-Plans/Estuary-Module.cfm.

National Oceanic and Atmospheric Administration Coastal Change Analysis Program (NOAA C-CAP). 2004. "C-CAP Zone 2 and Zone 7 1996-2001-Era Land Cover Change Analysis Metadata, NOAA's Ocean Service, Coastal Services Center (CSC).” Webpage: http://www.csc.noaa.gov/crs/lca

Natural Resource Conservation Service (NRCS). 2002. Wetland determination (WETS) table for Clark County, Washington. Available at

http://www.wcc.nrcs.usda.gov/ftpref/support/climate/wetlands/wa/53011.txt.

National Research Council (NRC). 1992. Restoration of aquatic ecosystems. National Academy Press, Washington, D.C.

National Research Council (NRC). 2000. Ecological Indicators for the Nation. National Academies Press, Washington, D.C.

National Research Council (NRC). 2004a. Adaptive management for water resources project planning. Panel on Adaptive Management for Resource Stewardship, Committee to Assess the U.S. Army Corps of Engineers Methods of Analysis and Peer Review for Water Resources Project Planning, The National Academies Press, Washington, D.C.

National Research Council (NRC). 2004b. Analytical methods and approaches for water resources project planning. Panel on Methods and Techniques of Project Analysis, Committee to Assess the U.S. Army Corps of Engineers Methods of Analysis and Peer Review for Water Resources Project Planning, The National Academies Press, Washington, D.C.

National Research Council (NRC). 2004c. River basins and coastal systems planning within the U.S. Army Corps of Engineers. Panel on River Basin and Coastal Systems Planning, Committee to Assess the U.S. Army Corps of Engineers Methods of Analysis and Peer Review for Water Resources Project Planning, The National Academies Press, Washington, D.C.

National Research Council (NRC). 2004d. U.S. Army Corps of Engineers water resources planning: a new opportunity for service. Coordinating Committee, Committee to Assess the U.S. Army Corps of Engineers Methods of Analysis and Peer Review for Water Resources Project Planning, The National Academies Press, Washington, D.C. 
Neal VT. 1972. "Physical Aspects of the Columbia River and Its Estuary." In The Columbia River Estuary and Adjacent Ocean Waters: Bioenvironmental Studies. AT Pruter and DL Alverson (eds.), University of Washington Press, Seattle, Washington.

Neckles HA, M Dionne, DM Burdick, CT Roman, R Buchsbaum, and E Hutchins. 2002. "A monitoring protocol to assess tidal restoration of salt marshes on local and regional scales." Restoration Ecology 10(3):556-563.

Nilsson D, CA Reidy, M Dynesius, and C Revenga. 2005. "Fragmentation and flow regulation of the world's large river systems." Science 308:405-408.

Opperman, JJ, GE Galloway, J Fargione, JF Mount, BD Richter, and S Secchi. 2009. "Sustainable Floodplains Through Large-Scale Reconnection to Rivers.” Science 326:1487-1488.

Paquette A, A Bouchard, and A Cogliastro. 2006. "Survival and Growth of Under-Planted Trees: A Meta-Analysis Across Four Biomes.” Ecological Applications 16:1575-1589.

Parker BB. 1991. "The relative importance of the various nonlinear mechanisms in a wide range of tidal interactions.” In Progress in Tidal Hydrodynamics, BB Parker (ed.), pp. 237-268, John Wiley, New York.

Pastorok RA, A MacDonald, JR Sampson, P Wilber, DJ Yozzo, and JP Titre. 1997. “An ecological decision framework for environmental restoration projects." Ecological Engineering 9(1-2):89-107.

Pawlowicz R, R Beardsley, and S Lentz. 2002. "Classical tidal harmonic analysis with errors in matlab using t-tide." Computers and Geosciences 28:929-937.

Peet RK, TR Wentworth, and PS White. 1998. “A flexible, multipurpose method for recording vegetation composition and structure." Castanea 63:262-274.

Pennings SC, MB Grant, and MD Bertness. 2005. "Plant zonation in low-latitude salt marshes: disentangling the roles of flooding, salinity and competition." Journal of Ecology 93:159-167.

Peterson M. 2003. "A conceptual view of environment-habitat-production linkages in tidal river estuaries." Reviews in Fisheries Science 11:291-313.

Pickett STA and PS White. 1985. The Ecology of Natural Disturbance and Patch Dynamics. Academic Press, San Diego.

Pielou EC. 1966. "Shannon's formula as a measure of specific diversity: its use and misuse." American Naturalist 100:463-465.

Pielou EC. 1969. An Introduction to Mathematical Ecology. John Wiley \& Sons New York.

Pinkas L, MS Oliphant, and ILK Iverson. 1971. "Food habits of the albacore, bluefin, tuna and bonito in California waters." California Fish and Game 152:1-105. 
Poff NL, JD Allan, MB Bain, JR Karr, KL Prestergaard, BD Richter, RE Sparks, and JC Stromberg. 1997. "The Natural Flow Regime: A Paradigm for River Conservation and Restoration." BioScience 47:769-784.

Pywell RF, JM Bullock, DB Roy, L Warman, KJ Walker, and P Rothery. 2003. "Plant Traits as Predictors of Performance in Ecological Restoration." Journal of Applied Ecology 40:65-77.

Ramirez MF. 2008. "Emergent Aquatic Insects: Assemblage Structure and Patterns of Availability in Freshwater Wetlands of the Lower Columbia River Estuary.” M.S. Thesis, University of Washington.

Ransom AM and G Mertz. 1998. "Reducing uncertainty in the biological basis of fisheries management by meta-analysis of data from many populations: a synthesis." Fisheries Research 37:51-60.

Rey Benayas JM, AC Newton, A Diaz, and JM Bullock. 2009. "Enhancement of Biodiversity and Ecosystem Services by Ecological Restoration: A Meta-Analysis.” Science 325:1121-1124

Robson DS and HA Regier. 1964. "Sample size in Petersen mark-recapture experiments." Transactions of the American Fisheries Society 93:215-226.

Richter A and SA Kolmes. 2005. "Maximum temperature limits for Chinook, coho, and chum salmon, and steelhead trout in the Pacific Northwest." Reviews in Fisheries Science 13:23-49.

Rieman B, J Dunham, and J Clayton. 2006. "Emerging concepts for management of river ecosystems and challenges to applied integration of physical and biological sciences in the Pacific Northwest, USA." International Journal of River Basin Management 4:85-97.

Riley SJ, SD De Gloria, and R Elliot. 1999. "A Terrain Ruggedness Index that Quantifies Topographic Heterogeneity." Intermountain Journal of Science 5(1-4):23-27.

Roegner GC, A Baptista, DL Bottom, J Burke, L Campbell, C Elliot, S Hinton, D Jay, MA Lott, T Lundrigan, R McNatt, P Moran, CA Simenstad, D Teel, E Volk, J Zamon, and E Casillas. 2008. Estuarine Habitat and Juvenile Salmon-Current and Historical Linkages in the Lower Columbia River and Estuary, 2002-04. Report prepared for the U.S. Army Corps of Engineers, Portland District, Northwest Division, Portland, Oregon, and Bonneville Power Administration, Environment, Fish, and Wildlife Division, Portland, Oregon, by the Northwest Fisheries Science Center, National Marine Fisheries Service, Seattle, Washington.

Roegner GC, EM Dawley AW Whiting, and BD Ebberts. 2007. "Monitoring Juvenile Salmon Use and Fish Community Structure in Restored Wetland Habitat." Chapter 7.0, in Evaluating Cumulative Ecosystem Response to Restoration Projects in the Columbia River Estuary, Annual Report 2006, Johnson GE (ed.). PNNL-16561, prepared for the U.S. Army Corps of Engineers, Portland District, Portland, Oregon, by Pacific Northwest National Laboratory, Richland, Washington.

Roegner GC, HL Diefenderfer, AB Borde, RM Thom, EM Dawley, AH Whiting, SA Zimmerman, and GE Johnson. 2009a. Protocols for Monitoring Habitat Restoration Projects in the Lower Columbia River and Estuary. U.S. Department of Commerce, National Oceanic and Atmospheric Administration Technical Memorandum NMFS-NWFSC-97, Northwest Fisheries Science Center, Seattle, Washington. 
Roegner GC, M Russell, and EM Dawley. 2009b. "Hydrology and Fish - Monitoring Data Summary." Appendix E in Evaluating Cumulative Ecosystem Response to Restoration Projects in the Lower Columbia River and Estuary, 2008, GE Johnson and HL Diefenderfer (eds.). PNNL-18677, prepared for the U.S. Army Corps of Engineers, Portland District, Portland, Oregon, by Pacific Northwest National Laboratory, Richland, Washington, and the National Marine Fisheries Service, Seattle, Washington.

Roegner GC, A Cameron, A Silva, M Russell, EW Dawley. 2010b. "Fish and Hydrography," pp. 2.1-2.5, in Evaluating Cumulative Ecosystem Response to Restoration Projects in the Columbia River and Estuary, 2009, GE Johnson and HL Diefenderfer (eds.). PNNL-19440, prepared for the U.S. Army Corps of Engineers, Portland District, Portland Oregon, by the Pacific Northwest National Laboratory, Richland, Washington.

Roegner GC, EW Dawley, M Russell, AH Whiting, and DJ Teel. 2010a. “Juvenile Salmonid Use of Reconnected Tidal Freshwater Wetlands in Grays River, Lower Columbia River Basin.” Transactions of the American Fisheries Society 139:1211-1232.

Roman CT, KB Raposa, SC Adamowicz, MJ James-Pirri, and JG Catena. 2002. "Quantifying vegetation and nekton response to tidal restoration of a New England salt marsh." Restoration Ecology 10:450-460.

Sather NK, DJ Teel, AJ Storch, GE Johnson, ES Van Dyke, EM Dawley, DL Kuligowski, TA Jones, A Bryson, and KL Sobocinski. 2011. "Juvenile Salmon and Fish Community Characteristics," pp. 2.1-2.38, in Ecology of Juvenile Salmon in Shallow Tidal Freshwater Habitats of the Lower Columbia River, 2007-2010, Johnson et al. 2011. PNNL-20083, Pacific Northwest National Laboratory, Richland, Washington.

Sauter ST, LI Crawshaw, and AG Maule. 2001. "Behavioral thermoregulation by juvenile spring and fall Chinook salmon, Oncorhynchus tshawytscha, during smoltification." Environmental Biology of Fishes 61:295-304.

Seaburg KG. 1957. “A stomach sampler for live fish.” Progressive Fish-Culturist 19:137-139.

Sherwood CR and JS Creager. 1990. "Sedimentary Geology of the Columbia River Estuary." Progress in Oceanography 25:15-79.

Sherwood CR, DA Jay, RB Harvey, P Hamilton, and CA Simenstad. 1990. "Historical Changes in the Columbia River Estuary." Progress in Oceanography 25:299-352.

Shreffler DK and RM Thom. 1993. Restoration of urban estuaries: New approaches for site location and design. Prepared by Battelle-Pacific Northwest Division, Richland, Washington, for Washington Department of Natural Resources, 1993107, Olympia, Washington.

Simenstad CA, JL Burke, IR Waite, TD Counihan, and JR Hatten. 2005. Lower Columbia River and Estuary Ecosystem Classification: Phase II. Report to the Lower Columbia River Estuary Partnership, Portland, Oregon, by the Wetland Ecosystem Team, School of Aquatic Fisheries Sciences, University of Washington, Seattle, Washington, and the U.S. Geological Survey, Water Resources Division, Oregon District Office, Portland, Oregon. 
Simenstad CA, CD MacIntire, and LF Small. 1990. "Consumption processes and food web structure in the Columbia River estuary.” Progress in Oceanography 25:271-297.

Small LF, CD McIntire, KB Macdonald, JR Lara-Lara, BE Frey, MC Amspoker, and T Winfield. 1990. "Primary production, plant and detrital biomass, and particle transport in the Columbia River estuary." Progress in Oceanography 25:175-210.

Smith JP, CR Olsen, TD Bullen, and DJ Brabander. 2009. "Strontium isotope record of seasonal scale variations in sediment sources and accumulation in low-energy, subtidal areas of the lower Hudson River estuary." Chemical Geology 264:375-384.

Smokorowski KE and TC Pratt. 2007. "Effect of a change in physical structure and cover on fish and fish habitat in freshwater ecosystems - a review and meta-analysis." Environmental Reviews 15:15-41.

Stanford JA, FR Hauer, SV Gregory, and EB Snyder. 2005. "Columbia River Basin.” In AC Benke and CE Cushing (eds.), Rivers of North America. Elsevier Academic Press, Amsterdam, pp. 591-653.

Storch AJ. 2011. "Bioenergetics." In Ecology of Juvenile Salmon in Shallow Tidal Freshwater Habitats of the Lower Columbia River, 2007-2010, Johnson et al. 2011, pp. 5.1-5.23, PNNL-20083, Pacific Northwest National Laboratory, Richland, Washington.

Storch AJ and NK Sather. 2011. "Feeding Ecology." In Ecology of Juvenile Salmon in Shallow Tidal Freshwater Habitats of the Lower Columbia River, 2007-2010, Johnson et al. 2011, pp. 4.1-4.20, PNNL-20083, Pacific Northwest National Laboratory, Richland, Washington.

Stronach JA and TS Murty. 1989. "Nonlinear river-tidal interactions in the Fraser River, Canada." Marine Geology 13:313-339.

Tabor JE. 1976. Inventory of Riparian Habitats and Associated Wildlife Along the Columbia and Snake Rivers. Vol. 2A, Lower Columbia River. Report to the U.S. Army Corps of Engineers, North Pacific Division, Portland, Oregon, by the Oregon Cooperative Research Unit, Oregon State University, Corvallis, Oregon.

Tagestad JD, JL Downs, MA Simmons, and KD Hand. 2006. Using Satellite Imagery and Field Information to Map Vegetation and Landcover in the Shoshone and Wood River Region. PNNL-15777, prepared for the U.S. Department of the Interior, Bureau of Land Management, Shoshone Field Office, Shoshone, Idaho, by Pacific Northwest National Laboratory, Richland, Washington.

Tarboton DG. 1997. "A New Method for the Determination of Flow Directions and Contributing Areas in Grid Digital Elevation Models.” Water Resources Research 33(2):309-319.

Thom RM. 1997. "System-development matrix for adaptive management of coastal ecosystem restoration projects." Ecological Engineering 8:219-232.

Thom RM. 2000. "Adaptive management of coastal ecosystem restoration projects." Ecological Engineering 15(3-4):365-372. 
Thom RM, MG Anderson, and HL Diefenderfer. 2007. Adaptive Management Plan for the Ecosystem Restoration Program of the Lower Columbia River Estuary Partnership. PNWD-3873, prepared for the Lower Columbia River Estuary Partnership by Pacific Northwest National Laboratory, Richland, Washington.

Thom RM, AB Borde, NR Evans, CW May, GE Johnson, and JA Ward. 2004. A Conceptual Model for the Lower Columbia River Estuary. Final report to the US Army Corps of Engineers, Portland District, Portland, Oregon, by Pacific Northwest National Laboratory, Richland Washington. Available at www.nwp.usace.army.mil/pm/lcr/science.asp.

Thom RM, HL Diefenderfer, JE Adkins, C Judd, MG Anderson, KE Buenau, AB Borde, and GE Johnson. 2011. "Guidelines, processes, and tools for coastal ecosystem restoration, with examples from the United States.” Plankton and Benthos Research 5(Suppl.):15-13.

Thom RM, HL Diefenderfer, AM Coleman, AB Borde, CG Roegner, JD Tagestad, and GE Johnson. In preparation. Ecology and Hydrology of Restored Wetlands in the LCRE.

Thom RM, HL Diefenderfer, BD Ebberts, GE Johnson, DA Putman, and JR Skalski. 2008. "Adaptive Management." Chapter 3.0, in Evaluating Cumulative Ecosystem Response to Restoration Projects in the Columbia River Estuary, Annual Report 2007, GE Johnson and HL Diefenderfer (eds.). PNNL-17437, prepared for the U.S. Army Corps of Engineers, Portland District, Portland, Oregon, by Pacific Northwest National Laboratory, Richland, Washington, and the National Marine Fisheries Service, Seattle, Washington.

Thom RM and KF Wellman. 1996. Planning Aquatic Ecosystem Restoration Monitoring Programs. IWR Report 96-R-23, Institute for Water Resources, U. S. Army Corps of Engineers Alexandria Virginia and Waterways Experimental Station U. S. Army Corps of Engineers Vicksburg Mississippi.

Thom RM, GD Williams, and HL Diefenderfer. 2005. "Balancing the need to develop coastal areas with the desire for an ecologically functioning coastal environment: is net ecosystem improvement possible?" Restoration Ecology 10:487-496.

Thom RM, R Zeigler, and AB Borde. 2002. "Floristic development patterns in a restored Elk River estuarine marsh, Grays Harbor, Washington.” Restoration Ecology 10:487-496.

Thomas DW. 1983. Changes in the Columbia River Estuary Habitat Types over the Past Century. Columbia River Estuary Data Development Program, Columbia River Estuary Study Task Force, Astoria, Oregon.

U.S. Army Corps of Engineers (USACE). 1999. Ecosystem Restoration - Supporting Policy Information. EP 1165-2-502, U.S. Army Corps of Engineers, Washington, D.C.

U.S. Army Corps of Engineers (USACE). 2000. Planning Guidance Notebook. ER 1105-2-100, U.S. Army Corps of Engineers, Washington, D.C.

U.S. Environmental Protection Agency (EPA). 2003. EPA Region 10 Guidance for Pacific Northwest State and Tribal Temperature Water Quality Standards. EPA 910-B-03-002, Region 10 Office of Water, Seattle, Washington. 
Walters C. 2001. Adaptive Management of Renewable Resources. The Blackburn Press, Caldwell, New Jersey.

Washington-Action Agencies. 2009. Estuary Habitat MOA. Memorandum of Agreement on Columbia River Estuary Habitat Actions Between the State of Washington, the Bonneville Power Administration, the U.S. Army Corps of Engineers, and the U.S. Bureau of Reclamation. Available at www.salmonrecovery.gov/.

White MA, JC Schmidt, and DJ Topping. 2005. "Application of wavelet analysis for monitoring the hydrologic effects of dam operation: Glen Canyon Dam and the Colorado River at Lees Ferry, Arizona." River Research and Applications 21:551-565.

Wiele SM and JD Smith. 1996. "A reach averaged model of diurnal discharge wave propagation down the Colorado River through the Grand Canyon." Water Resources Research 32:1375-1386.

Williams BK, RC Szaro, and CD Shapiro. 2007. Adaptive Management: The U.S. Department of the Interior Technical Guide. Adaptive Management Working Group, U.S. Department of the Interior, Washington, D.C.

Woodruff DL C Roegner, R Thom, E Dawley, A Silva, J Vavrinec, and GE Johnson. 2010. "2009 Field Data Summaries: Material Exchange." Section 2.3, in Evaluating Cumulative Ecosystem Response to Restoration Projects in the Lower Columbia River and Estuary, 2009, GE Johnson and HL Diefenderfer (eds.). PNNL-19440, prepared for the U.S. Army Corps of Engineers, Portland District, Portland, Oregon, by Pacific Northwest National Laboratory, Richland, Washington.

Woodward RT and YS Wui. 2001. "The economic value of wetland services: a meta-analysis." Ecological Economics 37:257-270.

Yixin Y, X Fumin, and M Lihua. 2001. "Analysis of Hydrodynamic Mechanics for the Change of the Lower-Section of the Jiuduan Sandbank in the Yangtze River Estuary." Proceedings of the CongressInternational Association for Hydraulic Research Conference 29:179-186.

Yozzo D, J Titre, and J. Sexton (eds.). 1996. Planning and Evaluating Restoration of Aquatic Habitats from an Ecological Perspective, IWR Report 96-EL-4, submitted in association with the U.S. Army Corps of Engineers Waterways Experiment Station and PTI Environmental Services, Bellevue, Washington, and prepared for the Institute for Water Resources, U.S. Army Corps of Engineers, Alexandria, Virginia.

Zedler JB (ed.). 2001. Handbook for Restoring Tidal Wetlands. CRC Press, Boca Raton, Florida.

Zolezzi G, A Bellin, MC Bruno, B Maiolini, and A Siviglia. 2009. "Assessing hydrological alterations at multiple temporal scales: Adige River, Italy.” Water Resources Research 45, W12421, doi:10.1029/2008WR007266. 


\section{Appendix A}

Temporal Land Cover Analysis for Net Ecosystem Improvement 


\title{
Appendix A
}

\section{Temporal Land Cover Analysis for Net Ecosystem Improvement}

\author{
Prepared by Yinghai Ke, André Coleman, and Heida Diefenderfer
}

\section{A.1 Introduction}

Assessment of the cumulative effects of ecosystem restoration projects in the lower Columbia River and estuary (LCRE) requires examination at multiple scales between the individual restoration site and the landscape. One element of the proposed levels-of-evidence assessment approach (Diefenderfer et al. 2011) is the analysis of net ecosystem improvement (Thom et al. 2005). Net ecosystem improvement (NEI) has been described as a quantitative measurement of the change in ecological function over a restored area and its probability of success; cumulative net ecosystem improvement (CNEI) accounts for multiple projects. In general, these measurements are expected to be positive accounts of the improvement directly resulting from restoration actions. However, during the multi-year time frames typical of large-scale restoration programs, current trends suggest that stressors on the environment unrelated to the programs may persist or even increase (Nilsson et al. 2005). Thus, to complete the analysis of NEI, it is important to complement restoration site-scale results with a measurement of trends in stressors unmitigated by the restoration program.

It is widely understood that land use influences river systems and estuaries (Allan 2004; Byrd et al. 2007). A variety of landscape indicators have been evaluated for their ability to predict effects on receiving aquatic ecosystems (Gergel et al. 2002; Hale et al. 2004). In the Pacific Northwest, watershedscale forest cover can provide an indicator of the watershed's ecological condition and, in rural areas, of hydrologic processes and stream quality (Booth et al. 2001, 2002). For example, increase in urbanization and agricultural development in contributing watersheds places pressure on freshwater inflows, water temperature, and sediment accretion, which have significant impacts on habitat. Thus, understanding of the distribution and changes of land cover in the LCRE is critical for evaluating the ecosystem state in pre- and post-restoration periods (Diefenderfer et al. 2011). In particular, changes in forest cover, urbanization, and wetlands are important landscape indicators for assessing stress on the estuarine habitats used by endangered salmonid fishes in the Pacific Northwest (Diefenderfer et al. 2009).

While land change analysis at individual sites supports the monitoring and evaluation of restoration outcomes, assessing larger ecosystem change at the reach and estuary scales provides important information about the overall condition of the surrounding ecosystem and reveals the impact of landscape change on the potential for salmon habitat restoration. Field surveys can provide detailed time-series information about land conditions at individual sites, complemented by satellite or airborne-based remotely sensed data for estuary-wide land cover and land change analysis (Johnson et al. 2008). The objectives of this study were to 1) determine land cover change, in particular change in forest cover, impervious surface/urban, area and wetlands, from 2001 to 2006, based on remote-sensing data; and 2) analyze and evaluate the change area at three spatial scales - contributing watershed scale, historic 
floodplain reach scale, and site scale. The primary goal was to develop the method for periodic land cover analysis at the reach and watershed scales to support the CNEI index.

\section{A.2 Methods}

The study area constitutes a 235-rkm section of the lower Columbia River from the river mouth to Bonneville Lock and Dam and its historic floodplain and primary contributing watersheds. The river was divided into eight hydrogeomorphic reaches of the historical floodplain in previous work (Jennifer Burke, University of Washington, personal communication; Johnson and Diefenderfer 2008). Contributing watersheds for each reach (Figure A.1) were defined based on the U.S. Geological Survey National Hydrography Dataset (NHD) watershed (10-digit Hydrologic Unit Code [HUC]) and sub-watershed (12-digit HUC) delineation. Three restoration sites-Kandoll Farm at Grays Bay (reach B), Vera Slough at Youngs Bay (reach A), and Crims Island along the main stem (reach C) - were selected for site-scale analysis because of the availability of 2005-2010 field data at these sites that were collected by the cumulative effects (CE) project team (Figure A.2).

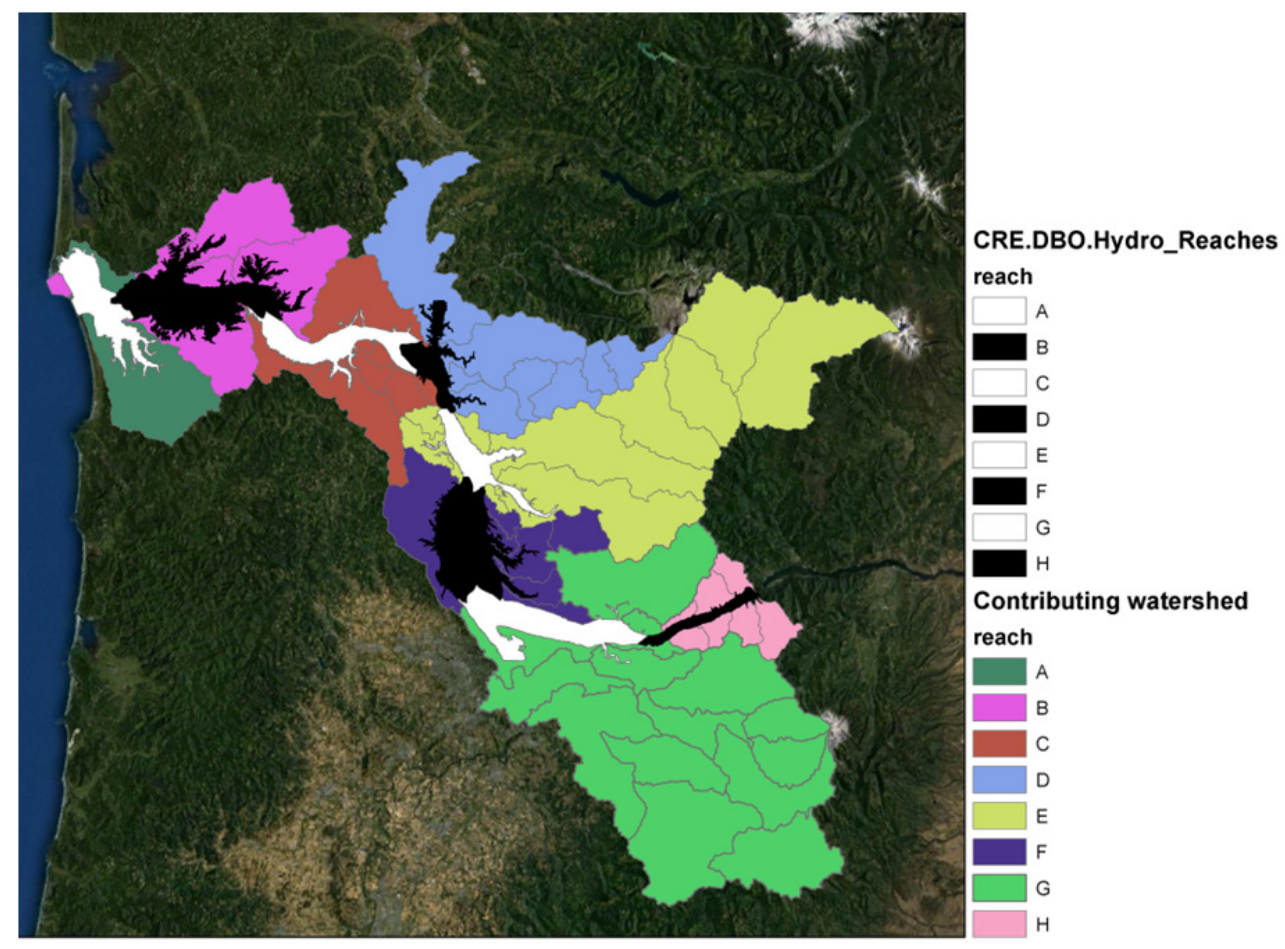

Figure A.1. Contributing Watersheds Defined for Eight Reaches (A-H) of the Lower Columbia River and Estuary 


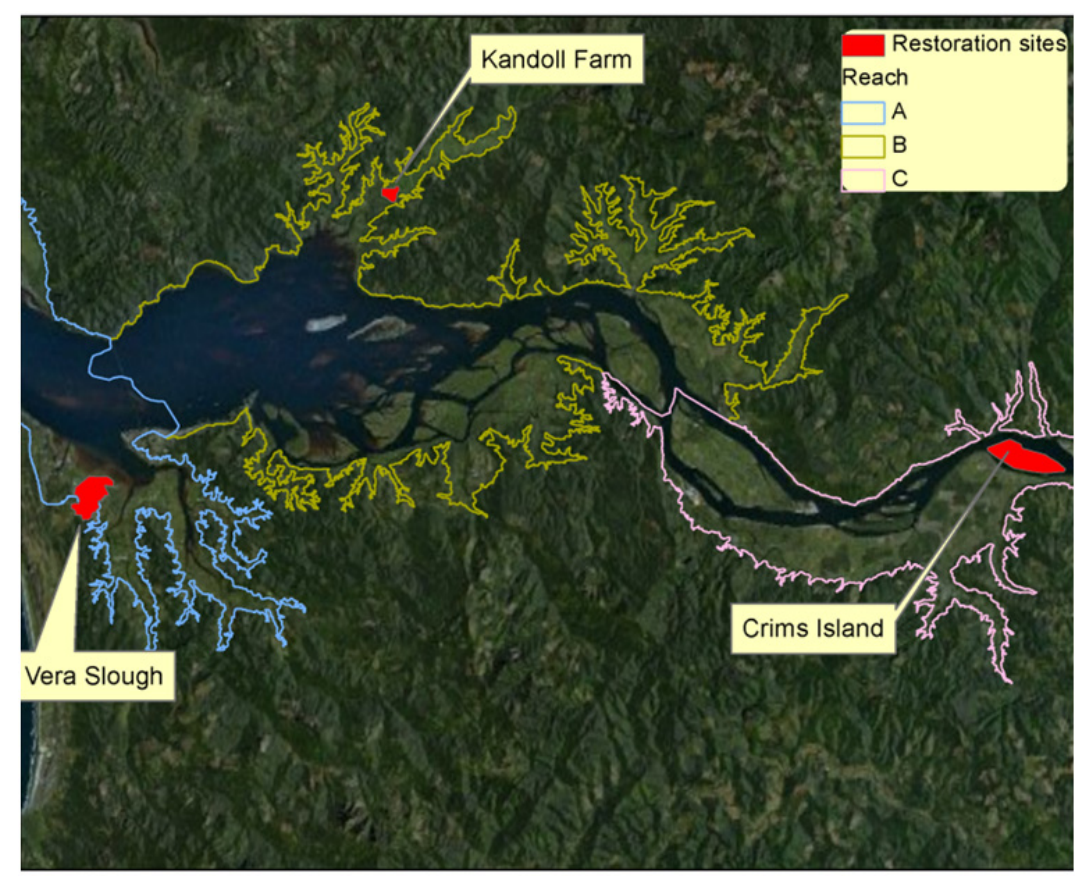

Figure A.2. Three Restoration Sites Selected for Site-Scale Analysis

Land cover change analysis involved three components: National Oceanic and Atmospheric Administration (NOAA) Coastal Change Analysis Program (C-CAP) land cover/land change data, land change at historical floodplain, and aerial imagery validation.

\section{A.2.1 NOAA C-CAP Land Cover/Land Change Data}

NOAA C-CAP land cover and land change products provide inventories of coastal intertidal areas, wetlands, and adjacent uplands every 5 years with the goal of monitoring these habitats. The products covering the LCRE include land cover in Oregon and Washington states in the years 1996, 2001, and 2006, and land cover change from 1996 to 2001 and 2001 to 2006. This study used the 2001 land cover product to represent estuary conditions at the time of the Biological Opinion (BiOp) for operation of the Federal Columbia River Power System for salmon and steelhead in the year 2000, prior to estuarine restoration actions undertaken pursuant to the BiOp. To represent the conditions when several sites such as Kandoll Farm, Vera Slough, and Crims Island were undergoing restoration, the C-CAP 2006 land cover product was used. The C-CAP 2001 land cover product was generated by classification of multiseasonal Landsat Thematic Mapper (TM) imagery collected during 2000 and 2001. The overall accuracy of the product was $86.1 \%$ and Kappa agreement was $85 \%$ for both Oregon and Washington states (NOAA C-CAP 2004). The 2006 land cover data were created by both 2001 land cover and 2001-2006 land cover change products. First, the difference between 2001 and 2006 imagery was used to determine change area using a cross-correlation analysis process (Koeln and Bissonnette 2000); the change layer was then classified into 625 from-to classes (e.g., evergreen forest to bare land, estuarine emergent wetland to high intensity developed); and the 2006 update was based on updating the change areas between 2001 and 2006 imagery, and overlaying the results over 2001 land cover (NOAA C-CAP 2004). Although high accuracy was achieved for the 2001 land cover product, note that the change analysis and 2006 land cover has not been evaluated with ground truth. 


\section{A.2.2 Land Cover Data Reclassification}

The NOAA C-CAP product consists of 24 classes representing coastal land cover. For the purpose of this study, both 2001 and 2006 C-CAP products were reclassified into broad classes of forest, wetland, urban, and other based on the definitions in Table A.1. Three land cover maps - forest/non-forest map, wetland/non-wetland map, and urban/non-urban map-were then created for each of the years 2001 and 2006. The difference between the 2001 and 2006 maps was used to create change maps for forest cover, wetland, and urban areas. The change maps were then clipped to the study area and the land cover change area was calculated at the aforementioned three scales.

Table A.1. NOAA C-CAP Land Cover and Reclassification

\section{C-CAP LAND COVER CLASSES}

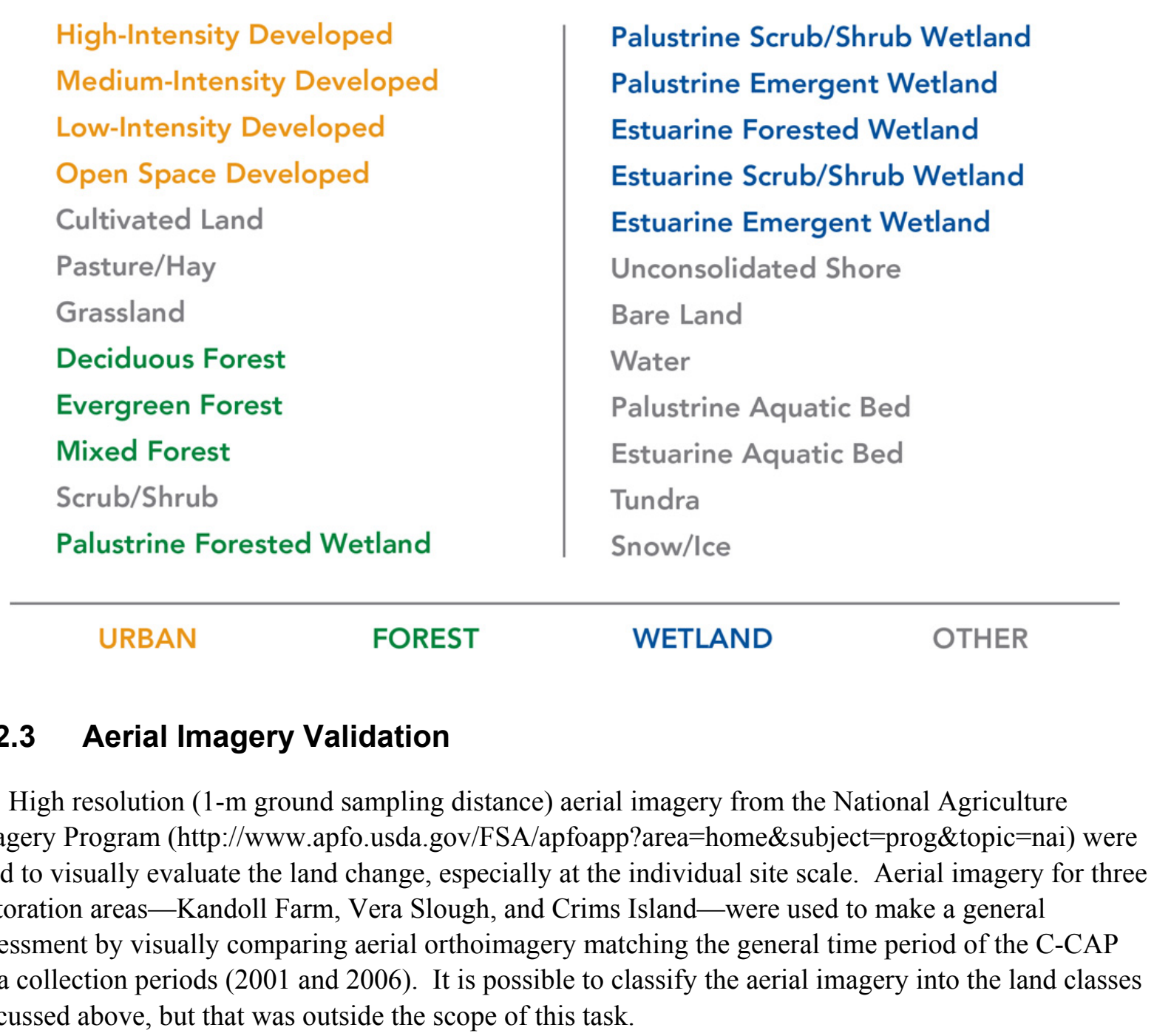




\section{A.3 Results}

The results cover land change 1) at the contributing watershed scale, 2) over the historical floodplain, and 3 ) at restoration sites.

\section{A.3.1 Land Change at Contributing Watershed Scale}

Forest land dominated the landscape of the LCRE, with more than $8000 \mathrm{~km}^{2}$ (over $60 \%$ of the land area) covered by evergreen, mixed, deciduous forest, and forested wetland. Between 2001 and 2006, $190 \mathrm{~km}^{2}$ of forest area was lost in all the primary contributing watersheds of the LCRE. Forest cover declined in the contributing watersheds of all reaches, with the exception of reach E, which saw a $10-\mathrm{km}^{2}$ increase (Table A.2). The contributing watersheds to reaches A and B revealed more intensive forest loss than other reaches: forest coverage decreased from $66.1 \%\left(409.2 \mathrm{~km}^{2}\right)$ to $61.4 \%\left(379.9 \mathrm{~km}^{2}\right)$ in reach A watersheds and decreased from $56.4 \%\left(850.2 \mathrm{~km}^{2}\right)$ to $51.5 \%\left(776.1 \mathrm{~km}^{2}\right)$ in reach B watersheds.

Documented wetland gains and losses were very small $\left(<0.3 \mathrm{~km}^{2}\right.$ total), which is within the margin of error of the satellite imagery analysis, particularly for the difficult to capture wetlands. Urbanization showed significant increases in reach $F$ with a $6.1-\mathrm{km}^{2}$ gain, and reach $\mathrm{G}$ with a $6.0-\mathrm{km}^{2}$ gain; total measured urbanization in the contributing watersheds of the estuary during this 5-year change analysis period was $15.2 \mathrm{~km}^{2}$.

Figure A.3 demonstrates the percentage of forest cover gains and losses contributing to the net change listed in Table A.2. It was calculated as area of forest cover loss/gain divided by forest cover area in 2001. For example, in reach B forest cover loss was around $9 \%$ and gain was less than $1 \%$. Although contributing watersheds for reach D do not show significant decrease in forest area $\left(17.6 \mathrm{~km}^{2}\right)$, Figure A.3 reveals that the small amount of net change was due to $7 \%$ of forest loss offsetting a $6 \%$ of forest gain and is thus indicative of greater landscape disturbance.

Table A.2. Land Cover Assessment in Contributing Watersheds

\begin{tabular}{ccccccc}
\hline $\begin{array}{c}\text { Land } \\
\text { Cover }\end{array}$ & Reach & $\begin{array}{c}2001 \\
\text { Area }\left(\mathrm{km}^{2}\right)\end{array}$ & Coverage $(\%)$ & $\begin{array}{c}2006 \\
\text { Area }\left(\mathrm{km}^{2}\right)\end{array}$ & $\begin{array}{c}\text { 2001-2006 Net } \\
\text { Coverage }(\%)\end{array}$ & \begin{tabular}{c} 
Change $\left(\mathrm{km}^{2}\right)$ \\
\hline Forest
\end{tabular} \\
& A & 409.2 & 66.1 & 379.9 & 61.4 & -29.3 \\
& B & 850.2 & 56.4 & 776.1 & 51.5 & -74.1 \\
& C & 670.0 & 57.2 & 641.7 & 54.7 & -28.3 \\
& D & 1041.7 & 68.4 & 1024.1 & 67.2 & -17.6 \\
& E & 2000.0 & 67.8 & 2010.0 & 68.1 & 10.0 \\
& F & 309.7 & 30.1 & 291.2 & 28.3 & -18.5 \\
& G & 2666.5 & 63.0 & 2636.1 & 62.3 & -30.4 \\
& H & 317.2 & 79.9 & 315.0 & 79.4 & -2.2 \\
& Overall & 8264.3 & 61.5 & 8074.1 & 60.1 & -190.2
\end{tabular}


Table A.2. (contd)

\begin{tabular}{ccccccc}
\hline $\begin{array}{c}\text { Land } \\
\text { Cover }\end{array}$ & Reach & $\begin{array}{c}2001 \\
\text { Area }\left(\mathrm{km}^{2}\right)\end{array}$ & Coverage $(\%)$ & $\begin{array}{c}2006 \\
\text { Area }\left(\mathrm{km}^{2}\right)\end{array}$ & $\begin{array}{c}\text { Coverage }(\%) \\
\text { Change }\left(\mathrm{km}^{2}\right)\end{array}$ \\
\hline Wetland & A & 57.5 & 9.3 & 57.4 & 9.3 & -0.1 \\
& B & 78.1 & 5.2 & 77.9 & 5.2 & -0.2 \\
& C & 62.4 & 5.3 & 62.6 & 5.3 & 0.2 \\
& D & 23.4 & 1.5 & 23.3 & 1.5 & -0.1 \\
& E & 48.1 & 1.6 & 48.2 & 1.6 & 0.1 \\
& F & 60.3 & 5.8 & 60.4 & 5.9 & 0.1 \\
& G & 58.9 & 1.4 & 58.7 & 1.4 & -0.2 \\
& H & 5.8 & 1.5 & 5.8 & 1.5 & 0.0 \\
& Overall & 394.5 & 2.9 & 394.2 & 2.9 & -0.3 \\
& A & 17.0 & 2.8 & 17.3 & 2.8 & 0.3 \\
& B & 17.1 & 1.1 & 17.1 & 1.1 & 0.0 \\
& C & 57.0 & 4.9 & 57.7 & 4.9 & 0.7 \\
& D & 62.0 & 4.1 & 62.3 & 4.1 & 0.3 \\
& E & 98.8 & 3.3 & 100.7 & 3.4 & 1.9 \\
& F & 287.7 & 27.9 & 293.8 & 28.5 & 6.1 \\
& G & 544.7 & 12.9 & 550.7 & 13.0 & 6.0 \\
& H & 7.3 & 1.8 & 7.3 & 1.8 & 0.0 \\
& Overall & 1106.8 & 8.1 & 1091.6 & 8.2 & 15.2 \\
\hline
\end{tabular}

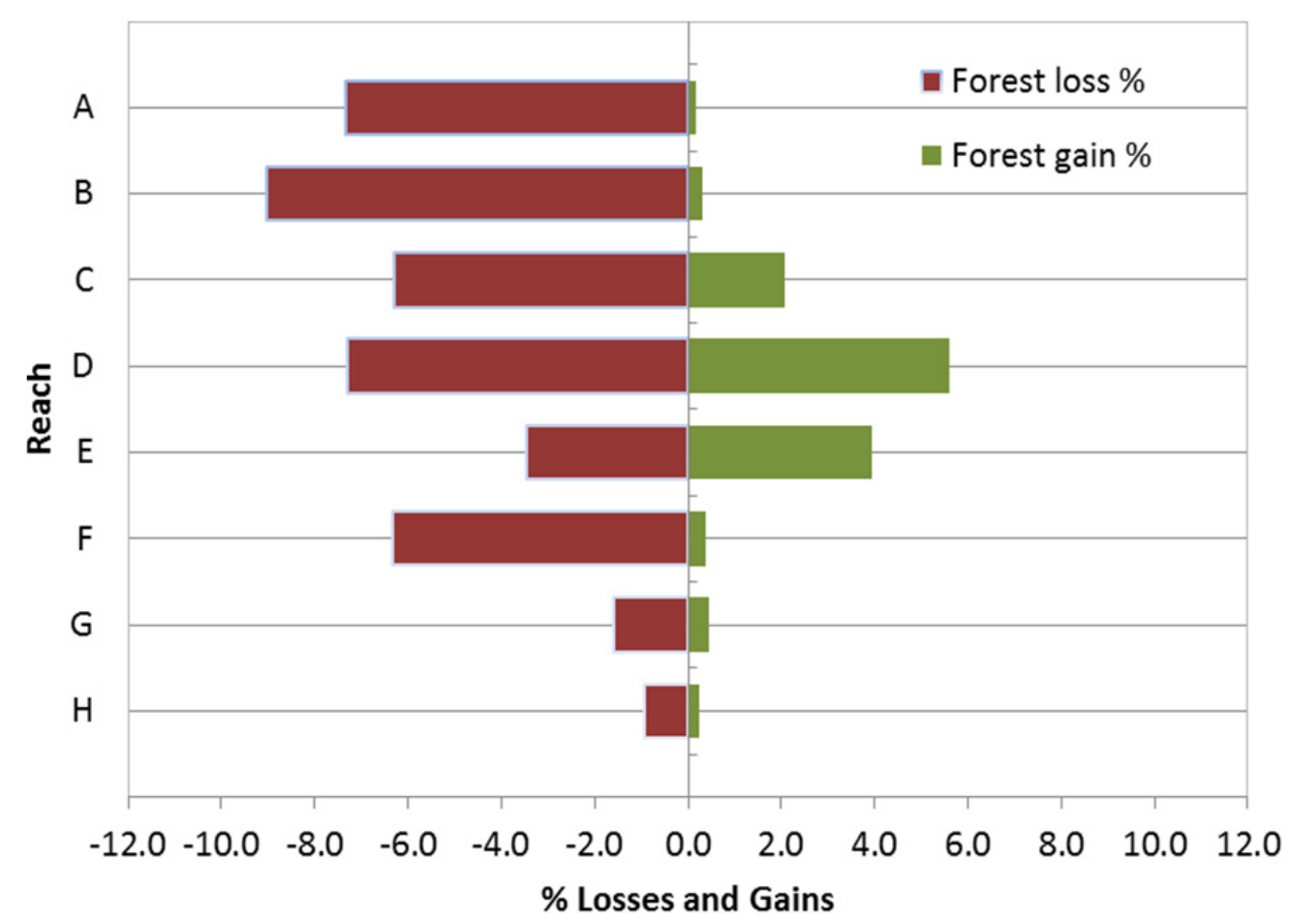

Figure A.3. Percentage of Forest Gains and Losses at the Contributing Watershed Scale 


\section{A.3.2 Land Change at Historical Floodplain}

Within the historical floodplain, very small declines in forest cover between 2001 and 2006 were detected in most reaches $\left(<0.8 \mathrm{~km}^{2}\right)$, while a somewhat greater decline was seen in reach $\mathrm{C}\left(3.1 \mathrm{~km}^{2}\right)$ (Table A.3; Figure A.4). The total measured change in forest cover in the historical floodplain was $5.0 \mathrm{~km}^{2}$. Examination of both Tables A.2 and A.3 indicates that the majority of forest loss occurs in the upland of the contributing watersheds. For example, forest area decreased by $74.1 \mathrm{~km}^{2}$ in the reach B watersheds, but only by $0.7 \mathrm{~km}^{2}$ within the floodplain. Similar to findings at the contributing watershed scale, wetland changes in the historical floodplain showed very small fluctuations, likely within the margin of remote-sensing classification error, with a total decline of $0.3 \mathrm{~km}^{2}$. A small increase of $2.7 \mathrm{~km}^{2}$ in urban area was measured in the historical floodplain, with the largest increases being seen in reaches D, E, and G.

Figure A.4 shows that forest transition was more dominant in reach $\mathrm{C}$ than in other reaches. Reach $\mathrm{C}$ lost almost 11\% of its forest between 2001 and 2006, and 5\% of forest areas was regained. This transition is evidenced by the comparison between a panchromatic orthoimage acquired in August 2000 and a true color orthoimage acquired in July 2006 (Figure A.5). It can be seen that the loss and gain of forest cover is largely due to harvest and reforestation of a plantation forest. Note that two restoration sites were located in the zoomed-in area in reach C (Figure A.5).

Table A.3. Land Cover Assessment of the Historical Floodplain

\begin{tabular}{ccccccc}
\hline $\begin{array}{c}\text { Land } \\
\text { Cover }\end{array}$ & Reach & $\begin{array}{c}2001 \\
\text { Area }\left(\mathrm{km}^{2}\right)\end{array}$ & $\begin{array}{c}2006 \\
\text { Coverage }(\%)\end{array}$ & $\begin{array}{c}\text { Area }\left(\mathrm{km}^{2}\right) \\
\text { Coverage }(\%)\end{array}$ & $\begin{array}{c}\text { 2001-2006 Net } \\
\text { Change }\left(\mathrm{km}^{2}\right)\end{array}$ \\
\hline Forest & A & 21.5 & 9.8 & 21.3 & 9.7 & -0.3 \\
& B & 69.3 & 15.9 & 68.6 & 15.7 & -0.7 \\
& C & 51.5 & 22.7 & 48.4 & 21.3 & -3.1 \\
& D & 26.0 & 19.7 & 26.0 & 19.7 & 0.0 \\
& E & 31.5 & 20.5 & 31.2 & 20.3 & -0.3 \\
& F & 42.2 & 12.4 & 41.4 & 12.2 & -0.8 \\
& G & 19.3 & 6.5 & 19.4 & 6.6 & 0.2 \\
& H & 14.7 & 23.1 & 14.7 & 23.1 & 0.0 \\
& Overall & 276.0 & 14.8 & 271.0 & 14.8 & -5.0 \\
& A & 48.8 & 22.2 & 48.7 & 22.2 & 0.0 \\
& B & 82.7 & 19.0 & 82.5 & 18.9 & -0.2 \\
& C & 39.2 & 17.3 & 39.5 & 17.4 & 0.3 \\
& D & 14.8 & 11.2 & 14.6 & 11.1 & -0.2 \\
& E & 23.7 & 15.4 & 23.6 & 15.3 & -0.1 \\
& F & 53.2 & 15.6 & 53.3 & 15.7 & 0.2 \\
& G & 19.9 & 6.7 & 19.7 & 6.7 & -0.2 \\
& H & 5.8 & 9.1 & 5.8 & 9.1 & 0.0 \\
& Overall & 288.0 & 15.4 & 287.7 & 15.4 & -0.3
\end{tabular}


Table A.3. (contd)

\begin{tabular}{ccccccc}
\hline $\begin{array}{c}\text { Land } \\
\text { Cover }\end{array}$ & Reach & $\begin{array}{c}2001 \\
\text { Area }\left(\mathrm{km}^{2}\right)\end{array}$ & Coverage (\%) & $\begin{array}{c}2006 \\
\text { Area }\left(\mathrm{km}^{2}\right)\end{array}$ & $\begin{array}{c}\text { Coverage (\%) } \\
\text { Change }\left(\mathrm{km}^{2}\right)\end{array}$ \\
\hline Urban & A & 11.6 & 5.3 & 11.6 & 5.3 & 0.0 \\
& B & 7.2 & 1.7 & 7.3 & 1.7 & 0.1 \\
& C & 18.7 & 8.3 & 18.9 & 8.3 & 0.1 \\
& D & 51.3 & 38.9 & 51.8 & 39.3 & 0.6 \\
& E & 22.1 & 14.3 & 22.8 & 14.8 & 0.7 \\
& F & 57.5 & 16.9 & 57.9 & 17.0 & 0.3 \\
& G & 165.7 & 56.1 & 166.6 & 56.4 & 0.9 \\
& H & 6.1 & 9.5 & 6.1 & 9.5 & 0.0 \\
& Overall & 340.2 & 18.2 & 342.9 & 18.4 & 2.7 \\
\hline
\end{tabular}

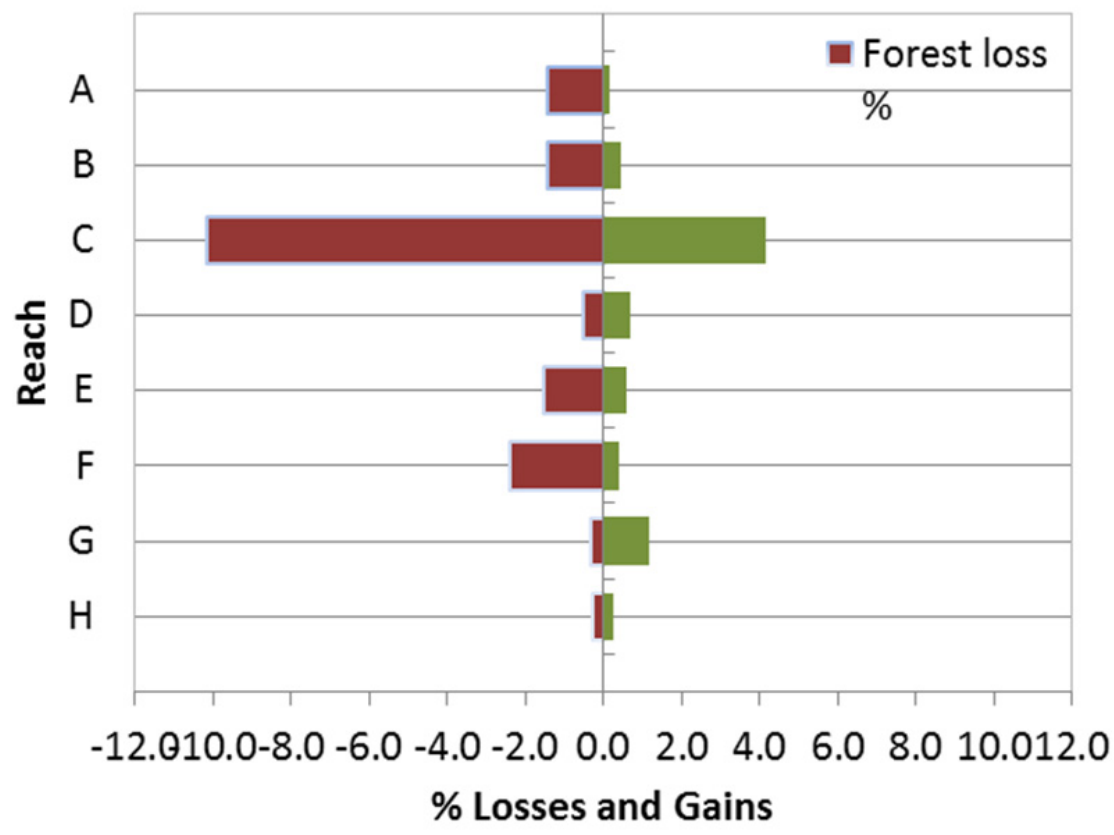

Figure A.4. Percentage of Forest Gains and Losses in the Reaches of the Historical Floodplain 


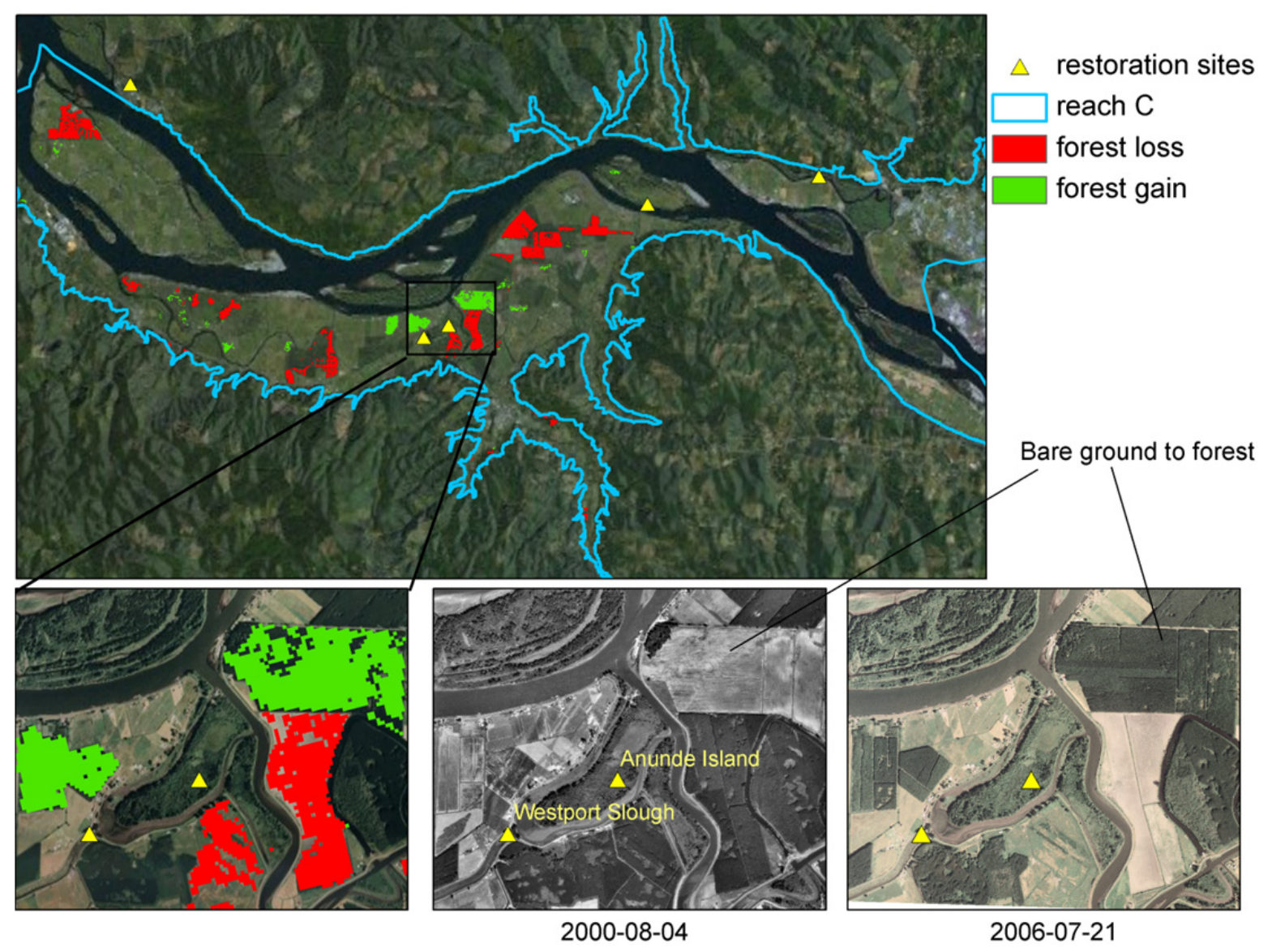

Figure A.5. Detail of Forest Cover Change in Reach C, with Aerial Imagery from 2000 and 2006. Project activities: 1) Anunde Island: tidal reconnection in 2002; 2) Westport Slough: levee removal in 2000.

\section{A.3.3 Land Change at Restoration Sites}

In general, no significant land cover change was measured with the C-CAP data at the restoration sites between 2001 and 2006 (Table A.4, bottom panel of Figure A.6 and Figure A.7). Aerial imagery, however, clearly shows that cultivated land at Kandoll Farm in 2000 had transitioned into a wetland by the time of the 2006 aerial image capture (Figure A.6 top panel), and channel excavation can be seen in the 2006 imagery over Crims Island (Figure A.7 top panel). This reveals that the C-CAP 30-m product may not be appropriate for land change analysis at a small scale/site scale, and suggests the use of higherresolution imagery for the purpose of site-scale change analysis. The land condition trajectory at the Vera Slough site based on aerial imagery (Figure A.8) shows little difference between 2003 and 2005, but a larger wetland area is seen around the tide gate in 2009 imagery, which indicates the change in land condition after restoration/tide gate replacement. 
Table A.4. NOAA C-CAP Land Cover at Three Example Restoration Sites in 2001 and 2006

\begin{tabular}{|c|c|c|c|c|c|c|c|c|c|}
\hline \multirow{3}{*}{$\begin{array}{l}\text { Site } \\
\text { Name }\end{array}$} & \multirow{3}{*}{$\begin{array}{c}\text { Condition } \\
\text { Prior to } \\
\text { Action }\end{array}$} & \multirow[b]{3}{*}{ Action } & \multirow{3}{*}{$\begin{array}{l}\text { Date of } \\
\text { Action }\end{array}$} & \multicolumn{6}{|c|}{ C-CAP Land Cover } \\
\hline & & & & \multicolumn{2}{|c|}{ Forest $(\%)$} & \multicolumn{2}{|c|}{ Wetland (\%) } & \multicolumn{2}{|c|}{ Urban $(\%)$} \\
\hline & & & & 2001 & 2006 & 2001 & 2006 & 2001 & 2006 \\
\hline $\begin{array}{l}\text { Kandoll } \\
\text { Farm }\end{array}$ & $\begin{array}{l}\text { Diked } \\
\text { farmland }\end{array}$ & $\begin{array}{l}\text { Tide gate } \\
\text { removal, } \\
\text { culvert } \\
\text { installation, } \\
\text { dike } \\
\text { breaching }\end{array}$ & 2005 & 7.6 & 8.4 & 70.1 & 69.3 & 0.6 & 0.6 \\
\hline $\begin{array}{l}\text { Vera } \\
\text { Slough }\end{array}$ & $\begin{array}{l}\text { Diked } \\
\text { wetland }\end{array}$ & $\begin{array}{l}\text { Tide gate } \\
\text { replacement }\end{array}$ & 2005 & 25.1 & 25.1 & 37.7 & 37.7 & 25.1 & 25.1 \\
\hline $\begin{array}{l}\text { Crims } \\
\text { Island }\end{array}$ & $\begin{array}{l}\text { Wet } \\
\text { pasture }\end{array}$ & $\begin{array}{l}\text { grading, } \\
\text { channel } \\
\text { excavation }\end{array}$ & 2005 & 18.8 & 19.4 & 40.7 & 40.1 & 0 & 0 \\
\hline
\end{tabular}




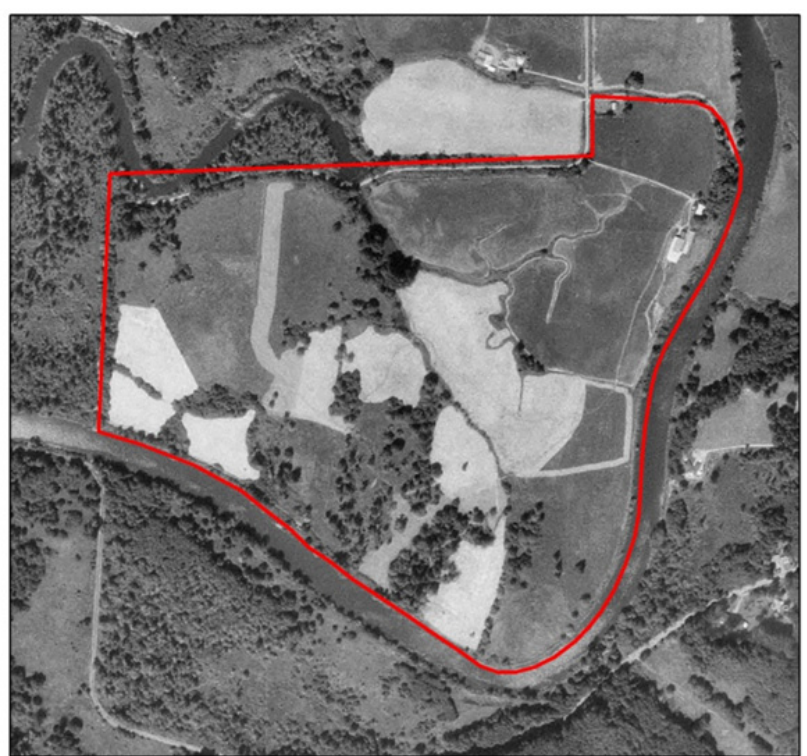

2000-08-08

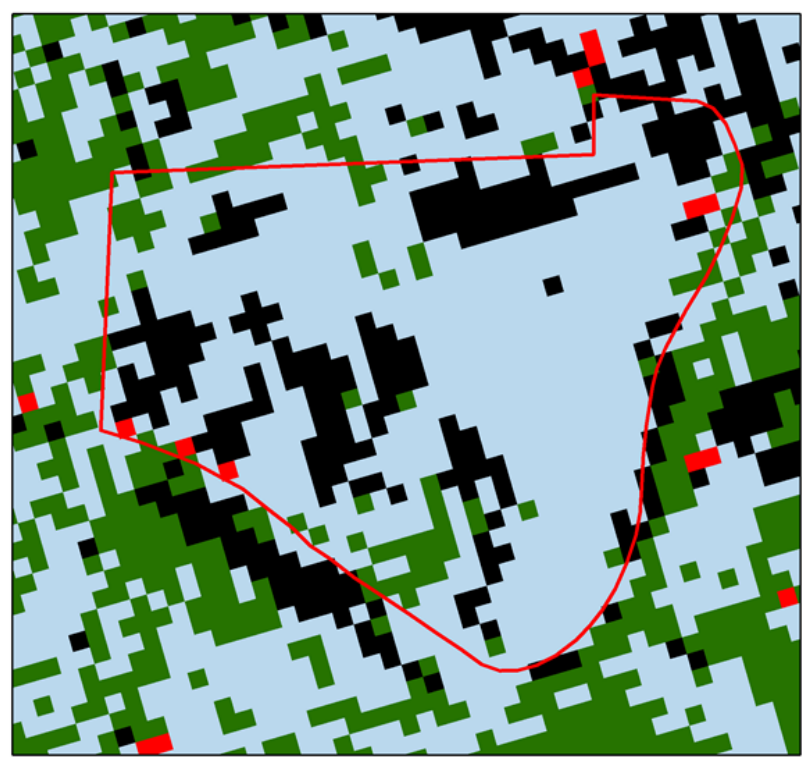

2001 reclassified C-CAP land cover

Wetland Urban Forest

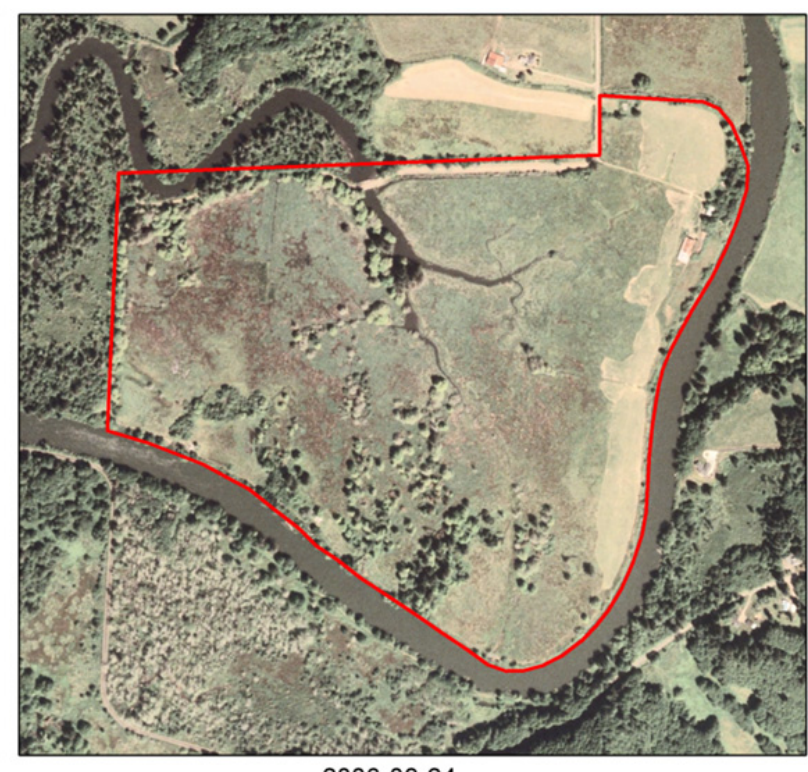

2006-08-24

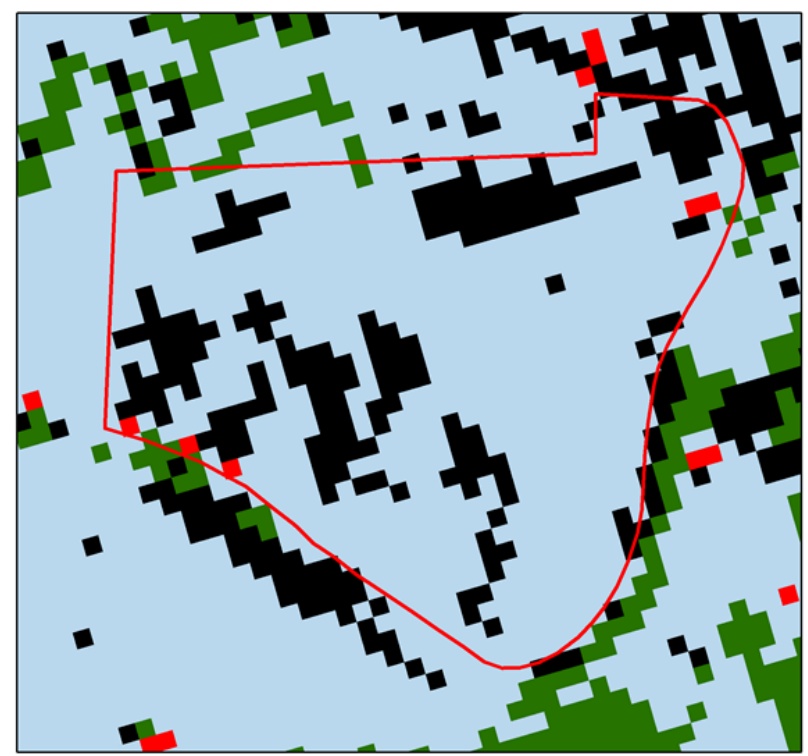

2006 reclassified C-CAP land cover

Figure A.6. High-Resolution Aerial Imagery of Kandoll Farm Closely Corresponding to the Years of C-CAP Data Collection, 2000 and 2006 (top panel); and Land Cover Based on C-CAP Data Reclassification for 2001 and 2006 (bottom panel) 

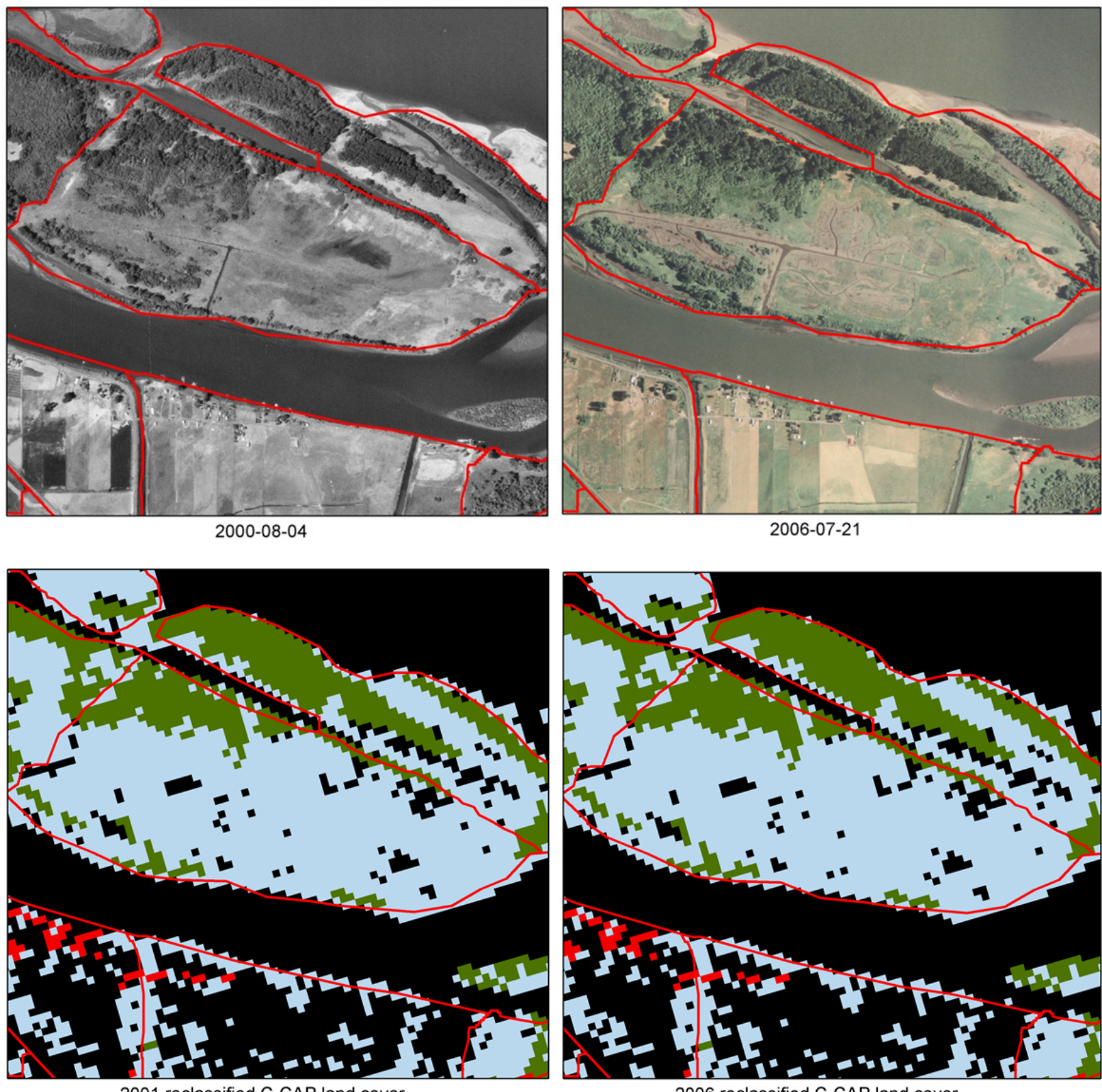

Wetland

2001 reclassified C-CAP land cover

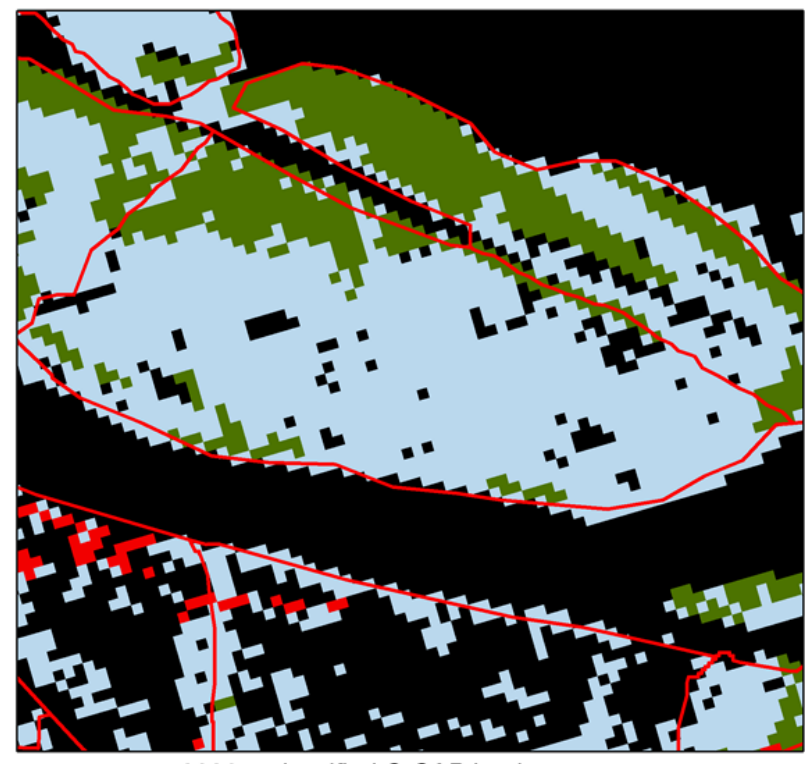

2006 reclassified C-CAP land cover

Other

Figure A.7. High-Resolution Aerial Imagery of the Eastern Portion of Crims Island Closely Corresponding to the Years of C-CAP Data Collection, 2000 and 2006 (top panel); and Land Cover Based on C-CAP Data Reclassification for 2001 and 2006 (bottom panel) 


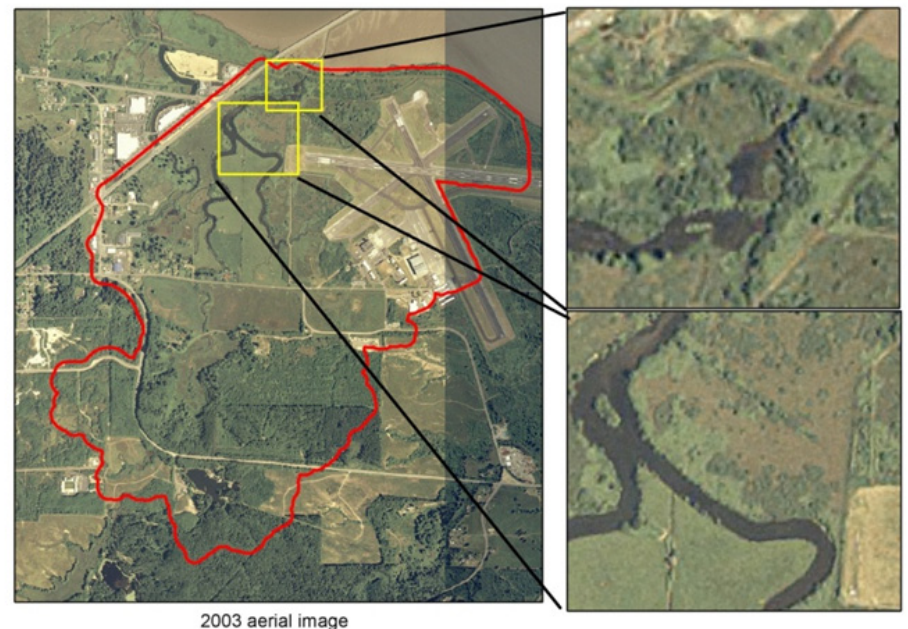

2003 aerial image
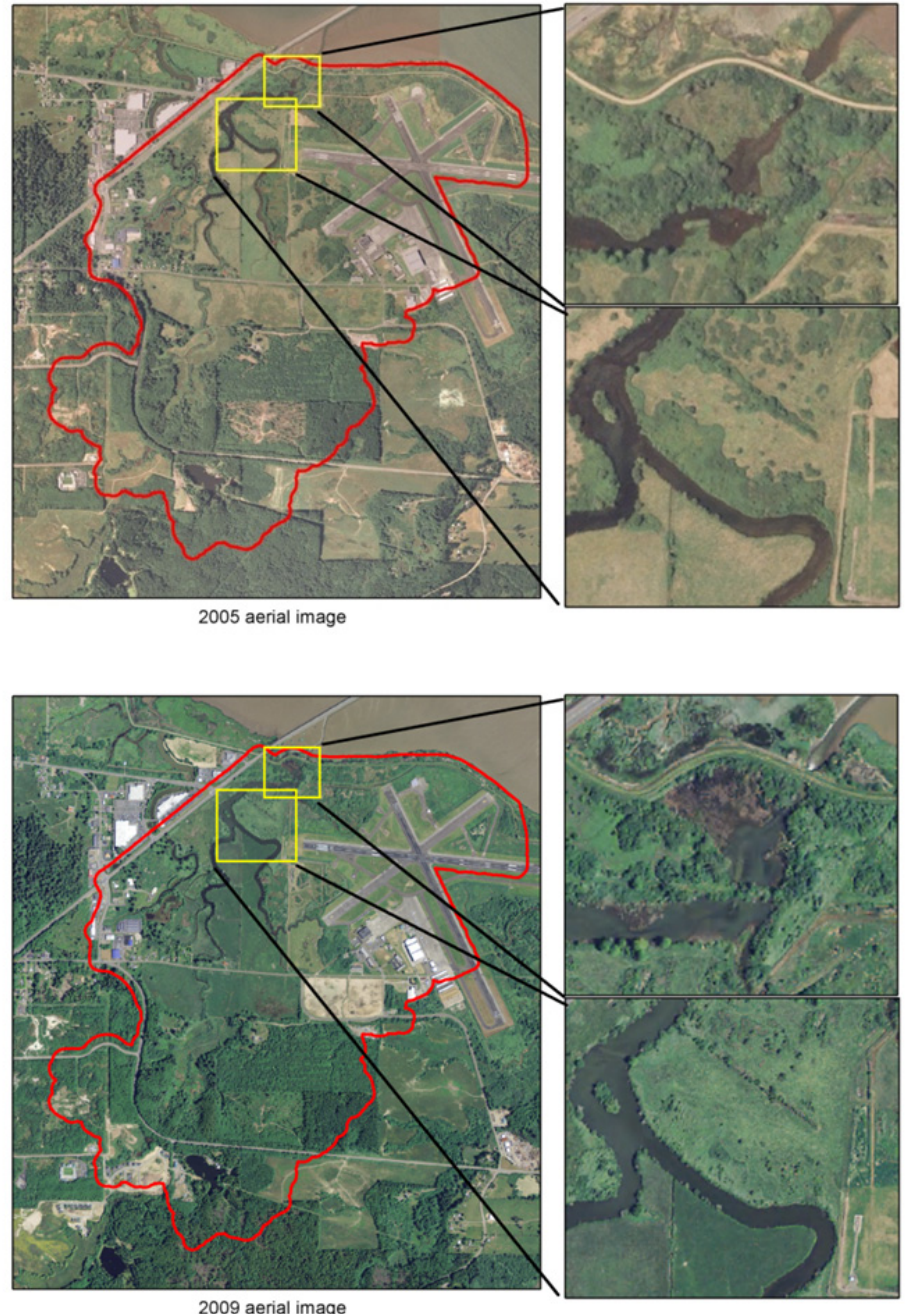

Figure A.8. High-Resolution Aerial Imagery of Vera Slough Restoration Site in 2003, 2005, and 2009. Note the significant change in the wetland area southwest of the dike/tide gate from 2005-2009. 


\section{A.4 Conclusion and Recommendations}

Understanding the distribution and changes of land cover in the LCRE is an important element of the evaluation of ecosystem state in pre- and post-restoration periods. While restoration activities are occurring at the site scale, evaluating larger ecosystem change at an estuary scale helps to provide guidance for future estuarine ecosystem management. In particular, forest cover, impervious surfaces, and wetlands are important landscape indicators for assessing stressors to salmon habitats.

The results of the analysis of NOAA C-CAP data showed losses of forest cover in the contributing watersheds of the estuary totaling $190.2 \mathrm{~km}^{2}$ during the first 6 years of BiOp implementation, 2001-2006. Previously, correlations between forest cover and receiving river water condition have been demonstrated in the Pacific Northwest (Booth et al. 2001, 2002). Riparian forests reduce sediment inputs to waterways (Lee et al. 2003) and riparian forest cover in a study of Elkhorn Slough marsh was shown to be the most significant land cover variable to explain sediment fan size (Byrd et al. 2007). Thus, this indicator of decline in the LCRE may be used to balance measurements of NEI at the restoration site scale.

Alternatively, deforestation may be viewed as a source of sediment for accretion during the restoration of previously subsided marshes and swamps of the LCRE (Diefenderfer et al. 2008). In addition, in some watersheds and reaches, both gains and losses in forest cover were recorded (Figure A.3, Figure A.4). This is indicative of harvest management in the region, which affects watershed hydrologic and sedimentary processes through activities such as clear-cut logging and road building.

The results of the analysis for wetland land cover change were inconclusive. Although small losses of wetlands were measured, these are likely within the combined margin of error of the original C-CAP data product and our re-analysis. It is possible that future analysis could make use of new rule-based object-oriented classification methods for the classification of wetlands (Coleman 2010).

The land cover and change analysis in this study was based on the existing NOAA C-CAP data sets. Because the accuracy of 2006 data set is not officially available, the confidence in the results in this study can be hardly inferred. In future work, the confidence can be quantitatively evaluated by accuracy assessment of 2006 data in our study area based on aerial imagery.

According to our analysis, NOAA C-CAP data are not recommended for site-scale monitoring, because higher-resolution aerial imagery or high-resolution multi-spectral imagery, such as Quickbird, provide a better guide to site-scale change than the C-CAP data product.

Unfortunately, land cover data for the ecosystem condition in 2009 were not available for this method development study in 2010. However, NOAA C-CAP is planning to release an updated land cover data set in 2011, in accordance with their normal 5-year release cycle. Upon the availability of these products, the analysis of land cover change trajectories during the first 10 years of BiOp implementation from 2001 to 2010 , can be conducted based on the methods described above. 


\section{Appendix B}

The Columbia River Tidal-Fluvial Regime: Water-Level Variations, Inundation, and Vegetation Patterns 


\title{
Appendix B
}

\section{The Columbia River Tidal-Fluvial Regime: Water-Level Variations, Inundation, and Vegetation Patterns}

\author{
Prepared by David Jay, Heida Diefenderfer, Amy Borde, Carly McNeil, and Keith Leffler
}

\section{B.1 Abstract}

The water-level regime in the lower Columbia River is influenced by tides, river flow, hydropower operations, and atmospheric effects. Analyses of 12 multi-year tide gauge records and one pressure gauge record for thalweg ("channel") stations between the ocean and Bonneville Dam suggest that the system consists of four zones: 1) the lower estuary with salinity intrusion, from the ocean to rkm 21 ; 2) the energy minimum, rkm 21 to $\mathrm{rkm} 87$; 3) the tidal river from rkm 87 to rkm 229; and 4) a much steeper section just below Bonneville Dam, from rkm 229 to rkm 235. Below rkm 87, tidal processes largely control water levels, with some influence from river flow and atmospheric effects. In the estuarine and energy-minimum zones, adjustment to an increasing ocean tidal range from neap to spring tides is divided almost equally between a decrease in lower low water (LLW) levels and an increase in higher high water (HHW) levels. In the tidal river, tidal daily/monthly variance decreases/increases, seasonal-fluvial and hydropower operations ("power peaking") largely control water levels, and tides are strongly damped by high river flows. An increasing ocean tidal range results (due to nonlinear friction) in a small increase in LLW levels and a large increase in HHW levels in the tidal river. Analyses of records from 35 "floodplain" stations (located in peripheral and/or wetland areas exposed to the tide) showed the same zonation as the channel stations, but with considerable modification of tidal properties. Analyses of vegetation patterns suggest that the system can be divided into three zones: 1) the estuary plus energy minimum, 2) tidal-river, and 3) the landslide zone immediately downstream from Bonneville Dam. Water-level characteristics were also examined in using four lateral "slices" encompassing multiple floodplain stations along an elevational gradient, three in the tidal river and one in the energy minimum zone.

\section{B.2 Introduction}

Systematic integration of physical and biological concepts and analyses is essential to the understanding, conservation, and restoration of fluvial and estuarine ecosystems (Geyer et al. 2000; Rieman et al. 2006). Anthropogenic controls further complicate disturbance regimes and affect ecosystem resilience (Pickett and White 1985; Kingsford 2000). In particular, the natural and regulated variability of hydrologic regimes is fundamental to the distribution of biota in river floodplains (Poff et al. 1997; Junk 1999; Bunn and Arthington 2002), tidal freshwater (Hudon 1997; Baldwin et al. 2001), and tidal marshes (Cornu and Sadro 2002; Moffett et al. 2010). Identifying the complex of factors affecting zonation and productivity in these types of ecosystems, e.g., salinity, competition, root-zone aeration, and drying, remains a research challenge and is likely subject to geographic variability at multiple scales from the latitudinal to local, within a single river delta (Ewing 1986; Pennings et al. 2005). Recent calls for large-scale reconnection of floodplains and rivers to maximize the societal benefits of floodplains (Opperman et al. 2009), in addition to coastal and river restoration programs to benefit endangered species, emphasize the need to increase our ability to effectively relate plant community development to hydrologic processes. 
A program is underway in the 235-km lower Columbia River and estuary (LCRE; Figure B.1) to restore tidal wetlands, because of the potential to increase populations of threatened and endangered salmonid fish species by increasing the survival of outmigrating juveniles (Peterson 2003; NMFS 2008). The LCRE exhibits tidal, tidal-fluvial, and fluvial dominated hydrologic zones (Sherwood et al. 1990; Jay and Smith 1990; Chawla et al. 2008). Like large river floodplains in general, both lateral and longitudinal gradients in hydrologic regimes and biota exist (Bunn and Arthington 2002). Yet the quantification of these gradients needed to support ecological restoration designs (Poff et al. 1997) has been accomplished in only a partial manner, with emphasis on the lower estuary (Fox et al. 1984), where the extent of saltwater intrusion as governed by seasonal flows is usually about $20 \mathrm{~km}$ to $40 \mathrm{~km}$ (Jay and Smith 1990). While it is known that marsh, shrub, and swamp communities are arrayed on elevational gradients in the lower river, the associated hydrologic regimes of these distribution zones have not been quantified sufficiently along either lateral or longitudinal gradients for predictive models of restoration effects to be developed, particularly in the 195 - to $215-\mathrm{km}$ tidal freshwater region. In an associated study, we have collected plant community, environment, and water-level data on more than 50 tidal wetlands throughout the LCRE, which we reexamine herein in conjunction with new hydrologic analyses of the tidal-fluvial regime.

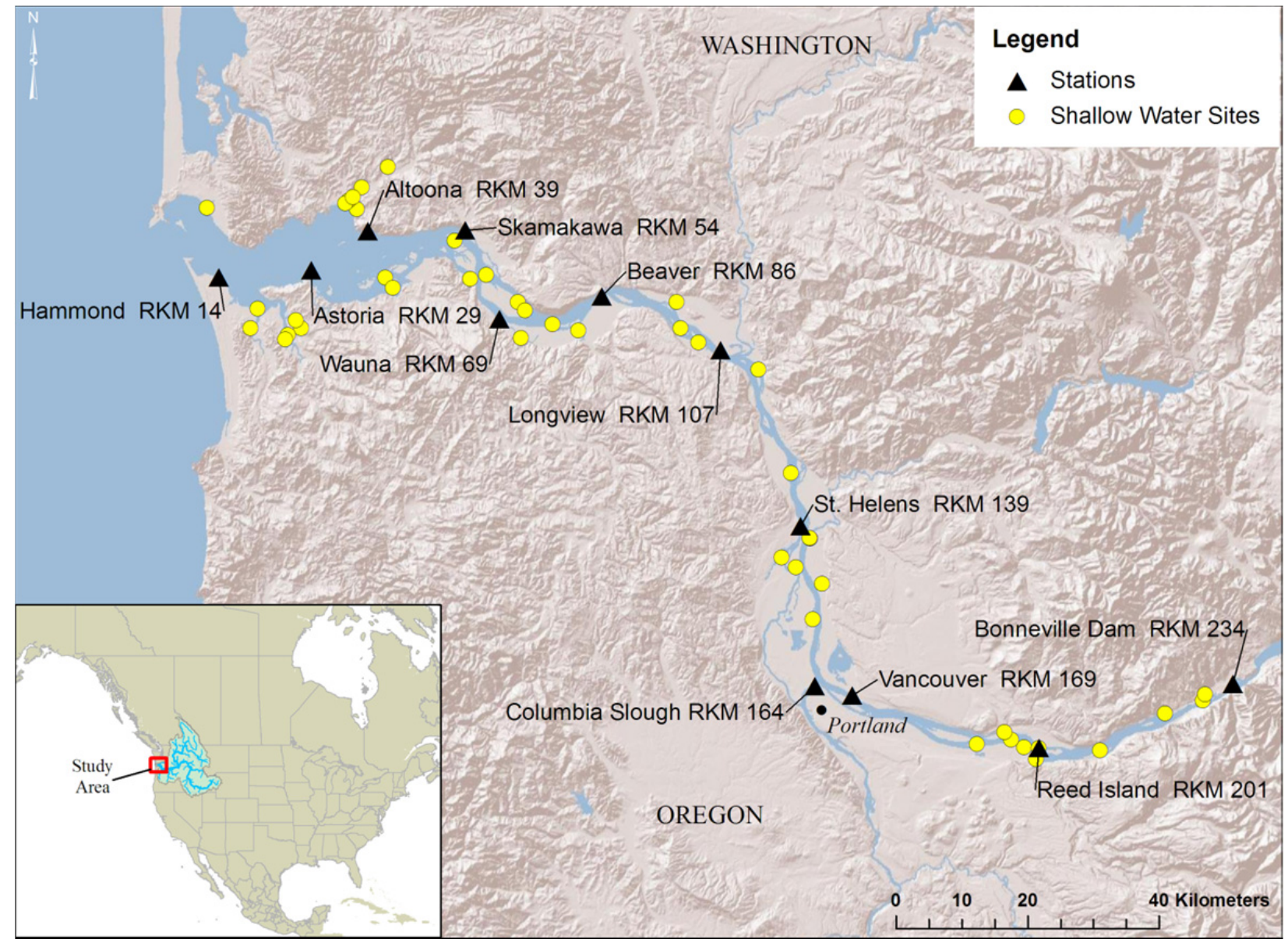

Figure B.1. Location Map for Tide Stations in the Lower Columbia River and Estuary (with river kilometer designations for the channel stations [triangles]). Floodplain stations are shown as yellow dots. 
The LCRE (Figure B.1) has highly variable water levels that are influenced by tides, river flow, atmospheric forcing, and hydropower system operation ("power peaking"). These factors have definite spatial patterns and distinctive although overlapping spectral signatures; they interact through quadratic bed friction. Water levels, in turn, influence ecosystem processes. This contribution seeks to quantify and separate water-level variations related to the various sources of external forcing, to represent with simple models the dominant process interactions, and to describe the impacts of water-level variations on wetland vegetation patterns, a fundamental indicator of ecosystem processes.

\section{B.2.1 Study Area}

The LCRE (Figure B.1) extends $240 \mathrm{~km}$ from the Pacific Ocean up the main stem to Bonneville Dam, built on a rapids (The Cascades) that has formed the head of the tide since an immense landslide ca. 600 years before present (YBP). The $660,000-\mathrm{km}^{2}$ Columbia River basin can be viewed as consisting of an Interior Subbasin east of the Cascade Mountains and a Western or Coastal Subbasin to the west of the Cascades. Historic Columbia River flows, measured daily since 1878 at The Dalles Dam (rkm 310), varied from $\sim 1,000$ to $35,000 \mathrm{~m}^{3} \mathrm{~s}^{-1}$ (Naik and Jay 2005). Present regulated flows vary from about 2,000 to $16,000 \mathrm{~m}^{3} \mathrm{~s}^{-1}$; the average $1991-2010$ flow was $5,025 \mathrm{~m}^{3} \mathrm{~s}^{-1}$. The Columbia Interior Subbasin flows measured at The Dalles are fed primarily by spring snowmelt, so that the peak flow or freshet occurs in late May, although before 1900, peak flows typically occurred in June. In addition to long-term changes in flow seasonality due to earlier snowmelt, irrigation withdrawal, reduced precipitation, and flow regulation for flood control and power generation have reduced spring freshet amplitude by 40 to $45 \%$ (Naik and Jay 2011). The mean flow at The Dalles Dam is about $97 \%$ of the mean flow at Bonneville Dam and $75 \%$ of the flow at the mouth.

The Willamette River, the largest Western Subbasin tributary, enters the Columbia River at Portland, $160 \mathrm{~km}$ from the ocean and accounts for about $40 \%$ of the Western Subbasin flow. It is tidal for $26 \mathrm{~km}$ to Oregon City. Western Subbasin flows respond much more rapidly to precipitation, because snow-pack storage is much less than in the Interior Subbasin, and flows are much less regulated. However, the largest flow events represent winter snow-on-rain events (Jay and Naik 2011). Willamette River flows over the 1991-2010 period ranged from 140 to $11,900 \mathrm{~m}^{3} \mathrm{~s}^{-1}$ (the latter in a brief flood in February 1996, the largest since 1964). The mean flow over the same period was $950 \mathrm{~m}^{3} \mathrm{~s}^{-1}$. The total flow through the LCRE is best represented by the flow at Beaver ( $r k m ~ 86)$. Over the 1991-2010 period, the minimum, maximum, and mean flows at Beaver were $1,800,24,500$, and $6,460 \mathrm{~m}^{3} \mathrm{~s}^{-1}$, respectively.

\section{B.2.2 Previous Studies}

Previous studies of tidal-fluvial interactions in the LCRE have been carried out by Jay and Flinchem (1997), Kukulka and Jay (2003a, b; henceforth KJ2003), and Jay et al. (2011; henceforth, JDL2011). Jay and Flinchem quantified the damping of LCRE tides and generation of overtides as a function of river flow from the mouth to Bonneville Dam. They also pioneered the use of continuous wavelet transform methods to analyze non-stationary tides. KJ2003 again used wavelet methods for extracting tidal properties (tidal amplitudes, phases, and ranges) and developed a regression analysis approach to parameterize tidal-fluvial interactions. This regression analysis is an application of the theoretical tidal propagation model developed by Jay (1991). JDL2011 extended the KJ2003 regression approach to the analysis of historical changes in tidal datum levels. This form of the regression analysis is used here. 
Tidal-fluvial forcing factors have been studied in other tidally influenced rivers worldwide. These include the Amazon River in Brazil (Amphlett and Brabben 1991; Hida et al. 1998; Gallo and Vinzon 2005; Bezerra et al. 2008), the Berau in Indonesia (Buschman et al. 2010), the Thames in England (Amin 1983), the Yangtze River in China (Yixin et al. 2001; Jiao et al. 2006) the Gironde estuary in France (Castaing and Allen 1981; Mikhailova and Isupoya 2006), and the Rhine River in The Netherlands. In North America, tidal-fluvial forcing has been studied in several systems including the Delaware (Parker 1991; DiLorenzo et al. 1993), Fraser (LeBlond 1978; Stronach and Murty 1989; Levings et al. 1991; Kostachuk 2002), and St. Lawrence (Godin 1999) rivers in Canada, and the Hudson River in New York (Smith et al. 2009). Power-peaking effects have been studied in the Colorado River in the western United States (Wiele and Smith 1996; White et al. 2005) and the Alto Adige in Italy (Zolezzi et al. 2009), although in a non-tidal context in both cases.

\section{B.3 Methods}

The water-level, river-flow, and atmospheric data on which our analysis is based cover a 20 -year period, 1991-2010. This period was chosen to represent "the present" in terms of hydrology and flow management, and to be long enough to encompass a large dynamic range of river-flow conditions, including major winter freshets in 1996 and 1997, several moderate to large spring freshets (1997, 1999, and 2008), and very dry conditions in 2001. In terms of tidal forcing, this period also covers slightly more than one 18.6-year nodal-variational cycle. To relate the water levels observed at the 12 tide gauges on the tidal river (Figure B.1) to wetland vegetation patterns, water-level data collected from 2005 through 2010 through 35 pressure gauges deployments (1- to 2-year duration) at wetland stations were analyzed, using both the time and frequency domain methods. Attention was focused on four lateral "slices," in two of three distinct vegetational regimes, where multiple pressure gauge deployments allowed analysis of water-level variations from the main channel up an elevational gradient into the wetlands. The statistical properties of the long-term stations were combined with the wetland station data to hindcast 20-year elevation patterns at the wetland stations.

\section{B.3.1 Water Data Collection and Processing}

\section{B.3.1.1 Shallow Water Sites}

These stations (Table B.1) were designed to reflect water-level and tidal conditions in floodplain, shallow-water, wetland, and island areas of the LCRE. They are designated here as "wetland" stations. HOBO ${ }^{\circledR}$ model U20 water-level logger absolute pressure sensors (made by Onset Computer Corp.) were installed in tidal wetland reference channels connected to tidal waters in locations where flows were not obstructed by dikes, culverts, or tide gates. Sampling was hourly or (at some stations), every 30 minutes. Sensor elevations were determined using Trimble real-time kinematic global positioning system (RTK-GPS) methods; we imported and viewed the position data using Trimble Geomatics Office (TGO) software. Pressure data recorded were between 2005 and 2009 for periods of 1 to 2 years at each station, although some records were truncated or have gaps due to very low water levels. Pressure data were corrected for atmospheric pressure and converted to water level relative to North American Vertical Datum of 1988 (NAVD88) or the Columbia River Datum (CRD) as needed for analyses. The CRD was used when the effects of the longitudinal vertical gradient from river mouth to Bonneville Dam needed to be removed for between-station comparisons. In addition, data were removed from the record whenever 
water levels indicated that the sensor was within $0.06 \mathrm{~m}$ of the surface, because of possible corruption of the temperature record (needed to convert pressure to depth) by direct atmospheric heating of the sensor, which was partially out of the water under these conditions.

Table B.1. Floodplain Stations

\begin{tabular}{|c|c|c|c|c|c|c|}
\hline Rkm & PNNL Site Names & Code & Deployment & Retrieval & $\begin{array}{l}L^{L O R^{(a)}} \\
\text { (days) }\end{array}$ & $\%$ Good \\
\hline 12 & Chinook & $\mathrm{CHM}$ & $8 / 17 / 2008$ & $8 / 18 / 2009$ & 365 & 100 \\
\hline 24 & Walluski River Natural Breach & WAB & $6 / 5 / 2008$ & $6 / 28 / 2009$ & 388 & 90 \\
\hline 24 & Walluski River Marsh & WAM & $6 / 5 / 2008$ & $6 / 28 / 2009$ & 389 & 100 \\
\hline 35 & Secret River Marsh & SRM & $7 / 30 / 2007$ & $7 / 2 / 2008$ & 338 & 100 \\
\hline 38 & Secret River Swamp & SRS & $7 / 30 / 2007$ & $6 / 29 / 2008$ & 335 & 100 \\
\hline 39 & Crooked Creek & $\mathrm{CCS}$ & $8 / 1 / 2007$ & $8 / 4 / 2008$ & 337 & 100 \\
\hline 43 & Karlson Island & KIS & $8 / 16 / 2007$ & $8 / 1 / 2008$ & 339 & 100 \\
\hline 53 & Welch Island & WIM & $7 / 20 / 2008$ & $8 / 3 / 2009$ & 379 & 100 \\
\hline 61 & Ryan Island & RIM & $7 / 23 / 2009$ & $8 / 10 / 2010$ & 383 & 100 \\
\hline 62 & Bradwood Slough & BSM & $7 / 23 / 2009$ & $8 / 10 / 2010$ & 383 & 100 \\
\hline 73 & Whites Island & WHM & $7 / 22 / 2009$ & $7 / 13 / 2010$ & 384 & 100 \\
\hline 73 & Westport Slough & WSS & $8 / 17 / 2009$ & $7 / 11 / 2010$ & 328 & 100 \\
\hline 77 & Wallace Island & WAC & $7 / 22 / 2009$ & $7 / 15 / 2010$ & 356 & 100 \\
\hline 80 & Clatskanie River Marsh & CRM & $8 / 18 / 2008$ & $7 / 24 / 2009$ & 340 & 100 \\
\hline 98 & Coal Creek Riparian & $\mathrm{CCR}$ & $7 / 20 / 2008$ & $8 / 8 / 2009$ & 384 & 90 \\
\hline 100 & Lord Island 2 & LI2 & $8 / 18 / 2008$ & $7 / 21 / 2009$ & 337 & 100 \\
\hline 113 & Cottonwood Island 1 & CI1 & $3 / 12 / 2009$ & $8 / 12 / 2010$ & 358 & 90 \\
\hline 131 & Goat Island & GIC & $8 / 18 / 2008$ & 8/9/2009 & 356 & 100 \\
\hline 141 & Gee Creek & GCR & $8 / 10 / 2009$ & $7 / 24 / 2010$ & 348 & 90 \\
\hline 145 & Cunningham Lake & CLM & $7 / 25 / 2009$ & $7 / 28 / 2010$ & 368 & 100 \\
\hline 149 & Campbell Slough & $\mathrm{CS} 1$ & $7 / 21 / 2008$ & $7 / 26 / 2010$ & 370 & 100 \\
\hline 154 & Sauvie Cove & $\mathrm{SCM}$ & $7 / 25 / 2009$ & $7 / 28 / 2010$ & 368 & 100 \\
\hline \multirow{2}{*}{191} & \multirow{2}{*}{ McGuire Island } & \multirow{2}{*}{ MICA } & $7 / 19 / 2006$ & $6 / 22 / 2007$ & 338 & 95 \\
\hline & & & $9 / 19 / 2008$ & 9/19/2009 & 364 & 100 \\
\hline 195 & Current Sandy River Mouth & Site D & $9 / 20 / 2008$ & $9 / 19 / 2009$ & 364 & 100 \\
\hline 195 & Washougal River mouth & WRM & $7 / 27 / 2009$ & $7 / 25 / 2010$ & 363 & 100 \\
\hline \multirow{2}{*}{196} & \multirow{2}{*}{ Old Sandy Channel } & \multirow{2}{*}{ Site N } & $8 / 14 / 2007$ & $8 / 14 / 2008$ & 365 & 100 \\
\hline & & & $8 / 14 / 2008$ & $9 / 24 / 2009$ & 406 & 100 \\
\hline \multirow{2}{*}{198} & \multirow{2}{*}{ Old Sandy Mouth } & \multirow{2}{*}{ Site C } & $8 / 7 / 2007$ & $7 / 11 / 2008$ & 339 & 100 \\
\hline & & & $8 / 13 / 2008$ & $10 / 15 / 2009$ & 428 & 100 \\
\hline 199 & Gary Island & Site E & $9 / 19 / 2008$ & $9 / 23 / 2009$ & 369 & 100 \\
\hline \multirow{2}{*}{201} & \multirow{2}{*}{ Chatham Island } & \multirow{2}{*}{$\mathrm{CIC}$} & $8 / 8 / 2007$ & $7 / 12 / 2008$ & 735 & 100 \\
\hline & & & $8 / 13 / 2008$ & $9 / 24 / 2009$ & 407 & 95 \\
\hline 201 & Reed Island & Site A & $8 / 7 / 2007$ & $7 / 11 / 2008$ & 338 & 99 \\
\hline 203 & Hwy 84 & Site F & $9 / 20 / 2008$ & $9 / 23 / 2009$ & 368 & 95 \\
\hline 211 & Sand Island (Rooster Rock) & SIM & $7 / 24 / 2008$ & $7 / 26 / 2009$ & 367 & 99 \\
\hline 221 & Franz Lake & FLM & $7 / 22 / 2008$ & $7 / 28 / 2009$ & 371 & 100 \\
\hline 229 & Hardy Creek & $\mathrm{HCM}$ & $7 / 23 / 2008$ & $7 / 26 / 2009$ & 368 & 100 \\
\hline 229 & Pierce Island & PIM & $7 / 25 / 2008$ & $7 / 26 / 2009$ & 366 & 95 \\
\hline
\end{tabular}


Time-series data from 16 of 35 of the wetland tide gauges have been analyzed. Processing and analysis includes quality control, calculation of power spectra and continuous wavelet transforms, and determination of inundation statistics (mean, median, quartiles, and extrema) for each station; see Appendix A for a sample station. Quality control includes de-spiking as necessary and plotting of scatter diagrams to look for anomalous datum shifts during each deployment. During the quality control step it was determined that temperature records collected in less than $0.06 \mathrm{~m}$ of water are unreliable (influenced by air temperature variations), these data were therefore flagged. Tidal constituents were resolved by harmonic analysis and plotted with constituents from appropriate nearby National Ocean and Atmospheric Administration (NOAA) tide gauges (Appendix A, pp. 5-6). Scatter diagrams (Appendix A, p. 7) were made of tidal constituents vs. flow at the appropriate nearby NOAA tide gauge. Calculation of the power spectrum (Appendix A, p. 8) provides a description of the average frequency content of a signal at high (frequency) resolution, while the continuous wavelet transform shows the time variations in frequency content at a lower level frequency resolution (Appendix A, p. 10). Preliminary analysis of the remaining 20 shallow-water tide gauge time-series data will be completed in 2012 .

\section{B.3.1.2 Main-Channel Tide Gauges}

Hourly data for the 1991-2010 period from the 12 long-term tide gauges shown in Figure B.1 and Table B.2 were collected from the responsible agencies. All of these stations are in or closely adjacent to deep water and may be considered to reflect tidal conditions in the main channel. We refer to them, therefore, as "channel" stations. NOAA-National Ocean Service (NOS) maintains most of the gauges, and data after March 2002 are available on-line (http://tidesandcurrents.noaa.gov/station_retrieve.shtml?type $=$ Historic + Tide+Data). Data for the 1991-2002 period are available from the U.S. Army Corps of Engineers (USACE or the Corps) Northwest Division (www.nwd-wc.usace.army.mil/perl/dataquery.pl). Data for the Beaver, Columbia Slough, and Bonneville Dam gauges were obtained from the U.S. Geological Survey (USGS), Portland District (personal communication, USGS, Portland District personnel).

No estuarine tide stations other than Tongue Point have been occupied for any length of time since 1990. Therefore, data from three stations occupied by NOAA-NOS during the 1980s were also included in the analysis (Figure B.1, Table B.2). One of the stations was occupied for $\sim 7$ years (Hammond 1982-1989), but with gaps. The remaining two (Knappton and Altoona) were occupied for $\sim 6$ months in 1981. There was a strong freshet in 1981, so these two stations provide a dynamic range of river flow sufficient for analysis, despite the short length of record (LOR). Because there are no tide gauges between Vancouver at rkm 171 and Bonneville Dam (rkm 234), one of the pressure gauges, deployed for 2 years (2007-2009) at Reed Island (rkm 198), was also used in the analysis of main channel water-level properties. This gauge was deployed close to open water, and appears to reflect tidal conditions in the channel. 
Table B.2. Long-Term, Channel Tide Stations

\begin{tabular}{lcccccc}
\hline \multicolumn{1}{c}{ Name } & Data Sources & River Km & Data Used $^{(\text {(a) }}$ & LOR $^{(\text {b) }}(\mathrm{hr})$ & $\begin{array}{c}\% \\
\text { Complete }\end{array}$ & $\begin{array}{c}\text { CRD on } \\
\text { NAV88 (m) }\end{array}$ \\
\hline Hammond & NOS & 15 & 1981 & 59496 & 89.1 & -0.143 \\
Knappton & NOS & 23 & 1981 & 4840 & 93.5 & -0.094 \\
Tongue Point & NOS & 29 & $1991-2010$ & 169440 & 100 & -0.182 \\
Altoona & NOS & 39 & 1981 & 5040 & 100 & 0.149 \\
Skamokawa & Corps, NOS & 54 & $1991-2010$ & 169440 & 93.7 & 0.273 \\
Wauna & Corps, NOS & 67 & $1991-2010$ & 169440 & 92.5 & 0.442 \\
Beaver & USGS & 87 & $1991-2010$ & 169440 & 88.2 & 0.63 \\
Longview & Corps, NOS & 107 & $1991-2010$ & 169440 & 95.9 & 0.88 \\
St Helens & Corps, NOS & 139 & $1991-2010$ & 169440 & 94.0 & 1.262 \\
Columbia & USGS & 154 & $1991-2010$ & 169440 & 94.6 & 1.336 \\
Slough & & & & & & \\
Vancouver & Corps, NOS & 171 & $1991-2010$ & 169440 & 95.0 & 1.634 \\
Reed Island & PNNL & 198 & $2007-2009$ & 19248 & 91.2 & 2.21 \\
Bonneville & USGS & 233 & $1991-2010$ & 169440 & 99.7 & 3.59 \\
\hline
\end{tabular}

(a) For the 1991-2010 stations, data from 1991/1/1 to 2010/4/30 were used.

(b) $\mathrm{LOR}=$ length of record.

The description of tidal-fluvial interactions provided below is based on analyses of the response to tidal, fluvial, and atmospheric forcing of three tidal datum levels: LLW, mean water level (MWL), and HHW. Time series of daily values of these three properties were extracted from hourly tidal records (interpolated to 6 minutes) using a 25-hour moving filter, centered at mid-day. HHW and LLW were the extrema within each 25-hour period, while MWL was the mean value over 25 hours.

\section{B.3.2 Frequency-Domain Analyses}

\section{B.3.2.1 Harmonic Analysis}

Tides are the oceanic response to gravitational interaction of the sun, moon, and earth. If heavenly bodies moved in circular orbits, and the earth were completely covered by water, this response would be fairly simple. Orbital complexities and the existence of continents and shallow coastal areas make the observed tides complicated. The complexities of the tides are described by the "harmonic model," which assumes that the observed signal is a sum of many sinusoidal signals of known frequencies derived from the expansion of astronomical forcing (Doodson 1921). Tidal constituents are given shorthand names, such as S1, the daily (diurnal) solar constituent, and M2, the principal twice daily (semidiurnal) lunar constituent. Each constituent has an associated amplitude and phase. The amplitude can be thought of as the contribution of each constituent to the observed height, while phase can be thought of as the delay from the passage of the sun or moon through its highest point until the peak of the response of the associated constituent. The harmonic model of the observed height hj, at time tj, with known tidal constituent frequencies $0,1 \ldots, n$ and unknown amplitudes a, b, and c0 (Leffler and Jay 2009) is as follows:

$$
h_{i}=c_{0}+\sum_{k=1}^{n}\left(a_{k} \operatorname{Cos}\left[2 \pi \theta_{k} t_{i}\right]+b_{k} \operatorname{Sin}\left[2 \pi \theta_{k} t_{i}\right]\right)
$$


A robust least squares fitting procedure ("harmonic analysis") is used to compute the unknowns (Huber 1996; Pawlowicz et al. 2003; Leffler and Jay 2009). Once the coefficients are estimated, the amplitude $\alpha$ of constituent $j$ is found as $\alpha=\sqrt{a_{j}^{2}+b_{j}^{2}}$, and the phase angle $\beta$ is found as $\beta_{\mathrm{j}}=\operatorname{Imag}\left[\log \left(a_{\mathrm{j}}\right.\right.$ $\left.+\mathrm{i} b_{\mathrm{j}}\right)$ ]. Confidence intervals of the estimated amplitudes and phases are computed using a modified version of the t-tide Matlab package (Pawlowicz et al. 2002). The results of a harmonic analysis may be considered to represent the average tidal properties over the period analyzed. The number of constituents resolved by a harmonic analysis is, however, limited by record length and the irregular and sometimes close frequency spacing (as little a 1-cycle $\mathrm{yr}^{-1}$ difference) of the major tidal frequencies.

The amplitudes and phases of the constituents vary only slowly across the open ocean. In estuaries, the tidal response may vary greatly over short distances, and multiple stations are needed. In addition, higher frequency "overtides" and low frequency "residual flows" are generated by nonlinear friction in shallow water at sums and differences of astronomical frequencies. Quadratic bed friction, for example, produces nonlinear constituents at twice the basic tidal frequencies, as well as tidal monthly variations. Because river flow varies over time and strongly modifies tides by friction, understanding system dynamics requires examination of the time-dependent behavior of the individual tidal constituents. In the LCRE, where time variations in tidal properties are large, short analyses periods are needed to resolve time variations in tidal properties. However, analysis of short records, especially those with high levels of non-tidal "noise," greatly limits the frequency resolution for any harmonic analysis. Thus, constituents used in an analysis must be selected taking into account LOR, the strength of astronomical forcing at each frequency, relevant physical processes, and the noise level (Foreman 1977).

\section{B.3.2.2 The Continuous Wavelet Transform}

The "continuous wavelet transform" (CWT) is a technique for optimizing (in terms of the Heissenberg uncertainty principle) the recovery of time-varying frequency information from a time series. The advantages of the CWT over harmonic analysis (which has a fixed analysis period for all frequencies) for present purposes are 1) more stable and accurate results for non-stationary processes like power peaking, and 2) better temporal resolution of variations in frequency content, because filter length is tuned for each frequency. A CWT operator is the convolution of a time series with a scaled wavelet. A wavelet is a function with zero mean, finite energy and duration, and a narrow frequency response or scale $s$ (Jay and Flinchem 1997). Following Jay and Flinchem, we use a Kaiser-windowed complex exponential as our basis wavelet filter; the Kaiser window minimizes energy leakage into side lobes (Kaiser 1966). The resulting wavelet $\Psi_{L}$ has the following form:

$$
\Psi_{L}(t, s)=N_{L}(s) \mathrm{I}_{0}\left(\beta \sqrt{1-\left(\frac{t}{s L}\right)^{2}}\right) \exp \left(2 \pi i \frac{t}{s}\right)
$$

where $\quad \mathrm{I}_{0}=$ a zero-order modified Bessel function of the first kind

$\beta=6.755$ determines the frequency roll-off

$L=$ establishes the wavelet length relative to $s$

$N_{L}(s)=$ chosen such that the maximal response to a unit wave is one. 
A wavelet transform $y_{L}$ is then defined by

$$
y_{L}(t, s)=\left[z * \operatorname{conj}\left(\Psi_{L}(s)\right)\right](t)
$$

where $*$ is the convolution operator, conj( $)$ the complex conjugate of the argument, and $z$ the water-level record. The choice of wavelet filter lengths always requires compromise. A filter that is too long yields poor time resolution. A filter that is too short has poor frequency resolution and cannot separate processes at the closely spaced frequencies characteristic of tides. In conventional wavelet transforms, the scales are arranged in strict logarithmic fashion (e.g., 1, 2, or 4 filters per power of two in frequency). Also, the length of the wavelet filter is proportional to the analysis time-scale $s$, so that higher frequencies have a relatively short filter length with reduced frequency resolution. Following the protocols of Flinchem and Jay (2000), we have chosen filter scales to correspond to the major tidal frequencies (and frequencies of power peaking) and increased the filter length for frequencies higher than semidiurnal to improve the frequency resolution and reduce noise. The resulting filter bank uses four filters per power of two in frequency, but there is some variation in frequency spacing to accommodate the known frequencies of tidal processes and power peaking. Filter lengths and nominal frequencies/periods corresponding to known processes are listed in Table B.3. A wavelet filter bank consisting of the frequencies (four per power of two in frequency) between D8 $\left(\sim 8 \mathrm{~d}^{-1}\right)$ and $1 / 29 \mathrm{~d}^{-1}$ were used for the analysis of the short ( $\sim 1$ - to 2-year) floodplain records. For analysis of the nine channel stations with $\mathrm{LOR}=\sim 20$, frequencies down to $1 \mathrm{yr}^{-1}$ were used.

Table B.3. Wavelet Analysis Properties (Selected Bands)

\begin{tabular}{ccccc}
\hline Name & Physical Process ${ }^{(\text {a) }}$ & Period, (d or hr) & Freq (hr) $)^{(\text {a) }}$ & $\begin{array}{c}\text { Filter Length } \\
\text { (hr or yr) }\end{array}$ \\
\hline Annual & W,S & $365.2 \mathrm{~d}$ & $1.141 \times 10^{-4}$ & $4.11 \mathrm{yr}$ \\
Semi-Annual & S & $182.6 \mathrm{~d}$ & $2.282 \times 10^{-4}$ & $2.24 \mathrm{yr}$ \\
29 d TM & S, TM & $720 \mathrm{hr}$ & 0.0014 & $4332 \mathrm{hr}$ \\
14 d TM & S & $475 \mathrm{hr}$ & 0.0021 & $2859 \mathrm{hr}$ \\
& S, TM & $336 \mathrm{hr}$ & 0.0030 & $2022 \mathrm{hr}$ \\
& W & $238 \mathrm{hr}$ & 0.0042 & $1430 \mathrm{hr}$ \\
$7 \mathrm{~d}$ PP & W, PP & $168 \mathrm{hr}$ & 0.0060 & $1011 \mathrm{hr}$ \\
& W & $119 \mathrm{hr}$ & 0.0084 & $715 \mathrm{hr}$ \\
$3.5 \mathrm{~d}$ PP & W, PP & $84 \mathrm{hr}$ & 0.0119 & $506 \mathrm{hr}$ \\
& W & $59 \mathrm{hr}$ & 0.0168 & $358 \mathrm{hr}$ \\
& W, PP & $42 \mathrm{hr}$ & 0.0238 & $253 \mathrm{hr}$ \\
D1 & T & $23.9 \mathrm{hr}$ & 0.0418 & $193 \mathrm{hr}$ \\
I & I & $16.6 \mathrm{hr}$ & 0.0602 & $131 \mathrm{hr}$ \\
D2 & T & $12.4 \mathrm{hr}$ & 0.0805 & $97 \mathrm{hr}$ \\
D3 & T & $8.2 \mathrm{hr}$ & 0.1222 & $73 \mathrm{hr}$ \\
D4 & T & $6.2 \mathrm{hr}$ & 0.1610 & $73 \mathrm{hr}$ \\
D6 & T & $4.1 \mathrm{hr}$ & 0.2415 & $73 \mathrm{hr}$ \\
D8 & T & $3.1 \mathrm{hr}$ & 0.3215 & $73 \mathrm{hr}$ \\
\hline
\end{tabular}

(a) $\mathrm{W}=$ weather; $\mathrm{PP}=$ power peaking; $\mathrm{I}=$ inertial; $\mathrm{T}=$ tidal; $\mathrm{TM}=$ tidal monthly; $\mathrm{S}=$ seasonal-fluvial. 


\section{B.3.3 Tidal Fluvial Interactions and Regression Models of Water-Level Records}

\section{B.3.3.1 Theoretical Approach}

Regression models are used below to determine the response of water levels to external forcing by tides, river flow, atmospheric processes and power peaking. The water levels modeled, for both channel and wetland stations, are LLW, MWL, and HHW. In a tidal river, these levels are not usefully described by long-term means. Rather, they need to be described in terms of their response to external processes. The modeling approach used here was developed by Jay and Flinchem (1997), KJ2003, and JDL2011. It is based on a theory of tidal propagation in convergent, strongly frictional channels (Jay 1991). Tidal propagation under these circumstances can be described in terms of a single (incident) wave - the reflected wave is insignificant except near reflecting barriers.

The governing equations for tidal propagation contain several nonlinearities through which distinct external forcing modes (e.g., tides and river flow) interact. In shallow channels, quadratic bed friction is the dominant interaction. KJ2003 developed a two-fold strategy for modeling tidal behavior under these circumstances. First, an admittance (complex ratio of tidal response at any station to ocean tidal forcing) is formed and resolved into an amplitude ratio and a phase difference. Second, the bedstress is expressed in terms of external parameters, the river flow $\mathrm{Q}_{\mathrm{R}}$ and $\mathrm{T}_{R, \mathrm{H}}$.

Bedstress, represented as $\tau_{\mathrm{B}}=\rho \mathrm{C}_{\mathrm{D}}|\mathrm{U}| \mathrm{U}$, is key, because $\tau_{\mathrm{B}}$ controls the tidal wavenumber and therefore tidal propagation; here, $\mathrm{U}$ is velocity, $\rho$ water is density, and $\mathrm{C}_{\mathrm{D}}$ is the drag coefficient. KJ2003 used a Chebyschev polynomial approach to representing $|\mathrm{U}| \mathrm{U}$ for the relevant case where tidal and fluvial flows are of similar magnitude and convergence moderate. Under these conditions, the KJ2003 models describe a tidal constituent amplitude (or tidal range) ratio between a station of interest and a reference station near the ocean in terms of the damping modulus $r$ ( $\mathrm{r}$ is the imaginary part of the complex wavenumber $\left.q=\left((-1)^{1 / 2}-1\right) r\right)$ :

$$
\begin{gathered}
\frac{\zeta[\mathrm{x}]}{\zeta_{\mathrm{H}}}=e^{-i q\left(x-x_{\mathrm{H}}\right)} \\
\log \left[\frac{|\zeta[\mathrm{x}]|}{\left|\zeta_{\mathrm{H}}\right|}\right]=+r\left(x-x_{\mathrm{H}}\right)
\end{gathered}
$$

where $\zeta[\mathrm{x}]$ is a tidal property (range or amplitude) at position $\mathrm{x}$, and $\zeta_{\mathrm{H}}$ is the same property at the reference station (Hammond), where $\mathrm{x}=\mathrm{x}_{\mathrm{H}}$. KJ2003 used the Dronkers (1964) representation of $|\mathrm{U}| \mathrm{U}$ to parameterize (1b) in terms of external variables as

$$
\log \left[\frac{|\zeta[\mathrm{x}]|}{\left|\zeta_{\mathrm{H}}\right|}\right]=\mathrm{a}_{0}+\mathrm{a}_{1} \mathrm{Q}_{\mathrm{R}}+\mathrm{a}_{2}\left(\frac{\mathrm{T}_{R, \mathrm{H}}^{2}}{\mathrm{Q}_{\mathrm{R}}^{\frac{1}{2}}}\right)
$$

where $\left(x-x_{H}\right)$ is assumed fixed for any given tide gauge and absorbed into the parameters. 
Expressions like Eq. (B.3) can be used to describe tidal excursions from MWL, e.g., tidal amplitude or range. MWL (which is effectively the mean river stage) can also be modeled; KJ2003 used a linear form, again based on the Chebyschev expansion for $|\mathrm{U}| \mathrm{U}$ :

$$
M W L \approx b_{0}+b_{1} \mathrm{Q}_{R}^{2 / 3}+b_{2} \frac{\left(T_{\mathrm{R}, \mathrm{H}}\right)^{2}}{Q_{\mathrm{R}}^{\frac{4}{3}}}
$$

Here we are interested in datum levels like LLW and HHW that combine tidal range and MWL; e.g., $L L W=M W L-1 / 2$ greater diurnal tidal range (GDTR) - how can these be modeled? A linear form must be used at least for LLW, because LLW has negative values. The key is a property of the natural log function:

$$
\log [1+\delta]=\delta \quad \text { limit } \delta \rightarrow 0
$$

For tidal amplitides (amplitude ratios near unity), (B.8) indicates that the departure, $\delta$, of the ratio in Eq. (B.5) from unity may be modeled linearly. In fact, the amplitude departures are usually negative (tides are smaller upriver than at Hammond, especially for large $\mathrm{Q}_{\mathrm{R}}$ ), and the ratio of tidal amplitudes is sometimes small $(|\delta|$ approaches 1). Nonetheless, a linear model is overall the best approach, because Eq. (B.7) is linear. Thus, if $\mathrm{Q}_{\mathrm{R}}$ is large and range small, the HHW and LLW models are only a small perturbation of the linear MWL model. Thus, a linear model is appropriate in both the low-flow ( $\delta$ small) and high-flow $(|\delta| \sim 1)$ limits.

\section{B.3.3.2 River Tides and Datum Levels - Practical Regression Models}

The above considerations suggest datum level models for the lower river of the following form:

$$
\begin{aligned}
& \mathrm{LLW}=\mathrm{a}_{0 \mathrm{k}}+\mathrm{a}_{1 \mathrm{k}} \mathrm{Q}_{\mathrm{B}}^{m_{1}}+\mathrm{a}_{2 \mathrm{k}} \mathrm{Q}_{\mathrm{WR}}^{n_{1}}+\mathrm{a}_{3 \mathrm{k}} P+\mathrm{a}_{4 \mathrm{k}}\left(\frac{\mathrm{T}_{R, \mathrm{H}}^{\mathrm{s}_{1}}}{\left(\mathrm{Q}_{\mathrm{B}}+\mathrm{Q}_{\mathrm{WR}}\right)^{\frac{1}{2}}}\right) \\
& \mathrm{HHW}=\mathrm{b}_{0 \mathrm{k}}+\mathrm{b}_{1 \mathrm{k}} \mathrm{Q}_{\mathrm{B}}^{m_{2}}+\mathrm{b}_{2 \mathrm{k}} \mathrm{Q}_{\mathrm{WR}}^{n_{2}}+\mathrm{b}_{3 \mathrm{k}} P+\mathrm{b}_{4 \mathrm{k}}\left(\frac{\mathrm{T}_{R, \mathrm{H}}^{\mathrm{s}_{2}}}{\left(\mathrm{Q}_{\mathrm{B}}+\mathrm{Q}_{\mathrm{WR}}\right)^{\frac{1}{2}}}\right) \\
& \mathrm{MWL}=\mathrm{c}_{0 \mathrm{k}}+\mathrm{c}_{1 \mathrm{k}} \mathrm{Q}_{\mathrm{B}}^{m_{3}}+\mathrm{c}_{2 \mathrm{k}} \mathrm{Q}_{\mathrm{WR}}^{n_{3}}+\mathrm{c}_{3 \mathrm{k}} P+\mathrm{c}_{4 \mathrm{k}}\left(\frac{\mathrm{T}_{R, \mathrm{H}}^{\mathrm{s}_{3}}}{\left(\mathrm{Q}_{\mathrm{B}}+\mathrm{Q}_{\mathrm{WR}}\right)^{\frac{1}{2}}}\right)
\end{aligned}
$$

where $\quad \mathrm{Q}_{\mathrm{B}}=$ Columbia flow at Bonneville Dam, 1000s of $\mathrm{m}^{3} / \mathrm{s}$, lagged 1 day

$\mathrm{Q}_{\mathrm{WR}}=$ Willamette flow at Portland, 1000s of $\mathrm{m}^{3} / \mathrm{s}$

$\mathrm{T}_{R, \mathrm{H}}=\operatorname{GDTR}(\mathrm{m})$ at Hammond

$\mathrm{P}=$ daily average atmospheric pressure deviation at Newport, Oregon, 10s of $\mathrm{mb}$

$\mathrm{a}_{\mathrm{ik}}$ to $\mathrm{c}_{\mathrm{ik}}, \mathrm{i}=0,4=$ regression parameters for each station and model

$\left\{\mathrm{s}_{1}, \mathrm{~s}_{2}, \mathrm{~s}_{3}\right\}=$ tide-flow interaction exponents for each station and model 


$$
\begin{aligned}
\mathrm{k} & =\text { index for stations, } \mathrm{k}=1,13 \\
\left\{\mathrm{~m}_{1}, \mathrm{~m}_{2}, \mathrm{~m}_{3}\right\} & =\text { Columbia flow exponent; varies with location and model } \\
\left\{\mathrm{n}_{1}, \mathrm{n}_{2}, \mathrm{n}_{3}\right\} & =\text { Willamette flow; varies with location and model. }
\end{aligned}
$$

The first three terms in each of Eq. (B.9) to (B.11) relate tidal datum levels to river flows $Q_{\mathrm{B}}$ and $\mathrm{Q}_{\mathrm{WR}}$ (all flows are positive). $Q_{\mathrm{B}}$ and $\mathrm{Q}_{\mathrm{WR}}$ are included separately, so that $Q_{\mathrm{B}}$ could be lagged 1 day for stations seaward of Vancouver. Also, the Willamette flow represents a backwater effect at some but not all stations, possibly changing the exponent $n_{\mathrm{j}}$. Although including the two flows separately adds a regression parameter and increases error bounds, it makes the model more effective in representing high flows that are not synchronized in the Columbia and Willamette rivers.

Jay (1991) argued that the dependence of tidal properties on flow should have the form $\alpha_{1} Q_{R}{ }^{1 / 2}+\alpha_{2} Q_{R}{ }^{3 / 2}$ (where $Q_{R}$ is either $Q_{\mathrm{B}}$ or $\mathrm{Q}_{\mathrm{WR}}$ in $\mathrm{m}^{3} \mathrm{~s}^{-1}$ ). To reduce the number of regression variables in equations like (B.6) to (B.8), KJ2003 made the linear approximation that $\alpha_{1} Q_{R}{ }^{1 / 2}+\alpha_{2} Q_{R}{ }^{3 / 2} \approx \alpha Q_{R}$. In principle, $\alpha_{1}$ and $\alpha_{2}$ depend on the ratio of $Q_{R}$ to the total current and are influenced by the presence or absence of peripheral intertidal areas. Moreover, the appearance of $Q_{R}$ in Eq. (B.9) to (B.11) is itself a simplification -in theory, $U_{\mathrm{R}}=Q_{R} / A\left(Q_{R}\right)\left(U_{\mathrm{R}}\right.$ is river flow in $\mathrm{ms}^{-1}$, and $A\left(Q_{R}\right)$ is channel cross-sectional) should be used. The variation of $A$ with $Q_{R}$, trivial in the estuary but quite large upriver, also causes variation in exponent $m$ with channel geometry. Moreover, this variation is a function of all the channel geometry seaward of the gauge, through which the tidal wave propagates. While $m$ may be kept constant by adding additional regression terms that represent the variation in $A$ with $Q_{R}$, this has an unfavorable effect on model confidence limits. A pragmatic solution is to tune $m$ and $n(0.5 \leq m, n \leq 1.5)$ by station. Optimal exponent values were determined at each station through iterative least-squares regression. However, because exponents should not change sharply between stations, discretion was exercised by forcing $m$ and $n$ to vary smoothly in space.

The fourth term in each of Eq. (B.9) to (B.11) represents the effects of atmospheric pressure (commonly known as the inverse barometer effect). The coastal atmospheric pressure record for Newport, Oregon, was found to be more useful in the regression analyses than stations closer to the river. The last term in Eq. (B.9) to (B.11) represents the effects of the nonlinear interaction of tides and river flow. In theory this interaction is quadratic in $\mathrm{T}_{R, \mathrm{H}}\left(s_{\mathrm{j}}=2 ; \mathrm{j}=1,3\right)$, but only for upriver stations where river flow and tidal currents are comparable in strength. Thus, the $s_{\mathrm{j}}$ was also tuned iteratively by station $\left(0.8 \leq s_{\mathrm{j}} \leq 2\right)$, with a smooth spatial variation imposed.

The coefficients $\mathrm{a}_{\mathrm{ik}}$ to $\mathrm{c}_{\mathrm{ik}}(\mathrm{i}=1,4, \mathrm{k}=1,21)$ in Eq. (B.9) to (B.11) were determined by robust multiple linear regression analyses (Huber 1996; Leffler and Jay 2009) to best fit the observations, with a different set of coefficients and exponents determined for each station. The robust method is also known as iteratively re-weighted least-squares regression (IRLS). IRLS iteratively down-weights outliers to achieve a more accurate result with tighter confidence limits. One departure from robust linear regression was used. Extremes of tidal range and river flow are rare, but these data are vital in determining the behavior of tidal datum levels for extreme forcing conditions. Data points were accordingly weighted by an analytical function that approximated the inverse square root of their frequency of occurrence. This weighting was applied along with the IRLS re-weighting, so that the total weight on each data point in each iteration was the product of the river-flow/range weight with the IRLS weight. The weighted $\mathrm{R}^{2}$ values for regressions of datum levels LLW, HHW, and MWL using Eq. (B.9) to (B.11) were 0.90 to 99 for stations landward of Wauna, but lower in the estuary, especially for MWL (0.55 to 0.9). There are two primary reasons for this lower success for estuarine stations: 1) the theory underlying the regression 
models is designed to describe tidal-fluvial interactions, but there are a variety of processes that affect estuarine water levels, not all considered here, and 2) there is very little dynamic range of estuarine elevations (especially MWL), so "noise" (related to processes not considered here) plays a larger role than in the tidal river.

Finally, note that the regression models, Eq. (B.9) to (B.11), are not "dynamic models" in the sense of representing time variations in tidal-fluvial processes. They are instead relatively simple statistical representations of these processes, but with a sound basin in the theory of tidal-fluvial interactions (KJ2003; JDL2011). Because of their nature, they can be used for extrapolation beyond the range of observed forcing parameters only with care.

\section{B.3.3.3 An Example of Regression Model Results}

Figure B.2 shows typical regression analysis properties and results, in this case for Vancouver HHW. The histogram of Bonneville daily flows is shown in Figure B.2a. There are very few days with flows outside the range of 2,500 to $16,000 \mathrm{~m}^{3} \mathrm{~s}^{-1}$, so hindcasts outside this range of flow are problematic. The properties of the resulting HHW model are shown as a function of Bonneville daily flow $Q_{\mathrm{B}}$ in Figure B.2b, with Willamette river flow held at $500 \mathrm{~m}^{3} \mathrm{~s}^{-1}$; HHW varies with $Q_{\mathrm{B}}{ }^{1.6}$ and $Q_{\mathrm{WR}}{ }^{1.1}$. The points above the lines in Figure B.2b represent cases for which $Q_{\mathrm{WR}}$ is greater than the assumed $500 \mathrm{~m}^{3} \mathrm{~s}^{-1}$. The adjusted $\mathrm{R}^{2}$ for this case was 0.982 , so the model was quite successful (Figure B.2c). As suggested by the fact that the hindcast vs. observed HHW values fall close to the 1:1 line in Figure B.2c, there is little bias in the residuals (Figure B.2d). The largest spikes in the residual represent cases where the timing of the predicted flow is incorrect.

\section{B.3.3.4 Hindcast Inundation, 1991-2010}

Tidal data were complete during the 1991-2010 period for only 1 of 13 channel stations (Tongue Point). In contrast, forcing data (predicted Hammond GDTR, Bonneville and Willamette river flows and atmospheric pressure) were complete for the 1991-2010 period, except for a 5-month gap in Newport pressure in 1991-1992, which was filled with the long-term average value. To provide a complete time series of tidal properties at the main-channel stations, the regression models described above were used to hindcast a uniform 1991-2010 time series of daily values of LLW, HHW, and MWL. These hindcast time series of LLW, MWL and HHW were compiled into elevation frequency and cumulative elevation frequency plots. To validate the hindcasts, statistics of the residuals (hindcast-observed) were calculated. Root Mean Square (RMS) errors for LLW, MWL and HHW did not exceed $0.21 \mathrm{~m}$ except at Bonneville, where they were $0.28 \mathrm{~m}, 0.21 \mathrm{~m}$, and $0.32 \mathrm{~m}$, respectively. Below Reed Island, RMS LLW and MWL errors did not exceed $0.18 \mathrm{~m}$. Errors for HHW may be expected to be somewhat larger, because HHW is the water level exhibiting the highest variability. There was some degree of negative skewness in the predictions (observed values $>$ predicted), especially for the rare excursions of HHW during floods. Similar 1991-2010 hindcasts are in progress for peripheral stations on the lateral "slices." The models for peripheral stations are based on the main-channel stations. Specifically, the choice of exponents $\mathrm{m}_{\mathrm{j}}, \mathrm{n}_{\mathrm{j}}$, and $\mathrm{s}_{\mathrm{j}}$ in Eq. (B.9) to (B.11) at each peripheral station is based on values at a nearby main-channel station. 


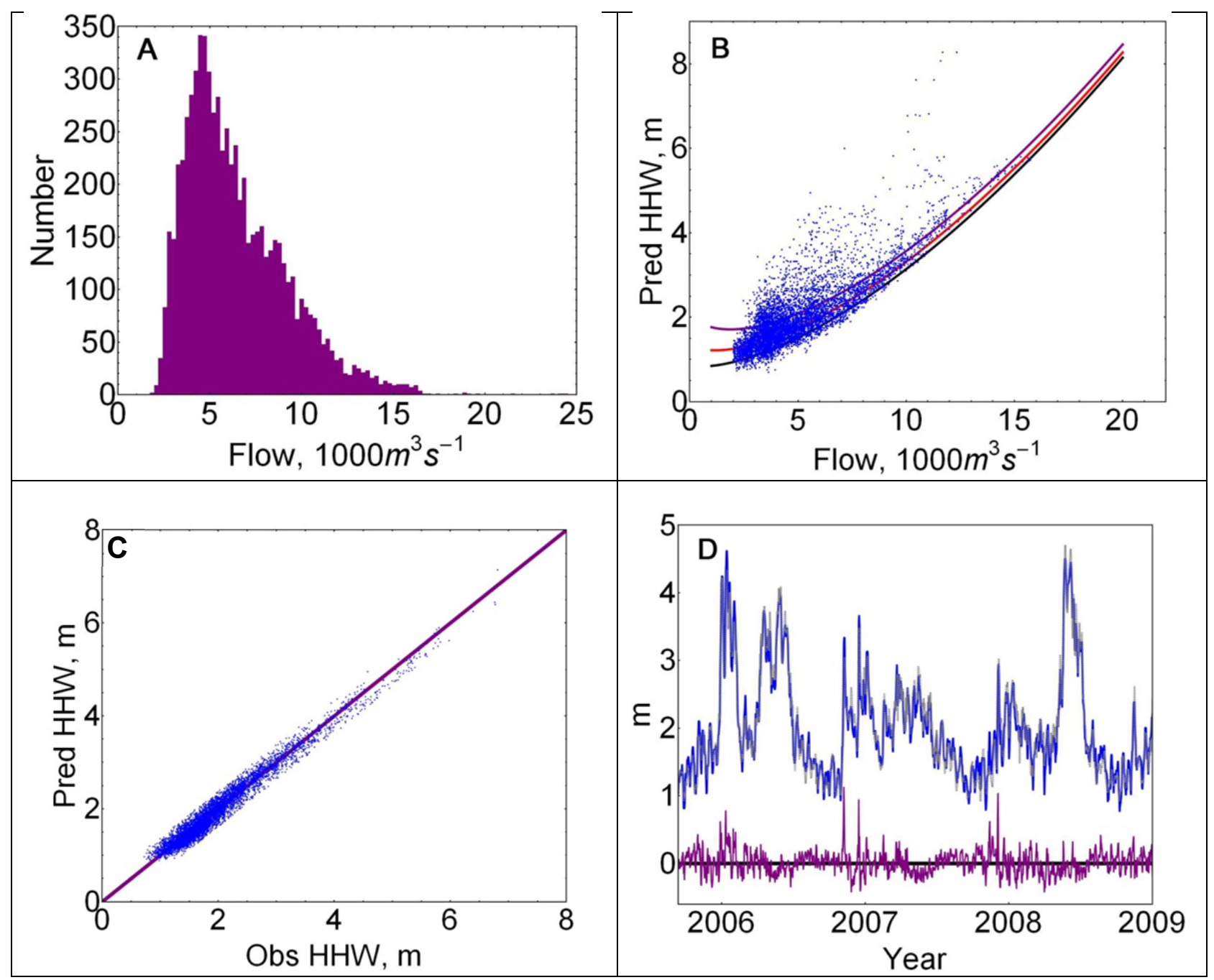

Figure B.2. Typical Model Results for Vancouver HHW. (A) histogram of Bonneville daily flows; (B) modeled HHW for three Hammond GDTR values (1.6, 2.6 and $3.6 \mathrm{~m})$ and a range of Bonneville flows (Willamette flow $=500 \mathrm{~m}^{3} \mathrm{~s}^{-1}$ ) on a scatter plot of observed HHW vs. flow; (C) hindcast vs. observed HHW; and (D) observed HHW (blue), hindcast HHW (grey), and residual HHW (observed-hindcast).

\section{B.3.4 Separation of Variance}

Water levels in the LCRE respond to forcing by tides, weather, power peaking, and fluvial processes. To separate the effect of these processes and provide an along-channel view of variations in controlling processes, the variance $\left(\right.$ in $\mathrm{m}^{2}$ ) in each wavelet band was calculated. For each frequency band variance $=$ $1 / 2(\mathrm{RMS})^{2}$ of the wavelet amplitude time series for that band; frequencies corresponding to known physical processes are listed in Table B.3. Variances for related bands were then summed to give the total energy level for each process. Thus, the tidal energy is defined as the sum of variance of D1 and D2. The overtide variance is the sum of all bands from D3 to D8; the tidal monthly variance is taken as the sum of the 15 and 29-day bands. Power peaking energy is defined as the sum of variance in bands with periods from 1.3 to 7 days. Weather-band energy is the sum of all bands from 8 to 12 days. Because power peaking is very broad-band, it contaminates the weather-band estimates at the more landward stations, 
and there is no simple way to provide a complete separation. Fortunately, harmonic analysis and regression modeling provide further information regarding the strength of power peaking. Seasonalfluvial energy is the sum (for channel stations with long records) of all bands from 17 to 24 days and 36 days to 1 year. Because of the limited LOR for floodplain stations, 29 days was the lowest frequency estimated. For these stations, seasonal-fluvial energy was taken as the low-passed energy remaining after application of a 761-hour boxcar filter to the record. Variance for each process is plotted below as a function of along-channel distance in two forms: 1) as variance in $\mathrm{m}^{2}$, and 2) as a percentage of total variance. The total variance is the sum over all bands plus the lowpass. Because of overlap between filters, the total variance estimated in this manner is larger than the variance estimated from the raw time series. Moreover, because wavelet bands have been tuned to tidal frequencies (causing some unevenness in the frequency spacing), and filter lengths are longer for high frequencies than for low frequencies, the degree of overlap is a function of frequency. Thus, the overlap cannot be easily removed. Despite these qualifications, the variance plots provide realistic estimates of the importance of the various forcing processes as a function of along-channel distance.

\section{B.3.5 Vegetation Analysis Methods}

Understanding the distribution of vegetation across and along the $\sim 235-\mathrm{km}$ floodplain of the LCRE is vital for understanding the system and for restoration efforts. Variations in floodplain plant species composition and distribution caused by reductions in water-level fluctuations because of flow regulation (e.g., by dams and reservoirs) can be predicted from hydrological data (Leyer 2005). To compare sitescale data on plant community and hydrologic regime to the analysis of forcing factors in the LCRE, we used two methods: a sum exceedance value (SEV) index of hydrologic conditions during the growing season (Gowing and Spoor 1998), and discriminant analysis of herbaceous plant community percent cover data in Statistica 9 software. SEVs have been calculated using various values; e.g., the daily value of the elevation of the water above a datum located $30 \mathrm{~cm}$ below the soil surface, or a combination of $10 \%$ air-filled porosity in the first $10 \mathrm{~cm}$ of soil (aeration threshold) and the depth where plants begin showing water stress effects (drying threshold) (Araya et al. 2011). We calculated the SEV using only surface-water elevation and topographic data, not water table levels:

$$
S E V=\sum_{i=1}^{n} h_{\text {elev }}
$$

where $n$ is the number of days present in the growing season, and $h_{\text {elev }}$ is the hourly water-level elevation above the average marsh elevation. The SEV may also be calculated from daily mean water levels, however, we observed that this method did not adequately incorporate the large tidal fluctuations in the seaward portion of the LCRE.

The growing season was based on the number of frost-free days for the region as determined by the Natural Resource Conservation Service (NRCS) in the wetland determination (WETS) table for Clark County, Washington (NRCS 2002). The start of the growing season was determined to be April 12 and the end was October 12. The Clark County growing season is used for all the sites in the estuary so that the inundation calculations are standardized to one period. However, because of gaps in time-series water-level data at some marsh sites, a common series of data within the growing season was deleted so that the cumulative sum could be compared equitably between sites. These dates were June 22 to August 19, which are after the spring freshet and before the lowest water periods of the season. We 
verified that this deletion did not affect relative SEVs at the 20 sites for which complete growing season data were available. Sufficient topographic and water-surface-level data were available to calculate SEVs for 28 emergent marsh sites along the main channel, of which 9 were created sites and 2 were formed by accidental dike breaches in decades past. For the purposes of comparisons along the longitudinal axis of the river floodplain, we excluded sites along tributaries to the LCRE, low marshes, shrub wetlands, and forested wetlands, as well as one site where data were collected during 2007, which had an unusual hydrograph relative to other study years 2008-2010. The SEV was calculated using the average elevation of the surveyed floodplain vegetation plots in the CRD.

To further examine the relevance to the biota of the system zonation developed from analyses of multi-year tide gauge data, we analyzed herbaceous plant species cover data collected at 20 historically present marshes throughout the LCRE (Borde et al. in preparation). These cover data were collected between 2005 and 2010 in $1-\mathrm{m}^{2}$ plots situated along transects proximal to the channel using a systematic sampling with a random start method, and encompass the elevation gradient away from the channel. We used the 75th percentile of cover data and because of a lack of data no sites in the landslide-controlled zone could be included in these analyses. We used the Plymouth Routines in Multivariate Ecological Research (PRIMER) software package (Clarke and Warwick 1994; Clarke and Gorley 2006) to calculate the Bray-Curtis similarity coefficient (S') as a measure of distance between sites, and a non-metric multidimensional scaling (NMDS) ordination plot to visualize results. The observed differences between the three most seaward zones evinced in the physical process data analysis were compared with the differences among sites within zones using a nonparametric test statistic based on the ranked Bray-Curtis similarity coefficients (ANOSIM; Clarke 1993). The distribution of the test statistic, R, is estimated by randomly assigning each observation to groups 999 times and calculating $\mathrm{R}$ for each permutation, and the observed value of $\mathrm{R}$ is compared with the random distribution.

To assess which of several available classification systems provides the best rule to separate historical marsh sites based on the percent correct classification matrix, we used discriminant analysis (forward stepping). Classification systems compared with this method using the herbaceous plant percent cover data from 20 historical marshes were our proposed hydrologic zonation of the LCRE predicted by the forcing factors analysis, as well as five other previous classification systems: ecoregions, Kunze (1994), Simenstad et al. (2005), and two previously published estimates (Jay et al. 1990 and Kukulka and Jay 2003a).

\section{B.4 Results}

Tidal-fluvial water levels are nonlinear, non-stationary (with temporally variable statistical properties at any location), and influenced by a number of processes - astronomical tidal forcing, spatially variable channel width and depth, the presence (or absence) of peripheral intertidal areas, river flow (from multiple sources), atmospheric processes (included winds influence by local topography), and power peaking. For purposes of understanding how water-level properties relate to peripheral floodplain ecosystems (e.g., vegetation properties), we describe water-level variance in terms of simple, regression models based in the dynamics of tidal-fluvial systems. However, a broader view of water-level variations is also needed, one that more fully encompasses the complex time-space variability of the system. For this purpose, we examine the system in both the time and frequency domains. 


\section{B.4.1 Time-Space Variations of Water Levels}

The character of water-level variations changes dramatically landward of the estuary. The channel stations provide the simplest view. Shown in Figure B.3 are water levels for a 60-day period during the rather weak 2009 spring freshet (starting 1 June 2009), when Bonneville flows reached $\sim 10,500 \mathrm{~m}^{3} \mathrm{~s}^{-1}$ and Willamette River flows peaked at $750 \mathrm{~m}^{3} \mathrm{~s}^{-1}$. Channel stations are on the left side of the plot. Near the river mouth at Tongue Point ( $\mathrm{rkm} 29$ ), water-level variations are largely tidal and exhibit a strong degree of regularity. Subtidal variability is closely related to atmospheric forcing of continental shelf waters. Tidal properties are only slightly non-stationary, river-flow has a rather modest impact on water levels and tidal ranges, and conventional tidal analysis and prediction methods can be used to represent tidal processes (Jay and Flinchem 1999). Water-level variations at Beaver (rkm 87) are superficially similar to those at Tongue Point, although wavelet analyses (below) reveal significant differences. The most noticeable difference between the two stations seen in Figure B.3 is that tidal amplitudes are smaller at Beaver, a consequence of frictional energy loss and transfer of energy to overtides and subtidal frequencies. The spring freshet raises water levels at Beaver only slightly.

Tidal variability decreases landward of Beaver, tidal range varies inversely with river flow, and water levels appear to be much less periodic (Figure B.3). At Vancouver (rkm 171), tides are greatly suppressed during the first half of the record when flows are high. Tides become more evident after 1 July as MWL drops. At Bonneville (rkm 233), it is difficult to see the tidal variability because of the influence of varying river flow and power peaking. Separation of power peaking from tides by casual inspection is difficult, because, like the tides, power peaking exhibits a strong diurnal signal. However, power peaking also shows a weekly signal (power demand is usually lower on weekends) that is not present in the tides. In contrast, the tides show tidal monthly variability at $\sim 13$ - to 15 -day and $\sim 29$-day periods. Thus, MWL is systematically higher in the tidal river on springs than on neap tides. The relationship of water levels at Vancouver and Bonneville to those near the ocean (at Tongue Point) is obviously complex and influenced by non-tidal processes.

Times series of water levels at four floodplain stations are shown on the right in Figure B.3; the stations (Table B.1) are Chinook River Marsh (CHM, rkm 12), Clatskanie River Marsh (CRM, rkm 98), Goat Island Creek (GIC, rkm 131), and Hardy Creek Marsh (HCM, rkm 229). Note that the floodplain stations have been chosen to roughly correspond (in terms of along-channel position) to the channel stations. These records show the same along-channel progression as the channel stations, from control by tidal processes near the ocean to control by fluvial processes upriver. However, water-level variations at floodplain stations are different and more complex for several reasons. These include a strong nonlinearity caused by the distortion of the tides in shallow water, the effects of sills that truncate low waters at a base level at all stations except (HCM, rkm 229), and reduction of tidal range by friction in shallow water. The neap-spring percentage change in water depth is much higher in shallow water, and the truncation of LLW may decrease or disappear during neap tides. Thus, tidal monthly variability at floodplain stations may be stronger than, or quite different from that at nearby channel stations. 

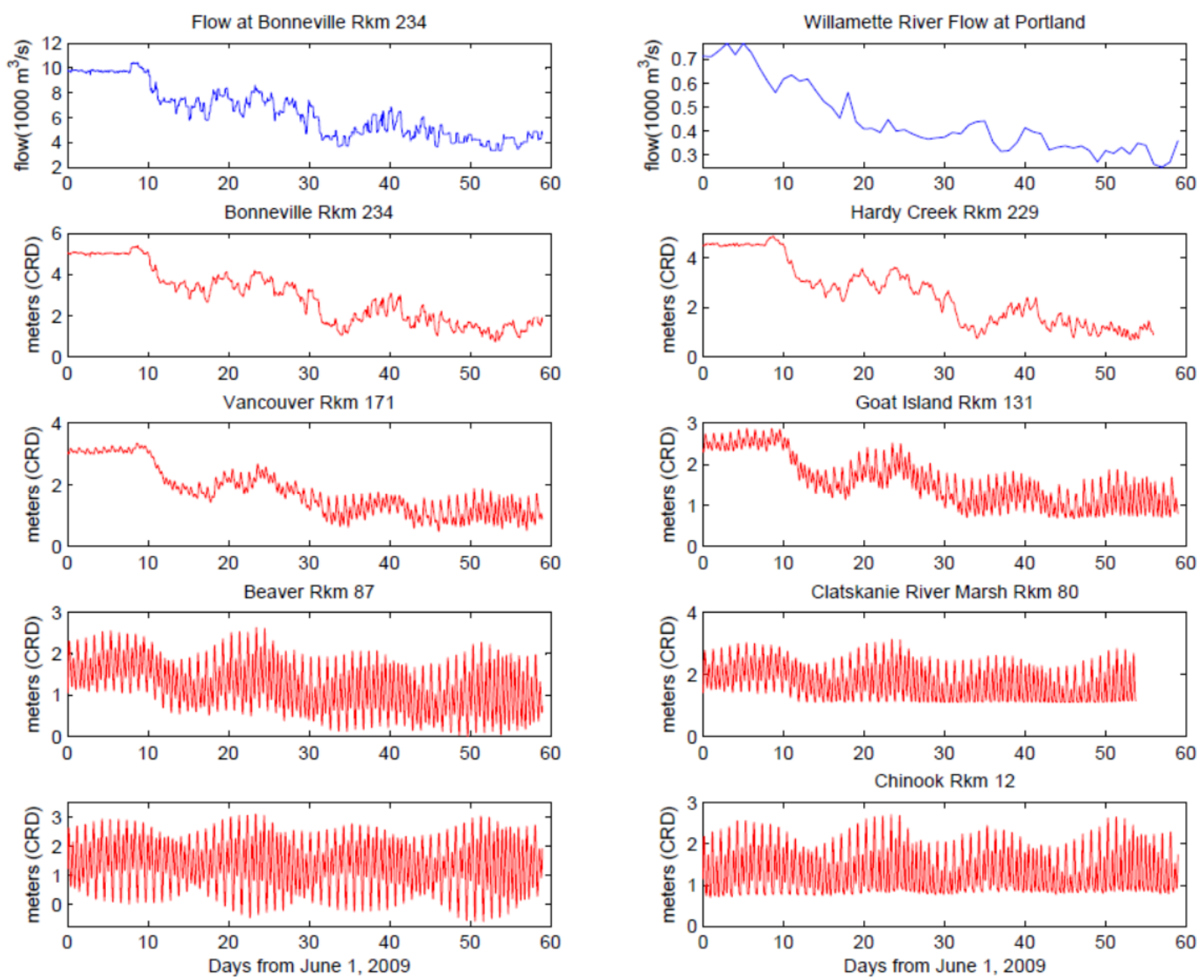

Figure B.3. River Inflow at Bonneville Dam (hourly) and From the Willamette River at Portland (daily) with Time Series of Hourly Tidal Heights for (at left) Five Channel Stations and (at right) Five Floodplain Stations

\section{B.4.2 The Frequency Structure of Water-Level Variations}

River tides and water levels are non-stationary. Conventional power spectra (which estimate the frequency content of a signal under the assumption that the signal is stationary) are limited in their ability to represent their frequency structure. A method is needed that represents the time-variability of waterlevel frequency content, and the continuous wavelet transform provides a convenient tool.

The wavelet amplitude scaleograms for selected channel stations (Figure B.4) show the time-varying frequency content at frequencies from D8 $\left(\mathrm{d}^{-1}\right)$ down to $1 \mathrm{yr}^{-1}$ over the $1990-2010$ period. The color scale represents amplitude in meters. The primary signal at Tongue Point (Astoria, rkm 29) consists of two horizontal bands, the diurnal (D1) and semidiurnal (D2) tides with amplitudes of up to 1.4 and $0.8 \mathrm{~m}$, respectively. Horizontal bands on a scaleogram are characteristic of relatively stationary, periodic processes, present at all times. Time variability in these bands is the result of neap spring variations and smaller annual and interannual variations - the D1 tides were, for example, at an 18.6 minimum in about 1996. Overtides (nonlinear tidal constituents caused by frictional interactions in shallow water) at frequencies higher than D2 are small near the ocean. There is also visible energy in the "storm band" 
with periods of 4-15 days (amplitudes up to $\sim 0.2 \mathrm{~m}$ ), but this is irregular. It is broad-band (not narrowly focused at one frequency), appears as vertical streaks in the scaleogram (indicating episodic rather than period occurrence), and is often strongest in winter. In addition to storms, river-flow events and neapspring variability may contribute in this frequency range. Lower frequency energy at $\sim 6$ and $12 \mathrm{mo}^{-1}$ is related to the annual cycle of coastal sea-level and river-flow variations.

The amplitude scaleogram at Beaver (rkm 87, Figure B.4), at the division between the lower estuary and tidal river, shows a mix of tidal and fluvial effects. D1 and D2 tidal energy is weaker (amplitudes smaller) than at Tongue Point, and composes a smaller part of the total signal. Overtides (frequencies $>$ D2) are larger than at Tongue Point, and there is considerable energy at $\sim 13-15 \mathrm{~d}^{-1}$, a neap-spring signal — due to nonlinear friction, water levels are systematically higher on spring tides. There are is also more vertical "event-like" energy associated with river-flow events. There is also considerable energy associated with seasonal river-flow variations. There is little energy evident at 7 days, characteristic of power peaking. Here, at all stations further landward, gaps in the data are evident in the form of vertical bands of zero amplitude. The amplitude scaleogram for Vancouver (rkm 171, Figure B.4), near the head of the tidal river, continues the trends evident at Beaver relative to Tongue Point. D1 and D2 tides are weaker, overtides are (relative to D1 and D2) stronger, neap-spring variability is larger, the seasonal riverflow signal is quite large, interannual variability associated with wet and dry years is more evident, and there is some energy in the weekly power-peaking band. The annual flow cycle is much larger than the tidal signal. The highest energy is associated with river-flow events like that in February 1996. These events are very broad-band, due to their abrupt nature - they resemble a square wave, which (in a formal Fourier decomposition) requires an infinite number of frequencies to describe.

The amplitude scaleogram for Bonneville (rkm 233, Figure B.4), shows the following: little D2 tidal energy, most of the energy in the D1 band power peaking, more energy in the $7-\mathrm{d}^{-1}$ power-peaking band than in the 13 - to $15-\mathrm{d}^{-1}$ neap-spring band, and some energy around $3.5 \mathrm{~d}^{-1}$ associated with the irregularity and abrupt nature of weekly power peaking. In some, but not all cases, strong weekly power peaking is associated with strong D1 power peaking. The energy in high-flow events, distinctly separated in time at time scales of $15-$ to $30-\mathrm{d}^{-1}$, merges together in the 6- and $12-\mathrm{mo}^{-1}$ bands, due to the multi-year length (up to $\sim 5$ year) length of these filters. For the same reason, the high-flow periods in 1996 to 1999 appear as a single, long period of high flow in the annual band.

Amplitude scaleograms are shown (Figure B.5) for the same four floodplain stations, CHM (rkm 12), CRM (rkm 98), GIC (rkm 131), and HCM (rkm 229), used in Figure B.3. Floodplain scaleograms are similar to those for the main stations, but show some differences. The most important is that the 1- to 2-year LOR for these stations limits the duration shown and lowest frequency resolved $\left(30 \mathrm{~d}^{-1}\right)$ in these scaleograms. The D1 and D2 tidal signals are diminished somewhat (relative to nearby channel stations). Overtides (frequencies $>$ D2) are more prominent at all floodplain stations (except HCM), because of the distortion of the tidal wave as it moves into shallow water; this is also evident in harmonic analyses (below). There is also more energy in the $15-$ to $30-\mathrm{d}^{-1}$ neap-spring band than at channel stations. Weekly power peaking is strong at HCM and evident at GIC. At HCM, a fall period of low Columbia River flow (about d 50 to d 100) and several periods thereafter are "quiet" with no tidal daily-weekly variability. During these periods, the system is relatively isolated from outside influences. 

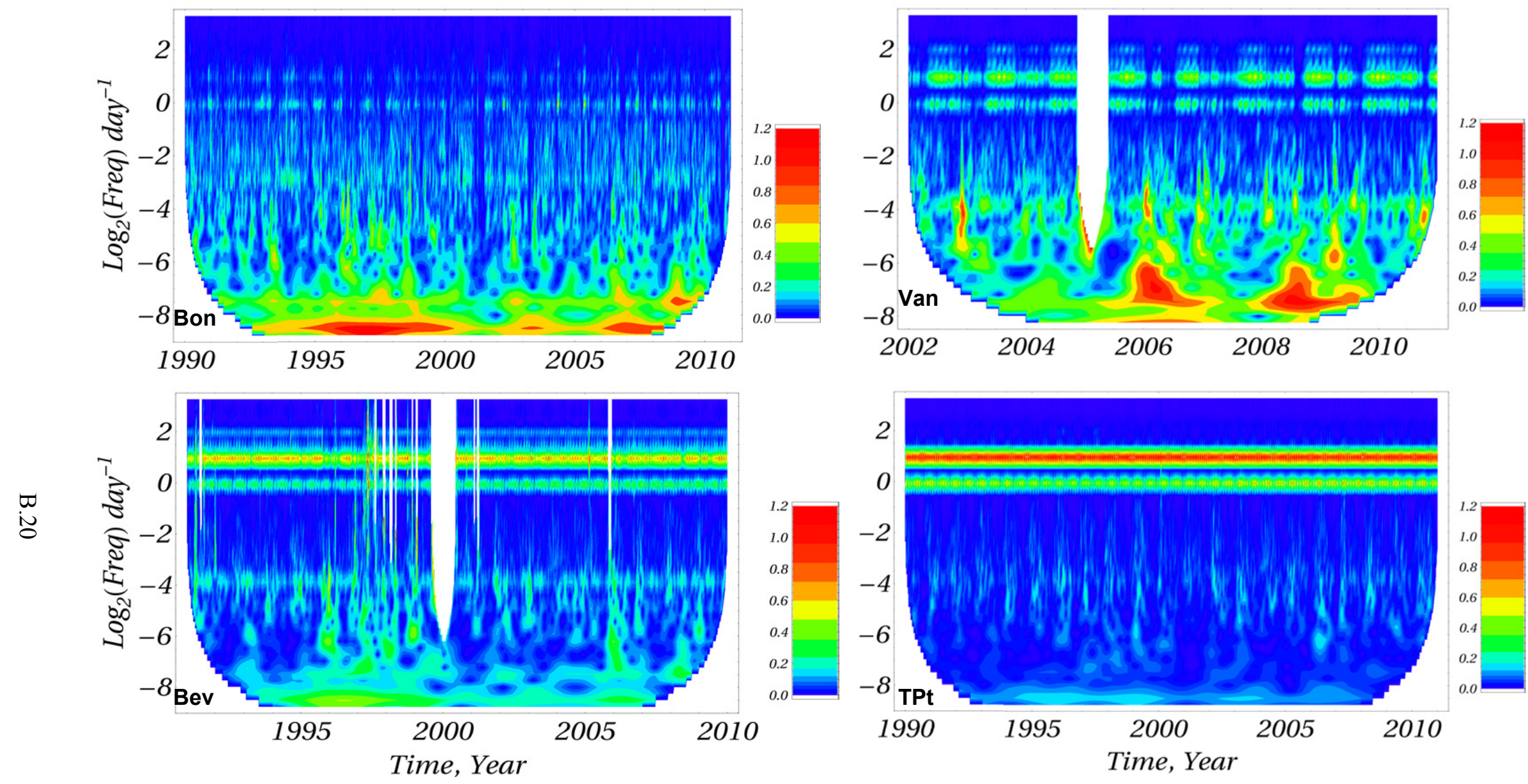

Figure B.4. Wavelet Amplitude Scaleograms for Channel Stations: Bonneville (Bon, rkm 233), Vancouver (Van, rkm 171), Beaver (Bev, rkm 87), and Tongue Point (TPt, rkm 29). Amplitudes in color bars are in meters. 


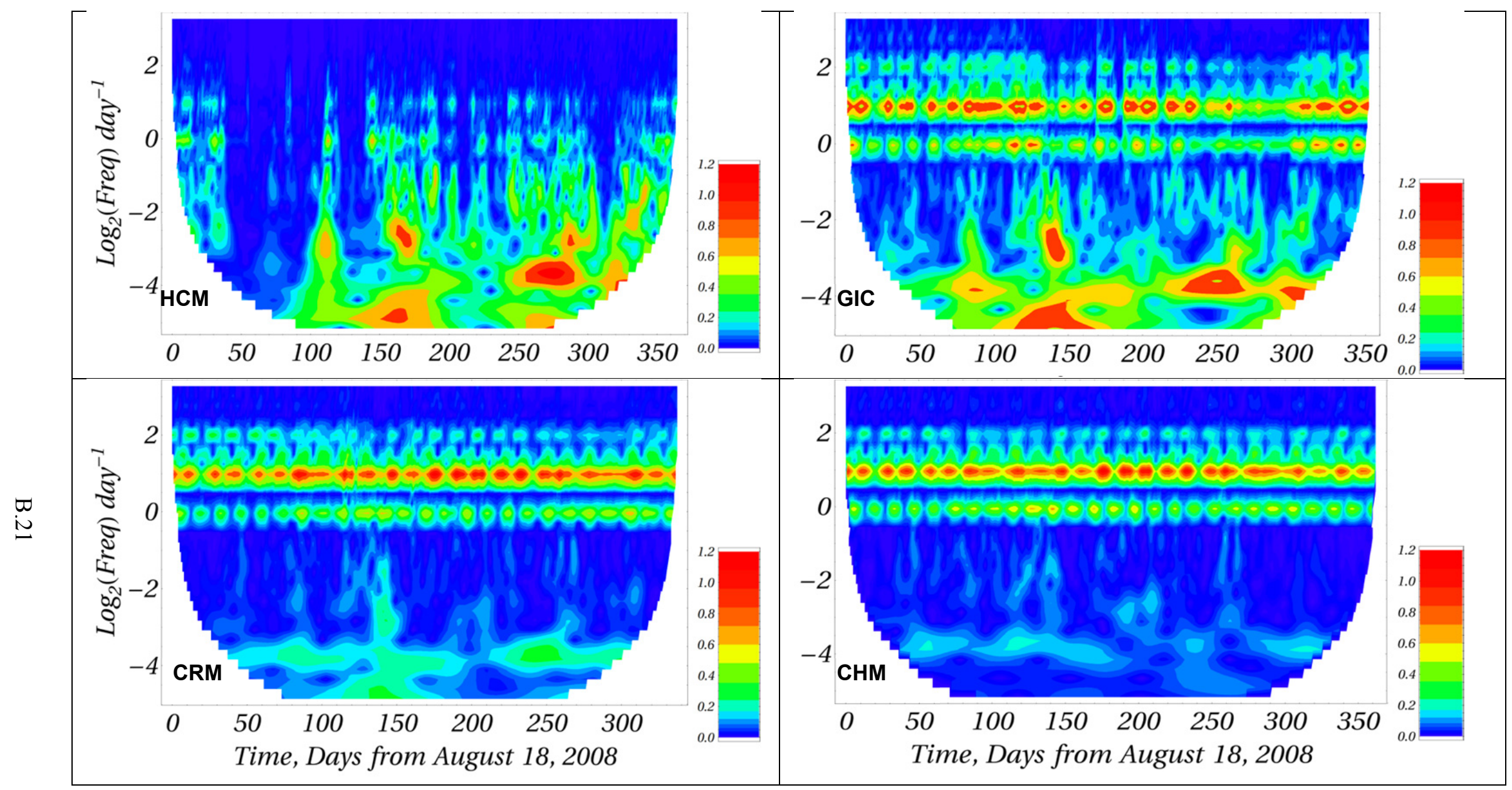

Figure B.5. Wavelet Amplitude Scaleograms for Hardy Creek March (HCM, rkm 229), Goat Island Creek (GIC, rkm 131), Clatskanie River Marsh (CRM, rkm 98), and Chinook River Marsh (CHM, rkm 12). Amplitudes in color bars are in meters. 


\section{B.4.3 Harmonic Analysis Results}

Tidal properties play a major role in inundation of the LCRE floodplain. Figure B.6 shows the amplitudes and phases of eight selected constituents as a function of rkm for both channel and floodplain stations. The lunar semidiurnal $\left(\mathrm{D}_{2}\right)$ constituent $\mathrm{M}_{2}$ is the largest, with an estuarine amplitude of $\sim 0.95$ to $0.98 \mathrm{~m} . \mathrm{S}_{2}$ and $\mathrm{N}_{2}$ are the second and third largest $\mathrm{D}_{2}$ constituents, with estuarine amplitudes of $\sim 0.25$ and $0.2 \mathrm{~m}$, respectively. $\mathrm{K}_{1}$ has an amplitude in the estuary of $\sim 0.45 \mathrm{~m}$ and is the largest diurnal constituent; other diurnals (e.g., $\mathrm{O}_{1}$ and $\mathrm{S}_{1}$ ) are smaller. While $\mathrm{O} 1$ is the second largest $\mathrm{D}_{1}$ constituent, $\mathrm{S}_{1}$ is small in the estuary and has anomalous properties, discussed below. The overtides $\mathrm{MK}_{3}$ and $\mathrm{M}_{4}$ are not astronomically forced, but derive from frictional nonlinearities. They are important indicators of the mechanisms of tidal dynamics. The floodplain stations generally follow the trends set by the channel stations, but with considerable irregularity related to local topography.

Tidal wave propagation in a convergent river estuary is a balance between convergence of crosssectional area (topographic funneling; Jay 1991), frictional damping, and nonlinear generation of overtides and residual (tidal monthly) variations. Topographic funneling concentrates tidal energy and tends to increase amplitudes, but the potential for funneling is limited in the LCRE, because channel cross sections (at low flow) are relatively constant above Beaver. Friction, which increases landward because of high river-flow velocities, decrease amplitudes. Nonlinear energy transfer to overtides and tidal monthly variations increases energy at these frequencies at the cost of the astronomical constituents. These considerations and the wavelet amplitude scaleograms in Figures B.4 and B.5 suggest that tidal energy should decrease in the landward direction. This is generally the case for the astronomically forced constituents shown in Figure B.6: the diurnal $\left(D_{1}\right)$ constituents $K_{1}$, and $O_{1}$, and the semidiurnal $\left(D_{2}\right)$ constituents $\mathrm{M}_{2}, \mathrm{~S}_{2}$, and $\mathrm{N}_{2}$. However, there is a local maximum in $\mathrm{M}_{2}$ at Tongue Point (rkm 27) due to wave reflection as the estuary narrows at that point. Moreover, there are small increases at Bonneville in $\mathrm{K}_{1}, \mathrm{O}_{1}$, and $\mathrm{S}_{2}$, and $\mathrm{S}_{1}$ (period $24 \mathrm{hr}$, which is insignificant in the estuary) increases in amplitude by $>12 \times$ relative between rkm 50 and Bonneville ( $\mathrm{rkm} 233$ ). $\mathrm{K}_{1}$, which is only half as large as $\mathrm{M}_{2}$ in the estuary, is much larger than $\mathrm{M}_{2}$ at Bonneville. These anomalous results betray the influence of power peaking. All constituents with periods of $\sim 1 \mathrm{~d}$ are excited, because power peaking is broad-band - it does not repeat exactly from day to day. $S_{2}$ increases at Bonneville because power peaking is not a smooth, sinusoidal wave - it is highly irregular, with sharp transitions. Thus, just as $\mathrm{M}_{4}$ is needed to represent the frictional steepening of the $\mathrm{M}_{2}$ wave, the irregular nature of power peaking causes $\mathrm{S}_{2}$ to appear in harmonic analysis results as an "overtide" of $S_{1}$. The overtides $\mathrm{MK}_{3}$ (caused by the interactions of $\mathrm{M}_{2}$ with $\mathrm{K}_{1}$ ) and $\mathrm{M}_{4}$ (from the quadratic interaction of $\mathrm{M}_{2}$ with itself) are very small in the estuary, but increase landward to a maximum at Beaver, at rkm 87. They decay further landward, because the $\mathrm{M}_{2}$ with $\mathrm{K}_{1}$ constituents needed for their generation decrease sharply landward of Beaver.

The timing of the tide is represented by the phases shown in Figure B.6. Phases for most constituents increase in the landward direction; i.e., high water (the crest of the tidal wave) arrives later at upriver points because the astronomical tide propagates landward from the ocean. Phase can be converted to propagation time using the wave period for each constituent. Thus, for $\mathrm{M}_{2}$ with a period of $12.42 \mathrm{hr}$, the phase change per hour is $360^{\circ}$ divided by $12.42 \mathrm{hr}$ or $28.99^{\circ} \mathrm{hr}^{-1}$. For $\mathrm{K}_{1}$, with a period of $23.93 \mathrm{hr}$, the phase change per hour is $15.04^{\circ} \mathrm{hr}^{-1}$. The average $\mathrm{M}_{2}$ phase change between Hammond (rkm 15) and Vancouver ( $\mathrm{rkm} \mathrm{171)}$ is $\sim 175^{\circ}$ or $\sim 6 \mathrm{hr}$. The corresponding phase difference and time for $\mathrm{K}_{1}$ are $149^{\circ}$ or $\sim 9.9 \mathrm{hr}$. The actual high-water propagation time, influenced also by overtides, varies with flow from $\sim 8$ to $12 \mathrm{hr}$, with slower propagation during high-flow periods. The average propagation times to 
Bonneville for $\mathrm{M}_{2}$ and $\mathrm{K}_{1}$ are 9.4 and $20.1 \mathrm{hr}$, respectively, but longer during high-flow periods. Thus, depending on flow, the length of the system from the ocean to Bonneville Dam is $\sim 0.5$ to 1 tidal wavelength.
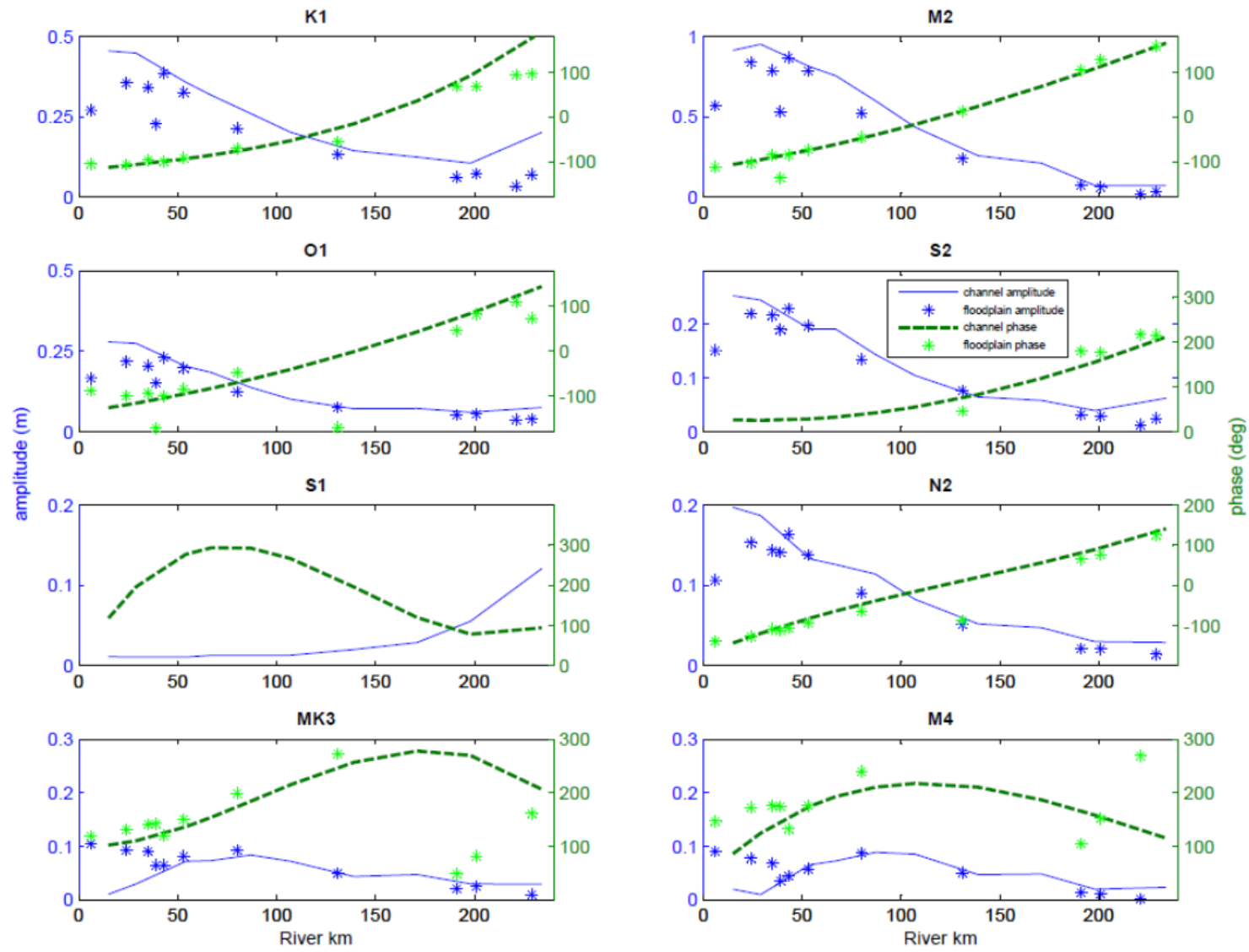

Figure B.6. Harmonic Analysis Results: Amplitude (blue) Phases (green) as a Function of rkm for Channel (fitted curve) and Floodplain Stations (symbols). $\mathrm{D}_{1}$ constituents $\mathrm{K}_{1}, \mathrm{O}_{1}$, and $\mathrm{S}_{1}$ and overtide $\mathrm{MK}_{3}$ are shown at left, with the $\mathrm{D}_{2}$ constituents $\mathrm{M}_{2}, \mathrm{~S}_{2}$, and $\mathrm{N}_{2}$ and overtide $\mathrm{M}_{4}$ at right. These results are based on a -yr analysis window. The curves are fit to the channel stations, while the more irregular floodplain stations are show by symbols. $\mathrm{S}_{1}$ cannot be accurately fit at the floodplain stations for statistical reasons.

Interestingly, the $S_{1}$ phase does not increase uniformly upriver because $S_{1}$ is caused by power peaking, which travels seaward from Bonneville Dam. Power peaking does not repeat from day-to-daythe timing and amount of water released is quite variable. Thus, the phase of S1 represents an average. Also, the amplitude of $\mathrm{S}_{1}$ would be considerably larger than it is ( $\sim 0.12 \mathrm{~m}$ at Bonneville) were its phase consistent. The phases of $\mathrm{M}_{4}$ and $\mathrm{MK}_{3}$ initially increase and then decrease again. The initial increase is related to the fact that they are generated by $\mathrm{M}_{2}$ and $\mathrm{K}_{1}$, whose phases increase upriver. The later decrease in phase for both overtides results from the changing shape of the tidal wave. The phase of $\mathrm{MK}_{3}$ at Bonneville is influenced by power peaking, because power peaking influences $\mathrm{K}_{1}$.

Figures B.7-B.10 resolve time variations in tidal properties using the results of short (761-hour) overlapping (7-day interval) harmonic analyses for paired channel and floodplain stations. In Figure B.7, $\mathrm{K}_{1}$ and $\mathrm{M}_{2}$ are considerably larger at Tongue Point than at CHM. This is caused by the clipping of low 
waters at CHM (Figure B.3) - low waters are higher at CHM than at nearby channel locations. Even high waters are somewhat lower at CHM, because tidal exchange is limited. Phase differences between the two locations are $<1$ hour. However, $\mathrm{M}_{2}$ is earlier at $\mathrm{CHM}$, likely because $\mathrm{CHM}$ is closer to the ocean, while $\mathrm{K}_{1}$ is later, likely due to clipping. The phase of $\mathrm{M}_{2}$ is quite consistent at Tongue Point, but the $\mathrm{M}_{2}$ tide arrives at CHM somewhat earlier in winter, likely due to deeper water from local inflow. The strong phase variability of $\mathrm{K}_{1}$ is due to the influence of a nearby constituent $\left(\mathrm{P}_{1}\right)$ that cannot be resolved with a 761-hr analysis. The $\mathrm{S}_{2} / \mathrm{M}_{2}$ amplitude ratio is an indicator of friction. Because $\mathrm{M}_{2}$ is the largest constituent, it damps all other constituents through nonlinear friction, an effect that should be enhanced at high flows. While this expectation is generally fulfilled, there is so much variability in the $\mathrm{S}_{2} / \mathrm{M}_{2}$ ratio here that it is difficult to see any differences between the two stations. The $\mathrm{M}_{4} / \mathrm{M}_{2}{ }^{2}$ amplitude ratio is an indicator of wave distortion and the frictional interaction of $\mathrm{M}_{2}$ with itself, which drives wave steepening. The $\mathrm{M}_{4} / \mathrm{M}_{2}{ }^{2}$ ratio increases with flow at Tongue Point, as expected in an open channel, but decreases with flow at CHM. This latter effect may be due to a slight reduction in clipping of the tide at higher flows.
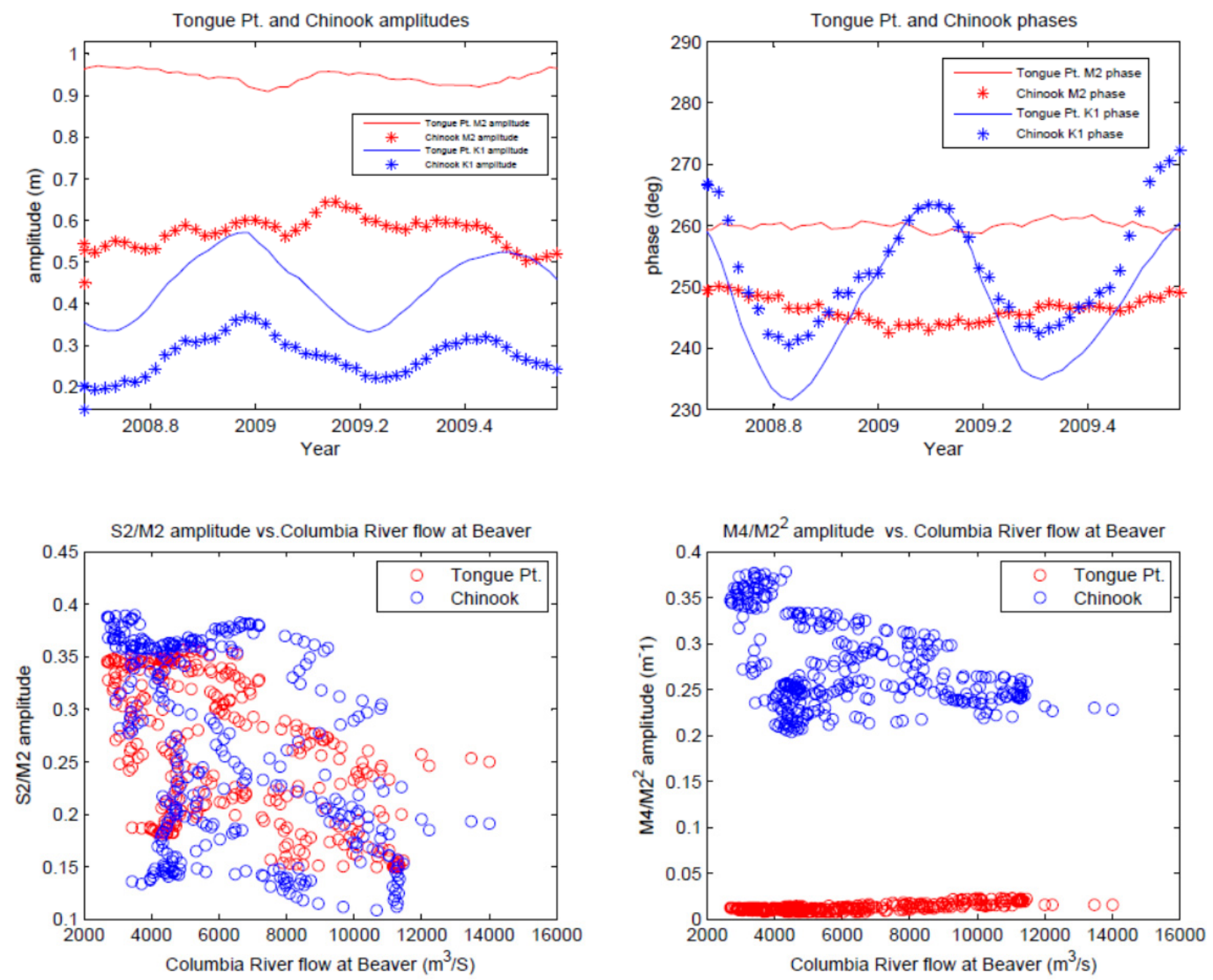

Figure B.7. Harmonic Analysis Results for Floodplain and Nearby Channel Stations: Tongue Point (rkm 29) and Chinook River Marsh (CHM, rkm 12). Shown are time series of $\mathrm{M}_{2}$ and $\mathrm{K}_{1}$ amplitudes (top left) as a function of time, time series of $\mathrm{M}_{2}$ and $\mathrm{K}_{1}$ phases (top right), $\mathrm{S}_{2} / \mathrm{M}_{2}$ amplitude ratio vs. river flow (bottom left), and $\mathrm{M}_{4} / \mathrm{M}_{2}{ }^{2}$ amplitude ratio vs. river (bottom right). These results are based on overlapping 761 harmonic analyses, 7-day intervals. 

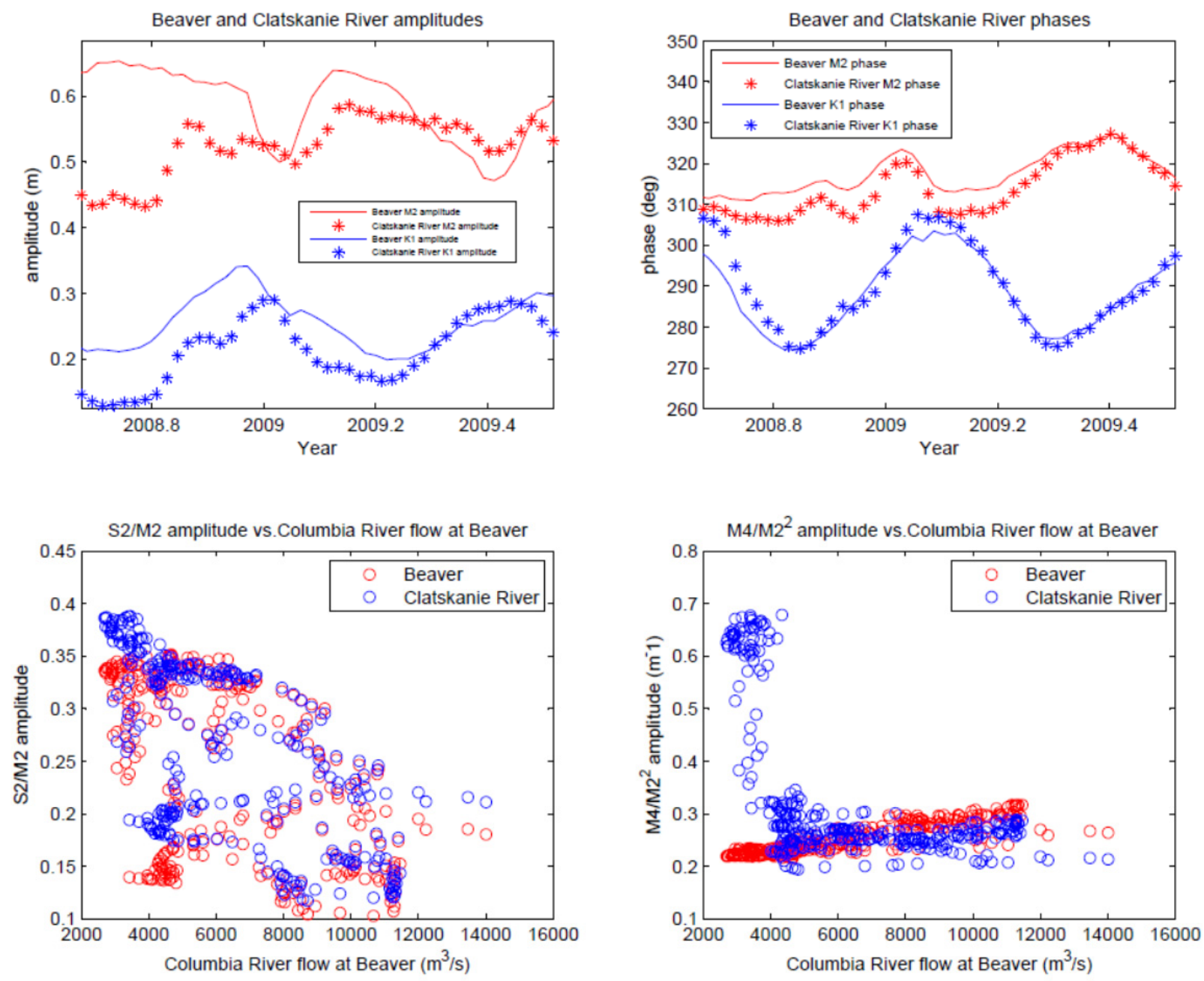

Figure B.8. Harmonic Analysis Results for Floodplain and Nearby Channel Stations: Beaver (rkm 87) and Clatskanie River Marsh (CRM, rkm 98). See Figure B.7 for details.

$\mathrm{K}_{1}$ and $\mathrm{M}_{2}$ properties at Beaver and CRM are quite similar (Figure B.8), but periods of high river flow reduce $M_{2}$ amplitudes and increase $M_{2}$ phases. $K_{1}$ is apparently less affected by river flow, but this may only appear to be true because frictional damping of $\mathrm{K}_{1}$ is compensated by nonlinear generation of $\mathrm{K}_{1}$ during high flows. The decrease in the $\mathrm{S}_{2} / \mathrm{M}_{2}$ amplitude ratio with increasing flow is clearer here than in Figure B.7, but again, there is little difference between Beaver and CRM. The $\mathrm{M}_{4} / \mathrm{M}_{2}{ }^{2}$ amplitude ratio increases with flow at Beaver, but exhibits a threshold behavior at CRM. Referring to Figure B.3, it is evident that low waters are clipped at CRM during low-flow periods, but not during high-flow periods, thereby explaining this bimodal behavior. 

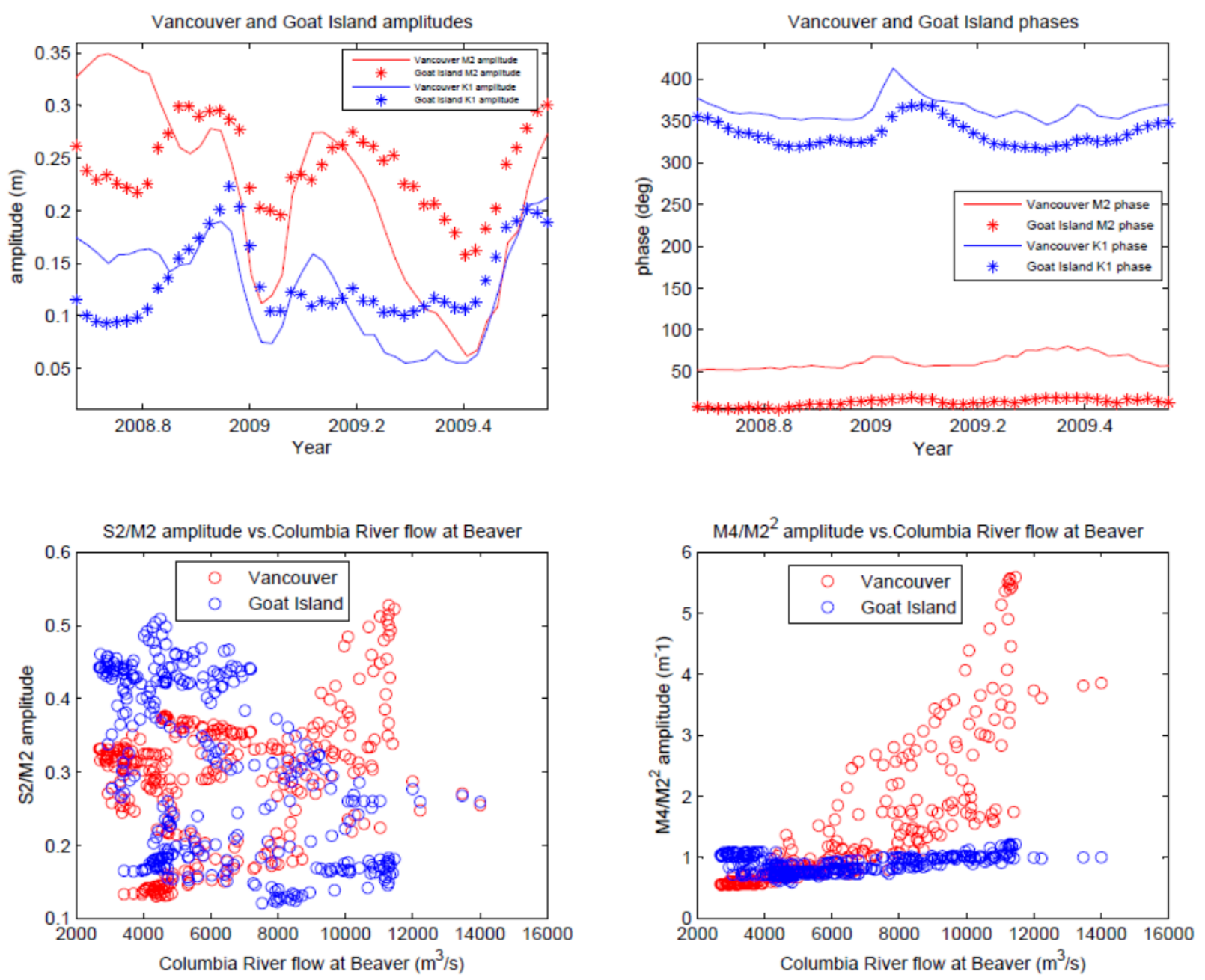

Figure B.9. Harmonic Analysis Results for Floodplain and Nearby Channel Stations: Vancouver (rkm 171) and Goat Island Creek (GIC, rkm 131). See Figure B.7 for details.

$\mathrm{K}_{1}$ and $\mathrm{M}_{2}$ properties at Vancouver (rkm 171) and GIC (rkm 131) are somewhat different (Figure B.9), but most of the differences are related to the fact that Vancouver is $40 \mathrm{~km}$ landward of GIC. GIC $\mathrm{K}_{1}$ and $\mathrm{M}_{2}$ are sometimes larger than at Vancouver, and Vancouver $\mathrm{M}_{2}$ amplitudes are more influenced by flow than is the case for GIC. Phases are large at Vancouver, reflecting a longer propagation time of the tide. For reasons that are unclear, the $\mathrm{S}_{2} / \mathrm{M}_{2}$ amplitude ratio increases at Vancouver with flow, even though it decreases at GIC. There is very strong generation of $\mathrm{M}_{4}$ at Vancouver, considerably stronger than at GIC. 

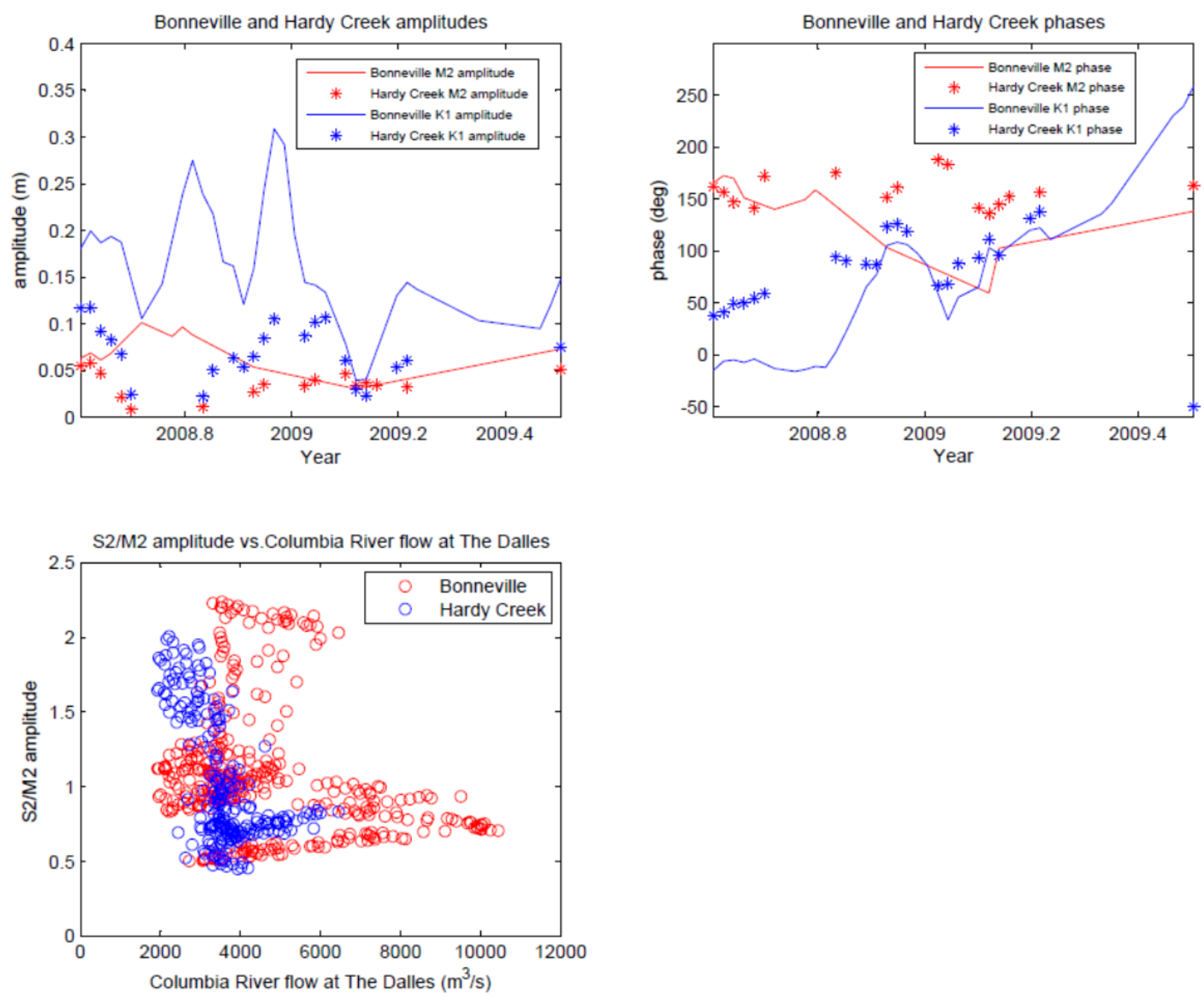

Figure B.10. Harmonic Analysis Results for Floodplain and Nearby Channel Stations: Bonneville (rkm 233) and Hardy Creek Marsh (HCM, rkm 229). See Figure B.7 for details; $\mathrm{M}_{4}$ could not be consistently resolved in 761-h analyses at this station.

$\mathrm{K}_{1}$ and $\mathrm{M}_{2}$ properties at Bonneville ( $\mathrm{rkm} 233$ ) and $\mathrm{HCM}$ ( $\left.\mathrm{rkm} 229\right)$ are very irregular (Figure B.9), and strongly influenced by river flow and power peaking. $\mathrm{K}_{1}$ here is mostly power peaking, not tide. It is not even possible to define $\mathrm{M}_{4}$ on a consistent basis at this station. The clearest signals are that $\mathrm{M}_{2}$ is strongly reduced by high flows, and that $\mathrm{S}_{2} / \mathrm{M}_{2}$ decreases with increasing flow. In fact, $\left|\mathrm{S}_{2}\right|>\left|\mathrm{M}_{2}\right|$ for low flows. This is again an indication of power peaking, which generates $\mathrm{S}_{2}$ as a nonlinear "overtide" of $\mathrm{S}_{1}$.

\section{B.4.4 Along-Channel Variations: Regression Model Results}

\section{B.4.4.1 River and Tidal Range Effects on Water Levels}

Regression model results provide an overview of the system-wide water-level response to important processes, including fluctuations in river flow, tidal range, atmospheric pressure, and power peaking. The system response to fluctuations in river flow and tidal range are shown in Figure B.11, which is based on 13 channel stations. Figure B.11 shows the effects of a change in Hammond GDTR and river flow on 
HHW, LLW, and LLW for six combinations of Bonneville flows (QB $=2,500,6,000,9,500$, and $\left.13,000 \mathrm{~m}^{3} \mathrm{~s}^{-1}\right)$ and Willamette River at Portland flows $\left(\mathrm{QW}=500,2,000\right.$, and 5,000 $\left.\mathrm{m}^{3} \mathrm{~s}^{-1}\right)$. The maximum Bonneville flow level modeled here $\left(13,000 \mathrm{~m}^{3} \mathrm{~s}^{-1}\right)$ is less than half $\left(\sim 30,000 \mathrm{~m}^{3} \mathrm{~s}^{-1}\right)$ of the historic maximum flow, but spring flow reduction due to the reservoir system irrigation diversion greatly limited 1990-2010 flows on which the model is based. Although small relative to the historic range of flows, the modeled range represents typical modern, managed flow conditions. Perhaps the most obvious point is the very high water levels attained for high-flow levels at upriver stations, up to 11-m NAVD88 at Bonneville. Water levels below Beaver at rkm 87 are, however, very little affected by high flows. The effects of flow variations on tidal range (GDTR $=$ HHW-LLW) are also subtle below Beaver. At more landward points, high flows greatly reduce GDTR (for any given ocean tidal forcing) and also suppress neap-spring variability. Even though the impacts on water levels are limited in the lower estuary, Giese and Jay (1989) found that high flows have a strong effect on vertically averaged currents there-river outflow is greatly increased and tidal currents much reduced, the latter due to reduced tidal prism upriver. Increases in Willamette River flow in the bottom two panels of Figure B.11 illustrate a backwater effect, especially at Vancouver and Reed Island (rkm 171 and 198, respectively); the backwater effect at Bonneville is minor. Downstream from St. Helens, the effects of Willamette River flow are indistinguishable from those of Columbia River flow. (The perturbation of LLW for some estuarine stations for high Willamette River flows is an artifact of the short record available for these stations, which does not include any significant Willamette River flow events.)

The GDTR fluctuations illustrated in Figure B.11 are $\pm 0.5 \mathrm{~m}$, half of the maximum deviation of about $\pm 1 \mathrm{~m}$ from mean of $\sim 2.6 \mathrm{~m}$ at Tongue Point, but very close to the standard deviation of the predicted Hammond GDTR $(0.49 \mathrm{~m})$. Because actual tidal monthly variation are related to the phase differences between the D1 and D2 waves as well as their individual amplitudes, Figure B.11 does not fully capture neap-spring effects. Nonetheless, regression model results can be used to understand neap-spring variability in the system in relation to river-flow variations. For low to average Bonneville flows $\left(2,500\right.$ and $\left.6,000 \mathrm{~m}^{3} \mathrm{~s}^{-1}\right)$, neap-spring variability increases upriver of Beaver ( $\left.\mathrm{rkm} \mathrm{87}\right)$ and reaches a maximum at Vancouver; this effect disappears for higher flows. The strongest neap-spring perturbations are of HHW and MWL, but LLW exhibits a very interesting effect, not shown by either MWL or HHW. For all flow conditions and values of Hammond GDTR, increasing tidal range decreases LLW below Beaver but increases it above Beaver. HHW and MWL increase with increasing tidal ranges at all stations for all flow levels, but the increase is strongest upriver from Beaver at low flows, because of the increased elevation of LLW. Beaver is, therefore, effectively the boundary between the lower estuary and the tidal-river zone. Another interesting point in Figure B.11 is that the effects of variations in Hammond forcing GDTR have almost no effect on the tidal range at Bonneville. The reason is simple - most of the nominal "range" at Bonneville (HHW-LLW) is due to power peaking, and very little of it is due to actual tides, especially during high-flow periods. 


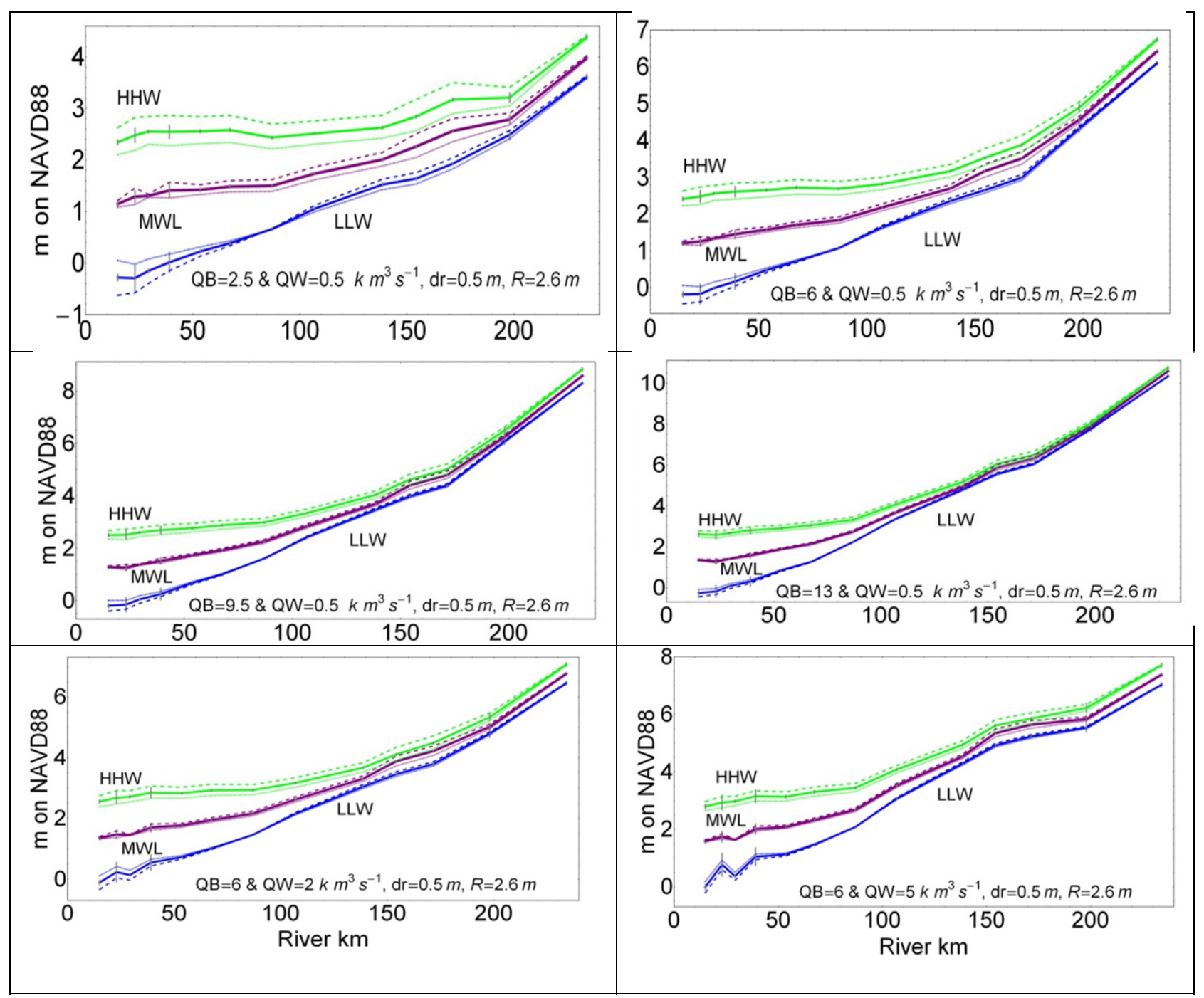

Figure B.11. Predicted Effects of Changes in Hammond GDTR and River Flow on HHW, MWW, and LLW for Six Selected Combinations of Columbia River at Bonneville Flow (QB $=2.5,6$, 9.5, or $13 \mathrm{k}$ [thousand] $\mathrm{m}^{3} \mathrm{~s}^{-1}$ ) and Willamette River at Portland Flow (QW $=0.5,2$, or $\left.5 \mathrm{k} \mathrm{m}^{3} \mathrm{~s}^{-1}\right)$. The solid lines indicate the system response for the base tidal condition $($ GDTR $=2.6 \mathrm{~m}$ at Hammond $)$, dotted/dashed lines indicate the effect of changing Hammond GDTR by $-0.5 /+0.5 \mathrm{~m}$, respectively. Note the variable vertical scales. Vertical gray bars indicate $95 \%$ confidence limits.

\section{B.4.4.2 Atmospheric Pressure Effects on Water Levels}

The system response to changes in atmospheric pressure can be seen in Figure B.12. All stations exhibit "an inverse barometer" effect; i.e., when atmospheric pressure increases, water levels decrease. The amplitude of this effect is, however, spatially variable. In the lower estuary up to Beaver, amplitudes for MWL are $\geq$ to the $\sim 0.01 \mathrm{~m} \mathrm{mb}^{-1}$ expected from hydrostatic pressure considerations (the inverse barometer effect), reaching $\sim 0.015 \mathrm{~m} \mathrm{mb}^{-1}$ at Hammond (rkm 15). An amplified response might be expected in the broad lower estuary at Hammond, if pressure changes were also associated with crossestuary slopes set up by wind (KJ2003). Because low pressures are associated with northward winds and high pressures with southward winds, this mechanism may apply. Interestingly, HHW and MWL are 
more strongly affected by pressure fluctuations than LLW, although the effect is significant at the $95 \%$ confidence limit only for lower-estuary stations. This phenomenon may also be related to winds; because of the presence of broad intertidal areas, the estuary is effectively much broader at HHW than at LLW. Above Beaver, the inverse barometer effect decreases and is not statistically significant above Vancouver (rkm 171). This result suggests that friction in the system is very strong, and the adjustment time is correspondingly large, so that an equilibrium response is not achieved within the relatively short time period of typical pressure fluctuations associated with fronts. It is also possible that the tidal-fluvial part of the system responds to winds in such a manner as to partially cancel the inverse barometer effect. That is, the gorge drainage winds associated with coastal low pressure (which should increase water levels) are associated with strong winds out of the east, which may decrease water levels by pushing water seaward. The separate effects of winds were not tested here.

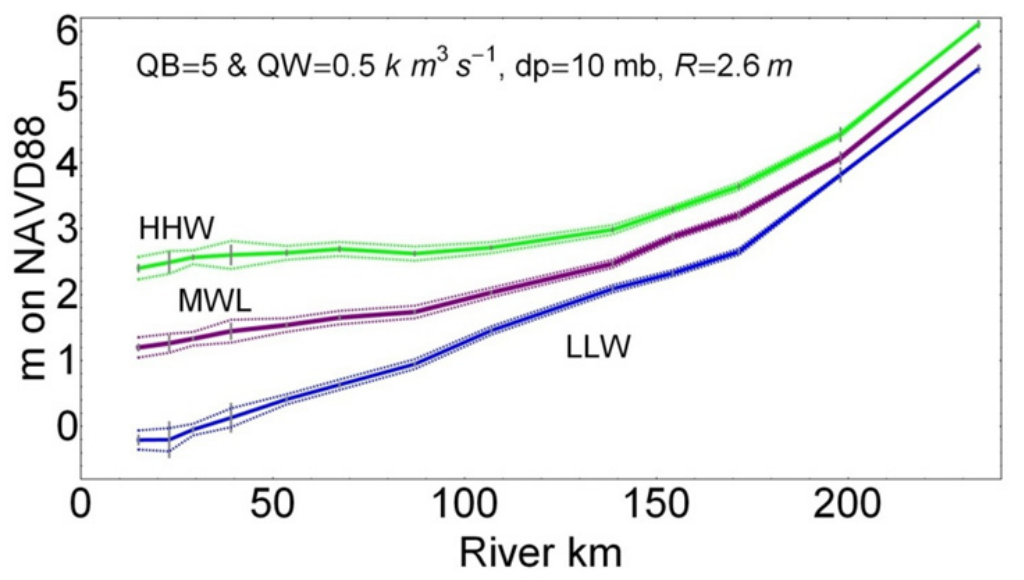

Figure B.12. The Effect of a Change $(\mathrm{dp}=10 \mathrm{mb})$ in Atmospheric Pressure on HHW, MWL, and LLW for a Columbia River at Bonneville Flow $\left(\mathrm{QB}=5 \mathrm{k} \mathrm{m}^{3} \mathrm{~s}^{-1}\right)$ and Willamette River at Portland Flow $\left(\mathrm{QW}=0.5 \mathrm{k} \mathrm{m}^{3} \mathrm{~s}^{-1}\right)$. Vertical gray bars indicate $95 \%$ confidence limits.

\section{B.4.4.3 Power-Peaking Effects on Water Levels}

Figure B.13 shows the predicted power-peaking impacts on HHW and LLW for four Bonneville flows $\left(\mathrm{QB}=2,500,6,000,9,500\right.$, and $\left.13,000 \mathrm{~m}^{3} \mathrm{~s}^{-1}\right)$ with Willamette River at Portland flows $(\mathrm{QW}=250$ or $\left.500 \mathrm{~m}^{3} \mathrm{~s}^{-1}\right)$. The power peaking in each case is assumed to be $\pm 600 \mathrm{~m}^{3} \mathrm{~s}^{-1}$, which is the median daily power-peaking amplitude. Above Vancouver, the power-peaking amplitude accounts for almost all of difference between MWL and HHW or LLW, which explains the difficulties in resolving the tide in this part of the river. Power-peaking effects are strongest above Vancouver (rkm 171), with LLW being affected more strongly than HHW in this part of the system. Power-peaking effects are damped at highflow levels, but are evident downstream to Beaver (rkm 87) for all flow levels. For the lowest flow levels, power-peaking impacts, especially on HHW, are evident (though small) to Hammond at rkm 15. 


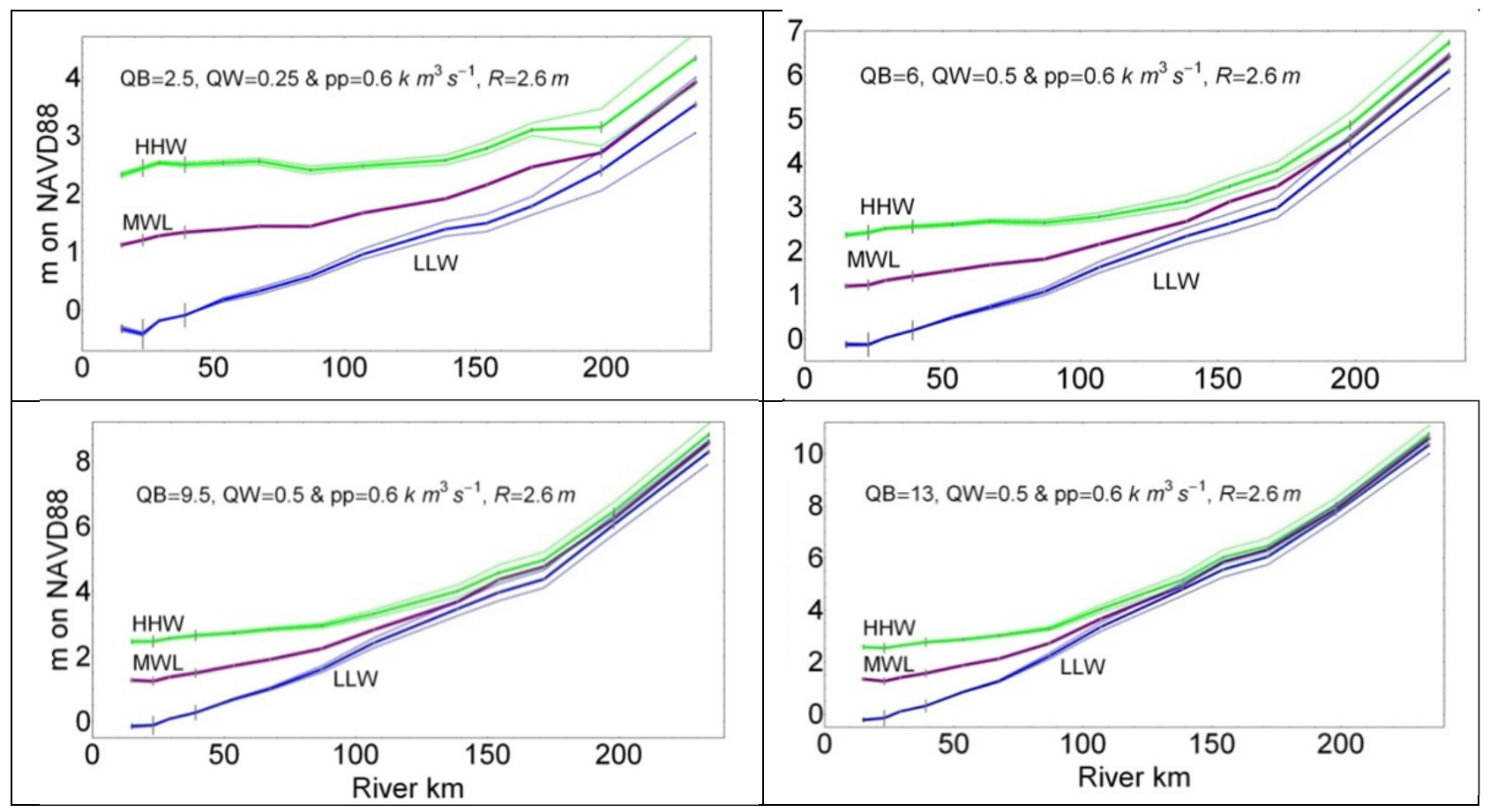

Figure B.13. Predicted Daily Power-Peaking Impacts on HHW and LLW (MWL assumed unaffected) for Four Bonneville Flows $\left(\mathrm{QB}=2.5,6,9.5\right.$, and $\left.13 \mathrm{k} \mathrm{m}^{3} \mathrm{~s}^{-1}\right)$ with Willamette River at Portland Flows $\left(\mathrm{QW}=0.25\right.$ or $\left.0.5 \mathrm{k} \mathrm{m}^{3} \mathrm{~s}^{-1}\right)$. The power peaking in each case is assumed to be $600 \mathrm{~m}^{3} \mathrm{~s}^{-1}$. Vertical gray bars indicate $95 \%$ confidence limits.

The relationship of this analysis to the actual dynamics of power peaking are important. Because of the nature of the model, the estimates in Figure B.13 assume that power peaking behaves in the same way as a steady increase or decrease in flow. In reality, both daily and weekly power peaking propagates as waves moving downstream from Bonneville Dam. The weekly power-peaking wave is nearly stationary relative to the tide, because the propagation time of tidal high water or low water is only $12-16 \mathrm{hr}$, small relative to its $\sim 7$-day period. Thus, during the period of the weekly wave, there will be a tide for which weekly power peaking increases HHW and another for which it decreases LLW along the river, as shown in Figure B.13. That is, the peak (or trough) of the weekly power-peaking wave will correspond to the peak (or trough) of the tidal wave at each point in the channel. The daily wave has, however, a period commensurate with that of the D1 tide. For present purposes, the variation in phase (or arrival time) of the daily power-peaking wave matters only in terms of its phase relative to the landward propagating tidal wave. The tide and power-peaking waves propagate in opposite directions, so the two will reinforce each other fully only at one point in the channel; at other points, the phase difference between the waves will cause them to interfere positively or negatively to a spatially variable degree. Over any extended period, the phase difference at any point in the channel between the two waves is essentially random. Thus, the above estimate of effects of the daily power peaking on HHW and LLW should be understood as an envelope defining maximal impacts, impacts reached at only one point in the channel on any given day.

\section{B.4.5 Separation of Variance}

Figure B.14 shows results for the partition of variance as a function of river kilometer. Shown in Figure B.14a- d are the total variance, tidal (sum of tidal daily, tidal monthly and overtide), tidal daily 
$\left(\mathrm{D}_{1}+\mathrm{D}_{2}\right)$, tidal monthly, seasonal-fluvial, power peaking, and weather-band variance. Variables are shown both in square meters and as a percentage of the total variance. Water-level variance in the lower estuary and energy minimum zones up to rkm 87 is largely controlled by tidal processes, especially $\mathrm{D}_{1}$ and $\mathrm{D}_{2}$. The maximum tidal variance occurs near at Tongue Point, caused by a maximum in $\mathrm{D}_{2}$ amplitude at $\sim \mathrm{rkm} 20$ to 29; this local maximum is a resonance phenomenon related to the combined topographic obstructions represented by Harrington and Tongue Points. Tidal monthly energy is maximal at Bonneville (in absolute terms), but accounts for the largest percentage of variance at St. Helens (rkm 139). Power-peaking and weather-band energy are summed, because everywhere that either plays a substantial role, it is likely that power peaking is contributing most of the energy. In the tidal river landward of Beaver at rkm 87, tidal energy variance decreases and is less than fluvial variance, which increases sharply in the landward direction. There is about four times as much total variance at Bonneville as at Tongue Point (Figure B.14c). In percentage terms (Figure B.14d), tides account for $\sim 70 \%$ of the variance in the lower estuary and seasonal-fluvial variations account for $\sim 70 \%$ of the variance from rkm 154 landward. The floodplain stations (not shown) generally follow the trend of the channel stations, but with considerable variability related to local topographic features.

The minimum water-level variance occurs at Beaver, at the landward end of what we will call below the "energy minimum zone." Water levels and water-level variance are likely the relevant factors for understanding floodplain vegetation, but water-level variance should not be confused with flow energy. Thus, Jay et al. (1990) found that the minimum in tidal+fluvial energy dissipation at the bed occurs in the broadest part of the estuary from rkm 15 to 40 . Tidal+fluvial energy dissipation (in watts $\mathrm{m}^{-2}$ ) at Beaver is approximately four times as large as that in the lower estuary, even though the water-level variance is lower at Beaver, but this does not account for the important role of wave energy in dissipation in the lower estuary. Water-level variance is low at Beaver, despite high dissipation, because most of the dissipation is due to fluvial currents, which vary slowly, relative to the tides.

Figures B.14c and d show the total variance from the CWT analysis and selected components: lowpass or interannual variance at periods $>433 \mathrm{~d}$, and all CWT bands (subtidal+tidal). Interannual variability at frequencies too low to be captured by the tidal or subtidal wavelet bands (longest period, $433 \mathrm{~d}$ ) increases upriver, in both absolute and percentage terms; it is negligible in the estuary, but accounts for 10 to $15 \%$ of variance above rkm 150. This is expected, given the dominance of seasonal fluvial energy in this reach. Also shown is the actual time-series variance, which is $\sim 55$ to $75 \%$ of the total variance output by the CWT analysis. That is, the CWT analysis outputs somewhat more energy than is present in the time series. As noted above, this is a consequence of overlapping bands in the wavelet analysis, especially at low frequencies where filters are shorter (broader in their frequency response) than in the tidal band. Use of these shorter filters is both an accommodation to the finite length of the time series - the 433-day wavelet band has a filter length of $\sim 4.75$ year or four wave periods - and a recognition of the broad-band nature of subtidal energy. In contrast, the tidal frequencies are more sharply focused on known frequencies, and longer filters ( 8 wave periods for $D_{1}$ and $D_{2}$ ) with less overlap can be used. The increase in subtidal (seasonal-fluvial) variance upriver, both as a percentage of total variance and in absolute terms, explains the increasing discrepancy between time-series variance and the variance output by the analysis. The "excess" variance does not interfere with qualitative interpretation of the variance analysis. 

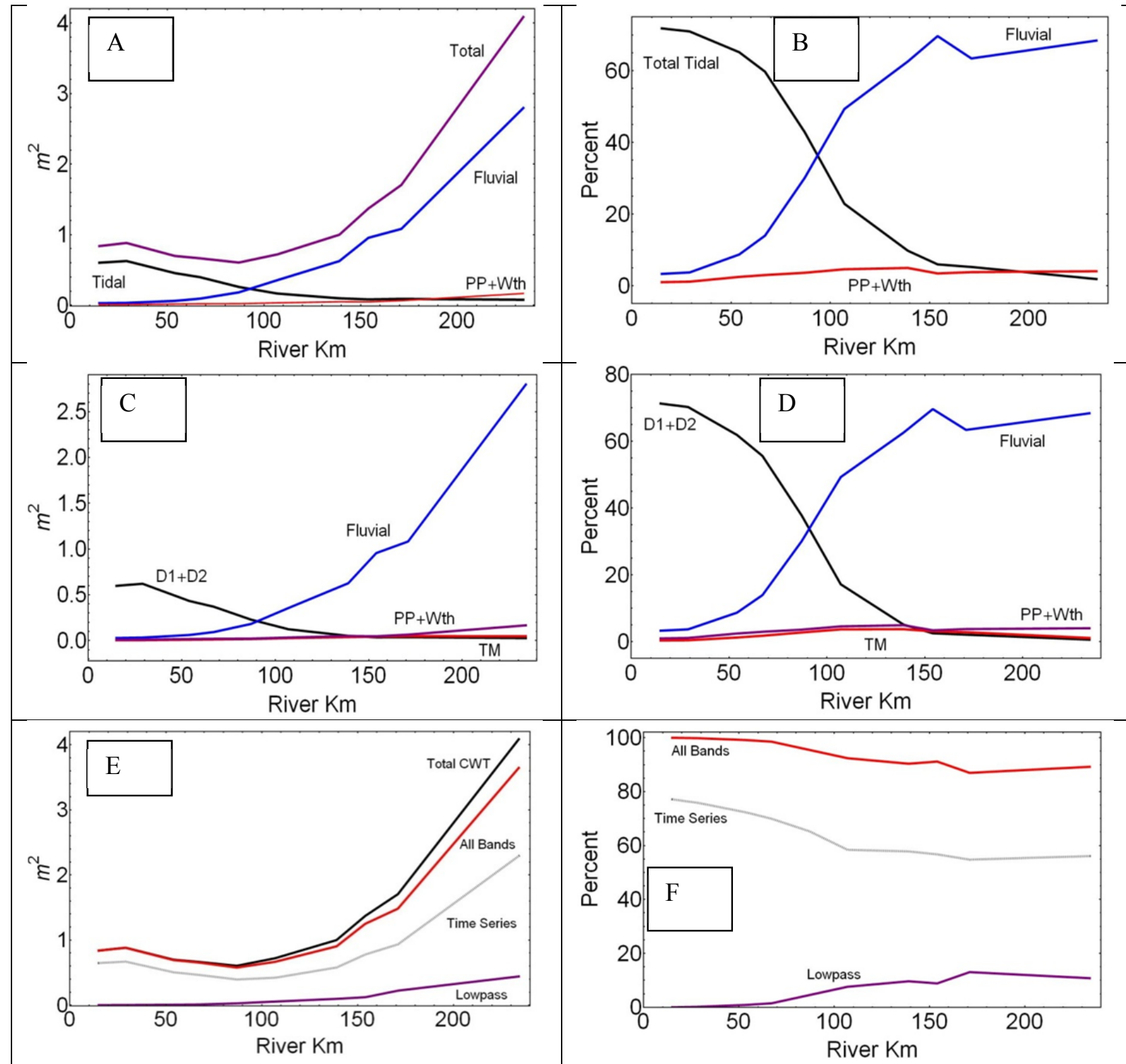

Figure B.14. Division of Variance for Channel Stations as a Function of Along-Channel Distance as Variance $\left(\mathrm{m}^{2}\right.$, left) and as Percent Variance (right). (A) and (B) show the contributions of tidal (as tidal daily + tidal monthly + overtide), fluvial, and power peaking + weather-band variance; (C) and (D) the tidal daily, tidal monthly, fluvial and power peaking + weatherband variance; and (E) and (F) the total variance in the wavelet analysis (total CWT), the lowpass variance in the wavelet analysis, the sum of the wavelet bands (all bands) in the wavelet analysis, and the total variance of the time series.

\section{B.4.6 Inundation}

Figure B.15 shows the results for the 1991-2010 inundation analysis for selected channel stations, Tongue Point (rkm 29, Figure B.15), Beaver (rkm 87, Figure B.16), Vancouver (rkm 171, Figure B.17), and Bonneville (rkm 233, Figure B.18). For each station, the vertical distribution of hindcast LLW, MWL, and HHW are each shown in three ways: as percent occurrence, as cumulative percent 
occurrence, and as cumulative percent exceedance (which is $100 \%$ cumulative percent occurrence). Elevations were aggregated in $0.01-\mathrm{m}$ bins, and the percent occurrence was smoothed over seven bins using a triangular filter. The absolute percent occurrence is dependent on the number of bins used. Given a fixed bin size of $0.01 \mathrm{~m}$, the number of bins is dependent on the range of the water-level variable, which depends on variable and station. The maximum percent occurrence also varies with the bin size, but the shape of the percent occurrence is unaffected by bin size. The cumulative curves are important for understanding vegetation distributions, but the percent occurrence provides more insight into physical mechanisms causing the distributions.

The distributions of LLW, MWL, and HHW at Tongue Point (Figure B.15) are compact, especially for MLW. This reflects domination of water-level variations by a relatively predictable tide of moderate range, perturbed seasonally by river flow and occasionally by storm surges. LLW shows a skew toward low values (tail to the left) and LLW and HHW show a skew toward high values. LLW shows considerably less elevation range than the other two parameters. While storm surges play some role in determining this skewness, it is mostly determined by the interaction of the D1 and D2 tides. On tides of large range, LLW follows HHW, and the following high water is much lower. Also, moderate values of LLW and HHW are common, and tides of small-to-moderate range have less diurnal inequality than very large tides. Thus, the tail of LLW occurs toward low elevations and that for HHW toward high elevations. The shapes of the cumulative percent occurrence and cumulative percent exceedance curves reflect integration of the percent occurrence. There is a gradual change in the upriver direction in the form of the elevation distributions, but the distributions for the other three stations (Beaver, Vancouver, and Bonneville, Figures B.16-18) all differ from Tongue Point (Figure B.15) in three respects: 1) elevation ranges increase; 2) the skew for all three parameters (LLW, MWL, and HHW) is toward high values (tail to the right); and 3) differences between LLW, MWL, and HHW decrease, being scarcely noticeable at Bonneville even in the percent occurrence curves. The skewness of the distributions is very clear in the integral presentations (cumulative percent exceedance and cumulative percent occurrence) most values are within 1 to $2 \mathrm{~m}$ of CRD, but there are occasional very high values. The reason for the sharp peaks of LLW, MWL, and HHW at Bonneville between 0.5 and $1.5 \mathrm{~m}$ is unknown. 


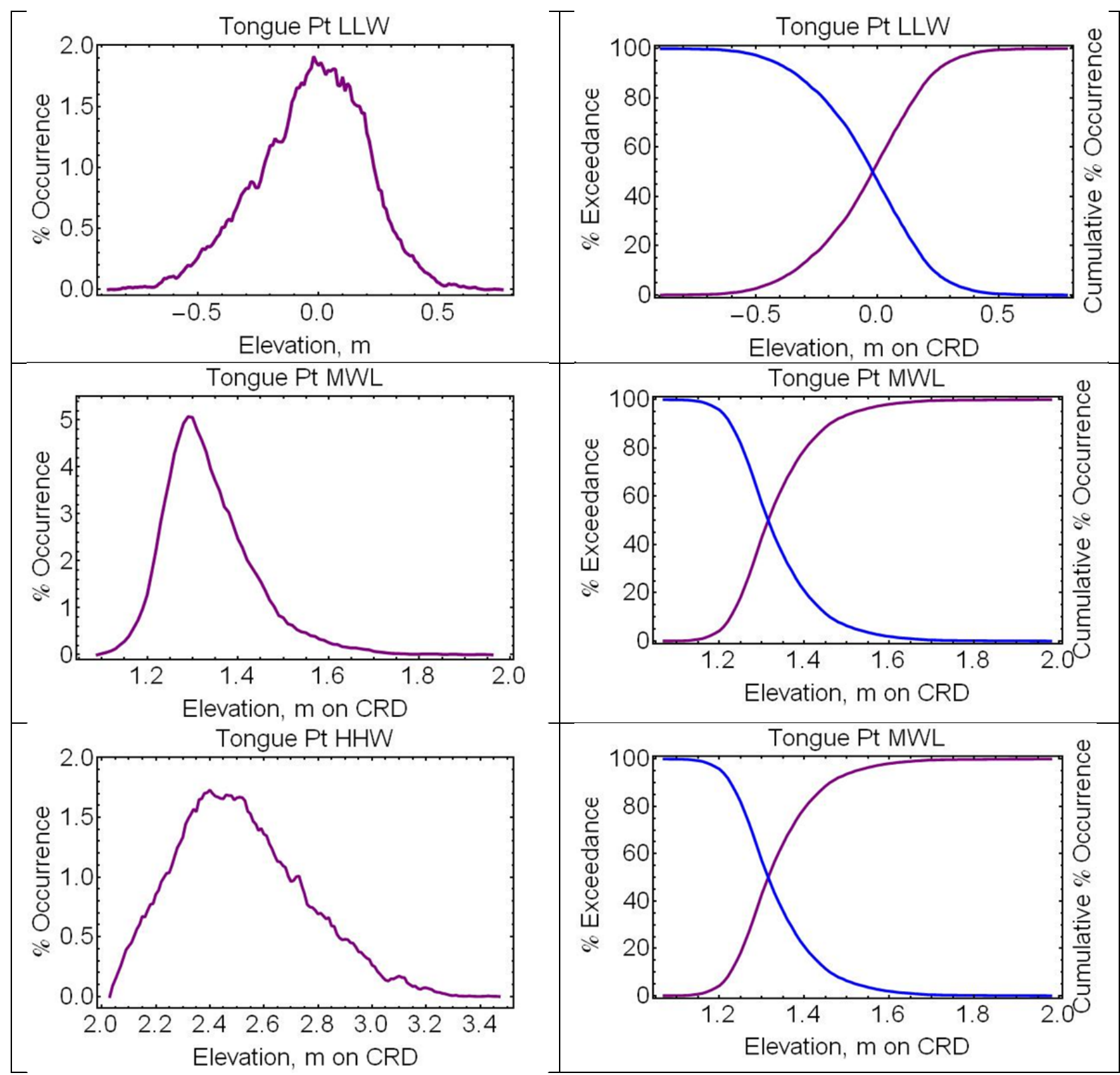

Figure B.15. Hindcast Percent Occurrence, Cumulative Percent Exceedance, and Cumulative Percent Occurrence for Tongue Point, 1991-2010 


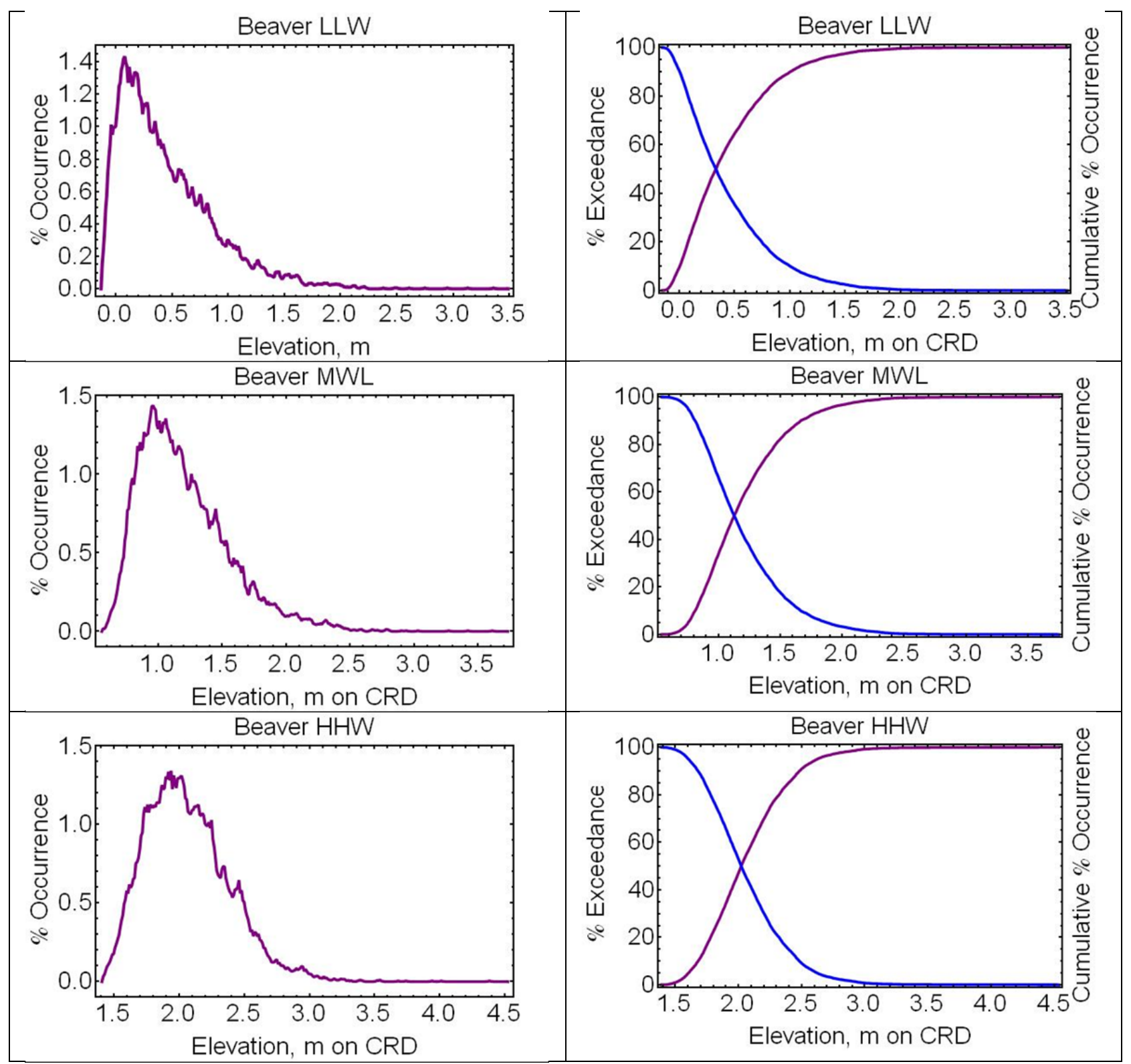

Figure B.16. Hindcast Percent Occurrence, Cumulative Percent Exceedance, and Cumulative Percent Occurrence for Beaver, 1991-2010 

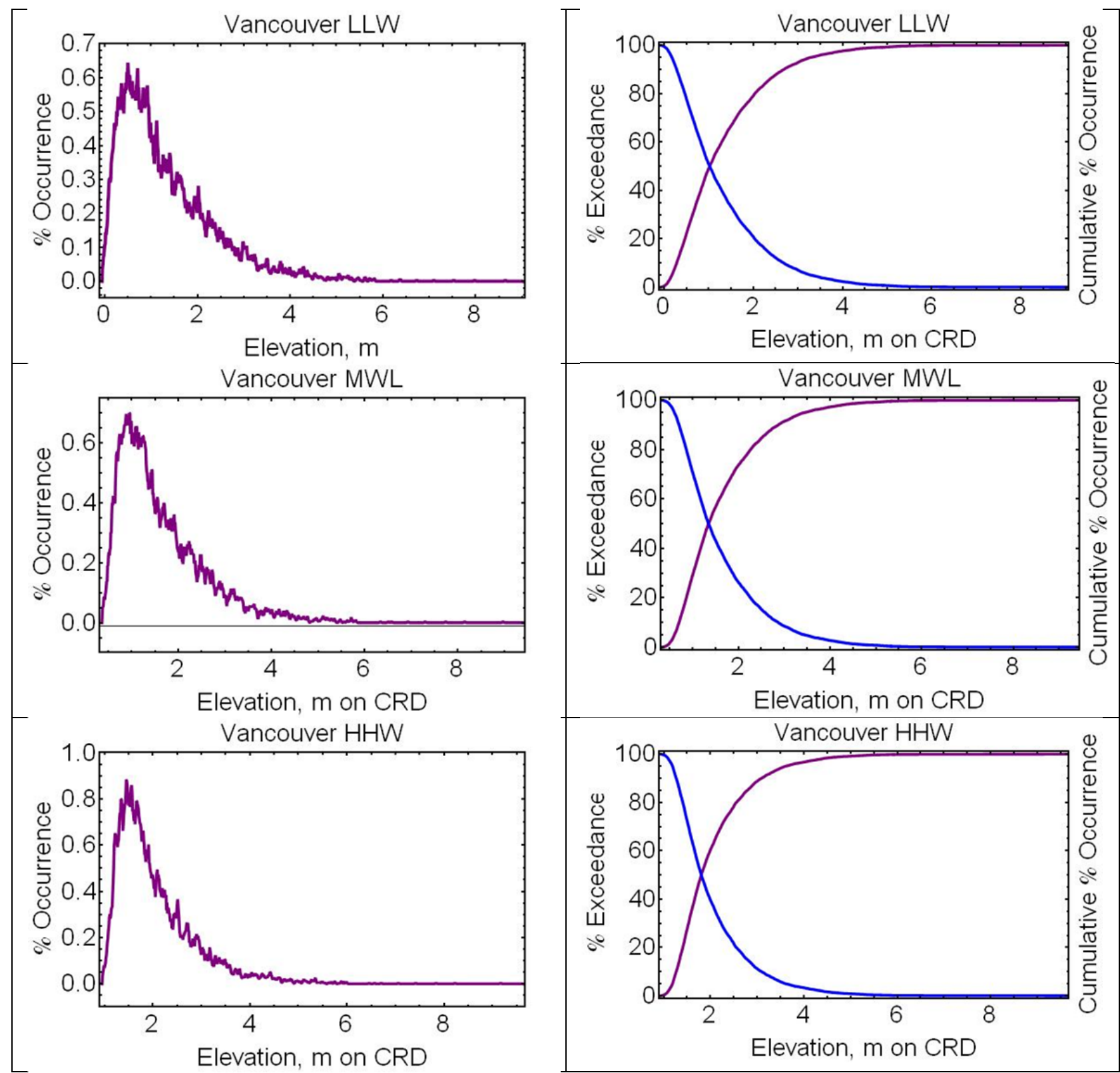

Figure B.17. Hindcast Percent Occurrence, Cumulative Percent Exceedance, and Cumulative Percent Occurrence for Vancouver, 1991-2010 

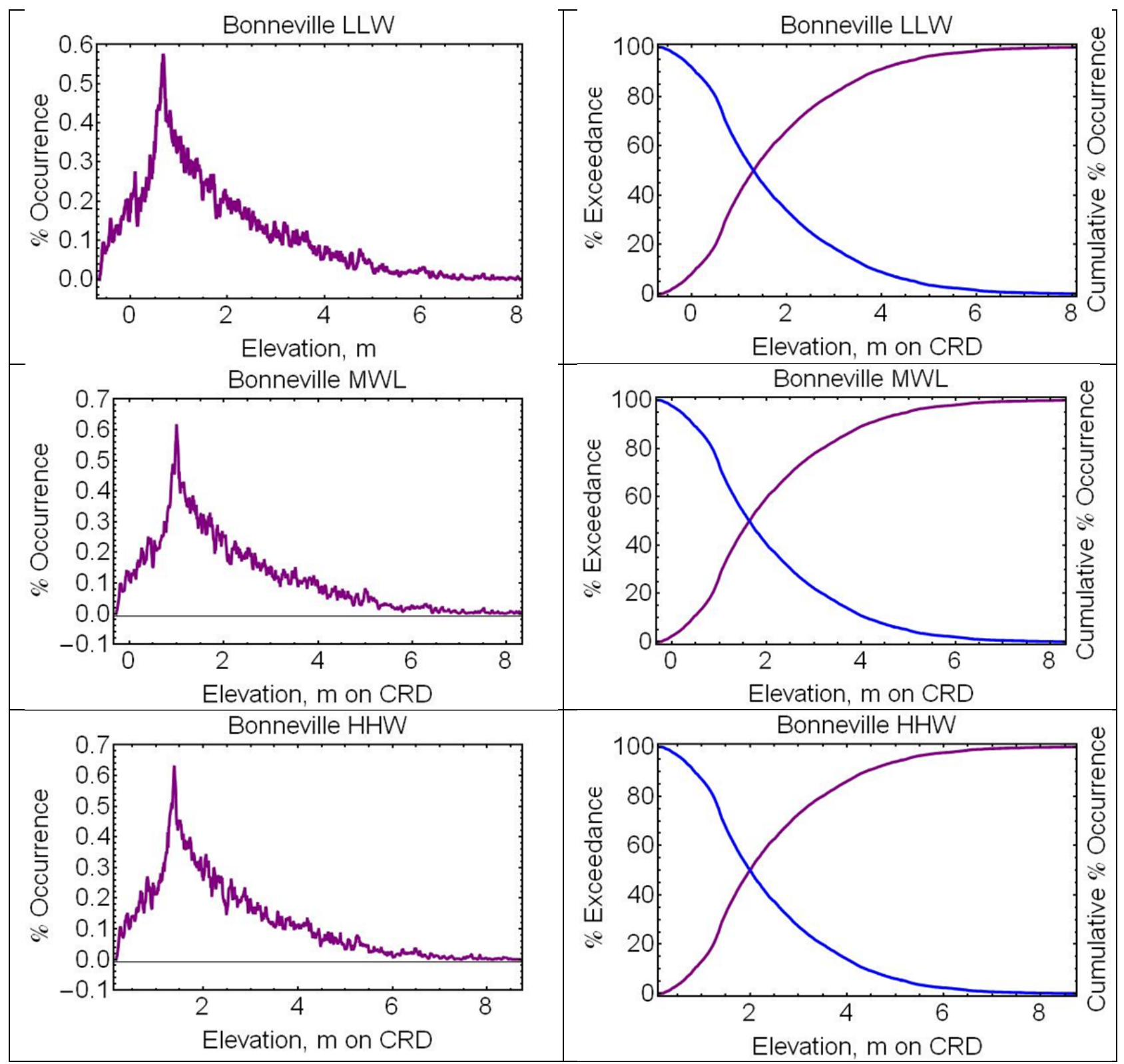

Figure B.18. Hindcast Percent Occurrence, Cumulative Percent Exceedance, and Cumulative Percent Occurrence for Bonneville, 1991-2010

\section{B.4.7 Sum Exceedance Values}

Sum exceedance values (SEVs) are related to the 20-year inundation statistics in the previous section. However, 20-year inundation statistics were calculated only from in-channel water-level data, most of which had long records to support such calculations. Moreover, SEVs are calculated only during the growing season (not the entire year) and describe inundation relative to a marsh surface, not relative to CRD. Thus, SEV statistics have distinctive properties. The marsh, shrub, and swamp wetlands proximal to tidal channels throughout the floodplain exhibit a low range of vertical distribution of average surface elevation: 0.39-3.82 m CRD, with the lowest being the Secret River low marsh at rkm 37, and the highest Gee Creek, a riparian zone at rkm 141 dominated by Oregon ash (Fraxinus latifolia) (Borde et al. in 
preparation). The range of the average elevations of the marshes for which SEVs were calculated is even narrower: between 0.98 and $2.35 \mathrm{~m} \mathrm{CRD}$. The SEVs for high emergent marshes generally follow an upward trend in the landward direction, as do the percent power peaking, percent seasonal fluvial, and percent weather components of the variance calculated from 15 peripheral stations (Figure B.19). This landward increase is expected, because of 1) the increasing fluvial influence at landward stations, 2) the greater excursion in elevations at landward stations where seasonal river-flow variations are much larger than the tidal range, and 3) the high spring water levels seen close to Bonneville Dam. Marsh SEV values appear to fall into three spatial groups (Figure B.19). At the most seaward and tidally influenced stations in the estuary and energy minimum at and below rkm 89 (Gull Island), SEVs tend to remain lower than $315 \mathrm{~m} /$ growing season. Three exceptions to this are Bradwood Slough, a highly disturbed marsh at rkm 62, and two created sites: Jackson Island (rkm 71) and Wallace Island (rkm 77). Sites between rkm 100 (Lord Island) and rkm 154 (Sauvie Cove) in the tidal river zone seem to fall into a middle category of SEVs from 718 to $1297 \mathrm{~m}$ /growing season; however, the upward bound of this category is unknown because of a lack of sites landward of this in the vicinity of Portland until the former mouth of the Sandy River at rkm 198. A third category with the highest SEV values occurs at the most landward sites sampled at the head of the tidal, between rkm 198 and 228, where SEVs are between 2160 and $2844 \mathrm{~m} /$ growing season.

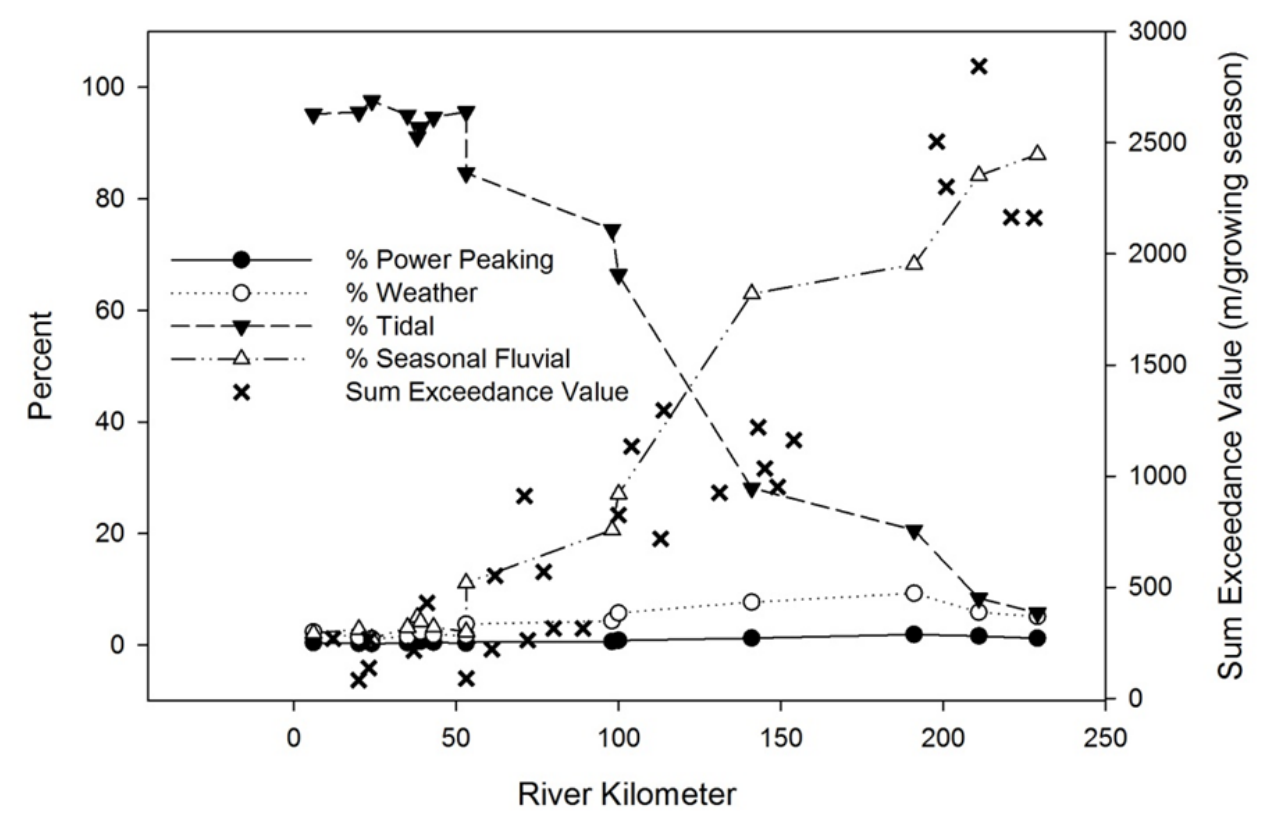

Figure B.19. The Separation of Variance for 15 Wetland Channel Stations, and Sum Exceedance Values for 28 Floodplain Marshes. The SEVs represent the surface water inundation of marshes during a standardized growing season for the floodplain.

\section{B.4.8 Tidal Marsh Classification}

Available herbaceous marsh cover data sets from historically present marshes for analysis of the tidal marsh classification for the LCRE included 2 in the lower estuary zone, 7 in the estuary minimum zone, and 21 in the tidal river zone; thus, the 6-km landslide-controlled zone was not examined. Based on ANOSIM analysis using a nonparametric test statistic and ranked Bray-Curtis similarity coefficients, the lower estuary and tidal river zones clearly separated $(\mathrm{R}=0.981$, significance level $\%=0.4)$, as did the 
estuary minimum and tidal river zones $(\mathrm{R}=0.832$, significance level $\%=0.1)$, but the lower estuary and estuary minimum zones did not $(\mathrm{R}=0.071$, significance level $\%=52.8)$. The test statistic, $\mathrm{R}$, measures the degree of separation between clusters and ranges between -1 and 1, i.e., $\mathrm{R}=1$ indicates all sites within a group are more similar to each other than to any sites from different groups. Sites clustered by the three zones in the non-metric, multi-dimensional scaling plot (Figure B.20) with stress of 0.09, indicating that distances between points closely match similarity values on the Bray-Curtis matrix.

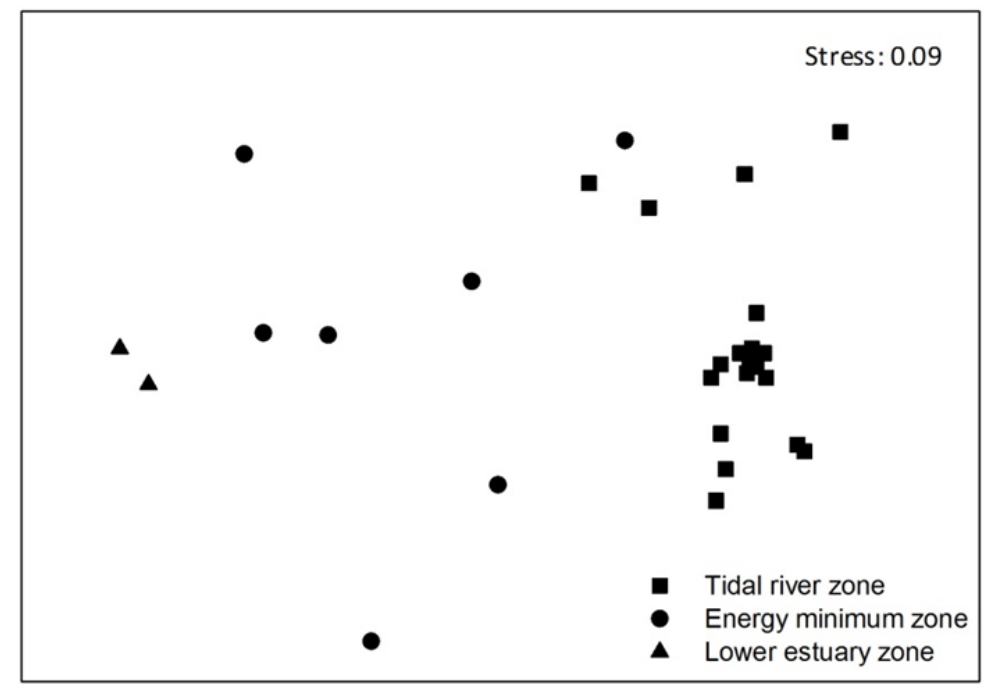

Figure B.20. Non-Metric Multi-Dimensional Scaling Plot of Bray-Curtis Distance Between Marsh Sites in the Lower Estuary Zone, Energy Minimum Zone, and Tidal River Zone. Plant cover data for sites in the landslide-controlled zone were unavailable.

The Wilks' lambda for the hydrologic zonation proposed herein (three groups = lower estuary, energy minimum, and tidal river) was 0.00035 , and the proportion of the variance unexplained by the model was the least relative to the other five other proposed zonation systems we analyzed. Wilks' lambda is a number between 0 and 1, and is a ratio of the variation not explained by the model over the total variation. The model classified all observations correctly. Classifications previously proposed by Kunze (1994) and Jay et al. (1990; Kukulka and Jay 2003a) (0-15 rkm, 15-50 rkm, 50-135 rkm, and 135-235 rkm) also classified all observations correctly (with less of the variance explained by the model). The ecoregion, rkm 135 (above/below), and University of Washington reach systems all misclassified one or more observations.

\section{B.5 Discussion and Conclusions}

In this section, we discuss system zonation and the time-space distribution of water levels and the influences thereon.

\section{B.5.1 System Zonation}

We identify four zones in the LCRE, defined in terms of physical dynamics and vegetation effects, as described below. 
The lower estuary zone is affected by tides and salinity intrusion. There are several possible locations where the landward boundary of this zone might be drawn, depending on whether one considers seasonal minimum, mean, or maximum salinity intrusion. Consistent with the essentially freshwater nature of floodplain vegetation, we take the boundary to be at $\mathrm{rkm} 21$, the narrowest point of the estuary near Astoria. This is near the landward limit of salinity intrusion in spring high-flow periods. This zone corresponds to the most seaward reach identified by Simenstad et al. (2005) and is close to the downstream end of the energy minimum zone identified by Jay et al. (1990).

The energy minimum zone is affected by tides and river flow, but not by salinity intrusion. This zone extends from rkm 21 to Beaver at rkm 87, at the lower end of the tidal river. This zone includes, but extends beyond (on the landward end) the energy minimum originally defined by Jay et al. (1990). There is, however, a clear demarcation at Beaver, founded in the geology. The Beaver reach is narrow and deep; it is the most seaward point at which installation of a river gauge (to measure flow) is feasible. This boundary is located at a point where channel curvature has forced the river up against a steep cliff to the north, with a broad area of mostly diked floodplain south of the channel. Tidal properties change here also - seaward of this point, spring-tide LLW values are lower than on neap-tide. Landward of this point, the spring-tide increase in river surface slope is sufficient to cause spring-tide LLW values to be elevated above those on neap tides. At the landward end of the energy minimum, the increase (over that during low-flow periods) of MWL during floods is comparable to the tidal range. At and below Beaver, tidal variance exceeds seasonal-fluvial variance. Landward of Beaver, seasonal-fluvial variance is larger.

The tidal river zone is where river-flow effects increasingly dominate in the landward direction over tidal effects. The tidal river extends from Beaver at rkm 87 to rkm 229, $6 \mathrm{~km}$ below Bonneville Dam. The seasonal excursion of river stage (MWL) is much larger in the landward part of the system than the tidal range, even during low-flow periods, and tidal ranges vary seasonally by as much as an order of magnitude, due to damping of the tide by river flow. Seasonal-fluvial variance is much larger and powerpeaking variance modestly larger than tidal variance in the more landward parts of the tidal river.

The landslide-controlled zone consists of the final $6 \mathrm{~km}$ of the system (rkm 229 to 235) below Bonneville Dam. This zone is identified by a distinctive vegetation assemblage and a much steeper bed slope than the tidal river; seasonal MWL fluctuations are correspondingly greater. The steep slope reflects the impact of the $\sim 600$ YBP "Bridge of the Gods" landslide.

\section{B.5.2 Tidal Marsh Development and Distribution}

Three categories of tidal marsh inundation are evident in the LCRE, based on analysis of SEVs for 28 marshes. One includes the lower estuary and estuary minimum hydrologic zones. The remaining two encompass the tidal river zone and landslide-controlled hydrologic zones, but additional water-level and marsh-cover data are needed to further specify the location of the break between them. At this time, the lower bound of the middle SEV category appears to be at $\sim 198 \mathrm{rkm}$. Factors in the variability in the SEVs are continuing to be explored; e.g., wetland community type, created versus natural wetlands, landscape position, beaver activity, etc. (Borde et al. in preparation). It is hoped that through this examination, the patterns in SEVs between rkm 60 and rkm 90 (a portion of the estuary minimum zone), and those between rkm 154 and rkm 198 (a portion of the tidal river zone) will be further illuminated. Additional, complete growing season water-level data not presently available for marsh sites in these areas are needed to determine the points of transition more accurately. The categories of sites that we 
excluded from these comparisons - sites along tributaries to the LCRE, low marshes, shrub wetlands, forested wetlands, and 2007 data — are further explored by Borde et al. (in preparation).

The hydrologic zonation proposed herein discriminated the aggregate plant species cover of 20 historical marshes better than the other 5 classifications previously proposed. However, sufficient marsh plant-cover data were not available to include the proposed $6-\mathrm{km}$ landslide-controlled zone at the most landward end of the LCRE in this analysis. Findings for other previously proposed classification systems are further detailed by Borde et al. (in preparation). As new plant community data are collected on the LCRE, the reexamination of existing zonation systems based on different controlling factors (e.g., geomorphology, hydrology) has the potential to further refine our understanding of the relationship between anthropogenic effects on environmental structures and processes, and tidal wetland development. Understanding of these types of relationships is foundational to implementation of successful ecological restoration projects for salmon habitat recovery.

\section{B.5.3 The Time-Space Distribution of Water Levels and Influences Thereon}

We have provided a spatially and spectrally comprehensive view of water-level variations in a major tidal river and estuary, the LCRE. The water-level regime of the system is complex and influenced by several factors: seasonal river inflow; hydropower generation (power peaking); brief high-flow events; daily, overtide, and low-frequency tidal variations; and atmospheric pressure variations. The importance of these factors varies strongly along the channel from the lower estuary up to Bonneville Dam. Water levels in the estuary (both the part with salinity intrusion and upstream of salinity intrusion) are controlled primarily by daily $\left(D_{1}\right.$ and $\left.D_{2}\right)$ tidal oscillations, with some influence of coastal processes related to atmospheric pressure and winds. This is evident in the harmonic analysis results for estuarine stations and wavelet analysis. In the wavelet scaleograms, most of the variance is in horizontal bands associated with the D1 and $\mathrm{D}_{2}$ tides. Tidal monthly and overtide variations in water level are weak in the estuary, but they begin to increase toward the landward end of the estuary, due to nonlinear, frictional energy transfer from the $\mathrm{D}_{1}$ and $\mathrm{D}_{2}$ tides. Accordingly, the tidal daily and atmospheric influence decreases toward the head of the lower estuary, while fluvial influences increase. The influence of atmospheric pressure is of the same sign as predicted by the inverse barometer effect, but the amplitude of the effect varies spatially and between the different datum levels modeled (HHW, LLW, and MWL). Deviations from the response predicted by the inverse barometer effect may be related to winds and frictional effects.

Further upstream in the tidal river above Beaver, there is a rapid growth of fluvial influences, both natural (seasonal and event-like flow fluctuations) and human (power peaking and flow regulation). Tidal and atmospheric influences decrease sharply in the landward direction. The decrease in atmospheric influence is likely due mostly to the strongly frictional flow regime - the response time of the system is longer than the duration of typical frontal weather events. Local winds, which may oppose the effects of atmospheric pressure fluctuations, may also decrease the apparent response to pressure fluctuations. At and beyond the head of the tidal river $\sim 5 \mathrm{~km}$ below the Bonneville gauge (or $\sim 6 \mathrm{~km}$ below Bonneville Dam), tides and atmospheric effects are minor, and water-level fluctuations are almost totally dominated by river-flow variations, natural and human. 


\section{Appendix C}

Estimating Realized Habitat Utilization for Chinook, Chum,
and Coho Salmon in a Restoring Tidal Freshwater Wetland 


\title{
Appendix C
}

\section{Estimating Realized Habitat Utilization for Chinook, Chum, and Coho Salmon in a Restoring Tidal Freshwater Wetland}

\author{
Prepared by Curtis Roegner and Earl Dawley
}

In intertidal wetlands, cumulative annual habitat use by migrating juvenile salmonids is determined by biological and physical constraints. Biological bounds are determined by species-specific migration timing and seasonal residency characteristics, while physical limits are set by periods of inundation and water quality. The potential habitat opportunity (PHO) is the total time available that salmon can access intertidal sites based on physical drivers, and the realized habitat utilization (RHU) is the subset of the PHO when salmon are residing or migrating through the system.

Salmon stocks have different juvenile life-history traits that determine when they use habitats along the migration corridor. In the Grays River system, chum salmon have a fry migrant life history with emergence in early spring, limited residency in riverine and tidal freshwater habitats, and a relatively rapid migration to the estuary and ocean (Roegner et al. 2010b). Fall Chinook salmon are subyearling migrants that rear for up to several months in riverine and tidal freshwater areas before migrating to the estuary in late spring or early summer. Coho salmon have a yearling juvenile life history with a long residency in riverine, tidal freshwater, and estuarine environments before ocean entry, and the freshwater phase may include upstream movements to avoid suboptimal water-quality conditions (Miller and Sadro 2003). Thus, there may be differences in seasonal residency patterns within the marsh that limit overall habit use.

Access to the wetland habitats depends on inundation. The instantaneous area of inundation of an intertidal marsh is controlled by water level and topography, while water level in turn is a function of base stage and tidal height. The base stage is controlled by rainfall patterns and the resultant gravitational stream flow. Storms can significantly increase the base flow, but in the Grays River system these effects are usually restricted to the months of November through February and each storm has a relatively ephemeral (3- to 7-day) impact. Tidal height varies on semidiurnal (12.4 hr and multiples) and synodic (fortnightly) time scales. Semidiurnal fluctuations distinguish daily periods of inundation and exposure along the intertidal gradient, while the synodic, or spring-neap cycle, influences maximum high and minimum low water levels. Spring tides have higher highs and lower lows than neap tides with corresponding differences in total inundation times and total wetted areas.

Water temperature exerts a physiological constraint on salmonids by affecting metabolic rate. The upper criterion for optimum thermal conditions in considered to be $16^{\circ} \mathrm{C}$ (EPA 2003; Richter and Kolmes 2005). Higher temperatures can cause stress (McCullough 1999), and increasing water temperature has been shown to influence juvenile salmonid migration by stimulating movement both downstream to the estuary and ocean (Sauter et al. 2001), as well as upstream to thermal refugia (Miller and Sadro 2003).

Salmon are thought to benefit from increased prey resources in wetland systems. However, the distribution of prey varies across wetland habitat types, and salmon access to prey resources is dependent on water level. In particular, the preferred chironomid insect prey of juvenile salmonids may be more 
available at the channel edge of emergent marshes (Ramirez 2008). Theoretically, the potential benefit to salmon is maximized when water levels enable fish to access habitat where insect prey abound. Low intertidal, non-vegetated channel habitats below the emergent marsh height likely provide fewer or less energetically beneficial feeding opportunities than does the marsh edge. For this reason, it is important to consider access to channel, marsh edge (lower marsh at the bank-filled level), and marsh surface habitats.

Here we estimate the seasonal RHU by Chinook, chum, and coho salmon in the Kandoll Farm restoration $(\mathrm{KF})$ site based on field measurements of salmon presence, area of inundation, and temperature values.

\section{C.1 Methods}

\section{C.1.1 Determination of Biological Habitat Opportunity}

We used trap nets to monitor the seasonal presence of salmon at the KF site from 2007 through 2009 (Roegner et al. 2009b). For each species and year, we determined the initial and final dates and the total duration salmon were present in the wetland. We also computed the mean seasonal duration for the 3-year period.

\section{C.1.2 Determination of Physical Habitat Opportunity}

\section{C.1.2.1 Wetted Area}

We used time series of water level and wetland bathymetry to determine the PHO in the KF wetland. The water-level time series were recorded in 2009 from our long-term KF pressure-temperature sensor measurements (Hobo model U20-001-04, Onset Corp). Data were recorded at 1.0-hr intervals, and waterlevel readings were corrected for atmospheric pressure and calibrated to the North American Vertical Datum of 1988 (NAVD88) vertical datum (Roegner et al. 2009a). These data encompass both tidal and base level water variations experienced at the site. Wetted area $\left(\mathrm{m}^{2}\right)$ was determined with a hydrological model using a topographic map of the KF site generated by light detection and ranging (LiDAR) (Coleman et al. 2010). An empirical relationship (hypsograph) between vertical height and wetted area was then developed. For each time interval under consideration, we used the height-area hypsograph to calculate PHO, the potential number of hours fish had access to each wetland level. We also used the hypsograph to designate the vertical height of channel, marsh edge, and marsh surface habitats.

\section{C.1.2.2 Temperature}

A temperature time series was used to evaluate periods of suitable water-quality conditions for rearing salmonids. We calculated the 7-day average maximum (7-DAM) daily temperature, and deemed temperatures above $16^{\circ} \mathrm{C}$ to be suboptimal. Low dissolved oxygen has not been found to be problematic for salmonids in the Grays River system. 


\section{C.1.3 Determination of Realized Habitat Utilization}

\section{C.1.3.1 Species and Interannual Considerations}

We determined RHU using the dates of salmon residency. For each species and year, we calculated the number of water-level observations that fell within each $10-\mathrm{cm}$ vertical level and computed the total hours those levels were inundated. We used the water-level data from 2009; thus, any interannual differences are driven solely by the timing of salmon in the wetland. The results are presented as percent and cumulative hours of access as functions of wetted area.

\section{C.1.3.2 Spring-Neap Variation}

We considered spring-neap variation in PHO and RHU by habitat type. For these calculations, we blocked the tidal time series into 7- to 8-day intervals encompassing the spring and neap periods, and computed the inundation at $0.5-\mathrm{m}$ intervals from $0.5 \mathrm{~m}$ to $2.5 \mathrm{~m}$. These levels bracket channel, marsh edge, and marsh surface habitats. For PHO, we examined variation in spring and neap inundation times by differencing hours of inundation between sequential spring-neap periods (i.e., inundation during spring tide 1 minus inundation during neap tide 1, and so on). We produced a time series of this anomaly for each $0.5-\mathrm{m}$ interval. We then computed RHU for each species per level per week, and compared the average spring and neap RHU values. All data are from 2009.

\section{C.2 Results}

\section{C.2.1 Determination of Biological Habitat Utilization}

The seasonal presence of salmon in the KF site varied by species and year (Figure C.1; Table C.1). Chinook salmon generally first appeared in February but had a variable seasonal residency lasting from only mid-April (2007) through late May-early June (2008 and 2009). However, note that the overall abundance of Chinook salmon was very low in most years (Roegner et al. 2010a). The average (SD) seasonal residency was $77.3 \pm 22.1$ days. Chum salmon presence was very consistent among years and extended from February to early May, for an average residency of $75.5 \pm 1.2$ day. Coho salmon were present until at least the end of June each year, but their first appearance varied from the end of February in 2007 and 2008 to early April in 2009, for an average residency of $102.7 \pm 19.7$ days. Thus, Chinook and chum had a similar average presence in the wetland while coho had an extended presence.

Table C.1. Migration Timing (Julian Day) for Salmon in the Kandoll Farm Restoration Site

\begin{tabular}{cccccccccc}
\hline & \multicolumn{3}{c}{ Chinook } & \multicolumn{3}{c}{ Chum } & \multicolumn{3}{c}{ Coho } \\
\cline { 2 - 10 } Year & First & Last & Duration & First & Last & Duration & First & Last & Duration \\
\hline 2007 & 53 & 100 & 47 & 53 & 129 & 76 & 53 & 172 & 119 \\
2008 & 62 & 162 & 100 & 46 & 120 & 74 & 62 & 176 & 114 \\
2009 & 64 & 147 & 85 & 48 & 125 & 77 & 98 & 173 & 75 \\
Average & 59.7 & 136.3 & 77.3 & 49 & 124.7 & 75.7 & 71 & 173.7 & 102.7 \\
StDev & 4.8 & 26.4 & 22.3 & 2.9 & 3.7 & 1.2 & 19.4 & 1.7 & 19.7 \\
\hline
\end{tabular}




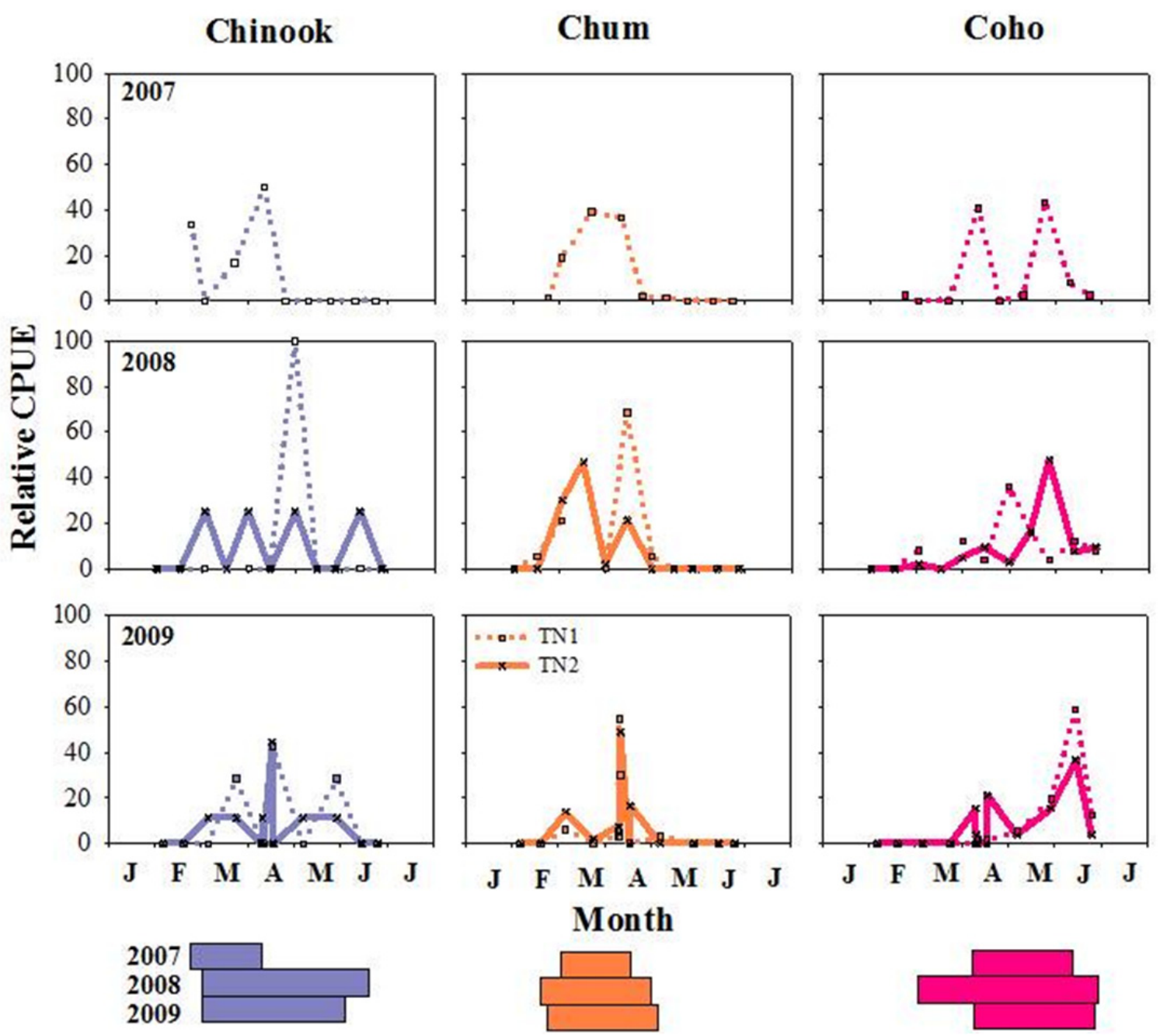

Figure C.1. Time Series of Salmon Presence (relative catch per unit effort) in Kandoll Farm Trap Net Sites (TN1 and TN2). Migration seasons for the years 2007-2009 are depicted in the bars below the graphs.

\section{C.2.2 Determination of Physical Habitat Opportunity}

Tidal fluctuations and the 7-DAM daily temperature in the KF site and river stage (base flow) in the Grays River are shown in Figure C.2. The stage data indicate a single storm event in January; otherwise variation in the hydrograph was mainly the result of tidal fluctuations. The 7-DAM daily temperature record shows suboptimal water-quality conditions occurred in June; however, these temperatures $\left(16-17.5^{\circ} \mathrm{C}\right)$ were not likely to be severely stressful to salmonids. 

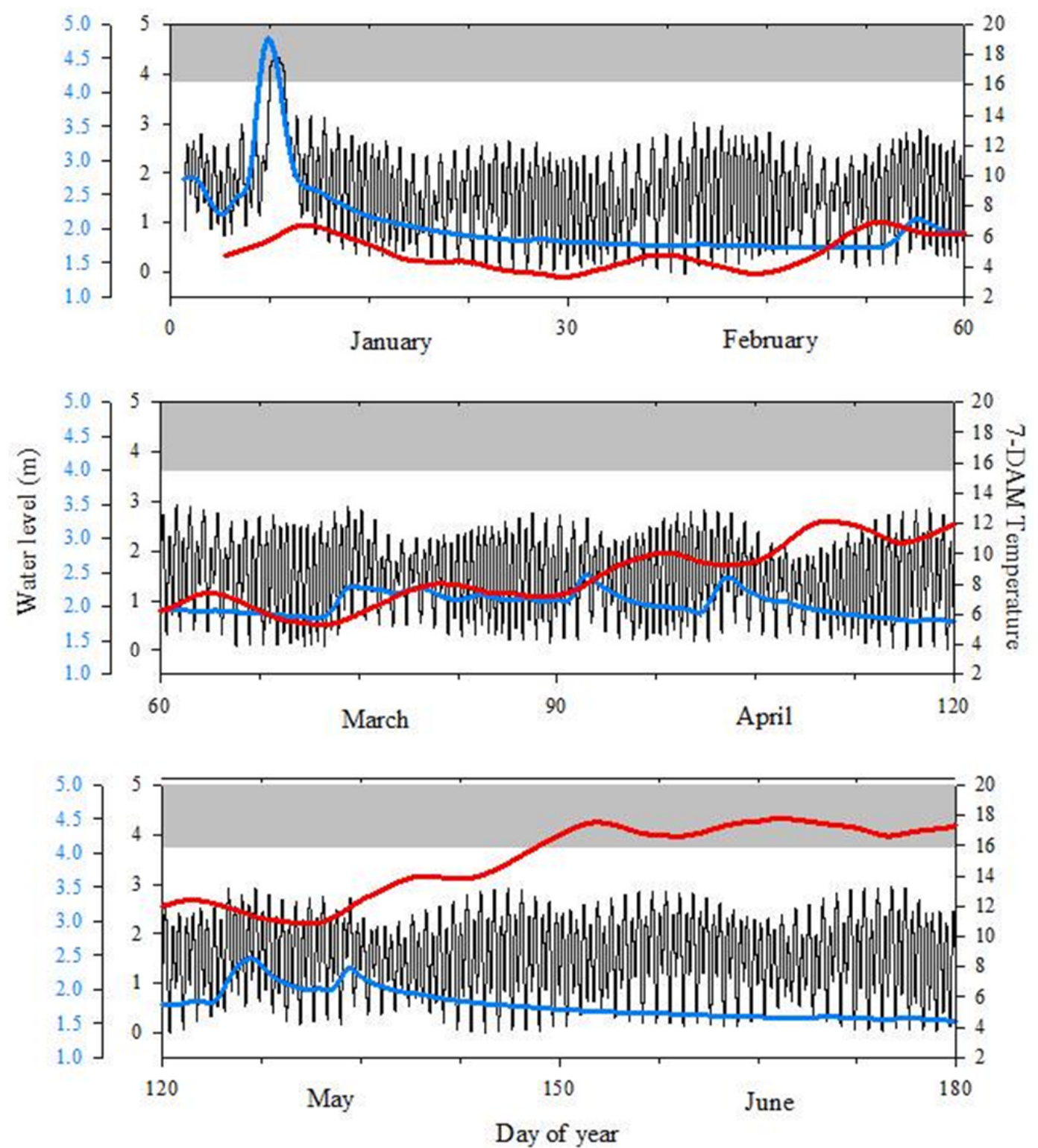

Day of year

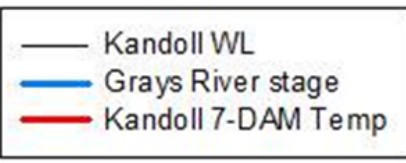

Figure C.2. Time Series of Water Level and 7-DAM Daily Temperature at Kandoll Farm and River Stage in the Grays River During the Salmon Migration Period, 2009

The water-level wetted area hypsograph of the KF wetland shows the typical pattern of a channelincised floodplain (Figure C.3). Wetted area varied little over the vertical range of 0 to $1.5 \mathrm{~m}$ as water filled the intertidal channels, then wetted area increased greatly with increasing water level as the marsh surface became inundated. The bank-full water level is approximately $1.6 \mathrm{~m}$. Given these data, we partitioned the wetland habitat into channel $(<1.5 \mathrm{~m})$, marsh edge $(1.5-2.0 \mathrm{~m})$, and upper marsh $(>2.0 \mathrm{~m})$ habitats. A time series of the high-tide and low-tide wetted areas with high-tide temperature is shown in Figure C.4. There was no appreciable difference in high and low water temperatures (data not shown). 


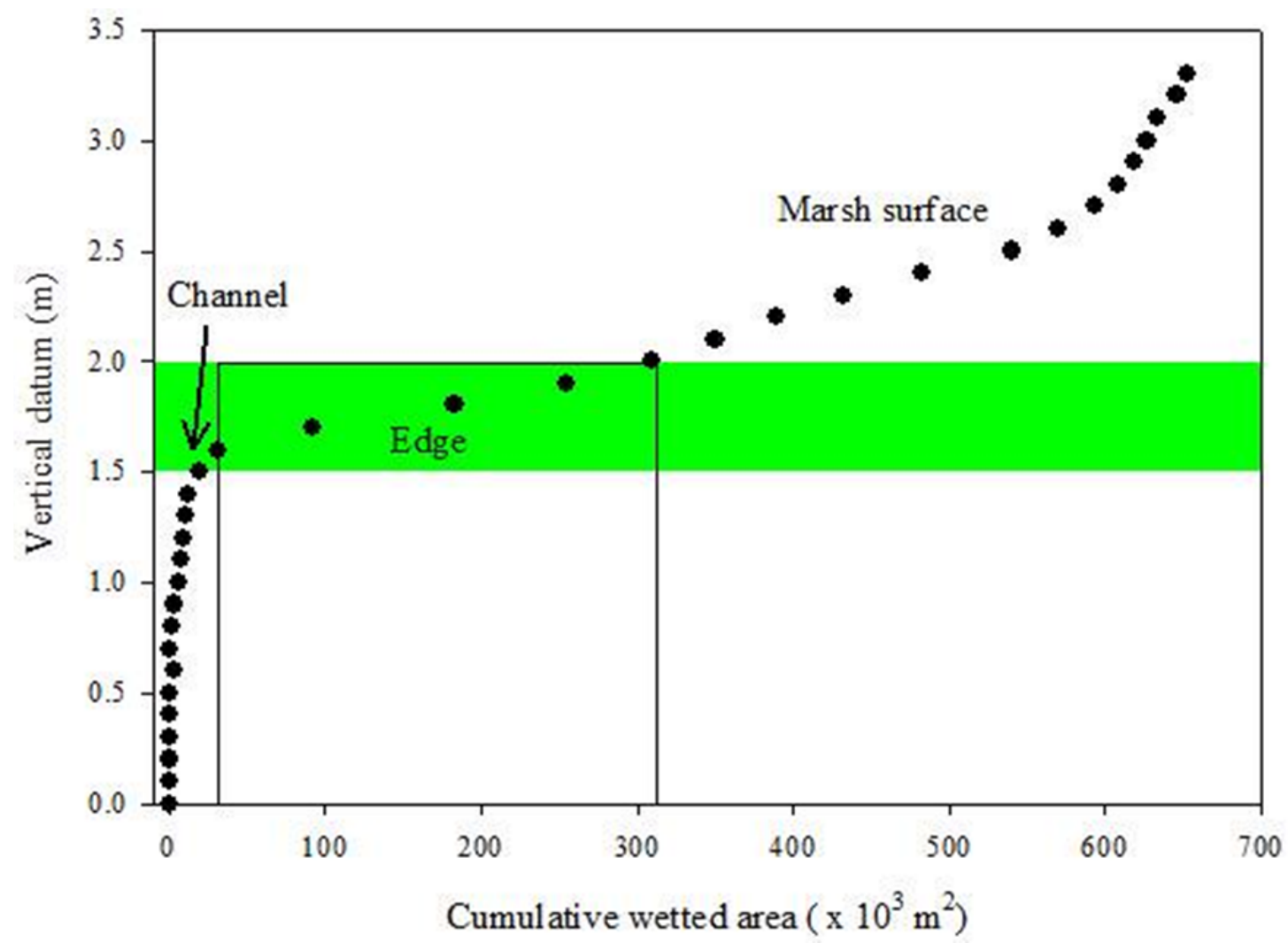

Figure C.3. Hypsographic Curve Relating Intertidal Height to Wetted Area, Including a Designation of Habitats. Green bar signifies marsh edge.

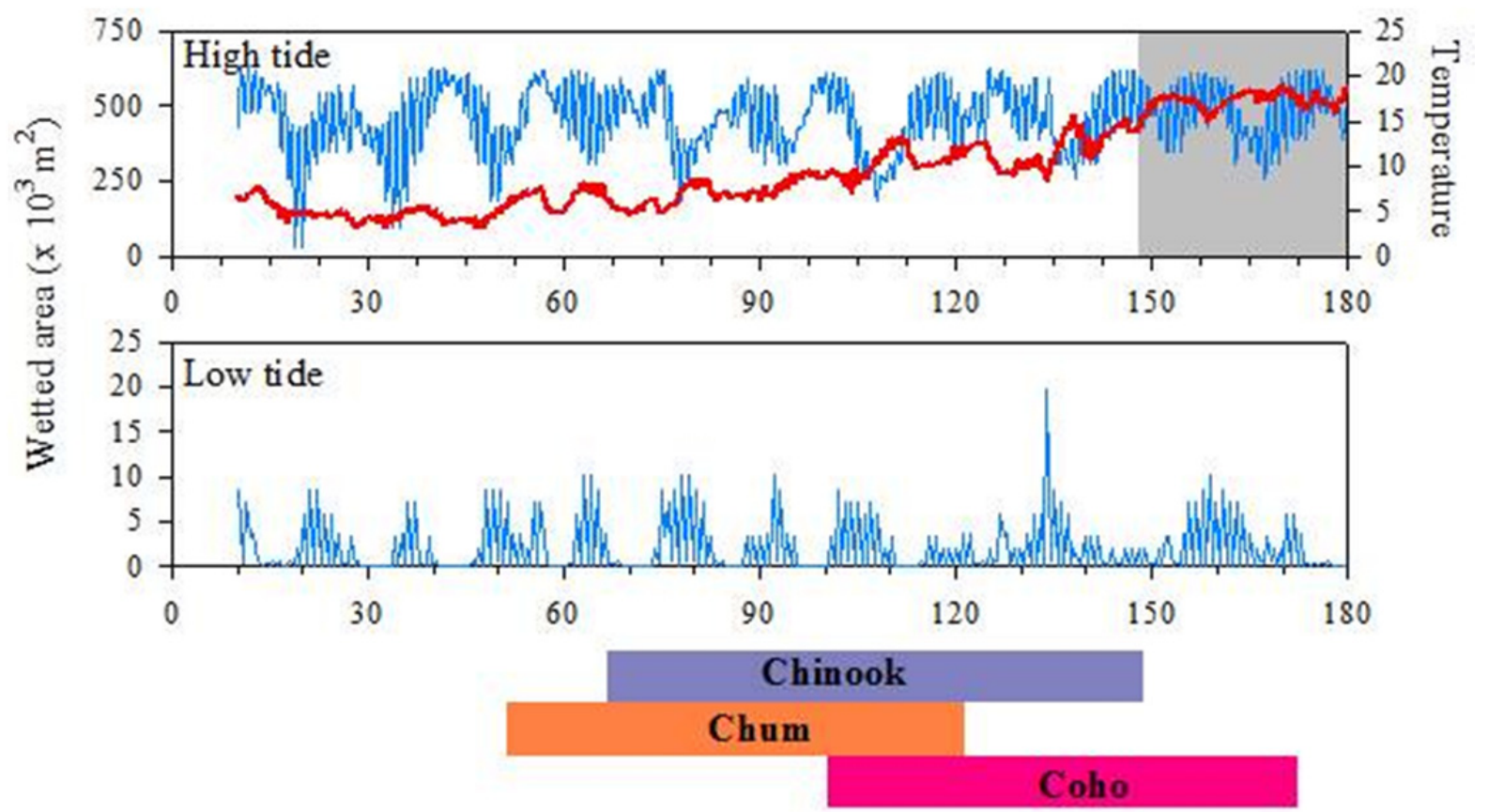

Figure C.4. Time Series of Wetted Area at High Tide and Temperature (upper plot) and Wetted Area at Low Tide (lower plot). Colored bars below signify salmon migration period during 2009. 


\section{C.2.3 Determination of Realized Habitat Utilization}

There was very little difference in the cumulative percent inundation by wetted area among either species or years (Figure C.5). This is because the vertical range of water due to tidal variation was similar over the periods salmon were present in the system (i.e., average tidal range did not vary over the time intervals considered). For all runs, access to the marsh edge and above was available for 40 to $50 \%$ of the time.
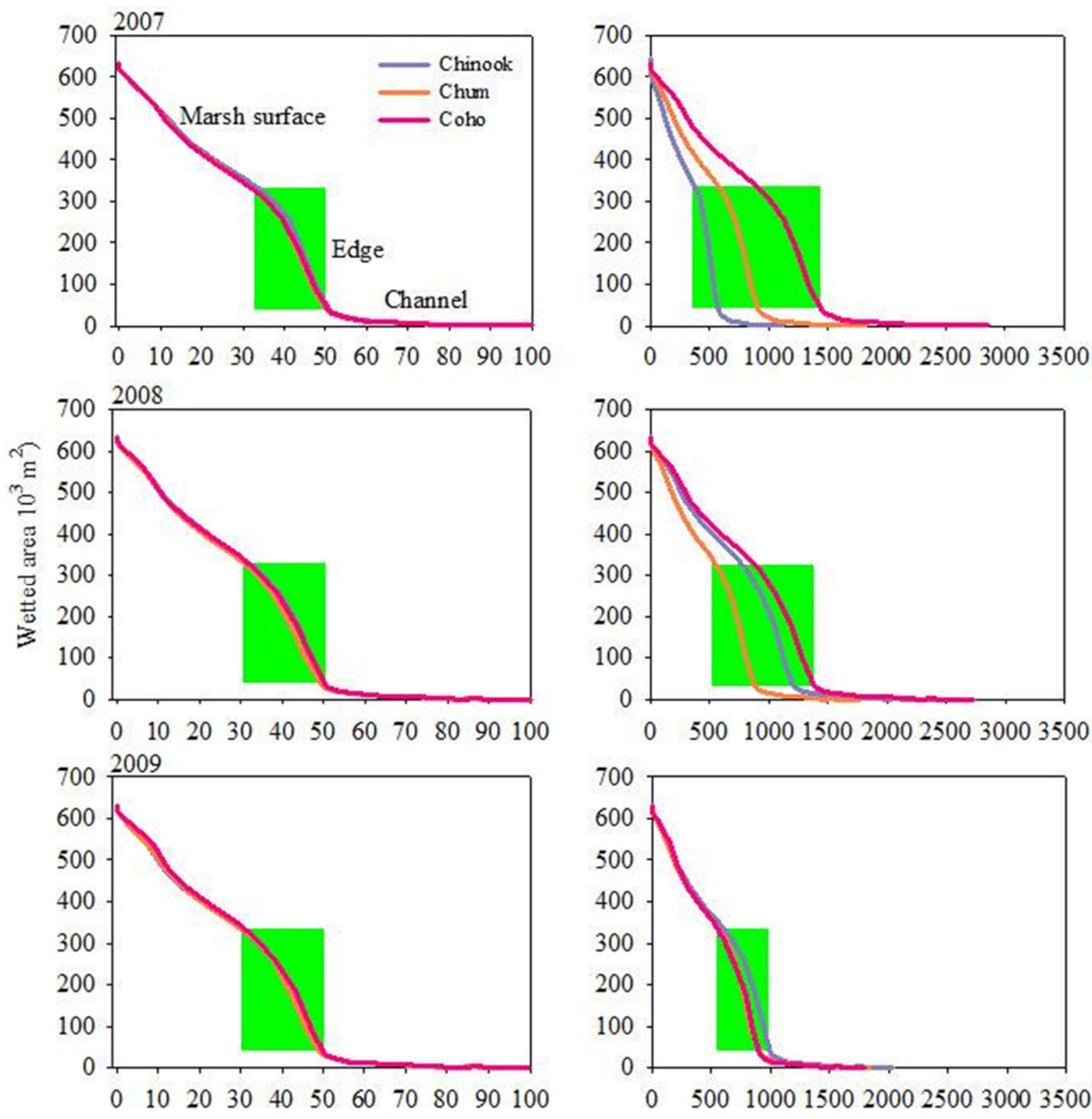

Cumulative percent inundation

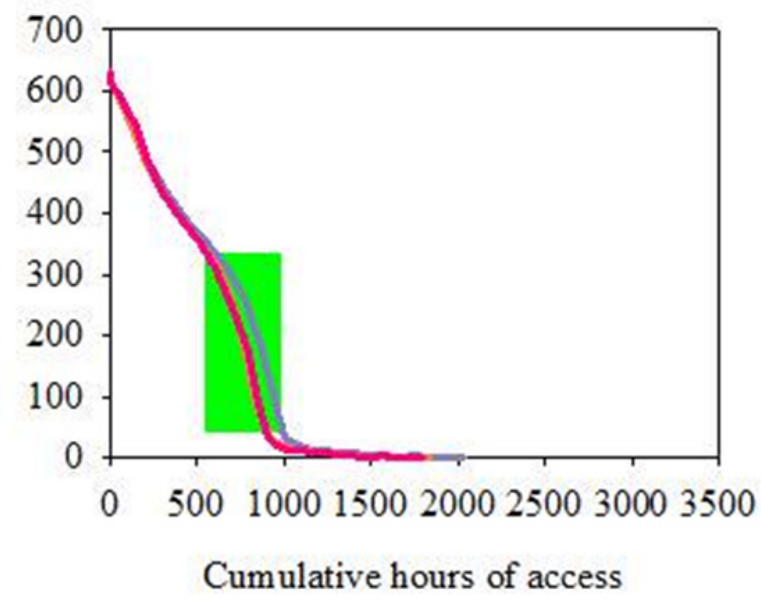

Figure C.5. Area Inundation Curves (left plots) and Area-Time Curves (right plots) During the Migration Periods of Chinook, Chum, and Coho Salmon During 2007-2009. Green boxes designate marsh edge habitat. 
In contrast, the total amount of time used by salmon varied greatly by species and year (Figure C.5; Table C.2). This was a consequence of the differences in the duration of residency by salmon. Chum exhibited little variation between years, with an average total RHU of $1816 \pm 29.9 \mathrm{hr}$; however there was an average of only $929 \pm 13.3 \mathrm{hr}$ available to access high quality habitat. Chinook and coho salmon both exhibited wider ranges in RHU in accordance with their migration patterns, with Chinook using the marsh for the fewest hours in 2007 and coho in 2009. The greatest difference in RHU among species was in 2007 and the least difference in 2009.

Table C.2. Cumulative Hours with Access to the Wetland

\begin{tabular}{cccc}
\hline & \multicolumn{3}{c}{ Hours in Marsh } \\
\hline Year & Chin & Chum & Coho \\
\hline 2007 & 581 & 922 & 1451 \\
2008 & 1297 & 948 & 1476 \\
2009 & 1010 & 918 & 909 \\
Average & 962.6 & 929.3 & 1278.7 \\
StDev & 294.2 & 13.3 & 261.6 \\
\hline
\end{tabular}

Time series of spring-neap anomalies in PHO show variation up to $\sim 50 \mathrm{hr} /$ week (Figure C.6). Anomalies in the marsh channel were negative, indicating water levels remained higher during neap than spring tides (i.e., incomplete draining). The converse was true for the marsh surface, where spring tides allowed longer access to the marsh surface. The marsh edge, situated near the mean tidal level, exhibited anomalies of $<10 \mathrm{hr} /$ week.

RHU exhibited little variation by spring-neap period or salmon species (Figure C.6). Aside from the strong dependence of fish access on intertidal height, paired spring-neap comparisons yielded few results where the RHU anomaly was $>10 \mathrm{hr} /$ week, and all but coho at the 1.0-m level had overlapping variance. Trends, however, mirrored PHO results, with neap RHU exceeding spring RHU in the channel and the converse for the marsh surface. No species effects due to differences in seasonality were detected in the mean values.
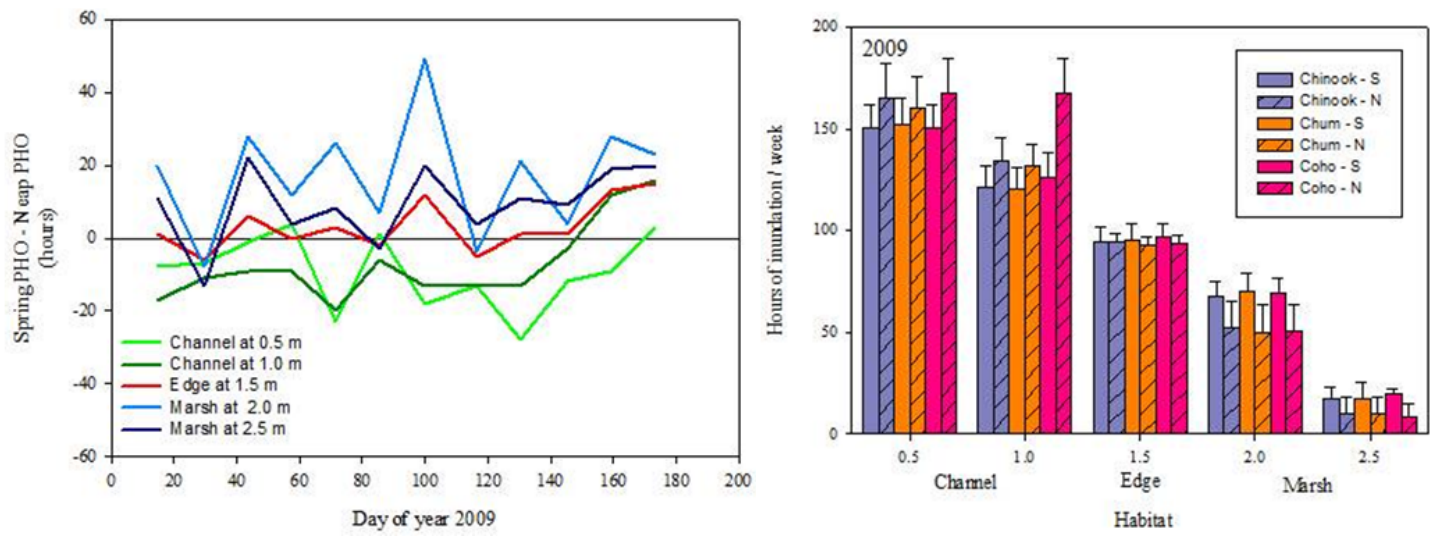

Figure C.6. Time Series of the Time Anomaly Between Consecutive Spring (S) and Neap (N) Periods by Intertidal Height (upper plot), and Mean Weekly Inundation Between S and N Periods by Intertidal Height During the Migration Period of Chinook, Chum, and Coho Salmon During 2009 


\section{C.3 Conclusions}

We examined physical and biological factors influencing the time juvenile salmon had access to wetland habitats. Semidiurnal tidal fluctuations were the primary determinant of access to productive marsh zones. Wetland inundation varied nonlinearly with tidal height, and fish had access to the productive marsh edge for only about 40 to $50 \%$ of the time periods evaluated. The marsh surface was available $<40 \%$ of the time. In contrast, there was a relatively minor impact of spring-neap variation on $\mathrm{PHO}$ over most measurement periods, with weekly differences usually being $<50$ hours ( $\sim 30 \%$ difference).

Interannual variation in salmon presence had a strong impact on the cumulative hours salmon could use the wetland habitat. Note that seasonal presence measures the entire juvenile migration, and not necessarily individual residency. Chum salmon were most consistent in timing and duration. The average migration of Chinook was similar to that of chum but was more variable, with 2007 having a truncated season. Low Chinook salmon abundance in the KF marsh at present further limits actual habitat use. Coho salmon presence was the most extended within the wetland and also peaked later than chum or Chinook salmon; however, coho migration was delayed in 2009. This variation in the timing and duration of salmon migration period contributed to relatively large total variation in RHU among species and years. On average, chum had remarkably consistent seasonal use of marsh habitat ( $929 \pm 13 \mathrm{hr}$ ), while Chinook and coho salmon were more variable (962 $\pm 294 \mathrm{hr}$ and $1278 \pm 261 \mathrm{hr}$, respectively). The marsh was thus used by the different salmon species for different lengths (and periods) of time.

A primary goal of habitat restoration activities in the lower Columbia River and estuary is to enhance salmonid growth, condition, and survival. These desired benefits can only be achieved by salmon through successful integration of physical and biological factors. In this study we found tidal inundation levels constrain access to productive marsh habitat, but biological factors dictate the realized cumulative benefit to the salmon run. Metrics such as the RHU are one method for assessing the cumulative effects of restoration on salmon. 


\section{Appendix D}

Electrofishing in Swamp Habitats in the Vicinity of Grays Bay During Spring 2010 - Data Summary 


\title{
Appendix D
}

\section{Electrofishing in Swamp Habitats in the Vicinity of Grays Bay During Spring 2010 - Data Summary}

\author{
Prepared by Gary Johnson \\ Data provided by Kenneth Ostrand, Benjamen Kennedy, and James Samagaio (USFWS)
}

The electrofishing effort to sample juvenile salmon in swamp habitats in the lower Grays River (Figure D.1), a tributary of the Columbia River estuary, was conducted by the U.S. Fish and Wildlife Service (USFWS)/Abernathy Technology Center under contract to the U.S. Army Corps of Engineers (USACE) Portland District for the purposes of the cumulative effects (CE) study. In the CE study design, Kandoll Farm reference (KR) swamp was paired with the Kandoll Farm restoration (KF) site, forming 1 of 3 pairs of long-term (6-year) reference-restoration sites as part of action-effectiveness research in the CE study (Diefenderfer et al. 2006). In addition, two other swamps in the vicinity, Secret River (SR) and Crooked Creek (CC), were sampled as part of critical uncertainties research in the CE study (Johnson [ed.] 2007). On this basis, the CE study team designed an electrofishing effort at the three swamps for the final year of CE field sampling (2010) to address hypotheses that 1) juvenile salmon species composition, density, and length-frequency distribution would be the same for the restoration and reference sites (Johnson [ed.] 2007), and 2) juvenile salmon, particularly coho salmon, would be present in the tidal swamp habitats (Diefenderfer 2007; Diefenderfer and Montgomery 2009).

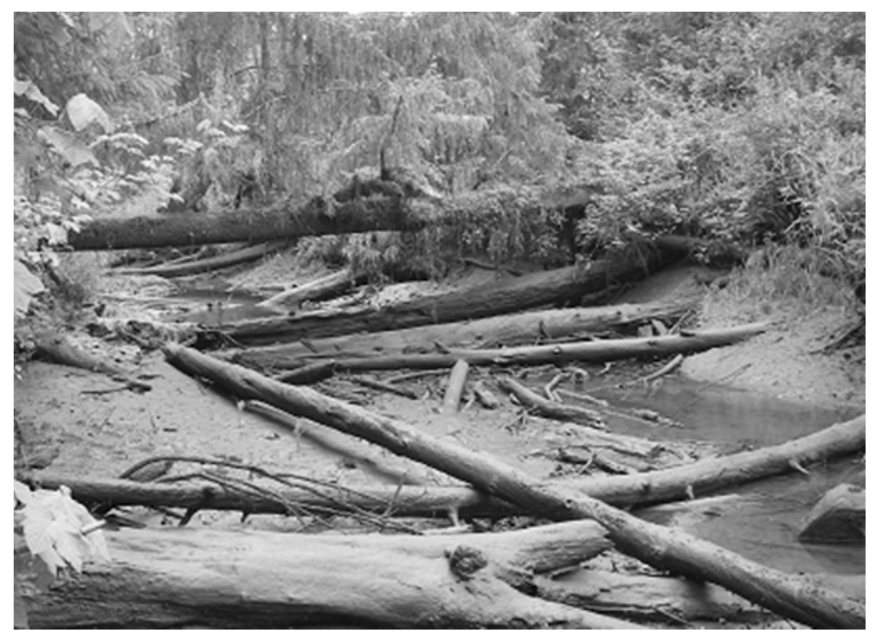

Figure D.1. Tidal Channel at the KR Site at Low Tide

During field work in 2005 and 2006, fish-sampling attempts at the KR site by the CE study team did not produce acceptable results because the gear types used (minnow traps, beach seines, and trap nets) could not successfully capture fish in the muddy, woody, steep-banked conditions at the site, a Sitka spruce swamp (Figure D.1). CE researchers, however, were able to use a beach seine in larger swamp channels adjacent to the KR site, such as Seal Slough, but they could not seine fish inside the reference site itself (Roegner et al. 2007), where the mean channel width is only $12.8 \mathrm{~m}$ (Diefenderfer and Montgomery 2009). This meant fish data for the KR site and other swamp sites would be lacking and we would be unable to complete the before-after-reference-restoration statistical design unless a successful 
fish-sampling method could be found. As an alternative to the gear types recommended in the protocols developed and field-tested by the CE study team starting in 2005 (Roegner et al. 2009a), a CE study team member recommended investigating the use of electrofishing methods for swamp sites (E. Dawley, pers. comm. to H. Diefenderfer, October 27, 2008). The USACE Portland District supported this work and the USFWS/Abernathy performed it at the USACE's behest. The CE study team designed the spatial and temporal elements of the electrofishing effort to be consistent with 1) the overall paired restoration and reference sites design (described by Diefenderfer et al. 2006), 2) the three-site swamp critical uncertainties investigation (described by Diefenderfer 2007; Johnson [ed.] 2007; Diefenderfer et al. 2008; Diefenderfer and Montgomery 2009), and 3) the temporal patterns of salmon presence in the Grays River previously documented by the multi-year CE study beach seine effort (Roegner et al. 2010b).

The electrofishing data in this appendix are reproduced with permission of the USACE Portland District from the USFWS report, Fish Assemblage Structure of Tidal Forested Wetlands in the Columbia River Estuary, delivered by the USFWS to the USACE in August 2010. There are three CE study work products where the electrofishing data are planned for publication: the CE 2010 Annual Report (this appendix); a Columbia Estuary Ecological Relationships paper by Thom et al. based on Chapter 2.0 of this report; and a Columbia Estuary Sitka Spruce Swamp. The objectives of this research were to use an electrofishing technique to sample fish at three swamps in the lower Grays River during spring 2010 to estimate 1) species composition of the catch, 2) catch counts by species, and 3) mean length, weight, and condition factor for juvenile salmon.

\section{D.1 Methods}

The CE study team based the temporal elements of the sampling design on its findings previously reported by Roegner et al. (2010a) and Roegner et al. (2007). Electrofishing samples were obtained once per month per site during March, April, and May 2010 (Table D.1). In addition, the KR site was sampled in June 2010, because during the May sampling at that site a bucket of fish was accidentally released without processing. At the KR, SR, and CC sites, the same channel segments that Diefenderfer and Montgomery (2009) surveyed were electrofished. While all three sites are characterized by the Sitka spruce swamp plant community, they vary widely in watershed characteristics, e.g., KR $\left(0.078 \mathrm{~km}^{2}\right.$, 3.2-km channel length) and CC $\left(0.776 \mathrm{~km}^{2}, 44.3-\mathrm{km}\right.$ channel length) (Diefenderfer et al. 2008).

Samples were collected only during daylight hours for safety reasons. Tide stage was chosen based on accessibility to permit in-channel access because of heavy shrub growth along the banks and large accumulations of wood in the channels (Figure D.1). Thus, electrofishing passes were initiated on the ebb and only occurred at or near low tide, with the longest sampling effort being 110 minutes (Table D.1). The total electrofishing effort from March through June encompassed 208 minutes at the CC site, 225 minutes at the SR site, and 165 minutes at the KR site (not including the unsuccessful 50-minute effort in May). The sampling sequence involved a single pass with the electroshocker per site per sampling trip. The equipment included an electroshocker (Model LR24, Smith Root Inc.), two dip nets, a scale, and a ruler. Standard electrofishing methods were used. Prior to the start of the USFWS electrofishing effort, Pacific Northwest National Laboratory (PNNL) deployed HOBO model U20 waterlevel logger absolute pressure sensors in each of the three channels in February, which recorded pressure at half-hourly intervals, following the protocol described by Roegner et al. (2009a). At the conclusion of electrofishing, PNNL retrieved the sensors and corrected the data for measured water level and atmospheric pressure (Table D.1). 
Table D.1. Sampling Events for Electrofishing and In-Channel Water-Surface Elevation Records. The water-surface elevation record nearest the midpoint of the electrofishing pass is shown, along with the preceding highest water level and the following lowest water level recorded in the channel. May sampling duration at KR is not included in total reported electrofishing duration per site.

\begin{tabular}{|c|c|c|c|c|c|c|c|c|c|c|c|c|}
\hline Site & Date & $\begin{array}{c}\text { Start-End } \\
\text { Times }\end{array}$ & $\begin{array}{l}\text { Water- } \\
\text { Level } \\
\text { Record, } \\
\text { Local Time } \\
\text { (GMT- } \\
\text { 07:00) }\end{array}$ & $\begin{array}{c}\text { Water- } \\
\text { Level } \\
\text { Record, } \\
\text { Time } \\
\text { (GMT + } \\
00: 00) \\
\end{array}$ & $\begin{array}{c}\text { Surface- } \\
\text { Water } \\
\text { Level (m- } \\
\text { NAVD } \\
88)\end{array}$ & $\begin{array}{l}\text { Preceding } \\
\text { High Water } \\
\text { Level, Time } \\
(\text { GMT + } \\
00: 00)\end{array}$ & $\begin{array}{l}\text { Preceding } \\
\text { High } \\
\text { Water } \\
\text { Level (m- } \\
\text { NAVD 88) } \\
\end{array}$ & $\begin{array}{c}\text { Following } \\
\text { Lowest } \\
\text { Water } \\
\text { Level, Time } \\
\text { (GMT + } \\
00: 00) \\
\end{array}$ & $\begin{array}{l}\text { Following } \\
\text { Low } \\
\text { Water } \\
\text { Level (m- } \\
\text { NAVD } \\
88) \\
\end{array}$ & $\begin{array}{c}\text { Tide } \\
\text { Stage } \\
\text { During } \\
\text { Electro- } \\
\text { fishing }\end{array}$ & $\begin{array}{c}\text { Electro- } \\
\text { fishing } \\
\text { Duration } \\
\text { (minutes) }\end{array}$ & $\begin{array}{c}\text { Total } \\
\text { Electro- } \\
\text { fishing } \\
\text { (minutes/ } \\
\text { site) }\end{array}$ \\
\hline $\mathrm{CC}$ & 17-Mar & $8: 20-10: 10$ & 9:00 & $16: 00$ & 0.358 & 10:00 & 2.657 & 18:00 & 0.355 & low & 110 & \\
\hline $\mathrm{CC}$ & 22-Apr & $13: 30-14: 15$ & 14:00 & 21:00 & 0.342 & $15: 00$ & 2.299 & 23:00 & 0.316 & $\begin{array}{l}\text { near } \\
\text { low }\end{array}$ & 45 & \\
\hline $\mathrm{CC}$ & 20-May & $13: 10-14: 03$ & $13: 30$ & 20:30 & 0.354 & 14:00 & 2.603 & 21:00 & 0.352 & low & 53 & 208 \\
\hline SR & 19-Mar & $9: 30-10: 40$ & 10:00 & 17:00 & 0.697 & 11:00 & 2.473 & 20:00 & 0.649 & low & 70 & \\
\hline SR & 16-Apr & $8: 45-10: 10$ & 9:30 & $16: 30$ & 0.771 & 10:00 & 2.815 & 19:00 & 0.744 & low & 85 & \\
\hline SR & 14-May & $14: 50-16: 00$ & $15: 30$ & $22: 30$ & 2.196 & $22: 30$ & 2.196 & 4:00 & 0.717 & high & 70 & 225 \\
\hline KR & 18-Mar & $9: 20-10: 20$ & 10:00 & 17:00 & 0.652 & 11:00 & 2.646 & 19:30 & 0.637 & $\begin{array}{l}\text { near } \\
\text { low }\end{array}$ & 60 & \\
\hline KR & 15-Apr & $8: 00-8: 45$ & 8:00 & 15:00 & 0.938 & 10:00 & 2.948 & 18:30 & 0.658 & $\begin{array}{l}\text { near } \\
\text { low }\end{array}$ & 45 & \\
\hline KR & 14-May & $7: 20-8: 10$ & 8:00 & 15:00 & 0.686 & 9:00 & 2.882 & 18:30 & 0.641 & $\begin{array}{l}\text { near } \\
\text { low }\end{array}$ & 50 & \\
\hline KR & 3-Jun & $12: 30-13: 30$ & 13:00 & 20:00 & 0.949 & $13: 30$ & 2.464 & 21:00 & 0.86 & $\begin{array}{l}\text { near } \\
\text { low }\end{array}$ & 60 & 165 \\
\hline
\end{tabular}




\section{D.2 Results}

The total catch comprised 12 species belonging to 8 families (Table D.2). The most abundant fish in the total catch was threespine stickleback followed by sculpin (Table D.3). Chinook, coho, and/or chum salmon were present in the swamps during the sampled months (Table D.3). The total catch of Chinook $(\mathrm{n}=3)$, chum $(\mathrm{n}=8)$, and coho $(\mathrm{n}=36)$ salmon averaged 58,41 , and $67 \mathrm{~mm}$ in fork length (Table D.4). Weights and condition factors had similar relative differences among species.

Table D.2. Species Composition of Total Combined Catch

\begin{tabular}{lll}
\hline \multicolumn{1}{c}{ Family } & \multicolumn{1}{c}{ Common Name } & \multicolumn{1}{c}{ Scientific Name } \\
\hline Catostomidae & Largescale sucker & Catostomus macrocheilus \\
Centrarchidae & Bluegill & Lepomis macrochirus \\
Cottidae & Sculpin spp. & \\
Cyprinidae & Northern pikeminnow & Ptychocheilus oregonensis \\
Cyprinidae & Peamouth & Mylocheilus caurinus \\
Cyprinodontidae & Banded killifish & Fundulus diaphanus \\
Gasterosteidae & Threespine stickleback & Gasterosteus aculeatus \\
Petromyzonidae & Pacific lamprey & Lampetra tridentata \\
Salmonidae & Chinook salmon & Oncorhynchus tshawytscha \\
Salmonidae & Chum salmon & O. keta \\
Salmonidae & Coho salmon (marked) & O. kisutch \\
Salmonidae & Coho salmon (unmarked) & O. kisutch \\
Salmonidae & Cutthroat trout & O. clarkii \\
\hline
\end{tabular}

Table D.3. Swamp Catch. Salmon are highlighted. Note: For quality assurance purposes, the data for this table remain to be checked against the raw data sheets.

\begin{tabular}{lcccccccccc}
\hline & \multicolumn{3}{c}{ Crooked Creek } & \multicolumn{3}{c}{ Kandoll Reference (Seal Slough) } & \multicolumn{3}{c}{ Secret River } \\
\hline \multicolumn{1}{c}{ Common Name } & March & April & May & March & April & May & June & March & April & May \\
\hline Bluegill & 0 & 1 & 0 & 0 & 0 & 0 & 0 & 0 & 0 & 0 \\
Chinook salmon & 0 & 2 & 0 & 0 & 0 & 0 & 0 & 0 & 1 & 0 \\
Chum salmon & 5 & 0 & 0 & 1 & 0 & 0 & 0 & 1 & 1 & 0 \\
Coho salmon (H) & 0 & 1 & 0 & 0 & 0 & 0 & 0 & 7 & 1 & 0 \\
Coho salmon (W) & 8 & 9 & 0 & 4 & 2 & 0 & 2 & 1 & 1 & 0 \\
Cutthroat trout & 0 & 1 & 0 & 1 & 0 & 0 & 0 & 0 & 0 & 0 \\
Banded killifish & 0 & 7 & 1 & 0 & 0 & 0 & 0 & 0 & 4 & 1 \\
Pacific lamprey & 0 & 0 & 0 & 0 & 0 & 0 & 0 & 2 & 0 & 0 \\
Peamouth & 10 & 50 & 2 & 0 & 2 & 0 & 0 & 0 & 0 & 0 \\
Northern pikeminnow & 0 & 0 & 0 & 1 & 0 & 0 & 0 & 1 & 1 & 0 \\
Sculpin spp. & 183 & 176 & 212 & 96 & 43 & 55 & 60 & 69 & 71 & 30 \\
Threespine stickleback & 406 & 60 & 236 & 416 & 73 & 30 & 39 & 233 & 112 & 31 \\
Largescale sucker & 34 & 45 & 34 & 7 & 8 & 0 & 0 & 27 & 4 & 14 \\
\hline
\end{tabular}


Table D.4. Mean Fork Length (mm), Weight (g), and Fulton's Condition Factor (K) for the Total Combined Catch for Three Juvenile Salmon Species. Note: For quality assurances purposes, the data for this table remain to be checked against the raw data sheets.

\begin{tabular}{cccc}
\hline Species & Length (SE) & Weight (SE) & K (SE) \\
\hline Chinook salmon & $58.0(5.6)$ & $2.0(0.61)$ & $0.98(0.13)$ \\
Chum salmon & $41.3(0.8)$ & $0.54(0.07)$ & $0.77(0.05)$ \\
Coho salmon & $66.6(5.6)$ & $5.6(1.4)$ & $1.06(0.05)$ \\
\hline
\end{tabular}

\section{D.3 Conclusions}

The results of the electrofishing data collection effort verify that Chinook, chum, and coho salmon are present in the smaller, woody channels of spruce swamps where neither trap nets nor beach seines are viable gear types. The duration of successful electrofishing from March through June was limited to just under 10 hours, during which a total of 47 salmon were captured. Anomalies that should be considered in interpretation of these data include 1) the high tide during one sampling event at SR relative to the nearor at-low tide stages of all other events, and 2) data from June not May are available for the KR site, while previous beach seine sampling in the larger channel in spruce swamp immediately outside of this site (Seal Slough) during the spring migration showed peak abundances and relative catch per unit effort of all three salmon species occurring before June (Roegner et al. 2010b). Coho salmon were the most abundant salmon species collected by electrofishing, which was consistent with limited data previously reported for the Seal Slough site (Diefenderfer and Montgomery 2009), but Roegner et al. (2010a) reported substantial interannual variability in the abundances of salmon species collected in Seal Slough in spring, with Chinook and chum salmon exceeding coho salmon abundance in one of three sampling years.

Because data collection efforts were limited in duration and necessarily focused during periods of low water level, these data are not a holistic representation of fish community composition of lower Columbia River and estuary (LCRE) spruce swamps. These results represent fish that are holding in pools that retain water at or near low tides in the spring months. To document fish community composition would require data collection over a complete range of tidal conditions and throughout all seasons of the year. Interpretation of the salmon presence results relative to the landscape position of the three swamp sites is also not appropriate, because of the differences in watershed features, mean channel width, dewatering patterns, and water levels and volume at sampling times. Thus, the limited results from the three sites are interpreted collectively, relative to the goals of this study, as follows: 1) the three salmon species present in trap nets at the KF restoration site in 2006 and 2007 (Roegner et al. 2010a, b) are also present at the KR swamp during the spring migration of 2010, and 2) the presence of juvenile salmon of all three species was verified in three small channels of the Sitka spruce swamp ecosystem in the vicinity of Grays Bay during the spring migration in 2010.

This effort indicates that electrofishing methods have utility in the smaller channels of swamps of the LCRE, where other gear is not viable. The development of methods to electrofish at higher tides would improve the ability to describe fish community composition using this technique. 


\section{Appendix E}

Material and Nutrient Flux from Restoring Wetlands in the Tidal Freshwater of the Lower Columbia River and Estuary 


\title{
Appendix E
}

\section{Material and Nutrient Flux from Restoring Wetlands in Tidal Freshwater of the Lower Columbia River and Estuary}

\author{
Prepared by Dana Woodruff, Ron Thom, Curtis Roegner, and Steve Breithaupt
}

\begin{abstract}
Among the key functions of tidal wetland systems is their ability to produce, trap, process, and export various materials (Mitsch and Gosselink 2000). These materials include sediments, organic matter, nutrients, and organisms. In this role, tidal wetlands contribute to the overall trophic network and productivity of the broader system, while supporting autochthonous productivity and wetland-associated wildlife. In the lower Columbia River (LCR), diking and levee construction designed to create pastureland for agricultural production have removed approximately $70 \%$ of the tidal wetland area from the estuary (Thomas 1983), and this loss is believed to have resulted in a significant reduction in the export of marsh macrodetritus to the estuary (Simenstad et al. 1990). Reductions in macrodetrital transport coupled with the enhanced production of phytoplankton in the reservoirs has shifted the foodweb structure in the estuary from marsh-based to phytoplankton-based (Bottom et al. 2005b; Maier and Simenstad 2009). Restoration of hydrologically isolated wetlands to more natural tidal and fluvial forces may lead to re-establishment of productive tidal wetland systems with concurrent increases in such processes as macrodetritus export, nutrient processing, and the sequestering of sediments. So far this outcome has not been tested in the Columbia River, and there are minimal studies throughout the world that focus on exchange between restoring tidal wetland systems and the larger system.
\end{abstract}

One of the ways to understand the effects of restoration actions on tidal wetland systems is to measure the exchange of water and its associated constituents (e.g., suspended sediments, dissolved organic matter, nutrients, macrodetritus, invertebrate prey, and fish) in and out of a tidal wetland. A comparison of these constituents before a site restoration and after a site restoration, or comparison to a reference site provides relevant information regarding the effectiveness of restoration actions focusing on hydrological reconnection. Our goal is to develop these types of data sets that can be used to predict the cumulative effect of multiple restoration actions on the transport of ecosystem-relevant materials from the restored sites to the estuary. To extrapolate results from our study sites to broader areas, we are developing and collecting data that relate straightforward metrics about aspects of the wetland (e.g., average daily wetted area) to the broader estuary through mass flux of materials to the estuary.

The purpose of this appendix is to present key results of material and nutrient flux components from the Kandoll Farm restoration (KF) project, pre- and post-removal of the culvert and answer the following questions:

1. Is the tidal freshwater wetland a source of or sink for organic and inorganic matter and nutrients?

2. Is there a detectable difference between pre- and post-restoration in ecological processes and function related to dissolved and particulate matter?

This appendix includes the following components related to the KF project: a synthesis of the intensively sampled material/nutrient flux field collection during April 2009, the results of a recently 
completed particulate organic matter (POM) modeling effort, and a synthesis of flux results from prerestoration (2005) through 4 years post-restoration (2009).

\section{E.1 Methods}

\section{E.1.1 Intensive Material and Nutrient Flux Field Measurements}

Methods for this experiment are described in detail in the previous annual report (Woodruff et al. 2010). Briefly, water samples were collected approximately every 2 hours at the KF culvert for approximately 48 hours during a spring tide (two semidiurnal periods of four ebb and four flood tides) and 36 hours during a neap tide (one semidiurnal tide of one ebb and one flood tide) in April 2009. Samples were analyzed for total organic carbon (TOC), total suspended sediments (TSS) including inorganic and organic fractions, chlorophyll_a, and nutrients $\left(\mathrm{NO}_{3}, \mathrm{NO}_{2}, \mathrm{NH}_{4}+, \mathrm{PO}_{4}, \mathrm{SiO}_{4}\right)$. Exchange calculations were derived from the following equations:

$$
\begin{aligned}
& \text { Concentration } \mathbf{C}\left(\mathrm{kg} \mathrm{m}^{-3}\right)=\text { basic unit of water property measurements } \\
& \text { Material Transport Rate } \mathbf{Q}\left(\mathrm{kg} \mathrm{s}^{-1}\right)=\operatorname{Tv}\left(\mathrm{m}^{3} \mathrm{~s}^{-1}\right) * \text { Concentration of material }\left(\mathrm{kg} \mathrm{m}^{-3}\right) \\
& \text { Total Transport } \mathbf{T}(\mathrm{kg})= \\
& \text { dVolume }\left(\mathrm{m}^{3}\right) * \text { Concentration }\left(\mathrm{kg} \mathrm{m}^{-3}\right) \\
& \text { (integrated over area and tidal time periods) }
\end{aligned}
$$

Nutrient and material exchange through the ebb and flood tidal cycles was based on the Area-Time Inundation Index Model (ATIIM) that calculated a total volume of water within the KF site for each hourly time-step through the study period (see Chapter 2.0). For our application, we assumed continuity of volume so that a change in water level over a given time step equated to the volume exchanged from or to the KF site through the culvert. The water-level data were measured with a temperature-pressure sensor (HOBO model U20, Onset Corporation) calibrated to topography (Borde et al. 2010) that was operational at the KF site from 2005 through 2010. By convention we expressed ebb tide flow as negative transport, flood tide as positive transport.

\section{E.1.2 Particulate Organic Matter Modeling}

We estimated POM flux from the KF site into the Grays River-Columbia River system using physics-based models. The models include the key POM processes of mobilization from fluid shear stress during tidal exchange, flooding, and variable river flow, entrainment into the water column, transport via channel and overland flow, and entrapment as wetted surfaces dry. Figure E.1 shows features relevant to the POM analysis, including the locations where water-level measurements were made. The period of analysis covers the seasonal changes from early summer 2006 through mid-winter 2007, as defined by the field sampling of vegetation at the KF site. 


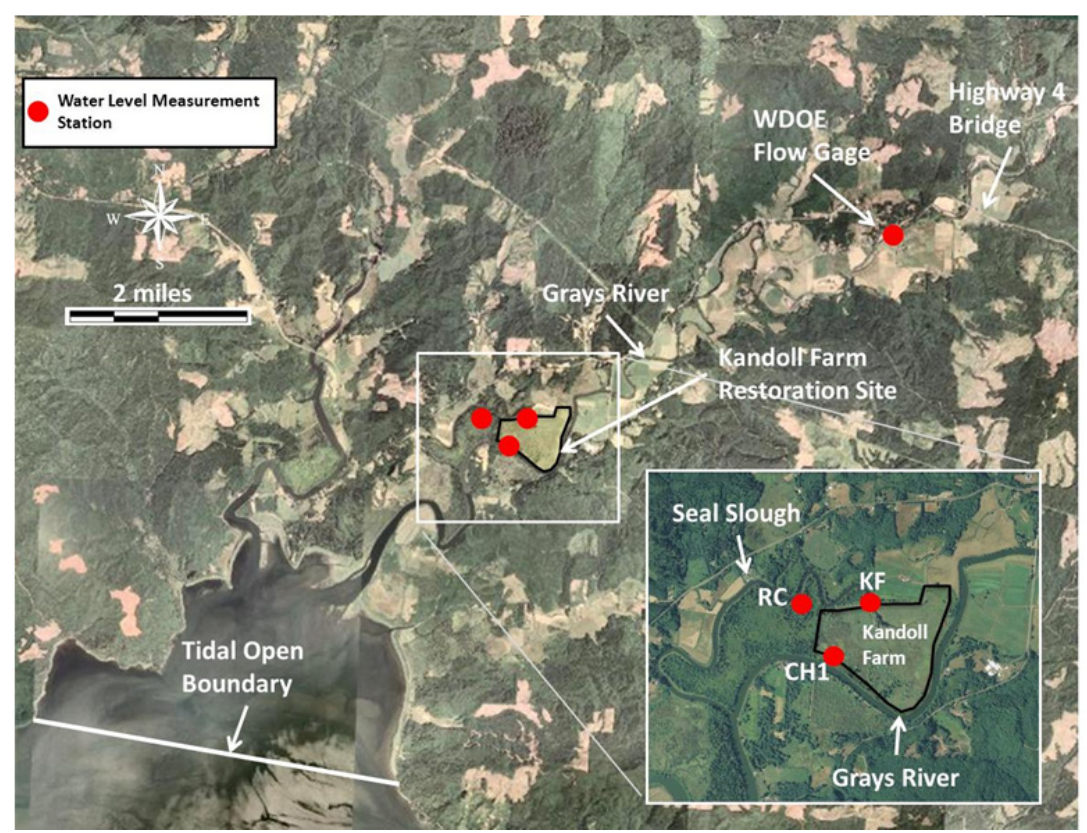

Figure E.1. Locations of Water-Level Stations, the Kandoll Farm Restoration Site, and Water Body Features Used in the POM Modeling Analysis

\section{E.1.2.1 Model Description}

We used the hydrodynamic model FVCOM (Chen et al. 2006) for the hydrodynamic simulation of the Grays River, including Seal Slough and Grays Bay. FVCOM is a three-dimensional finite volume model that uses an unstructured grid (composed of triangular elements) for defining the system's complex geometry. The hydrodynamic model solves depths, velocities, and water-surface elevations (WSEs) within the model domain based on the geometry of the system and the boundary conditions specified in the analysis. The model includes wetting and drying to handle the inundation of land surfaces due to WSE changes from tidal and runoff forcing. The boundary conditions for tidal and inflow data define the hydrodynamic forcing for the analysis. Because FVCOM is a fluid dynamics model, it uses a drag coefficient and roughness height to calculate bed friction of the channels and the floodplain.

We used the sediment transport model in FVCOM version 2.5.3 to simulate POM flux with the following assumptions:

- The POM loss occurred only in the herbaceous and leafy portions of the vegetation at the KF site. No loss or transport of woody debris was included in the analysis.

- The POM mass loss from the vegetation is approximated using a functional relation between fluid velocity, bed shear stress, and mass loss. The form of the relation is the same for sediment transport.

- After being stripped from the vegetation, the transport of POM is made using the advectiondispersion equation with no loss from POM decay.

- Settling from the water column does not occur during transport; however, POM can become stranded in grid cells that have dried after floodwaters have subsided or the tide has receded.

- No base flow is input to Seal Slough from tributary streams, so that during dry conditions all of the flow is due to tidal exchange. 


\section{E.1.2.2 Setup of the Hydrodynamic Model}

We previously developed a hydrodynamic model of the Grays River to evaluate the effect on flooding due to restoration (Breithaupt and Khangaonkar 2008), which used the finite element model RMA2 (King 2005). The RMA2 model domain included the Grays River, Seal Slough, and the floodplain from the mouth of the Grays River at Grays Bay to approximately 5 miles upstream of the mouth. The RMA2 model used an unstructured, two-dimensional grid to represent all the hydraulic features of the system. Because the RMA2 model grid is compatible with the FVCOM model grid, we used it as the starting point for the POM analysis. Modifications included improvements in grid resolution at the KF site, updating the floodplain topography with higher resolution light detection and ranging (LiDAR) data, improvements in channel geometry, and setting all grid cells as triangular. The updated grid and the corresponding grid bathymetry are shown in Figure E.2.

a)

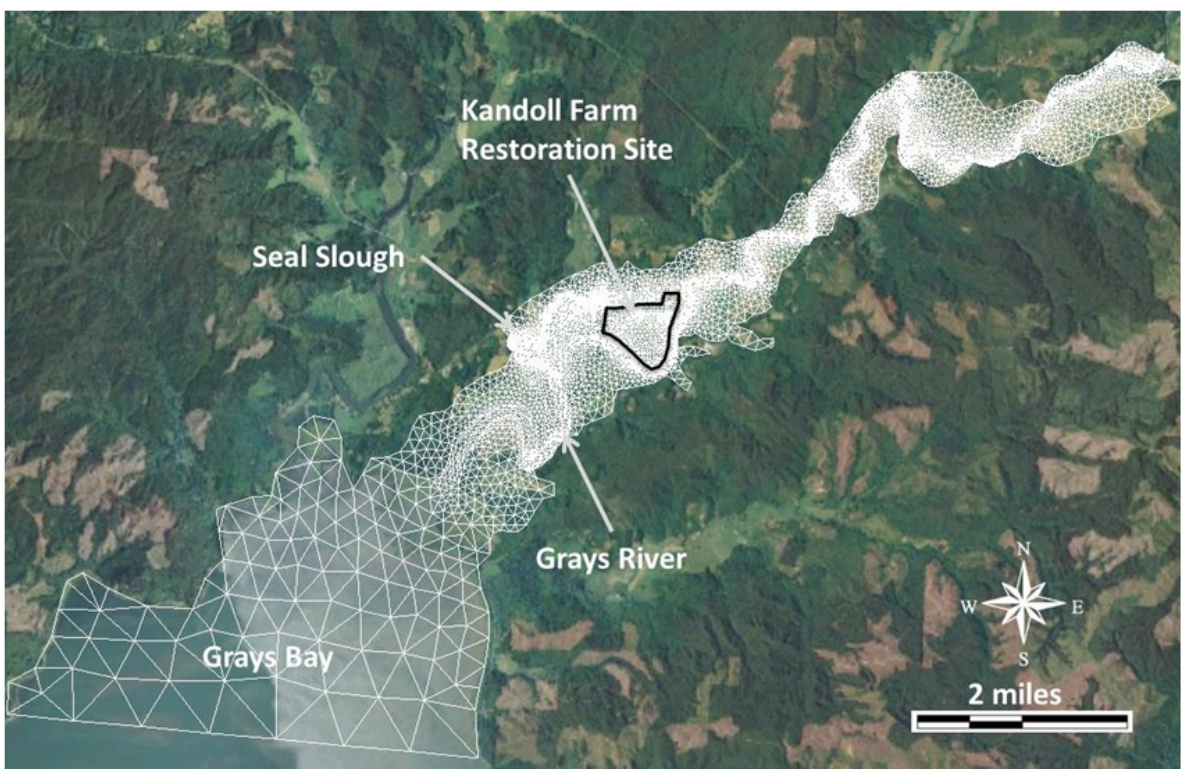

b)

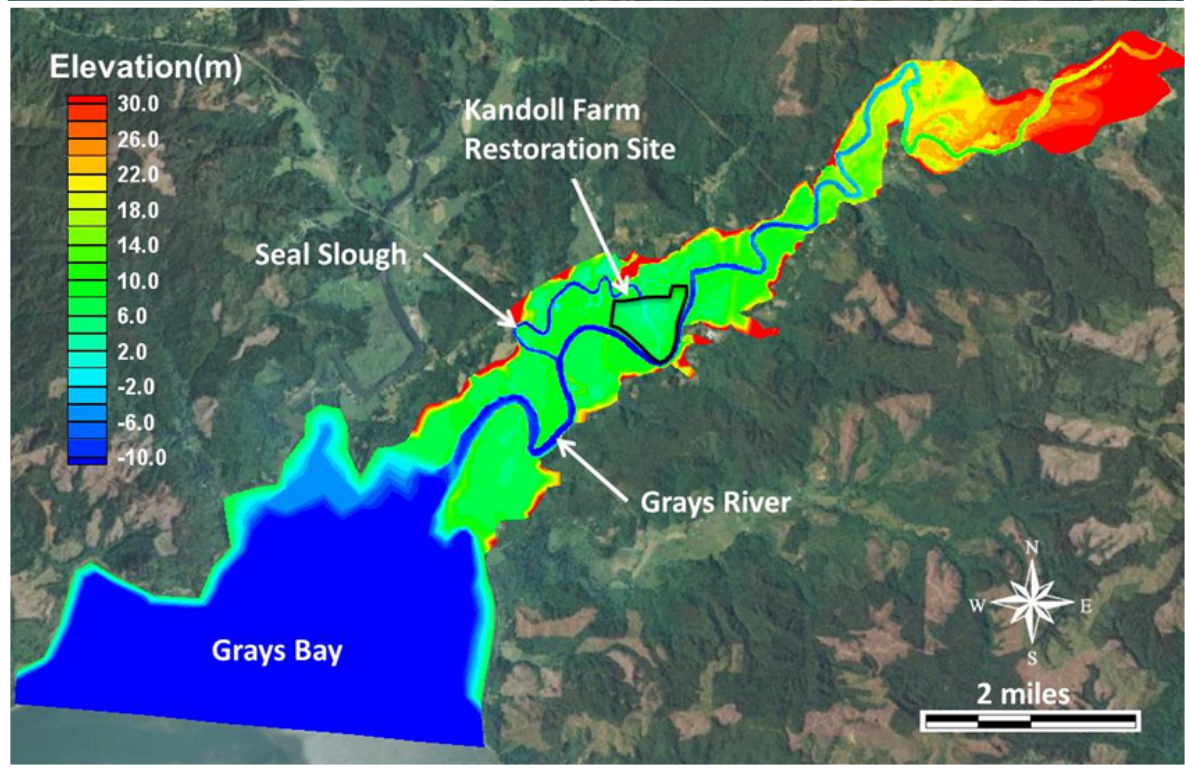

Figure E.2. The Grays River Basin Showing a) the Model Domain and b) the Bathymetry, Including the Kandoll Farm Restoration Site, Seal Slough, Grays River, and Grays Bay 


\section{E.1.2.3 Boundary Conditions}

The boundary condition inputs for the hydrodynamic model were tidal elevations at Grays Bay and the Grays River discharge. Streamflow data from the Grays River gauge station (ID 25B060) were obtained from the Washington Department of Ecology (WDOE) (H. Christensen, personal communication, April 1, 2008, now available on the website (https://fortress.wa.gov/ecy/wrx/wrx/ flows/station.asp?sta=25B060) for the period of record, including the POM analysis period from June 2006 through February 2007 (Figure E.3). Note that discharge above approximately $147 \mathrm{~m}^{3} / \mathrm{s}$ was estimated, with the largest measured discharge for developing the stage-flow rating curve equal to $75.9 \mathrm{~m}^{3} / \mathrm{s}$ (H. Christensen, personal communication, April 17, 2006). The flow records for Grays River show a distinct dry period when the flows were less than $20 \mathrm{~m}^{3} / \mathrm{s}$ until early November 2006 . This was followed by an abrupt change to a wet period with flows reaching $467 \mathrm{~m}^{3} / \mathrm{s}$ in November 2006 shortly after the onset of the wet period. Several smaller peak flow events occurred during the remainder of the POM analysis period (Figure E.3). These episodic peaks in streamflow are the result of winter storms.

Water-level data for the Columbia River and near Grays Bay, Washington, were obtained from the National Oceanic and Atmospheric Administration (NOAA) station near Astoria, Oregon, at Tongue Point (ID 9439040). This station includes effects from upstream flow from Bonneville Dam discharge as well as tidal influence. We also obtained tidal predictions for Harrington Point, Washington, the station closest to Grays Bay, using the NOAA tide prediction software, then combined both data sets to provide the water-level time series for Grays Bay.
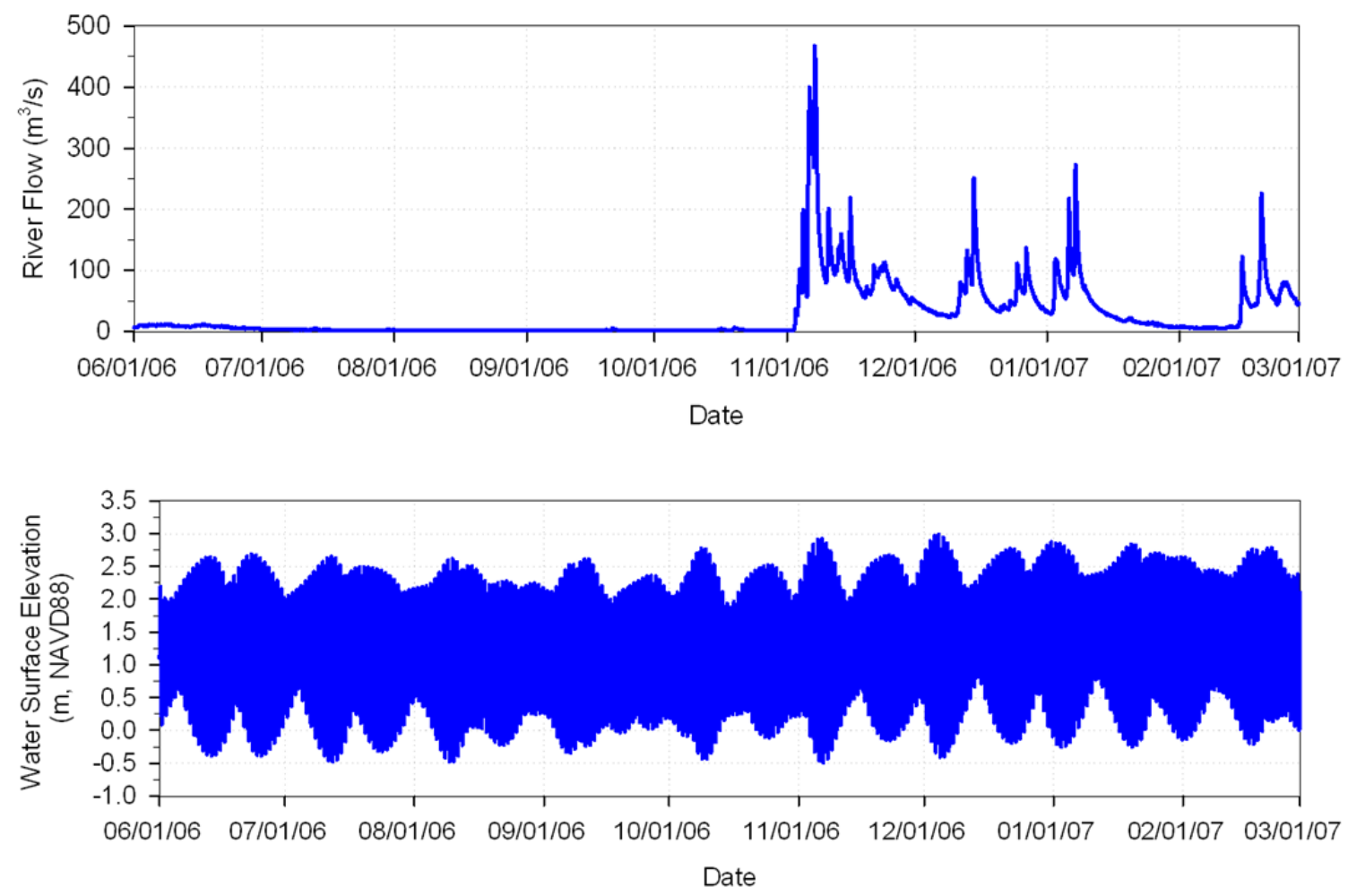

Figure E.3. Grays River Discharge from Station ID 25B060 and Tidal Elevations for Grays Bay Derived from NOAA Tide Measurements and Predictions 


\section{E.1.2.4 Validation of the Hydrodynamic Model}

The investigation of flooding in the Grays River by Breithaupt and Khangaonkar (2007) included the calibration of the RMA2 to WSEs measured at the KF site. For the POM analysis, we used the same WSE data set to validate the FVCOM hydrodynamic model (Figure E.4). The comparison shows that the FVCOM model closely follows the measured water levels at the sensor locations. In addition, the measured stage at the WDOE gage was included in the validation (Figure E.4). While the vertical datum of the gage is arbitrary, the comparison shows the trend of modeled WSE closely follows that of the measured stage. These comparisons show the model represents the hydrodynamics of the Grays River over the whole model domain.
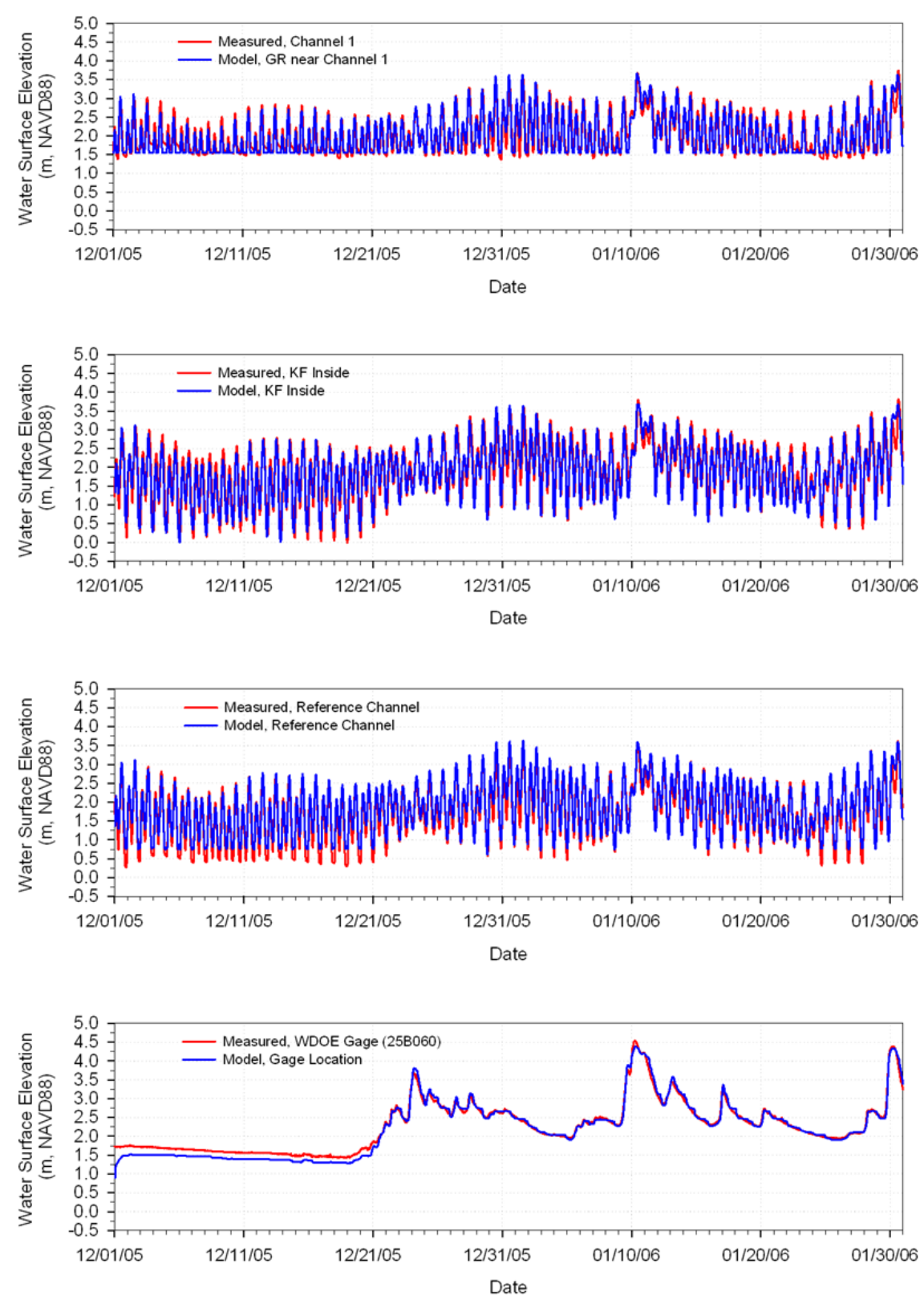

Figure E.4. Comparisons of Measured WSE and Model Results at Water-Level Sensor Station Locations and at the WDOE Gage Location 


\section{E.1.2.5 Calibration of the POM Model}

From vegetation sampling at the KF site, we estimated the vegetation biomass density (expressed as kilograms dry weight per square meter) during June 2006 to be $0.779 \mathrm{~kg} / \mathrm{m}^{2}$ (see Chapter 2.0 for collection methods and analysis). During February 2007 field sampling, the estimated biomass density was $0.372 \mathrm{~kg} / \mathrm{m}^{2}$. This was a loss of $0.407 \mathrm{~kg} / \mathrm{m}^{2}$ over the 246 -day interval. We calibrated the POM model via the loss rate coefficient to produce the estimated loss of biomass between the June 2006 and February 2007 analysis period. We compared the loss of the average biomass density from the model to data collected from the field sampling location (Figure E.5).

The calibration was conducted in two steps to streamline the efficiency needed for the complete 246-day simulation. The first step involved simulation over a 2-week period (late October 2006) during the dry period and a 4-week period (November 2006) during the wet period. We extrapolated the loss results for this step with a short duration simulation, to the entire POM analysis period. We adjusted the loss rate coefficient until the extrapolated biomass loss from the model was close to the measured biomass density loss of $0.407 \mathrm{~kg} / \mathrm{m}^{2}$. After this adjustment, the second step involved simulation over the entire analysis period of 246 days between June 1, 2006 and February 28, 2007 to confirm the modeled biomass loss using the extrapolated loss rate coefficient produced a result close to the measured biomass loss.

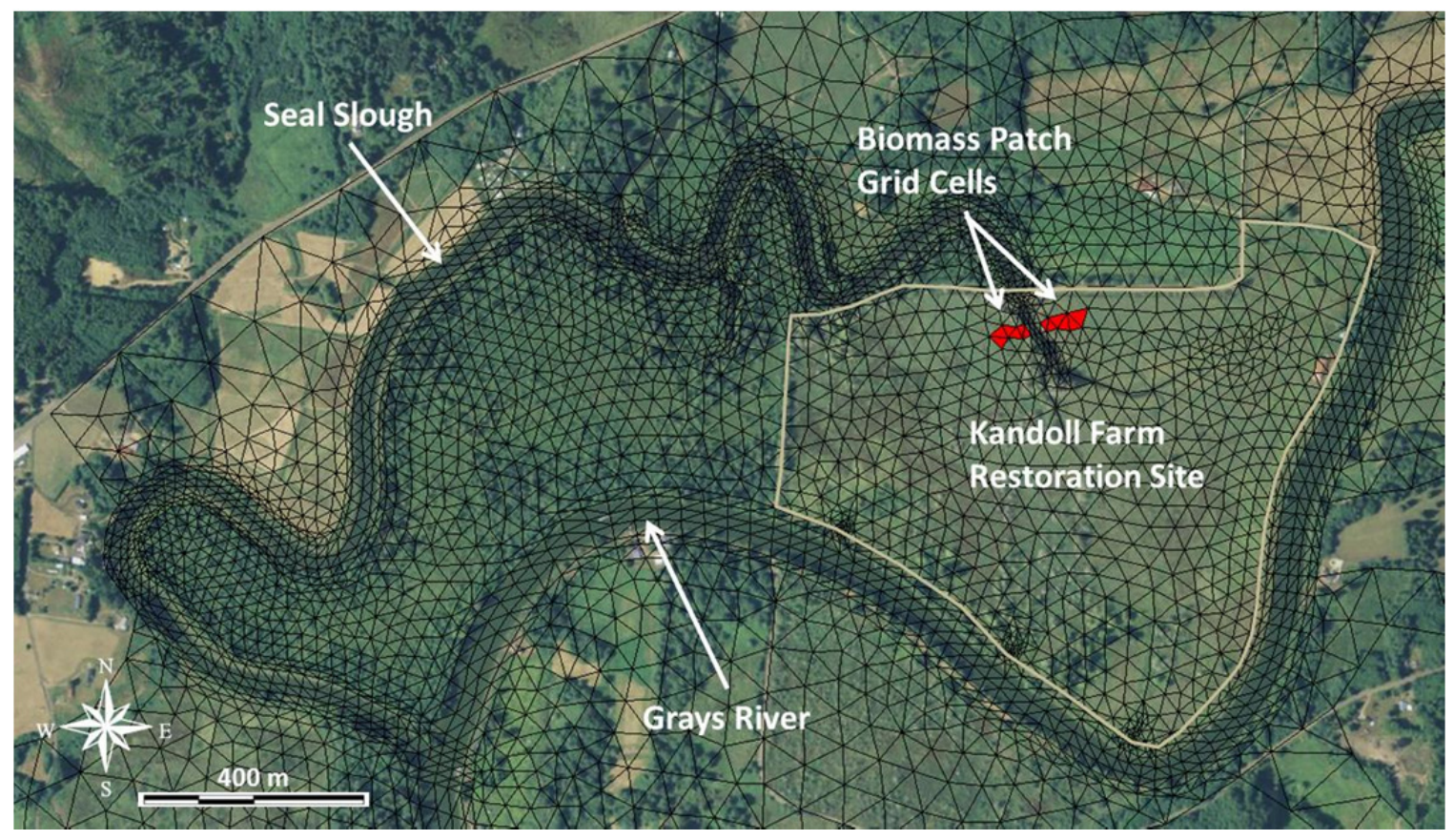

Figure E.5. Biomass Patch Grid Cells (indicated in red) Used for Calibration of Biomass Loss Based on Field Measurements Between June 2006 and February 2007

\section{E.2 Results}

The results cover the 2009 intensive material and nutrient flux field measurements at the KF site, the modeling analysis of flux of POM, and the KF pre- and post-restoration water properties. 


\section{E.2.1 2009 Intensive Material and Nutrient Flux Field Measurements}

The time series of nutrient, TOC, and suspended sediment data collected during April 2009 neap and spring tides were designed to provide detailed information about the rates of fine particulate and dissolved material exchange during the spring season. This information was designed to complement nutrient and TOC data collected on a coarser scale during 2005, 2006, and 2007 (discussed in Section E.3.3).

Spring and neap tidal conditions resulted in differences in water residency and exchange. Water level during the spring tide series of 8-10 April ranged between 0.17 and $2.78 \mathrm{~m}$, with a range of $2.61 \mathrm{~m}$ during the approximate 48-hour sampling period (Figure E.6a - Flood 1 through Ebb 5). Flood and ebb ranges were approximately equal and led to a substantial flushing of the marsh. The time series of water level and the concentration of selected water-property constituents are shown in Figures E.6b-d. The mean concentration for each constituent during the ebb and flood tide are shown in Table E.1. Both Table E.1 and Figure E.6 show high variability in concentrations between sequential sample collections for most constituents, although notable temporal trends exist for a few parameters. The concentration of TOC progressively increases through time during each ebb tide and progressively decreases through time during each flood tide, while $\mathrm{NO}_{3}$ shows the opposite trend with a progressive increase during each flood tide and decrease during each ebb tide. This is expressed in a correlation matrix (Table E.2) as a statistically significant negative correlation between water level and TOC (-0.94) and a significant positive correlation between water level and nitrate (0.92). There is also a significant negative correlation between TOC and $\mathrm{NO}_{3}(-0.95)$. A positive correlation exists between TSS and inorganic suspended sediments (ISS) (0.97), which is explained by the high inorganic fraction (79\%) of TSS reported in the last annual report (Woodruff et al. 2010).

Table E.1. Mean Concentration $\left(\mathrm{mg} / \mathrm{m}^{3} \pm 1 \mathrm{SD}\right)$ of Water Property Constituents from the Spring Ebb and Flood Tide (two full semidiurnal periods) and the Neap Ebb and Flood Tide (one full semidiurnal period) During April 2009 at the Kandoll Farm Restoration Site

\begin{tabular}{lcccc}
\hline & \multicolumn{2}{c}{ Spring Tide (2 semidiurnal tides) } & \multicolumn{2}{c}{ Neap Tide (1 semidiurnal tide) } \\
\hline $\mathrm{mg} / \mathrm{m}^{3}$ & $\mathrm{Ebb}$ & Flood & $\mathrm{Ebb}$ & Flood \\
\hline $\mathrm{TOC}$ & $2348(946)$ & $1806(1038)$ & $3786(777)$ & $3344(583)$ \\
& $\mathrm{n}=17$ & $\mathrm{n}=15$ & $\mathrm{n}=9$ & $\mathrm{n}=8$ \\
$\mathrm{PO}_{4}$ & $125(111)$ & $112(139)$ & $139(138)$ & $104(63)$ \\
& $\mathrm{n}=17$ & $\mathrm{n}=15$ & $\mathrm{n}=9$ & $\mathrm{n}=8$ \\
$\mathrm{SiO}_{4}$ & $4347(1575)$ & $4128(1762)$ & $2403(1116)$ & $2745(786)$ \\
& $\mathrm{n}=17$ & $\mathrm{n}=15$ & $\mathrm{n}=9$ & $\mathrm{n}=8$ \\
$\mathrm{NO}_{3}$ & $188(60)$ & $233(81)$ & $156(22)$ & $164(16)$ \\
& $\mathrm{n}=17$ & $\mathrm{n}=15$ & $\mathrm{n}=9$ & $\mathrm{n}=8$ \\
$\mathrm{NH}_{4}$ & $39(19)$ & $27(17)$ & $34(14)$ & $40(34)$ \\
& $\mathrm{n}=17$ & $\mathrm{n}=15$ & $\mathrm{n}=9$ & $\mathrm{n}=8$ \\
$\mathrm{TSS}$ & $9025(4012)$ & $8876(2683)$ & $5862(1001)$ & $6810(2712)$ \\
& $\mathrm{n}=17$ & $\mathrm{n}=15$ & $\mathrm{n}=9$ & $\mathrm{n}=8$ \\
\hline
\end{tabular}



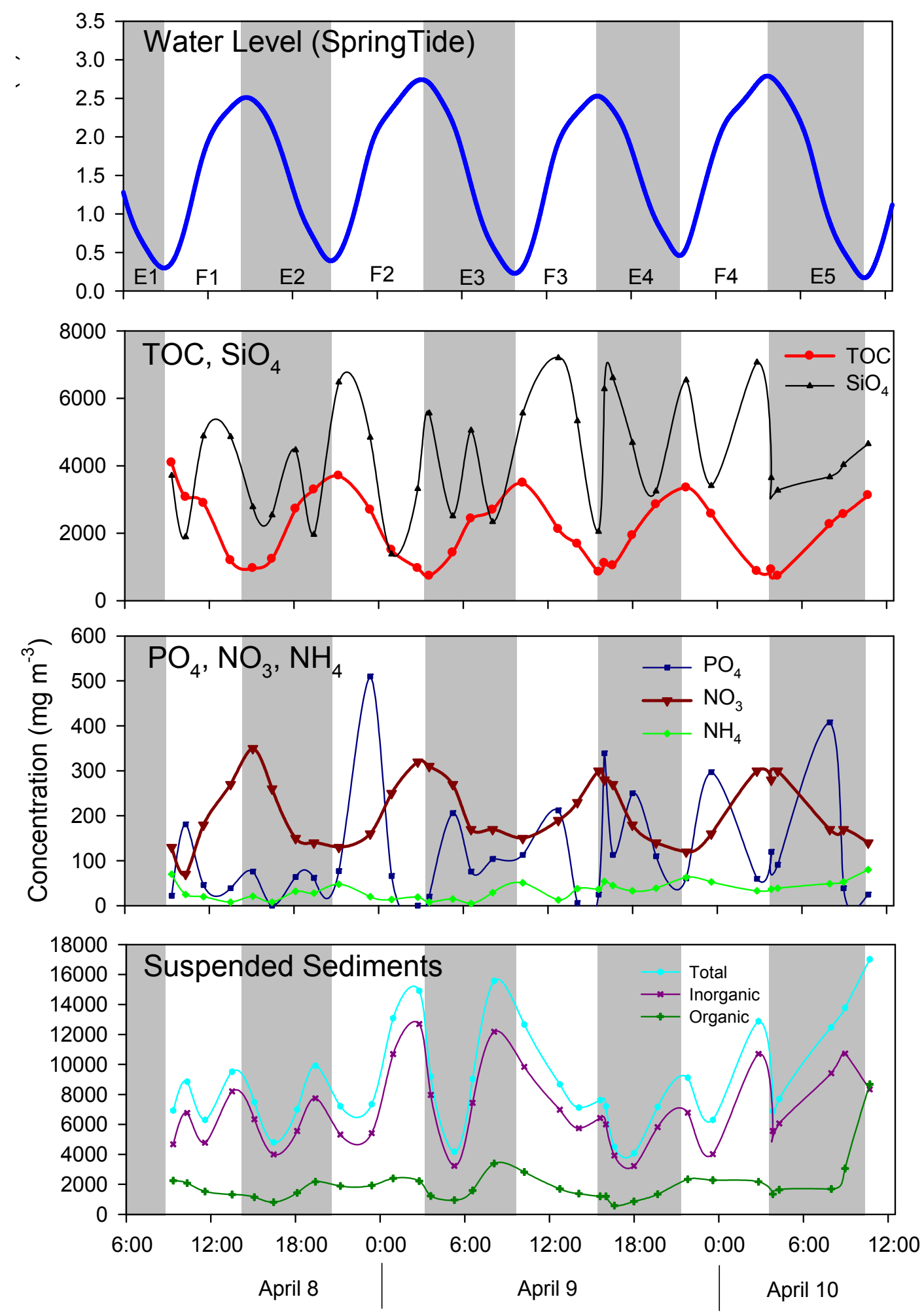

Figure E.6. April 2009 Spring Tide Series Showing a) Water Level for Flood (F1-F4) and Ebb (E2-E5) Tides and Concentrations of b) TOC and $\mathrm{SiO}_{4}$, c) $\mathrm{PO}_{4}, \mathrm{NO}_{3}$, and $\mathrm{NH}_{4}$, and

d) Total Inorganic and Organic Suspended Sediments Through Time. Ebb tides are shaded gray. 
Table E.2. Correlation Matrix of Variables Analyzed with Spring Tide Series (8-10 April 2009; $n=$ 32 variable pairs) Shown in Lower Left (bold) and Neap Tide Series (15-16 April 2009; n= 19 variable pairs) Shown in Upper Right (italics). Correlations greater than 0.7 are highlighted in gray.

\begin{tabular}{|c|c|c|c|c|c|c|c|c|c|}
\hline & $\begin{array}{l}\text { Water } \\
\text { Level } \\
(\mathrm{cm}) \\
\end{array}$ & TOC & $\mathrm{PO}_{4}$ & $\mathrm{SiO}_{4}$ & $\mathrm{NO}_{3}$ & $\mathrm{NH}_{4}$ & TSS & ISS & OSS \\
\hline Water level $(\mathrm{cm})$ & 1.00 & 0.14 & -0.34 & -0.32 & -0.10 & 0.02 & 0.36 & 0.31 & 0.10 \\
\hline TOC & -0.94 & 1.00 & -0.07 & 0.38 & -0.84 & 0.89 & -0.20 & -0.23 & 0.12 \\
\hline PO4 & -0.06 & 0.10 & 1.00 & -0.06 & 0.05 & -0.03 & 0.01 & 0.08 & -0.02 \\
\hline $\mathrm{SiO} 4$ & -0.02 & 0.04 & 0.04 & 1.00 & -0.42 & 0.56 & -0.02 & 0.01 & 0.18 \\
\hline NO3 & 0.92 & -0.95 & -0.17 & -0.00 & 1.00 & -0.77 & -0.15 & -0.06 & -0.32 \\
\hline NH4 & -0.42 & 0.36 & 0.13 & 0.19 & -0.40 & 1.00 & -0.10 & -0.11 & 0.11 \\
\hline TSS & -0.18 & 0.06 & -0.26 & -0.05 & -0.04 & -0.00 & 1.00 & 0.94 & 0.57 \\
\hline ISS & -0.05 & -0.06 & -0.26 & -0.05 & 0.09 & -0.07 & 0.97 & 1.00 & 0.33 \\
\hline OSS & -0.58 & 0.56 & -0.09 & -0.05 & -0.52 & 0.34 & 0.68 & 0.59 & 1.00 \\
\hline
\end{tabular}

ISS = inorganic suspended sediments; OSS = organic suspended sediments; TOC = total organic carbon; TSS $=$ total suspended sediments.

The water levels during the neap tide series of 15-16 April 2009 were unequal, and ranged between 0.23 and $2.38 \mathrm{~m}$, with an overall water-level exchange of $2.15 \mathrm{~m}$ through the approximate 36-hour tidal exchange sampled (Figure E.7a). Ebb2 and flood2 were of moderate amplitude, which resulted in less flushing of the wetland. Water levels and the concentrations of nutrients and suspended sediments are given in Table E.1 and Figure E.7b-d. The strong correlations found between water level and TOC, and water level and $\mathrm{NO}_{3}$ during the spring tide series are not evident during the neap tide series (Table E.2, upper right). However, the strong negative correlation between $\mathrm{TOC}$ and $\mathrm{NO}_{3}$ is still evident in the neap tide series (-0.84) (Figure E.7b-c, Table E.2) as is the correlation between TSS and ISS (0.94) (Table E.2). During the neap tide, a strong positive correlation was present between $\mathrm{NH}_{4}$ and $\mathrm{TOC}(+0.89)$ as well as a negative correlation between $\mathrm{NH}_{4}$ and $\mathrm{NO}_{3}(-0.77)$. Overall the trends between water level and constituent concentrations are less pronounced compared to the spring tide series.

The transport rates of specific constituents through time for the spring and neap tides are shown in Figures E.8 and E.9. Not surprisingly, most constituents exhibit an increase in transport rate during the mid to latter part of each tidal cycle when the flow rate is the greatest, with minimal transport near slack high or low tide. The peak transport rates for all constituents are higher during the spring tide ebb and flood components compared to the neap tide ebb and flood. The averaged transport rate of specific constituents for each ebb and flood period of the neap and spring tide are shown in Figure E.10 (TOC, $\left.\mathrm{SiO}_{4}, \mathrm{TSS}\right)$ and Figure E.11 $\left(\mathrm{NO}_{3}, \mathrm{NH}_{4}, \mathrm{PO}_{4}\right)$. In most cases, the average transport rate of all constituents is higher during all spring flood and ebb tidal cycles when compared to the neap tidal cycles. A notable exception is the neap flood tide (F2) TOC transport rate, which is higher than most spring flood tides (F2, F3, F4) (Figure E.10). 

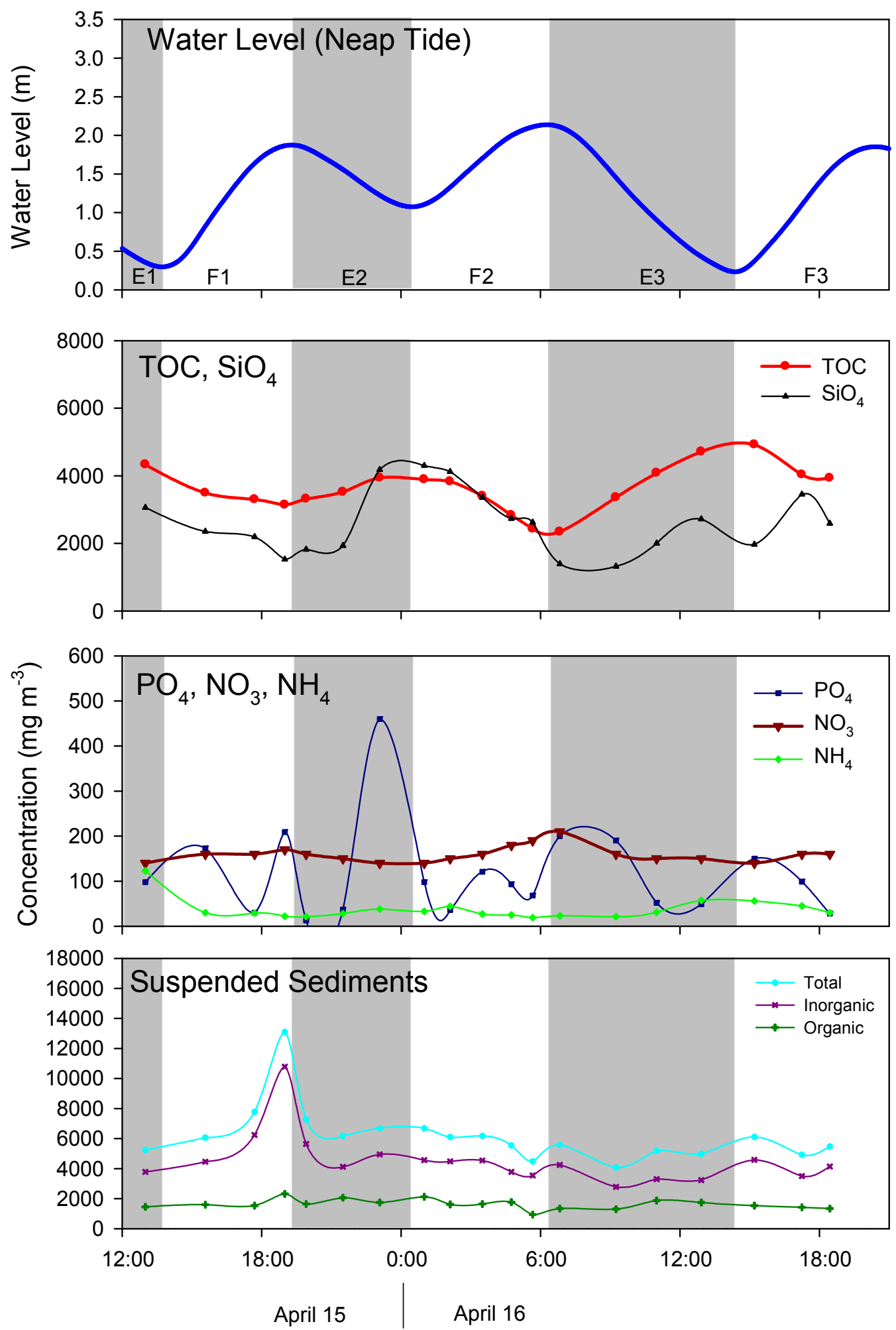

Figure E.7. April 2009 Neap Tide Series Showing a) Water Level for Flood (F1-F3) and Ebb (E1-E3) Tides and Concentrations of b) TOC and $\mathrm{SiO}_{4}, \mathrm{c}$ ) $\mathrm{PO}_{4}, \mathrm{NO}_{3}$, and $\mathrm{NH}_{4}$, and d) Total Inorganic and Organic Suspended Sediments over Time. Ebb tides are shaded gray. 

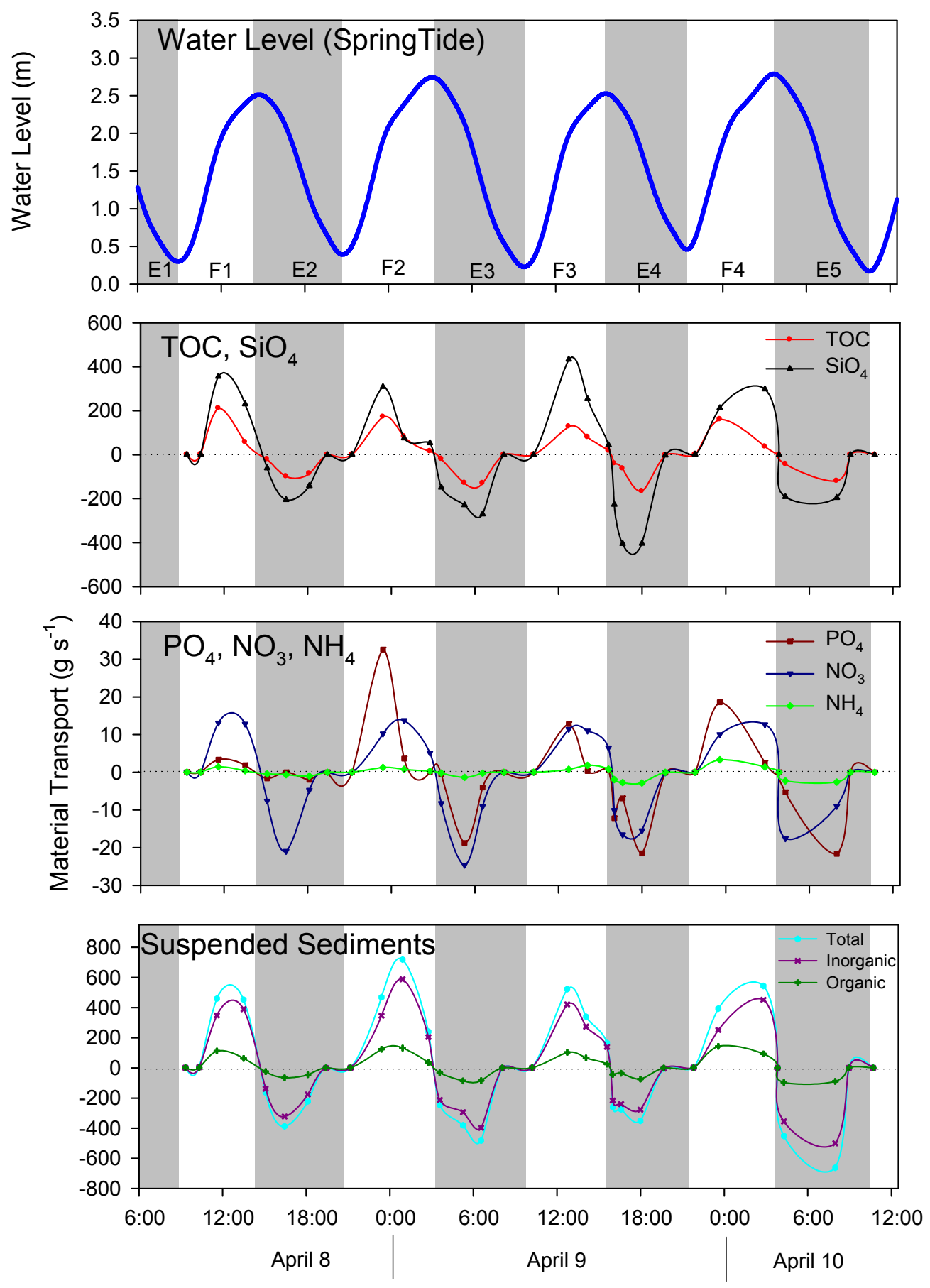

Figure E.8. The Rate of Transport of Nutrients, TOC, and Suspended Sediments Collected Through Time During the April 2009 Spring Tide 

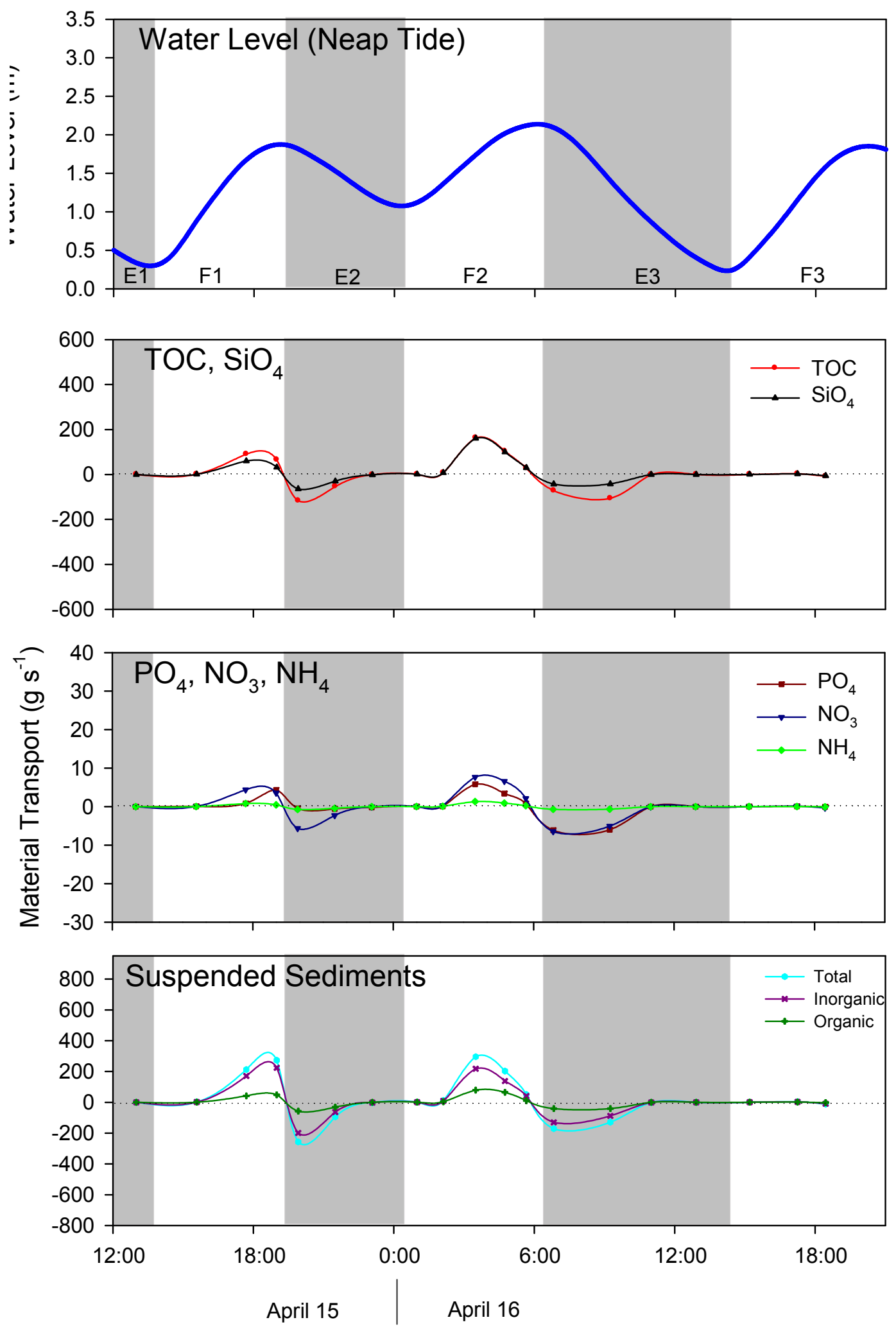

Figure E.9. The Rate of Transport of Nutrients, TOC, and Suspended Sediments Collected Through Time During the April 2009 Neap Tide 


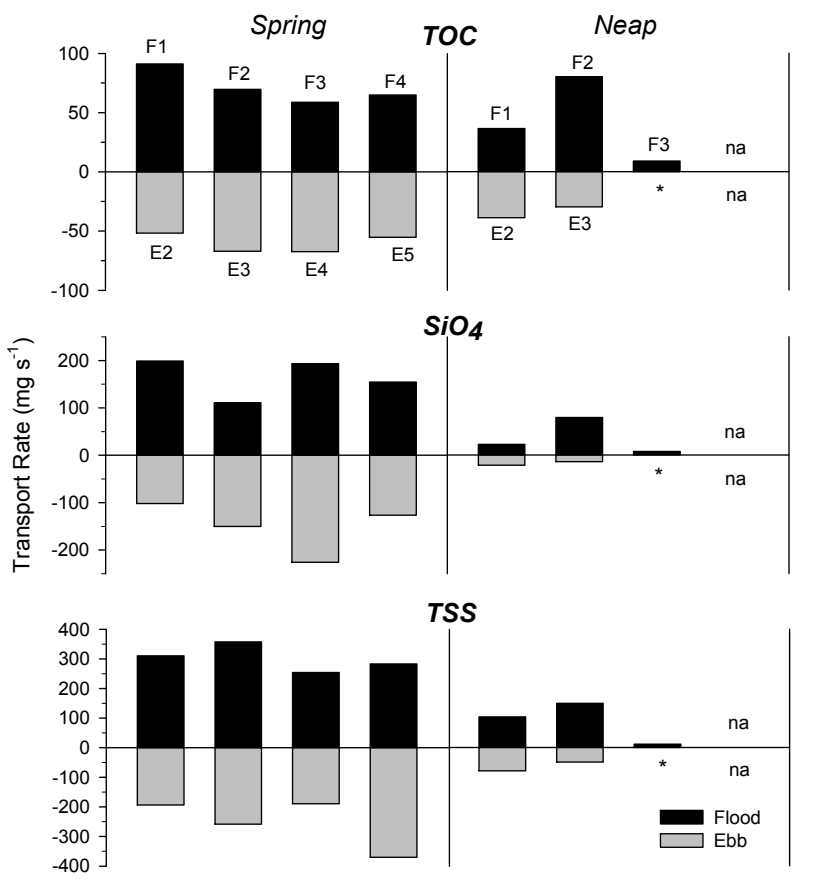

Figure E.10. The Average Transport $\left(\mathrm{mg}^{\mathrm{s}-1}\right.$ ) for Each Ebb and Flood Tide Paired for $\mathrm{TOC}, \mathrm{SiO}_{4}$, and TSS Separately for Spring and Neap Tidal Cycles
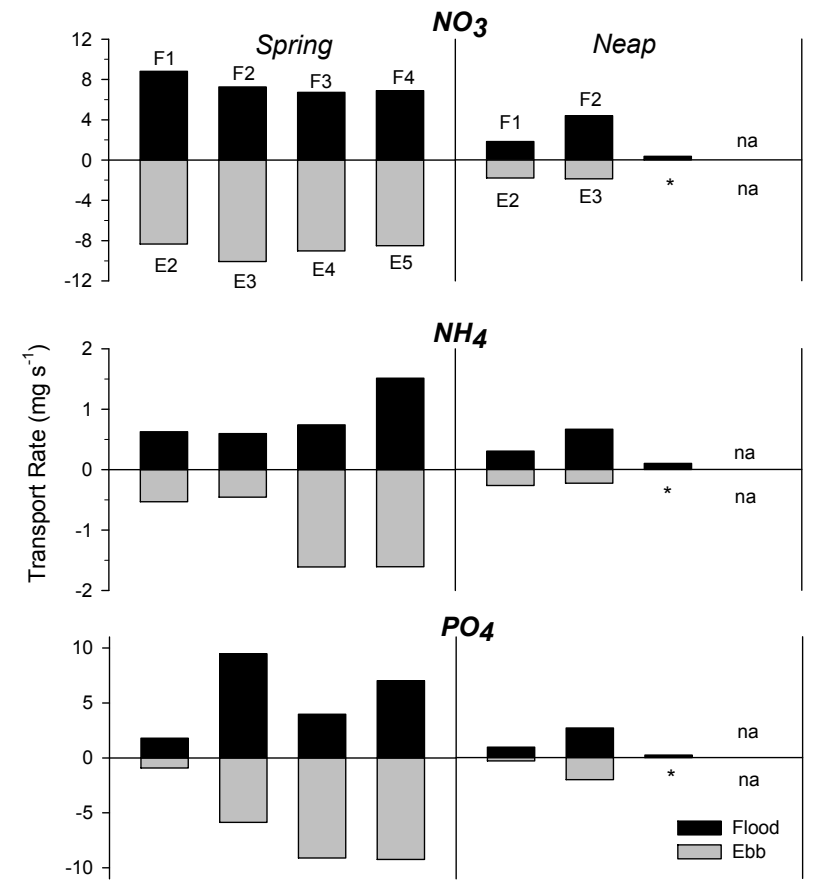

Figure E.11. The Average Transport $\left(\mathrm{mg} \mathrm{s}^{-1}\right)$ for Each Ebb and Flood Tide Paired for $\mathrm{NO}_{3}, \mathrm{NH}_{4}$, and $\mathrm{PO}_{4}$ Separately for Spring and Neap Tidal Cycles 
Using the concentration data collected at each time period and the volume of water exchanged, we estimated the total amount material transported in and out of the KF marsh for a 24-hour tidal cycle during the April 2009 neap and spring tides. The net exchange of this material is shown in Table E.3. With a few exceptions, the predominant trend is toward an import of constituents during both the spring and neap tides, including TOC, $\mathrm{SiO}_{4}, \mathrm{NH}_{4}$, and suspended sediments. $\mathrm{NO}_{3}$ was exported during both neap and spring tides and $\mathrm{PO}_{4}$ was imported during the spring tide and exported during the neap tide.

Table E.3. Total Kilograms of Material Transported During a Semidiurnal Tidal Cycle During Spring and Neap Tides in April 2009. Positive values reflect material transported into the KF site, negative values reflect material transported out of the KF site.

\begin{tabular}{ccccccc}
\hline & Spring Tide (8-9 April, 2009) & \multicolumn{4}{c}{ Neap Tide (15-16 April 2009) } \\
\hline $\mathrm{kg}$ & Flood & Ebb & Net exchange & Flood & Ebb & Net exchange \\
\hline $\mathrm{TOC}$ & 3365 & -2524 & 841 & 2184 & -2119 & 65 \\
$\mathrm{PO}_{4}$ & 270 & -143 & 127 & 67 & -91 & -24 \\
$\mathrm{SiO}_{4}$ & 6324 & -5355 & 969 & 1847 & -1071 & 776 \\
$\mathrm{NO}_{3}$ & 339 & -392 & -53 & 115 & -120 & -5 \\
$\mathrm{NH}_{4}$ & 26 & -21 & 5 & 18 & -16 & 2 \\
$\mathrm{TSS}$ & 14493 & -9602 & 4891 & 4900 & -3847 & 1053 \\
$\mathrm{ISS}$ & 11587 & -7850 & 3737 & 3746 & -2815 & 931 \\
$\mathrm{OSS}$ & 2907 & -1753 & 1154 & 1154 & -1028 & 126 \\
\hline
\end{tabular}

\section{E.2.2 Analysis of POM Flux}

For the POM flux analysis, we specified an initial biomass density of $0.779 \mathrm{~kg} / \mathrm{m}^{2}$ for the entire KF site (Figure E.12a, blue background). We computed the flux from the biomass density loss, which provided the upper bound of biomass available for transport. Figures E.12a, c, e show the biomass density changes between the June 2006 and February 2007 simulation periods. The largest biomass losses occurred during the wet period between the times shown in Figure E.12c (early November 2006) and Figure E.12e (mid-February 2007). Large biomass losses occurred primarily during storm events when high flow rates entered (northeast corner) and exited (dike breaches and west side) the KF site. To calculate the POM flux from biomass density loss, the average biomass density at each hourly output time was multiplied by the area of the KF site to compute total biomass remaining, and the difference between biomass over each interval provided the average flux $(\mathrm{kg} / \mathrm{s})$ throughout the KF site for each hourly interval.

Figures E.12b, d, f show the spatial distribution of POM concentration due to loss of biomass from the KF site and transport downstream between the June 2006 through February 2007 simulation period. At the outset of the simulation (hour 1) (Figure E.12b), POM concentrations were negligible, but before the onset of the wet period in November 2006, POM concentration had increased at the KF site; however there was negligible concentration in nearby channels (Figure E.12d). During this time period tidal exchange was driving the mobilization and redistribution of POM around the KF site, with little efflux from the site. Efflux from the KF site occurred only after the onset of the wet period in November 2006. The peak flood in November 2006 flushed through the KF site and was followed by high flows in the Grays River, which produced a greater range of inundation at the site (Figure E.12f). 
To evaluate the potential capture of POM in various locations in the floodplain, we calculated POM flux due to efflux from the KF site at hourly intervals at four locations: 1) the KF site, 2) downstream of the KF site (Below KF), 3) downstream of the confluence of Seal Slough with the Grays River (Confluence), and 4) the mouth of the Grays River (Mouth) (Figure E.13). At locations downstream of the KF site, we used three transects (shown in red in Figure E.13) that crossed the floodplain and channels to compute instantaneous POM flux. The flux was computed along the transect at each grid cell face and the individual cell-face fluxes were summed to provide the total flux along the transect at the hourly output times. The velocity of each grid cell was multiplied by the width and average depth at the cell face to estimate flow $\left(\mathrm{m}^{3} / \mathrm{s}\right)$. The average POM concentration $\left(\mathrm{kg} / \mathrm{m}^{3}\right)$ on the grid cell face was multiplied by the flow to then estimate POM mass flux $(\mathrm{kg} / \mathrm{s})$. The cumulative POM mass change was computed by summing the instantaneous fluxes over the simulation period after multiplying by $3600 \mathrm{~s} / \mathrm{hr}$. Note that the cumulative mass change magnifies any mass conservation errors resulting from the model's internal computations of POM transport at 2.5-s intervals and the external calculations of POM flux at hourly intervals.

a)
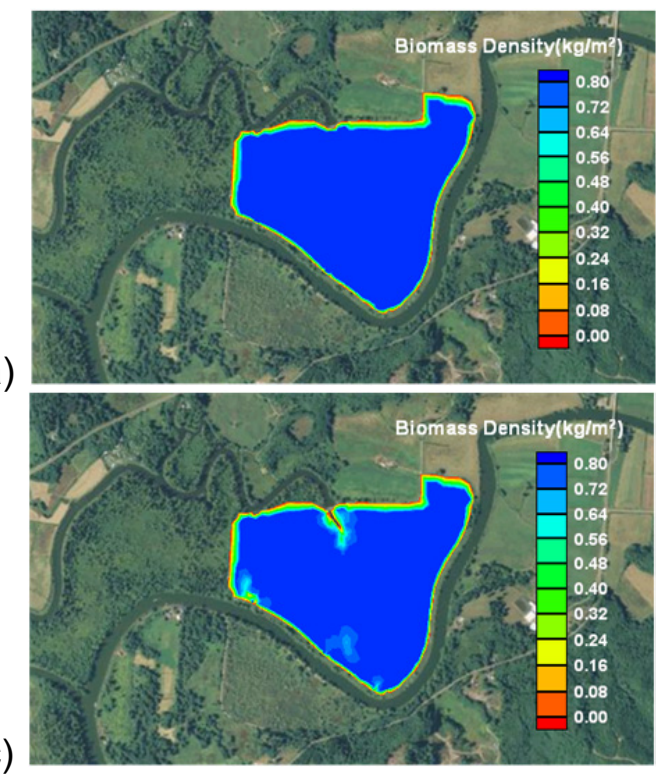

c)

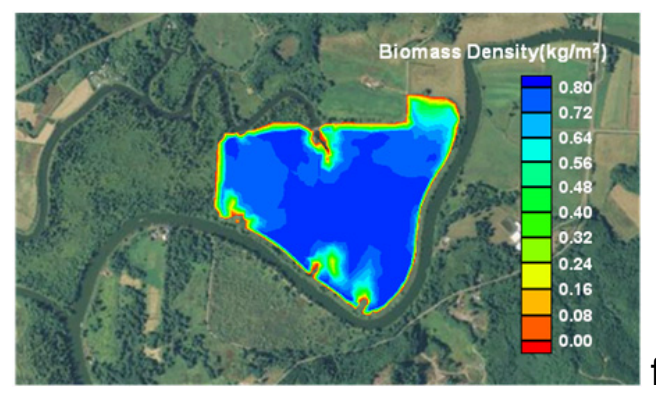

b)

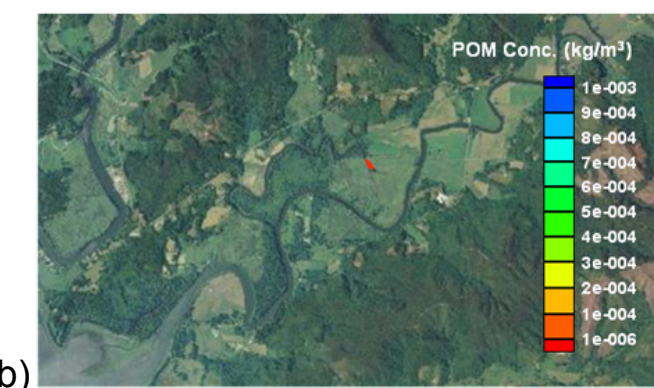

d)
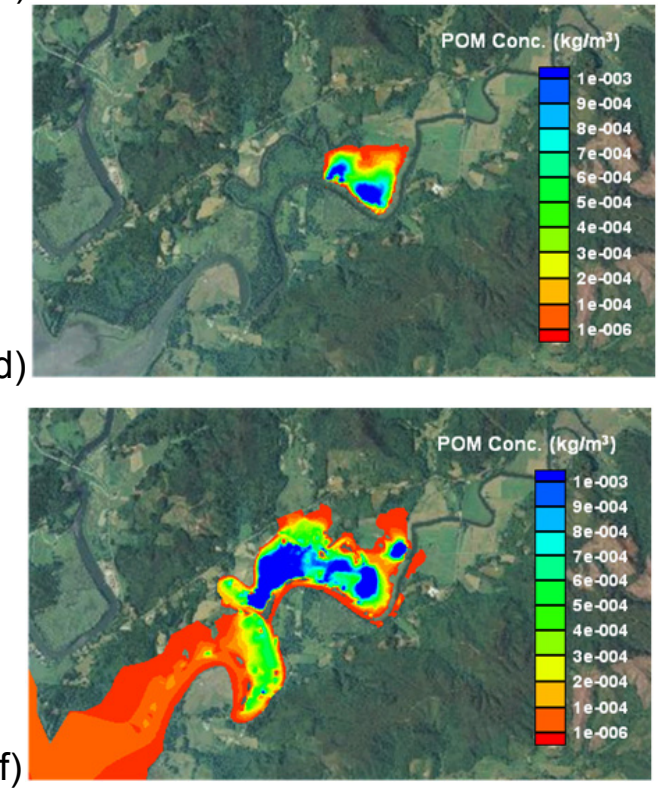

Figure E.12. Biomass Density (a) and POM Concentration (b) at the Beginning (Hour 1; 15 Jun 2006); Density (c) and Concentration (d) Prior to the Onset of the Wet Season (Hour 3394; 03 Nov 2006); and Density (e) and Concentration(f) at the End of the Simulation (Hour 5904; 15 Feb 2007) 


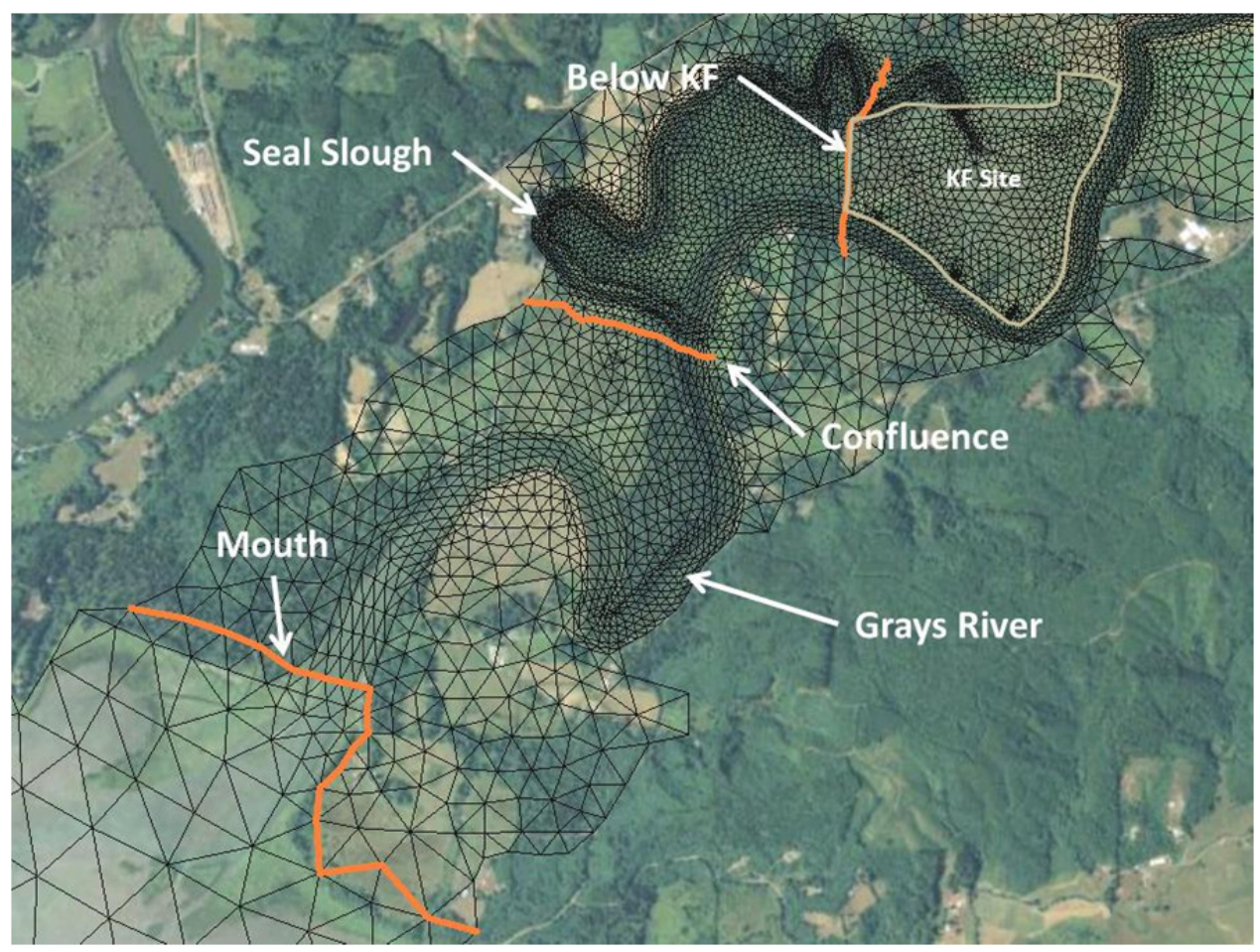

Figure E.13. Locations of POM Flux Calculations. 1) KF site, 2) downstream of the KF site (Below KF), 3) downstream of the confluence of Seal Slough with the Grays River (Confluence), and 4) at the mouth of the Grays River (Mouth). Red lines indicate the location of the three transects where POM flux was calculated.

Figure E.14 shows the instantaneous flow across the three transects referenced in Figure E.12. Negative flow indicates the direction is outward from the system (i.e., downstream from the KF site). The peak flood event of the year can be seen in early November 2006, with higher river flows and smaller floods later. The peak flood overtopped the dike upstream of the KF site, which resulted in a flush of floodwater through the site. The peak flood was composed of two events separated by about 12 hours, with other smaller floods occurring later. During the peak flood event and the remainder of November 2006, net flows at all transects were directed downstream (negative flows). After mid-January 2007 the flow returns to conditions similar to the period prior to the peak flood. Note the increase in tidal exchange from upstream (Below KF) to downstream (Mouth) as indicated by the larger range of flows (Figure E.14).

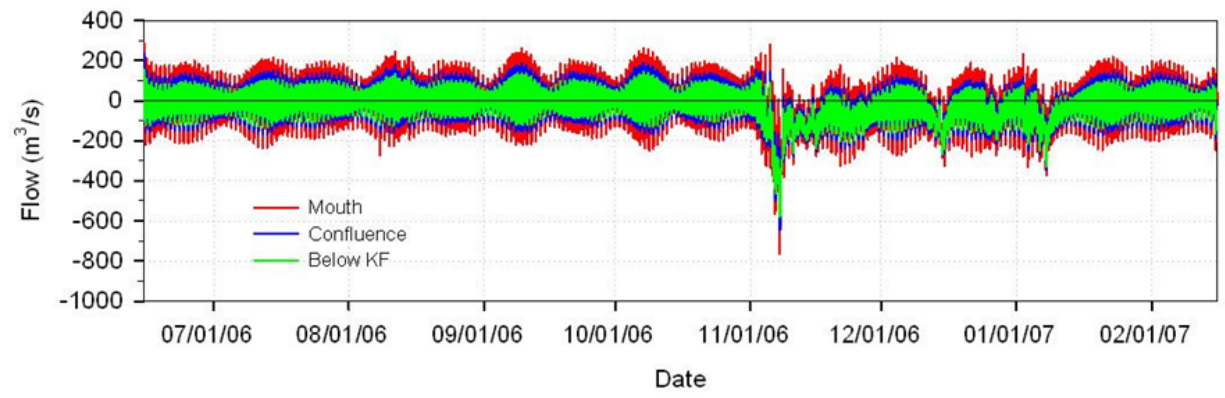

Figure E.14. Flow Variation at the Three Transects Where Flux Calculations Were Computed (at the mouth of the Grays River [Mouth], downstream of the confluence of Seal Slough [Confluence] and Grays River, and downstream of the KF site [Below KF]) 
The instantaneous POM flux at hourly intervals for the entire simulation period is shown in Figure E.15. The largest flux is at the KF site and the smallest is at the Mouth. At the KF site, the pulses of increased flux prior to the peak flood do not result in transport downstream, instead any POM entrained into transport is redistributed around the KF site, as noted in Figure E.12d. It is not until the peak flood event that transport occurs through the downstream transects (negative POM flux or efflux). After the pulse of efflux during the peak flood event, the Confluence transect exhibited oscillating transport, with positive (inflow) and negative (outflow) flux, indicating net POM flux from the system is reduced. We attribute this to the reduction in outflow after mid January 2007 shown in Figure E.14.

Figure E.15b shows the detailed response of POM flux during the peak flood and several days after the flood. During the peak flood, the KF site initially exhibits large spikes in flux. During this early stage of the peak flood, river flows increased, resulting in larger inundations at flood tide and spikes in POM mobilization. As the peak flood washed through the KF site during November 6, 2006, because of overtopping of dikes upstream, POM flux at the KF site continued to respond to tidal exchange, but with the additional influence of the flood washing through the site. POM flux from the KF site increased, producing increased flux through the Below KF transect. This was followed by smaller increases in flux at transects downstream of the Confluence in the subsequent ebb of the flood tide. POM flux at the Mouth increased only slightly during this tidal ebb. A larger pulse of POM flux occurred on November 7, 2006, at the KF site, with sequentially decreasing magnitudes of flux occurring through each downstream transect. This decrease is attributed to storage in the Grays River system (floodplain and channels).

a)
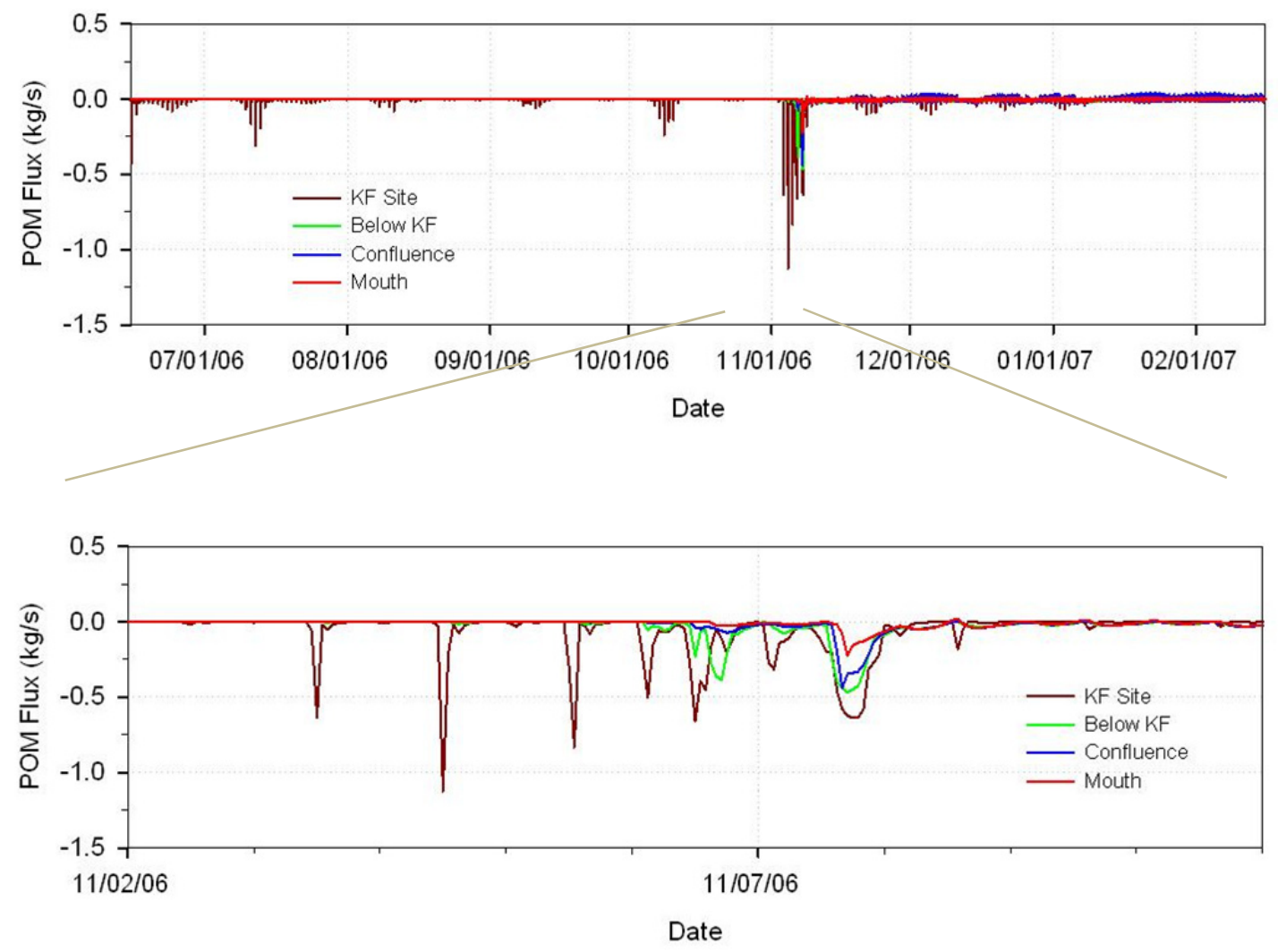

b)

Figure E.15. POM Flux at Four Locations (a). The inset (b) shows a 9-day period illustrating details of the flux during the peak flood of November 2006. 
The cumulative POM mass change at the four site locations is presented in Figure E.16. The effect of the peak flood produced a sharp decrease in POM from the system. Note that the cumulative mass change at the KF site shows the total POM mass mobilized by hydrodynamic forces. By the end of the simulation, approximately 94,000 (metric ton $=1000 \mathrm{~kg}$ ) $\mathrm{kg}$ dry weight of POM had been mobilized at the KF site. At the transect location Below KF, the estimated cumulative POM mass change was approximately $96,000 \mathrm{~kg}$ dry weight; this slightly larger value of KF mass mobilized is attributed to the difference in methods used to calculate flux at the KF site and the other three locations, with the likelihood of error magnification in the instantaneous hourly POM flux calculations at each transect location. However, the overall trend shows the mass change was smaller Below KF, at the Confluence, and at the Mouth than the mass mobilization at the KF site. The decrease also occurred at each successive transect downstream, which is attributed to storage in the Grays River system floodplain and channels. The Confluence transect exhibited no increase after mid-January 2007, which is attributed to the change in flow regime shown in Figure E.14 and the oscillatory POM flux noted in Figure E.15. At the Mouth, $50,000 \mathrm{~kg}$ dry weight of POM had been transported from the Grays River into Grays Bay by the end of the simulation.

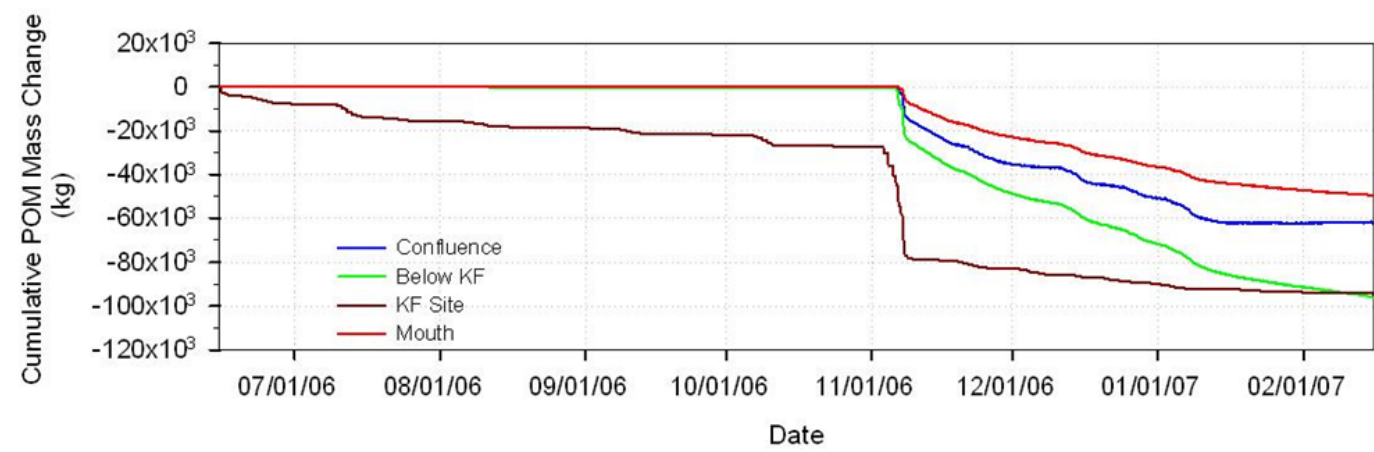

Figure E.16. Cumulative POM Mass Change at the KF Site, Below KF, the Confluence, and the Mouth

Table E.4 shows the cumulative POM mass change at three times during the simulation for the four locations, and shows how the mass change of each transect was partitioned between the channels and the floodplain. Prior to peak flooding, only mobilization of POM mass at the KF site was notable $\left(-27.4 \times 10^{3} \mathrm{~kg}\right.$ dry weight), with very little mass transport out of the site. After the peak flooding period, cumulative POM mobilization had increased to $-76.2 \times 10^{3} \mathrm{~kg}$ dry weight, with a total of $-22.0 \times 10^{3} \mathrm{~kg}$ dry weight POM transported through the Below KF transect (Table E.4). Of the transport through this transect, about $21 \%\left(-4.54 \times 10^{3} \mathrm{~kg}\right.$ dry weight) of the POM flux was through Seal Slough, with the bulk of POM transport down the Grays River or over the floodplain. At the Confluence transect, the bulk of POM transport was down the Grays River (96\%), with little POM flux over the floodplain. Note that during the peak flood there was only a short period during which the dike along the south bank of Seal Slough was overtopped, and only $4 \%$ of the POM mass transport washed through the floodplain portion of the transect.

By the end of the simulation, approximately 94,000 kg dry weight of POM had been exported from the KF site between mid-summer and early spring the following year. Of this mobilized POM, nearly $100 \%$ had passed the Below KF transect, $66 \%$ had passed through the Confluence, and over 50\% had passed through the Mouth. POM was redistributed to the floodplain during the peak flood events, and was then available for transport during moderate flow conditions. The mobilized POM that was not transported through a transect was stored in the Grays River system floodplain and channels. 
The total export of POM (96.2 mT dry weight) converts to an average of $1480 \mathrm{~kg}$ dry weight per ha $\left(=148 \mathrm{~g} / \mathrm{m}^{2}\right)$ for the 65 -ha KF site. The total peak summer stand crop at the KF site (2006-2007) was $635.2 \mathrm{~g} / \mathrm{m}^{2}$ (see Chapter 2.0). This equates to a total net aerial primary production (NAPP) for the entire 65 ha of $532.4 \mathrm{mT}$ dry weight. Thus the POM exported was equivalent to approximately $18 \%$ (i.e., $96.2 \mathrm{mT}$ ) of the $532.4 \mathrm{mT}$ produced.

Emergent vascular plant standing crop in July (the period we sampled) reported by Small et al. (1990) in the lower estuary ranged from 274 to $1,646 \mathrm{~g} / \mathrm{m}^{2}$. Simenstad et al. (1990) suggest that herbivores remove $15 \%$ of annual emergent plant carbon production, and that translocation to the roots removes $38 \%$, leaving approximately $47 \%$ to enter the POM pool. When applying these values to the KF site, NAPP results in the availability of about $250 \mathrm{mT}$ dry weight of POM, with about $38 \%(96.2 \mathrm{mT}$ dry weight) exported from the site. According to the model, about $50 \%$ of that moves onto the floodplain and the other $50 \%$ enters Grays Bay.

Table E.4. Cumulative POM Mass $\left(\times 10^{3} \mathrm{~kg}\right.$ dry weight $)$ Change During the Simulation (June 2006-February 2007). Negative values indicate a loss of POM mass from the site or upstream of the transect.

\begin{tabular}{|c|c|c|c|c|c|c|c|c|c|}
\hline \multirow[b]{2}{*}{ Time $^{(a)}$} & \multirow[b]{2}{*}{$\begin{array}{l}\text { KF } \\
\text { Site }^{(b)}\end{array}$} & \multicolumn{4}{|c|}{$\begin{array}{c}\text { Transect: Downstream of KF Site } \\
\text { (Below KF) }\end{array}$} & \multicolumn{3}{|c|}{$\begin{array}{l}\text { Transect: Downstream of } \\
\text { Confluence (Confluence) }\end{array}$} & \multirow[b]{2}{*}{$\begin{array}{l}\text { Transect } \\
\text { Mouth }\end{array}$} \\
\hline & & $\begin{array}{l}\text { Seal } \\
\text { Slough }\end{array}$ & $\begin{array}{l}\text { Grays } \\
\text { River }\end{array}$ & Floodplain & Total & $\begin{array}{l}\text { Grays } \\
\text { River }\end{array}$ & Floodplain & Total & \\
\hline $\begin{array}{l}\text { Prior to } \\
\text { Peak Flood }\end{array}$ & -27.4 & -0.111 & -0.020 & 0.0 & -0.131 & -0.003 & 0.0 & -0.003 & 0.0 \\
\hline $\begin{array}{l}\text { Following } \\
\text { Peak Flood }\end{array}$ & -76.2 & -4.54 & -9.21 & -8.26 & -22.0 & -11.9 & -0.485 & -12.4 & -5.16 \\
\hline $\begin{array}{c}\text { End of } \\
\text { Simulation }\end{array}$ & -94.2 & -1.50 & -86.4 & -8.29 & -96.2 & -61.7 & -0.476 & -62.2 & -49.6 \\
\hline
\end{tabular}

(a) Start of simulation $=6 / 15 / 06$ 00:00; prior to peak flood $=\mathrm{hr} 3394,11 / 3 / 06$ 10:00; following peak flood $=$ hr 3504, 11/8/06 00:00; end of simulation $=$ hr 5904, 2/16/07 00:00.

(b) The POM mass change at the KF site is the mobilization from the POM source.

If the simulation had continued, we anticipate that the cumulative POM mass change at each transect would tend toward the total mass mobilized, minus any storage. Note that the cumulative POM mass change for the Seal Slough portion of the Below KF transect had decreased by the end of the simulation from the high value following the peak flood. We attribute this to the longitudinal difference of POM concentration in the upper reach of Seal Slough, with POM concentration at the downstream end of the upper reach relatively large compared to the head of Seal Slough. Therefore, little POM was available for transport downstream at this location. In addition, the Confluence transect falls across the upper end of another restoration site (southwest of the confluence), with that floodplain POM portion decreasing slightly. We attribute this to tidal exchange in the floodplain at the upper end of this wetland, redistributing POM transported into the location during the peak flood period.

The following summary points about POM flux from the KF site can be made:

- During the low-flow period, little transport of mobilized POM occurred out of the KF site. The mobilized POM remained onsite due a lack of net outflow from the site. 
- During low- and moderate-flow periods after the peak flood, oscillatory flow of POM flux due to tidal flux occurred in Seal Slough, producing a negligible net flux of POM out of the slough. Because Seal Slough was not set up as a flow-through channel in the model, outflows occurred only when floodwaters overtopped the dikes upstream and flushed the KF site.

- A similar pattern was observed at the Confluence transect after the November 2006 flood as the Grays River flow decreased. The peak flood event had two effects: 1) a large pulse of POM was transported into the Grays River system from the KF site, with approximately half then transported out of the Grays River system; and 2) POM was redistributed throughout the floodplain and channels downstream of the KF site, and was then available for transport during the moderate flow conditions after the peak flood.

The initial conditions are an important factor in this analysis. Because the POM concentration at the start of the simulation was zero in the entire model domain, POM flux from the Grays River system did not begin until the POM at the KF site was mobilized and transported into the system. This was shown to occur primarily under flooding conditions that flushed the KF site and mobilized the major portion of POM produced during the simulation period. Once that process began, transport downstream through the Grays River system occurred. Also, after the flood subsided, POM was available for redistribution and transport downstream due to tidal exchange processes.

\section{E.2.3 Kandoll Farm Pre- and Post- Restoration Water Properties}

Water-property measurements were collected at the KF site in 2005, 2006, 2007, and 2009. Various aspects of each of these field efforts were reported in previous annual reports, but this is the first reporting of all years summarized. The mean and standard deviation (SD) for nutrient and TOC concentrations are shown for each year in Table E.5 and Figure E.17. The differences between flood and ebb tide for each year are shown in Figure E.18. TSS is not shown presented here because it was only collected in 2009. The samples collected each year $(2005,2006,2007,2009)$ spanned a 5-month time period (April to August) (Table E.5) making it difficult to estimate interannual variability.

Table E.5. Mean Concentration ( $\left.\mathrm{mg} / \mathrm{m}^{3}+/-1 \mathrm{SD}\right)$ of Water-Property Constituents Collected from the Kandoll Farm Restoration Site During 2005 (pre-breach) and 2006, 2007, and 2009 (postbreach)

\begin{tabular}{ccccc}
\hline & \multicolumn{4}{c}{ Kandoll Farm Restoration Site } \\
\hline & 2005 (pre-breach) & 2006 & 2007 & 2009 \\
$\mathrm{mg} / \mathrm{m}^{3}$ & June & May, June, July & August & April \\
\hline $\mathrm{TOC}$ & $5389(1750)$ & $2960(1269)$ & $8627(1326)$ & $2663(1165)$ \\
& $\mathrm{n}=8$ & $\mathrm{n}=22$ & $\mathrm{n}=8$ & $\mathrm{n}=51$ \\
$\mathrm{PO}_{4}$ & $15(4)$ & $8(2)$ & $4(1)$ & $118(115)$ \\
& $\mathrm{n}=13$ & $\mathrm{n}=22$ & $\mathrm{n}=8$ & $\mathrm{n}=51$ \\
$\mathrm{SiO}_{4}$ & $2105(708)$ & $3269(1505)$ & $3404(883)$ & $3636(1618)$ \\
& $\mathrm{n}=13$ & $\mathrm{n}=22$ & $\mathrm{n}=8$ & $\mathrm{n}=51$ \\
$\mathrm{NO}_{3}$ & $33(14)$ & $135(77)$ & $40(3)$ & $191(64)$ \\
& $\mathrm{n}=13$ & $\mathrm{n}=22$ & $\mathrm{n}=8$ & $\mathrm{n}=51$ \\
$\mathrm{NH}_{4}$ & $79(25)$ & $40(23)$ & $42(22)$ & $35(21)$ \\
& $\mathrm{n}=13$ & $\mathrm{n}=22$ & $\mathrm{n}=8$ & $\mathrm{n}=51$ \\
\hline
\end{tabular}




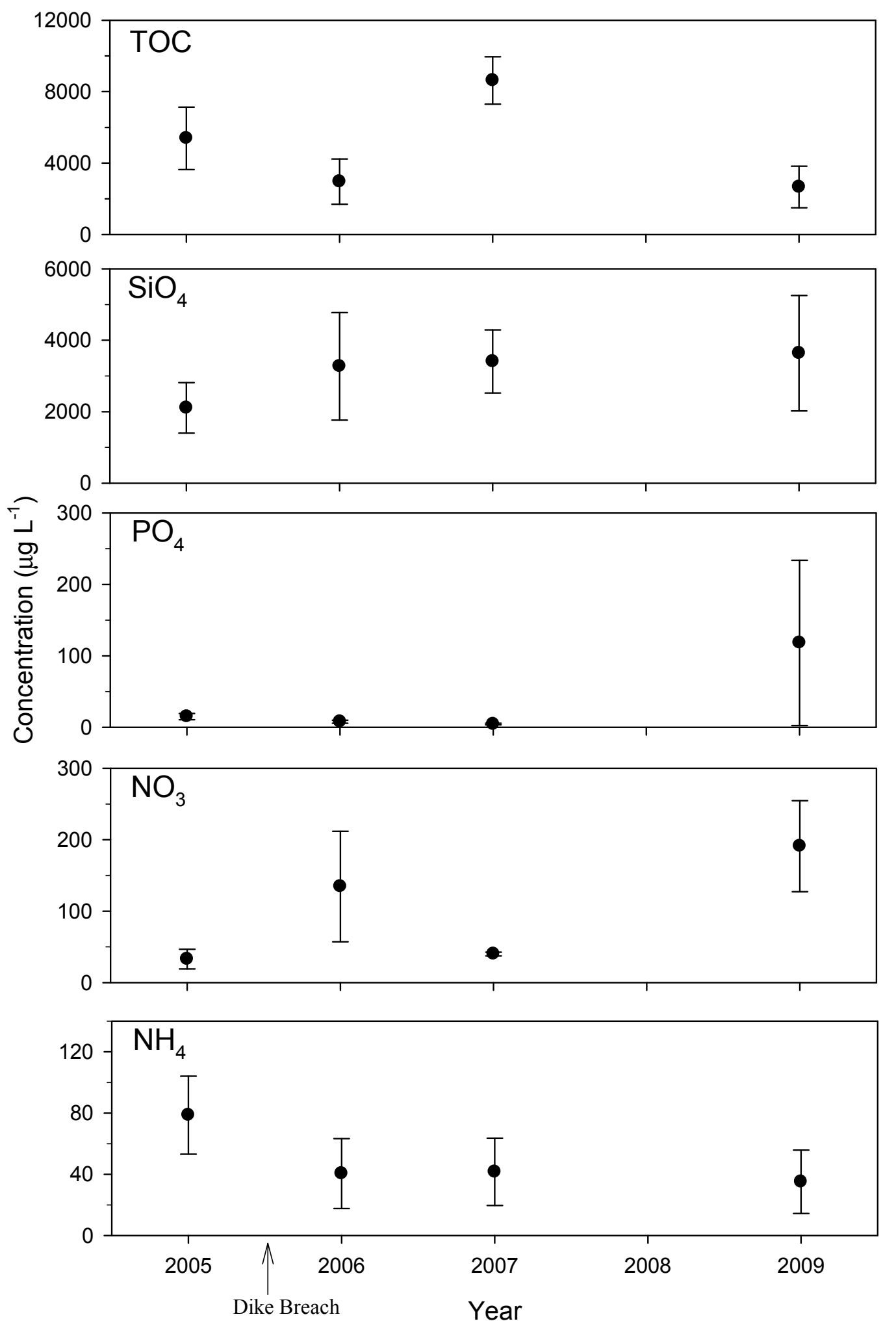

Figure E.17. Mean Concentration ( \pm 1 SD) of TOC and Nutrients for Each Year Sampled: 2005 (prebreach) and 2006, 2007, and 2009 (post-breach) 

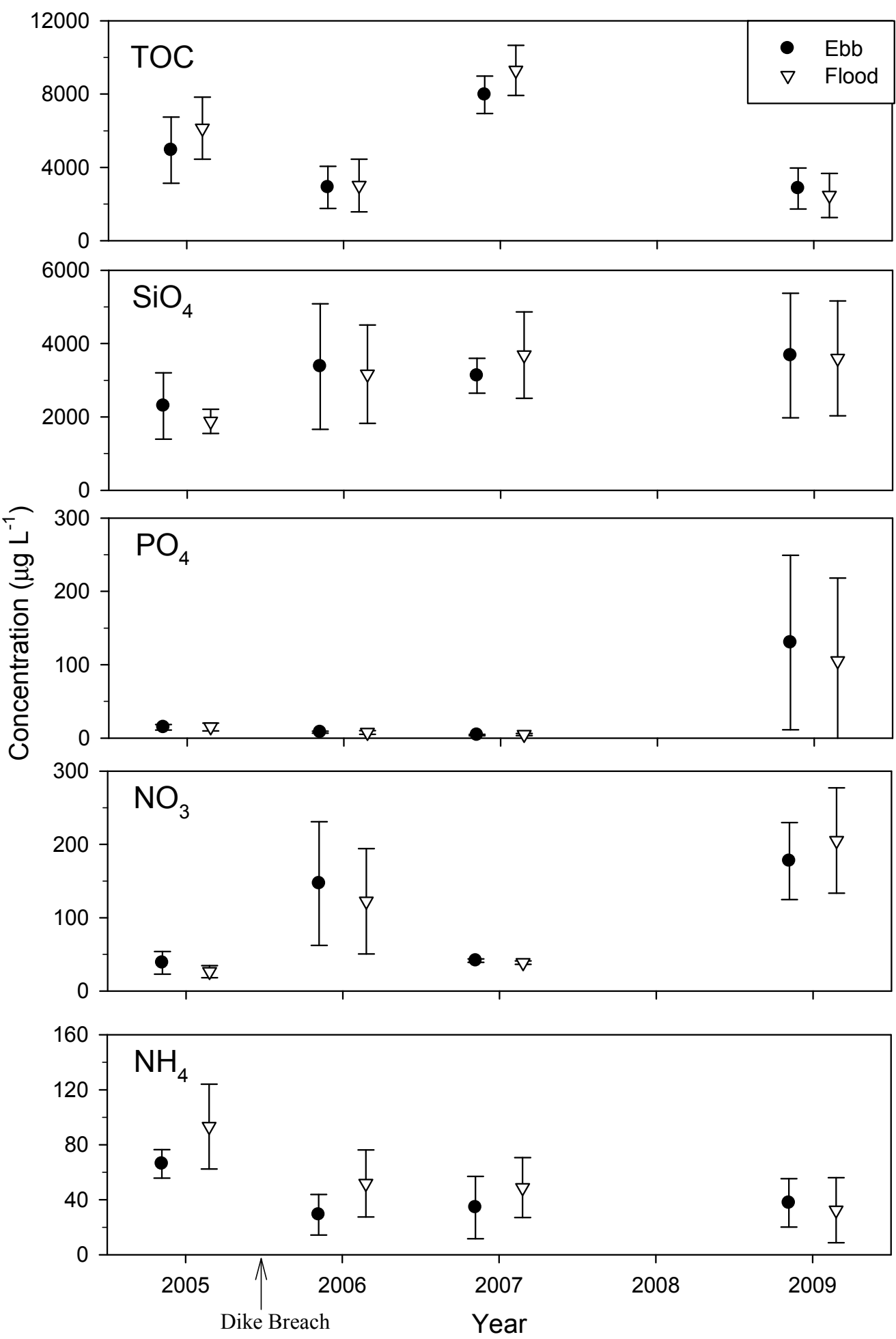

Figure E.18. Mean Concentration ( \pm 1 SD) of TOC and Nutrients for Each Flood and Ebb Tidal Cycle Sampled Each Year (2005 [pre-breach] and 2006, 2007, and 2009 [post-breach]) 


\section{E.3 Discussion and Recommendations}

In this section, we discuss each of the three main topics for the flux research: the intensive flux study at the KF site in 2009, the POM modeling effort, and the water properties pre- and post-restoration at the KF site.

\section{E.3.1 Intensive Flux Study}

The April 2009 intensive flux study at the KF site provided an opportunity to examine trends in nutrient and organic matter exchange over several days during spring and neap tides. One of the notable patterns to emerge was the extremely high range of sample concentrations observed during the course of the study for all water properties $\left(\mathrm{NO}_{3}, \mathrm{NH}_{4}, \mathrm{TOC}, \mathrm{SiO}_{4}, \mathrm{TSS}\right)$ (Table E.1; Figures E.6 and E.7). We attribute this to the large volume and rapid tidal exchange of water moving in and out of the KF marsh, which our sampling captured. In spite of this variability, there were several consistent trends of key constituents that emerged from the data. During both the spring and neap tides, TOC steadily increased in concentration during the outgoing (ebb) tide, maximizing around low slack, followed by a steady decrease during a flood tide, producing an oscillating pattern over time. An equally pronounced but contrasting pattern was observed as $\mathrm{NO}_{3}$ increased steadily during flood tides and decreased steadily during ebb tides. While these patterns were more pronounced during the spring tidal cycle, they were present during both spring and neap tides. In addition, during the spring tide, TSS concentrations showed a less pronounced but distinct pattern of the lowest TSS values corresponding to the water height of $1.6 \mathrm{~m}$ (Figure E.6), which is considered the bankfull elevation (inundation of the floodplain) at the KF site (Chapter 2.0, Coleman et al. in preparation). This also produced an oscillating but more complex pattern because the lowest TSS concentrations were evident on both an incoming and outgoing tide corresponding to this elevation. While the specific interactions between these properties and floodplain need to be further explored, the observed pattern is reflecting the hydrological reconnection at the KF site to a fully semidiurnal tide noted shortly after the dike breach and tide gate removal (Chapter 2.0, Figure 2.2).

The transport rate of material, Q, accounts for the volume of water exchanged through the culvert over time as well as the concentration of materials, and as such, presents trends for all constituents that largely reflect an increased flow rate during the mid-late ebb and flood tidal stage (Figure E.8 and E.9).

The trends are more pronounced during the spring tide (Figure E.8) than during the neap tide (Figure E.9). Based on the calculated weight of material exchanged (Table E.3), the KF site appears to be a sink for TOC, $\mathrm{SiO}_{4}$, and TSS, as evidenced by the net exchange of material into the KF site during a spring and neap tide, with a greater import during a spring tide. This is particularly notable for TSS with 4.6 times greater import on the marsh during spring tide compared to neap tide. In contrast, the KF site appears to be a source of $\mathrm{NO}_{3}$ during both a spring and neap tide (i.e., net export). Without exception, there is a greater exchange of all water properties (import and export) during the spring tide compared to the neap tide. The intensive flux study at the KF site allowed us the opportunity to examine the movement of dissolved material in greater detail, and provided useful insights into the functioning of exchange processes during the spring season.

\section{E.3.2 POM Modeling}

To complement the intensive flux study, we examined coarse POM flux through a modeling effort that provided a greater temporal and spatial perspective on exchange of materials at the KF site. The 
model evaluated POM flux between June 2006 and February 2007, providing a seasonal perspective from early summer through late winter. During the summer and early fall period of low river discharge, there was little net export of mobilized POM out of the KF site, but tidal hydrodynamics alone produced a repeated oscillation of material in and out of the marsh. When a peak flood event occurred in November, a large pulse of POM was transported out of the KF site into the Grays River system. Three subsequent smaller flood events also contributed to movement of POM out of the wetlands and into the floodplain and Grays Bay. Overall, the modeling showed that a substantial proportion of the POM that was mobilized left the KF site. Of this mobilized material, approximately $52 \%$ reached the estuary and $48 \%$ remained in the floodplain and river.

The picture thus emerges of a seasonal variance in the interaction of the KF site with the Grays and lower Columbia River systems. For most of the year, there appears to be net deposition of particulate organic and inorganic matter within the restoring marsh as well as an annual accumulation of herbaceous biomass (Chapter 2.0). Tidal fluctuations "slosh" material within a tidal excursion, resulting in local redistribution and/or remineralization, with little export to the Grays River system. During autumn, there is the seasonal senescence of the marsh plants and their conversion into detritus, which accumulates on the marsh surface. Winter storms can generate flood conditions that remobilize material on the marsh surface and have the hydrodynamic force necessary to transport material past the tidal excursion barriers and into the Grays River where further distribution occurs. Although the seasonal aspects of the nutrient and dissolved organic matter flux could not be examined in the intensive flux study, the oscillatory movement of material via tidal cycling was confirmed for all constituents examined. While the KF site appeared to be a sink for $\mathrm{TOC}, \mathrm{SiO}_{4}$, and TSS during the spring, we expect this would vary seasonally, and is influenced significantly by storm and flood activities as well.

\section{E.3.3 Pre- and Post-Restoration at Kandoll Farm}

The pre- and post-restoration data comparisons of dissolved water properties showed a fair amount of variability for most constituents between years as well as variability within a year (Table E.5,

Figures E.17 and E.18). The within-year variability is primarily reflective of the collections occurring throughout the range of a tidal cycle, which was shown to be highly variable from the intensive flux study. The inter-annual variability is difficult to assess because the timing of sample collections each year varied seasonally between April and August throughout the 4 years sampled (Table E.5).

\section{E.3.4 Recommendations}

Based on the collective multi-year field efforts conducted for the CE study, we offer the following recommendations concerning material and nutrient flux:

- Examine seasonal components to a greater extent in future in situ flux research to better understand the source/sink cycling of nutrients and organic matter.

- Encourage the use of continuous sampling devices that sample water properties, flow rate, and volumes automatically to facilitate collection of seasonal and interannual data.

- Extend the POM modeling to include dissolved organic matter, nutrients, and suspended sediment components to better understand the interactions and physical transfer of both coarse and fine particulate matter. Closely coordinate in situ sample collections to provide inputs to modeling. 
- Extend the POM modeling to examine system functions at several sites and/or an entire floodplain to better estimate POM transport out of the system. Parameterize the modeling analysis over a range of hydrologic and tidal conditions to provide a wider range of POM estimates.

- Integrate nutrient and organic matter flux components into prioritization of restoration actions to better support habitat restoration goals related to salmonids.

- Include select nutrient and organic matter flux metrics as key tidal exchange components of actioneffectiveness "extensive" monitoring and further action-effectiveness "intensive" research.

- Develop a better quantification of the transfer efficiencies between organic matter produced and the contribution to juvenile salmon growth, e.g., link carbon exported from the systems to potential salmon prey through methods such as stable isotope analysis.

The following detailed, technical recommendations are suggested for future POM modeling efforts:

- Compute cumulative POM flux at each transect. This would eliminate the computational errors found for cumulative POM flux at transects when compared to the flux computed at the KF site.

- Examine how the system functions with several sites or the whole floodplain included in the model runs. This would provide a better estimate of POM mass transported from the entire system.

- Include a POM decay term in the modeling analysis. Because of the extended seasonal duration of the simulation, POM decay would provide a more realistic estimate with a somewhat reduced mass transport from the system.

- Parameterize the modeling analysis over a range of hydrologic and tidal conditions that would allow an estimate of POM flux over extended time periods such as multiple years. 


\section{Appendix F}

Statistical and Other Considerations for Restoration ActionEffectiveness Monitoring and Research 


\title{
Appendix F
}

\section{Statistical and Other Considerations for Restoration Action- Effectiveness Monitoring and Research}

\author{
Prepared by Gary Johnson, John Skalski, and Jerry Tagestad
}

The Action Agencies and the National Marine Fisheries Service (NMFS) developed the scientific basis for action-effectiveness monitoring and research (AEMR) in the comprehensive federal research, monitoring, and evaluation (RME) plan for the lower Columbia River and estuary (LCRE) (Johnson et al. 2008). NMFS incorporated many elements of this plan into the 2008 Biological Opinion (BiOp) of Federal Columbia River Power System (FCRPS) operations (NMFS 2008; Reasonable and Prudent Alternative actions 58-61), including actions covering status and trends monitoring, AEMR, and critical uncertainties research. The estuary RME plan also contained an action plan for implementation, compliance, synthesis, and evaluation. It used the Columbia River Estuary Conceptual Model (Thom et al. 2005) as a basis for the selection of monitored indicators for each monitoring objective. The content and recommendations in the estuary RME plan (Johnson et al. 2008) are still pertinent today, including the scientific basis and recommendations for AEMR.

Action effectiveness is a critical element of the Columbia Estuary Ecosystem Restoration Program (CEERP) adaptive management process (see Chapter 3.0). As explained above, it important to monitor the effectiveness of restoration actions to know how well they are performing relative to the intended purpose. Funds for AEMR, however, are limited and need to be spent wisely to obtain useful, costeffective information for management (material below addresses this issue). It is fundamental that restoration program needs drive the restoration project AEMR. One basic program need is action effectiveness in terms of restoration accounting; i.e., the number of miles or acres restored, the number of tidal reconnections, and the assigned survival benefit units (SBUs). The SBU data will be needed to fulfill the $\mathrm{BiOp}$ requirements and need to be recorded for past, present, and future sites. The restoration accounting measures are common-sense indicators of restoration effort and provide tangible, quantitative results in units of effort that biologists, policymakers, and the public can readily understand.

Action-effectiveness monitoring involves spatially extensive sampling of basic restoration indicators, whereas action-effectiveness research involves locally intensive sampling at restoration and reference sites to characterize ecosystem structures, processes, and functions. There are many potential monitored indicators, depending on program needs and project-specific conditions, ranging over a spectrum from simple monitoring to complex research and from extensive to intensive sampling (Figure F.1). While there is no designated minimum suite of monitored indicators, every project site should have pre- and post-restoration photo points and measurements of latitude and longitude. It is also straightforward to apply the Roegner et al. (2009a) protocols and install data loggers for water-surface elevation and water temperature. Other basic monitored indicators, such as cross-sectional area, topography, sediment accretion, and plant community characteristics, can be assessed using the "rapid habitat assessment" approach developed by Borde et al. (2009b). The rapid assessment measures are a few site-specific, postrestoration measurements that are biologically and ecologically related to survival benefits that can be relatively easily measured at all sites. The selection of monitored indicators for rapid habitat assessments should be based on their relationship to higher-order ecological responses to restoration. Relationships 
between extensive and intensive indicators can be established through research so that future studies can use measurements of extensive indicators to predict responses of related intensive indicators.

Photo points
Latitude and longitude
Water-surface elevation (logger)
Temperature (logger)
Salinity (logger)
Channel cross-sectional area
Sediment accretion
Elevation (bathymetry/topography)
Catchment area
Plant species comp
Plant percent cover
Plant biomass
Aerial photos
Fish presence/species/size
Fish density
Satellite imagery land cover
Water velocity
Water properties (DO,TOC,chloro.etc.)
Nutrients (NH3,PO4, SiO3)
Fish diet
Fish residence time
Neuston prey
Benthic-invertebrate prey
Insect fallout prey
Fish condition (FIT)

Figure F.1. Monitored Indicators for Action Effectiveness Over the Monitoring/Research Spectrum and the Extensive/Intensive Spectrum

Our purpose in this appendix is to present program- and project-level considerations for AERM. The objectives are as follows:

- Establish a methodology for specifying statistical relationships between intensive action-effectiveness research and extensive action-effectiveness monitoring, including a method to indicate how much AEMR sampling is enough.

- Provide a statistical approach for quantitative meta-analysis of AEMR data.

- Offer approaches for prioritizing AEMR and critical uncertainties research. 
- Summarize considerations in selecting the appropriate remote-sensing data for monitoring vegetation.

- Develop or revise templates for project descriptions, AEMR plans, and Site Evaluation Cards (SECs).

\section{F.1 Extensive Monitoring and Intensive Research}

Although SBUs may be an official measure of restoration progress, they alone may be inadequate in conveying to all parties the benefits of CEERP efforts for salmon. The assumptions and adequacy of the SBU calculations could be challenged and research is needed to support and independently verify SBU assertions. The complexity of such information can only reasonably be derived from intensively sampling restoration sites over time. Nevertheless, inferences concerning salmon benefits of restoration activities must be regional in scope to be meaningful. Therefore, we provide a statistical basis and implications for the CEERP of relationships between extensive monitoring and intensive research.

\section{F.1.1 Statistical Basis}

There is a general framework in sampling theory to combine expensive and precise measurements at a few sites with inexpensive and ubiquitous information collected at many or all sites. This statistical framework goes by the name "ratio estimates," as regression estimates in finite sampling theory (Cochran 1977, Chapters 6 and 7). As an example, consider interest in estimating total nutrient flux. At a random sample of restoration sites, intensive monitoring would be used to estimate site-specific values of nutrient flux (NF). These measurements would be relatively costly to perform and, as such, could only be performed at a limited number of locations. However, suppose research at these intensively monitored sites found that NF was highly correlated with wetted area (WA) that is relatively easy and inexpensive to collect. In this case, total NF at all restoration sites could be estimated by the following ratio estimate:

$$
\hat{Y}=X \cdot \frac{\sum_{i=1}^{n} y_{i}}{\sum_{i=1}^{n} x_{i}}=X \cdot \frac{\bar{y}}{\bar{x}}
$$

where

$$
\begin{aligned}
\hat{Y} & =\text { estimated total NF for all restoration sites } \\
X=\sum_{i=1}^{N} x_{i} & =\text { total WA across all restoration sites } \\
y_{i} & =\text { the NF value at an intensively sampled site } i(i=1, \ldots, n) \\
x_{i} & =\text { the WA value at an intensively sampled site } i(i=1, \ldots, n) .
\end{aligned}
$$


The estimate $\hat{Y}$ has the variance

$$
\begin{aligned}
\operatorname{Var}(\hat{Y}) & =\frac{N^{2}\left(1-\frac{n}{N}\right)}{n}\left[\frac{\sum_{i=1}^{N}\left(y_{i}-R x_{i}\right)^{2}}{N-1}\right] \\
& =\frac{N^{2}\left(1-\frac{n}{N}\right)}{n}\left(1-\rho^{2}\right) S_{y}^{2},
\end{aligned}
$$

where $\quad R=\frac{\bar{Y}}{\bar{X}}$,

$$
\begin{aligned}
S_{y}^{2}= & \frac{\sum_{i-1}^{N}\left(y_{i}-\bar{Y}\right)^{2}}{N-1}, \\
\rho= & \text { correlation between } y_{i} \text { and } x_{i} .
\end{aligned}
$$

Inspection of variance equation (F.2) indicates the estimate $\hat{Y}$ will be more precise as the number of intensively monitored sites $(n)$ increases and as the correlation $(\rho)$ between intensive/expensive $\left(y_{i}\right)$ and extensive/inexpensive $\left(x_{i}\right)$ measurements increases. Equation (F.2) can serve as a framework to determine the number of intensive sites $(n)$, and the selection of $y_{i} / x_{i}$ measures that are highly correlated $(\rho)$ and should be jointly monitored. The ratio estimate (F.1) is based on the assumption of a straight-line relationship between $y_{i}$ and $x_{i}$ that goes through the origin. Regression estimates (Cochran 1966, Chapter 7) generalize the relation to straight-line relations and curvilinear relationships are ready extensions.

The responses $x_{i}$ would be incorporated in the rapid assessment part of the SECs. Consequently, the rapid assessment measures $\left(x_{i}\right)$ in part D of the SEC should be selected so that they can be quickly and cost-effectively sampled and correlated with higher-order metrics the program wishes to monitor. In turn, these higher-order metrics should be estuary-level responses that are associated with salmon benefits and are expected to respond monotonically with increases in SBUs. Beyond that, these higher-order metrics are selected as a conscious effort to develop "weight of evidence" in assessing overall benefits of restoration efforts to salmon.

\section{F.1.2 Implications for CEERP}

CEERP managers must make decisions about the trade-off between extensive and locally intensive sampling efforts. As part of the cumulative effects (CE) study, we ascertained which extensive restoration indicators to measure, and when and how often to measure them, from intensively studied reference and restoration areas. The Crims Island, Kandoll Farm, and Vera Slough sites were intensively sampled to develop effectiveness monitoring sampling protocols (Roegner et al. 2009a) and to map trajectories of physical and biological responses to restoration (see Chapter 2.0). These intensively sampled sites provide a virtual model of the restoration process that we use to guide the selection of basic 
restoration indicator measurements at the extensively monitored sites and they provide the inferential framework to help assess the success of restoration from the cursory, extensive observations taken over time at individual restoration projects. By developing a proper mix of extensively monitored sites and intensively monitored sites in the CEERP, individual restoration projects may be surveyed with minimal effort while providing maximum opportunities to detect benefits at large spatial scales. The CE study developed several relationships between extensively and intensively monitored indicators (Table F.1). More work remains to be done to provide peer-reviewed, statistically valid relationships.

Table F.1. Example Relationships Between "Extensive" Independent Monitored Indicator(s) and "Intensive" Dependent Monitored Indicator(s)

\begin{tabular}{|c|c|c|}
\hline "Extensive" Independent Variable(s) & "Intensive" Dependent Variable(s) & Reference \\
\hline Water-surface elevation + land elevation & Floodplain wetted area; area-time inundation & $\begin{array}{l}\text { Coleman et al. (in } \\
\text { preparation) }\end{array}$ \\
\hline Water temperature & Juvenile salmon presence & Roegner et al. (2010a) \\
\hline $\begin{array}{l}\text { Land elevation }+ \text { lateral and longitudinal } \\
\text { location in floodplain }+ \text { sediment } \\
\text { accretion rate }\end{array}$ & Plant community composition & $\begin{array}{l}\text { Borde et al. (in } \\
\text { preparation); } \\
\text { Chapter } 2.0\end{array}$ \\
\hline Catchment area & $\begin{array}{l}\text { Channel cross-sectional area at outlet; wetted- } \\
\text { channel edge length }\end{array}$ & $\begin{array}{l}\text { Diefenderfer and } \\
\text { Montgomery (2008) }\end{array}$ \\
\hline Tidal exchange volume & $\begin{array}{l}\text { Material flux (chlorophyll, dissolved organic } \\
\text { matter, nutrients, plant biomass, macro- } \\
\text { invertebrates) }\end{array}$ & Appendix E \\
\hline
\end{tabular}

\section{F.1.3 Projection of Post-Restoration Conditions}

Rapid assessment sampling is likely to occur 2 to 5 years post-restoration. However, some of the restoration benefits may occur over the period of 20,50 , or 100 years. It would be desirable to have a mechanism for projecting long-term benefits of current restoration activities into the future. One possibility is to once again consider the ratio estimate (F.1). Let

$$
\begin{gathered}
\qquad y_{i}=\text { estuary response at the } i \text { th reference/control site, } \\
x_{i}=\text { estuary response at the } i \text { th restoration site } 2 \text { years post-restoration. }
\end{gathered}
$$

Then

$$
\hat{Y}=X \cdot \frac{\bar{y}}{\bar{x}}
$$

is an estimate of the long-term benefits at the restoration sites when fully reestablished and where

$$
X=\sum_{i=1}^{N} x_{i}
$$


measures the total short-term, post-restoration measurements at all restoration sites to date. Again, the relationship between reference/control and restored sites might require a linear or curvilinear estimator. The proper $x_{i}$ vs. $y_{i}$ relationship would be determined by an empirical examination of the data.

This last example illustrates the potential value of incorporating reference sites into the regional monitoring design above and beyond extensively and intensively monitored restoration sites (Figure F.1).

\section{F.1.4 How Much Sampling is Enough}

In monitoring the estuary to estimate the salmon benefits of restoration activities, the question of sample size is two-fold. The extensive sampling and the SEC were conceived to cover all restoration sites. From the perspective of tallying SBUs, site-specific information would be ideal. One could, however, envision representing sampling restoration sites to estimate total SBUs, but it is not clear all parties would accept anything less than a complete tally.

With regard to the number of intensively monitored sites, the intent is to select only a sample of the total restoration sites for such effort, say, $n$ of $N$ sites. At these sites, higher-level ecological responses would be measured along with correlated rapid assessment measurements. Then using the rapid assessment data at all or most sites, an estimate of estuary-wide, total higher-level ecological response would be estimated by either ratio or regression estimation (Cochran 1977:150-203).

Using the variance formula for regression estimators, the number of intensive monitoring sites that should be sampled can be calculated. Let $\hat{Y}$ represent the estimate of the estuary-wide, total response and $Y$ be the true value. Furthermore, define precision as

$$
P\left(\left|\frac{\hat{Y}-Y}{Y}\right|<\varepsilon\right)=1-\alpha
$$

where the desire is for the relative error in estimation $\left(\right.$ i.e., $\left.\left(\frac{\hat{Y}-Y}{Y}\right)\right)$ to be less than $\varepsilon,(1-\alpha) 100 \%$ of the time. For example, if you wish to be within $\pm 25 \%$ of the true value $90 \%$ of the time, then

$$
P\left(\left|\frac{\hat{Y}-Y}{Y}\right|<0.25\right)=0.90 .
$$

Using the above definition of sampling precision, then

$$
\varepsilon \doteq Z_{1-\frac{\alpha}{2}} \cdot \frac{\sqrt{\operatorname{Var}(\hat{Y})}}{Y}
$$


and in the case of regression estimation (Cochran 1977:192)

$$
\mathcal{E} \doteq Z_{1-\frac{\alpha}{2}} \sqrt{\frac{\left(1-\frac{n}{N}\right) C_{Y_{i}}^{2}\left(1-\rho^{2}\right)}{n}} .
$$

Solving for $n$ for given precision defined by $\varepsilon$ and $\alpha$

$$
n=\frac{1}{\frac{\varepsilon^{2}}{Z_{1-\frac{\alpha}{2}}^{2} \mathrm{CV}_{Y_{i}}^{2}\left(1-\rho^{2}\right)}+\frac{1}{n}}
$$

where

$$
\begin{aligned}
\varepsilon= & \text { relative error size } \\
Z_{1-\frac{\alpha}{2}}= & Z \text {-value for a standard normal distribution at cumulative probability of } 1-\frac{\alpha}{2} \\
N= & \text { total number of restoration sites } \\
\rho= & \text { correlation between higher level ecological response and rapid assessment } \\
& \text { variable } \\
\mathrm{CV}_{Y_{i}}= & \text { coefficient of variation in the higher level ecological response between restoration } \\
& \text { areas, i.e., }=\frac{\sqrt{\operatorname{Var}\left(Y_{i}\right)}}{\bar{Y}} .
\end{aligned}
$$

Consequently, the number of intensively monitored restoration sites $(n)$ will be a function of the desired level of precision (i.e., $\varepsilon$ and $1-\alpha$ ); how correlated are the intensive and extensive responses (i.e., $\rho$ ) and how variable are the restoration sites (i.e., $\mathrm{CV}_{Y_{i}}$ ).

Robson and Regier (1964) recommended for rough management purposes precision should be $\pm 50 \%$, $95 \%$ of the time (i.e., $\varepsilon=0.50,1-\alpha=0.95$ ) and for accurate management, $\pm 25 \%, 95 \%$ of the time (i.e., $\varepsilon=0.25,1-\alpha=0.95$ ). Figure F.2 provides sample size curves for different levels of precision $(\varepsilon, 1-\alpha=0.95)$, levels of environmental variability, and correlation in extensive and intensive measured responses. For example, if environmental variability has a $\mathrm{CV}=0.50$, and $\rho=0.50$, then approximately $n=25$ intensively monitored sites are needed (Figure F.2b) for accurate management. On the other hand, if $\mathrm{CV}=0.30$ and $\rho=0.50$, this number of intensively monitored sites decreases to $n=6$ for accurate management needs (Figure F.2a). 
a. $\quad \mathrm{CV}=0.30$

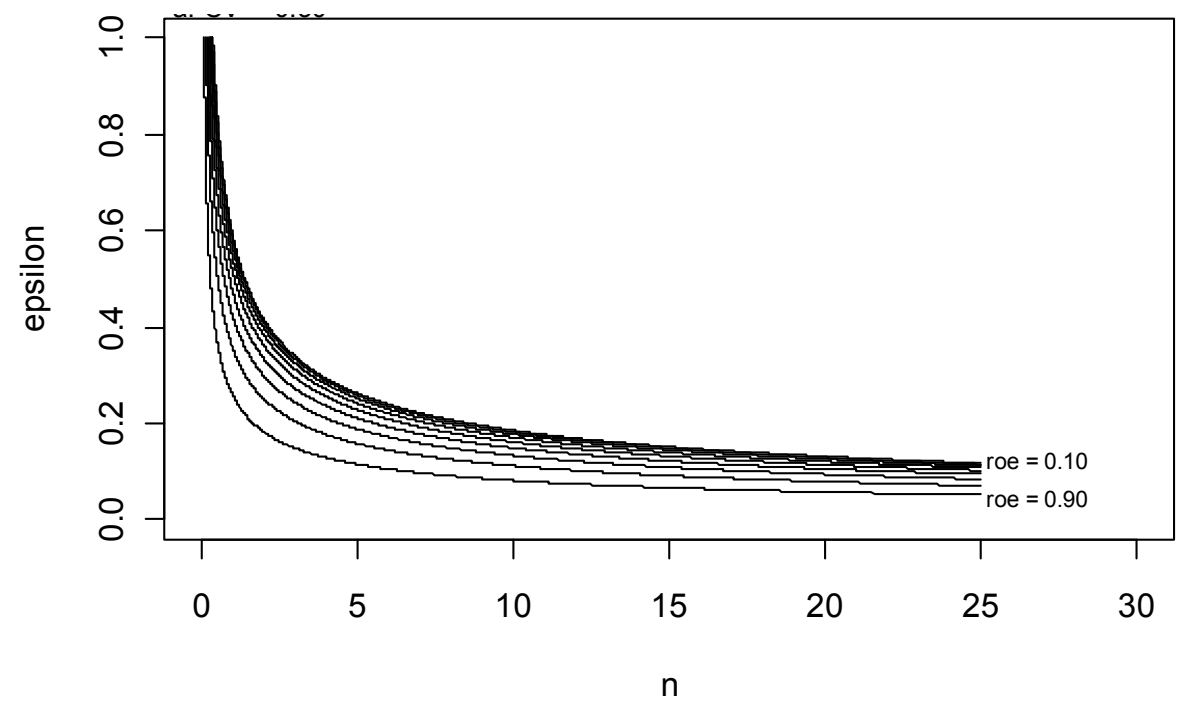

b. $\mathrm{CV}=0.50$

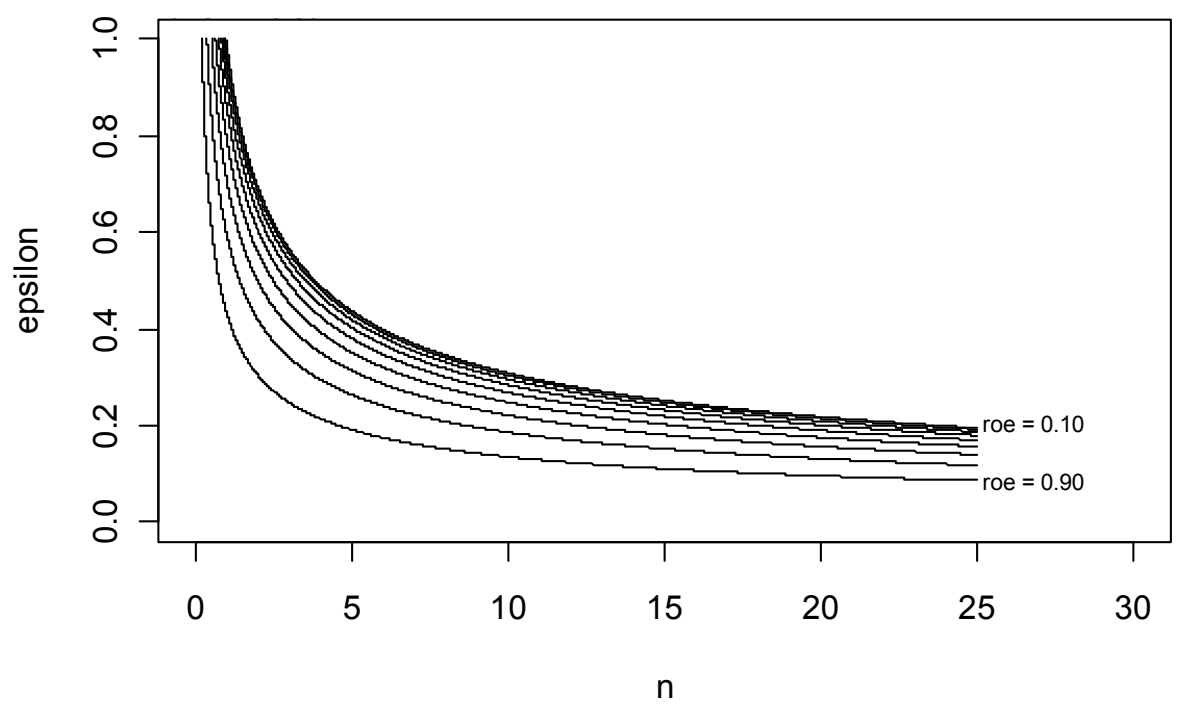


c. $\quad \mathrm{CV}=0.70$

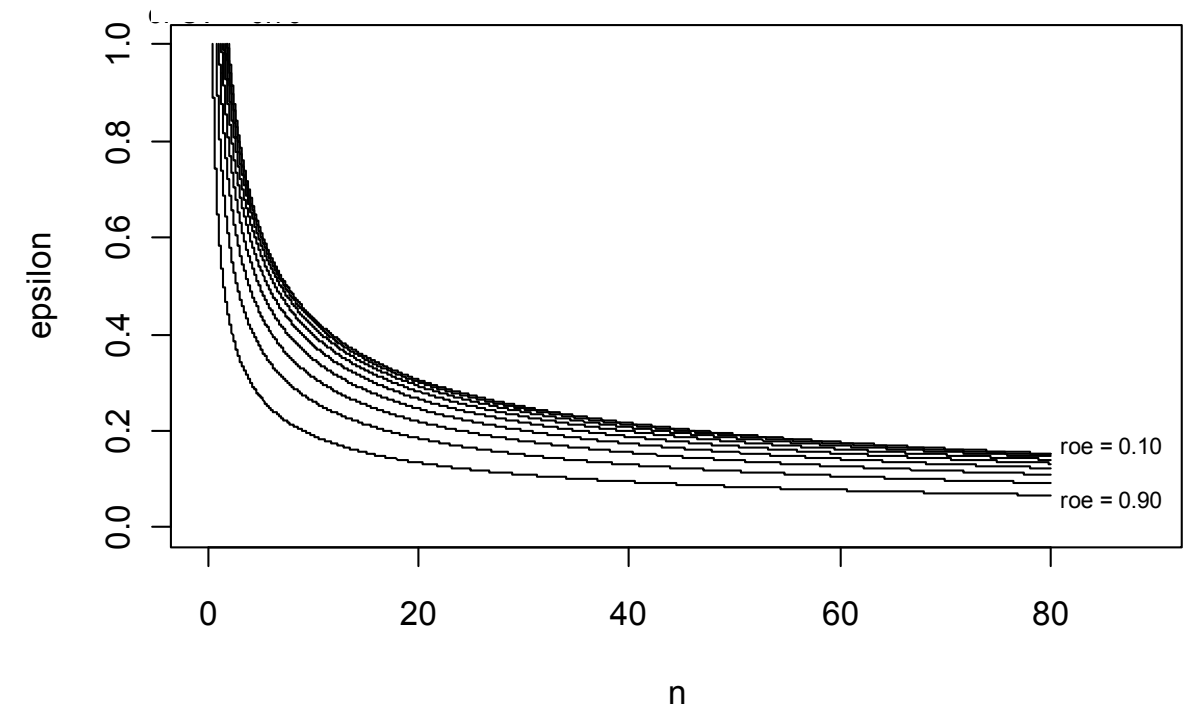

d. $\quad \mathrm{CV}=0.90$

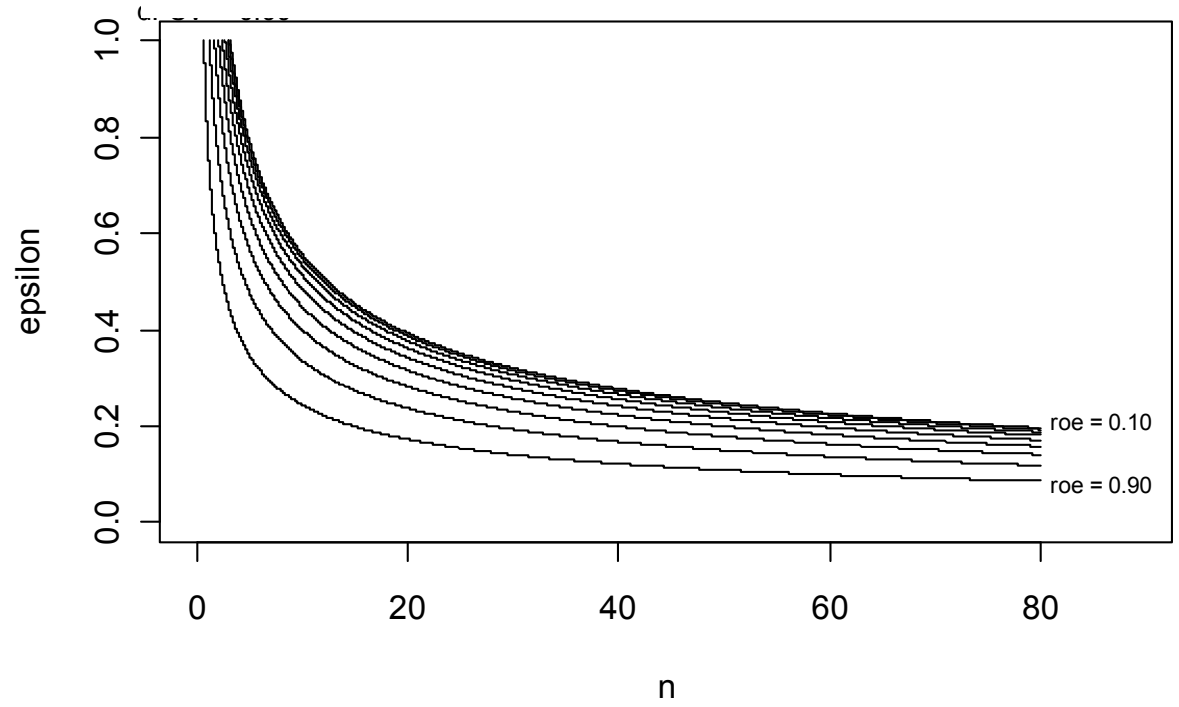

Figure F.2. Sample Sizes $(n)$ as a Function of Desired Precision $(\varepsilon)$ at $1-\alpha=0.95$ and the Correlation Between Sites $(\rho)$ When the Variability Between Restoration Sites has a Coefficient of Variation (CV) of (a) $\mathrm{CV}=0.30$, (b) $\mathrm{CV}=0.50$, (c) $\mathrm{CV}=0.70$, and (d) $\mathrm{CV}=$ 0.90

In conclusion, this is just one possible quantitative framework that can be used to determine how much sampling is enough in the estuary. There are other possibilities as well. Using this framework, investigators should use preliminary data to estimate $\rho$ and $\mathrm{CV}$ for important higher-level responses and work with management to select useful levels of $\varepsilon$ and $1-\alpha$ all parties can agree upon. 


\section{F.2 Statistical Approach to Meta-Analysis of AEMR Data}

Numerous sources of information, both direct and indirect, may be available to assess the overall benefits of restoration activities on salmon populations. Meta-analysis is one approach whereby these diverse data sources can be combined to provide an overall assessment of a hypothesis. Consider the set of hypotheses

$$
\begin{gathered}
\mathrm{H}_{\mathrm{o}} \text { : No improvement } \\
\text { vs. } \\
\mathrm{H}_{\mathrm{a}} \text { : Improvement. }
\end{gathered}
$$

Each of the diverse data sets could be used to test whether the response being monitored has increased or improved over time. These responses may include the SBUs, the high-order ecological responses, and ancillary studies of fish abundance, survival, etc. The weight of evidence is built by a compilation of positive indicators of success and hopefully by an absence of negative indicators or predictions. The more the scales tilt toward success with a preponderance of positive evidence, the greater the certainty of the conclusions.

This process should begin with an a priori set of hypotheses corresponding to the AEMR data being collected. For instance, working hypotheses might include the following:

- Numbers of adult salmon returning over time are increasing.

- Smolt densities in the estuary are increasing over time.

- The amount of desirable wetlands is increasing over time.

- The amount of nutrient flux is increasing over time.

- Smolt densities in the estuary have increased two-fold since 2008.

Each of these ancillary hypotheses is used to build the weight of evidence in testing the main hypotheses of concern; i.e., sampling is benefiting from the restoration activities. But not all tests or examinations may be of equal value. It is likely the strength of the individual analyses may depend on the precision and accuracy of the field trials used to test the ancillary hypotheses. A weight-of-evidence approach should therefore take into account the strength of the association between working and ancillary hypotheses and the conclusiveness of the individual tests of hypotheses.

One such approach is the retrospective weight-of-evidence approach of Chapman et al. (2002) and Landis et al. (2004), which develop "lines of evidence" from each possible source/stressor/habitat/effect linkage. For instance, increased salmon returns are a crucial linkage between restoration and salmon recovery. However, its importance to the hypothetical-deductive method may be relatively small because of the inherent natural variability in the response and the potential for serious confounding effects. Conversely, residence time in the estuary by fall Chinook salmon may be relatively easy to measure, but its linkage to salmonid recovery may be indirect. An expository approach to a weight-of-evidence argument should therefore take into consideration mitigating factors that might make one ancillary test more meaningful than another. The approach should also look at all possible linkages to identify mechanisms, likely and unlikely, for the changes observed. 
Positive inferences regarding the effects of estuary restoration will depend on demonstrating no serious challenges to this assertion from the various tests and a general consensus across the remaining lines of evidence. A robust conceptual model and expository argument may best serve this purpose. The problem with an expository weight-of-evidence argument is that no common standard of evidence exists for everyone. The threshold of proof or disproof may vary, and the relative weight of the evidence among different tests of ancillary hypotheses may not be the same. An objective decision rule can be used as one approach, but ideally the weights should be established a priori and the form of the decision rule preestablished.

Alternatively, a quantitative framework can be used to combine the results of multiple independent assessments into an overall statistical conclusion. In the case of independent and equally important tests of ancillary hypotheses, their separate $P$-values can be combined to provide an overall level of significance. Under the null hypothesis, a $P$-value (i.e., the probability of rejecting the null hypothesis when it is true) is uniformly distributed from 0 and 1 . This probability can be used to calculate an overall test of significance across $K$ independent analyses according to the formula,

$$
\chi_{2 K}^{2}=-2 \sum_{i=1}^{K} \ln P_{i}
$$

where $P_{i}$ is the $P$-value for the $i$ th data set and $\chi_{2 K}^{2}$ is a chi-square statistic with $2 K$ degrees of freedom. The overall $P$-value for the $K$ independent tests is then

$$
P=P\left(\chi_{2 K}^{2} \geq \chi^{2}\right)
$$

This method is called the "inverse chi-square" method of Fisher (1932) (Hedges and Olkin 1985:37-39). The overall $P$-value may be statistically significant when the individual values are not. For example, consider $K=5$ independent tests with individual $P$-values of $0.3257,0.1122,0.4219,0.1383$, and 0.1978. The overall $P$-value for the five tests is $P=P\left(\chi_{5}^{2} \geq 15.5372\right)=0.0083$. The meta-analysis takes into account that all of the observed $P$-values are less than 0.50 and some much less than 0.5 . Under the null hypothesis, half of the $P$-values would be above and half below 0.5 .

The disadvantage of the overall test (Eq. [F.3]) is that it ignores the possible difference in the biological or social importance of some tests over that of others. The combined statistic (Eq. [F.3]) treats all of the $K$ independent assessments as equally important and ignores the magnitude of the observed treatment differences and the statistical power of the individual studies to detect effects. The advantage of Eq. (F.3) is that it can combine disparate results into a single decision criterion that is objective and quantifiable.

A meta-analysis that is less influenced by one or few tests and relies more on the consistency across data sets is based on the estimated effect size. There are meta-analysis approaches for combining independent estimates of effect size based on the assumption they are all estimating the same effect, but these methods may be inappropriate when disparate responses are being analyzed (Hedges and Olkin 1985:108-128). Future meta-analyses of action-effectiveness data in the CEERP should strive to apply this or a similar statistical approach. 


\section{F.3 AERM Prioritization}

In the CEERP adaptive management (AM) framework (Chapter 3.0), prioritization of AEMR is the responsibility of the AM Stakeholders Team (AMST) and occurs during development of the annual RME planning element of the CEERP Action Plan. The AMST will have studied the annual Synthesis Memorandum and the Strategy Report to understand key uncertainties in the action-effectiveness knowledge base and their criticality to implementing CEERP restoration strategy. With this scientific underpinning, the AMST will examine the list of planned restoration projects for the coming year and decide the scope of AEMR for each site. This direction will be communicated to the restoration/ monitoring practitioners who will subsequently develop project-specific monitoring plans (see template below).

Approximately one-fifth of all restoration projects in the LCRE in the last 10 years have had AEMR of some kind, ranging from one-time pre-restoration baseline assessments to full-scale intensive research (Table F.2). Reporting of AEMR results, however, is incomplete. This makes it difficult to assimilate new knowledge to inform AEMR decision-making. A first matter of business for the AMST will be to summarize the AEMR knowledge base to date. Absent such a summary, CEERP stakeholders must rely on their collective professional judgment.

Table F.2. Approximate Number of Restoration Projects by Reach from 2000 Through 2010 and Number of Project with AEMR of Some Kind (as of September 29, 2010; based on data provided by the Lower Columbia River Estuary Partnership)

\begin{tabular}{|c|c|c|c|c|c|c|c|c|c|c|}
\hline Action & A & $\mathrm{B}$ & $\mathrm{C}$ & $\mathrm{D}$ & $\mathrm{E}$ & $\mathrm{F}$ & $\mathrm{G}$ & $\mathrm{H}$ & Total & AEMR \\
\hline Dike/levee removal & & & & & & & & & 7 & 3 \\
\hline Dike/levee breach/modification & 6 & 4 & 1 & & & 1 & 1 & & 13 & 3 \\
\hline Culvert removal & 1 & 2 & 1 & & & 4 & 1 & 1 & 10 & 4 \\
\hline Culvert modification & 1 & 1 & & & 1 & 1 & & 2 & 6 & 2 \\
\hline Tide gate removal & 2 & 2 & 1 & & & & & & 5 & 3 \\
\hline Tide gate modification & 7 & 14 & & & & & & & 21 & 0 \\
\hline Tide gate(s) removal/replacement with culvert(s) & & 1 & & & & & & & & 1 \\
\hline Excavation/grading & & 2 & & & 2 & 1 & & 2 & 7 & 1 \\
\hline Creation & 0 & 0 & 0 & 0 & 0 & 0 & 0 & 0 & 0 & 0 \\
\hline Invasive plant removal & & 1 & 1 & 1 & 1 & 1 & 5 & 1 & 11 & $\mathrm{XX}$ \\
\hline Riparian revegetation & 5 & 5 & 3 & & 1 & 5 & 15 & & 34 & 6 \\
\hline Total & 22 & 31 & 7 & 1 & 5 & 13 & 22 & 6 & 107 & 23 \\
\hline
\end{tabular}

From a programmatic point of view, the AMST might ask the following questions to help frame prioritization of AEMR (Figure F.3). These and similar questions could serve as a basis for scoring criteria in an AEMR prioritization process.

- For which restoration types are we uncertain about the predicted effects? Is the restoration type wellunderstood?

- What are key uncertainties about the benefits of the restoration action to juvenile salmon? 
- Which reaches are the highest priority? Which have been least studied?

- What is the relevance of a habitat type to the goals of the LCRE program?

- Where are the proposed restoration actions located and how well are the associated ecosystems known?

- What is the degree of loss and existing stress at a given site?

- What is the degree of uncertainty regarding highest potential restoration actions?

- Is the project high profile with high assigned SBUs?

- How much AEMR is enough? How long is enough?

- Is there a solid statistical relationship between extensively and intensively monitored indicators that could be applicable?

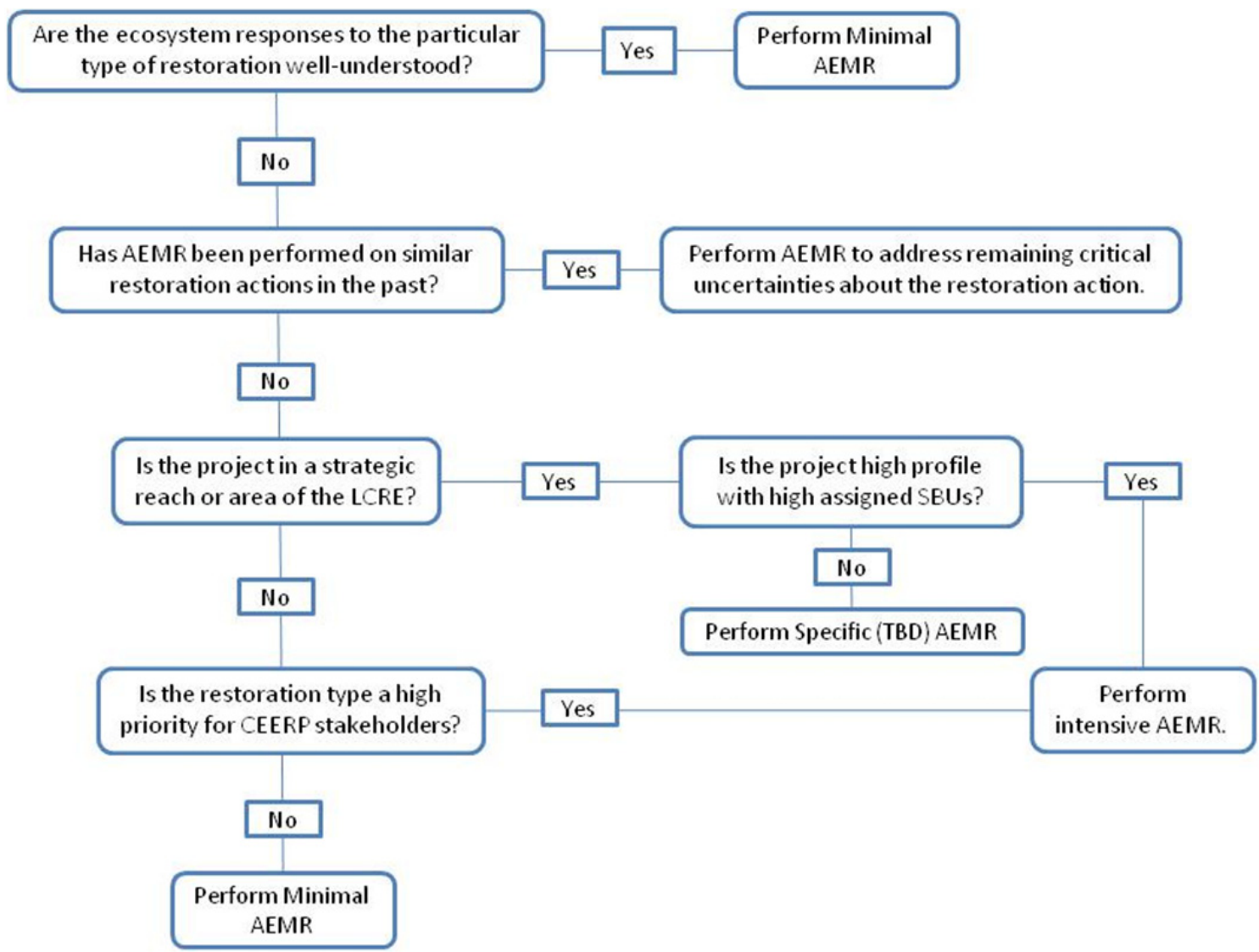

Figure F.3. Example Decision Tree for AEMR Prioritization

From a more general point of view than the question-based AEMR prioritization, the following steps could be used to prioritize monitoring and research for action effectiveness, status and trends, or critical uncertainties in the context of CEERP needs. The prioritization process would be the responsibility of the AMST with final say on funding actions being the role of the funding agencies. This is to say, prioritization is from the perspective of management decision-making, not fundamental ecosystem science. In the following scheme, monitoring and research objectives, as opposed to projects, are prioritized. 
1. List the most important decisions CEERP stakeholders must make.

2. Identify which decisions have the most uncertainty and highest risk of wasting funds.

3. Determine the fundamental scientific or non-scientific information required to make an informed decision.

4. Assess the level of understanding or state of science for the fundamental information.

5. Build a list of monitoring and research objectives ranked by the least understood but most important scientific information needed by CEERP stakeholders to make decisions.

6. Incorporate these monitoring and research objectives into the RME project portfolio.

\section{F.4 Remote Sensing for Vegetation}

Remote sensing has been used for vegetation mapping and assessment for many decades (Lunetta and Elvidge 1999). The data requirements and classification techniques for intensive mapping are different than those used at regional scales. Any investigation of vegetation or vegetation change must first be concerned with the ability to "see" and discriminate the phenomena of interest. For site-specific analyses this requires high-resolution data ( 0.25 - to $1-\mathrm{m}$ resolution). Historically, high-resolution imagery could only be collected via airborne sensors. The development of new high-resolution sensors provides a new source for high-resolution image data. Although airborne technology is still popular and available, there are some trade-offs between using airborne and satellite data. Table F.3 compares specific considerations in using each source.

Table F.3. Comparison of Airborne and Satellite Platform for Remote Sensing to Characterize Vegetation

\begin{tabular}{|c|c|c|c|}
\hline Feature & Airborne & Satellite & Implications for Vegetation Monitoring \\
\hline Cost & High cost of mobilization & $\begin{array}{l}\text { Always flying; } \\
\text { minimum order as low } \\
\text { as } \$ 1500\end{array}$ & $\begin{array}{l}\text { Fixed cost of airborne mobilization } \\
\text { favors large, continuous acquisition. } \\
\text { Satellite makes study of small, discrete } \\
\text { areas feasible }\end{array}$ \\
\hline $\begin{array}{l}\text { Spatial } \\
\text { resolution }\end{array}$ & $\begin{array}{l}\text { Very high; only limited by } \\
\text { sensor and flight elevation }\end{array}$ & $\begin{array}{l}\text { Currently limited to } \\
\sim 0.5 \mathrm{~m} \text {, panchromatic; } \\
\sim 2 \mathrm{~m} \text {, multi-spectral }\end{array}$ & $\begin{array}{l}\text { Very high spatial resolution is often } \\
\text { favorable for manual analysis, although } \\
\text { computer classification techniques may } \\
\text { favor lower resolution }\end{array}$ \\
\hline $\begin{array}{l}\text { Spectral } \\
\text { resolution }\end{array}$ & $\begin{array}{l}\text { Often does not include } \\
\text { near-infrared }\end{array}$ & $\begin{array}{l}\text { All sensors include } \\
\text { near-infrared }\end{array}$ & $\begin{array}{l}\text { Near-infrared sensitivity of a sensor is } \\
\text { very important because of sensitivity to } \\
\text { chlorophyll and plant structure at this } \\
\text { wavelength }\end{array}$ \\
\hline $\begin{array}{l}\text { Temporal } \\
\text { resolution }\end{array}$ & $\begin{array}{l}\text { Dependent on flight } \\
\text { schedule/budget }\end{array}$ & $\begin{array}{l}\text { Always flying; } 1 \text { - to } \\
\text { 3-day revisit time }\end{array}$ & $\begin{array}{l}\text { Very frequent revisit is often not } \\
\text { necessary, but is more feasible with } \\
\text { satellite sensors }\end{array}$ \\
\hline $\begin{array}{l}\text { Radiometric } \\
\text { resolution }\end{array}$ & $\begin{array}{l}\text { 8-bit; not as sensitive to } \\
\text { small variations in color }\end{array}$ & $\begin{array}{l}\text { 11-bit; more sensitive to } \\
\text { small variations in color }\end{array}$ & $\begin{array}{l}\text { Subtle color variations may be very } \\
\text { important to discriminate between cover } \\
\text { types. }\end{array}$ \\
\hline Geo-registration & $\begin{array}{l}\text { Airborne platform less } \\
\text { stable }\end{array}$ & $\begin{array}{l}\text { Stable, space-borne } \\
\text { platform allows for } \\
\text { simplified, accurate } \\
\text { geo-registration. }\end{array}$ & $\begin{array}{l}\text { Accurate and precise geo-registration is } \\
\text { critical because pixels will need to be } \\
\text { compared to ground data GPS positions. }\end{array}$ \\
\hline
\end{tabular}


Table F.3. (contd)

\begin{tabular}{llll}
\hline \multicolumn{1}{c}{ Feature } & \multicolumn{1}{c}{ Airborne } & \multicolumn{1}{c}{ Satellite } & \multicolumn{1}{c}{ Implications for Vegetation Monitoring } \\
\hline Calibration & Sensors rarely calibrated & Calibrated sensors & $\begin{array}{l}\text { Calibration is very important when } \\
\text { comparing between sensors and dates. }\end{array}$ \\
Timing & $\begin{array}{l}\text { Acquisition time can be } \\
\text { very carefully controlled. }\end{array}$ & $\begin{array}{l}\text { Cannot control timing } \\
\text { of satellite overpass }\end{array}$ & $\begin{array}{l}\text { Timing of overpass can be important to } \\
\text { avoid clouds or acquire at certain tidal } \\
\text { conditions. }\end{array}$ \\
Continuity & $\begin{array}{l}\text { Contractors and sensors } \\
\text { change over time. }\end{array}$ & $\begin{array}{l}\text { Reasonable assurance of } \\
\text { continuity }\end{array}$ & $\begin{array}{l}\text { Changes in camera configuration may } \\
\text { confound comparison studies. }\end{array}$ \\
\hline GPS = global positioning system. & & \\
\hline
\end{tabular}

The primary considerations for using these data for vegetation monitoring are timing, spatial resolution, consistency, spectral resolution, and geo-registration. The timing of the acquisition is important in that certain environmental conditions may be important to capture or avoid (low tide, clouds etc.), but an oft-overlooked timing issue is the phenological development of different communities at the time of acquisition. Data should be acquired when the communities of interest are most phenologically distinct. By maximizing the variation in phenological development you can increase the separability of certain vegetation types that may be spectrally similar at other stages of development. Although higher spatial resolution is often desirable, many computer-aided approaches cannot exploit the detail visible in the image, like an analyst can.

Consistency of remote-sensing images is imperative for before-after studies. Actual vegetation change is often difficult to separate from apparent change due to differences in classification approaches. Illumination and phenological differences between time periods can magnify apparent change, so increasing the comparability between sensors by selecting the identical (or at least a similar, calibrated sensor) is important.

Most commercially available remote-sensing data (airborne or satellite) have a limited spectral depth, but the commercial satellite sensors all collect data in the near-infrared, whereas many airborne images only collect in the visible color bands. The lack of the near-infrared band is a non-starter for vegetative studies because of the important interaction and response of near-infrared with chlorophyll and spongy mesophyll tissues.

Accurate geo-registration is imperative for imagery, regardless of the source, because the pixel data will need to be matched with global positioning system (GPS)-based ground data. If the wrong pixels are associated with the vegetation data from ground-truth efforts, misclassification can result. Some classification routines are more sensitive than others, in this regard, but all classifications rely on the proper association between ground data and pixel response.

\section{F.5 Templates}

We developed templates for project-specific AEMR plans and SECs to support restoration practitioners and promote standardization and efficiency within the CEERP. The Expert Regional Technical Group (ERTG) for the CEERP developed a project template for prospective restoration projects that is also included for completeness. The purpose is to provide the basic content for each document. Subsequent electronic forms with drop-down menus and automated population of certain fields should be constructed for the CEERP. 


\section{F.5.1 Project Description}

The ERTG project description template (Table F.4) is intended to standardize and organize the material restoration practitioners need to describe prospective restoration projects. If a project is designated to undergo the ERTG review process to assign SBUs, the funding agency will direct the restoration practitioner to prepare a project template. The ERTG uses the completed template, along with site visits and question/answer sessions with the proponents, to become familiar with the project. The project templates become part of CEERP records and database.

Table F.4. ERTG Project Description Template for Prospective Restoration Projects in the CEERP. (Reprinted from ERTG Document 2010-01; see this document for the attachments to the template: ERTG scoring criteria and Estuary Module subactions.)

\footnotetext{
Header:

Date State date the summary was prepared

Prepared by

State name, phone number, and email address

Sponsoring agency

State contact name, phone number, and email address

Funding agency

State contact name, phone number, and email address

Site

State the name, location, river, and river mile

Project status or stage

State the status or stage of the proposed project

\section{Proposed Project:}

Problem statement

Summarize the site-specific problem(s) the proposed restoration(s) is intended to address. What are the causes of the problems?

Vision/goal

Describe the expected outcome, i.e., what the site would look like if restoration is successful.

Objectives

State the project's objectives in terms of functions for salmon. For example, how will access, capacity etc. be increased or enhanced?

Project action(s)

List the proposed restoration action(s) (by year), e.g., restore tidal hydrology, protect riparian zone, etc.

Project elements(s)/phases by yr List the proposed restoration action(s) and phase(s) (by year) to meet the objectives.

Project size by yr

State number of barriers to be removed, the width of the breach or reconnection, and/or the number of acres/miles to be restored by year. Describe the method used to determine project size.

Linkage to Estuary Module:

Estuary Module Action.

Identify the appropriate subaction and state the number of acres or miles the Subaction(s) and Project Goal

Pre-Assessment:

Photo Point

Aerial image

Condition of physical metrics project subaction will provide. Document how the value was obtained. Whenever possible, provide summary data (values).

Provide a digital photograph(s) of the site; note the point and orientation of the photograph, time of year, and tide/water-level stage.

Provide an aerial image from a satellite or plane. Annotate the image to convey information about the project. Prepare map (s) with landform types delineated.

Describe the major stressors and physical controlling factors. Basically summarize the existing condition of the site. What is the average tidal range, salinity? What is the ordinary-high-water tide elevation? Higher-high-water elevation? Two-year flood elevation?
} 
Table F.4. (contd)

\begin{tabular}{|c|c|}
\hline \multirow{2}{*}{\multicolumn{2}{|c|}{ Pre-Assessment (contd): }} \\
\hline & \\
\hline Condition of habitat metrics & Describe the key results of a vegetation survey. \\
\hline Condition of functional metrics & $\begin{array}{l}\text { Assess or sample whether juvenile salmonids are present in the area and within } \\
\text { the site. Describe the species composition and population sizes in the } \\
\text { immediate watershed. }\end{array}$ \\
\hline \multicolumn{2}{|l|}{ Performance Anticipated: } \\
\hline Physical change & Describe how the action(s) will affect physical controlling factors. \\
\hline Habitat change & Describe the expected condition of habitat. \\
\hline Function change & $\begin{array}{l}\text { Describe the expected functional change, e.g., Juvenile salmon feeding, rearing, } \\
\text { refuge, water-quality improvement, off site food-web support. }\end{array}$ \\
\hline \multicolumn{2}{|l|}{ Certainty of Success: } \\
\hline Landowner support & Describe the willingness and support of the landowner. \\
\hline Constraints or show-stoppers & Describe potential issues that could inhibit or prevent execution of the project. \\
\hline Restoration technique & $\begin{array}{l}\text { Describe the level of acceptance and maturity of the restoration technique; } \\
\text { e.g., tried and true or experimental. }\end{array}$ \\
\hline $\begin{array}{l}\text { Natural processes and self- } \\
\text { maintenance }\end{array}$ & $\begin{array}{l}\text { Explain the extent to which natural processes would be restored and how well } \\
\text { the restoration action(s) are anticipated to be maintained }\end{array}$ \\
\hline \multicolumn{2}{|l|}{ Potential Access Benefit: } \\
\hline $\begin{array}{l}\text { Distance of the project to the } \\
\text { main stem Columbia River }\end{array}$ & State distance in river miles. \\
\hline Connectedness to main stem & $\begin{array}{l}\text { Describe how well the project site will be connected to the main stem after the } \\
\text { restoration. }\end{array}$ \\
\hline Species impacted & $\begin{array}{l}\text { Describe which species, stocks, or populations are likely to benefit, based on the } \\
\text { best available data. }\end{array}$ \\
\hline \multicolumn{2}{|l|}{ Potential Capacity Benefit: } \\
\hline Habitat complexity & Describe habitat complexity, channels, large woody debris. \\
\hline Water quality & Describe water quality. \\
\hline Invasive species & Describe impacts from invasive species. \\
\hline Adjacent lands & Describe the condition of adjacent lands. \\
\hline Comments & Include comments or other pertinent information. \\
\hline
\end{tabular}

\section{F.5.2 Action-Effectiveness Monitoring and Research Plan}

Every restoration project should have a plan for AEMR. Such plans can range from a paragraph describing pre- and post-restoration site conditions coupled with photo points to an intensive research design to be carried out over 5 to 10 years. Monitoring plans will be project-specific, depending on local conditions, type of restoration, available funding and time, and other factors. Most importantly, however, AEMR will depend on the needs of the CEERP, described above in the section on RME prioritization. Our purpose is to provide a template for project-specific AEMR plans that is consistent with the CEERP AM process (see Chapter 3.0).

Restoration practitioners can use these plans in project proposals and communications with CEERP stakeholders, who in turn can use them to organize and track AEMR activities and report up to their management. Each AEMR plan will include restoration "accounting" metrics, experimental design, 
monitored indicators, monitoring locations, frequency of monitoring, data management, and reporting. The monitored indicators include rapid assessment measures, which are a few site-specific, postrestoration measurements that are biologically and ecologically related to survival benefits that can be relatively easily measured at all sites. The selection of these responses should be based on their relationship to higher-order (intensive) ecological responses to restoration. The AEMR plan developed during the project planning phase is designed to feed the SEC of monitoring results from the project implementation phase (see SEC template below).

The terminology in the AEMR template (Table F.5) has the following working definitions:

- Experimental Design - The statistical framework to be used to collect the samples.

- Monitored Indicator - A measurable parameter that characterizes an important aspect of the ecosystem and is sensitive to changes in the system.

- Location - The spatial extent over which sampling or analysis will occur. Includes restoration sites and any reference sites.

- Frequency/Period - How often samples will be collected and the time period over which sampling will be performed.

- Method/Protocol - The primary technique used to collect the data and the citation for the data collection and analysis protocol.

- Derived Variables - Variables that are calculated, computed, or otherwise based on monitored indicator(s).

- Data Management - The location, responsible parties, and procedures for data management.

- Report and Schedule - A description of the type of report, what it will include, how and where it will be disseminated, and the reporting schedule.

Table F.5. Template for an Action-Effectiveness Monitoring/Research Plan - Description of the Intended Monitoring/Research

\begin{tabular}{llll}
\hline Project Name & & & \\
Project No. & & & \\
Project Site (name/lat/long) & & Phone \\
Reference or Control Site (name/lat/long) & & Email & \\
\hline Restoration/Monitoring Sponsor & Agency & & \\
Name 1 & & & \\
Name 2 & & Dimensions/acreages/miles & Comments \\
\hline Restoration: Physical Changes Planned & Number & & \\
Dike/levee removal & & & \\
Dike/levee breach & & & \\
Culverts replaced & & & \\
Culverts modified & & & \\
Tide gates replaced & & &
\end{tabular}


Table F.5. (contd)

\begin{tabular}{|c|c|c|c|}
\hline $\begin{array}{l}\text { Restoration: Physical Changes Planned } \\
\text { (contd) }\end{array}$ & Number & Dimensions/acreages/miles & Comments \\
\hline \multicolumn{4}{|l|}{ Tide gates modified } \\
\hline \multicolumn{4}{|l|}{$\begin{array}{l}\text { Tide gate(s) removed/replaced with } \\
\text { culvert(s) }\end{array}$} \\
\hline \multicolumn{4}{|l|}{ Excavation/grading } \\
\hline \multicolumn{4}{|l|}{ Creation } \\
\hline \multicolumn{4}{|l|}{ Invasive plant removal } \\
\hline \multicolumn{4}{|l|}{ Riparian revegetation } \\
\hline \multicolumn{4}{|l|}{ Other: $\mathrm{XXXX}$} \\
\hline \multicolumn{4}{|l|}{ Experimental Design } \\
\hline \multicolumn{4}{|l|}{ Before-after-reference-impact } \\
\hline \multicolumn{4}{|l|}{ Before-after-control-impact } \\
\hline \multicolumn{4}{|l|}{ Accident Response } \\
\hline \multicolumn{4}{|l|}{ Survey } \\
\hline \multicolumn{4}{|l|}{ Other } \\
\hline Monitoring/Research Planned & Period & & \\
\hline \multicolumn{4}{|l|}{ Pre-restoration } \\
\hline \multicolumn{4}{|l|}{ Post-restoration $(\sim 1 \mathrm{yr})$} \\
\hline \multicolumn{4}{|l|}{ Post-restoration ( $\sim 5 \mathrm{yr})$} \\
\hline \multicolumn{4}{|l|}{ Post-restoration ( $\sim 10 \mathrm{yr})$} \\
\hline Monitored Indicator Planned & Location & Frequency/Period & Method/Protocol \\
\hline \multicolumn{4}{|l|}{ Photo points } \\
\hline \multicolumn{4}{|l|}{ Water-surface elevation (logger) } \\
\hline \multicolumn{4}{|l|}{ Temperature (logger) } \\
\hline \multicolumn{4}{|l|}{ Salinity (logger) } \\
\hline \multicolumn{4}{|l|}{ Channel x-sec area } \\
\hline \multicolumn{4}{|l|}{ Sediment accretion } \\
\hline \multicolumn{4}{|l|}{ Elevation (bathymetry/topography) } \\
\hline \multicolumn{4}{|l|}{ Catchment area } \\
\hline \multicolumn{4}{|l|}{ Plant species comp } \\
\hline \multicolumn{4}{|l|}{ Plant percent cover } \\
\hline \multicolumn{4}{|l|}{ Plant biomass } \\
\hline \multicolumn{4}{|l|}{ Aerial photos } \\
\hline Fish presence/species/size & & & \\
\hline Fish density & & & \\
\hline Satellite imagery landcover & & & \\
\hline Water velocity & & & \\
\hline Water properties (DO, TOC, chloro, etc & & & \\
\hline
\end{tabular}


Table F.5. (contd)

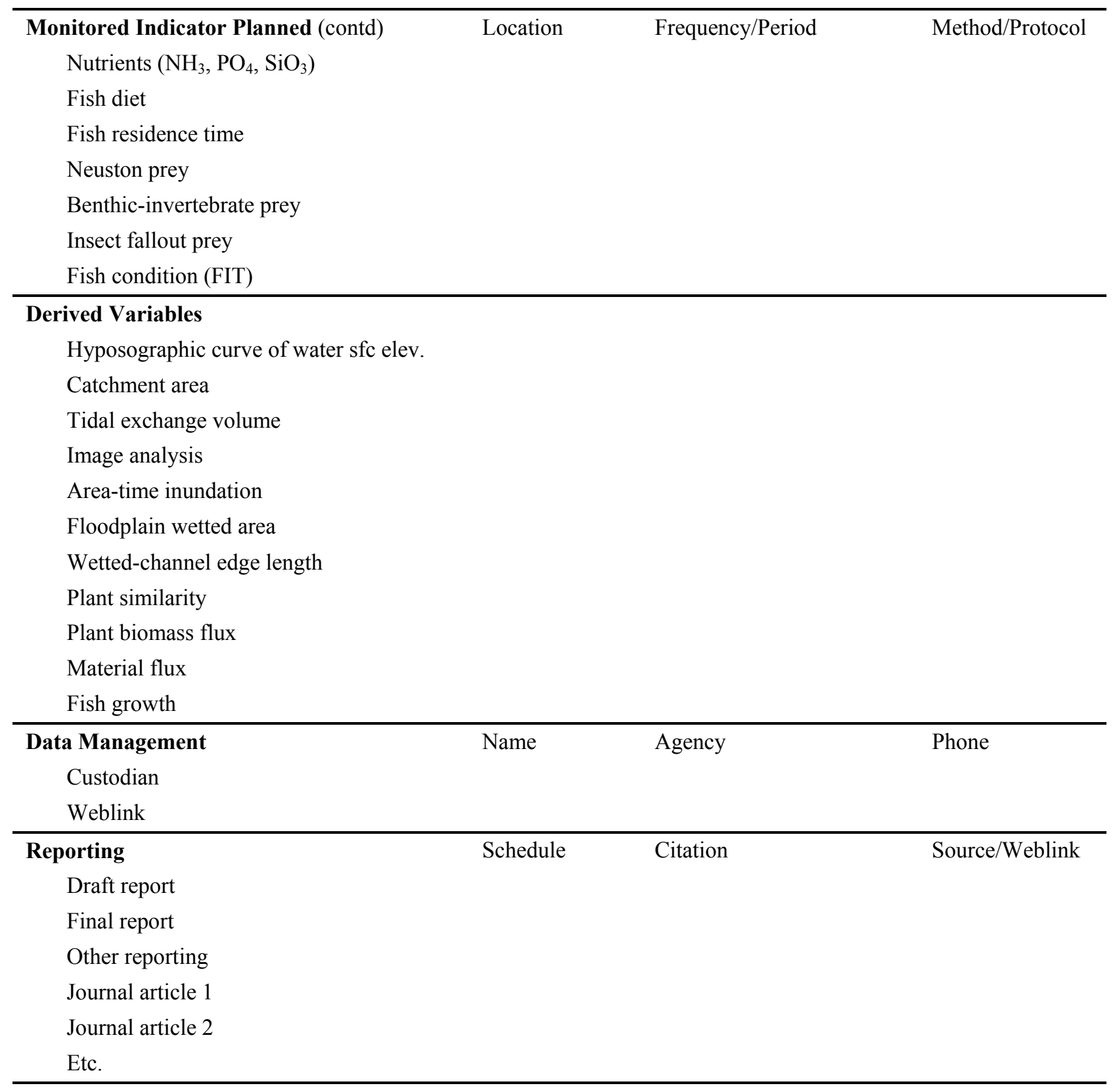

\section{F.5.3 Site Evaluation Card}

The SECs (Table F.6) are designed so that information in the AEMR plan can be copied and pasted directly into the SEC. SECs were first proposed by Thom et al. (2008) as a mechanism for systematically recording AEMR data from restoration projects. The intent was and still is to use the SECs to synthesize AERM data in periodic meta-analyses. To date, however, SECs are not part of the regular reporting by AERM practitioners. (See Chapter 3.0 for the role of SECs in CEERP AM and Appendix G for actual SECs for the Crims Island, Kandoll Farm, and Vera Slough restoration projects.) The SEC below has been updated with SBU data from the ERTG process because SBU data will be needed to fulfill 
$2008 \mathrm{BiOp}$ requirements and should be recorded as part of AERM documentation for past, present, and future sites. The restoration accounting measures are common-sense measurements of restoration effort and tangible, quantitative results. These measures will provide units of effort that biologists, policymakers, and the public can readily understand.

In constructing the SEC template, we kept in mind that its utility and value depend on the ability and ease with which it can be accurately completed by a wide range of restoration personnel. If the SEC were too large, too demanding, or too complicated it would decrease the chances of its being completed.

However, without the SEC, we diminish the ability to systematically capture AERM data and use the data to respond to BiOp requirements. It may well be that project sponsors need to complete the site and restoration goal descriptions, an expert panel needs to provide the SBU evaluation, and a professional rapid-assessment team needs to collect the field data at each site. Together, this process might help ensure all pertinent information is collected, reported, and stored. Finally, it should be recognized that the collective site information is more important to the Action Agencies because of their responsibilities under the BiOp than it is to the individual project sponsors. As such, professionally trained rapidassessment teams might be the only way to ensure the necessary information is accurately and properly collected. In addition, such a team might be the only prospect for gathering data at sites where restoration activities are completed.

Table F.6. Template for an Action-Effectiveness Monitoring/Research Site Evaluation Card Description of Monitoring/Research Performed and Key Findings

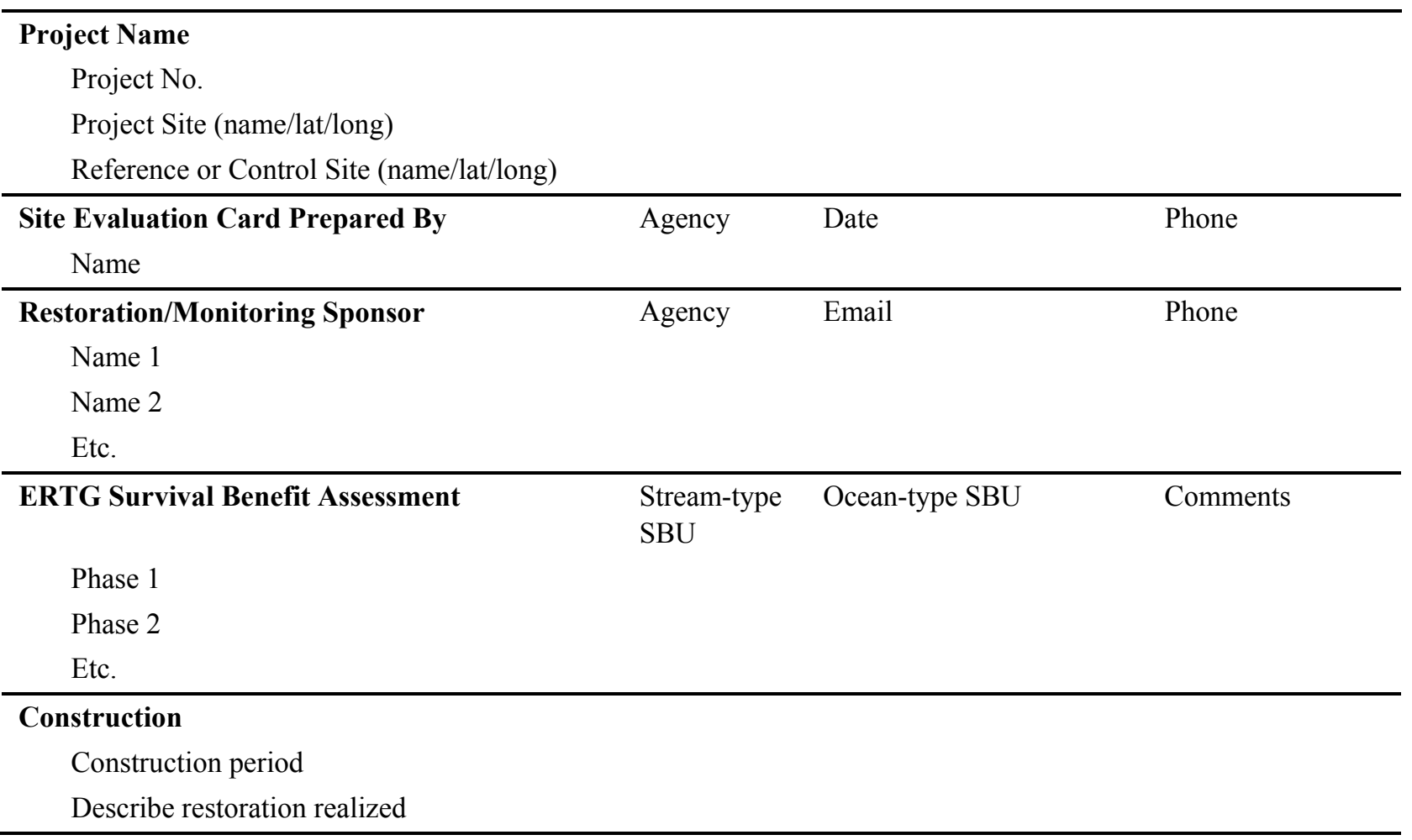


Table F.6. (contd)

\begin{tabular}{|c|c|c|c|}
\hline $\begin{array}{l}\text { Restoration Accounting: Physical Changes } \\
\text { Realized }\end{array}$ & Number & Restored Acres/Miles & Comments \\
\hline Dike/levee removal & & & \\
\hline Dike/levee breach/mod' & & & \\
\hline Culvert removal & & & \\
\hline Culvert modification & & & \\
\hline Tide gate removal & & & \\
\hline Tide gate modification & & & \\
\hline $\begin{array}{l}\text { Tide gate(s) removal/replacement with } \\
\text { culvert(s) }\end{array}$ & & & \\
\hline Excavation/grading & & & \\
\hline Creation & & & \\
\hline Invasive plant removal & & & \\
\hline Riparian revegetation & & & \\
\hline Other: XXXX & & & \\
\hline
\end{tabular}

\section{Experimental Design}

Before-after-reference-impact

Before-after-control-impact

Accident Response

Survey

Other: XXXX

\begin{tabular}{llll}
\hline Monitoring/Research & Period & & \\
Pre-restoration & & & \\
Post-restoration $(\sim 1 \mathrm{yr})$ & & & \\
Post-restoration $(\sim 5 \mathrm{yr})$ & Location & Frequency/Period/Date & Method/Protocol \\
Post-restoration $(\sim 10 \mathrm{yr})$ & & & \\
\hline Monitored Indicator & & & \\
Photo points & & & \\
Water-surface elevation (logger) & & \\
Temperature (logger) & & \\
Salinity (logger) & & \\
Channel x-sec area & & \\
Sediment accretion & & \\
Elevation (bathymetry/topography) & & \\
Catchment area & & \\
Plant species comp & & \\
Plant percent cover & & \\
Plant biomass & &
\end{tabular}


Table F.6. (contd)

\begin{tabular}{|c|c|c|c|}
\hline Monitored Indicator (contd) & Location & Frequency/Period/Date & Method/Protocol \\
\hline Fish presence/species/size & & & \\
\hline Satellite imagery land cover & & & \\
\hline Water velocity & & & \\
\hline Water properties (DO, TOC, chloro, etc.) & & & \\
\hline Nutrients $\left(\mathrm{NH}_{3}, \mathrm{PO}_{4}, \mathrm{SiO}_{3}\right)$ & & & \\
\hline Fish diet & & & \\
\hline Fish residence time & & & \\
\hline Neuston prey & & & \\
\hline Benthic-invertebrate prey & & & \\
\hline Insect fallout prey & & & \\
\hline Fish condition (FIT) & & & \\
\hline
\end{tabular}

\section{Derived Variables}

Hyposographic curve of water sfc elev.

Catchment area

Tidal exchange volume

Image analysis

Area-time inundation

Floodplain wetted area

Wetted-channel edge length

Plant similarity

Plant biomass flux

Material flux

Fish density

Fish growth

\begin{tabular}{llll}
\hline Data Management & Name & Agency & Phone \\
Custodian & & & \\
Weblink & & & Source/Weblink \\
\hline Reporting & Schedule & Citation & \\
Draft report & & & \\
Final report & & & \\
Other reporting & & & \\
Journal article 1 & & & \\
Journal article 2 & & & \\
Etc. & & & \\
\hline
\end{tabular}

Post-Construction Assessment: Year 1

Photo point/aerial photo

Condition of physical metrics

Condition of habitat metrics 
Table F.6. (contd)

\begin{tabular}{llc}
\hline Post-Construction Assessment: Year 1 (contd) & Description & Grade \\
Condition of functional metrics & & \\
CEERP adaptive management lessons & & Grade \\
\hline Post-Construction Assessment: Year 5 & Description & \\
Photo point/aerial photo & & \\
Condition of physical metrics & & \\
Condition of habitat metrics & & Grade \\
Condition of functional metrics & & \\
CEERP adaptive management lessons & Description & \\
\hline Final assessment ( 10 year) & & \\
Was the project successful in meeting its & & \\
goals? Explain the answer. Final grade? & & \\
If not, what should be changed for future & & \\
projects of this type & &
\end{tabular}




\section{Appendix G}

\section{Meta-Analysis of Action Effectiveness at Three Restoration Projects in the Lower Columbia River and Estuary}




\title{
Appendix G
}

\section{Meta-Analysis of Action Effectiveness at Three Restoration Projects in the Lower Columbia River and Estuary}

\author{
Prepared by Gary Johnson, Erin Donley, and April Cameron
}

\begin{abstract}
Gathering, merging, and analyzing effectiveness monitoring data from various restoration projects is fundamental to the evaluation of the success or failure of ecosystem restoration (Thom et al. 2011). The challenge is to integrate multiple site-scale monitoring results to make inferences at an estuary-wide scale. An applicable technique for this is meta-analysis, or the use of statistical methods to summarize research findings across studies (Gurevitch and Hedges 1999; Hedges et al. 1999). The strength of meta-analysis is its ability to statistically synthesize results from many studies having a common research question. Meta-analysis has been applied widely in ecology; e.g., species co-occurrence (Gotelli and McCabe 2002), forestry (Paquette et al. 2006), seagrasses (Heck et al. 2003), macroinvertebrates (Miller et al. 2010), fish-habitat associations (Smokorowski and Pratt 2007), fisheries management (Ransom and Mertz 1998), and wetland ecosystem services (Woodward and Wui 2001). There are numerous meta-analyses for ecosystem restoration, such as the synthesis by Pywell et al. (2003) of 25 vegetation studies in lowland Britain, which they applied to restoration program strategies. Rey-Benayas et al. (2009) performed a meta-analysis of 89 restoration-effectiveness studies across a wide range of ecosystems, although the suite of data did not include estuarine or tidal fluvial systems. To our knowledge, however, a meta-analysis of estuary restoration effectiveness has not been published.
\end{abstract}

Meta-analysis is one of the four primary analysis methods in the levels-of-evidence approach for evaluation of the cumulative effects of lower Columbia River and estuary (LCRE) ecosystem restoration (Figure 1.2; Diefenderfer et al. 2011). As such, meta-analysis of data from action- effectiveness monitoring of Columbia Estuary Ecosystem Restoration Program (CEERP) restoration projects has been a priority for the cumulative effects (CE) study. Johnson and Diefenderfer (eds.) (2008; Appendix H) completed an initial, preliminary, qualitative analysis of effectiveness data on water temperature, sediment accretion, and presence of juvenile salmon at five restoration sites that indicated improved ecosystem conditions after restoration. Johnson et al. (2010) identified 18 restoration projects in the LCRE and selected seven for analysis based on whether they had sufficient pre- and post-restoration effectiveness monitoring data, were proximal to the main stem Columbia River or a major tributary in tidal waters, and were tidal reconnections. They concluded that the restorations and monitored indicators studied, which were similar to those used by Johnson and Diefenderfer (eds.) (2009), were generally suggesting favorable restoration results but, again, the analysis was qualitative, not quantitative.

During 2010, significant improvements were made to the content and structure of two standardized sources of restoration project information, the project templates and Site Evaluation Cards (SECs). The project templates, designed through the Expert Regional Technical Group (ERTG) process, provide a succinct summary of the proposed restoration action. The SECs were developed to report monitoring results in a standard form within the CEERP adaptive management process (Thom et al. 2008). The intent eventually is to perform a meta-analysis to synthesize monitoring results reported in the SECs. When paired for a given project, why the restoration action was undertaken and its intended 
ecological outcomes (pre-restoration; the template) are integrated with what actually occurred physically and ecologically (post-restoration; the SEC).

Our objective is to perform a qualitative meta-analysis of the collective effectiveness of the restoration actions at Crims Island, Kandoll Farm, and Vera Slough. A statistical meta-analysis of CEERP effectiveness data is beyond the capabilities of the current state of the data, although such an analysis should be possible in the near future.

\section{G.1 Methods}

Project templates and SECs were prepared for the three main CE study sites - Crims Island, Kandoll Farm, and Vera Slough — because we had ready access to action-effectiveness monitoring data or technical reports for them and they had paired reference sites. With only three restoration sites, though, we performed a qualitative assessment synthesizing the results in a "Consumer Reports" summary table. The assessment was based on the indicator hypotheses identified in the levels-of-evidence approach for the CE evaluation (see Section 1.3 of this report; Diefenderfer et al. 2011). That is, for a given category in the SEC (condition of physical, habitat, and functional indicators), we graded effectiveness based on whether values measured at the restoration site suggest improvement over pre-restoration conditions and are trending toward reference site conditions. Three grades were possible: pass ( 0 ), fail ( 0 ), and incomplete (O). Grades for 1-year and 5-year post-restoration results are presented.

\section{G.2 Results}

The results include separate project templates and SECs for Crims Island, Kandoll Farm, and Vera Slough. The section closes with a summary table.

\section{G.2.1 Crims Island}

\begin{tabular}{|c|c|}
\hline \multicolumn{2}{|r|}{ PART 1: PROJECT TEMPLATE - Crims Island } \\
\hline Header: & \\
\hline Date & January 6,2011 \\
\hline Prepared by & Erin Donley, (360) 681-3623, erin.donley@pnl.gov \\
\hline $\begin{array}{l}\text { Sponsoring } \\
\text { agency }\end{array}$ & USACE, Blaine Ebberts, (503) 808-4763, blaine.d.ebberts@usace.army.mil \\
\hline Funding agency & USACE \\
\hline Site & Crims Island, Lower Columbia River, rkm 88 \\
\hline $\begin{array}{l}\text { Project status or } \\
\text { stage }\end{array}$ & Restoration and monitoring complete. \\
\hline \multicolumn{2}{|c|}{ Proposed Project: } \\
\hline $\begin{array}{l}\text { Problem } \\
\text { statement }\end{array}$ & $\begin{array}{l}\text { Important shallow-water habitat for juvenile salmon had been eliminated to create a cow } \\
\text { pasture. For example, the site elevation was too high, reed canarygrass had invaded, and tidal } \\
\text { channels had been filled. These actions resulted in poor habitat opportunity, poor habitat } \\
\text { capacity, and limited habitat access for juvenile salmon. }\end{array}$ \\
\hline Vision/goal & $\begin{array}{l}\text { Juvenile salmon would have access to shallow-water habitat characterized by tidal wetlands } \\
\text { with naturally regenerated native vegetation communities that provide prey and other } \\
\text { ecological support. }\end{array}$ \\
\hline
\end{tabular}


Objectives

Project action(s)

Project

elements(s)/

phases by yr

Project size by yr

Improve salmon habitat access and capacity by grading to intertidal elevations and excavating to build intertidal channels. ${ }^{1}$

Pre-restoration monitoring occurred in 2003 and 2004. Grading and excavating occurred beginning in August 2004 and concluded in September 2005. Post-restoration monitoring occurred in $2006 .^{1}$

2003-2004: Design and pre-restoration monitoring.

2004/2005: Construction

2006: Post-restoration monitoring

The site restored 94 acres of tidal wetland. Method used to determine project size was not reported. ${ }^{1}$

\begin{tabular}{ll}
\hline Linkage to Estuary Module: \\
\hline Estuary Module & $L C R E-9.4$. Elevation reduction would create 77 acres of tidal marsh and excavation would \\
Action. & create 17 acres of intertidal channels. (Method used to determine project size was not \\
Subaction(s) and & reported). ${ }^{1}$ \\
Project Goal & \\
\hline
\end{tabular}

\section{Pre-Assessment:}

Photo Point

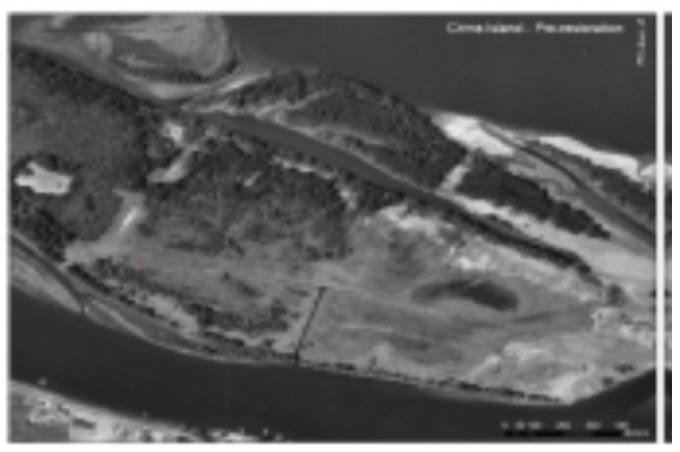

Photo taken in the year 2000 .

Aerial image

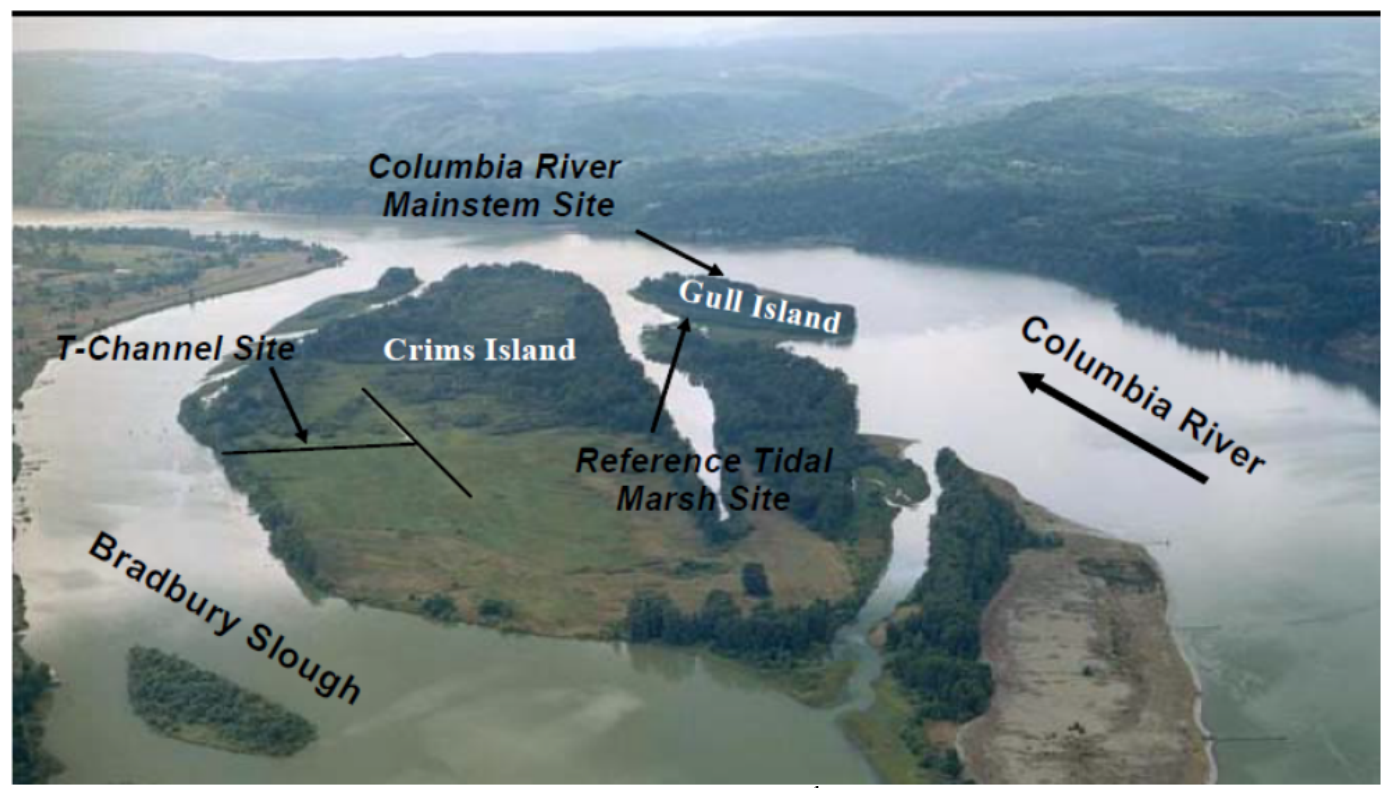

Photo taken in 2004.

\footnotetext{
${ }^{1}$ Haskell, C.A., Kenneth Tiffan and John Olson. 2007. Crims Island Habitat Restoration in the Columbia River Estuary - Fisheries Monitoring and Evaluation, 2006. Final Report of Research Submitted to U.S. Army Corps of Engineers, Portland District, by U.S. Geological Survey, Cook, Washington.
} 
Condition of physical metrics
Major stressors and physical controlling factors:

Elevation is too high.

Dominated by reed canarygrass.

Short durations of inundation.

Pre-restoration sediment was primarily clay. (USGS)

Off-channel habitats accreted and filled in.

Report: [average height of site pre-restoration minus 2 feet $=$ post- restoration site elevation...email sent to Cindy]

Tides at Crims Island are semi diurnal with approximately 7 hours of ebb and 5 hours of flood tide. Tidal flux ranges from 0.6 to 2.1 meters, as reported $1.1 \mathrm{~km}$ downstream of Crims Island (USGS gage \#14246900.

\section{Report: [salinity]}

Ordinary High Water Mark $=3.929 \mathrm{~m}$ relative to NAVD88.

Condition of

habitat metrics

Condition of

functional metrics
No pre-restoration vegetation survey. However, visual assessment indicates that the system is dominated by reed canarygrass.

Prior to restoration, subyearling Chinook salmon were present in March and early April in the area to be restored. Average catch per unit effort (CPUE) at Crims Island pre-restoration March-May is 34 fish per hour. ${ }^{1}$

\section{Performance Anticipated:}

Physical change Grading will lower the topography by 2 feet, thereby enabling natural hydrodynamic processes to shape the habitat. Excavating will create channels and remove passage impediments. These actions may result in improved water quality and lower water temperatures.

Percent soft sediment will be reduced.

Habitat change Reed canarygrass will be absent. Emergent tidal vegetation will have established in its place. Increase the amount of intertidal channel habitat.

Function change The expected functional change may include higher average catch-per-unit-effort for juvenile salmon, demonstrated salmon feeding and growth in the restored habitat, and increased export of macro-detritus to the main stem.

\begin{tabular}{|c|c|}
\hline \multicolumn{2}{|c|}{ Certainty of Success: } \\
\hline $\begin{array}{l}\text { Landowner } \\
\text { support }\end{array}$ & This site is on Federal property. \\
\hline $\begin{array}{l}\text { Constraints or } \\
\text { show-stoppers }\end{array}$ & $\begin{array}{l}\text { Design elevation is incorrect. } \\
\text { As-built elevation is not to the specifications. } \\
\text { Columbia River is in flood stage during the scheduled construction window. } \\
\text { Natural vegetation does not regenerate. Reed canarygrass repopulates the area. } \\
\text { Excavated channels re-fill. }\end{array}$ \\
\hline $\begin{array}{l}\text { Restoration } \\
\text { technique }\end{array}$ & $\begin{array}{l}\text { Grading and excavating are common restoration practices with a high level of acceptance and } \\
\text { maturity. }\end{array}$ \\
\hline $\begin{array}{l}\text { Natural processes } \\
\text { and self- } \\
\text { maintenance }\end{array}$ & $\begin{array}{l}\text { Natural hydrodynamic processes would once again come to bear on the tidal wetland habitat } \\
\text { consequently improving access to habitat for juvenile salmonids, improving water quality and } \\
\text { maintaining intertidal channel habitats. }\end{array}$ \\
\hline \multicolumn{2}{|c|}{ Potential Access Benefit: } \\
\hline $\begin{array}{l}\text { Distance of the } \\
\text { project to the } \\
\text { main stem } \\
\text { Columbia River }\end{array}$ & 0 river miles; the project is on a main stem island. \\
\hline $\begin{array}{l}\text { Connectedness to } \\
\text { mainstem }\end{array}$ & The project will reconnect an intertidal site directly to the main stem. \\
\hline Species impacted & All Columbia River salmonid ESUs originating in watersheds upstream of Longview, WA. \\
\hline
\end{tabular}




\begin{tabular}{ll}
\hline Potential Capacity Benefit: \\
\hline $\begin{array}{l}\text { Habitat } \\
\text { complexity }\end{array}$ & $\begin{array}{l}\text { T-channel is a steep banked man-made channel. The ends of the T-channel run to the interior } \\
\text { of the island and regularly dewater during low tide. Allochthonous macrodetritus from } \\
\text { emergent vegetation (including large wood) is the primary source of organic carbon in the } \\
\text { system. }\end{array}$ \\
$\begin{array}{l}\text { Mean water temperature between March and May ranged from } 10^{\circ} \mathrm{C} \text { to } 18^{\circ} \mathrm{C} . \\
\text { Invasive species }\end{array}$ & $\begin{array}{l}\text { Invasive reed canarygrass dominated the plant community. Purple loosestrife, celery-leaved } \\
\text { buttercup, threesquare tule, marsh cudweed, nodding beggar-ticks, and Eurasian watermilfoil } \\
\text { were also present. }\end{array}$ \\
Adjacent lands & $\begin{array}{l}\text { Report [Describe the condition of adjacent lands]. } \\
\text { Comments }\end{array}$ \\
\hline
\end{tabular}

\begin{tabular}{|c|c|c|c|c|}
\hline \multicolumn{5}{|c|}{ PART 2: SITE EVALUATION CARD - Crims Island } \\
\hline Project Name & \multicolumn{4}{|c|}{ Crims Island } \\
\hline Project No. & \multicolumn{4}{|l|}{$\mathrm{XXX}$} \\
\hline $\begin{array}{l}\text { Project Site } \\
\text { (name/lat/long) }\end{array}$ & \multicolumn{4}{|c|}{ Crims Island, $\mathrm{XXX} / \mathrm{XXXX}$} \\
\hline $\begin{array}{l}\text { Reference or Control } \\
\text { Site (name/lat/long) }\end{array}$ & \multicolumn{4}{|c|}{ Gull Island, $\mathrm{XX} / \mathrm{XXX}$} \\
\hline \multicolumn{2}{|c|}{ Site Evaluation Card Prepared By } & Agency & Date & Phone \\
\hline \multicolumn{2}{|c|}{ Erin Donley } & PNNL & $1 / 6 / 11$ & \\
\hline $\begin{array}{l}\text { Restoration/Monitoring } \\
\text { Practitioner }\end{array}$ & Agency & Email & & Phone \\
\hline Blaine Ebberts & USACE & & & \\
\hline Craig Haskell & USGS & & & \\
\hline Amy Borde & PNNL & & & \\
\hline $\begin{array}{l}\text { ERTG Survival Benefit } \\
\text { Assessment }\end{array}$ & $\begin{array}{l}\text { Stream- } \\
\text { type SBU }\end{array}$ & Ocean-type SBU & & Comments \\
\hline Phase 1 & XXX & XXXX & & $2007 \mathrm{BA}$ \\
\hline
\end{tabular}

\section{Construction}

Construction Period

Describe restoration realized
August 2004-September 2005

Grading lowered the topography by 2 feet. Excavating created channels and removed passage impediments.

\begin{tabular}{lll}
\hline $\begin{array}{l}\text { Restoration Accounting: } \\
\text { Physical Changes }\end{array}$ & Number & Restorec \\
$\begin{array}{l}\text { Realized } \\
\quad \begin{array}{l}\text { Tide gates } \\
\text { replaced/mod }\end{array}\end{array}$ & 1 & unk \\
$\quad$ Excavation/grading & 1 & 94
\end{tabular}

Comments

stored Acres/Miles

Com

nk

4
Intertidal marsh

(77 acres) and

channels

(17 acres)

\begin{tabular}{ll}
\hline $\begin{array}{l}\text { Experimental Design } \\
\text { Monitoring/Research }\end{array}$ & Before-after-reference-impact \\
$\begin{array}{l}\text { Pre-restoration } \\
\text { period }\end{array}$ & 2003-2004: Design and pre-restoration monitoring during the months of March-July
\end{tabular}


Post-restoration

$(\sim 1 \mathrm{yr})$

Post-restoration Not scheduled

$(\sim 5 \mathrm{yr})$

Post-restoration Not scheduled

$(\sim 10$ yr $)$

\section{Monitored Indicators \\ Realized}

Derived Variables

Data Management

Custodian

Weblink

Haskell
Photo points; water-surface elevation (logger); temperature (logger); channel x-sec area; sediment accretion; elevation (bathymetry/topography); plant species comp; plant percent cover; fish presence/species/size; fish diet; fish residence time

Hyposographic curve of water sfc elev; floodplain wetted area; area-time inundation; wetted-channel edge length; plant similarity

Name Agency Phone

Craig USGS

Schedule

Citation

Source/Weblink

Draft report

2007

Final report

Spring

2011

Other reporting

2010

Haskell, C.A., Kenneth Tiffan and John Olson. 2007. Crims Island Habitat Restoration in the Columbia River Estuary - Fisheries Monitoring and Evaluation, 2006. Final Report of Research Submitted to U.S. Army Corps of Engineers, Portland District.

\section{XXXXX}

Johnson GE and HL Diefenderfer (eds.). 2010.
"Evaluating Cumulative Ecosystem Response to

Restoration Projects in the Lower Columbia River and Estuary, 2009." PNNL-19440, prepared by Pacific Northwest National Laboratory, Richland, Washington for the U.S. Army Corps of Engineers, Portland District, Portland, Oregon.

\begin{tabular}{ll}
\hline $\begin{array}{l}\text { Post-Construction Assessment: Yr } 1 \\
\text { Photo point/aerial photo }\end{array}$ & Description/Citation \\
Date XX & \\
Condition of physical metrics & $\underline{\text { Cross-sections pre, post, ref if avail; [info is }}$ \\
& available, but not sure which sites to include] \\
& Sediment accretion rates: 1.1 cm/yr post-restoration \\
& and 0.1 cm/yr at the reference site. (Sediment \\
accretion rates measured in September 2006 and & TBD \\
& February 2007.) Haskell and Tiffan 2011.
\end{tabular}


Condition of habitat metrics

Vegetation: Plant communities very different at

TBD

Crims Restoration and Reference sites. The restoration site is dominated by common rush. The reference site is dominated by slough sedge and forget me-not. Johnson and Diefenderfer (eds.) 2010 .

38 species of plant were detected at the restoration site and 16 species were detected at the reference sites. Haskell et al. 2007.

Condition of functional metrics

Fish presence

After restoration the number of subyearling

Chinook increased and density was lower than that observed in the reference site.

Fish residence time

Median residence time of the fish in the restoration site $($ median $=50.2 \mathrm{~h}$ ) in 2006 was longer compared to before restoration $($ median $=12.7 \mathrm{~h})$. Prerestoration, median residence time at the reference site was $1 \mathrm{~h}$. Whereas median reference residence time was 43.1 h. Haskell et al. 2007.

CEERP adaptive management

$\mathrm{XXXXXXX}$

lessons

\begin{tabular}{llc}
\hline $\begin{array}{l}\text { Post-Construction Assessment: Yr 5 } \\
\text { Photo point/aerial photo }\end{array}$ & $\begin{array}{l}\text { Description } \\
\text { (no plans for 5-yr assessment) }\end{array}$ & Grade \\
$\begin{array}{l}\text { Condition of physical metrics } \\
\text { Condition of habitat metrics }\end{array}$ & & TBD \\
Condition of functional metrics & & TBD \\
CEERP adaptive management & & TBD \\
lessons & Description & Grade \\
\hline $\begin{array}{l}\text { Final assessment ( 10 year) } \\
\text { Was the project successful in } \\
\text { meeting its goals? Explain the } \\
\text { answer. Final grade? }\end{array}$ & TBD & TBD \\
If not, what should be changed for \\
future projects of this type?
\end{tabular}

\section{G.2.2 Kandoll Farm}

\section{PART 1: PROJECT TEMPLATE - Kandoll Farm}

\begin{tabular}{ll}
\hline Header: & \\
$\begin{array}{l}\text { Date } \\
\text { Prepared by }\end{array}$ & January 6, 2011 \\
$\begin{array}{l}\text { Sponsoring } \\
\text { agency }\end{array}$ & Columbia Land Trust, Ian Sinks, (360) 213-1206, isinks@columbialandtrust.org \\
$\begin{array}{l}\text { Funding agency } \\
\text { Site }\end{array}$ & BPA \\
$\begin{array}{l}\text { Project status or } \\
\text { stage }\end{array}$ & Kandoll Farm, Lower Grays River, rkm 36 \\
\hline
\end{tabular}




\begin{tabular}{|c|c|}
\hline \multicolumn{2}{|l|}{ Proposed Project: } \\
\hline $\begin{array}{l}\text { Problem } \\
\text { statement }\end{array}$ & $\begin{array}{l}\text { The tidal freshwater swamp at Kandoll Farm once served as shallow-water habitat for juvenile } \\
\text { salmonids. However, the swamp ecosystem has been converted to farm land and hydrologic } \\
\text { barriers including culverts and tide gates have been installed. As a result of these activities, } \\
\text { juvenile salmonids have limited access to shallow-water habitat. Of the small amount of } \\
\text { shallow-water habitat that is accessible to juvenile salmonids, the capacity of the habitat to } \\
\text { support juvenile salmonids feeding and growth has been drastically reduced. }\end{array}$ \\
\hline Vision/goal & $\begin{array}{l}\text { Juvenile salmon would have access to shallow-water habitat characterized by lower water } \\
\text { temperatures, increased dissolved oxygen levels and naturally sustained food-web function. }\end{array}$ \\
\hline Objectives & $\begin{array}{l}\text { Permanently protecting and restoring } 163 \text { acres of diked tideland and approximately } 1 \text { mile of } \\
\text { shoreline in order to increase access to swamp habitat, lower water temperatures, raise dissolved } \\
\text { oxygen levels and increase food-web productivity. }\end{array}$ \\
\hline Project action(s) & $\begin{array}{l}\text { Pre-restoration monitoring occurred in the summer of } 2005 \text {. In September of } 2005 \text {, two tide } \\
\text { gates restricting flow into the slough were replaced with } 13 \mathrm{ft} \text {-diameter culverts. A dike along } \\
\text { the Gray River was breached in three places in September } 2005 \text {. }\end{array}$ \\
\hline $\begin{array}{l}\text { Project } \\
\text { elements(s)/ } \\
\text { phases by yr }\end{array}$ & $\begin{array}{l}\text { Summer 2005: Baseline data collection. } \\
\text { September 2005: Construction } \\
\text { 2006: Post-restoration monitoring } \\
\text { 2007: Post-restoration monitoring } \\
\text { 2009: Post-restoration monitoring }\end{array}$ \\
\hline $\begin{array}{l}\text { Project size by } \\
\text { yr }\end{array}$ & $\begin{array}{l}2 \text { tide gates will be replaced with culverts. } \\
1 \text { dike along the Grays River will be breached in } 3 \text { places. } \\
\text { Ultimately, } 163 \text { acres of tideland and } 1 \text { mile of shoreline will be restored to increase access of } \\
\text { juvenile salmonind access to swamps. Method used to determine project size not reported }\end{array}$ \\
\hline \multicolumn{2}{|c|}{ Linkage to Estuary Module: } \\
\hline $\begin{array}{l}\text { Estuary Module } \\
\text { Action. } \\
\text { Subaction(s) and } \\
\text { Project Goal }\end{array}$ & $\begin{array}{l}9.4 \text { (restoring degraded off-channel habitat - estimate channel area), } 10.1 \text { (dike breech), } \\
10.3 \text { (tide gate replacement). }\end{array}$ \\
\hline
\end{tabular}

${ }^{1}$ Diefenderfer HL, RM Thom, AB Borde, GC Roegner, AH Whiting, GE Johnson, EM Dawley, JR Skalski, J Vavrinec, and BD Ebberts. 2006. Evaluating Cumulative Ecosystem Response to Restoration Projects in the Columbia River Estuary, Annual Report 2005. PNNL-15934, report to US Army Corps of Engineers, Portland District, by Pacific Northwest National Laboratory, Richland, Washington. 


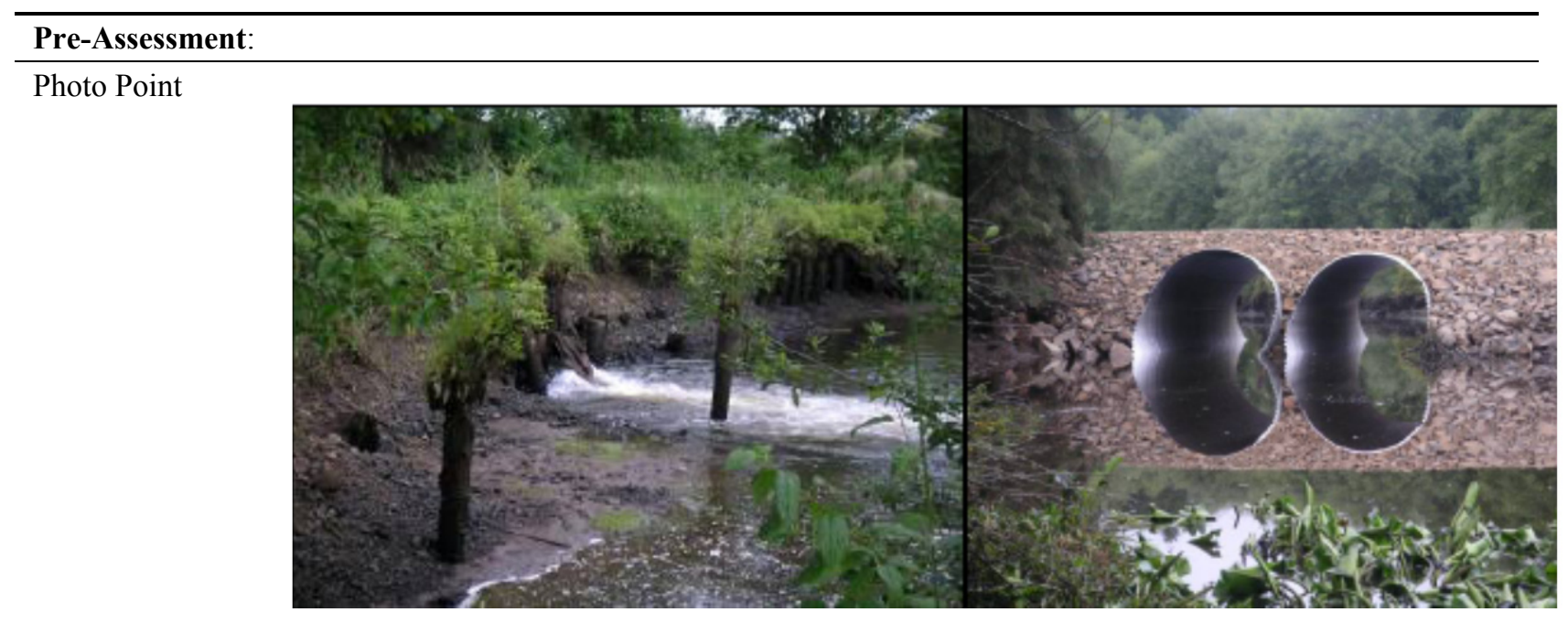

Pre-restoration tide gate on the left; post-restoration culvert on the right.

July 2005

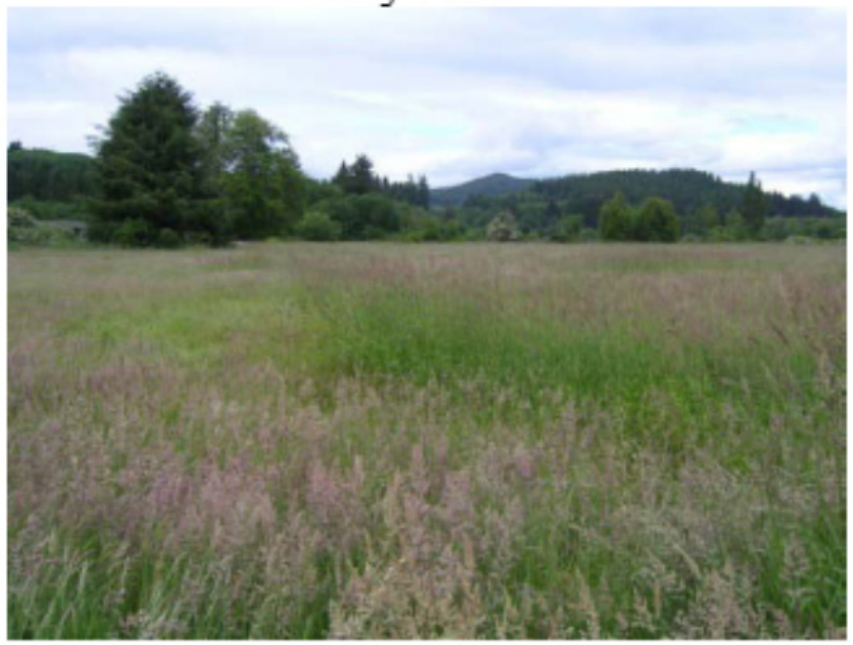


Aerial image

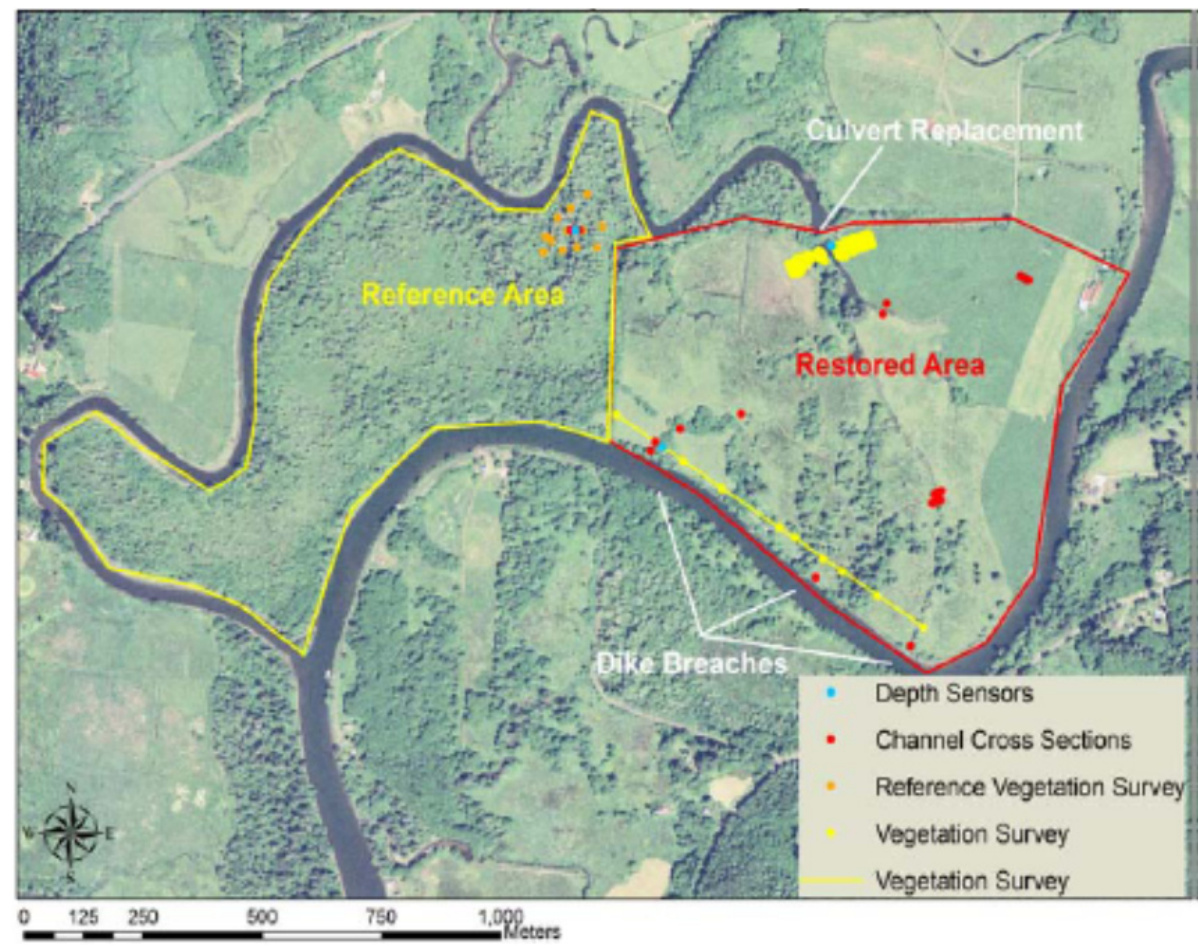

Kandoll Farm Dike Breach and culvert replacement site (right side of polygon). Reference site (left side of polygon), between Seal Slough and the Grays River in Washington.

Condition of Major stressors and physical controlling factors:

physical metrics Land elevation between 65 and $70 \mathrm{~cm}$.

Dominated by reed canarygrass.

Ordinary High Water Mark $=3.020 \mathrm{~m}$ relative to NAVD88

Prior to restoration, tidal influence was minimal with water level nearly always around one meter. salinity?

Condition of Vegetation dominated by wetland species (at elevations lower than $6 \mathrm{ft}$ ). Species-area curves habitat metrics indicate that the majority of species were found by sampling approximately thirty $1-\mathrm{m}^{2}$ plots.

Condition of One Coho salmon (Oncorhynchus kisutch) was captured in May 2005 (46 mm). Four Coho functional metrics salmon were captured in June $2005(80-81 \mathrm{~mm})$. Species composition was dominated by threespine stickleback, which comprised $81 \%$ of the catch. ${ }^{1}$

\begin{tabular}{ll}
\hline Performance Anticipated: \\
\hline Physical change & $\begin{array}{l}\text { Replacing the tide gates with culverts and breaching the dike at Kandoll Farm will increase } \\
\text { hydrologic connection between channel and shallow-water habitat. }\end{array}$ \\
Habitat change & $\begin{array}{l}\text { Reed canarygrass will be absent. Emergent tidal vegetation will have established in its place. } \\
\text { Increased amount and capacity of tidal freshwater swamp ecosystem. }\end{array}$ \\
Function change & $\begin{array}{l}\text { Higher average catch-per-unit-effort for juvenile salmonids. Demonstrated salmonid feeding } \\
\text { and increased residence time in restored habitat. }\end{array}$ \\
\hline
\end{tabular}

${ }^{1}$ Diefenderfer HL, RM Thom, AB Borde, GC Roegner, AH Whiting, GE Johnson, EM Dawley, JR Skalski, J Vavrinec, and BD Ebberts. 2006. Evaluating Cumulative Ecosystem Response to Restoration Projects in the Columbia River Estuary, Annual Report 2005. PNNL-15934, report to US Army Corps of Engineers, Portland District, by Pacific Northwest National Laboratory, Richland, Washington. 


\begin{tabular}{|c|c|}
\hline \multicolumn{2}{|c|}{ Certainty of Success: } \\
\hline $\begin{array}{l}\text { Landowner } \\
\text { support }\end{array}$ & Land is owned by the Columbia Land Trust. \\
\hline $\begin{array}{l}\text { Constraints or } \\
\text { show-stoppers }\end{array}$ & $\begin{array}{l}\text { Columbia River is in flood stage during the scheduled construction period. } \\
\text { Natural vegetation does not regenerate. Reed canarygrass repopulates the area. }\end{array}$ \\
\hline $\begin{array}{l}\text { Restoration } \\
\text { technique }\end{array}$ & $\begin{array}{l}\text { Culvert installation and dike breaching are common restoration practices with a high level of } \\
\text { acceptance and maturity. }\end{array}$ \\
\hline $\begin{array}{l}\text { Natural } \\
\text { processes and } \\
\text { self-maintenance }\end{array}$ & $\begin{array}{l}\text { Natural hydrodynamic processes would once again come to bear on the tidal wetland habitat } \\
\text { consequently improving access to habitat for juvenile salmonids, improving water quality and } \\
\text { maintaining intertidal channel habitats. }\end{array}$ \\
\hline \multicolumn{2}{|c|}{ Potential Access Benefit: } \\
\hline $\begin{array}{l}\text { Distance of the } \\
\text { project to the } \\
\text { main stem } \\
\text { Columbia River }\end{array}$ & State distance in river miles. \\
\hline $\begin{array}{l}\text { Connectedness } \\
\text { to mainstem }\end{array}$ & Describe how well the project site will be connected to the main stem after the restoration. \\
\hline $\begin{array}{l}\text { Species } \\
\text { impacted }\end{array}$ & Coho salmon and threespine stickleback. \\
\hline \multicolumn{2}{|c|}{ Potential Capacity Benefit: } \\
\hline $\begin{array}{l}\text { Habitat } \\
\text { complexity }\end{array}$ & Describe habitat complexity, channels, large woody debris. \\
\hline Water quality & $\begin{array}{l}\text { In the pre-restoration period between August and September, } 10 \% \text { of water temperature } \\
\text { observations were greater than } 18.2^{\circ} \mathrm{C} .80 \% \text { of temperatures were at or below } 20^{\circ} \mathrm{C} \text {. }\end{array}$ \\
\hline Invasive species & Describe impacts from invasive species. \\
\hline Adjacent lands & Describe the condition of adjacent lands. \\
\hline Comments & $\begin{array}{l}\text { CLT has restored salmonid access to } 400 \text { acres of formerly diked floodplain habitat and } \\
\text { enhanced } 116 \text { acres within the Seal Slough-Grays River parcel (the Kandoll Reference site) } \\
\text { through the removal of logging road crossings of tidal channels. }\end{array}$ \\
\hline
\end{tabular}

\begin{tabular}{|c|c|c|}
\hline \multicolumn{3}{|c|}{ PART 2: SITE EVALUATION CARD - Kandoll Farm } \\
\hline Project Name & Kandoll Farm & \\
\hline Project No. & XXXX & \\
\hline $\begin{array}{l}\text { Project Site } \\
\text { (name/lat/long) }\end{array}$ & Kandoll Farm (XXX/XX) & \\
\hline $\begin{array}{l}\text { Reference or Control } \\
\text { Site (name/lat/long) }\end{array}$ & Seal Slough Swamp $(\mathrm{XX} / \mathrm{XX})$ & \\
\hline $\begin{array}{l}\text { Site Evaluation Card } \\
\text { Prepared By }\end{array}$ & Agency & Phone \\
\hline Erin Donley & PNNL & \\
\hline $\begin{array}{l}\text { Restoration/Monitoring } \\
\text { Practitioner }\end{array}$ & Agency & Phone \\
\hline Ian Sinks & CLT & \\
\hline Blaine Ebberts & USACE & \\
\hline Heida Diefenderfer & PNNL & \\
\hline
\end{tabular}




\begin{tabular}{|c|c|c|c|}
\hline $\begin{array}{l}\text { ERTG Survival Benefit } \\
\text { Assessment }\end{array}$ & $\begin{array}{l}\text { Stream-type } \\
\text { SBU }\end{array}$ & Ocean-type SBU & Comments \\
\hline Phase 1 & $\mathrm{XXX}$ & $\mathrm{XXX}$ & $2007 \mathrm{BA}$ \\
\hline \multicolumn{4}{|l|}{ Construction } \\
\hline Construction Period & \multicolumn{3}{|l|}{ September 2005} \\
\hline $\begin{array}{l}\text { Describe restoration } \\
\text { realized }\end{array}$ & \multicolumn{3}{|c|}{$\begin{array}{l}\text { Tide gates replaced with two 14-ft diameter culverts; dike along Frays River breached } \\
\text { in three locations }\end{array}$} \\
\hline $\begin{array}{l}\text { Restoration Accounting: } \\
\text { Physical Changes } \\
\text { Realized }\end{array}$ & Number & Restored Acres/Miles & Comments \\
\hline Dike/levee breach & 1 & $\mathrm{XXX}$ & \\
\hline $\begin{array}{l}\text { Tide gate(s) } \\
\text { removed/replaced } \\
\text { with culvert(s) }\end{array}$ & 2 & 163 acres restored wetland & $\begin{array}{l}\text { Acreage method } \\
\text { not reported }\end{array}$ \\
\hline Experimental Design & \multicolumn{3}{|c|}{ Before-after-reference-impact } \\
\hline Monitoring/Research & \multicolumn{3}{|l|}{ Period } \\
\hline Pre-restoration period & \multicolumn{3}{|l|}{ Summer 2005} \\
\hline $\begin{array}{l}\text { Post-restoration } \\
(\sim 1 \mathrm{yr})\end{array}$ & \multicolumn{3}{|l|}{2006 and 2007} \\
\hline $\begin{array}{l}\text { Post-restoration } \\
(\sim 5 \mathrm{yr})\end{array}$ & \multicolumn{3}{|l|}{2009} \\
\hline $\begin{array}{l}\text { Post-restoration } \\
(\sim 10 \mathrm{yr})\end{array}$ & \multicolumn{3}{|l|}{ Not scheduled } \\
\hline $\begin{array}{l}\text { Monitored Indicators } \\
\text { Realized }\end{array}$ & \multicolumn{3}{|c|}{$\begin{array}{l}\text { Photo points; water-surface elevation (logger); temperature (logger); channel x-sec } \\
\text { area; sediment accretion; elevation (bathymetry/topography); catchment area; plant } \\
\text { species comp; plant percent cover; fish presence/species/size; fish diet; prey } \\
\text { availability }\end{array}$} \\
\hline Derived Variables & \multicolumn{3}{|c|}{$\begin{array}{l}\text { Hyposographic curve of water-sfc elev.; floodplain wetted area; wrea-time inundation; } \\
\text { wetted-channel edge length; plant similarity }\end{array}$} \\
\hline Data Management & Name & Agency & Phone \\
\hline Custodian & $\begin{array}{l}\text { H. } \\
\text { Diefenderfer }\end{array}$ & PNNL & (360) 681-3619 \\
\hline Weblink & TBD & & \\
\hline Reporting & Schedule & Citation & Source/Weblink \\
\hline Draft report & $\begin{array}{l}\text { March 31, } \\
2011\end{array}$ & TBD & \\
\hline Final report & $\begin{array}{l}\text { September } \\
30,2011\end{array}$ & TBD & \\
\hline Other reporting & $\begin{array}{l}\text { Annually } \\
\text { since } 2004\end{array}$ & $\begin{array}{l}\text { Johnson GE and HL Diefenderfer (eds.). } 2010 . \\
\text { "Evaluating Cumulative Ecosystem Response to } \\
\text { Restoration Projects in the Lower Columbia River } \\
\text { and Estuary, 2009." PNNL-19440, prepared by } \\
\text { Pacific Northwest National Laboratory, Richland, } \\
\text { Washington for the U.S. Army Corps of } \\
\text { Engineers, Portland District, Portland, Oregon. }\end{array}$ & CENWP/XX \\
\hline
\end{tabular}




\begin{tabular}{|c|c|c|}
\hline Post-Construction Assessment: Yr 1 & Description/Citation & Grade \\
\hline Photo point/aerial photo & July 2007 & $\mathrm{n} / \mathrm{a}$ \\
\hline Condition of physical metrics & $\begin{array}{l}\text { Cross-section: [pre, post, ref info is available, but } \\
\text { not sure which sites to include from the } 2009 \\
\text { annual report]. } \\
\text { Sediment accretion rates: } 2.6 \mathrm{~cm} / \mathrm{yr} \text { post- } \\
\text { restoration and }-0.1 \mathrm{~cm} / \mathrm{yr} \text { at the reference site. } \\
\text { Sediment accretion rates measure in September } \\
2006 \text { and February } 2007 .{ }^{1}\end{array}$ & TBD \\
\hline Condition of habitat metrics & $\begin{array}{l}\text { Vegetation: Line-intercept data from } 2009 \text { shows } \\
26 \text { herbaceous plant species that were not present } \\
\text { in } 2005-2006 \text {. }\end{array}$ & TBD \\
\hline Condition of functional metrics & $\begin{array}{l}\text { Fish presence: Large numbers of juvenile salmon } \\
\text { were sampled in the tidal channels at the } \\
\text { restoration site. As in previous years, juvenile } \\
\text { Chinook salmon were present in the trap-net } \\
\text { samples in low numbers. Coho salmon sampling } \\
\text { included fry, subyearling and yearling fishes. } \\
\text { Marked fish from the Grays hatchery were } \\
\text { captured at Kandoll Farm. }\end{array}$ & TBD \\
\hline CEERP adaptive management lessons & XXXXX & \\
\hline Post-Construction Assessment: Yr 5 & Description & Grade \\
\hline Photo point/aerial photo & TBD & $\mathrm{n} / \mathrm{a}$ \\
\hline Condition of physical metrics & TBD & TBD \\
\hline Condition of habitat metrics & TBD & TBD \\
\hline Condition of functional metrics & Juvenile salmon continue to use the site each year & TBD \\
\hline CEERP adaptive management lessons & XXX & \\
\hline Final assessment ( $\sim 10$ year $)$ & Description & Grade \\
\hline $\begin{array}{l}\text { Was the project successful in meeting } \\
\text { its goals? Explain the answer. Final } \\
\text { grade? }\end{array}$ & TBD & TBD \\
\hline $\begin{array}{l}\text { If not, what should be changed for } \\
\text { future projects of this type? }\end{array}$ & & \\
\hline
\end{tabular}

${ }^{1}$ Johnson GE and HL Diefenderfer (eds.). 2010. Evaluating Cumulative Ecosystem Response to Restoration Projects in the Lower Columbia River and Estuary, 2009. PNNL-19440, prepared for the U.S. Army Corps of Engineers, Portland District, Portland, Oregon, by Pacific Northwest National Laboratory, Richland, Washington. 


\section{G.2.3 Vera Slough}

PART 1: PROJECT TEMPLATE - Vera Slough

\begin{tabular}{|c|c|}
\hline Header: & \\
\hline Date & January $17^{\text {th }}, 2010$ \\
\hline Prepared by & Erin Donley, (360) 681-3623, erin.donley@pnl.gov \\
\hline Sponsoring agency & CREST, Micah Russell, (503) 325-0435, mrussell@columbiaestuary.org \\
\hline Funding agency & USACE \\
\hline Site & Vera Slough, Warrenton, Oregon, Columbia River km 19 \\
\hline $\begin{array}{l}\text { Project status or } \\
\text { stage }\end{array}$ & Complete. \\
\hline \multicolumn{2}{|l|}{ Proposed Project: } \\
\hline Problem statement & $\begin{array}{l}\text { The brackish freshwater marsh at Vera Slough once served as shallow-water habitat for } \\
\text { juvenile salmonids. However, the marsh ecosystem has been disconnected from the channel } \\
\text { by two tide gates that restrict flow to the slough. As a result of the flow restriction, water } \\
\text { quality has become less suitable for juvenile salmonid feeding and growth (water temperatures } \\
\text { are too high, there are depleted dissolved oxygen conditions and salinity is too low) in the } \\
\text { slough. Additionally, estuarine plant communities... and juvenile salmonids have limited } \\
\text { access to the shallow-water habitat. }\end{array}$ \\
\hline Vision/goal & $\begin{array}{l}\text { Juvenile salmonids would have access to shallow-water habitat characterized by lower water } \\
\text { temperatures, increased dissolved oxygen levels, developed estuarine plant communities and } \\
\text { naturally sustained food-web function. }\end{array}$ \\
\hline Objectives & $\begin{array}{l}\text { Increase fish access to backwater slough habitat; lower water temperatures; improve dissolved } \\
\text { oxygen conditions; increase salinity intrusion; develop estuarine plant communities; and } \\
\text { increase food-web productivity. }\end{array}$ \\
\hline Project action(s) & $\begin{array}{l}\text { Baseline data collection in Spring and Summer of } 2005 \text {. } \\
\text { October of } 2005 \text {, two tide gates restricting flow into the slough will be replaced with two } 5 \mathrm{ft} \\
\text { by } 5 \mathrm{ft} \text { square tide gates, both with lighter lids and fish-passable doors. }\end{array}$ \\
\hline $\begin{array}{l}\text { Project } \\
\text { elements(s)/phases } \\
\text { by yr }\end{array}$ & $\begin{array}{l}\text { Summer 2005: Baseline monitoring and data collection } \\
\text { October 2005: Restoration construction } \\
\text { 2006: Post-restoration monitoring } \\
\text { 2007: Post-restoration monitoring } \\
\text { 2009: Post-restoration monitoring }\end{array}$ \\
\hline Project size by yr & Two tide gates will be upgraded with lighter lids and fish-passable doors. \\
\hline \multicolumn{2}{|c|}{ Linkage to Estuary Module: } \\
\hline $\begin{array}{l}\text { Estuary Module } \\
\text { Action. } \\
\text { Subaction(s) and } \\
\text { Project Goal }\end{array}$ & $\begin{array}{l}\text { LCRE-10.3: Upgrade tide gates where (1) no other options exist, (2) upgraded structures can } \\
\text { provide appropriate access for juveniles, and (3) ecosystem function would be improved over } \\
\text { current conditions. }\end{array}$ \\
\hline
\end{tabular}




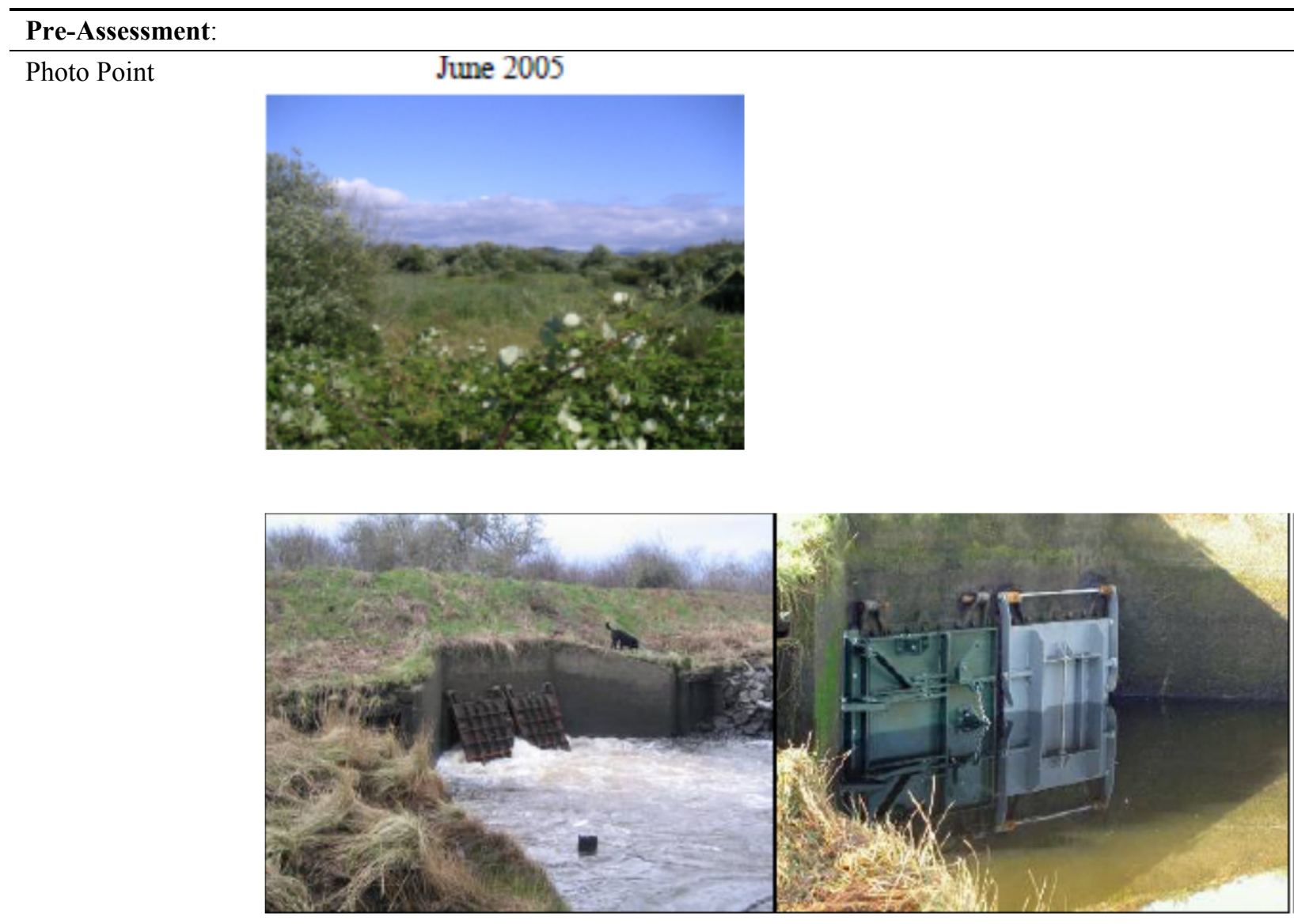

Tide gates at Vera Slough: pre-restoration tide gates on the left; post-restoration tide gates on the right. 
Aerial image

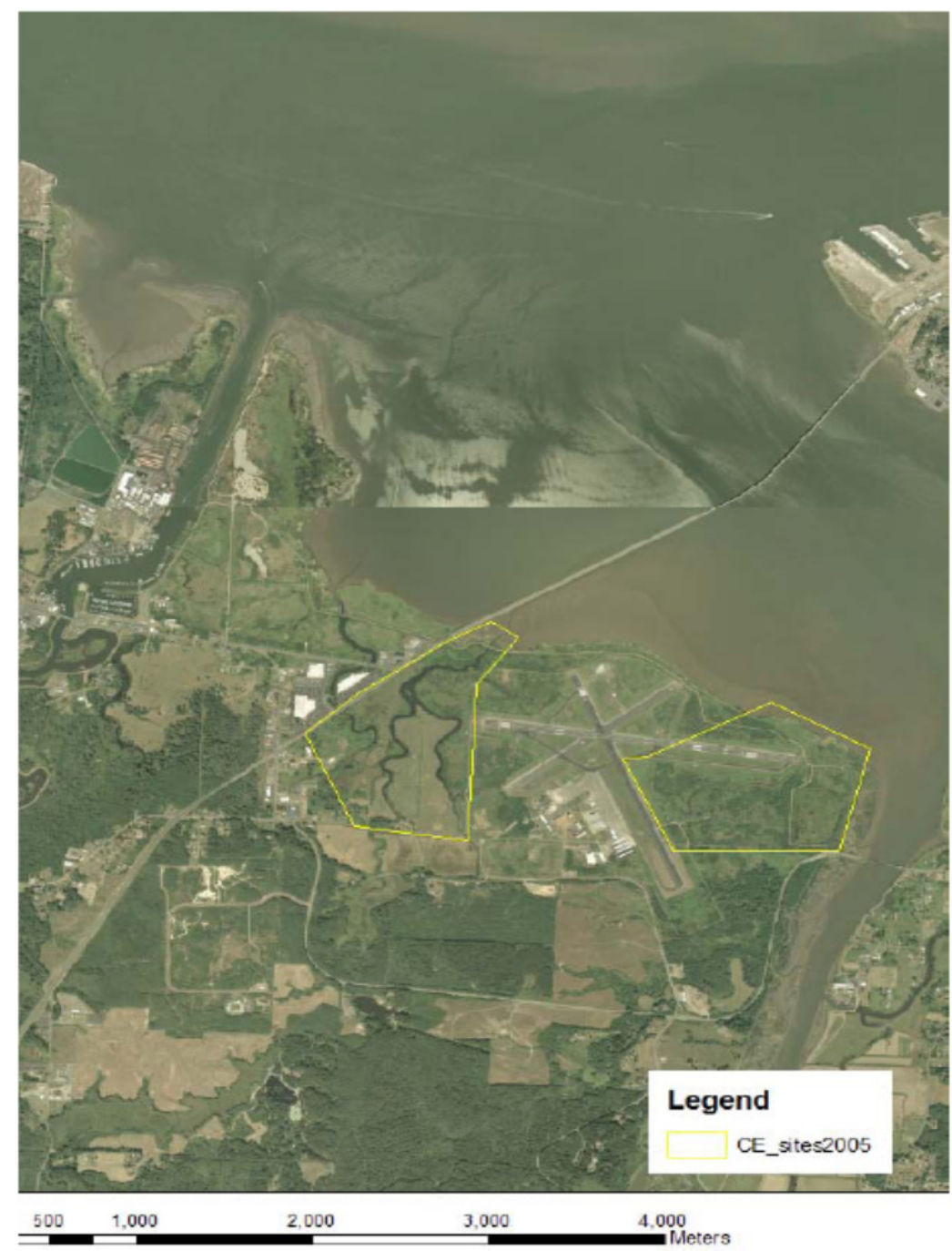

Vera Slough tide gate replacement site on left. Reference site polygon on right. Separated by the Astoria Regional Airport on Young's Bay, Oregon.

Condition of physical metrics

Condition of habitat metrics
Major stressors and physical controlling factors:

Between 35 and $40 \mathrm{~cm}$ average elevation pre-restoration.

Flow into slough restricted resulting in less inundation than would occur under natural hydrodynamic conditions.

Water temperatures too high.

Dissolved oxygen too low.

Salinity too low.

Ordinary High Water Mark = cannot calculate because it is too far downstream.

\section{Tides?}

\section{Salinity data?}

The vegetation communities at Vera Slough and Vera Reference sites were dominated by wetland species. Many of these species had a very narrow elevation range, with most less than $2 \mathrm{ft}$. Vera Slough contained four more species than Vera Reference (20 vs. 16, respectively). Vera Slough was dominated by Carex obnupta and Oenanthe sarmentosa. Vera Reference was dominated by Carex lyngbyei and Phalaris arundinacea. 
Condition of functional metrics

3 Coho salmon (Oncorhynchus kisutch), one Chinook salmon (Oncorhynchus tshawytscha) and one Chum salmon (Oncorhynchus keta) were captured in May 2005. All of these fish were less than $45 \mathrm{~mm}$ fork length. All salmon were captured outside of the tide gate or in the reference area; none were captured inside the area eventually to be affected by restoration.

\section{Performance Anticipated}

Physical change Replacing the tide gates will increase flow into the slough, improving water quality (lowering water temperature, increasing dissolved oxygen and increasing salinity). These improvements in water quality may provide better habitat capacity to support juvenile salmonid feeding and growth. The new tide gates may also improve juvenile salmonid access to shallow-water habitat.

Habitat change Describe the expected condition of habitat.

Function change The expected functional change may include higher average catch-per-unit effort for juvenile salmonids, demonstrated salmonid feeding and growth in the restored habitat.

\begin{tabular}{|c|c|}
\hline \multicolumn{2}{|c|}{ Certainty of Success: } \\
\hline $\begin{array}{l}\text { Landowner } \\
\text { support }\end{array}$ & Port of Astoria \\
\hline $\begin{array}{l}\text { Constraints or } \\
\text { show-stoppers }\end{array}$ & $\begin{array}{l}\text { As-built tide gate specifications are incorrect, resulting in status quo (insufficient) flows into } \\
\text { the slough. } \\
\text { Columbia River is in flood stage during the scheduled construction window. } \\
\text { Fish are unable to pass through the new tide gates. }\end{array}$ \\
\hline $\begin{array}{l}\text { Restoration } \\
\text { technique }\end{array}$ & $\begin{array}{l}\text { Tide gate replacement is a common restoration practice with a high level of acceptance and } \\
\text { maturity. }\end{array}$ \\
\hline $\begin{array}{l}\text { Natural processes } \\
\text { and self- } \\
\text { maintenance }\end{array}$ & $\begin{array}{l}\text { Natural hydrodynamic processes would come to bear on the marsh habitat consequently } \\
\text { improving access to habitat for juvenile salmonids and improved water quality. }\end{array}$ \\
\hline \multicolumn{2}{|c|}{ Potential Access Benefit: } \\
\hline $\begin{array}{l}\text { Distance of the } \\
\text { project to the main } \\
\text { stem Columbia } \\
\text { River }\end{array}$ & State distance in river miles. \\
\hline $\begin{array}{l}\text { Connectedness to } \\
\text { mainstem }\end{array}$ & Describe how well the project site will be connected to the main stem after the restoration. \\
\hline Species impacted & All Columbia River salmonid ESUs. \\
\hline \multicolumn{2}{|c|}{ Potential Capacity Benefit: } \\
\hline $\begin{array}{l}\text { Habitat } \\
\text { complexity }\end{array}$ & Describe habitat complexity, channels, large woody debris. \\
\hline Water quality & Describe water quality. \\
\hline Invasive species & Describe impacts from invasive species. \\
\hline Adjacent lands & Describe the condition of adjacent lands. \\
\hline
\end{tabular}




\begin{tabular}{|c|c|c|c|}
\hline & \multicolumn{3}{|c|}{ PART 2: SITE EVALUATION CARD - Vera Slough } \\
\hline Project Name & \multicolumn{3}{|l|}{ Vera Slough } \\
\hline Project No. & \multicolumn{3}{|l|}{ XXXX } \\
\hline $\begin{array}{l}\text { Project Site } \\
\text { (name/lat/long) }\end{array}$ & \multicolumn{3}{|c|}{ Vera Slough $(\mathrm{XX} / \mathrm{XXX})$} \\
\hline $\begin{array}{l}\text { Reference or Control } \\
\text { Site (name/lat/long) }\end{array}$ & \multicolumn{3}{|c|}{ Vera Slough East (XXX/XXX) } \\
\hline $\begin{array}{l}\text { Site Evaluation Card } \\
\text { Prepared By }\end{array}$ & Agency & Date & Phone \\
\hline Erin Donley & PNNL & $1 / 6 / 11$ & \\
\hline $\begin{array}{l}\text { Restoration/Monitoring } \\
\text { Practitioner }\end{array}$ & Agency & Email & Phone \\
\hline April Cameron & CREST & & \\
\hline Heida Diefenderfer & PNNL & & \\
\hline $\begin{array}{l}\text { ERTG Survival Benefit } \\
\text { Assessment }\end{array}$ & $\begin{array}{l}\text { Stream-type } \\
\text { SBU }\end{array}$ & Ocean-type SBU & Comments \\
\hline Phase 1 & XXX & XXX & $2007 \mathrm{BA}$ \\
\hline \multicolumn{4}{|l|}{ Construction } \\
\hline Construction Period & \multicolumn{3}{|l|}{ October 2005} \\
\hline $\begin{array}{l}\text { Describe restoration } \\
\text { realized }\end{array}$ & \multicolumn{3}{|c|}{$\begin{array}{l}\text { Two tide gates were replaced with new ones ( } 5 \mathrm{ft} \text { by } 5 \mathrm{ft} \text { ) having lighter lids and fish- } \\
\text { passable doors }\end{array}$} \\
\hline $\begin{array}{l}\text { Restoration Accounting: } \\
\text { Physical Changes } \\
\text { Realized }\end{array}$ & Number & Restored Acres/Miles & Comments \\
\hline Tide gates replaced & 2 & XXXX & \\
\hline Experimental Design & \multicolumn{3}{|c|}{ Before-after-reference-impact } \\
\hline Monitoring/Research & \multicolumn{3}{|l|}{ Period } \\
\hline Pre-restoration period & \multicolumn{3}{|l|}{ Summer 2005} \\
\hline $\begin{array}{l}\text { Post-restoration } \\
(\sim 1 \mathrm{yr})\end{array}$ & \multicolumn{3}{|l|}{2006,2007} \\
\hline $\begin{array}{l}\text { Post-restoration } \\
(\sim 5 \mathrm{yr})\end{array}$ & \multicolumn{3}{|l|}{2009} \\
\hline $\begin{array}{l}\text { Post-restoration } \\
(\sim 10 \mathrm{yr})\end{array}$ & \multicolumn{3}{|l|}{ Not scheduled } \\
\hline $\begin{array}{l}\text { Monitored Indicators } \\
\text { Realized }\end{array}$ & \multicolumn{3}{|c|}{$\begin{array}{l}\text { Photo points; water-surface elevation (logger); temperature (logger); channel x-sec } \\
\text { area; sediment accretion; elevation (bathymetry/topography); catchment area; plant } \\
\text { species comp; plant percent cover; fish presence/species/size; fish diet; prey } \\
\text { availability }\end{array}$} \\
\hline Derived Variables & \multicolumn{3}{|c|}{$\begin{array}{l}\text { Hyposographic curve of water-sfc elev.; floodplain wetted area; area-time inundation; } \\
\text { wetted-channel edge length; plant similarity }\end{array}$} \\
\hline Data Management & Name & Agency & Phone \\
\hline Custodian & $\begin{array}{l}\text { H. } \\
\text { Diefenderfer }\end{array}$ & PNNL & (360) 681-3619 \\
\hline Weblink & TBD & & \\
\hline
\end{tabular}




\begin{tabular}{|c|c|c|c|}
\hline Reporting & Schedule & Citation & $\begin{array}{l}\text { Source/Weblin } \\
\mathrm{k}\end{array}$ \\
\hline Draft report & $\begin{array}{l}\text { March 31, } \\
2011\end{array}$ & TBD & \\
\hline Final report & $\begin{array}{l}\text { September } \\
30,2011\end{array}$ & TBD & \\
\hline Other reporting & $\begin{array}{l}\text { Annually } \\
\text { since } 2004\end{array}$ & $\begin{array}{l}\text { Johnson GE and HL Diefenderfer (eds.). } 2010 . \\
\text { "Evaluating Cumulative Ecosystem Response to } \\
\text { Restoration Projects in the Lower Columbia River } \\
\text { and Estuary, 2009." PNNL-19440, prepared by } \\
\text { Pacific Northwest National Laboratory, Richland, } \\
\text { Washington for the U.S. Army Corps of Engineers, } \\
\text { Portland District, Portland, Oregon. }\end{array}$ & CENWP/XX \\
\hline \multicolumn{2}{|c|}{ Post-Construction Assessment: Yr 1} & Description/Citation & Grade \\
\hline \multicolumn{2}{|c|}{ Photo point/aerial photo } & TBD & $\mathrm{n} / \mathrm{a}$ \\
\hline \multicolumn{2}{|c|}{ Condition of physical metrics } & TBD & TBD \\
\hline \multicolumn{2}{|c|}{ Condition of habitat metrics } & TBD & TBD \\
\hline \multicolumn{2}{|c|}{ Condition of functional metrics } & Few juvenile salmon captured in seines. & TBD \\
\hline \multicolumn{2}{|c|}{ CEERP adaptive management lessons } & XXX & \\
\hline \multicolumn{2}{|c|}{$\begin{array}{l}\text { Post-Construction Assessment: Yr } 5 \\
\text { Photo point/aerial photo }\end{array}$} & $\begin{array}{l}\text { Description } \\
\\
\end{array}$ & $\begin{array}{c}\text { Grade } \\
\mathrm{n} / \mathrm{a}\end{array}$ \\
\hline \multicolumn{2}{|c|}{ Condition of physical metrics } & $\begin{array}{l}\text { Cross-section: data is available, but not sure which } \\
\text { sites to use. } \\
\text { Sediment accretion rates: } 1.2 \mathrm{~cm} / \mathrm{yr} \text { post-restoration } \\
\text { and } 0.45 \mathrm{~cm} / \mathrm{yr} \text { at the reference site. Sediment } \\
\text { accretion rates are calculated as the difference } \\
\text { between } 2005 \text { and } 2009 . \\
\text { Wetland behind tide gate replacement was } \\
\text { substantially lower than the reference site. }\end{array}$ & TBD \\
\hline \multicolumn{2}{|c|}{ Condition of habitat metrics } & TBD & TBD \\
\hline \multicolumn{2}{|c|}{ Condition of functional metrics } & $\begin{array}{l}\text { Sampling at Vera Reference site indicates that few } \\
\text { fish seem to migrate into the area along the western } \\
\text { shoreline of the bay. Also, there were few juvenile } \\
\text { salmon captured at the Vera Slough site. }\end{array}$ & TBD \\
\hline CEERP adaptive & sement lessons & XXXXX & \\
\hline
\end{tabular}




\begin{tabular}{llc}
\hline Final assessment $(\sim \mathbf{1 0}$ year) & Description & Grade \\
Was the project successful in meeting & TBD & TBD \\
its goals? Explain the answer. Final & & \\
grade? & & \\
If not, what should be changed for & \\
future projects of this type? & & \\
\hline
\end{tabular}

\section{G.2.4 Summary of Results}

The grading process is in process. Table G.1 shows the presentation format for the SEC grades. In formal assessments, independent scientists w/ actual knowledge of the restoration results need to do the grades.

Table G.1. Summary Table of Site Evaluation Grades. Three grades were possible: pass (O), fail (O), and incomplete $(\mathrm{O})$.

\begin{tabular}{|c|c|c|c|c|c|c|c|c|c|}
\hline & \multicolumn{3}{|c|}{ Condition of Physical Metrics } & \multicolumn{3}{|c|}{ Condition of Habitat Metrics } & \multicolumn{3}{|c|}{ Condition of Functional Metrics } \\
\hline & $1-\mathrm{yr}$ & $5-\mathrm{yr}$ & Final & $1-\mathrm{yr}$ & $5-\mathrm{yr}$ & Final & $1-\mathrm{yr}$ & $5-\mathrm{yr}$ & Final \\
\hline $\begin{array}{l}\text { Crims Island } \\
\text { Kandoll Farm } \\
\text { Vera Slough }\end{array}$ & & & & & & & & & \\
\hline
\end{tabular}

\section{G.3 Discussion and Recommendations}

What conclusions can be drawn about the collective effectiveness of the three restorations analyzed here? The fact that water temperature, sedimentation, vegetation, and fish access (except for Vera Slough) seem to have improved since restoration indicates that the actions are restoring ecological processes that form and maintain habitats, and that juvenile salmon have a better opportunity to benefit from processes like prey production and refuge afforded by these newly opened habitats than before restoration. Importantly, these changes were detectable within 2 years and apparently continued to be maintained 4 years after the restorative actions.

The summary table could be a useful vehicle for synthesizing the results across multiple sites and monitored indicators, but a more quantitative approach will be necessary as the restoration and effectiveness monitoring universe expands. When data on a suite of common metrics from 15 to 30 sites of various project types and locations are available (see 19 possibilities in Table G.2), it will be possible to perform statistical analyses to determine restoration effectiveness by project type, location, and other factors important to CEERP management. Researchers could also incorporate ancillary data such as climate, flooding, and fisheries information to help explain interannual or longer-term results from the restoration sites. Furthermore, as the data become more widely developed and robust, CEERP managers will be able to order estimates of the net ecosystem improvement in the LCRE as another level of evidence to quantify the cumulative effects of multiple restoration projects. Such comprehensive and quantitative meta-analyses must be undertaken carefully and could still have limitations based on experience to date with meta-analysis of LCRE restoration effectiveness. 
Table G.2. CEERP Restoration Sites to Consider for Future Meta-Analyses of Effectiveness

\begin{tabular}{|c|c|c|c|c|c|}
\hline ID & Site & $\begin{array}{l}\text { Col. River } \\
\text { Kilometer }\end{array}$ & Year & Restoration Type & Comment \\
\hline 1 & Crims Island & 88 & 2005 & Dike breach and excavation & Intensively monitored \\
\hline 2 & Ft. Clatsop & $\begin{array}{l}24 \text { (Lewis \& } \\
\text { Clark River) }\end{array}$ & 2007 & Culvert replacement & Ibid. \\
\hline 3 & Ft. Columbia & 21 & 2010 & Culvert replacement & $\begin{array}{l}\text { Pre-restoration data } \\
\text { collection }\end{array}$ \\
\hline 4 & Haven Island & $\begin{array}{l}15 \text { (Youngs } \\
\text { River) }\end{array}$ & 2011 & Dike breaches & $\begin{array}{l}\text { Pre-restoration data } \\
\text { collection }\end{array}$ \\
\hline 5 & $\begin{array}{l}\text { Johnson } \\
\text { Property }\end{array}$ & $\begin{array}{l}35 \text { (Grays } \\
\text { River) }\end{array}$ & 2004 & Dike breach & $\begin{array}{l}1 \text { year pre-restoration and } \\
3 \text { years post; completed }\end{array}$ \\
\hline 6 & $\begin{array}{l}\text { Julia Butler } \\
\text { Hanson }\end{array}$ & 55 & 2009 & Tide gate replacement & Further construction 2010 \\
\hline 7 & Kandoll Farm & $\begin{array}{l}36 \text { (Grays } \\
\text { River) }\end{array}$ & 2005 & Culvert replacement & Intensively monitored \\
\hline 8 & $\begin{array}{l}\text { Lewis and } \\
\text { Clark }\end{array}$ & $\begin{array}{l}26 \text { (Lewis \& } \\
\text { Clark River) }\end{array}$ & 2006 & Dike breaches & $\begin{array}{l}\text { Intensively monitored; pre- } \\
\text { and post-monitoring; } \\
\text { completed }\end{array}$ \\
\hline 9 & Megler Creek & 23 & 2010 & Culvert replacement & $\begin{array}{l}\text { Pre-restoration data } \\
\text { collection }\end{array}$ \\
\hline 10 & Mirror Lake & 205 & 2007 & $\begin{array}{l}\text { Culvert, stream, and riparian } \\
\text { habitat improvements }\end{array}$ & $\begin{array}{l}\text { Intensively monitored but } \\
\text { not a tidal reconnection }\end{array}$ \\
\hline 11 & Otter Point & $\begin{array}{l}25 \text { (Lewis } \\
\& \text { Clark River) }\end{array}$ & 2010 & Dike breach & $\begin{array}{l}\text { Pre-restoration data } \\
\text { collection; construction } \\
2010\end{array}$ \\
\hline 12 & Perkins Creek & $\begin{array}{l}14 \text { (Skipanon } \\
\text { River) }\end{array}$ & 2009 & Culvert replacement & $\begin{array}{l}\text { No post-restoration } \\
\text { monitoring }\end{array}$ \\
\hline 13 & $\begin{array}{l}\text { Sandy River } \\
\text { Delta }\end{array}$ & 123 & $\begin{array}{l}\text { 2004- } \\
\text { present }\end{array}$ & $\begin{array}{l}\text { Invasives removal and } \\
\text { plantings }\end{array}$ & $\begin{array}{l}\text { No baseline; post- } \\
\text { restoration monitoring } \\
\text { since } 2008\end{array}$ \\
\hline 14 & $\begin{array}{l}\text { Scappoose } \\
\text { Bottoms }\end{array}$ & 142 & $\begin{array}{l}2005,2007 \\
\text { to present }\end{array}$ & $\begin{array}{l}\text { Riparian improvements } \\
(2007+) \text { and cattle exclusion } \\
(2005)\end{array}$ & $\begin{array}{l}\text { No pre-restoration } \\
\text { monitoring for fish }\end{array}$ \\
\hline 15 & $\begin{array}{l}\text { Skipanon River } \\
\text { Floodplain }\end{array}$ & $\begin{array}{l}14 \text { (Skipanon } \\
\text { River) }\end{array}$ & 2008 & $\begin{array}{l}\text { Alcove excavation and } \\
\text { riparian planting }\end{array}$ & No pre-restoration data \\
\hline 16 & Trestle Bay & 11 & 1995 & Dike breach & No pre-restoration data \\
\hline 17 & Vera Slough & 19 & 2005 & Tide gate replacement & Intensively monitored \\
\hline 18 & Waluski River & & 2010 & Dike breaches & No pre-restoration data \\
\hline 19 & Willow Grove & 104 & 2011 & Habitat enhancement & $\begin{array}{l}\text { Pre-restoration monitoring } \\
\text { postponed }\end{array}$ \\
\hline
\end{tabular}

Our attempts to summarize the results from a suite of restoration projects illustrate several points. First, variability in level of monitoring effort, lack of pre-restoration sampling, and other factors significantly reduced the breadth of analysis. That said, projects excluded from meta-analysis for one reason or another may have data that can be used for planning and evaluation purposes. Second, the level of effort in terms of the common monitored indicators sampled can limit comparisons. Having a 
large number of metrics commonly sampled will improve the power of comparisons. Third, the duration of assessment must be long enough to more fully evaluate the long-term (e.g., longer than 10 years) condition of the site. Over the long-term, channel morphology will change due to sedimentation and erosion, possibly affecting water temperature and fish access. A statistically rigorous, quantitative metaanalysis is possible in the LCRE provided that standardized AEMR data are collected and reported from restoration project sites. In conclusion, the next steps for meta-analysis of action-effectiveness monitoring data could be as follows:

- Develop the database, compiling all available action-effectiveness data from restoration projects.

- Form an inter-agency team for technical collaboration and analytical work to produce periodic metaanalyses.

- Identify response ratios.

- Develop a statistical methodology for meta-analysis of CEERP action-effectiveness monitoring data (see Appendix F). 
Appendix $\mathrm{H}$

Detailed Outline for the FY 2012 CEERP Action Plan 


\title{
Appendix H
}

\section{Detailed Outline for the FY 2012 CEERP Action Plan}

\author{
Prepared by Gary Johnson
}

The Action Plan is the most important deliverable from the adaptive management process for the Columbia Estuary Ecosystem Restoration Program (CEERP). To initiate a formal CEERP adaptive management process, we developed a draft for the 2012 Action Plan with the intent to communicate, coordinate, and modify the plan in collaboration with the U.S. Army Corps of Engineers, Portland District, the Bonneville Power Administration, and other regional stakeholders. This collaboration should take place through the soon to be established CEERP Adaptive Management Stakeholders Team (AMST). The plan below has been informed by lower Columbia River and estuary (LCRE)-related strategies in the 2008 Federal Columbia Power System Biological Opinion (BiOp; NMFS 2008); the Supplemental 2010 BiOp (NMFS 2010a); the Adaptive Management Implementation Plan (Action Agencies 2009); the federal research, monitoring, and evaluation plan for the LCRE (Johnson et al. 2008); the Estuary Module (NMFS 2011); and the ecosystem-based approach to estuary restoration (Johnson et al. 2003). The Action Plan would be a working, living document that is formally modified each year and adjusted midyear, if necessary.

The Action Agencies and other CEERP stakeholders, along with restoration and monitoring/research practitioners, will systematically use the Action Plan for guidance and tracking progress. The Action Plan will also serve as a vehicle for communicating CEERP activities to 1) upper management in the Action Agencies, 2) regional resource agencies through the Anadromous Fish Evaluation Program Science Review Work Group and Systems Configuration Team, 3) regional restoration partners and interested parties on the Lower Columbia River Estuary Partnership's Science Work Group, and 4) the Northwest Power and Conservation Council and its Independent Scientific Review Panel.

The purpose of the 2012 Action Plan is to provide a blueprint and justification for LCRE restoration and monitoring/research actions during FY 2012 (October 2011 through September 2012). It also lays tentative plans for said activities in out-years (2013-2018) to the end of the 2008 BiOp period of performance.

The Action Plan comprises sections on restoration project implementation, monitoring and research, and adaptive management (AM). Attachments A and B contain Expert Regional Technical Group (ERTG) templates and summary reports for the FY 2012 projects, respectively. In the remainder of this appendix, we present a detailed outline for the FY 2012 CEERP Action intended for use by the AMST.

\section{H.1 Restoration Project Implementation Plan}

Introductory statement. CEERP's current status. Opening statement about overall goal for FY 2012. Emphasis in 2012 will be on XXXXX. Include all LCRE restoration work no matter the funding agency.

Restoration Priorities -- Identify priorities of actions to implement on the site and reach scales; Identify priorities for estuary-wide, programmatic actions, e.g., pile structure or creation programs. 
Project Inventory -- Describe and explain in general the inventory of projects and why it is what it is.

Reference TABLE 1. Master CEERP Project Inventory

Reference FIGURE 1. Master Map of the Inventory of Planned and Proposed CEERP Projects.

\section{H.1.1 Current Projects (FY 2012)}

Paragraphs describing each project. Include any project-specific adjustments to restoration actions already implemented but still in progress.

Provide links to ERTG project templates for the FY 2012 projects (Attachment $A$ to the AP) and to ERTG summary reports for the FY 2012 projects (Attachment B to the AP).

Reference TABLE 2. FY 2012 Project Implementation Plan.

\section{H.1.2 Plans for Out-Year Projects (FY 2013-2018)}

Describe needs and objectives relative to the CEERP goal. Include justifications and key strategies to implement projects. What are the expected outcomes in the out-years? ETC.

\section{H.2 Monitoring and Research}

Include an opening statement about overall goal and objectives for CEERP RME.

Describe the current status for CEERP's RME.

Include all LCRE RME work no matter the funding agency.

Describe and justify adjustments to action-effectiveness monitoring and research program.

Describe and justify adjustments to CUR and STM.

Incorporate the approach in Appendix G for considerations to prioritize action-effectiveness monitoring and research.

Reference TABLE 3. Master RME Project Inventory - Basic Information

Reference FIGURE 2. Master Map of FY 2012 RME Projects.

\section{H.2.1 Current Projects (FY 2012)}

Opening statement about overall goal and objectives for FY 2012. Emphasis in 2012 will be on $X X X X X$.

Paragraphs describing each project [???]. 


\section{H.2.2 Plans for Out-Year Projects (FY 2013-2018)}

Needs and objectives. Justifications. Key strategies to implement projects. Describe the anticipated evolution of projects. ETC.

Reference TABLE 4. Master RME Project Inventory - FY 2012 Objectives, Study Area, Milestones, Schedule, Deliverables, and Restoration Project Id. (for AEMR projects).

\section{H.3 Adaptive Management}

Introductory statement.

\section{H.3.1 Adjustments and Strategy}

Describe adjustments to key elements in the CEERP AM process, including program goals, objectives and management questions, and stakeholder needs

Bullet list -- Key strategies and policies guiding CEERP (e.g., Action Agencies' position on land acquisition).

\section{H.3.2 Tracking and Coordination Methods}

Describe AM methods that will be used to track and report progress and results and prepare for next year.

Bullet list-- Teams that will be implementing AM-person, agency, contact info.

\section{H.3.3 Schedule}

Gantt chart.

\section{H.4 Literature Cited}

List the literature cited.

\section{H.5 Tables and Figures}

Templates for key tables and figures in the Action Plan. 
Table H.1. Master CEERP Project Inventory

\begin{tabular}{|c|c|c|c|c|c|c|c|}
\hline $\begin{array}{l}\text { CEERP Id } \\
\text { No. }\end{array}$ & $\begin{array}{l}\text { Project } \\
\text { Name }\end{array}$ & $\begin{array}{c}\text { Funding Agency/ } \\
\text { Contact }\end{array}$ & $\begin{array}{l}\text { Lead Entity/ } \\
\text { Contact }\end{array}$ & $\begin{array}{c}\text { Project } \\
\text { Type }\end{array}$ & $\begin{array}{l}2012 \\
\text { Status }\end{array}$ & $\begin{array}{l}\text { Out-Year } \\
\text { Plans }\end{array}$ & $\begin{array}{l}\text { Risk } \\
\text { Points }\end{array}$ \\
\hline \multicolumn{8}{|l|}{$\mathrm{P}-1$} \\
\hline \multicolumn{8}{|l|}{ P-2 } \\
\hline \multicolumn{8}{|l|}{ P-3 } \\
\hline \multicolumn{8}{|l|}{ P-4 } \\
\hline \multicolumn{8}{|l|}{ P-5 } \\
\hline \multicolumn{8}{|l|}{ P-6 } \\
\hline \multicolumn{8}{|l|}{ P-7 } \\
\hline \multicolumn{8}{|l|}{ P-8 } \\
\hline \multicolumn{8}{|l|}{ P-9 } \\
\hline \multicolumn{8}{|l|}{ P-10 } \\
\hline \multicolumn{8}{|l|}{ P-11 } \\
\hline \multicolumn{8}{|l|}{ P-12 } \\
\hline \multicolumn{8}{|l|}{ P-13 } \\
\hline \multicolumn{8}{|l|}{ P-14 } \\
\hline P-15 & & & & & & & \\
\hline
\end{tabular}

\section{INSERT GIS MAP of Restoration Projects}

Figure H.1. Master Map of the Inventory of Planned and Proposed Projects. The legend designates FY 2012 and FY 2013-2018 projects. Would be good to have an interactive map to communicate project information.

Table H.2. FY 2012 Project Implementation Plan

\begin{tabular}{|c|c|c|c|c|c|}
\hline CEERP Id No. & Project Name & ERTG SBUs & Construction Schedule & AEMR Project & XXXX \\
\hline \multicolumn{6}{|c|}{ P-1 } \\
\hline \multicolumn{6}{|c|}{$\mathrm{P}-2$} \\
\hline \multicolumn{6}{|c|}{$\mathrm{P}-3$} \\
\hline \multicolumn{6}{|c|}{ P-4 } \\
\hline \multicolumn{6}{|l|}{ P-5 } \\
\hline \multicolumn{6}{|l|}{ P-6 } \\
\hline \multicolumn{6}{|l|}{ P-7 } \\
\hline \multicolumn{6}{|l|}{ P-8 } \\
\hline \multicolumn{6}{|l|}{ P-9 } \\
\hline \multicolumn{6}{|l|}{ P-10 } \\
\hline \multicolumn{6}{|l|}{ P-11 } \\
\hline \multicolumn{6}{|l|}{$\mathrm{P}-12$} \\
\hline \multicolumn{6}{|l|}{ P-13 } \\
\hline \multicolumn{6}{|c|}{$\mathrm{P}-14$} \\
\hline P-15 & & & & & \\
\hline
\end{tabular}


Table H.3. Master RME Project Inventory - Basic Information

\begin{tabular}{lllll}
\hline CEERP Id. & \multicolumn{1}{c}{ Project Name } & Funding Agency & Project No. & Lead Entity/Collaborators \\
\hline RME-1A & $\begin{array}{l}\text { Fixed-Array AT Post-FCRPS } \\
\text { Survival }\end{array}$ & USACE & EST-P-02-01 & PNNL \\
RME-1B & Mobile AT Post-FCRPS Survival & USACE & EST-P-02-01 & NMFS \\
RME-2 & Cumulative Effects & USACE & EST-P-02-04 & PNNL/NMFS/UW/CREST \\
RME-3 & Action Effectiveness at JBH & USACE & EST-P-05-07 & USFWS \\
& NWR & & & \\
RME-4 & Tidal Fluvial & USACE & EST-P-09-01 & NMFS/UW/OSU/OHSU \\
RME-5 & Salmon Benefits & USACE & EST-P-10-01 & PNNL/UW \\
RME-6 & Juvenile Salmon Ecology and & USACE & EST-P-11-01 & PNNL/ODFW/NMFS/UW \\
& Restoration Effectiveness & & & \\
RME-7 & LCRE Ecosystem Monitoring & BPA & 2003-007-00 & EP/NMFS/USGS/PNNL \\
RME-8 & EP Restoration Program - AEMR & BPA & $2003-011-00$ & EP/CREST \\
RME-9 & EP Restoration and Reference & BPA & $2003-011-00$ & EP/PNNL \\
& Integration & & & \\
RME-11 & EP Pile Structure Program & BPA & XXX & EP \\
RME-10 & CLT Restoration Program - & BPA & XXX & CLT/XXX \\
& AEMR & & & \\
RME-11 & CREST Restoration Program - & BPA & XXX & CREST \\
& AEMR & & & \\
RME-12 & Etc. & & & \\
\hline
\end{tabular}

\section{INSERT GIS MAP of RME Projects}

Figure H.2. Master Map of FY 2012 RME Projects - Legend Designations for STM, CUR, AEM, AER. Would be good to have an interactive map to communicate project information. 
Table H.4. Master RME Project Inventory - FY 2012 Objectives, Study Area, Milestones, Schedule, Deliverables, and Restoration Project Identification Number (for AEMR Projects)

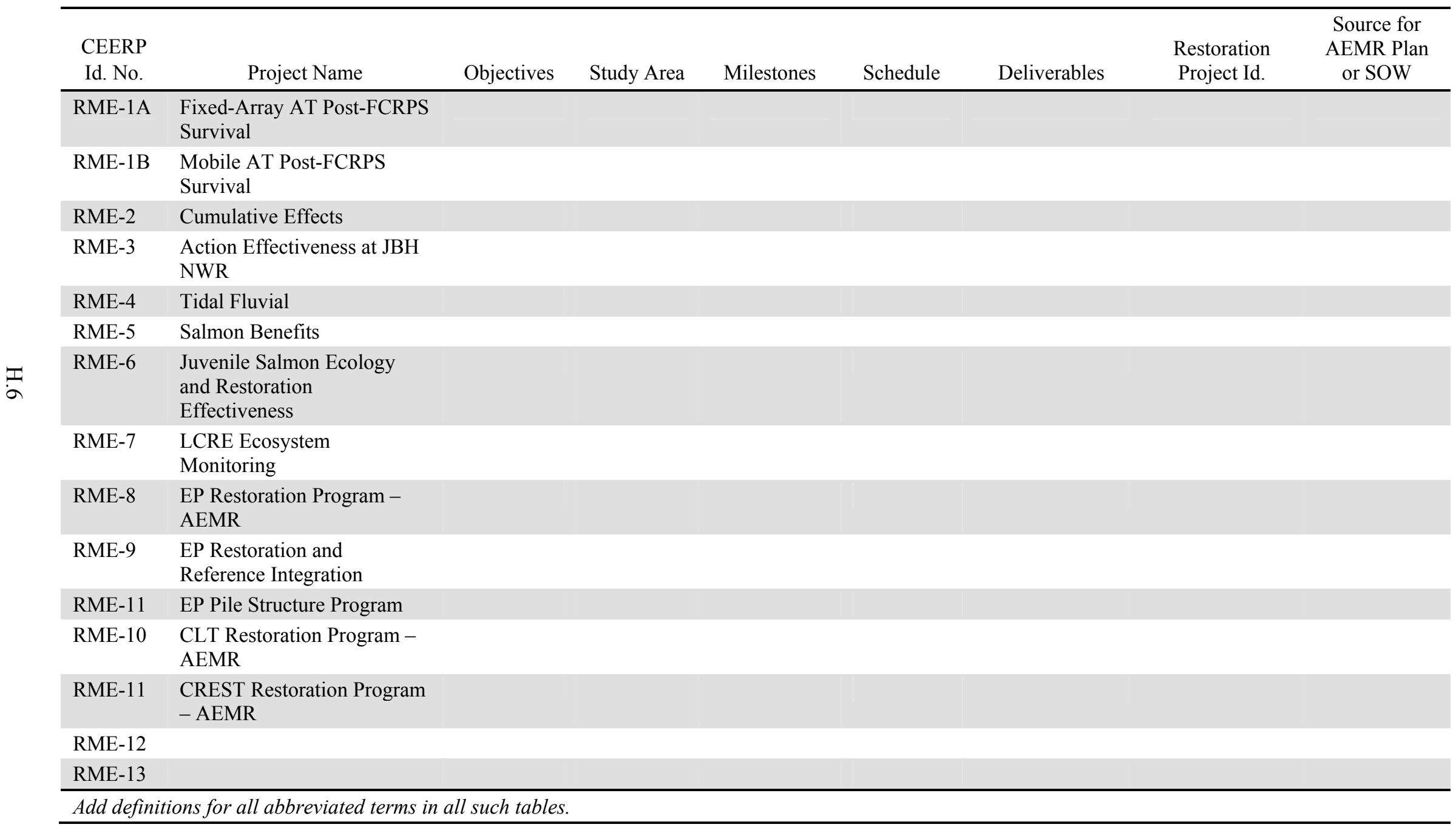


Table H.5. Master RME Project Inventory - Out-Year Objectives and Expected Final Outcome

\begin{tabular}{|c|c|c|c|c|c|c|c|c|}
\hline $\begin{array}{l}\text { CEERP } \\
\text { Id. No. }\end{array}$ & Project Name & 2013 & 2014 & 2015 & 2016 & 2017 & 2018 & $\begin{array}{l}\text { Expected Final } \\
\text { Outcome }\end{array}$ \\
\hline RME-1A & $\begin{array}{l}\text { Fixed-Array AT Post-FCRPS } \\
\text { Survival }\end{array}$ & & & & & & & \\
\hline RME-1B & $\begin{array}{l}\text { Mobile AT Post-FCRPS } \\
\text { Survival }\end{array}$ & & & & & & & \\
\hline RME-2 & Cumulative Effects & & & & & & & \\
\hline RME-3 & $\begin{array}{l}\text { Action Effectiveness at JBH } \\
\text { NWR }\end{array}$ & & & & & & & \\
\hline RME-4 & Tidal Fluvial & & & & & & & \\
\hline RME-5 & Salmon Benefits & & & & & & & \\
\hline RME-6 & $\begin{array}{l}\text { Juvenile Salmon Ecology and } \\
\text { Restoration Effectiveness }\end{array}$ & & & & & & & \\
\hline RME-7 & LCRE Ecosystem Monitoring & & & & & & & \\
\hline RME-8 & $\begin{array}{l}\text { EP Restoration Program - } \\
\text { AEMR }\end{array}$ & & & & & & & \\
\hline RME-9 & $\begin{array}{l}\text { EP Restoration and Reference } \\
\text { Integration }\end{array}$ & & & & & & & \\
\hline RME-11 & EP Pile Structure Program & & & & & & & \\
\hline RME-10 & $\begin{array}{l}\text { CLT Restoration Program - } \\
\text { AEMR }\end{array}$ & & & & & & & \\
\hline RME-11 & $\begin{array}{l}\text { CREST Restoration Program - } \\
\text { AEMR }\end{array}$ & & & & & & & \\
\hline \multicolumn{9}{|l|}{ RME-12 } \\
\hline RME-13 & & & & & & & & \\
\hline
\end{tabular}


Table H.6. Schedule for CEERP, Restoration Construction, and Monitoring/Research Activities FY2011 FY2012

\begin{tabular}{|c|c|c|c|c|c|c|c|c|c|c|c|c|c|c|c|c|c|c|c|c|c|c|c|c|}
\hline ADAPTIVE MANAGEMENT & 0 & $\mathrm{~N}$ & D & J & $F$ & M & A & M & $\mathbf{J}$ & $\mathbf{J}$ & A & $S$ & 0 & $\mathrm{~N}$ & D & $\mathbf{J}$ & $\mathrm{F}$ & $\mathrm{M}$ & A & M & J & J & A & $\mathrm{S}$ \\
\hline \multicolumn{25}{|l|}{ Act } \\
\hline \multicolumn{25}{|l|}{ M\&R Data } \\
\hline \multicolumn{25}{|l|}{ M\&R Reporting } \\
\hline \multicolumn{25}{|l|}{ Evaluate } \\
\hline \multicolumn{25}{|l|}{ Strategize } \\
\hline \multicolumn{25}{|l|}{ Decide } \\
\hline \multicolumn{25}{|c|}{$\begin{array}{l}\text { FY11 Synthesis Memo } \\
\text { FY11 Strategy Report } \\
\text { FY12 Action Plan }\end{array}$} \\
\hline AMST Meetings & & & & & & $*$ & $*$ & * & $*$ & $*$ & * & * & * & * & * & * & * & * & * & * & * & * & * & * \\
\hline AMTAT Meetings & & & & & & & & & & & & & & & $*$ & $*$ & $*$ & & & & & & & \\
\hline Monitoring Coor. Mtg. & & & & & & & $*$ & & & $*$ & & & $*$ & & & $*$ & & & $*$ & & & $*$ & & \\
\hline Restoration Practioners Mtg. & & & & & & & & * & & & & & & & & & & & & * & & & & \\
\hline Col. R. Estuary Conference & & & & & & & & * & & & & & & & & . & & & & & & & & \\
\hline AFEP Annual Review & & & * & & & & & & & & & & & & * & & & & & & & & & \\
\hline ERTG Meetings & * & & * & & * & & $*$ & & $*$ & & $*$ & & $*$ & & * & 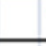 & $*$ & & $*$ & & * & & * & \\
\hline RESTORATION IMPLEMENTATION & 0 & $\mathrm{~N}$ & D & $J$ & $\mathrm{~F}$ & M & A & M & J & J & A & $\mathrm{S}$ & 0 & $\mathrm{~N}$ & D & J & $\mathrm{F}$ & M & A & M & J & J & A & $\mathrm{S}$ \\
\hline \multicolumn{25}{|l|}{ P-1 } \\
\hline \multicolumn{25}{|l|}{ P-2 } \\
\hline \multicolumn{25}{|l|}{ P-3 } \\
\hline \multicolumn{25}{|l|}{ P-4 } \\
\hline \multicolumn{25}{|l|}{ P-5 } \\
\hline \multicolumn{25}{|l|}{ P-6 } \\
\hline \multicolumn{25}{|l|}{ P-7 } \\
\hline \multicolumn{25}{|l|}{ P-8 } \\
\hline P-9 & & & & & & & & & & & & & & & & & & & & & & & & \\
\hline P-10 & & & & & & & & & & & & & & & & & & & & & & & & \\
\hline P-11 & & & & & & & & & & & & & & & & & & & & & & & & \\
\hline P-12 & & & & & & & & & & & & & & & & & & & & & & & & \\
\hline P-13 & & & & & & & & & & & & & & & & & & & & & & & & \\
\hline $\mathrm{P}-14$ & & & & & & & & & & & & & & & & & & & & & & & & \\
\hline MONITORING AND RESEARCH & 0 & $\mathrm{~N}$ & D & J & $F$ & M & A & M & $\mathbf{J}$ & $\mathbf{J}$ & A & $S$ & 0 & $\mathrm{~N}$ & D & J & $\mathrm{F}$ & M & A & M & J & J & A & $\mathrm{S}$ \\
\hline RME-1A & & & & & & & & & & & & & & & & & & & & & & & & \\
\hline RME-1B & & & & & & & & & & & & & & & & & & & & & & & & \\
\hline RME-2 & & & & & & & & & & & & & & & & & & & & & & & & \\
\hline RME-3 & & & & & & & & & & & & & & & & & & & & & & & & \\
\hline RME-4 & & & & & & & & & & & & & & & & & & & & & & & & \\
\hline RME-5 & & & & & & & & & & & & & & & & & & & & & & & & \\
\hline RME-6 & & & & & & & & & & & & & & & & & & & & & & & & \\
\hline RME-7 & & & & & & & & & & & & & & & & & & & & & & & & \\
\hline RME-8 & & & & & & & & & & & & & & & & & & & & & & & & \\
\hline RME-9 & & & & & & & & & & & & & & & & & & & & & & & & \\
\hline RME-11 & & & & & & & & & & & & & & & & & & & & & & & & \\
\hline RME-10 & & & & & & & & & & & & & & & & & & & & & & & & \\
\hline RME-11 & & & & & & & & & & & & & & & & & & & & & & & & \\
\hline
\end{tabular}


H.6 Attachment A - ERTG Templates for FY 2012 Projects

INSERT any available templates

\section{H.7 Attachment B - ERTG Summary Reports for FY 2011 Projects}

INSERT any available reports. 
Appendix I

Photo Points 


\section{Appendix I - Photo Points}

\section{Prepared by Amy Borde and Heida Diefenderfer}

Photo points are presented for the Kandoll Farm, Vera Slough, and Crims Island study areas at various times from 2005 through 2009 . Photo points are an important landscape indicator (Roegner et al. 2009). However, it is not always possible to take photo points at the same tide stage or water level each time. Caution should therefore be used in interpreting the photographs below, although large scale changes are evident, such as die back of trees at Kandoll Farm.

\section{I.1 Kandoll Farm}

Kandoll Farm and Reference Photo Points 2005-2009

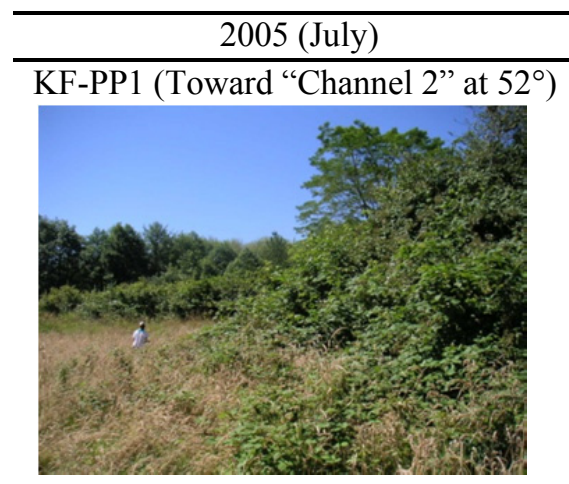

KF- PP2 (Area A at $\left.307^{\circ}\right)$

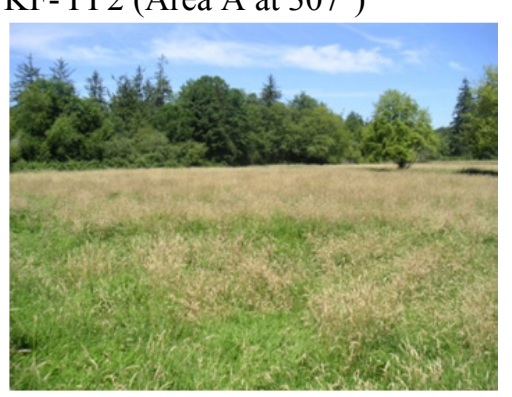
2006 (October) 2007 (July)
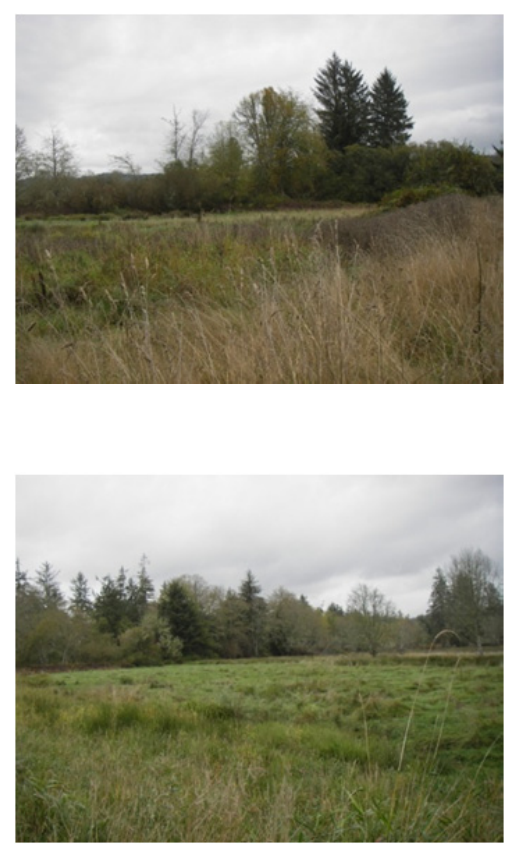
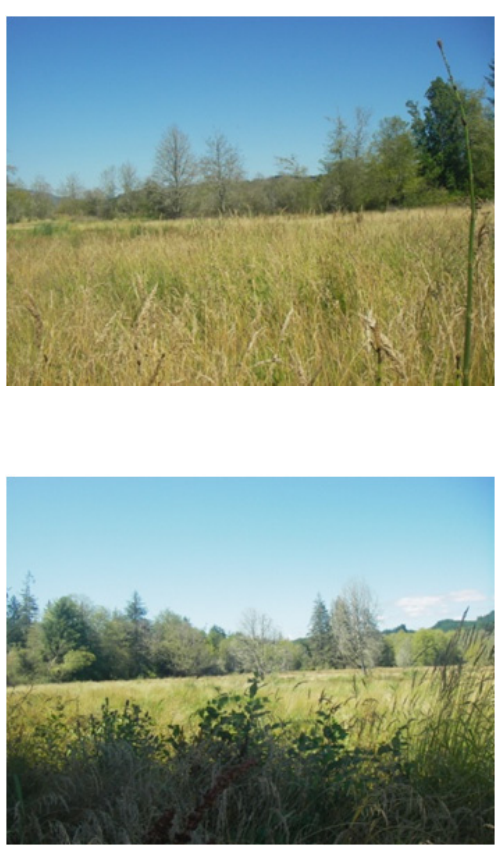

2009 (July)

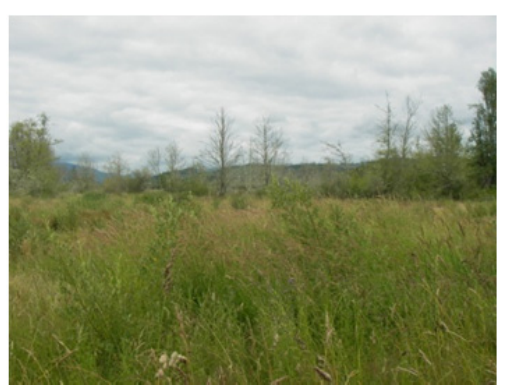

SASP/COST plantings in foreground

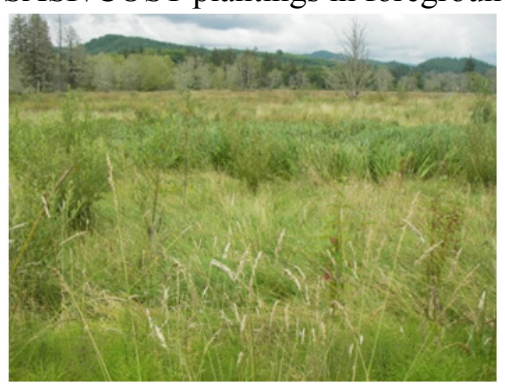



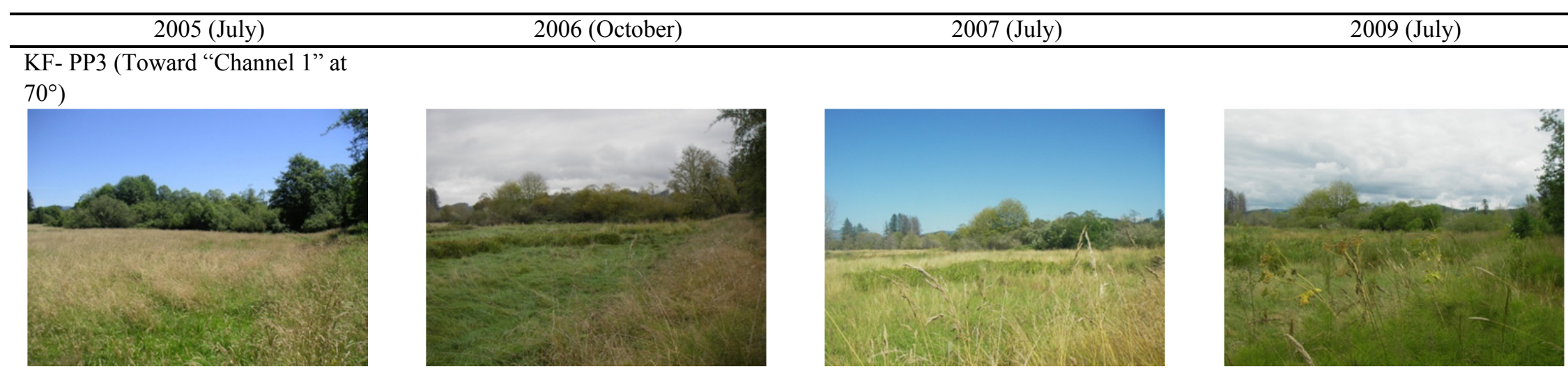

Point Name: KF-PP4

KF- PP4 SW $\left(202^{\circ}\right)$
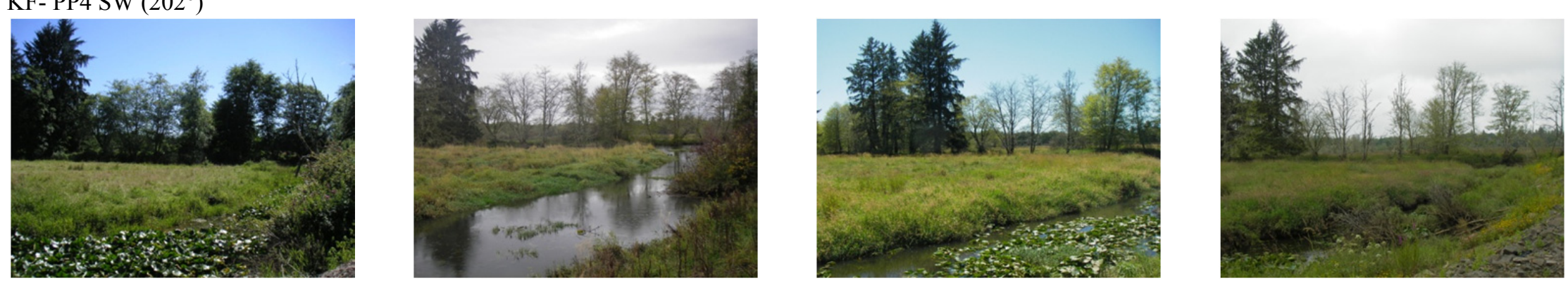

KF- PP4 E
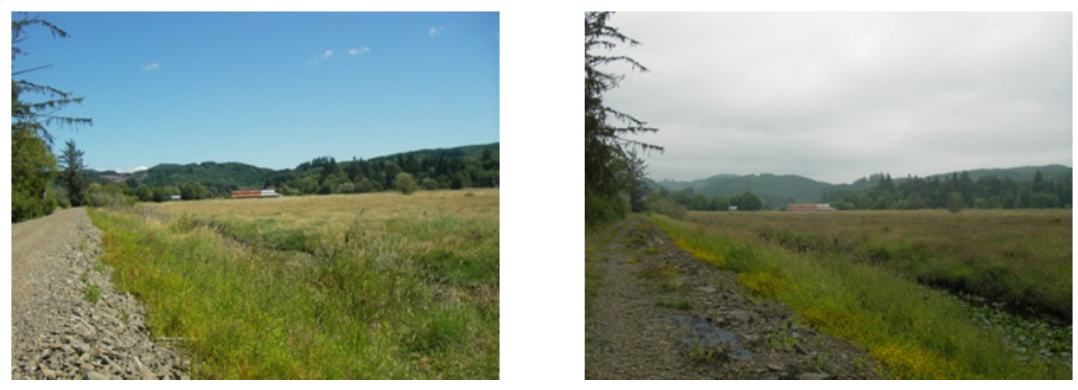


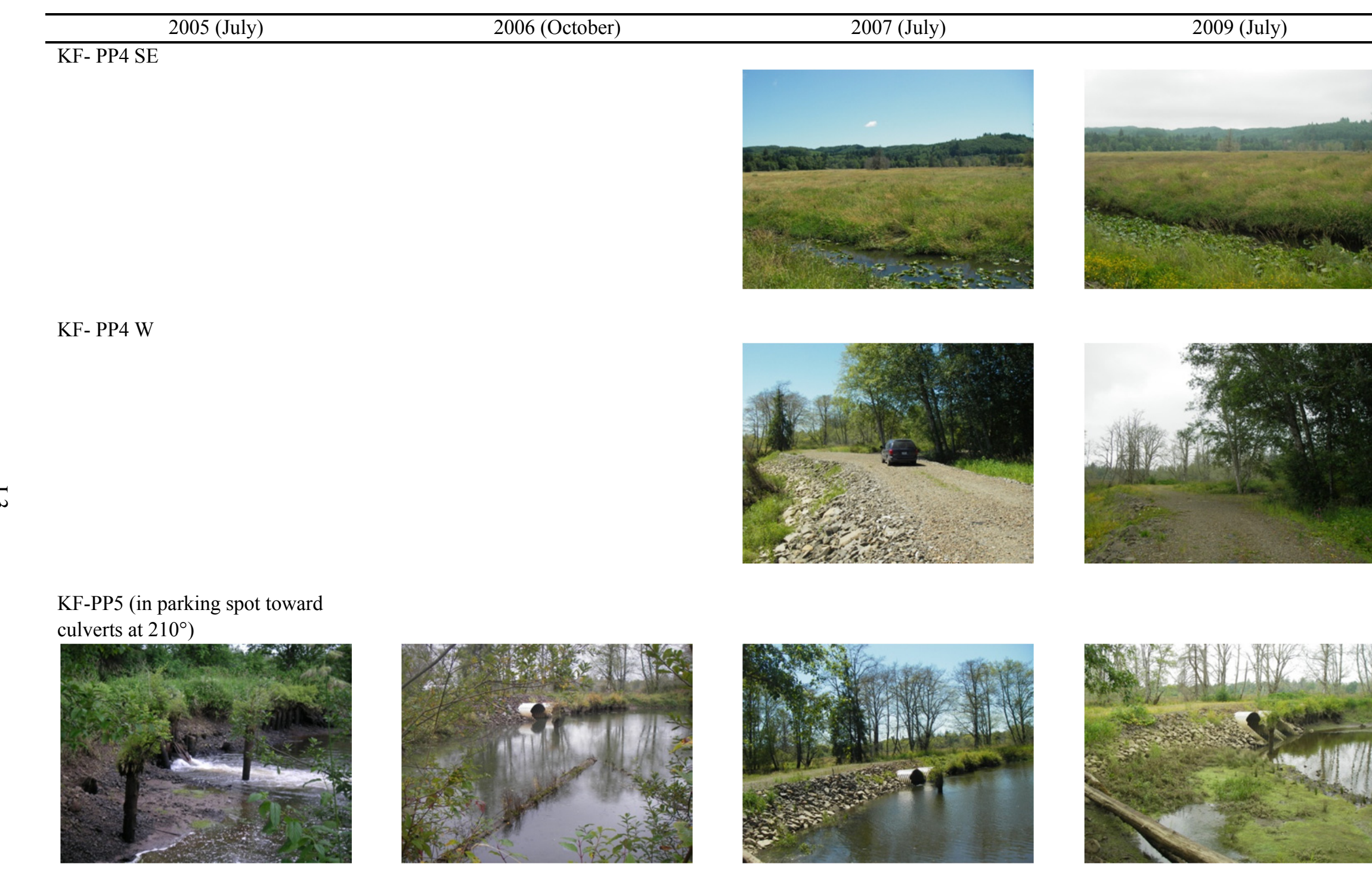




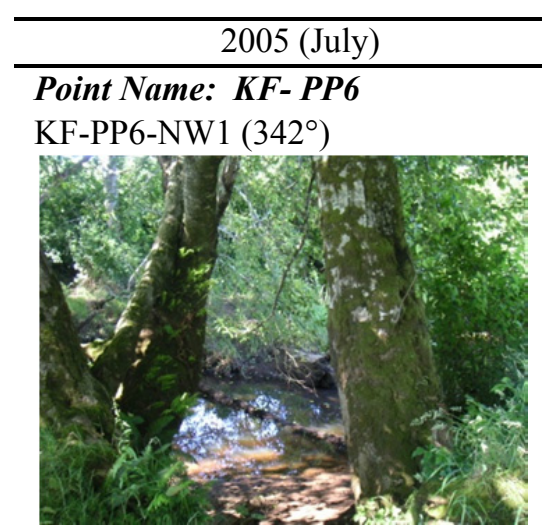

2006 (October)

2007 (July)

2009 (July)

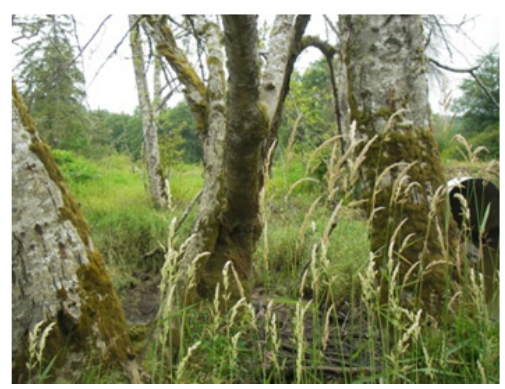

Point Name: KF-PP6

KF-PP6-NW1 $\left(342^{\circ}\right)$
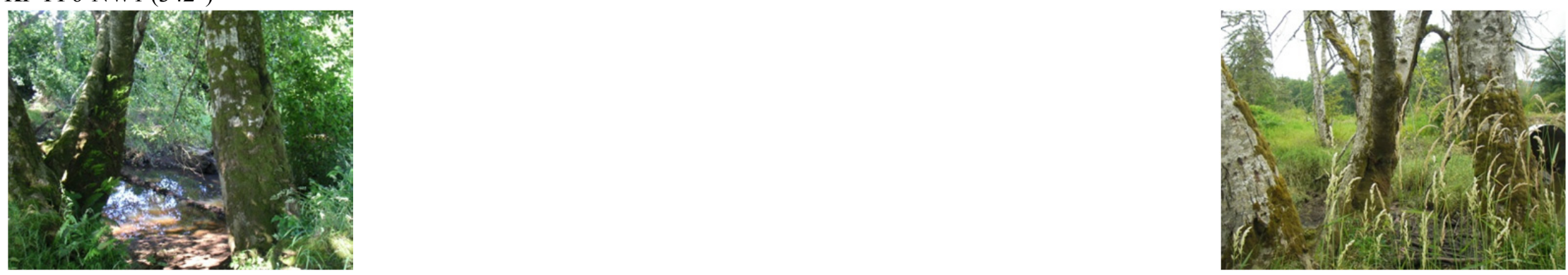

KF-PP6-NW2 (298 $)$
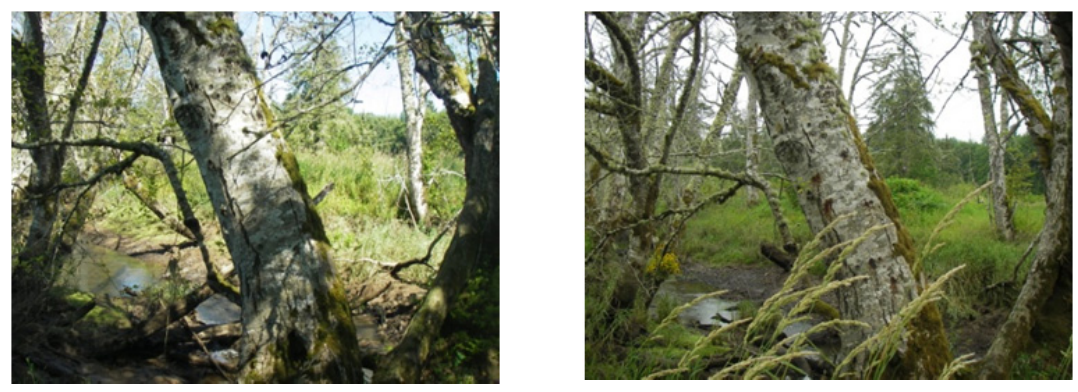
2005 (July)

2006 (October)

2007 (July)

2009 (July)

KF-PP6-N (toward culverts)
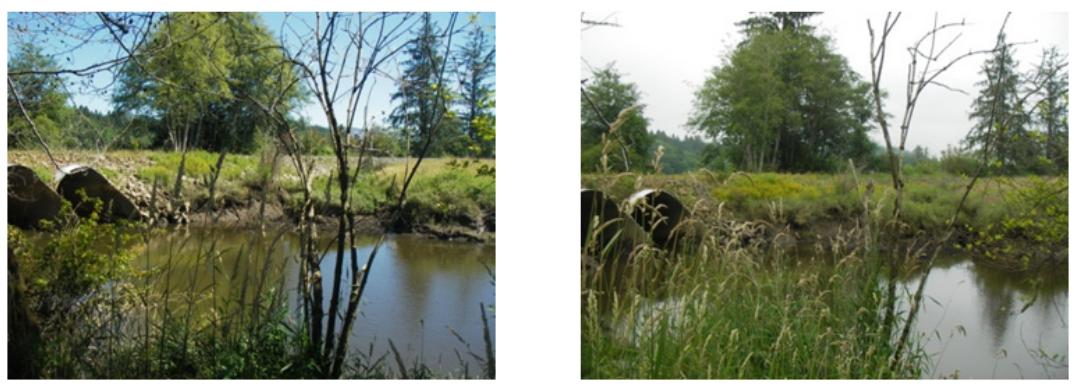

KF-PP6 E
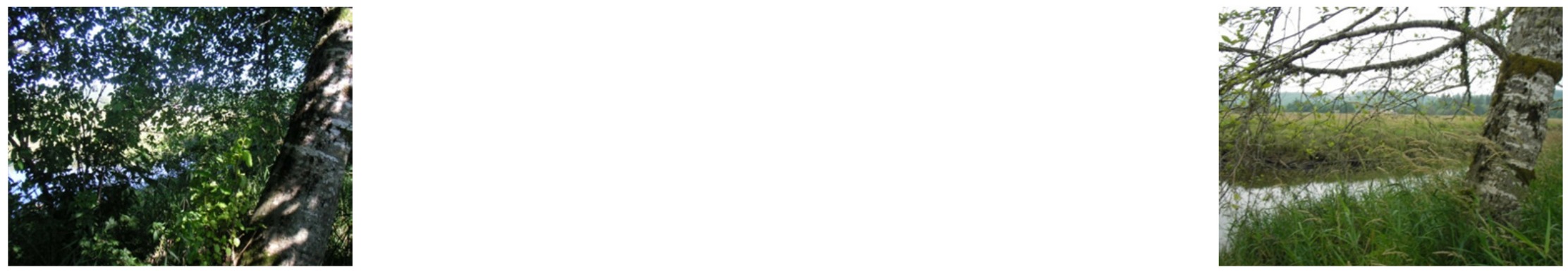

KF-PP6-Baseline
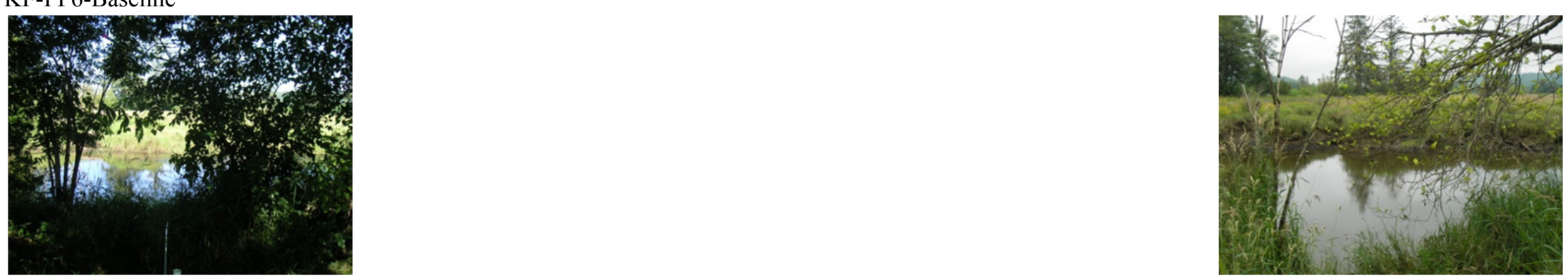


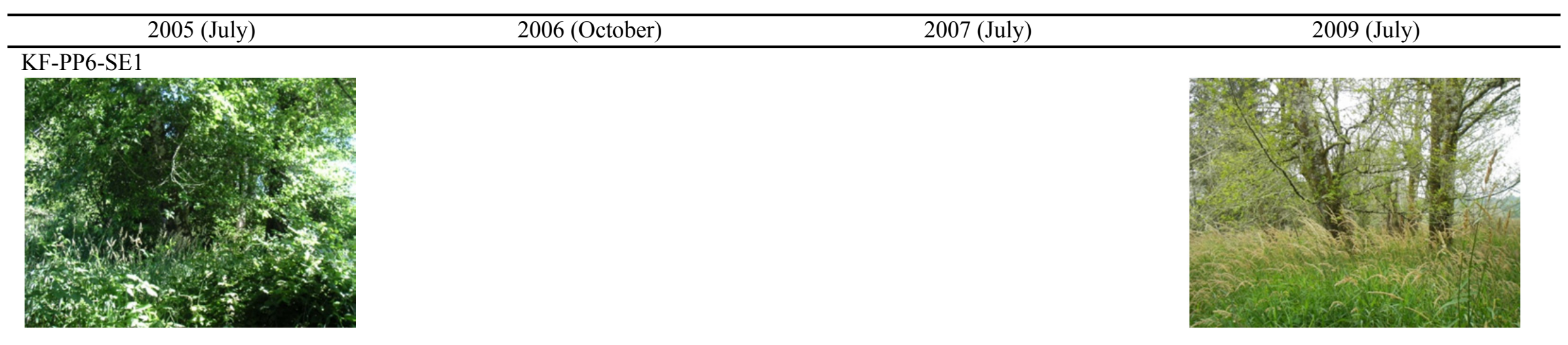

KF-PP6-SE2
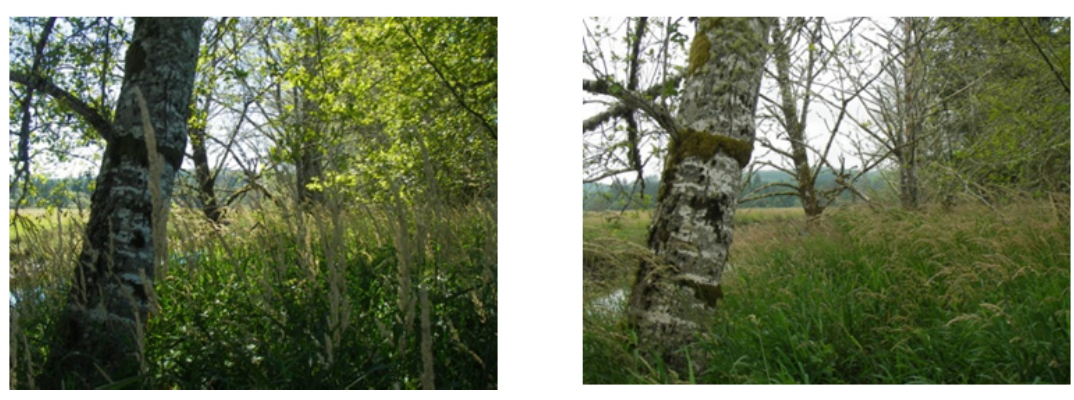

KF- PP6-SW1 (doesn't have tree)
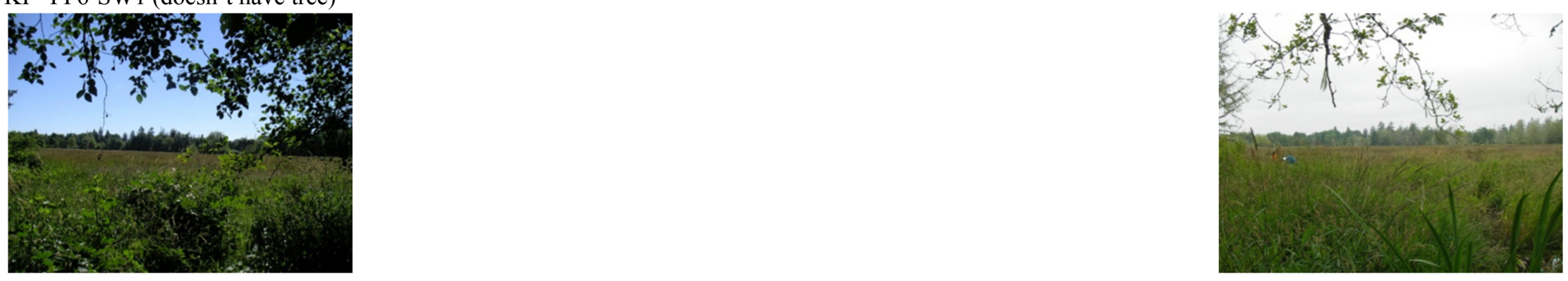

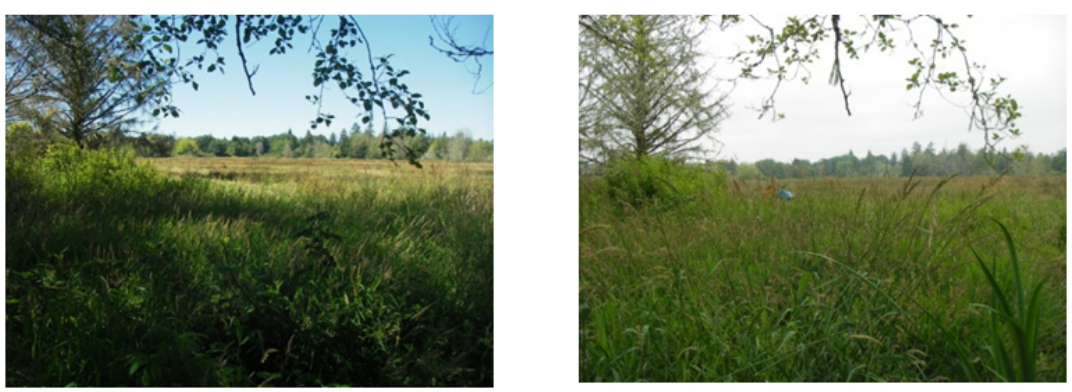

KF-PP6-W

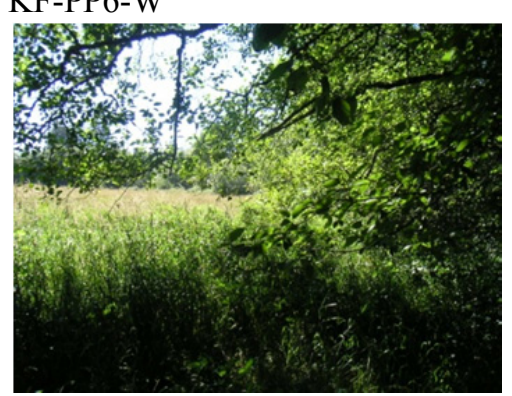

Point Name: $K F-P P 7$

KF-PP7-N

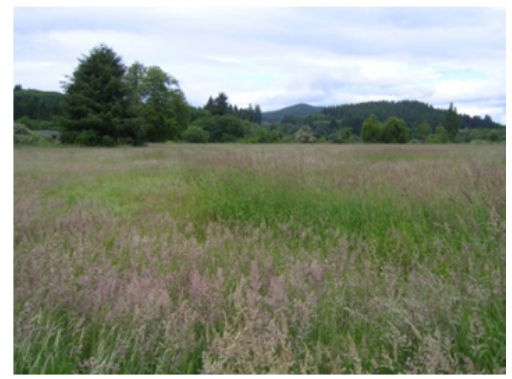

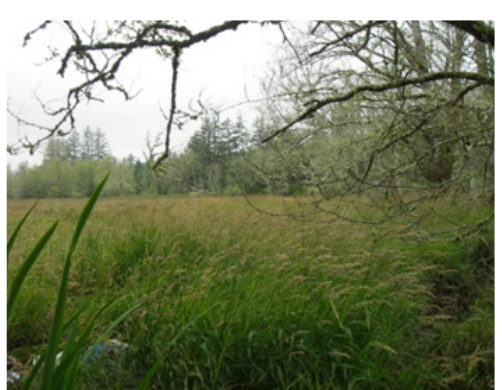
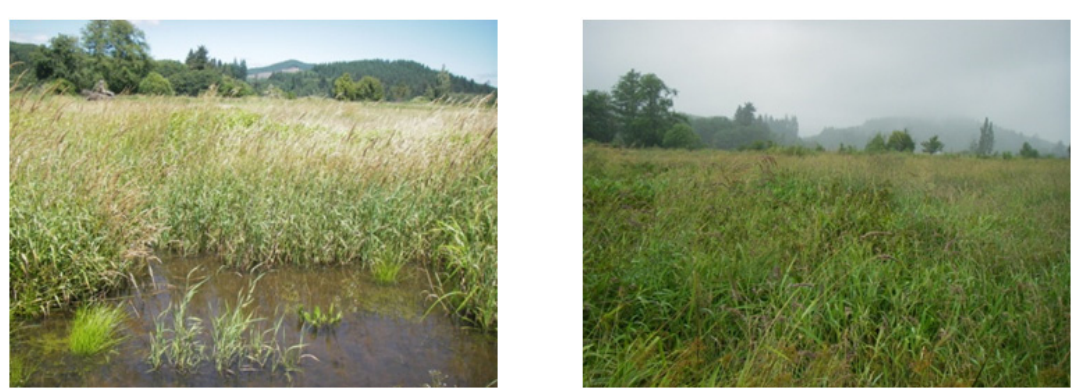

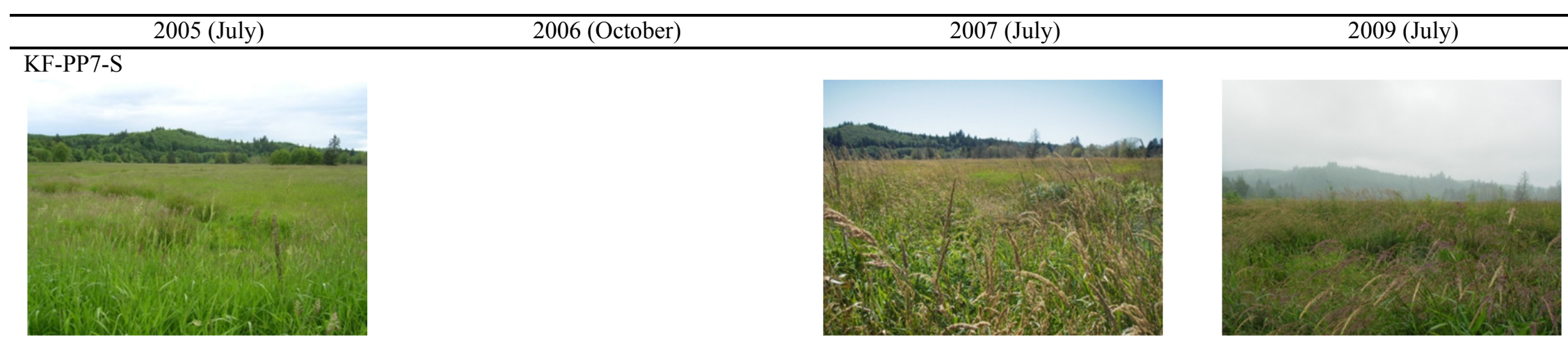

Point Name: KF-PP8

KF-PP8-S
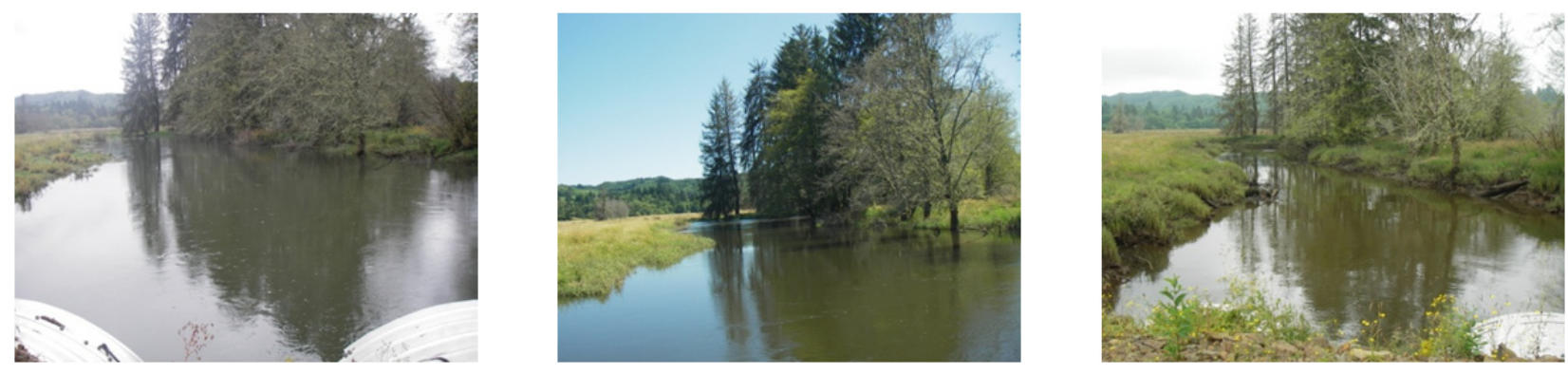

KF-PP8-N
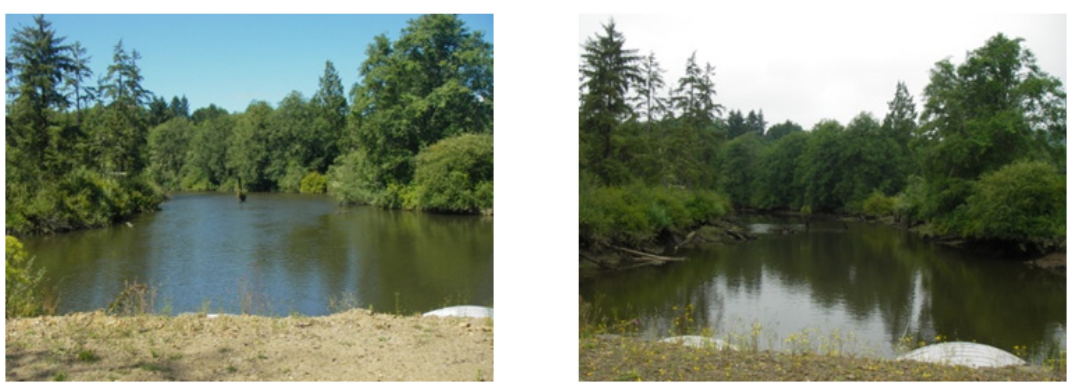
2005 (July)

2006 (October)

2007 (July)

2009 (July)

KF-Misc. Photos from July 2007

Wetland veg on Driveway @, PP7

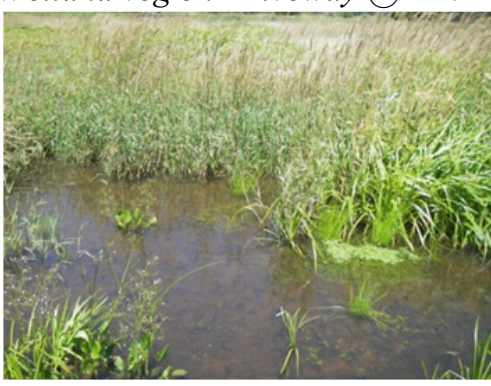

Dying spruce from PP7
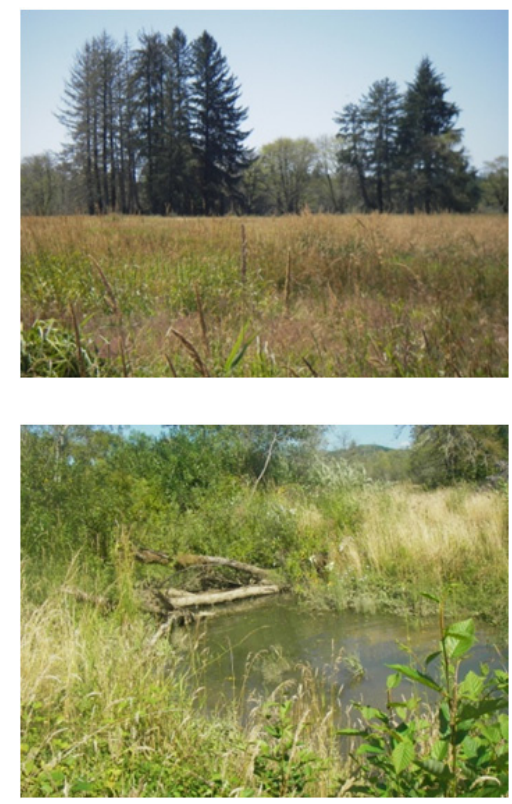

\section{Channel1@modhigh tide}

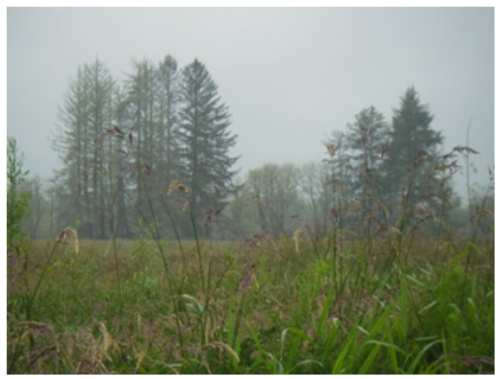




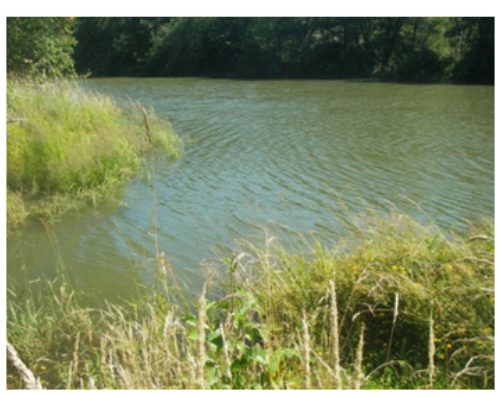

Kandoll Reference Photo Point

KR-PP1. Looking Upriver from

Depth Sensor
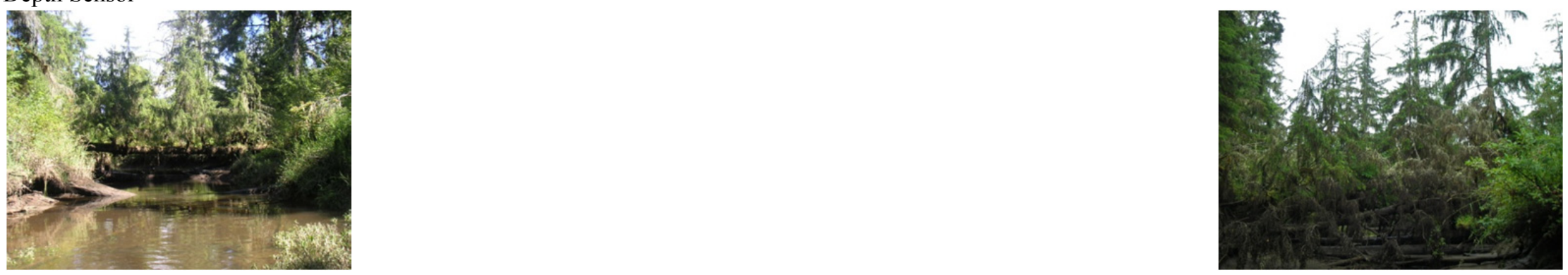

-PP2. Depth Sensor from Right Bank (looking east)
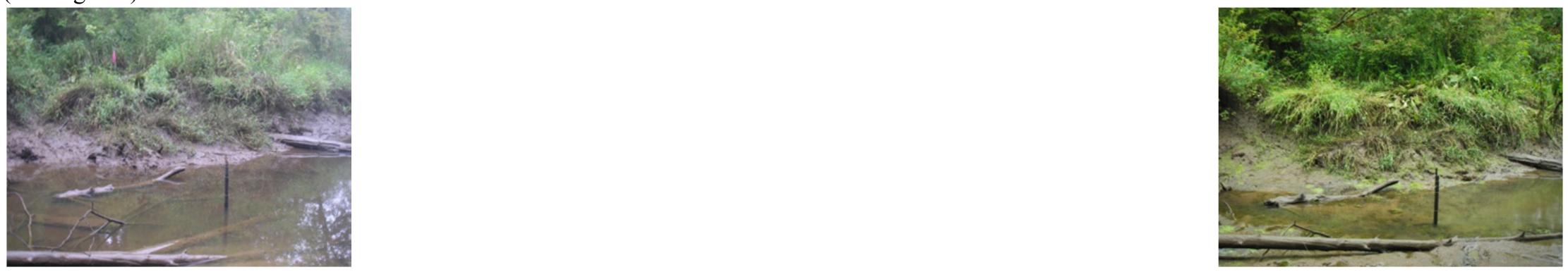


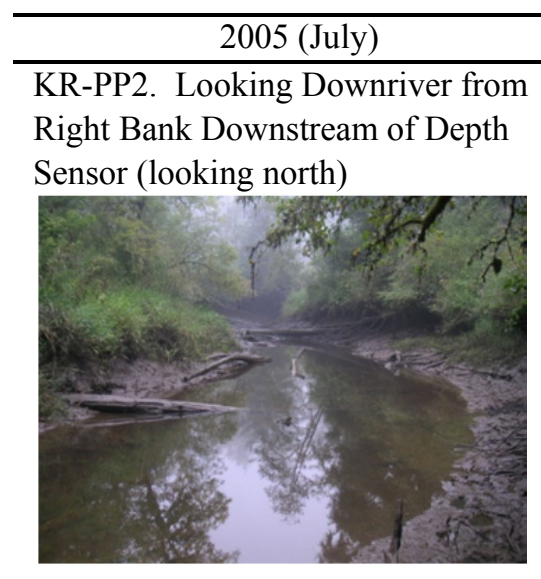

Right Bank Downstream of Depth

Sensor (looking north)

KR-PP3. Seal Slough \& Reference

Swamp from Seal Slough near mouth of Ref Channel (looking SW)
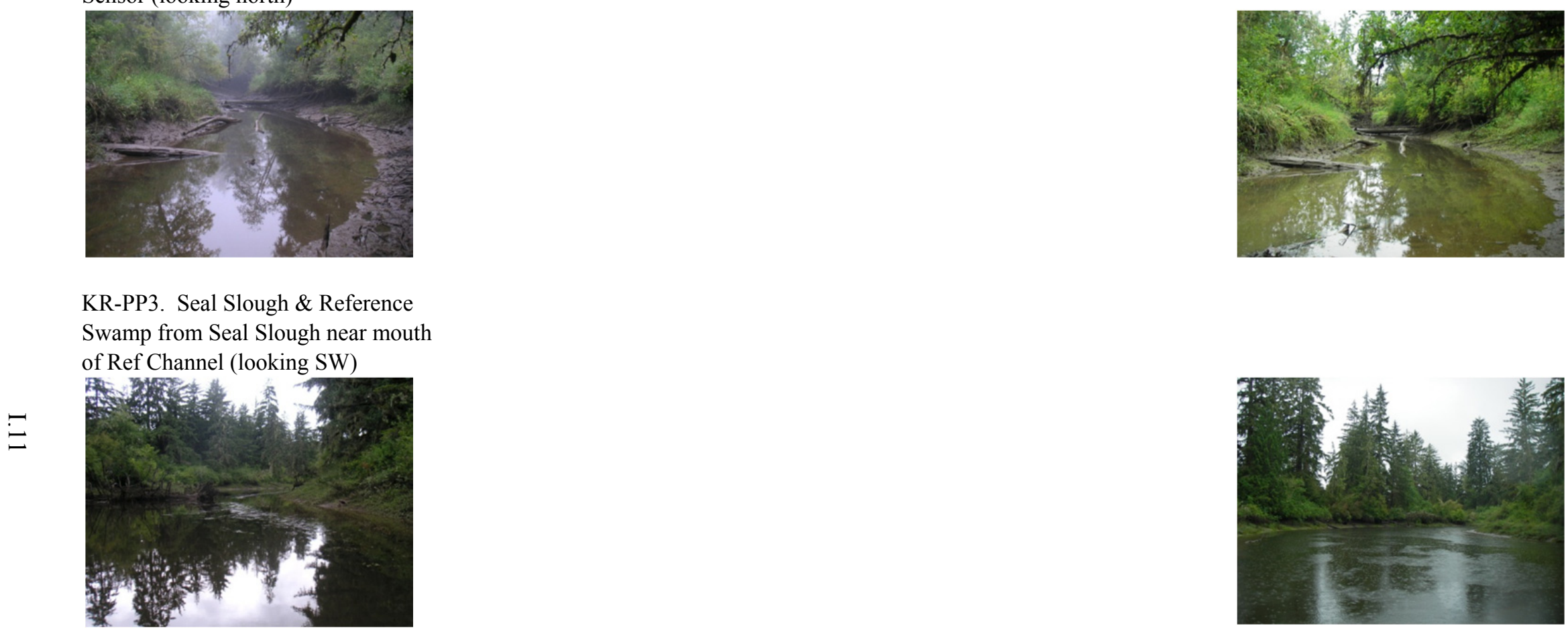


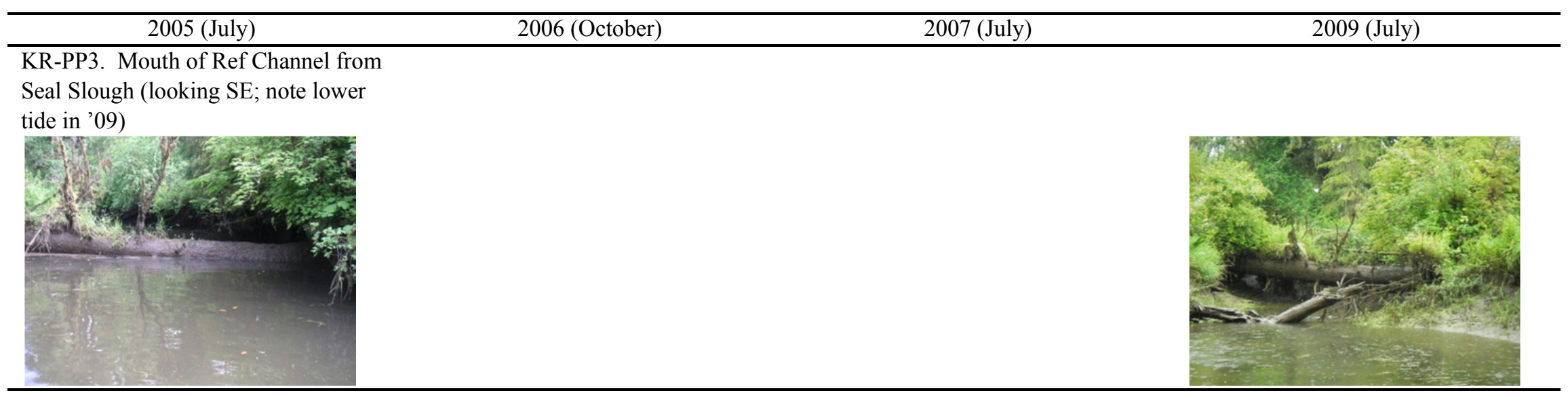

\section{I.2 Vera Slough}

$=\quad$ Vera Slough and Reference Photo Points 2005-2009

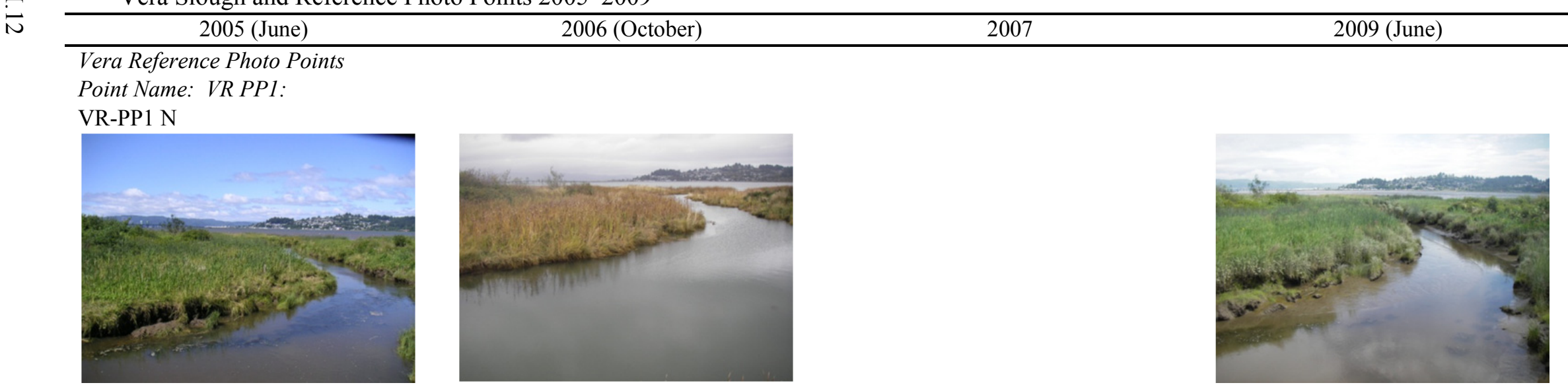



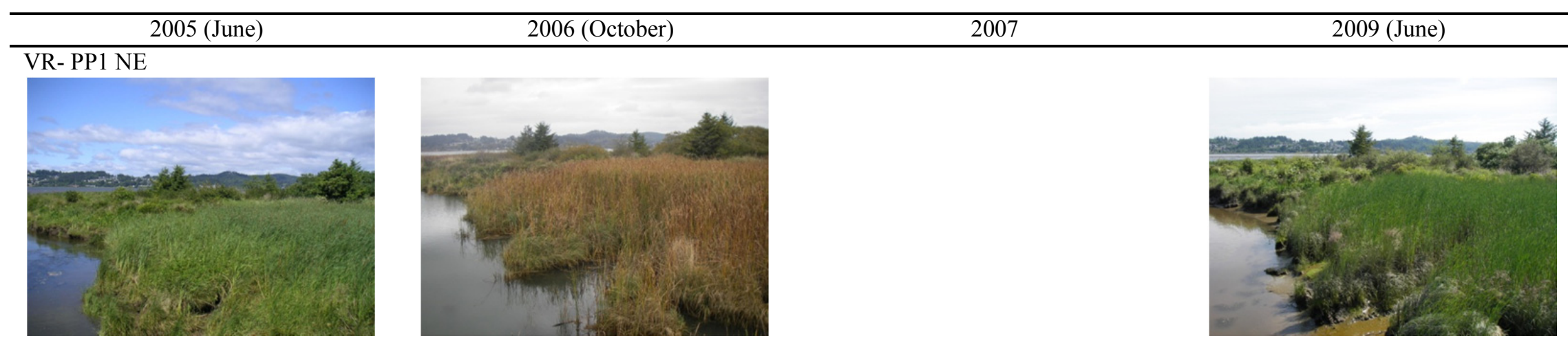

VR- PP1 E
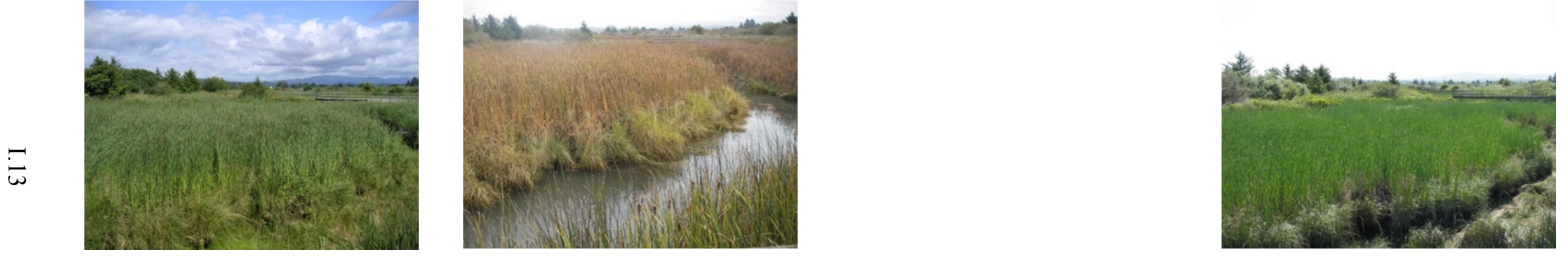

VR- PP1 S
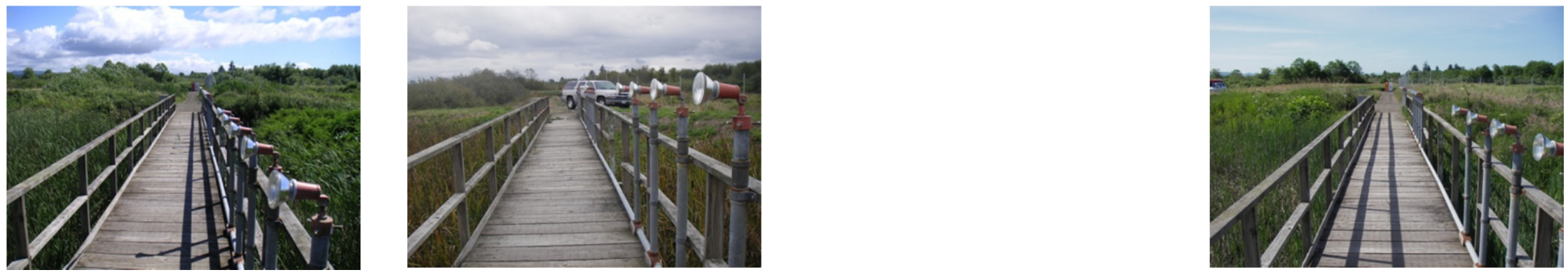

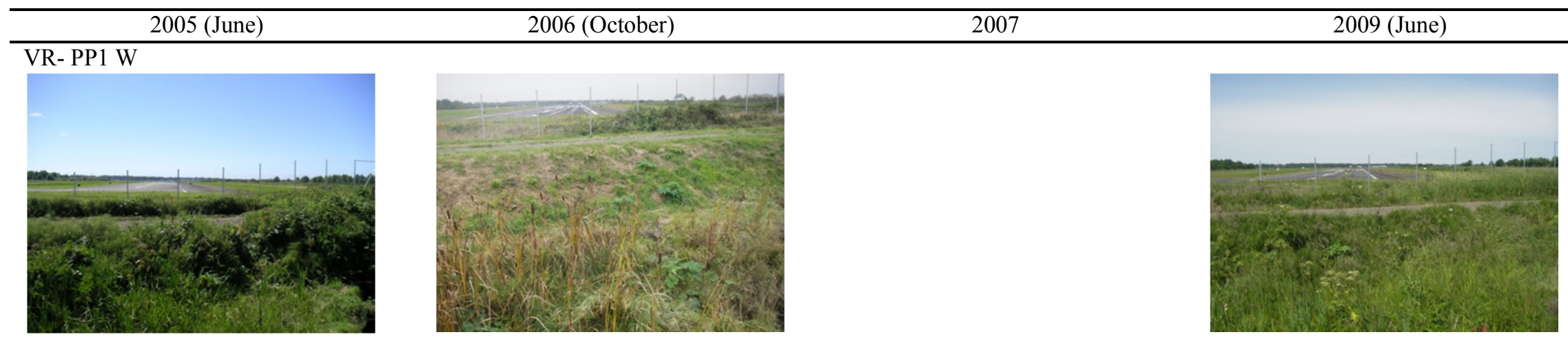

VR- PP1 NW
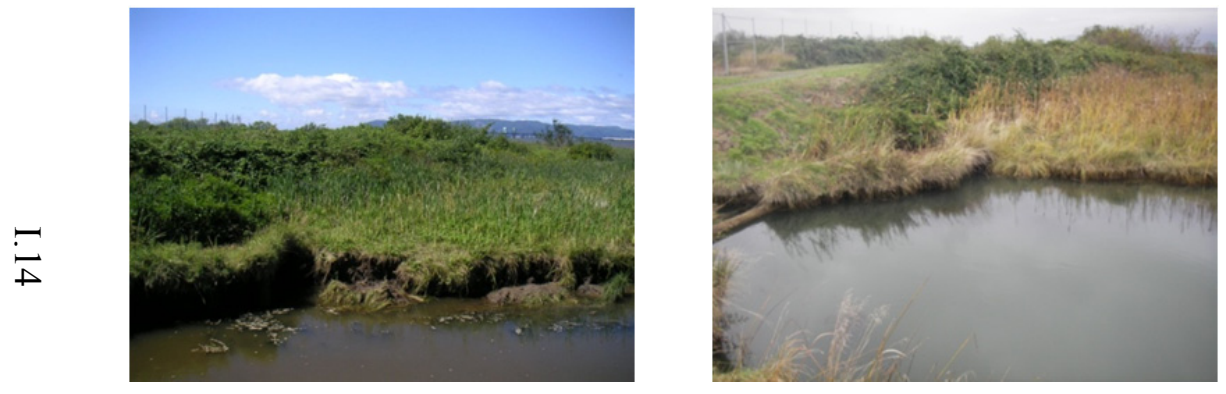

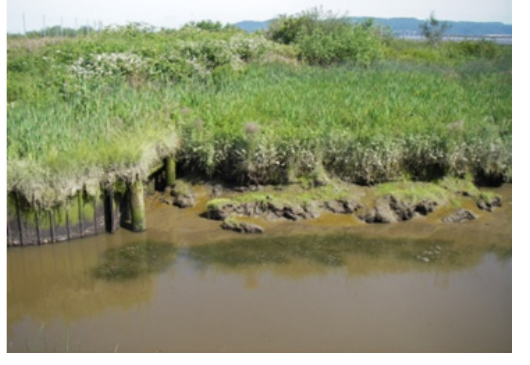

VR- PP1 X-SECT
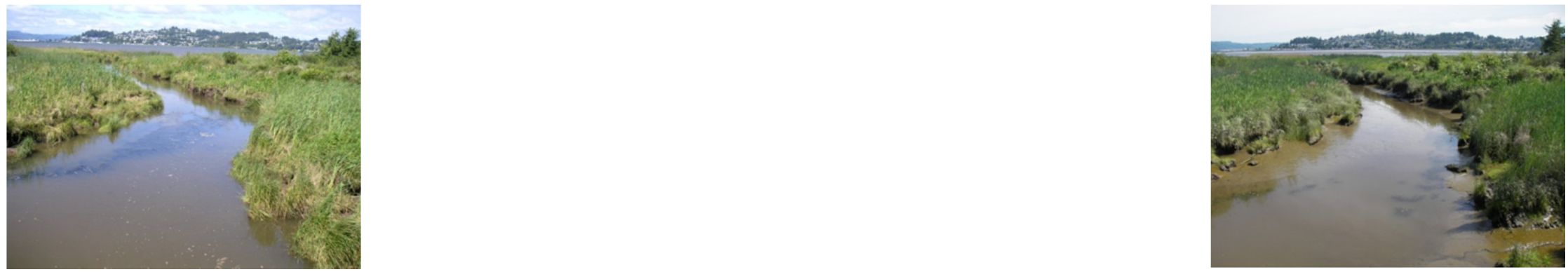


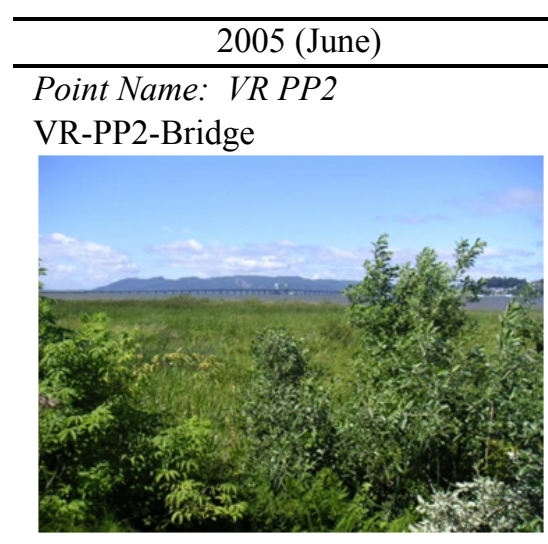

VR-PP2-Town

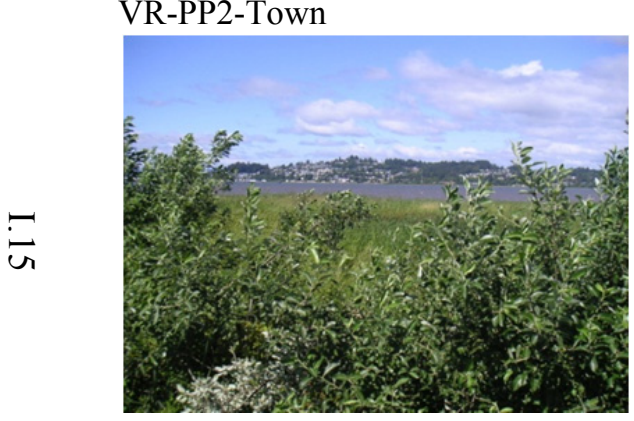

VR-PP2-New
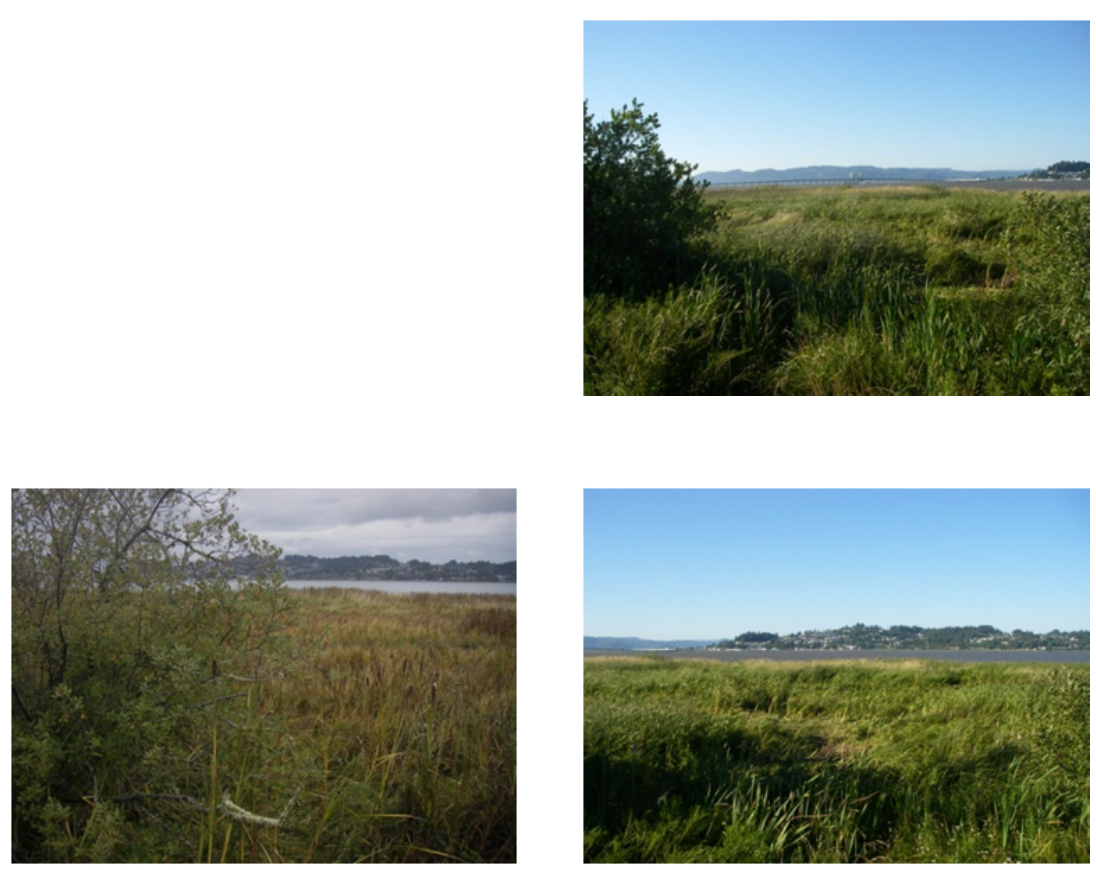

Changed location (100\% willow)

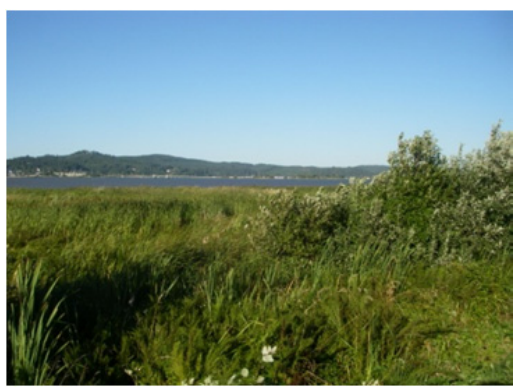

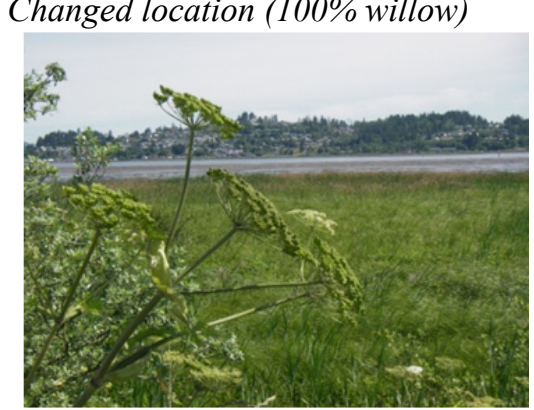
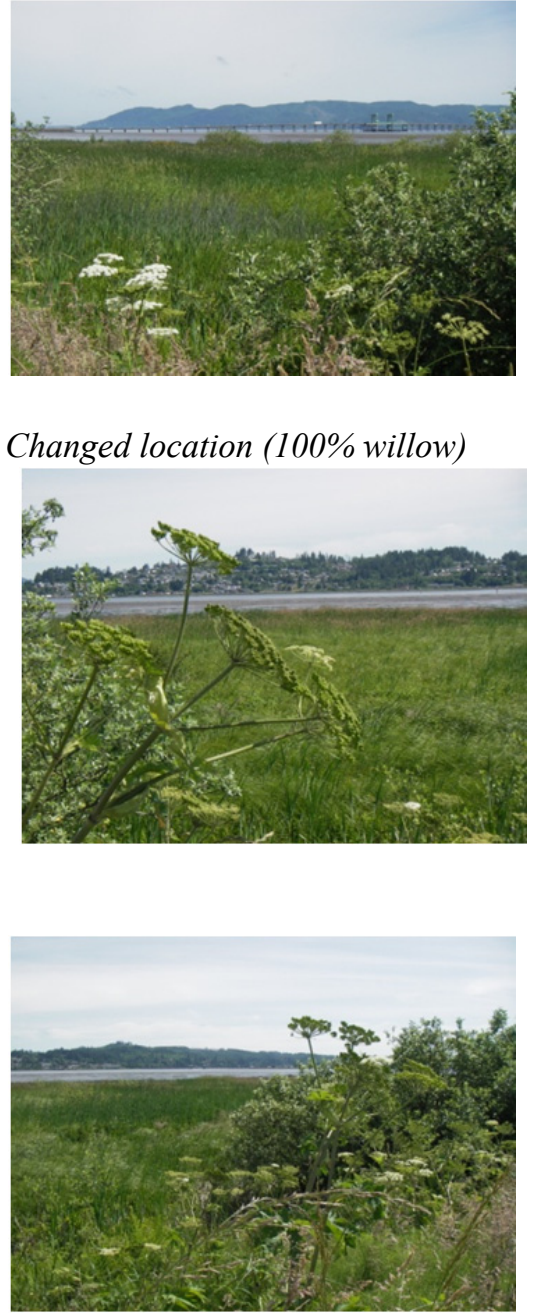

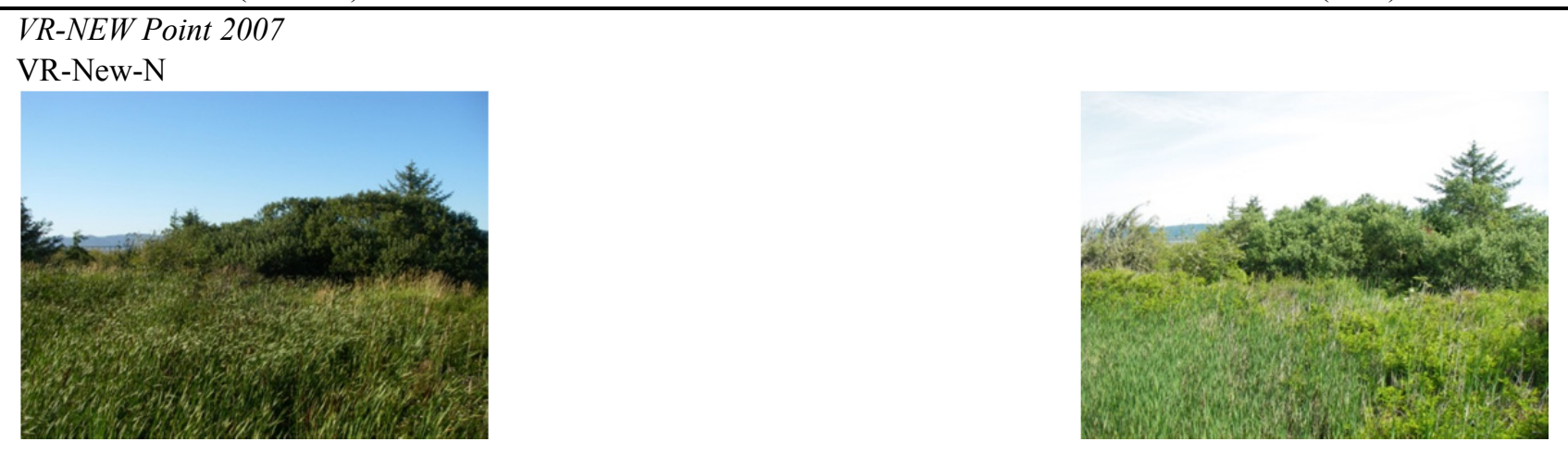

VR-New-E

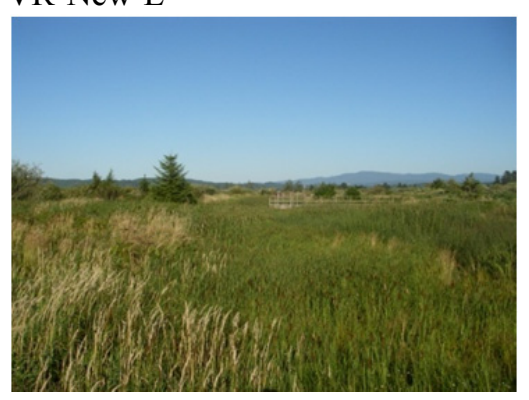

VR-New-S

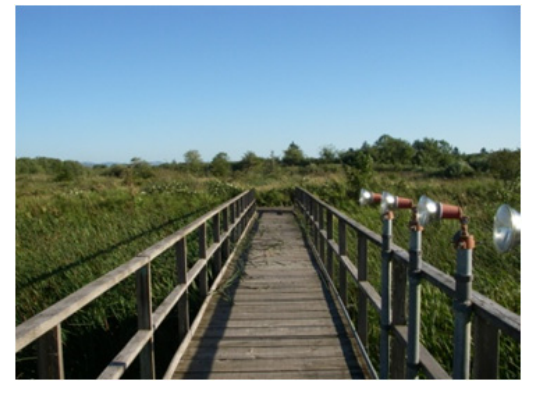

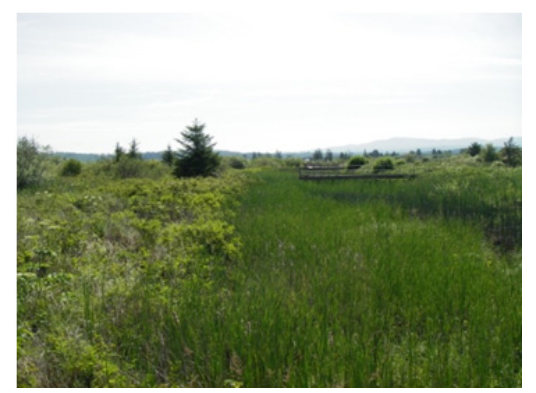

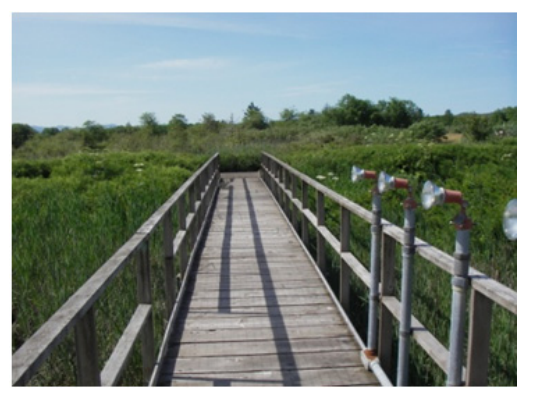




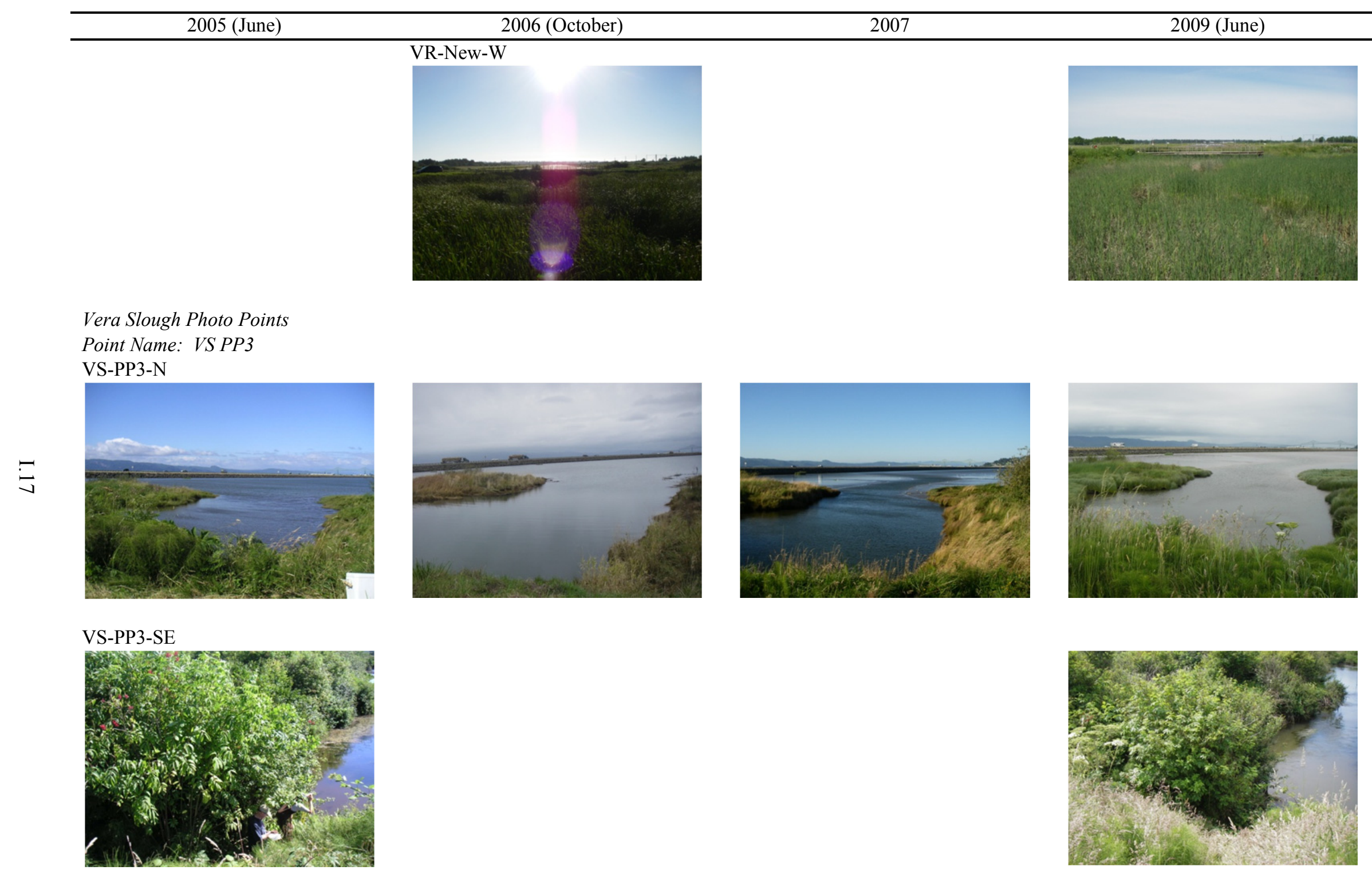



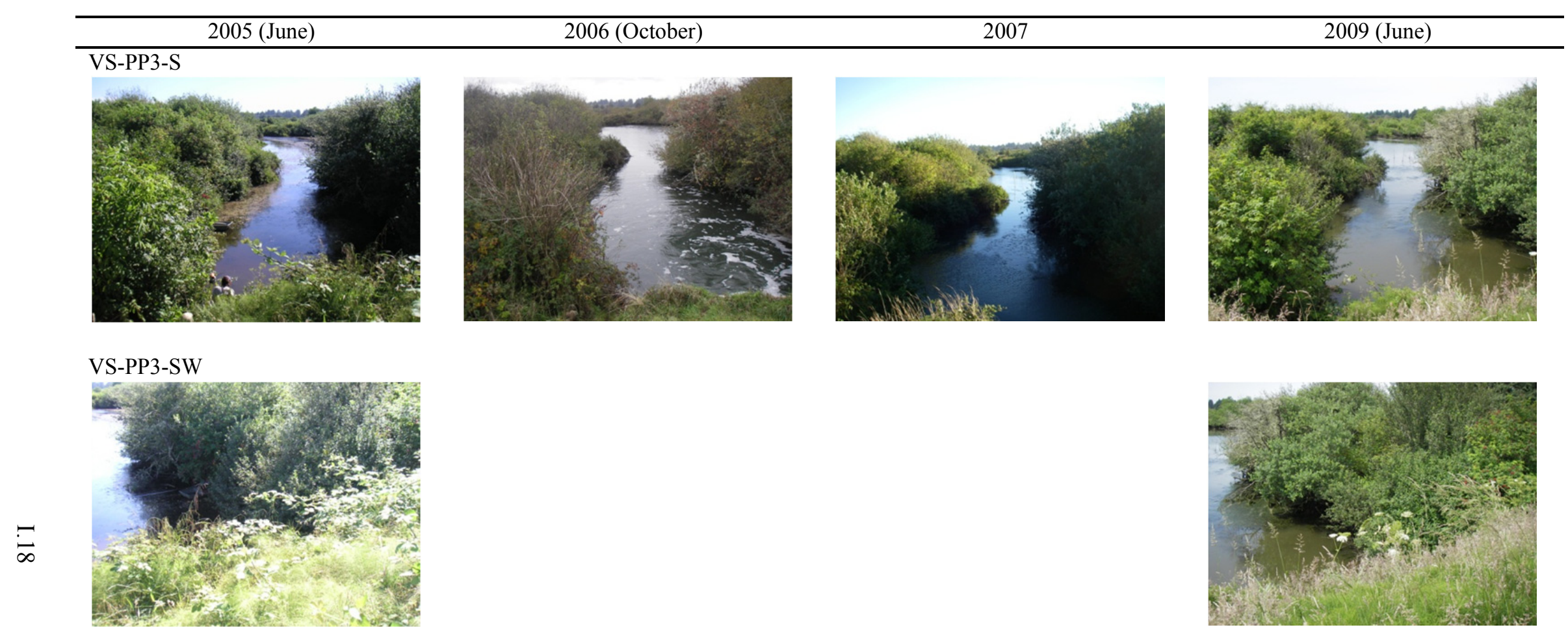

VS-PP3-VS Outside 1
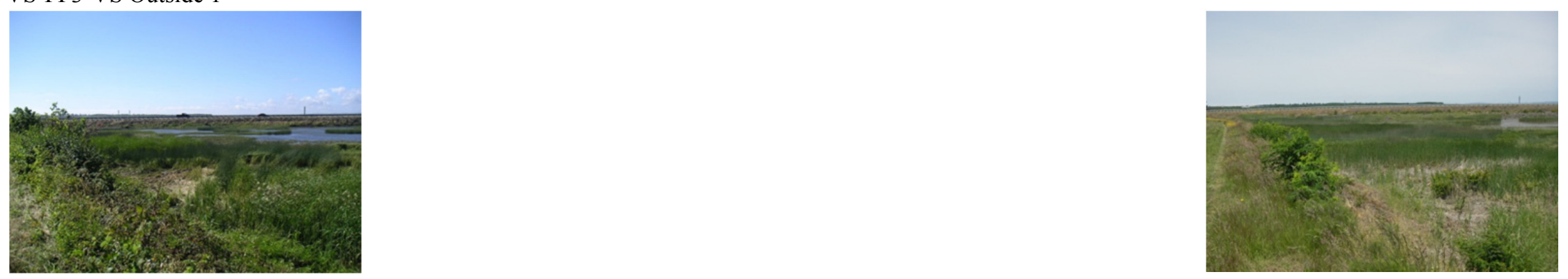

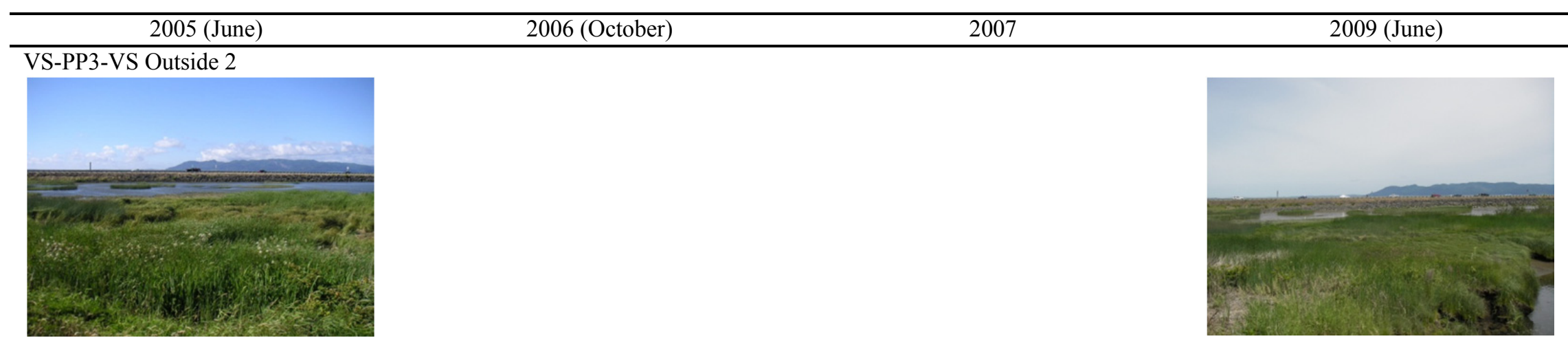

VS-PP3-Outside 3
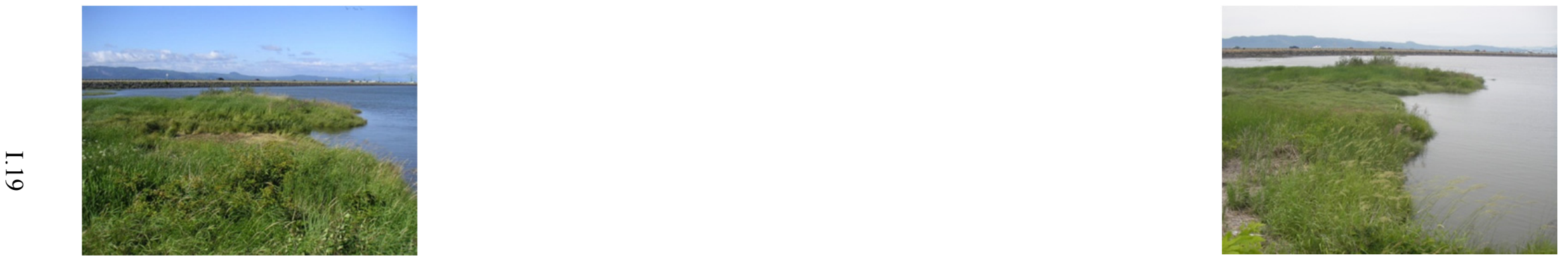

VS-PP3-Outside 4
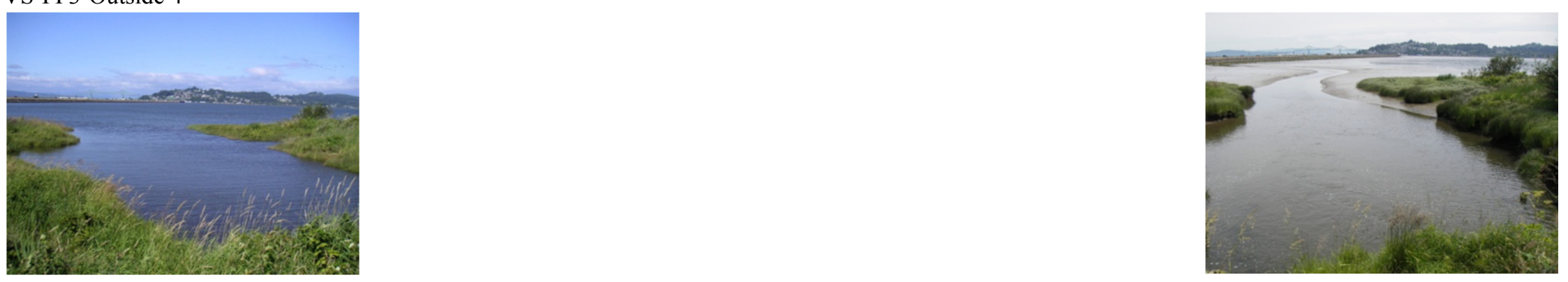

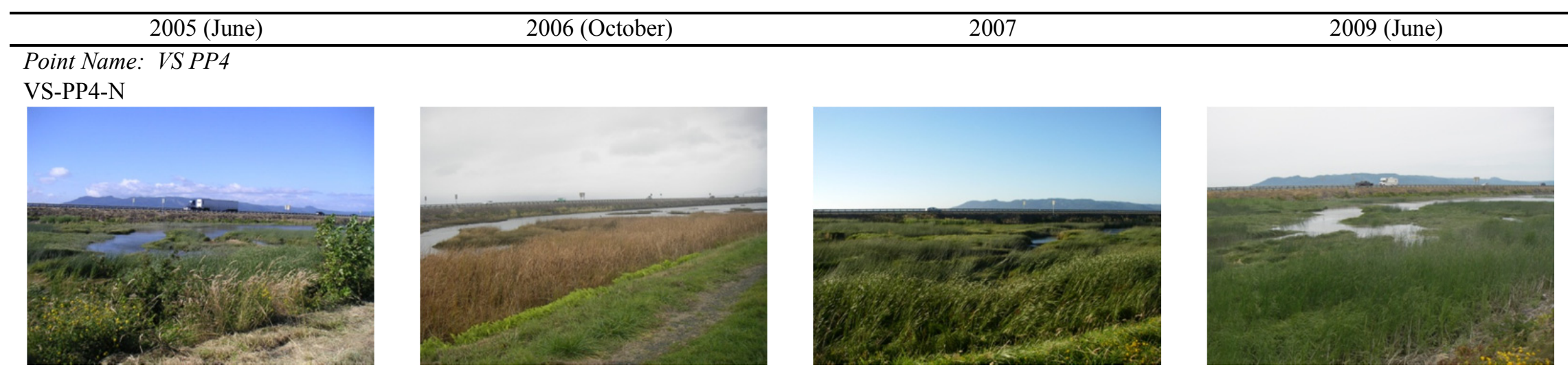

VS-PP4-E
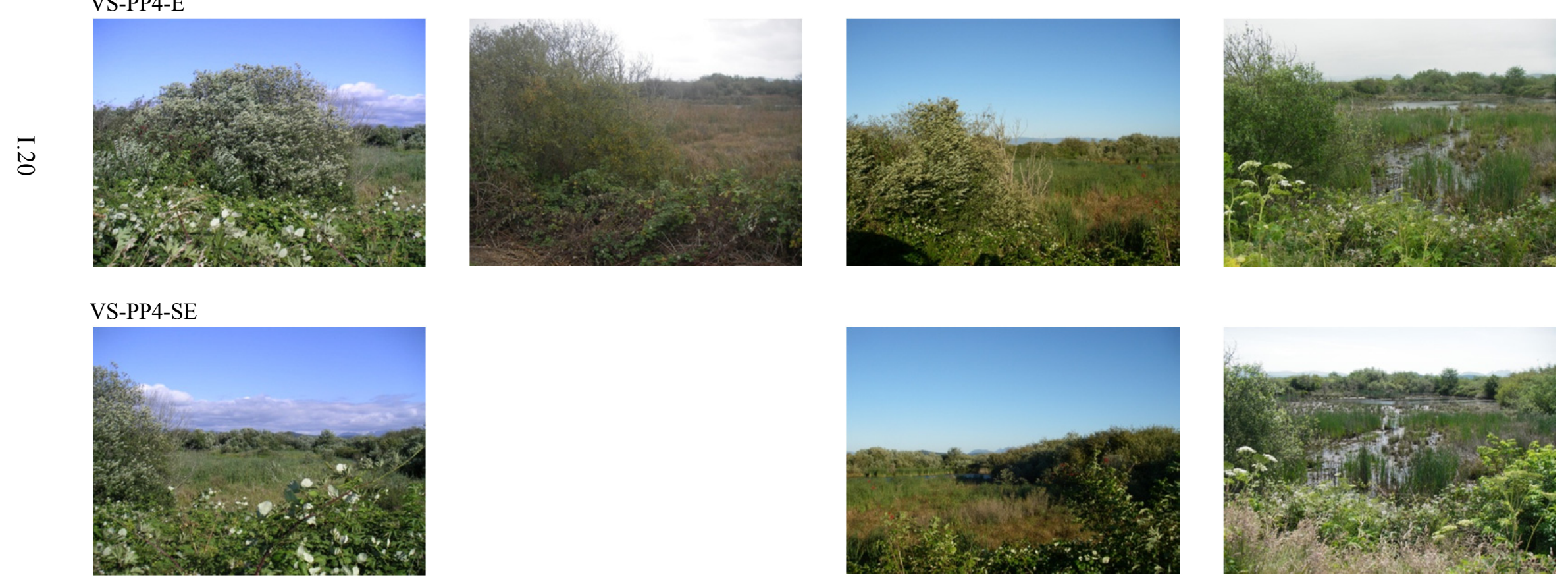


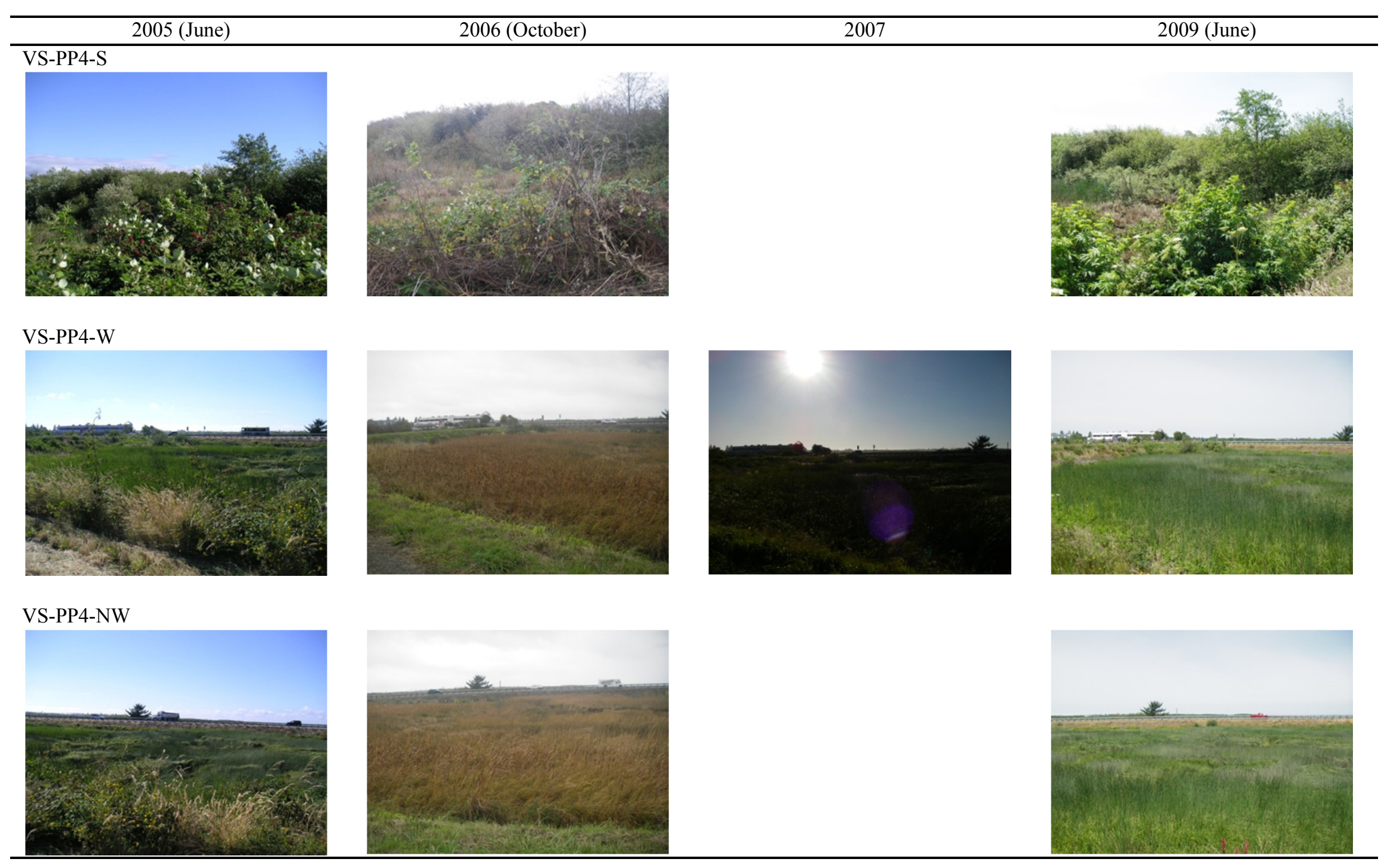




\section{I.3 Crims Island}
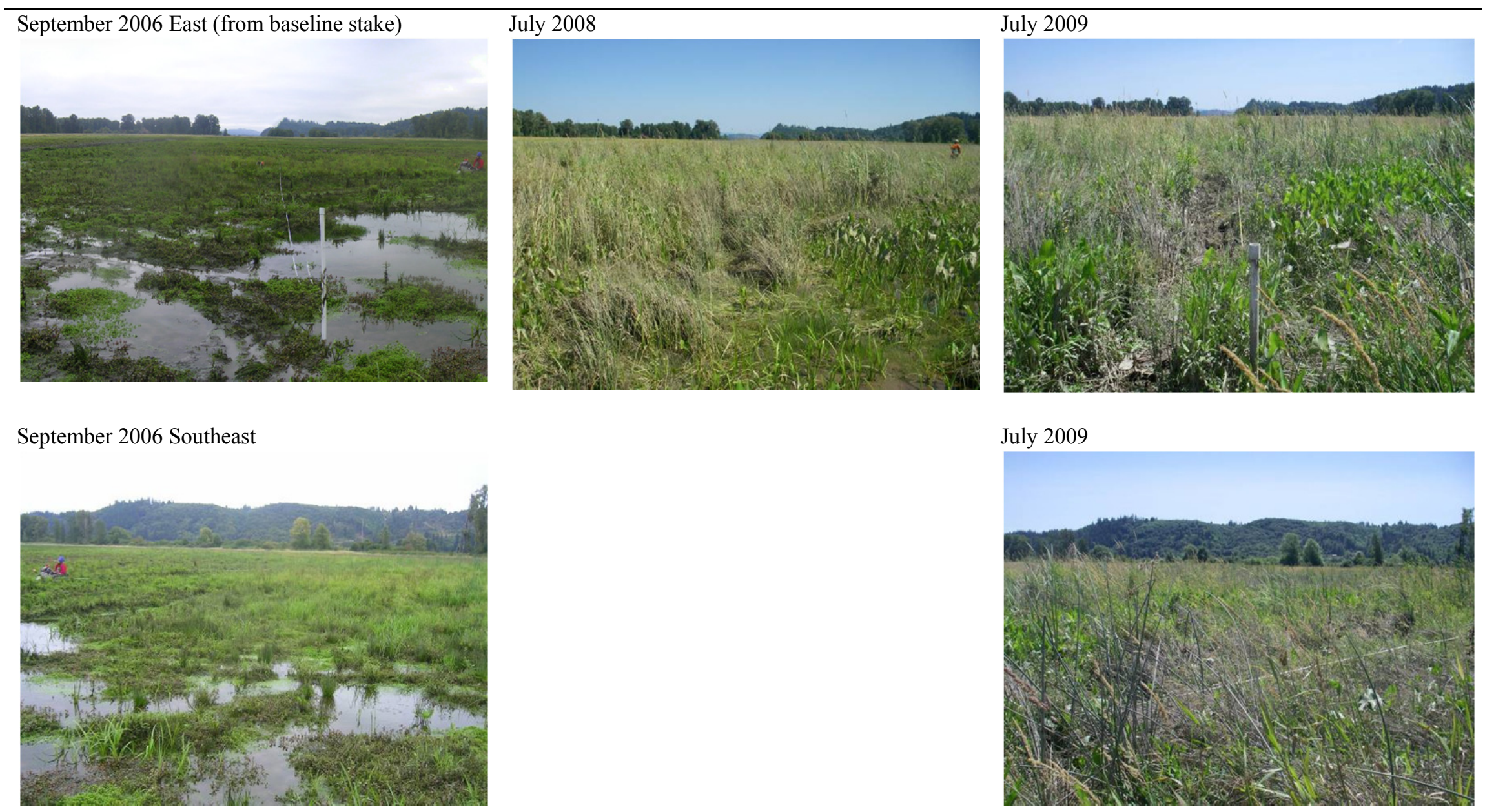
September 2006 South (from baseline stake)

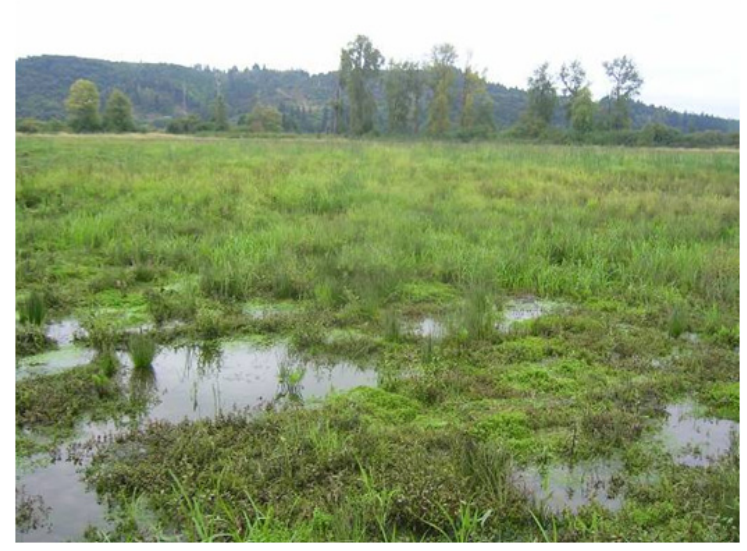

September 2006 Southwest

i

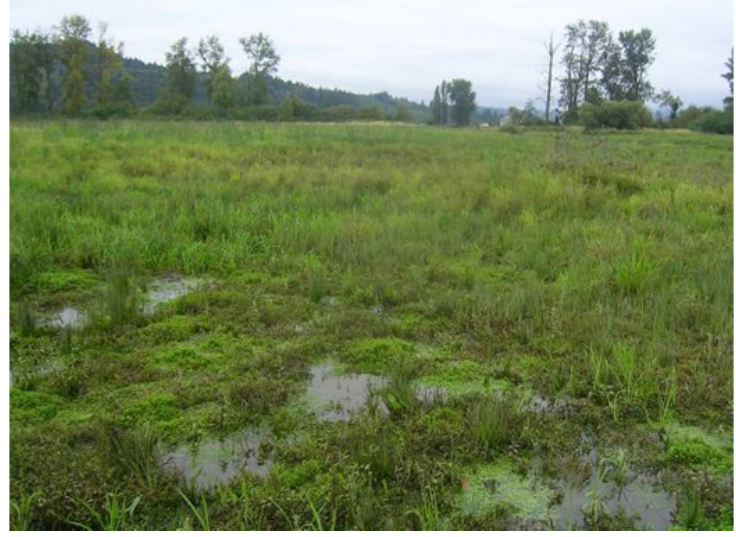

July 2008

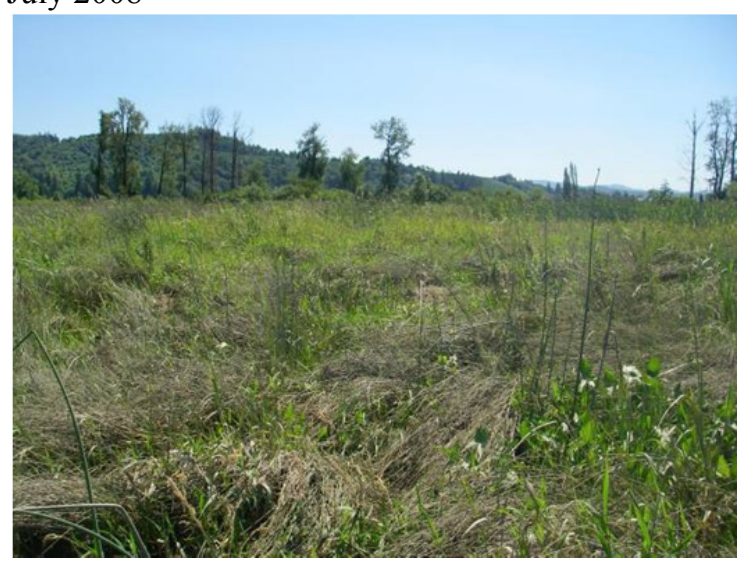

July 2009

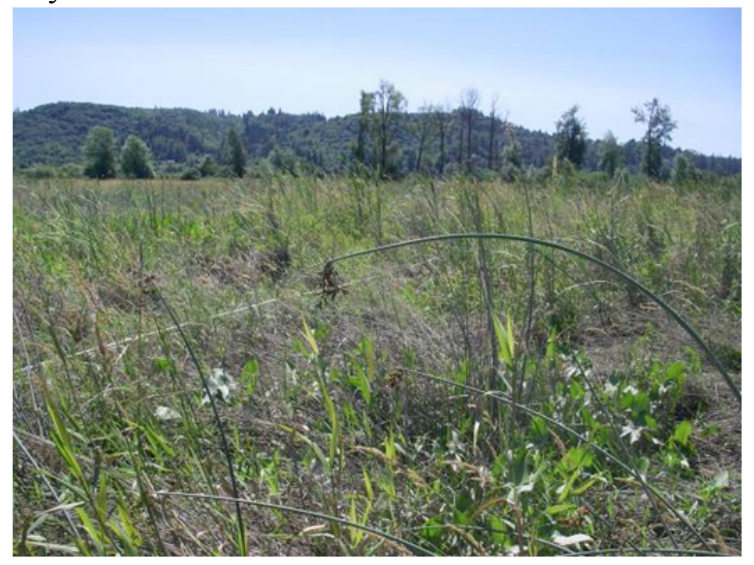

July 2009

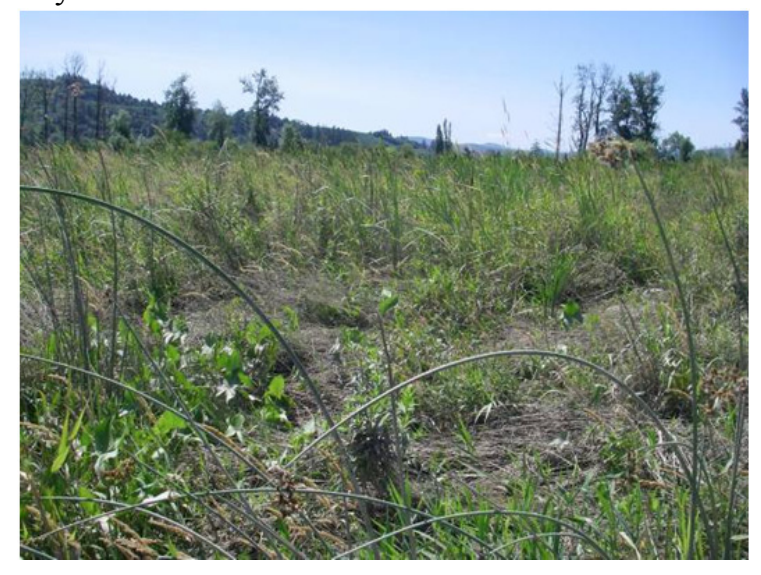




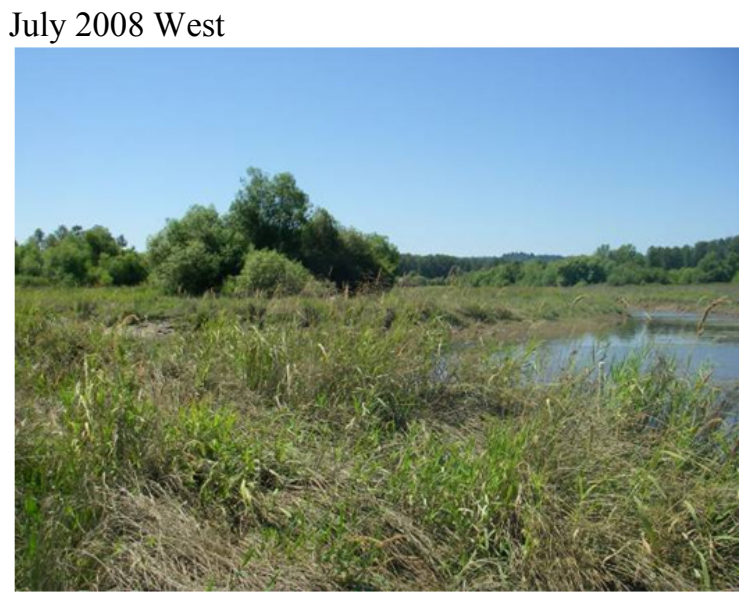

July 2009

July 2008 North
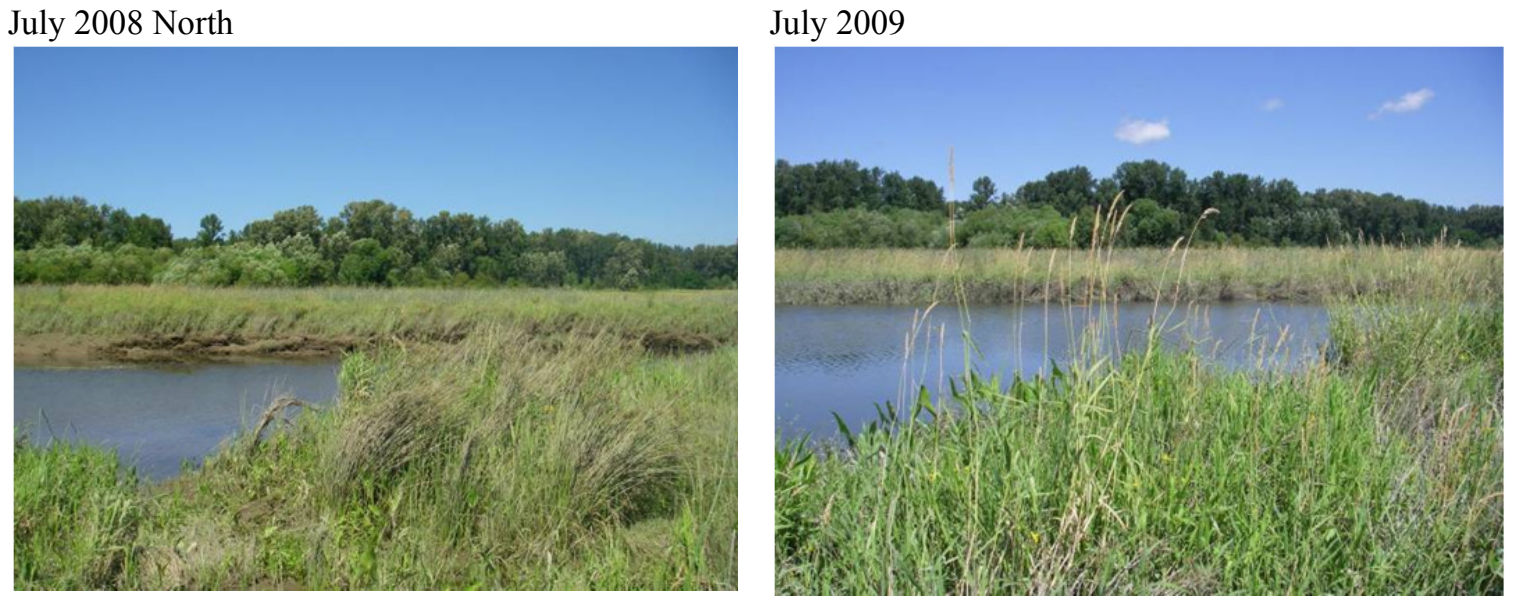
Crims Reference Site (Gull Island)

September 2006

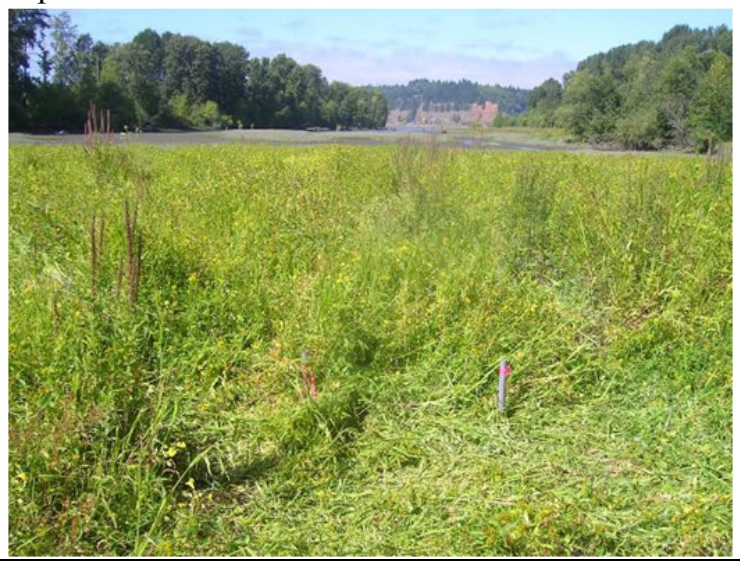

July 2009

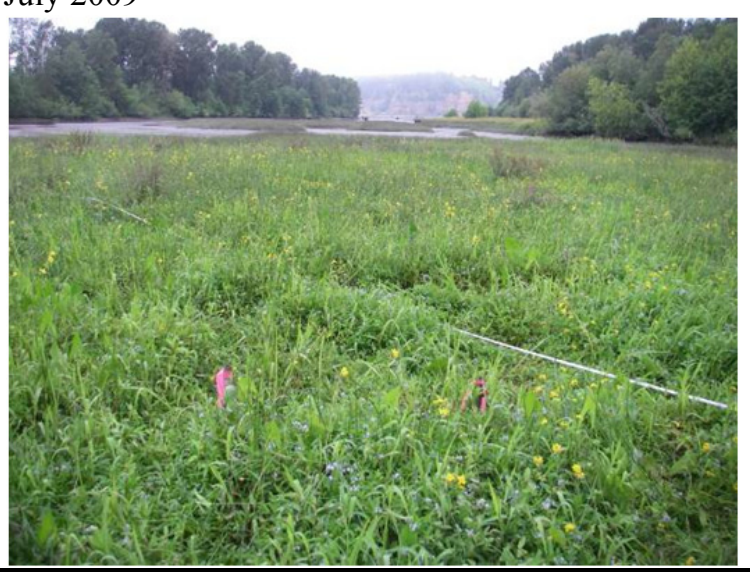




\section{Appendix J}

\section{Plant List}




\section{Appendix J}

\section{Plant List}

Multiple manuals were used to identify plants in the field. All species names were standardized to U.S. Department of Agriculture (plants.usda.gov) as of January 2011. Plant species codes are composed of the first two letters of the genus and species. Wetland status is defined by information in the U.S. Department of Agriculture (USDA) plants database at http://plants.usda.gov/wetinfo.html\#categories.

\begin{tabular}{|c|c|c|c|c|c|c|}
\hline Code & Scientific Name & Common Name & $\begin{array}{c}\text { Wetland } \\
\text { Status }\end{array}$ & Category & Native & $\begin{array}{c}\text { Invasive/ } \\
\text { Weedy }\end{array}$ \\
\hline ACCI & Acer circinatum & Vine maple & FAC- & Shrub & yes & \\
\hline ADAL & Adiantum aleuticum & Aleutian Maidenhair fern & FAC & Fern & yes & \\
\hline AGCA & Agrostis capillaris & Colonial bentgrass & FAC & Grass & no & \\
\hline AGEX & Agrostis exarata & Spike bentgrass & FACW & Grass & yes & \\
\hline AGGI & Agrostis gigantea & Redtop; black bentgrass & $\mathrm{NI}$ & Grass & no & \\
\hline AGOR & Agrostis oregonensis & Oregon bentgrass & FAC & Grass & yes & \\
\hline AGST & Agrostis stolonifera $L$. & Creeping bentgrass & FAC & Grass & no & yes \\
\hline ALTR & Alisma triviale & Northern water plaintain & $\mathrm{OBL}$ & Herb & yes & \\
\hline ALRU & Alnus rubra & Red alder & FAC & Tree & yes & \\
\hline ALPR & Alopecurus pratensis & Meadow foxtail & FACW & Grass & no & \\
\hline AMAL & Amelanchier alnifolia & Saskatoon serviceberry & FACU & Shrub & yes & \\
\hline AMFR & Amorpha fruticosa & Indigo bush & FACW & Shrub & no & yes \\
\hline ANAR & Angelica arguta & Sharptooth angelica & FACW & Herb & yes & \\
\hline ANGE & Angelica genuflexa & Kneeling angelica & FACW & Herb & yes & \\
\hline APCA & Apocynum cannabinum & Dogbane, Indian hemp & $\mathrm{FAC}+$ & Herb & yes & \\
\hline ARDI & Aruncus dioicus & Goat's beard & FACU+ & Herb & yes & \\
\hline ASTR & $\begin{array}{l}\text { Asplenium trichomanes- } \\
\text { ramosum }\end{array}$ & Green spleenwort & FACU & Herb & yes & \\
\hline ATFI & Athyrium filix-femina & Lady fern & FAC & Fern & yes & \\
\hline ATPA & Atriplex patula & Spear saltbush & FACW & Herb & yes & \\
\hline BESY & Beckmannia syzigachne & American sloughgrass & OBL & Grass & yes & \\
\hline $\mathrm{BICE}$ & Bidens cernua & Nodding beggars-ticks & FACW+ & Herb & yes & yes \\
\hline BIFR & Bidens frondosa & Devil's beggartick & $\mathrm{FACW}+$ & Herb & yes & \\
\hline BLSP & Blechnum spicant & Deer fern & $\mathrm{FAC}+$ & Fern & yes & \\
\hline CACA & Calamagrostis canadensis & Bluejoint & FACW+ & Grass & yes & \\
\hline CASP2 & Calamagrostis spp. & Reedgrass & & Grass & yes & \\
\hline CAHE & Callitriche heterophylla & Water starwort & OBL & Herb & yes & \\
\hline CAPA & Caltha palustris & Yellow marsh marigold & $\mathrm{OBL}$ & Herb & yes & \\
\hline CAAN & Cardamine angulata & Angled bittercress & FACW & Herb & yes & \\
\hline CAPE & Cardamine pensylvanica & Pennsylvania bittercress & FACW & Herb & no & \\
\hline CAAP & Carex aperta & Columbia sedge & FACW & Sedge & yes & \\
\hline CAAT & Carex athrostachya & Slender-beak sedge & FACW & Sedge & yes & \\
\hline $\mathrm{CACO}$ & Carex comosa & Bearded sedge & $\mathrm{OBL}$ & Sedge & yes & \\
\hline CADE2 & Carex densa & Dense dedge & $\mathrm{OBL}$ & Sedge & yes & \\
\hline CADE & Carex deweyana & Dewey sedge & $\mathrm{FAC}+$ & Sedge & yes & \\
\hline CADI & Carex disperma & Soft-leaved sedge & FACW & Sedge & yes & \\
\hline CAEC & Carex echinata & Star sedge & NI & Sedge & yes & \\
\hline
\end{tabular}




\begin{tabular}{|c|c|c|c|c|c|c|}
\hline Code & Scientific Name & Common Name & $\begin{array}{c}\text { Wetland } \\
\text { Status }\end{array}$ & Category & Native & $\begin{array}{c}\text { Invasive/ } \\
\text { Weedy }\end{array}$ \\
\hline CALY & Carex lyngbyei & Lyngby sedge & $\overline{\mathrm{OBL}}$ & Sedge & yes & \\
\hline $\mathrm{CAOB}$ & Carex obnupta & Slough sedge & OBL & Sedge & yes & \\
\hline CASP & Carex sp. & Carex & mixed & Sedge & yes & \\
\hline CAST & Carex stipata & Sawbeak sedge & FACW & Sedge & yes & \\
\hline CAVE & Carex vesicaria & $\begin{array}{l}\text { Inflated sedge, blister } \\
\text { sedge }\end{array}$ & OBL & Sedge & yes & \\
\hline CAAM & Castilleja ambigua & $\begin{array}{l}\text { Paint-brush owl-clover; } \\
\text { johnny-nip }\end{array}$ & FACW+ & Herb & yes & \\
\hline CEDE & Ceratophyllum demersum & Coontail & OBL & Herb & yes & \\
\hline CHAN & Chamerion angustifolium & Fireweed & FACU+ & Herb & yes & \\
\hline CHAL & Chenopodium album & Lambsquarters & FAC & Herb & no & yes \\
\hline CIDO & Cicuta douglasii & Western water-hemlock & OBL & Herb & yes & yes \\
\hline CIAR & $\begin{array}{l}\text { Cirsium arvense var. } \\
\text { horridum }\end{array}$ & Canada thistle & FACU+ & Herb & no & yes \\
\hline CIVU & Cirsium vulgare & Bull thistle & FACU & Herb & no & yes \\
\hline CLSI & Claytonia sibirica & $\begin{array}{l}\text { Candy flower; Siberian } \\
\text { spring beauty }\end{array}$ & FAC & Herb & yes & \\
\hline COPA & Comarum palustre & $\begin{array}{l}\text { Purple marshlocks, marsh } \\
\text { cinquefoil }\end{array}$ & OBL & Herb & yes & \\
\hline COMA & Conium maculatum & Poison hemlock & FAC + & Herb & no & \\
\hline COAR & Convolvulus arvensis & $\begin{array}{l}\text { Morning glory; Field } \\
\text { Bindweed }\end{array}$ & UPL & Herb & no & yes \\
\hline COSE1 & Convolvulus sepium & Hedge bindweed & FAC & Herb & no & \\
\hline COTI & Coreopsis tinctoria & Golden tickseed & FACU & Herb & yes & \\
\hline COCA & Cornus canadensis & Bunchberry & FAC & Shrub & yes & \\
\hline COSE & Cornus sericea & Red-osier dogwood & FACW & Shrub & yes & \\
\hline $\mathrm{COCO} 2$ & Corylus cornuta & Beaked hazelnut & FACU & Tree & yes & \\
\hline $\mathrm{COCO}$ & Cotula coronopifolia & Common brassbuttons & FACW+ & Herb & no & \\
\hline CRDO & Crataegus douglasii & Black hawthorn & FAC & Shrub & yes & \\
\hline CYSP & Cyperus sp. & Flatsedge & & Herb & mixed & \\
\hline CYST & Cyperus strigosus & $\begin{array}{l}\text { Strawcolor flatsedge; } \\
\text { nutsedge }\end{array}$ & FACW & Sedge & yes & \\
\hline DAGL & Dactylis glomerata & Orchard-grass & FACU & Grass & no & \\
\hline DECE & Deschampsia cespitosa & Tufted hairgrass & FACW & Grass & yes & \\
\hline DIIS & Digitaria ischaemum & Smooth crabgrass & FACU & Grass & no & \\
\hline DISA & Digitaria sanguinalis & Hairy crabgrass & FACU & Grass & yes & \\
\hline DISP & Digitaria $s p$. & Crabgrass & FACU & Grass & mixed & \\
\hline DISP2 & Distichlis spicata & Saltgrass & FACW & Grass & yes & \\
\hline ELAC & Eleocharis acicularis & Needle spikerush & OBL & Sedge & yes & \\
\hline ELOV & Eleocharis ovata & Ovoid spikerush & OBL & Sedge & yes & \\
\hline ELPA & Eleocharis palustris & Common spikerush & OBL & Sedge & yes & \\
\hline ELPAR & Eleocharis parvula & Dwarf spikerush & OBL & Sedge & yes & \\
\hline ELSP & Eleocharis spp. & Spikerush & OBL & Sedge & yes & \\
\hline ELCA & Elodea canadensis & Canada waterweed & OBL & Herb & yes & \\
\hline ELNU & Elodea nuttallii & $\begin{array}{l}\text { Nuttall's waterweed, } \\
\text { western waterweed }\end{array}$ & OBL & Herb & yes & \\
\hline ELRE & Elymus repens & Quackgrass & FAC- & Grass & no & \\
\hline EPCI & Epilobium ciliatum & Willow herb & FACW- & Herb & yes & \\
\hline EQFL & Equisetum fluviatile & Water horsetail & OBL & Fern & yes & \\
\hline
\end{tabular}




\begin{tabular}{|c|c|c|c|c|c|c|}
\hline Code & Scientific Name & Common Name & $\begin{array}{l}\text { Wetland } \\
\text { Status }\end{array}$ & Category & Native & $\begin{array}{c}\text { Invasive/ } \\
\text { Weedy }\end{array}$ \\
\hline EQHY & Equisetum hyemale & Scouringrush horsetail & FACW & Fern & yes & \\
\hline EQPA & Equisetum palustre & Marsh horsetail & FACW & Fern & yes & \\
\hline EQSP & Equisetum spp. & Horsetail & mixed & Fern & yes & \\
\hline EQTE & Equisetum telmateia & Giant horsetail & FACW & Fern & yes & \\
\hline EUOC & Euthamia occidentalis & Western goldentop & $\mathrm{FACW}^{*}$ & Herb & yes & \\
\hline FRPU & Frangula purshiana & Cascara & FAC- & Tree & yes & \\
\hline FRLA & Fraxinus latifolia & Oregon ash & FACW & Tree & yes & \\
\hline FUDI & Fucus distichus & Rockweed & $\mathrm{OBL}$ & Algae & yes & \\
\hline GAAP & Galium aparine & Cleavers bedstraw & FACU & Herb & yes & yes \\
\hline GASP & Galium spp & $\begin{array}{l}\text { Pacific bedstraw; cleavers; } \\
\text { small bedstraw }\end{array}$ & mixed & Herb & yes & \\
\hline GATR3 & Galium trifidum & Small bedstraw & FACW+ & Herb & yes & \\
\hline GATR & $\begin{array}{l}\text { Galium trifidum var. } \\
\text { pacificum }\end{array}$ & Pacific bedstraw & FACW & Herb & yes & \\
\hline GATR2 & Galium triflorum & Fragrant bedstraw & FACU & Herb & yes & \\
\hline GASH & Gaultheria shallon & Salal & FACU & Shrub & yes & \\
\hline GEMA & Geum macrophyllum & Largeleaf avens & FACW- & Herb & yes & \\
\hline GLMA & Glaux maritima & Sea milkwort & FACW+ & Herb & yes & \\
\hline GLHE & Glechoma hederacea & Creeping Charlie & FACU+ & Herb & no & yes \\
\hline GLGR & Glyceria grandis & American mannagrass & $\mathrm{OBL}$ & Grass & yes & \\
\hline GLST & Glyceria striata & Fowl mannagrass & $\mathrm{OBL}$ & Grass & yes & \\
\hline GNUL & Gnaphalium uliginosum & Marsh cudweed & FAC + & Herb & no & \\
\hline GREB & Gratiola ebracteata & Bractless hedgehyssop & $\mathrm{OBL}$ & Herb & yes & \\
\hline GRNE & Gratiola neglecta & American Hedge-hyssop & $\mathrm{OBL}$ & Herb & yes & \\
\hline HEHE & Hedera helix & English ivy & UPL & Herb & no & yes \\
\hline HEAU & Helenium autumnale & Common sneezeweed & FACW & Herb & yes & \\
\hline HEMA & Heracleum maximum & Cow-parsnip & FAC + & Herb & yes & \\
\hline HOLA & Holcus lanatus & Common velvetgrass & FAC & Grass & no & \\
\hline HOBR & Hordeum brachyantherum & Meadow barley & FACW- & Grass & yes & \\
\hline HYRA2 & Hydrocotyle ranunculoides & Water pennywort & $\mathrm{OBL}$ & Herb & yes & \\
\hline HYSC & Hypericum scouleri & Western St. Johns wort & FAC & Herb & yes & \\
\hline HYRA & Hypochaeris radicata & Spotted cat's ear & FACU & Herb & no & \\
\hline ILAQ & Ilex aquifolium & English holly & UPL & Tree & no & \\
\hline ILSP & Ilex sp. & Holly & UPL & Tree & no & \\
\hline IMSP & $\begin{array}{l}\text { Impatiens capensis,Impatiens } \\
\text { noli-tangere }\end{array}$ & $\begin{array}{l}\text { Spotted touch-me-not, } \\
\text { Common touch-me-not }\end{array}$ & FACW & Herb & yes & \\
\hline IRPS & Iris pseudacorus & Yellow iris & OBL & Herb & no & \\
\hline JUAC & Juncus acuminatus & Tapertip rush & $\mathrm{OBL}$ & Rush & yes & \\
\hline JUBA & Juncus balticus & Baltic rush & $\mathrm{FACW}+$ & Rush & yes & \\
\hline JUBU & Juncus bufonius & Toad rush & FACW & Rush & yes & \\
\hline JUEF & Juncus effusus & Soft rush & FACW & Rush & mixed & \\
\hline JUEN & Juncus ensifolius & Daggerleaf rush & FACW & Rush & yes & \\
\hline JUFA & Juncus falcatus & Sickleleaf rush & FACW- & Rush & yes & \\
\hline JUGE & Juncus gerardii & Saltmeadow rush & FACW+ & Rush & yes & \\
\hline JUNE & Juncus nevadensis & Sierra rush & FACW & Rush & yes & \\
\hline JUOX & Juncus oxymeris & Pointed rush & FACW+ & Rush & yes & \\
\hline JUSP & Juncus spp. & Rush & mixed & Rush & mixed & \\
\hline JUSU & Juncus supiniformis & Spreading rush & $\mathrm{OBL}$ & Rush & yes & \\
\hline
\end{tabular}




\begin{tabular}{|c|c|c|c|c|c|c|}
\hline Code & Scientific Name & Common Name & $\begin{array}{l}\text { Wetland } \\
\text { Status }\end{array}$ & Category & Native & $\begin{array}{c}\text { Invasive/ } \\
\text { Weedy }\end{array}$ \\
\hline JUTE & Juncus Tenuis & Slender rush, poverty rush & FACW- & Rush & yes & \\
\hline LAPA & Lathyrus palustris & Marsh peavine & $\mathrm{OBL}$ & Herb & yes & \\
\hline LEOR & Leersia oryzoides & Rice cutgrass & $\mathrm{OBL}$ & Grass & yes & \\
\hline LEMI & Lemna minor & Duckweed & $\mathrm{OBL}$ & Herb & yes & \\
\hline LEVU & Leucanthemum vulgare & Oxeye daisy & UPL & Herb & no & yes \\
\hline LEMO & Leymus mollis & American dunegrass & UPL & Grass & yes & \\
\hline LIOC & Lilaeopsis occidentalis & Western lilaeopsis & $\mathrm{OBL}$ & Herb & yes & \\
\hline LIAQ & Limosella aquatica & Water mudwort & $\mathrm{OBL}$ & Herb & yes & \\
\hline LOIN & Lonicera involucrata & Black twinberry & $\mathrm{FAC}+$ & Shrub & yes & \\
\hline LOCO & Lotus corniculatus & Birdsfoot trefoil & FAC & Herb & no & \\
\hline LUPA & Ludwigia palustris & False loosestrife & $\mathrm{OBL}$ & Herb & yes & \\
\hline LUPO & Lupinus polyphyllus & Large-leaved lupine & $\mathrm{FAC}+$ & Herb & yes & \\
\hline LYAM2 & Lycopus americanus & American water horehound & $\mathrm{OBL}$ & Herb & yes & \\
\hline LYSP & Lycopus sp. & Bugleweed; horehound & $\mathrm{OBL}$ & Herb & yes & \\
\hline LYUN & Lycopus uniflorus & Northern bugleweed & $\mathrm{OBL}$ & Herb & yes & \\
\hline LYAM & Lysichiton americanus & Skunk cabbage & $\mathrm{OBL}$ & Herb & yes & \\
\hline LYNU & Lysimachia nummularia $L$. & $\begin{array}{l}\text { Moneywort, Creeping } \\
\text { Jenny }\end{array}$ & FACW & Herb & no & \\
\hline LYSA & Lythrum salicaria & Purple loosestrife & $\mathrm{FACW}+$ & Herb & no & yes \\
\hline MASA & Madia sativa & Coast tarweed & UPL & Herb & yes & \\
\hline MADI & Maianthemum dilatatum & Wild lily-of-the-valley & FAC & Herb & yes & \\
\hline MARA & Maianthemum racemosum & $\begin{array}{l}\text { Large false lily of the } \\
\text { valley }\end{array}$ & UPL & Herb & yes & \\
\hline MAFU & Malus fusca & Pacific crab apple & FACW & Tree & yes & \\
\hline MAPO & Marchantia polymorpha & Lung liverwort & NA & NV & yes & \\
\hline MEAR & Mentha arvensis & Wild mint & FACW- & Herb & yes & \\
\hline MESP3 & Mentha spicata $L$. & Spearmint & $\mathrm{OBL}$ & Herb & no & \\
\hline MESP & Mentha spp. & $\begin{array}{l}\text { Mint (field mint, } \\
\text { spearmint) }\end{array}$ & mixed & Herb & mixed & \\
\hline MIAL & Mimulus alsinoides & Chickweed monkey-flower & OBL & Herb & yes & \\
\hline MIGU & Mimulus guttatus & Yellow monkeyflower & OBL & Herb & yes & \\
\hline MILE & Mimulus lewisii & $\begin{array}{l}\text { Great purple monkey } \\
\text { flower }\end{array}$ & FACW + & Herb & yes & \\
\hline MIRI & Mimulus ringens & Allegheny monkeyflower & $\mathrm{OBL}$ & Herb & yes & \\
\hline MITR & Mitella trifida & Three-toothed mitrewort & NA & Herb & yes & \\
\hline MYLA & Myosotis laxa & Small forget-me-not & $\mathrm{OBL}$ & Herb & yes & \\
\hline MYSP & Myosotis laxa, M. scorpioides & $\begin{array}{l}\text { Small forget-me-not, } \\
\text { Common forget-me-not }\end{array}$ & mixed & Herb & mixed & \\
\hline MYSC & Myosotis scorpioides & Common forget-me-not & FACW & Herb & no & \\
\hline MYAQ & Myriophyllum aquaticum & Parrot-feather milfoil & $\mathrm{OBL}$ & Herb & no & yes \\
\hline MYHI & Myriophyllum hippuroides & Western milfoil & $\mathrm{OBL}$ & Herb & yes & \\
\hline MYSI & Myriophyllum sibiricum & $\begin{array}{l}\text { Northern milfoil, short } \\
\text { spike milfoil }\end{array}$ & $\mathrm{OBL}$ & Herb & yes & \\
\hline MYSP3 & Myriophyllum spicatum & Eurasian water milfoil & $\mathrm{OBL}$ & Herb & no & yes \\
\hline MYSP2 & Myriophyllum spp. & Milfoil & $\mathrm{OBL}$ & Herb & mixed & \\
\hline NULU & Nuphar lutea & Yellow pond-lily & OBL & Herb & yes & \\
\hline OECE & Oemleria cerasiformis & Indian-plum & FACU & Shrub & yes & \\
\hline OESA & Oenanthe sarmentosa & Water parsley & $\mathrm{OBL}$ & Herb & yes & \\
\hline
\end{tabular}




\begin{tabular}{|c|c|c|c|c|c|c|}
\hline Code & Scientific Name & Common Name & $\begin{array}{c}\text { Wetland } \\
\text { Status } \\
\end{array}$ & Category & Native & $\begin{array}{c}\text { Invasive/ } \\
\text { Weedy }\end{array}$ \\
\hline OXOR & Oxalis oregana & Redwood sorrel & UPL & Herb & yes & \\
\hline PACA & Panicum capillare & Witchgrass & FACU+ & Grass & yes & \\
\hline PAOC & $\begin{array}{l}\text { Panicum } \\
\text { occidentale/Dichanthelium } \\
\text { acuminatum }\end{array}$ & Western panicgrass & FACW & Grass & yes & \\
\hline PAVI & Parentucellia viscosa & Yellow parentucellia & FAC- & Herb & no & \\
\hline PADI & Paspalum distichum & Knotgrass & FACW & Grass & yes & \\
\hline PENE & Pellia neesiana & Ring pellia & & Liverwort & yes & \\
\hline PHHA & Phacelia hastata & Silver-leaf phacelia & UPL & Herb & yes & \\
\hline PHAR & Phalaris arundinacea & Reed canary grass & FACW & Grass & no & yes \\
\hline PHCA & Physocarpus capitatus & Pacific ninebark & FACW- & Shrub & yes & \\
\hline PISI & Picea sitchensis & Sitka spruce & FAC & Tree & yes & \\
\hline PLLA & $\begin{array}{l}\text { Plantago lanceolata var. } \\
\text { lanceolata }\end{array}$ & Rib plantain & FAC & Herb & no & \\
\hline PLMA & Plantago major & Common plantain & FACU+ & Herb & no & \\
\hline PLDI & Platanthera dilatata & White bog orchid & FACW + & Herb & yes & \\
\hline POAN2 & Роа аппиа & Annual bluegrass & FAC & Grass & no & \\
\hline POAM & Polygonum amphibium & $\begin{array}{l}\text { water ladysthumb, water } \\
\text { smartweed }\end{array}$ & OBL & Herb & yes & \\
\hline POCU & Polygonum cuspidatum & Japanese knotweed & FACU & Herb & no & yes \\
\hline POHY & $\begin{array}{l}\text { Polygonum hydropiper, } \\
\text { P. hydropiperoides }\end{array}$ & $\begin{array}{l}\text { Waterpepper, mild } \\
\text { Waterpepper, swamp } \\
\text { smartweed }\end{array}$ & OBL & Herb & mixed & \\
\hline POLA & Polygonum lapathifolium & Curly top knotweed & FACW & Herb & yes & \\
\hline POPE & Polygonum persicaria & Spotted ladysthumb & FACW & Herb & no & yes \\
\hline POSP & Polygonum sp. & Knotweed, Smartweed & mixed & Herb & mixed & \\
\hline POGL & Polypodium glycyrrhiza & Licorice fern & FACU & Fern & yes & \\
\hline POMU & Polystichum munitum & Sword fern & FACU & Fern & yes & \\
\hline POBA & Populus balsamifera & Black cottonwood & FAC & Tree & yes & \\
\hline POCR & Potamogeton crispus & Curly leaf pondweed & OBL & Herb & no & yes \\
\hline PONA & Potamogeton natans & Floating-leaved pondweed & OBL & Herb & yes & \\
\hline POPU & Potamogeton pusillus & Small pondweed & OBL & Herb & yes & \\
\hline PORI & Potamogeton richardsonii & Richardson's pondweed & OBL & Herb & yes & \\
\hline POSP2 & Potamogeton sp. & Pondweed & OBL & Herb & mixed & \\
\hline $\mathrm{POZO}$ & Potamogeton zosteriformis & Eelgrass pondweed & OBL & Herb & yes & \\
\hline POAN & $\begin{array}{l}\text { Potentilla anserina ssp. } \\
\text { Pacifica/Argentina egedii ssp. } \\
\text { Egedii }\end{array}$ & Pacific silverweed & OBL & Herb & yes & \\
\hline PRVU & Prunella vulgaris & Self heal & FACU+ & Herb & yes & \\
\hline PREM & Prunus emarginata & Bitter cherry & FACU & Tree & yes & \\
\hline PSCA & Pseudognaphalium canescens & $\begin{array}{l}\text { Slender cudweed; Wright's } \\
\text { cudweed }\end{array}$ & UPL & Herb & yes & \\
\hline PTAQ & Pteridium aquilinum & Bracken fern & FACU & Fern & yes & \\
\hline PUPU & Puccinellia pumila & Dwarf alkaligrass & FACW + & Herb & yes & \\
\hline RACY & Ranunculus cymbalaria & Alkali buttercup & OBL & Herb & yes & \\
\hline RAFL & Ranunculus flammula & Small creeping buttercup & FACW & Herb & yes & \\
\hline RARE & Ranunculus repens & Creeping buttercup & FACW & Herb & no & \\
\hline RASC & Ranunculus sceleratus & Celery-leaved buttercup & OBL & Herb & yes & \\
\hline RAUN & Ranunculus uncinatus & Woodland buttercup & FAC- & Herb & yes & \\
\hline
\end{tabular}




\begin{tabular}{|c|c|c|c|c|c|c|}
\hline Code & Scientific Name & Common Name & $\begin{array}{l}\text { Wetland } \\
\text { Status }\end{array}$ & Category & Native & $\begin{array}{c}\text { Invasive/ } \\
\text { Weedy }\end{array}$ \\
\hline RIBR & Ribes bracteosum & Stink currant & FAC & Shrub & yes & \\
\hline RIDI & Ribes divaricatum & $\begin{array}{l}\text { Wax currant, coast black } \\
\text { currant }\end{array}$ & FAC & Shrub & yes & \\
\hline RILA & Ribes lacustre & Swamp gooseberry & FAC + & Shrub & yes & \\
\hline RIFL & Riccia fluitans & Liverwort & NA & Liverwort & yes & \\
\hline RINA & Ricciocarpos natans & Purple fringed liverwort & NA & Liverwort & yes & \\
\hline ROSP & $\begin{array}{l}\text { Rorippa calycina, } \\
\text { R.curvisiliqua }\end{array}$ & Yellow cress & mixed & Herb & yes & \\
\hline $\mathrm{ROCO}$ & Rorippa columbiae & Columbian yellowcress & OBL & Herb & yes & \\
\hline ROCU & Rorippa curvisiliqua & Curvepod yellow cress & OBL & Herb & yes & \\
\hline RONA & $\begin{array}{l}\text { Rorippa nasturtium- } \\
\text { aquaticum/Nasturtium } \\
\text { officinale }\end{array}$ & Watercress & OBL & Herb & no & \\
\hline ROPA & Rorippa palustris & Marsh yellow-cress & OBL & Herb & yes & \\
\hline RONU & Rosa nutkana & Nootka rose & FAC & Shrub & yes & \\
\hline ROPI & Rosa pisocarpa & $\begin{array}{l}\text { Clustered wild rose, } \\
\text { peafruit rose, swamp rose }\end{array}$ & FAC & Shrub & yes & \\
\hline RUAR & Rubus armeniacus & Himalayan blackberry & FACU & Shrub & no & \\
\hline RULA & Rubus laciniatus & Evergreen blackberry & FACU+ & Shrub & no & \\
\hline RUPA & Rubus parviflorus & Thimbleberry & FAC- & Shrub & yes & \\
\hline RUSP & Rubus spectabilis & Salmonberry & $\mathrm{FAC}+$ & Shrub & yes & \\
\hline RUUR & Rubus ursinus & Trailing blackberry & FACU & Shrub & yes & \\
\hline RUAC & Rumex acetosella & Common sheep sorrel & FACU+ & Herb & no & yes \\
\hline RUAQ & Rumex aquaticus & Western dock & FACW+ & Herb & yes & \\
\hline RUCR & Rumex crispus & Curly dock & FAC + & Herb & no & \\
\hline RUMA & Rumex maritimus & Golden dock, seaside dock & FACW+ & Herb & yes & \\
\hline RUMA2 & Ruppia maritima & Widgeongrass & OBL & Herb & yes & \\
\hline SALA & Sagittaria latifolia & Wapato & OBL & Herb & yes & \\
\hline SAVI & Salicornia virginica & Pickleweed & OBL & Herb & yes & \\
\hline SAFL & Salix fluviatilis & $\begin{array}{l}\text { Columbia River willow, } \\
\text { river willow }\end{array}$ & OBL & Shrub & yes & \\
\hline SALU & Salix lucida & Pacific willow & FACW+ & Shrub & yes & \\
\hline SASI & Salix sitchensis & Sitka willow & FACW & Shrub & yes & \\
\hline SASP & Salix spp. & Willow & mixed & Shrub & yes & \\
\hline SARA & Sambucus racemosa & Red elderberry & FACU & Shrub & yes & \\
\hline SCAC & Schoenoplectus acutus & Hardstem bulrush, tule & OBL & Sedge & yes & \\
\hline SCAM & Schoenoplectus americanus & $\begin{array}{l}\text { American bulrush, } \\
\text { threesquare bulrush }\end{array}$ & OBL & Sedge & yes & \\
\hline SCMA & Schoenoplectus maritimus & Seacoast bulrush & OBL & Sedge & yes & \\
\hline SCSP & Schoenoplectus spp. & $\begin{array}{l}\text { Hybrid sedge; also when } \\
\text { hardstem and softstem } \\
\text { bulrush were not } \\
\text { distinguished }\end{array}$ & OBL & Sedge & mixed & \\
\hline SCTA & $\begin{array}{l}\text { Schoenoplectus } \\
\text { tabernaemontani }\end{array}$ & Softstem bulrush, tule & OBL & Sedge & Yes & \\
\hline SCTR & Schoenoplectus triqueter & Threesquare tule & OBL & Sedge & no & \\
\hline SCCY & Scirpus cyperinus & Woolly sedge & OBL & Sedge & yes & \\
\hline SCMI & Scirpus microcarpus & Small-fruited bulrush & OBL & Sedge & yes & \\
\hline SCLA & Scrophularia lanceolata & Lance-leaf figwort & FAC & Herb & yes & \\
\hline
\end{tabular}




\begin{tabular}{|c|c|c|c|c|c|c|}
\hline Code & Scientific Name & Common Name & $\begin{array}{l}\text { Wetland } \\
\text { Status }\end{array}$ & Category & Native & $\begin{array}{c}\text { Invasive/ } \\
\text { Weedy }\end{array}$ \\
\hline$\overline{\text { SISU }}$ & Sium suave & Hemlock waterparsnip & OBL & Herb & yes & \\
\hline SODU & Solanum dulcamara & Bittersweet nightshade & $\mathrm{FAC}+$ & Herb & no & \\
\hline SOCA & Solidago canadensis & Canada goldenrod & FACU & Herb & yes & \\
\hline SPAN & Sparganium angustifolium & Narrowleaf burreed & $\mathrm{OBL}$ & Herb & yes & \\
\hline SPDO & Spiraea douglasii & Douglas spiraea & FACW & Shrub & yes & \\
\hline STCO & Stachys cooleyae & Cooley's hedge-nettle & FACW & Herb & yes & \\
\hline STCR & Stellaria crispa & Curled starwort & $\mathrm{FAC}+$ & Herb & yes & \\
\hline STLO & Stellaria longifolia & Longleaf starwort & FACW & Herb & yes & \\
\hline SYAL & Symphoricarpos albus & Common snowberry & FACU & Shrub & yes & \\
\hline SYSU & Symphyotrichum subspicatum & Douglas aster & FACW & Herb & yes & \\
\hline TAOF & Taraxacum officinale & Common dandelion & FACU & Herb & no & \\
\hline TEGR & Tellima grandiflora & Fringe cup & UPL & Herb & yes & \\
\hline THPL & Thuja plicata & Western redcedar & FAC & Tree & yes & \\
\hline TITR & Tiarella trifoliata & Foamflower & FAC- & Herb & yes & \\
\hline TOME & Tolmiea menziesii & Piggy-back plant & FAC & Herb & yes & \\
\hline TODI & Toxicodendron diversilobum & Pacific poison oak & UPL & Shrub & yes & \\
\hline TRAR & Trifolium arvense & rabbitfoot clover & UPL & Herb & no & yes \\
\hline TRSP & $\begin{array}{l}\text { Trifolium pratense, T. repens, } \\
\text { T. dubium }\end{array}$ & $\begin{array}{l}\text { Red clover, white clover, } \\
\text { small hop-clover }\end{array}$ & mixed & Herb & no & \\
\hline TRWO & Trifolium wormskioldii & Springbank clover & $\mathrm{FACW}+$ & Herb & yes & \\
\hline TRMA & Triglochin maritima & Seaside arrowgrass & $\mathrm{OBL}$ & $\begin{array}{l}\text { Arrow- } \\
\text { grass }\end{array}$ & yes & \\
\hline TSHE & Tsuga heterophylla & Western hemlock & FACU- & Tree & yes & \\
\hline TYAN & Typha angustifolia & Narrowleaf cattail & $\mathrm{OBL}$ & Herb & no & \\
\hline TYSP & Typha angustifolia, T. latifolia & $\begin{array}{l}\text { Narrowleaf cattail, } \\
\text { common cattail }\end{array}$ & $\mathrm{OBL}$ & Herb & mixed & \\
\hline TYLA & Typha latifolia & Common cattail & $\mathrm{OBL}$ & Herb & yes & \\
\hline URDI & Urtica dioica & Stinging Nettle & $\mathrm{FAC}+$ & Herb & yes & \\
\hline UTVU & Utricularia vulgaris & Common bladderwort & $\mathrm{OBL}$ & Herb & yes & \\
\hline VAPA & Vaccinium parvifolium & Red huckleberry & FACU & Shrub & yes & \\
\hline VECA & Veratrum californicum & California false hellebore & $\mathrm{FACW}+$ & Herb & yes & \\
\hline VETH & Verbascum thapsus & Common mullein & UPL & Herb & no & \\
\hline VEAM & Veronica americana & American speedwell & $\mathrm{OBL}$ & Herb & yes & \\
\hline VEAN & Veronica anagallis-aquatica & Water speedwell & $\mathrm{OBL}$ & Herb & yes & \\
\hline VESC & Veronica scutellata & Marsh speedwell & $\mathrm{OBL}$ & Herb & yes & \\
\hline VESP & Veronica spp. & speedwell & $\mathrm{OBL}$ & Herb & yes & \\
\hline VIED & Viburnum edule & Highbush cranberry & FACW & Shrub & yes & \\
\hline VIAM & Vicia americana & American vetch & FAC & Herb & yes & \\
\hline VISP & Vicia spp & Vetch & & Herb & mixed & \\
\hline WOSP & Wolffia spp. & Watermeal & $\mathrm{OBL}$ & Herb & yes & \\
\hline XAST & Xanthium strumarium & Rough cocklebur & FAC & Herb & yes & \\
\hline ZAPA & Zannichellia palustris & Horned pondweed & $\mathrm{OBL}$ & Herb & yes & \\
\hline ZOJA & Zostera japonica & Japanese eelgrass & $\mathrm{OBL}$ & Herb & no & \\
\hline ZOMA & Zostera marina & Eelgrass & $\mathrm{OBL}$ & Herb & yes & \\
\hline MGA & & Matting green algae & $\mathrm{OBL}$ & Algae & & \\
\hline FGA & & Filamentous green algae & $\mathrm{OBL}$ & Algae & & \\
\hline MG & & Mixed Grass & mixed & Grass & mixed & \\
\hline SMG & & Small mixed grass & & Grass & & \\
\hline
\end{tabular}




\begin{tabular}{|c|c|c|c|c|c|c|}
\hline Code & Scientific Name & Common Name & $\begin{array}{l}\text { Wetland } \\
\text { Status }\end{array}$ & Category & Native & $\begin{array}{c}\text { Invasive/ } \\
\text { Weedy }\end{array}$ \\
\hline$\overline{\mathrm{MH}}$ & & Mixed herbs & & Herb & & \\
\hline SMH & & Small mixed herbs & & Herb & & \\
\hline $\mathrm{OM}$ & & Organic matter & NA & mixed & mixed & \\
\hline MOSS & & Moss & NA & Moss & yes & \\
\hline
\end{tabular}




\section{Distribution}

No. of

PDF Copies

OFFSITE

1 Blaine D. Ebberts

USACE Portland District

CENWP-PM-E

333 SW First Avenue

Portland, OR 97208-2946

1 Cynthia Studebaker

USACE Portland District

CENWP-PM-E

333 SW First Avenue

Portland, OR 97208-2946

1 April Cameron

CREST

1 Earl Dawley

NMFS-retired

1 David Jay

PSU

1 Curtis Roegner

NMFS

1 John Skalski

UW
No. of

PDF Copies

ONSITE

4 PNNL

Amy Borde Sequim

Steve Breithaupt

SEA

$\mathrm{RCH}$

Andre Coleman

Heida Diefenderfer

Sequim

BPO

Gary Johnson

Ron Thom

Dana Woodruff
Sequim

Sequim

Distr.1 


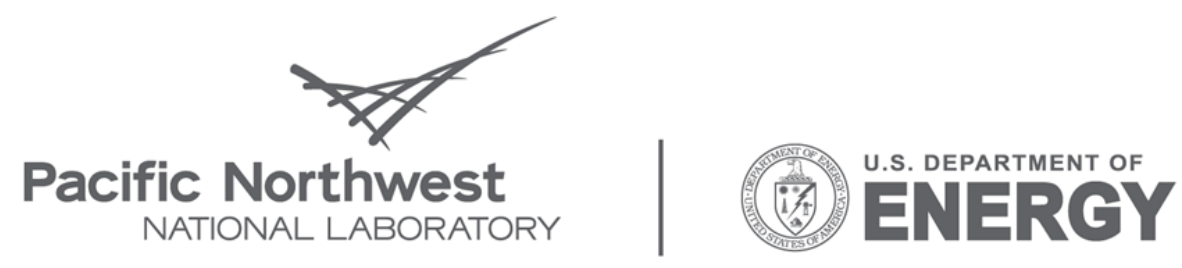

Proudly Operated by Battelle Since 1965

902 Battelle Boulevard

P.O. Box 999

Richland, WA 99352

1-888-375-PNNL (7665)

www.pnl.gov 